AlllOO 985771

NATL INST OF STANDARDS \& TECH R.I.C.

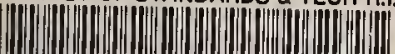

A11100985771

Slattery, WIIllam J/Index of U.S. nuclea

QC100.U57 V483;1977 C.1 NBS-PUB-C 1977

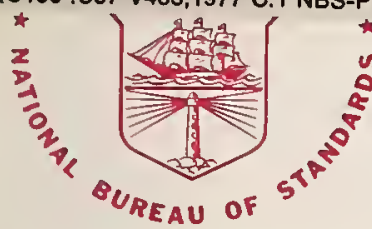

U.S. DEPARTMENT OF COMMERCE / National Bureau of Standards

\section{NBS SPECIAL PUBLICATION 483}




\section{NATIONAL BUREAU OF STANDARDS}

The National Bureau of Standards ${ }^{1}$ was established by an act of Congress March 3, 1901. The Bureau's overall goal is to strengthen and advance the Nation's science and technology and facilitate their effective application for public benefit. To this end, the Bureau conducts research and provides: (1) a basis for the Nation's physical measurement system, (2) scientific and technological services for industry and government, (3) a technical basis for equity in trade, and (4) technical services to promote public safety. The Bureau consists of the Institute for Basic Standards, the Institute for Materials Research, the Institute for Applied Technology, the Institute for Computer Sciences and Technology, the Office for Information Programs, and the Office of Experimental Technology Incentives Program.

THE INSTITUTE FOR BASIC STANDARDS provides the central basis within the United States of a complete and consistent system of physical measurement; coordinates that system with measurement systems of other nations; and furnishes essential services leading to accurate and uniform physical measurements throughout the Nation's scientific community, industry, and commerce. The Institute consists of the Office of Measurement Services, and the following center and divisions:

Applied Mathematics - Electricity - Mechanics - Heat - Optical Physics - Center for Radiation Research — Laboratory Astrophysics ${ }^{2}$ - Cryogenics ${ }^{2}$ - Electromagnetics ${ }^{2}$ - Time and Frequency ${ }^{2}$.

THE INSTITUTE FOR MATERIALS RESEARCH conducts materials research leading to improved methods of measurement, standards, and data on the properties of well-characterized materials needed by industry, commerce, educational institutions, and Government; provides advisory and research services to other Government agencies; and develops, produces, and distributes standard reference materials. The Institute consists of the Office of Standard Reference Materials, the Office of Air and Water Measurement, and the following divisions:

Analytical Chemistry - Polymers - Metallurgy - Inorganic Materials — Reactor Radiation — Physical Chemistry.

THE INSTITUTE FOR APPLIED TECHNOLOGY provides technical services developing and promoting the use of available technology; cooperates with public and private organizations in developing technological standards, codes, and test methods; and provides technical advice services, and information to Government agencies and the public. The Institute consists of the following divisions and centers:

Standards Application and Analysis - Electronic Technology - Center for Consumer Product Technology: Product Systems Analysis; Product Engineering - Center for Building Technology: Structures, Materials, and Safety; Building Environment; Technical Evaluation and Application - Center for Fire Research: Fire Science; Fire Safety Engineering.

THE INSTITUTE FOR COMPUTER SCIENCES AND TECHNOLOGY conducts research and provides technical services designed to aid Government agencies in improving cost effectiveness in the conduct of their programs through the selection, acquisition, and effective utilization of automatic data processing equipment; and serves as the principal focus wthin the executive branch for the development of Federal standards for automatic data processing equipment, techniques, and computer languages. The Institute consist of the following divisions:

Computer Services - Systems and Software - Computer Systems Engineering — Information Technology.

THE OFFICE OF EXPERIMENTAL TECHNOLOGY INCENTIVES PROGRAM seeks to affect public policy and process to facilitate technological change in the private sector by examining and experimenting with Government policies and practices in order to identify and remove Government-related barriers and to correct inherent market imperfections that impede the innovation process.

THE OFFICE FOR INFORMATION PROGRAMS promotes optimum dissemination and accessibility of scientific information generated within NBS; promotes the development of the National Standard Reference Data System and a system of information analysis centers dealing with the broader aspects of the National Measurement System; provides appropriate services to ensure that the NBS staff has optimum accessibility to the scientific information of the world. The Office consists of the following organizational units:

Office of Standard Reference Data - Office of Information Activities — Office of Technical Publications - Library Office of International Standards - Office of International Relations.

\footnotetext{
${ }^{2}$ Headquarters and Laboratories at Gaithersburg, Maryland, unless otherwise noted; mailing address Washington, D.C. 20234.
}

${ }^{2}$ Located at Boulder, Colorado 80302. 


\section{Index of U.S. Nuclear Standards}

William J. Slattery

Institute for Applied Technology

National Bureau of Standards

Washington, D.C. 20234

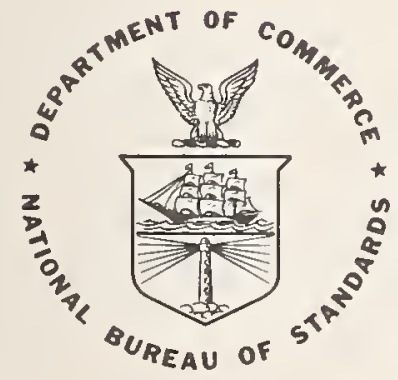

U.S. DEPARTMENT OF COMMERCE, Juanita M. Kreps, Secretary

Dr. Sidney Harman, Under Secretary

Jordan J. Baruch, Assistant Secretary for Science and Technology

US, NATIONAL BUREAU OF STANDARDS, Ernest Ambler. Acting Director. 
National Bureau of Standards Publication 483

Nat. Bur. Stand. (U.S.), Spec. Publ. 483, 127 pages (Aug. 1977) CODEN: XNBSAV

U.S. GOVERNMENT PRINTING OFFICE

WASHINGTON: 1977

For sale by the Superintendent of Documents, U.S. Government Printing Office

Washington, D.C. 20402 - Price $\$ 2.75$

Stock No. 003-003-01822-8 


\section{Acknowledgements}

The editor appreciates the efforts of the following for their contributions to this Index: the American Nuclear Society (ANS) which initiated the idea; Mrs. Annette Rachlin, former Nuclear Coordinator with the American National Standards Institute (ANSI); Ms. Mary Monty, former Assistant Program Administrator, ANSI; Mrs. Mary Crehan Vaca, Assistant Program Administrator-Nuclear, ANSI, for her editorial review of the Index; Mrs. Ethelene Lewis, Library Technician, Standards Information and Analysis Section (SIAS), National Bureau of Standards (NBS), for keypunching the standards data; and Paul Majewski, Computer Specialist (SIAS), for programming assistance. 



\title{
Index of U.S. Nuclear Standards
}

\author{
William J. Slattery, Editor
}

\begin{abstract}
This Index contains the permuted titles of more than 1,200 nuclear and nuclear-related standards, specifications, test methods, codes and recommended practices published by 34 U.S. government agencies, technical societies, professional organizations and trade associations. Each title can be found under all the significant key words which it contains. These key words are arranged alphabetically down the center of each page together with their surrounding context. Each entry includes the date of publication or last revision, the standard number, an acronym designating the standards-issuing organization, any cross reference standard number, and price.
\end{abstract}

Key words: Engineering standards, index of; index of nuclear standards; nuclear standards; KWIC index of standards

\section{Introduction}

\subsection{Background}

In 1974, the American Nuclear Society (ANS) asked NBS to cooperate in the publication of a KeyWord-In-Context (KWIC) Index of U.S., foreign national and international standards. That Index would update the 1974 "Catalog of Nuclear Industry Standards" published by the American National Standards Institute (ANSI). After a series of meetings and correspondence between NBS and ANS, and NBS and ANSI, NBS decided it would compile the present index with ANSI as the co-sponsoring organization.

An earlier publication, the Compilation of Nuclear Standards, was a project of the Nuclear Safety Information Center (NSIC) and was prepared under the auspices of ANSI's Nuclear Technical Advisory Board (NTAB). That compilation, which was published by Oak Ridge National Laboratory (ORNL), consisted of two parts, one on U.S. activities in 1973 and the other on foreign and international activities in 1972. Each part included information on committee activities and projects, and a KWIC Index of the standards themselves. The ORNL compilation was discontinued upon the recommendation of the NTAB Executive Committee and the USAEC Standards Program because a new document was available to replace it. The new document, the "Catalog of Nuclear Industry Standards," referenced above, was also prepared under the NTAB and published at ANSI. The catalog greatly expanded the information contained in the original compilation and employed subject headings rather than a KWIC index.

\subsection{Scope}

This Index, which includes only U.S. industry and government standards, is designed to serve as an interim reference tool for the nuclear community. The standards are current as of July 31, 1976. NBS plans to format ANSI's Catalog of Nuclear Standards into a more comprehensive Key-Word-Out-ofContext (KWOC) Index. Both NBS and ANSI hope that this present Index will meet the needs for the immediate future of all who are interested in nuclear standards. NBS plans to prepare a separate Index of foreign national and international standards. Please send all comments on this index to the Editor, William J. Slattery, National Bureau of Standards, Room B-162, Technology Building, Washington, D.C. 20234, or Dr. Irving G. Young, Program Administrator-Nuclear, American National Standards Institute, 1430 Broadway, New York, New York 10018.

\section{How To Use The KWIC Index}

\subsection{Index Entries}

An index entry contains at least four items of information, and may contain as many as eight, e.g.,:

(4) (5) (8)

(1) 891 140, 1971$) \$ 175$

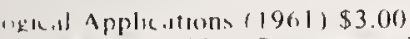

themual. Mins Spectrometric, Spectrochemical, Nuclear and

Beta Particle

Beta Particle

Alpha Particle

a Manual of
(1)

(2)

(3)

Radioactivity of Water, Method of Test for (1973) ASTM

Radioactivity of Water. Test for (1966) (R1971) \$1.75

Radioactivity of Water, Test for (1966) (R I97I) \$1.75

Radioactivity Procedures (A) Stds. (B) Medical and Biol

Radiochemical Analysis of Nuclear Grade Plutonium Metal
(6)

ANSI

ASTM

ASTM

NCRP

ANSI
(7)

N15I

DIXY()

DI943

R28

$\mathrm{N} 572$ 
(1) Title

(2) Date of Approval

(3) Acronym for issuing organization

(4) Standard no. of issuing organization

(5) Date of Standard of issuing organization

(6) Acronym of organization from which available

(7) Standard no. of organization from which available

(8) Price
Occasionally both ends of a title will be truncated. When this condition occurs, the virgule will be omitted. Missing portions of a title can be found by locating in the Index one or more of the title's other key words.

\section{SAMPLE ENTRIES-}

ement of Patients Who Have Received Therapeutic Amounts of $1970 \$ 1.75$
Radionuclides $(1970) \$ 4.00$

Radionuclides of

Radionuclides of
(Revision 1, 6/76)

Radium in Water, Method of Test for ( 197
Precautions in the Manag NCRP R37 IO NRC $\quad$ RC; 6.7 ANSI Nin! ASTM D2460

\subsection{Reading the KWIC Index}

The title of each standard can be found under all the significant key words which it contains. These key words are arranged alphabetically down the center of each page together with their surrounding context. Each such permuted title is assigned. only one line per key word entry in the Index; therefore, titles longer than one line have been cut by the computer. This truncation is indicated by a virgule (/) at the point where the title was cut.
All standards in this index should be ordered from the organizations listed in section 3.2., except standards with CFR (Code of Federal Regulations) as part of their designation, for example, USCG 46 CFR 146. This designation means that the standard was prepared by the U.S. Coast Guard, appears in Title 46, Code of Federal Regulations, Part 146, and is available in that Title for the price shown from the Superintendent of Documents, Government Printing Office, Washington, D.C. 20402. In some cases, it may be possible to obtain such standards directly from the responsible organization.

\section{List of Organizations}

\subsection{Alphabetical by Acronym}

ABS

$\mathrm{ACI}$

ACGIH

American Bureau of Shipping

American Concrete Institute

AIHA

AISC

ANS

ANSI

API

ASME

ASNT

ASTM

\section{AWS}

BRH

CMAA

DOL

vi Industrial Hygienists ation tion

American Nuclear Society

American Petroleum Institute neers Testing terials

American Welding Society America

Department of Labor
DOT
EPA
ERDA

FDA

HMI

IEEE

American Industrial Hygiene Associ-

American Institute of Steel Construc-

American National Standards Institute

American Society of Mechanical Engi-

American Society for Nondestructive

American Society for Testing and Ma-

Bureau of Radiological Health

Crane Manufacturers Association of

MSS

NAS
Department of Transportation

Environmental Protection Agency

Energy Research and Development Administration

Food and Drug Administration

Hoist Manufacturers Institute

Institute of Electrical and Electronics Engineers

IES Illuminating Engineering Society

ISA Instrument Society of America

NCRPM National Council on Radiation Protec-

Manufacturers Standardization Society of the Valve and Fittings Industry

National Academy of Sciences

NEMA National Electrical Manufacturers Association

NFPA National Fire Protection Association

NRC Nuclear Regulatory Commission

NSF National Sanitation Foundation

SAE Society of Automotive Engineers

SNAME Society of Naval Architects and Marine Engineers

USCG United States Coast Guard

USPS United States Postal Service 


\subsection{Alphabetical by Organization}

American Bureau of Shipping (ABS)

45 Broad Street

New York, New York 10004

American Concrete Institute (ACI)

Box 19150, Redford Station

Detroit, Michigan 48219

American Conference of Governmental Industrial Hygienists (ACGIH)

P.O. Box 1937

Cincinnati, Ohio 45201

American Industrial Hygiene Association (AIHA)

66 S. Miller Road

Akron, Ohio 44313

American Institute of Steel Construction, Inc. (AISC)

1221 Avenue of the Americas

New York, New York 10020

American National Standards Institute (ANSI)

1430 Broadway

New York, New York 10018

American Nuclear Society (ANS)

555 North Kensington Avenue

La Grange Park, Illinois 60525

American Petroleum Institute (API)

2101 L Street, NW.

Washington, D.C. 20037

American Society for Nondestructive Testing, Inc. (ASNT)

3200 Riverside Drive

Columbus, Ohio 43221

American Society for Testing and Materials (ASTM)

1916 Race Street

Philadelphia, Pennsylvania 19103

American Society of Mechanical Engineers (ASME)

345 East 47 th Street

New York, New York 10017

American Welding Society, Inc. (AWS)

2501 NW., 7th Street

Miami, Florida 33125

Bureau of Radiological Health (BRH)

12720 Twinbrook Parkway

Rockville, Maryland 20852

Crane Manufacturers Association of America, Inc. (CMAA)

1326 Freeport Road

Pittsburgh, Pennsylvania 15238
Department of Labor (DOL)

Occupational Safety and Health Administration

200 Constitution Avenue, NW.

Washington, D.C. 20210

Department of Transportation (DOT)

Materials Transportation Bureau

2100-2nd Street, SW.

Washington, D.C. 20595

Environmental Protection Agency (EPA)

401 M Street, SW.

Washington, D.C. 20460

Energy Research and Development Administration (ERDA)

Reactor Development and Demonstration

Route 270

Germantown, Maryland 20767

Food and Drug Administration (FDA)

Bureau of Foods

200 C Street, SW.

Washington, D.C. 20204

Hoist Manufacturers Institute (HMI)

1326 Freeport Road

Pittsburgh, Pennsylvania 15238

Illuminating Engineering Society (IES)

345 East 47 th Street

New York, New York 10017

Institute of Electrical and Electronics Engineers, Inc. (IEEE)

445 Hoes Lane

Piscataway, New Jersey 08854

Instrument Society of America (ISA)

400 Stanwix Street

Pittsburgh, Pennsylvania 15222

Manufacturers Standardization Society of the Valve and Fittings Industry (MSS)

1815 North Fort Myer Drive

Arlington, Virginia 22209

National Academy of Sciences (NAS)

2101 Constitution Avenue, NW.

Washington, D.C. 20418

National Council on Radiation Protection and Measurements (NCRPM)

7910 Woodmont Avenue

Suite 1016

Washington, D.C. 20014

National Electrical Manufacturers Association (NEMA)

2101 L Street, NW.

Washington, D.C. 20037 


\subsection{Alphabetical by Organization-Continued}

National Fire Protection Association (NFPA)

470 Atlantic Avenue

Boston, Massachusetts 02110

Nuclear Regulatory Commission (NRC)

Nuclear Reactor Regulation

7920 Norfolk Avenue

Bethesda, Maryland 20555

National Sanitation Foundation (NSF)

NSF Building, 3475 Plymouth Road

Ann Arbor, Michigan 48105

Society of Automotive Engineers, Inc. (SAE) 400 Commonwealth Drive

Warrendale, Pennsylvania 15096
Society of Naval Architects and Marine Engineers (SNAME)

74 Trinity Place

New York, New York 10006

U.S. Coast Guard (USCG)

Merchant Marine Technical Division

400-7th Street, SW.

Washington, D.C. 20590

U.S. Postal Service (USPS)

475 L'Enfant Plaza West, SW.

Washington, D.C. 20260

\section{Abbreviations}

\begin{tabular}{|c|c|c|c|}
\hline $\begin{array}{l}\text { AEC } \\
\text { AMS }\end{array}$ & $\begin{array}{l}\text { Atomic Energy Commission } \\
\text { Aerospace Material Specification }\end{array}$ & & $\begin{array}{l}\text { to ASME Boiler and Pressure Vessel } \\
\text { Code }\end{array}$ \\
\hline $\mathrm{BD}$ & Bound & $\mathrm{NC}$ & Subsection C, etc. (see NA) \\
\hline CFR & Code of Federal Regulations & $\mathrm{NC}-\mathrm{T}$ & See NB-T \\
\hline DIH & Delta-In-Hours & ND & Subsection D, etc. (see NA) \\
\hline EMF & Electromotive Force & ND- $T$ & See NB-T \\
\hline FFTF & Fast Flux Test Facility & $\mathrm{NE}$ & Subsection $\mathrm{E}$, etc. (see NA) \\
\hline GM & Geiger Muller & $\mathrm{NE}-\mathrm{T}$ & See NB-T \\
\hline HEPA & High Efficiency Particulate Air & $\mathrm{NF}$ & Subsection F, etc. (see NA) \\
\hline IEC & $\begin{array}{l}\text { International Electrotechnical Commis- } \\
\text { sion }\end{array}$ & $\begin{array}{l}\mathrm{NG} \\
\mathrm{PTC}\end{array}$ & $\begin{array}{l}\text { Subsection G, etc. (see NA) } \\
\text { Power Test Code }\end{array}$ \\
\hline ISO & $\begin{array}{l}\text { International Organization for Standard- } \\
\text { ization }\end{array}$ & RDT & $\begin{array}{l}\text { Reactor Development and Technology } \\
\text { Regulatory Guide }\end{array}$ \\
\hline LL & Loo & $\mathrm{RP}$ & Recommended Practice \\
\hline $\begin{array}{l}\text { LMFBR } \\
\text { MC }\end{array}$ & Liquid Metal Fast Breeder Reactor & SA & $\begin{array}{l}\text { Section II , Part A, ASME Boiler and } \\
\text { Pressure Vessel Code }\end{array}$ \\
\hline MSV & Mean Square Voltage & $\mathrm{SB}$ & Section II, Part B, ASME Boiler and \\
\hline $\mathrm{N}$ & $\begin{array}{l}\text { Nuclear Power Plant Components, Sub- } \\
\text { section A, Section III, Division I, }\end{array}$ & SEC & $\begin{array}{l}\text { Pressure Vessel Code } \\
\text { Section }\end{array}$ \\
\hline & $\begin{array}{l}\text { ASME Boiler and Pressure Vessel } \\
\text { Code }\end{array}$ & SFA & $\begin{array}{l}\text { Section II, Part C, ASME Boiler and } \\
\text { Pressure Vessel Code }\end{array}$ \\
\hline $\mathrm{NH}$ & Subsection B & TA & Technology (Reactor) Analysis-Branch \\
\hline NF & Subsection F, etc. (see NA) & & \\
\hline NC & Subsection $\mathrm{G}$, etc. (see NA) & TI & Unified Inch Screw Thread \\
\hline NE & National Bureau of Standards & UNR & Unified Inch External Screw Thread \\
\hline & See NB; T refers to ERDA's supplement & JNS & Unified Numbering System \\
\hline
\end{tabular}

\section{Stop List}

$\begin{array}{lll}\text { addenda } & \text { edition } & \text { method } \\ \text { additional } & \text { eight } & \text { methods } \\ \text { against } & \text { following } & \text { needed } \\ \text { agrees } & \text { free } & \text { occur } \\ \text { amendment } & \text { have } & \text { only } \\ \text { all } & \text { inches } & \text { partial } \\ \text { appendix } & \text { includes } & \text { per } \\ \text { between } & \text { including } & \text { practice } \\ \text { booklet } & \text { issued } & \text { reasonably } \\ \text { comment } & \text { lbs. } & \text { received } \\ \text { committee } & \text { leaf } & \text { recommended } \\ \text { draft } & \text { loose } & \text { redesignation }\end{array}$

relating
requirements
revised
revision
section
see
separately
sold
specification
standard
subpart
subsections

supersedes superseded supplement supplementary test testing tests through trial where which who 
2.00

os Angeles Machine, Method of Test for ( $19 /$

Resistance to ement System, Flush Mounted, Eddy Current Type, Inductive, $970 \$ 1.75$

Gamma Rays (1961) $\$ 2.00$ Rec. Practice for Calculation of

Measurement of rous Sulfate-Cupric Sulfate Dosimeter, Method of Test F/ rous Sulfate-Cupric Sulfate Dosimeter, Test for (1971)

1972) $\$ 1.75$

3

Std. Method of Test for

Use of Borosilicate Glass Raschig Rings as a Neutron Use of Borosilicate-Glass Raschig Rings as a Neutron ntrol of Analytical Chemistry Laboratories for Control Rod Analytical Chemistry Methods for Boron Carbide

$-30 \mathrm{~T},(8-71)$

ersedes E6-25T, (11-71)

$\mathrm{g}$ the $(1971) \$ 1.75$

Control Rod or (1973) ASTM C626-1971/ Estimating the Thermal Neutron 1972) $\$ 1.75$ ms (1972) $\$ 1.75$

Test for Impedance and Test for Sound 1.75

Method of Test for Specific Gravity and Method of Test for Specific Gravity and Metals in Water and Waste Water by Atomic

Uranium and Plutonium Concentrations and Isotopic Uranium and Plutonium Concentrations and Isotopic

1.75 Guidance to aterial Licenses $(3 / 76)$ de as Used in Sheathed Type Electric Heating Elements (1/ astm D1149-1970 \$1.75

Method of Test for (Revision 6, 5/76)

$5 / 76$ )

for a Bioassay Program (9/73)

Code Case

Code Case

ts $(10 / 73)$

Guide for

ly Licensed Items Containing Byproduct Material (6/74)

ts (Revision 1, 12/28/72)

Structural onnel Access to Protected Areas, Vital Areas, and Material cess Areas (6/73) Control of Personne ium/ Welder Qualification for Welding in Areas of Limited Welder Oualification for Areas of Limited

Criticality

Criticality

e Potential Radiological Consequences of a Loss of Coolan Potential Radiological Consequences of a Steam Line Break e Potential Radiological Consequences of a Loss of Coolant Assumptions Used for Evaluating a Control Rod Ejection the Potential Radiological Consequences of a Fuel Handling

Concentrations in Containment Following a Loss of Coolant

Plants to Assess Plant Conditions During and Following an of Impl/ Estimating Aquatic Dispersion of Effluents from $\mathrm{n}$ of Nuclear Power Plant Control Room Operators Against an Dosimetry for Criticality Methods for the Control and

edures for (1972) $\$ 4.50$ Methods for the

cedures for (1972) $\$ 6.00$

inology and Notation for Special Nuclear Materials Control $t$ and Content for the Special Nuclear Material Control and nology (1975) $\$ 4.00$ Krypton-85 in the Atmosphere

ng Occupational Radiation Exposure as Low as 1s Reasonably ng Occupational Radiation Exposure as Low as Is Reasonably for (1974) $\$ 1.75$

erating Performance of Anion Exchange Materials for Strong 5 Duct Liner Materials and Prefabricated Silencers for Test for Impedance and Absorption of Test for Sound Absorption of Test for Airflow Resistance of 5

s (1973.) $\$ 1.75$ Definition of Terms Relating to systems for Material Protection Measurements, Part 1: Data 137 Contamination (1965) Protective Test for Buffering Manual Initiation of Protective ) $\$ 1.75$

Recommended Practice for Liquid Phase Evaluation of

Apparent Density of Particle Size Distribution of Granular Moisture in

t for (1974) ASTM/ Oxygen Content Using a 14-MeV Neutron $t$ for (1973) $\$ 1.7 /$ 1973) $\$ 1.75$

$19-1973 \$ 1.75$ Oxygen Content Using a 14-MeV Neutron Neutron

f Test for Fast Neutron Flux by Analysis of Molybdenum-99
Abbreviations for Use in Drawings and in Text (1972) \$1

Abrasion of Small Size Coarse Aggregate by Use of the

Absolute or Gage (10-70) Amendment 1 (10-71)

Absorbed Dose from Gamma Radiation (1971) ASTM D2568-1

Absorbed Dose of Neutrons, and Mixtures of Neutrons and

Absorbed Gamma and Electron Radiation Dose with the Cer

Absorbed Gamma and Electron Radiation Dose with the Fer Absorbed Gamma and Electron Radiation Dose with the Fer Absorbed Gamma Radiation Dose in the Fricke Dosimeter ( Absorber in Solutions of Fissile Material (1971) ANS-8 Absorber in Solutions of Fissile Material (1/73)

Absorber Material Analysis (7-73)

Absorber Material (7-73)

Absorber Pin Boron Carbide Pellet (5-73) Supersedes E6

Absorber Pin for Liquid Metal Fast Reactors (5-73) Sup

Absorption Cross Section of Nuclear Graphite, Estimatin

Absorption Cross Section of Nuclear Graphite, Methods F

Absorption of Acoustical Materials by the Tube Method (

Absorption of Acoustical Materials in Reverberation Roo

Absorption of Coarse Aggregate (1974) ASTM C127-1973 \$

Absorption of Fine Aggregate (1973) \$1.75

Absorption Spectrophotometry (1970) $\$ 1.75$

Abundances, Method of Test for (1970) $\$ 1.75$

Abundances, Method of Test for (1973) ASTM E267-1970

Academic Institutions Applying for Specific Byproduct $M$

Accelerated Life Test of Electrical Grade Magnesium Oxi

Accelerated Ozone Cracking of Vulcanized Rubber (1971)

Accelerator Installations (1964) $\$ 2.00$

Accelerators (1969) NBS Handbook $107 \$ 3.00$

Acceptability: ASME Section III Design and Fabrication

Acceptability: ASME Section 111 Materials (Revision L,

Acceptable Concepts, Models, Equations, and Assumptions

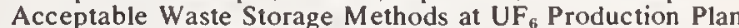

Acceptance Sampling Plans (11-73)

Acceptance Sampling Procedures for Exempted and General

Acceptance Test for Concrete Primary Reactor Containmen

Access Areas (11/73)

Access Areas (6/73)

Access to Protected Areas, Vital Areas, and Material Ac Control of Pers

Accessibility in Fuel Reprocessing Plants and in Pluton

Accessibility (12/73)

Accident Alarm System (1969) ANS-8.5 $\$ 3.00$

Accident Alarm Systems (12/74)

Accident for Boiling Water Reactors (Revision 2, 6/74)

Accident for Boiling Water Reactors (Safety Guide 5, 3/

Accident for Pressurized Water Reactors (Revision 2, 6/

Accident for Pressurized Water Reactors (5/74)

Accident in the Fuel Handling and Storage Facility for

Accident (Safety Guide 7, 3/10/71) Supplement to (Safe

Accident (12/75) /R Light-Water-Cooled Nuclear Power

Accidental and Routine Reactor Releases for the Purpose

Accidental Chlorine Release (2/75)

Accidents (1969) $\$ 4.25$

Accountability of Plutonium Dioxide Powder (12/74)

Accountability of Plutonium in Waste Material (2/75)

Accountability of Plutonium Nitrate Solutions (1/74)

Accountability of Uranium Hexafluoride, Analytical Proc

Accountability of Uranium Tetrafluoride, Analytical Pro

Accountability (2/2/73)

Statistica

Accounting Section of a Special Nuclear Material Licens
Accumulation, Biological Significance, and Control Tech

Accumulators, Class 2 Pressure Vessel (3-73)

Achievable (Nuclear Power Reactors) (Revision 1, 9/75)

Achievable (Revision 1, 9/75)

/Hilosophy for $\mathrm{M}$

Acid Insoluble Content of Copper and Iron Powders, Test

Acid Removal (1972) \$1.75

Acoustical and Airflow Performance, Testing (1973) \$1.7

Acoustical Materials by the Tube Method (1972) $\$ 1.75$

Acoustical Materials in Reverberation Rooms (1972) $\$ 1.7$

Acoustical Materials (1969) $\$ 1.75$

Acoustical Tests of Building Constructions and Materia

Acquisition Systems (Revision 1,5/74)

Action Guides for Environmental Sr-89, Sr-90, and Cs-

Action of Metal Cleaners (1971) $\$ 1.75$

Actions (10/73)

Activated Carbon (1970) $\$ 1.75$

Activated Carbon, Definition of Terms Relating to (1974

Activated Carbon, Test for (1970) \$1.75

Activated Carbon, Test for (1970) $\$ 1.75$

Activated Carbon, Test for (1970) $\$ 1.75$

Activated Carbon, Test for (1970) $\$ 1.75$

Activation and Direct Counting Technique, Method of Tes

Activation and Direct Counting Technique, Method of Tes

Activation Detector Materials, Guide for Selection of (

Activation Detector Materials, Guide for (1974) ASTM E4

Activity from Uranium-238 Fission (1974) ASTM E343-19
ANSI

ANSI

ERDA

ANS1

NCR

ANS1

ANS1

ASTM

NRC

ERDA

ERDA

ERDA

ASTM

ANS1

ASTM

ASTM

ANSI

ASTM

ASTM

ASTM

ANS1

NRC

ASTM

ANS1

ANSI

NRC

NRC

NRC

NRC

ERDA

NRC

NRC

NRC

NRC

NRC

NRC

NRC

ANSI

NRC

NRC

NRC

NRC

NRC

NRC

NRC

NRC

NRC

NRC

ANSI

NRC

NRC

NRC

ANSI

ANS1

NRC

NRC

NCRP

ERDA

NRC

NRC

ASTM

Op ASTM

ASTM

ASTM

ASTM

ASTM

ASTM

NRC

EPA

ASTM

NRC

ASTM

ASTM

ASTM

ASTM

ASTM

ASTM

ANSI

ASTM

ASTM

ANS1

ANSI

Y 1.1

A37.

RDT C6-3T

K65.218

R25

K65.230

K65.229

D2954

D 1671

RG 3

RDT F2-8T

RDT F11-2T 
Fast Neutron Flux by Analysis of Molybdenum-99 Recommended Practice for Measurement of Low Level Periodic Testing of Protection System iodic Testing of Fuel Reprocessing Plant Protection System .75 Test for Evaluating ntended for Use in the Production, Processing, and Test for s (1974) $\$ 1.75$

Test for

Practice for Preparation of Metal Surfaces for Recommended Practice for Determination of Corrosivity of or (1973) ASTM D 1879-1970 \$1.75 ice for $(1970) \$ 1.75$

ratures (Metal-to-Metal), Meth/

Exposure of
Exposure of

Strength Properties of n (1969) \$1.75 Test for Fatigue Properties of 3)

Test for Shear Strength and Shear Modulus of Structural

\section{ANS-3.2\$10.00}

Shipping Nuclear Materials (1973) $\$ 3.50$

ain NRC Requirements Over Radioactive Material Shipments/ ioactive Material $(6 / 74)$

ials (1973) $\$ 4.50$

aging Requirements for Shipments of Radioactive Material/ ation Special Permits for Radioactive Materials Shipments, de for Management) (1969) $\$ 4.25$

for (1975) \$1.75 Water Soluble Chlorides Present as Sampling and Testing Fly Ash for Use as an Specification for Air Entraining

ompounds (10-73) Supersedes M16-1T, (6-72) $\quad \begin{array}{r}\text { Air Entraining } \\ \text { Gas Phase }\end{array}$ High Efficiency Gas Phase

Criteria for Atmosphere Cleanup System Air Filtration and eview of Operating License App/ Information Needed by the .00 Radiological Factors

as Used in Construct/

Practice for Inspection and Testing Sodium Carbonate, Low Chloride Fire Extinguishing

hreshold Limit Values for Chemical Substances and Physical -75) Supersedes M8.1T, (2.73)

Helical and Shape/ Specification for Hot Rolled and Cold Finished test for (19/ Resistance to Abrasion of Small Size Coarse 1971) \$1.75 Potential Alkali Reactivity of CementTest for (1972) \$1.75 Moisture Content of Soil and Soil 197/ Method of Test for Moisture Content of Soil and Soil tests for (1971) \$1.75 Density of Soil and Soil70) ASTM C87.1969/Effect of Organic Impurities in Fine Scratch Hardness of Coarse Watcr Soluble Chlorides Present as Admixes in Graded Method of Test for Lightweight Pieces in method of Test for Specific Gravity and Absorption of Fine thod of Test for Specific Gravity and Absorption of Coarse e, Method of Test for (1973) \$1.75 Soundness of 117-1969/ Materials Finer Than No. 200 Sieve in Mineral ve Nomenclature of (1973) Petrographic Examimation of (1973) $\$ 1.75$

ve Nomenclature of (1975) ASTM C638-197/ Constituents of tion for (1975) ASTM C637-1973 \$1.75

1970) ASTM C330-1969\$1.75

ASTM C289.1971 \$1.75

1.75

1.75 Lightweight
Potential Reactivity of
ysis of Fine and Coarse Screen Analysis of Fine and Coarse
Clay Lumps and Friable Particles in Recommended Practice for General Ambient and Maximum Permissible Concentrations of Radionuclides in particles (1972) $\$ 2.50$ particles $(1 / 73)$ Efficiency Testing of
Efficiency Testing of

ethod, Method of Test for (1975) $\$ 1.75$

Method, Method of Test for (1975) \$1.75

stems $(3-71)$

Test for Unit Weight, Yield, and

$\$ 1.75$

Laminar-Flow Clean Specification for

$\mathrm{ng}$, and Maintenance Criteria for Atmosphere Cleanup System $r$ Power Plants (12/73) Additional Information: ment 2(12-72), Amendment 3 (11-73), Amendme/ Sodium to sical Measurements, Method of Test for (1973)/ Density in Test for Average Particle Size of Alumina and Silica by pheric Contaminents, 4th Edition (1972) $\$ 12.50$

Preoperational Testing of Instrument equipment and Pipe Operating at Temperatures Above Ambient equipment and Pipe Operating at Temperatures Above Ambient uide to (1969) ISO $2889 \$ 7.00$

or Measurement (1971) \$1.75

Sampling

$r$ Materials and Prefabricated Silencers for Acoustical and
Activity from Uranium-238 Fission, Test for (1972) \$1.

Activity in Water (1972T $\$ 1.75$

Actuation Functions (Safety Guide 22, 2/17/72)

Actuation Functions (6/74)

Acute Toxicity of Water to Fresh Water Fishes (1970) \$1

Additives, Subpart G. Radiation and Radiation Sources I

Adhesion or Cohesive Strength of Flame-Sprayed Coating

Adhesive Bonding (1973) ASTM D2651-1973 \$1.75

Adhesive Bonds, Standard Method of Test for (1972) \$1.7

Adhesive Materials (1974) \$1.75

Adhesive Specimens to High Energy Radiation, Practice F Adhesive Specimens to High Energy Radiation, Rec. Pract Adhesives in Shear by Tension Loading at Elevated Tempe Adhesives in Shear by Tension Loading (1973) $\$ 1.75$

Adhesives Relative to Their Use as Electrical Insulatio Adhesives (1970) $\$ 1.75$

Administration Practices in Radiation Monitoring (2/2/7

Administrative Controls for Nuclear Power Plants (1972)

Administrative Guide for Liability Insurance Aspects of

Administrative Guide for Obtaining Exemptions from Cert Administrative Guide for Packaging and Transporting Rad Administrative Guide for Transporting Radioactive Mater Administrative Guide for Verifying Compliance with Pack Administrative Guide for (1973) $\$ 3.00$ /Nt of Tran Administrative Practices in Radiation Monitoring (A Gui Admixes in Graded Aggregate Road Mixes, Method of Admixtures for Concrete (1974) \$1.75

Admixtures for Concrete, Testing (1973) $\$ 1.75$

Adsorbents for Trapping Radioactive lodine and lodine C Adsorber Cells-Including Amendment 1973 (1972) $\$ 2.00$ Adsorption Units of Light-Water Cooled Nuclear Power AEC Regulatory Staff in Connection with Its Antitrust R Affecting Decision Making in a Nuclear Attack (1974) \$4 Agencies for Concrete, Steel, and Bituminous Materials Agent (12-73)

Agents in the Workroom Environment with Intended Change Age-Hardenable Nickel-Chromium-Iron Alloy Springs ( 5 Age-Hardening Stainless and Heat Resisting Steel Bars Aggregate by Use of the Los Angeles Machine, Method of Aggregate Combinations (Mortar-Bar Method), Test for ( Aggregate in Place by Nuclear Methods (Shallow Depths), Aggregate in Place by Nuclear Methods (Shallow Depth) ( Aggregate in Place by Nuclear Methods (Shallow Depth), Aggregate on Strength of Mortar, Method of Test for (19 Aggregate Particles, Method of Test for (1968) \$1.75 Aggregate Road Mixes, Method of Test for (1975) $\$ 1.75$ Aggregate (1970) ASTM C123-1969 \$1.75

Aggregate (1973) $\$ 1.75$

Aggregate (1974) ASTM C127-1973 \$1.75

Aggregates by Use of Sodium Sulfate or Magnesium Sulfat Aggregates by Washing, Method of Test for (1970) ASTM C

Aggregates for Concrete, Rec. Practice for (1973) \$1.75

Aggregates for Radiation-Sheilding Concrete, Descripti Aggregates for Radiation-Sheilding Concrete, Spec. for Aggregates for Radiation-Shielding Concrete, Descripti Aggregates for Radiation-Shielding Concrete, Specifica Aggregates for Structural Concrete, Specification for ( Aggregates (Chemical Method), Method of Test for (1973) Aggregates, Method of Test for (1973) ASTM C136-1971 \$ Aggregates, Method of Test for (1973) ASTM C142-1971 Air Analyzer Procedures (1973T) \$1.75

Air and in Water for Occupational Exposure (1959) $\$ 2.00$ Air Cleaning Systems Containing Devices for Removal of Air Cleaning Systems Containing Devices for Removal of Air Cleaning Systems, Testing of (1975) $\$ 5.00$

Air Content of Freshly Mixed Concrete by the Pressure M Air Content of Freshly Mixed Concrete by the Volumetric Air Content (Gravimetric) of Concrete (1975) \$1.75 Air Cooled Heat Exchanger for Nuclear Steam Supplied Sy Air Devices (1968) $\$ 1.50$

Air Entraining Admixtures for Concrete (1974) \$1.75 Air Entraining Admixtures for Concrete, Testing (1973) Air Filtration and Adsorption Units of Light-Water Co Air Filtration Systems and Containment Sumps for Nuclea Air Heat Exchanger (6-71), Amendment 1 (10-71), Amend Air of Manufactured Carbon and Graphite Articles by Phy Air Permeability (1972) $\$ 1.75$

Air Sampling Instruments Manual for Evaluation of Atmos Air Systems (6/74)

Air (1972) $\$ 1.75$ Anual for Evaluation of Atmos

Air (1974) ASTM C667-1972 \$1.75

Airborne Radioactive Materials in Nuclear Facilities, G

Airborne Sound Insulation in Buildings, Rec.

Airflow Performance, Testing (1973) \$1.75

Airflow Resistance of Acoustical Materials (1969) $\$ 1.75$
ASTM

ASTM

NRC

Per NRC

ASTM

FDA

ASTM

ANSI

ASTM

ASTM

ANSI

ASTM

ANS1

ASTM

ASTM

ASTM

NRC

ANSI

ANS

NRC

NRC

ANSI

ANSI

ANSI

ANS1

ASTM

ASTM

ASTM

ASTM

ERDA

IES

NRC

NRC

NCRP

ANS1

ERDA

ACGIH

ERDA

ASTM

ANS1

ASTM

ASTM

ANSI

ASTM

ANSI

ASTM

ASTM

ANSI

ASTM

Me ANS1

ASTM

ANSI

ASTM

ASTM

ASTM

ANSI

ANSI

ANSI

ANSI

ANSI

ANSI

ASTM

NCRP

ANSI

NRC

ANSI

ASTM

ASTM

ASTM

ERDA

IES

ASTM

ASTM

NRC

NRC

ERDA

ANSI

ASTM

ACGIH

NRC
ASTM

ANSI

ANSI

ASTM

ASTM

ASTM

E343

D3085

RG 1.22

RG 3.22

D 1345

2ICFR 121

C633

Z197.28

D903

D3310

N141

D1 879

Z197.5

D3166

D1304

E229

N1 8.7

N14 GUIDE

RG 7.5

RG 7.1

N14.10.1

NI4.10.3

NI4.10.2 
Expansion Joint Containment Vessel Inflatable Seal Containment Vessel Gaskets Containment Vessel Criticality Accident Criticality Accident Perimeter Intrusion Potential
Detectors

rtar-Bar Method), Test for (1971) $\$ 1.75$ ce for Testing for Leaks Using the Hal aws A5.6-1969 \$2.50 Carbon, Ferritic

with Additional Requirements) (3-75)/

Copper and Copper-

Copper and Copper-

Nickel and Nickel-

Titanium and Titanium-

es M1-15T, (1-72) Amendme/ Nickel-Molybdenum-Chromium t 1 (1) 2-1/4-Percent-Chromium, 1-Percent-Molybdenum or (1973) AWS A 5.14-1969 \$2.50

or (1974)

ature Serv/ Nickel and NickelZirconium and Zirconium

Cobalt-Chromium Std. Spec. for Precipitation Hardening Cobalt Containing ature Service (ASTM a 637/ Precipitation Hardening Nickel th Additional Requirements) (4-76) Sup/ Nickel-Chromium istant Nickel Base-19Cr-3.1 Mo-5.1 (Cb+Ta)-/

Spec. for $\mathrm{n}$ for Hot Rolled and Cold Finished Zirconium and Zirconium fic/ Hot Rolled and Cold Finished Zirconium and Zirconium quirements) ( $1-72$ ) Supersedes M/ Zirconium and Zirconium (10-75) Supersedes M4-5/ Nickel-Molybdenum-Chromium Cobalt-Chromium

Titanium and Titanium

Nickel and Nickel-Base and Strip, Hot Rolled and Cold Rolled, High Strength, Low for (1974) $\$ 1.75$ Seamless Nickel and Nickel 73) AWS A5uirements) (3-75) Supers/

74) Nickel and Nicke Nickel and NickelNickel and Nickel1.75 Specification for AluminumAluminum-

Std. Spec. for Copper and Copper angers, Specification for (1974) ASTM B234 197/ Aluminum.75 Aluminum9-75)
m B221-73 $\$ 1.75$-1/4-Percent-Chromium, 1-Percent-Molybdenum Molybdenum

Spec. for Copper and Copper al Requirements) (1-72) Superse/ Zirconium and Zirconium ts) $(7-75)$ Supersedes M2-1 Nickel-Molybdenum-Chromium Specification for Titanium and Titanium Spec. for Titanium and Titanium (1973) $\$ 1.75$ Zirconium and Zirconium(1974) ASTM B350-1973 $\$ 1.75$ Zirconium and Zirconium Zirconium and Zircosium (1-72) Supersedes M10-1T, (5-) Specification for Columbium and Columbium on for (1975A) $\$ 1.75$

Columbium and Columbium on for ( $1975 \mathrm{~A}) \$ 1.75$ Copper-Nickel Supplementary Requirements for Nickel entary Requirements for (1970) \$1.75 Nickel

Requirements) (/ Nickel-Chromium-Molybdenum-Columbium onal Requirements) (1-75) Supers/ onal Requirements) (9-75) Supers/ al Requirements) (1-72) Superse/ Nickel-Chromium-Iron Nickel-Iron-Chromium Zirconium and Zirconium irements) (8-75/ Nickel-Chromium-Molybdenum-Columbium ASTM B168-1970 \$1.75 Nickel-Chromium-Iron (ASTM B443-197/ Nickel-Chromium-Molybdenum-Columbium ASTM B409-1973\$1.75 upplementary Requirements for (1970) $\$ 1.75$ Nickel-lron-Chromium ments) (3-75) Supersedes M7-4T,/ ments) (9-75) Supersedes $M$ ments) (9.75) Supersedes M7-10T/

Nickel-Chromium-lron Nickel-Molybdenum-Chromium Nickel-Iron-Chromium Specification for Nickel-Iron-Chromium Specification for Copper-Silicon

75 ecification for (1973) A/ ec. for $(1971) \$ 1.75$

3) ASTM B394-1970 \$1.75 fication for (1974A) $\$ 1.75$ stm B24l $1973 \$ 1.75$ specification for / Supplementary Requirements for Nickel
spec. for Supplementary Requirements for (1970) \$/ Nickel Wrought Zirconium and Zirconium Wrought Zirconium and Zirconium Columbium and Columbium Copper and CopperSpecification for AluminumSpecification for Nickel-Chromium-lron onal Requirements) (7-75)/ Nickel-Molybdenum-Chromium ional Requirements) (7-75) Super/ Nickel-lron-Chromium ents) (7-75) Su/ Nickel-Chromium-Molybdenum-Columbium ents) (8-75) Su/ Nickel-Chromium-Molybdenum-Columbium uirements) (4-76) Supersed/ Nickel-Molybdenum-Chromium
Airlock (3-72) Amendment I (8-73)

ERDA

Airlock (6-72)

Airlock (6-72)

Alarm System (1969) ANS-8.5 \$3.00

Alarm Systems (12/74)

Alarm Systems (1/75)

Alkali Reactivity of Cement-Aggregate Combinations (Mo Alkali-Ion Diode) (1971) $\$ 1.75$

Alloy and Austenitic Alloy Steel Tubes, Specification F

Alloy Arc Welding Electrodes, Specification for (1973)

Alloy Arc Welding Electrodes, Specification for (1974)

Alloy Bare Welding Rods and Electrodes (ASME SFA-5.14

Alloy Bare Welding Rods and Electrodes (1970) $\$ 3.00$

Alloy Bare Welding Rods and Electrodes (7-75) Supersed

Alloy Bare Welding Rods and Electrodes (9-75) Amendmen

Alloy Bare Welding Rods and Electrodes, Specification F

Alloy Bare Welding Rods and Electrodes, Specification F

Alloy Bare Welding Rods (ASTM B 351 with Additional Req

Alloy Bars and Rods, Tantalum (90Ta-10W) (1975) $\$ 3.00$

Alloy Bars and Shapes (4-75) Supersedes M7-7T, (7-71

Alloy Bars, Forgings, and Forging Stock for High Temper

Alloy Bars, Forgings, and Forging Stock for High Temper

Alloy Bars, Forgings, and Forging Stock for High Temper

Alloy Bars, Forgings, and Forging Stock (ASME SA $637 \mathrm{Wi}$

Alloy Bars, Forgings, and Rings, Corrosion and Heat Res

Alloy Bars, Rod and Wire for Nuclear Application (1973)

Alloy Bars, Rod and Wire for Nuclear Application, Speci

Alloy Bars, Rod and Wire (ASTM B 351 with Additional Re

Alloy Bars, Rods, and Wire (1974) ASTM B211-1973 \$1.75

Alloy Castings (ASTM a 494 with Additional Requirements

Alloy Castings (7-75) Supersedes M4-3T, (6-72)

Alloy Castings, Spec. for (1969) \$1.75

Alloy Clad Steel Plate, Specification for (1974A) \$1.75

Alloy Columbium and/or Vanadium, Specification for ( 197

Alloy Condenser and Heat Exchanger Tubes, Specification

Alloy Covered Welding Electrodes (ASME SFA-5.11 with a

Alloy Covered Welding Electrodes, Specification for (19

Alloy Covered Welding Electrodes, Specification for ( 19

Alloy Die and Hand Forgings (1974) ASTM B247-1973 \$1.7

Alloy Die and Hand Forgings, Specification for (1974) \$

Alloy Die Forgings (Hot Pressed) (1974) $\$ 1.75$

Alloy Drawn Seamless Tubes for Condensers and Heat Exch

Alloy Drawn Seamless Tubes, Specification for (1975) \$1

Alloy Electrodes and Fluxes for Submerged Arc Welding

Alloy Extruded Bars, Rods, Shapes, and Tubes (1974) Ast

Alloy Forging Rod, Bar, and Shapes (1974) $\$ 1.75$

Alloy Forgings and Extrusions (ASTM B 356 with Addition

Alloy Forgings (ASME SA-182 with Additional Requiremen

Alloy Forgings (1970) ASTM B381-1969 \$1.75

Alloy Forgings (1975) $\$ 1.75$

Alloy Ingots for Nuclear Applications, Specification Fo

Alloy Ingots for Nuclear Application, Specification for

Alloy Ingots (ASTM B 350 with Additional Requirements)

Alloy Ingots (1973) ASTM B 391-64 \$1.75

Alloy Ingots, Specification for (1964) \$1.75

Alloy Plate and Sheet for Pressure Vessels, Specificati

Alloy Plate for Nuclear Applications, Specification for

Alloy Plate for Nuclear Applications, Spec. for Supplem

Alloy Plate, Sheet, and Strip (AMS 5596 with Additional

Alloy Plate, Sheet, and Strip (ASME SB-168 with Additi

Alloy Plate, Sheet, and Strip (ASME SB-409 with Additi

Alloy Plate, Sheet, and Strip (ASTM B 352 with Addition

Alloy Plate, Sheet, and Strip 5597 with Additional Requ

Alloy Plate, Sheet, and Strip, Specification for (1973)

Alloy Plate, Sheet, and Strip, Specification for (1973)

Alloy Plate, Sheet, and Strip, Specification for (1974)

Alloy Rod and Bar for Nuclear Applications, Spec, for S

Alloy Rod and Bar (ASME SB-166 with Additional Require

Alloy Rod and Bar (ASME SB-336 with Additional Require

Alloy Rod and Bar (ASME SB-408 with Additional Require

Alloy Rod and Bar, (1974) ASTM B408-1973 \$1.75

Alloy Rod, Bar, and Shapes (1974A) \$1.75

Alloy Sand Castings for General Applications (1974) \$1

Alloy Seamless and Welded Tubes for Nuclear Service, Sp

Alloy Seamless and Welded Tubes for Nuclear Service, $\mathrm{Sp}$

Alloy Seamless and Welded Tubes, Specification for (197

Alloy Seamless Condenser Tubes and Ferrule Stock, Speci

Alloy Seamless Pipe and Seamless Extruded Tube (1974) a

Alloy Seamless Pipe and Tube for Nuclear Applications,

Alloy Seamless Pipe and Tube for Nuclear Applications,

Alloy Seamless Pipe and Tube (1973) ASTM B I67-1970 \$1.

Alloy Seamless Pipe and Tubes (ASME SB-167 with Additi

Alloy Seamless Pipe and Tubing (ASME SB-407 with Addit

Alloy Seamless Tubes (AMS 5589 with Additional Requirem

Alloy Seamless Tubes (AMS 5590 with Additional Requirem

Alloy Seamless Tubes (ASME SB - 163 with Additional Req

ERDA

ERDA

ANS ]

NRC

ASTM

ASTM

ASTM

ASME

ERDA

AWS

ERDA

ANSI

ASME

ERDA

SAE

ERDA

ANS1

ANS]

ERDA

ANS1

ASTM

ANSI

ERDA

ANS1

ERDA

ERDA

ASTM

ASTM

ANS!

ASTM

ERDA

ANS1

ASME

ANSI

ASTM

ASTM

ANSI

ASTM

ERDA

ANSI

ASTM

ERDA

ERDA

ANSI

ASTM

ASTM

ANSI

ERDA

ASTM

ASTM

ANS1

ASTM

ERDA

ERDA

ERDA

ERDA

ERDA

ANS1

ANSI

ANSI

ASTM

ERDA

ERDA

ERDA

ANSI

ASTM

ASTM

ANSI

ASTM

ANSI

ASTM

ANSI

ANSI

ASTM

ANSI

ERDA

ERDA

ERDA

ERDA

ERDA 
irements) (7-75) Supersedes M3-4T, (1-74)

Nickel quirements) (1/-75) Supers/ $34-1971 \$ 1.75$

Nickel-Molybdenum-Chromium $09.1973 \$ 1.75$

Nickel-Molybdenum-Chromium-lron Aluminum specification for (1973) ASTM B3/ Zirconium and Zirconium specification for (1967) $\$ 1.75$ Zirconium and Zirconium tant Nickel Base-19Cr-3.1 Mo-5.1 (Cb \& Ta)-0.90Ti-0./ tant Nickel Base-19Cr-3.1 Mo-5.1 (Cb \& Ta)-0.90Ti-0. Helical Age-Hardenable Nickel-Chromium-Iron 974) ASTM B308-1973 \$1.75 Specification for AluminumSpecification for Hot Rolled

Exchanger Tubes, Speci/ Seamless Ferritic and Austenitic ce (ASME SA-193 with Additional Requirements) (2-75) S/ e (ASME SA-320 with Additional Requirements) (2-75) Su/ asme SA-540 with Additional Requirements) (2-75) Super/ Specification for (1970) $\$ 1.75$

ation for (1975) $\$ 1.75$

longitudinal-Beam Ultrasonic Inspection of Carbon and Low Control of Stainless Steel Weld Cladding of Low on for (1973) AWS A5.5-1969 \$3.50

on for (1974)

std. Spec. for Piping Fittings of Wrought Carbon Steel and

$t$ and Interpass Temperature Control for the Welding of Low ervice Specification for (1975) \$1.75

Spec. for Quenched and Tempered Vacuum Treated Carbon and irements) (4-76) Supersedes M2-2T, (/

irements) (11-74) Supersedes M2-4T, (4-72)

irements) (7-75) Supersedes M2-8T, (7-71)

e Outside Diameter (ASME SA-194 with Additional Requi/

on (1974A) $\$ 1.75$ Seamless-Ferritic ati/ Electric-Fusion-Welded Austenitic Chromium-Nickel ation for (1975) $\$ 1.75$

ents) (4-76) Supersedes M3-16T, (8-75)

ents) (4-76) Supersedes M3-12T, (12-1

Ceritrifugally Cast Ferritic

Seamless Ferritic Specification for Specialized Carbon and for (1974A) $\$ 1.75$

Molybdenum, ements/ 2-1/4-Percent-Chromium, I-Percent-Molybdenum ements) (5-75) Supersedes M5-5T, (7-71)

onal Requirements) (12-74) Supersedes M5-3T, (5-7/ Low

I Requirements) (4-76) Supersedes M3-2T,/, Stainless and 1 Requ/ 2-1/4-Percent-Chromium, 1-Percent-Molybdenum ation for (1974) \$1.75 Seamless and Welded Carbon and Specification for Seamiess Ferritic-Austenitic ional / 2-1/4-Percent-Chromium, 1-Percent-Molybdenum ts for (1974A) $\$ 1 . / \quad$ Carbon, Ferritic Alloy and Austenitic equirements) (5-75) Supersedes M 3-11T,/ Carbon and Low nal Requirements) (5-75) Supersedes M2-3T Carbon and

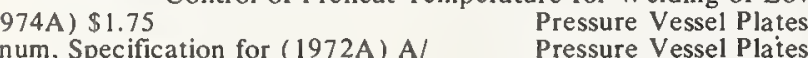
Control of Preheat Temperature for Welding of Low ification for (1974A) $\$ 1.75$ denum-Nickel, Specification For/

Specification for (1974) \$1.75 ent Nickel (1974)/ um and Mangane/

ybdenum-Chromium, Specification/

Spec for Pressure Vessel Plates, Pressure Vessel Plates, Pressure Vessel Plates, Pressure Vessel Plates, Specification for Pressure Vessel Plates, ASTM B265-1972 \$1.75

Titanium and Titanium Titanium and Titanium (1973) ASTM B393.1964 \$1.75 Columbium and Columbium Descaling and Cleaning Titanium and Titanium cation for (19/ Seamless and Welded Titanium and Titanium 1-72) Supersedes M3-8T, (5-70/

Zirconium and Zirconium Centrifugally Cast Iron-Chromium-Nickel High

ckel Consumable Electrode or Vacuum Induction Melted 195/ umable Electrode or Vacuum Induction Melted 1750F (954.4C) Tantalum and Tantalum ments) (7-75) Supersedes M/ Nickel-Molybdenum-Chromium b366-1972) \$1. Factory-Made Wrought Nickel and NickelFactory Made Wrought Aluminum and Aluminum or (1973) AWS A5.10-1969 \$2.50 Aluminum and Aluminum or (1974)

$1969 \$ 2.50$ Aluminum and Aluminum Copper and Copper Copper and CopperNickel-Copper $\mathrm{n}$ for $(1974) \$ 1.75$ Specification for Nickel-Coppe Specification for Nickel-Iron-Chromium Specification for Nickel-Iron-Chromium Specification for Nuclear Grade Silver-Indium-Cadmium Specification for Nuclear Grade Silver-Indium-Cadmium onents $(197)$

Specification for Steel Forgings, Carbon and 74)
Alloy Seamless Tubes (ASME SB-163 with Additional Requ Alloy Sheet and Plate (ASME SB .434 with Additional Re Alloy Sheet and Plate, Specification for (1973) ASTM B4 Alloy Sheet and Plate, Specification for (1974) ASTM B2 Alloy Sheet, Strip, and Plate for Nuclear Application, Alloy Sheet, Strip, and Plate for Nuclear Application, Alloy Sheet, Strip, and Plate, Corrosion and Heat Resis Alloy Sheet, Strip, and Plate, Corrosion and Heat Resis Alloy Springs (5-75) Supersedes M8-1T, (2-73)

Alloy Standard Structural Shapes, Rolled or Extruded (1 Alloy Steel Bars (1976) ASTM A322-1975 \$1.75 Alloy Steel Boiler, (1974B) \$1.75 Superheater, and Heat Alloy Steel Bolting Material for High Temperature Servi Alloy Steel Bolting Material for Low Temperature Servic Alloy Steel Bolting Material for Special Applications ( Alloy Steel Bolting Materials for Special Applications,

Alloy Steel Bolts for Structural Steel Joints, Specific

Alloy Steel Castings, Specification for (1973) ASTM A60 Alloy Steel Components $(5 / 73)$

Alloy Steel Covered Arc Welding Electrodes, Specificati Alloy Steel Covered Arc Welding Electrodes, Specificati Alloy Steel Covered Welding Electrodes (ASME SFA-5.5 W Alloy Steel for Low Temperature Service (1975) $\$ 1.75$ Alloy Steel for Use in Fuel Reprocessing Plants and in Alloy Steel Forged and Bored Pipe for High Temperature Alloy Steel Forgings for Pressure Vessels (1974A) $\$ 1.75$ Alloy Steel Forgings (ASME SA-182 with Additional Requ Alloy Steel Forgings (ASME SA-336 with Additional Requ Alloy Steel Forgings (ASME SA-541 with Additional Requ Alloy Steel Forgings, Vacuum Treated (ASME SA-508 with Alloy Steel Heat Exchanger Tubes with Integral Fins, $S_{p}$ Alloy Steel Nuts for Bolting for High Pressure and High Alloy Steel Pipe for Corrosive or High Temperature Serv Alloy Steel Pipe for High Temperature Service, Specific Alloy Steel Pipe for High Temperature Service, Specific Alloy Steel Pipe for High Temperature Service, Specific Alloy Steel Pipe (ASME SA-333 with Additional Requirem Alloy Steel Pipe (ASME SA-335 with Additional Requirem Alloy Steel Pipe (1975) $\$ 1.75$

Alloy Steel Plates for Pressure Vessels, Specification Alloy Steel Plates (ASME SA-387 with Additional Requir Alloy Steel Plates (ASME SA-387 with Additional Requir Alloy Steel Plates (ASME SA-533 with Additional Additi Alloy Steel Seamless Tubes (ASME SA-213 with Additiona Alloy Steel Seamless Tubes (ASME SA-213 with Additiona Alloy Steel Tubes for Low Temperature Service, Specific Alloy Steel Tubes (1974) ASTM A669-1972 \$1.75

Alloy Steel Tubesheet Forgings (ASME SA-336 with Addit Alloy Steel Tubes, Specification for General Requiremen Alloy Steel Welded Pipe (ASME SA-155 with Additional R Alloy Steel Welding Fittings (ASME SA-234 with Additio Alloy Steel (5/73)

Alloy Steel, Chromium-Molybdenum, Specification for ( 1 Alloy Steel, Five Percent Chromium, 0.5 Percent Molybde Alloy Steel, High Strength, Quenched and Tempered, Spec Alloy Steel, Manganese-Molybdenum and Manganese-Molyb Alloy Steel, Quenched and Tempered Chromium-Molybdenum Alloy Steel, Quenched and Tempered, Eight and Nine Perc Alloy Steel, Quenched and Tempered, Manganese-Molybden Alloy Steel, Quenched and Tempered, Nickel-Cobalt-Mol Alloy Steel, Requiring Notch Toughness Testing for Pipi Alloy Strip, Sheet, and Plate, Specification for (1973) Alloy Strip, Sheet, and Plate, Spec. for (1974) \$1.75 Alloy Strip, Sheet, Foil, and Plate, Specification for Alloy Surfaces, Rec. Practice for (1974) \$1.75

Alloy Tubes for Condensers and Heat Exchangers, Specifi Alloy Tubes (ASTM B 353 with Additional Requirements) Alloy Tubing for Pressure Application at High Temperatu Alloy Tubing (Seamless, Corrosion and Heat Resistant Ni Alloy Tubing, Seamless, Corrosion and Heat Resistant Ni Alloy Tubing, Specification for (1974) $\$ 1.75$

Alloy Welded Pipe (ASME SA-358 with Additional Require Alloy Welding Fittings, Specification for (1973) (ASTM Alloy Welding Fittings, Spec. for (1973) $\$ 1.75$

Alloy Welding Rods and Bare Electrodes, Specification F Alloy Welding Rods and Bare Electrodes, Specification F Alloy Welding Rods, Specification for (1973) AWS A5.7Alloy Welding Rods, Specification for (1974)

Alloy (UNS N04400) Plate, Sheet and Strip, Specificatio Alloy (UNS N04400) Seamless Pipe and Tube (1971) \$1.75 Alloy (UNS N08800) Rod and Bar, (1974) $\$ 1.75$

Alloy (UNS N08800) Seamless Pipe and Tube (1974) $\$ 1.75$ Alloy (1973) \$1.75

Alloy (1974) ASTM C752-1973 \$1.75

Alloy, Quenched and Tempered, for Pressure Vessel Comp Alloys for Core Components for Liquid Metal Service (5-
ERDA

ERDA

ANS

ANSI

ANSI

ASTM

ANS!

ANSl

ERDA

ANS1

ANS1

ASTM

ERDA

ERDA

ERDA

ASTM

ASTM

ANS1

NRC

ASME

ERDA

ASTM

NRC

ASTM

ASTM

ERDA

ERDA

ERDA

ERDA

ASTM

ERDA

ASTM

ASTM

ASTM

ASTM

ERDA

RA

ASTM

ASTM

ERDA

ERDA

ERDA

ERDA

ASTM

ANS1

ERDA

ASTM

ERDA

RDA

NRC

ASTM

ANSI

ATM

ASTM

ASTM

ASTM

ASTM

ANSI

ASTM

ANSI

ASTM

ASTM

ASTM

ERDA

ANS1

ANSI

ANSI

ASTM

ANSI

ASTM

ANSI

ASME

ASME

ASTM

ASTM

ASTM

ASTM

ASTM

ANSI

ASTM

ERDA

RDT M3-4T

RDT M5-8T

34.44

H38.2

N 123

B352

G87.84

G87.85

DT M8-1T

H38.10

G 24.11

A213 
$\$ 1.75$ Sampling Wrought Nonferrous Metals and phy as Applied to Preparation of Micrographs of Metals and al Analysis of Nickel-Chromium and Nickel-Chromium-Iron Macroetching Metals and chemical Analysis of Nuclear Grade Silver-Indium-Cadmium ic Methods for Chemical Analysis of Copper and Copper Base Titanium and Titanium-Base magnetic, and Other Similar Iron, Nickel, and Cobalt-Base Zirconium and Zirconium-Base granular Attack in Wrought Nickel-Rich, Chromium-Bearing spectrochemical Analysis of Nuclear Grade Silver-Cadmium us Corrosion Testing of Samples of Zirconium and Zirconium d, Manganese-Molybdenum and Manganese-Molybdenum-Nickel

ement of (1973) ASTM D1943-1966 \$1.75

(R1971) \$1.75

1972T) $\$ 1.75$

(1975) 1EEE 28-1974 \$5.00

Determination of Fuel Pellet Homogeneity by

Pressure Vessels Division 2:

d Sheathed Over Fi/ Thermocouple Material, Chromel-P and uple Material and Thermocouple Assembly, Chromel-P Versus

ions (1972) $\$ 1.75$ Test for Average Particle Size of Specification for

Factory Made Wrought Aluminum and cation for (1973) AWS A5.10-1969\$2.50 Aluminum and ication for (1974) Aluminum and

(1973) $\$ 1.75$ rodes, Specification for (1973) AWS A5.10-1969 $\$ 2.50$

rodes, Specification for (1974) Quality Control for Plate-Type Uranium-

thod for Measuring Fast Neutron Flux by Radioactivation of $1973 \$ 1.75$

$1973 \$ 1.75$

r (1974) \$1.75

Specification for

Heat Exchangers, Specification for (1974) ASTM B234 197/ (1975) $\$ 1.75$

(1974) ASTM B221.73 $\$ 1.75$

e (1974) ASTM B241 $1973 \$ 1.75$

4) ASTM B209-1973 $\$ 1.75$

xtruded (1974) ASTM B308-1973 \$1.75

Specification for Specification for Recommended Practice for General ems for Equipment and Pipe Operating at Temperatures Above ems for Equipment and Pipe Operating at Temperatures Above

n the Management of Patients Who Have Received Therapeutic n Detectors, Test Procedures for (1969) IEEE Std. 301-1/ $72 \mathrm{~T}) \$ 1.75$ Recommended Practice for Constant 1972T)/ Recommended Practice for Presentation of Constant echanical and Electrical Equipment Qualification Tests and clides in the Environment: Strontium-89 and Strontium-90 special Nuclear Material $(6 / 74)$

Radiation Safety for X-Ray Diffraction and Fluorescence Nuclear Power Reactors (3/76) on, Measuring (1973) $\$ 1.75$ m C $560-1969 \$ 1.75$

Cost-Benefit $6-1971 \$ 1.75$ Applying Statistics to for (1973) of Terms Relating to Fatigue Testing and the Statistical

for (1973) ASTM C136-1971 $\$ 1.75$ Sieve or Screen
Rec. Practice for Sampling Atmospheres for

$114-1969 \$ 1.75$

1) $\$ 1.75$

75 Photometric Methods for Chemical Method of Test for Fast Neutron Flux by
ission, Test for (1972) $\$ 1.75$
Fast Neutron Flux by ission, Test for (1972) \$1.75 Fast Neutron Flux by

Alloys (1973) $\$ 1.75$

Chemical

men Equilibration Device (Or Multipurpose Sampler) for the hods for Chemical, Mass Spectrometric, and Spectrochem ical Spectrometric, Spectrochemical, Nuclear and Radiochemical s Spectrometric, Spectrochemical Nuclear and Radiochemical ods for (1974) ASTM C760-1/ Chemical and Spectrochemical s (1974) $\$ 1.75$

Chemical and Spectrochemical $A$ hods for Chemical, Mass Spectrometric, and Spectrochemical hods for Chemical, Mass Spectrometric, and Spectrochemical hods for Chemical, Mass Spectrometric, and Spectrochemical Spectrometric, Spectrochemical, Nuclear and Radiochemical urements of Radionuclides in the Environment: Sampling and
Alloys for Determination of Chemical Composition (1972) ASTM Alloys (Including Metallography) (1974) \$1.75 /Hotogra ASTM Alloys (1973) $\$ 1.75$

Alloys $(1974) \$ 1.75$

Alloys (1974) $\$ 1.75$

Alloys (1975) $\$ 1.75$

Alloys, Chemical Analysis of (1971) $\$ 1.75$

Alloys, Chemical Analysis of (1973) $\$ 1.75$

Alloys, Chemical Analysis of (1974) $\$ 1.75$

Alloys, Method of (1973) ASTM G28-1972 \$1.75

Alloys, Methods for (1974) ASTM C760-1974 \$1.75

Alloys, Practice for (1974) \$1.75

Alloy, (1974) \$1.75 Aqueo ASTM

Alpha Emitting Particles in Lungs (1975) $\$ 3.00$

Alpha Particle Radioactivity of Water, Method of Measur

Alpha Particle Radioactivity of Water. Test for (1966)

Alpha Spectrometry of Water, Recommended Practice for (

Chemic ASTM

ASTM

Alpha Spectrometry of Water,

Alternating Current Power Circuits, Surge Arresters for

Alternative Rules (1977) bd ( $\$ 65.00), 11$ ( $\$ 95.00)$

Alumel, Solid Conductor (Bare, Fiberglass Insulated, an

Alumel, Stainless Steel Sheathed, Magnesium Oxide Insul

Alumina and Silica by Air Permeability (1972) $\$ 1.75$

Alumina Ceramics for Electrical and Electronic Applicat

Aluminum Alloy Welding Fittings, Spec. for (1973) \$1.75

Aluminum Alloy Welding Rods and Bare Electrodes, Specif

Aluminum Alloy Welding Rods and Bare Electrodes, Specif

Aluminum and Aluminum Alloy Welding Fittings, Spec. for

Aluminum and Aluminum Alloy Welding Rods and Bare Elect

Aluminum and Aluminum Alloy Welding Rods and Bare Elect

Aluminum Bronze Rod, Bar, and Shapes (1974) \$1.75

Aluminum Fuel Elements for Use in Research Reactors (Re

Aluminum Fuel Elements (1974) ANS $15.2 \$ 8.50$

Aluminum (1973) ASTM E266-1970 \$1.75

Aluminum-Alloy Bars, Rods, and Wire (1974) ASTM B211-

Aluminum-Alloy Die and Hand Forgings (1974) ASTM B247

Aluminum-Alloy Die and Hand Forgings, Specification Fo

Aluminum-Alloy Drawn Seamless Tubes for Condensers and

Aluminum-Alloy Drawn Seamless Tubes, Specification for

Aluminum-Alloy Extruded Bars, Rods, Shapes, and Tubes

Aluminum-Alloy Seamless Pipe and Seamless Extruded Tub

Aluminum-Alloy Sheet and Plate, Specification for (197

Aluminum-Alloy Standard Structural Shapes, Rolled or E

Aluminum, Measuring (1970) $\$ 1.75$

Ambient Air Analyzer Procedures (1973T) $\$ 1.75$

Ambient Air (1972) \$1.75 /D Reflective Insulation Syst ASTM

Ambient Air (1974) ASTM C667-1972 \$1.75 /Ulation Syst ANSI

Ammonia Nitrogen in Water, Tests for (1974) $\$ 1.75$ ASTM

Amounts of Radionuclides (1970) $\$ 4.00 \quad$ Precautions 1 NCRP

Amplifiers and Preamplifiers for Semiconductor Radiatio

Amplitude Axial Fatigue Tests of Metallic Materials (19

Amplitude Fatigue Test Results for Metallic Materials

Analyses $(2 / 75)$

Analyses (5/74)

/ls Reports: Environmental Design of $M$

Analysis and Use of Process Data for the Protection of

Analysis Equipment (1971) NBS Handbook $111 \$ 3.00$

Analysis for Radwaste Systems for Light-Water-Cooled

Analysis of Barium-140 Produced by Uranium-238 Fissi

Analysis of Carbon and Graphite, Methods for (1973) Ast

Analysis of Copper and Copper Base Alloys (1975) \$1.75

Analysis of Corrosion Data, Practice for (1973) ASTM G1

Analysis of Fatigue Data (1973) (ASTM E206-1972) \$1.75

Analysis of Fine and Coarse Aggregates, Method of Test

Analysis of Gases and Vapors (1973) \$1.75

Analysis of Hydraulic Cement, Methods for (1970) ASTM C

Analysis of Industrial Metal Cleaning Compositions (197

Analysis of I-131 in Milk (9/73)

Analysis of Metals, Recommended Practice for (1974) \$1.

Analysis of Molybdenum-99 Activity from Uranium-238 F

Analysis of Molybdenum-99 Activity from Uranium-238 F

Analysis of Nickel (1975) $\$ 1.75$

Analysis of Nickel-Chromium and Nickel-Chromium-lron

Analysis of Nonmetals in Liquid Sodium (1-72) Amendmen

Analysis of Nuclear Grade Plutonium Dioxide Powders and

Analysis of Nuclear Grade Plutonium Metal, Methods for

Analysis of Nuclear Grade Plutonium Nitrate Solutions (

Analysis of Nuclear Grade Silver-Cadmium Alloys, Meth

Analysis of Nuclear Grade Silver-Indium-Cadmium Alloy

Analysis of Nuclear Grade Uranium Dioxide Powders and P

Analysis of Nuclear Grade (1973) ASTM C696-1972 \$2.00

Analysis of Nuclear Grade (1973) ASTM C697-1972 \$2.00

Analysis of Nuclear (Revision 1, 5/75) /Chemical, Mass

Analysis of Phosphorus-32, Methods for (1974) \$1.75

Analysis of Plutonium in Soil (5/74)

Analysis of Radioisotopes (1973) ASTM E 181-1962 \$1.75

Analysis of Reactor and Commercial Columbium (1974) \$1.
E55

E2

E340

C760

E62

E120

E354

E146

G80.4

N574

G2

A533

R46

N 152

D 1943

D3084

RDT F11-5T

C62.1

SEC-V111/2

RDT C7-5T

RDT C7-6T

C721

D2442

B361

W3.10

SFA-5.10

B361

W3.10

SFA-5.10

B150

RG 2.3

N398

N114

H38.4

H38. 8

B247

H38. 6

B2 10

H38.5

H38.7

H38.2

H38.10

E266

D3249

C667

Z98.48

D1426

R37

N42.2

E466

RG 1.70.24

RG 4.6

RG 5.24

N43.2

RG 1.110

E393

K90.3

E62

G80.3

Z92.2

A 37.8

D 1605

A1.5

A1.5

D 800
RG 4.3

E60

N636

E343

E39

E38

RDT C8-8T

RG 5.6

N572

C759

N574

C760

RG 5.5

$\mathrm{N} 103$

N104

RG 5.16

E1 82

RG 4.5

N 148

E195 
or (1973) (ASTM E195-1968) \$1.75

40T, (1-73) Amendment 1 (5-76)

ormed (1973) $\$ 1.75$

ought Iron (1975) $\$ 1.75$

Spectrometric Spectrochemical Nuclear and Radiochemical c Distribution, and Impurity Det/ 75 Reporting Results of Radioisotopes,

ide Carrier D-C Arc Technique, Method for Spectrochemical Titanium and Titanium-Base Alloys, Chemical oxide Carrier DC Arc Technique, Method for Spectrochemical hods for Chemical, Mass Spectrometric, and Spectrochemical Phosphorus-32, Methods for

er Similar Iron, Nickel, and Cobalt-Base Alloys, Chemical Spectrometric, Spectrochemical, Nuclear and Radiochemical Zirconium and Zirconium-Base Alloys, Chemical u)o(2)), Chemical, Mass Spectrometric, and Spectrochemical pellets, Chemical, Mass Spectrometric, and Spectrochemical pellets, Chemical, Mass Spectrometric, and Spectrochemical Grade Uranyl Nitrate Solutions, Nuclear and Radiochemical carbide, Chemical, Mass Spectrometric, and Spectrochemical spectrometric, Spectrochemical, Nuclear and Radiochemical, powders, Chemical, Mass Spectrometric, and Spectrochemical powders, Chemical, Mass Spectrometric, and Spectrochemical

9/75) Standard Format and Content of Safety
74) Standard 5 -mat and Content of Safety ant Pressure Boundary Components Information for Safety Information for Safety Information for Safety Information for Safety Information for Safety Information for Safety Information for Safety Information for Safety Information for Safety Information for Safety Information for Safety Information for Safety Information for Safety Information for Safety Information for Safety Information for Safety Information for Safety Information for Safety Information for Safety Information for Safety Information for Safety Information for Safety Information for Safety Information for Safety Information for Safety Information for Safety Information for Safety Information for Safety

ion and Electrical Equipment (2/7/ $(4 / 75)$

modal Responses and Spatial Components in Seismic Response
Test for Nickel on Steel by Photometric

of Analytical Chemistry Laboratories for Mixed Oxide Fuel

1 Chemistry Laboratories for Control Rod Absorber Material ber Material Analysis (7-7) Qualification and Control of analysis (7-73)

Material (7-73)

ts $(9-75)$

3) Amendment I (12-74)

fluoride $\left(\mathrm{UF}_{4}\right)$ and Uranium Hexafluoride $\left(\mathrm{UF}_{6}\right) 2 /$ Standard

Accountability of Uranium Hexafluoride, Accountability of Uranium Tetrafluoride,

Using the Mass Spectrometer Leak Detector or Residual Gas Recommended Practice for General Ambient Air Abrasion of Small Size Coarse Aggregate by Use of the Los

for (1973) $\$ 1.75$

$\$ 1.75$

ASTM E509-74 \$1.75

) $\$ 1.75$ Recommended Guide for in Service 8-73)

r Reactor Plants (Issued Fo/

Draft Standard Evaluation of Regulatory Staff Position Statement on information Needed by the NRC Staff in Connection with Its Needed by the AEC Regulatory Staff in Connection with Its 4) (R 1970) 1EEE 21-1964\$4.00

Mechanical Power Transmission

1.75

onents ( 1977$)$ bd $(\$ 70.00) 11(\$ 90.00)$

cast Iron-Chromium-Nickel High Alloy Tubing for Pressure
Analysis of Reactor and Commercial Columbium, Methods F

ANSI

Analysis of Sodium and Cover Gas (1-76) Supersedes F3.

Analysis of Solvent Systems Used for Removal of Water F

A nalysis of Steel, Cast Iron, Open-Hearth Iron, and Wr

Analysis of Uranium Hexafluoride, Methods for (1974) as

Analysis of Uranyl Nitrate Solutions for Assay, Isotopi

Analysis of Waste Water, Standard Method for (1974) \$1.

Analysis of (1962) (R1968) \$1.75

Analysis of (1970) $\$ 1.75$

Uranium Oxide by Gallium $O x$

Analysis of (1971) $\$ 1.75$

Analysis of (1972) ASTM E402.1970 \$1.75

Analysis of (1973) ASTM C698-1972a \$1.75

Analysis of (1973) ASTM E182-1962 (1968) \$1.7

( by Gallium ANSI

1)o(2)), Met ANSI

ANSI

Analysis of (1973) $\$ 1.75$

Analysis of (1973) \$1.75

Analysis of (1974) $\$ 1.75$

Analysis of (1974) $\$ 1.75$

Analysis of (1974) $\$ 1.75$

Analysis of (1974) $\$ 1.75$

Analysis of (1975) $\$ 1.75$

Analysis of (1975) $\$ 1.75$

Lectrical, Magnetic, and Oth ASTM

/Tonium Metal, Chemical, Mass ASTM

ASTM

/Ear Grade Mixed Oxides ((U, P ASTM

/Uranium Dioxide Powders and ASTM

Utonium Dioxide Powders and ASTM

Nuclear ASTM

Analysis of (1975) $\$ 1.75$

Nuclear Grade Boron ASTM

Exafluoride, Chemical, Mass ASTM

Analysis of and Physical Tests on (1973) ASTM C699-19 ANSI

Analysis Reports for Fuel Reprocessing Plants (2/75)

Analysis Reports for Nuclear Power Plants (Revision 2,

Analysis Reports for Uranium Enrichment Facilities (12/

Analysis Reports: Code Cases Applicable to Reactor Cool

Analysis Reports: Electric Power (6/75)

Analysis Reports: Emergency Planning (12/74)

Analysis Reports: Environmental Design of Mechanical an

Analysis Reports: Fuel System Design ( $5 / 75$ )

Analysis Reports: Hydrologic Engineering (1/75)

Analysis Reports: Industrial Security for Nuclear Power

Analysis Reports: Initial Test Programs (5/75)

Analysis Reports: Inservice Inspection of ASME Code Cla

Analysis Reports: Instrumentation and Controls (2/75)

Analysis Reports: Internally Generated Missiles (6/75)

Analysis Reports: Mechanical Systems and Components (1/

Analysis Reports: Metallic Materials for Engineered Saf

Analysis Reports: Meteorology (4/75)

Analysis Reports: Missile Barrier Design Procedures (12

Analysis Reports: Plant Procedures (5/75)

Analysis Reports: Pressurizer Relief Discharge System (

Analysis Reports: Pump Flywheel Integrity (4/75)

Analysis Reports: Quality Assurance During Operations P

Analysis Reports: Radioactive Waste Management (4/75)

Analysis Reports: Reactor Coolant Pressure Boundary Mate

Analysis Reports: Reactor Materials (12/74)

Analysis Reports: Reactor Vessels (1975)

Analysis Reports: Reactor Water Cleanup System (5/75)

Analysis Reports: Seismic Qualification of Instrumentat

Analysis Reports: Steam and Feedwater System Materials

Analysis Reports: Steam Generators (1/75)

Analysis Reports: Training (6/75)

Analysis (Revision 1, 2/76)

Analysis (1972) $\$ 1.75$

Analysis (7-73)

Analysis (7-73)

Analytical Chemistry Laboratories for Control Rod Absor

Analytical Chemistry Methods for Boron Carbide Absorber

Analytical Chemistry Methods for Metallic Core Componen

Analytical Chemistry Methods for Mixed Oxide Fuel (7-7

Analytical Methods for the Measurement of Uranium Tetra

Analytical Procedures for (1972) $\$ 4.50$

Analytical Procedures for (1972) $\$ 6.00$

Analyzer in the Tracer Probe Mode (1973) $\$ 1.75$

Analyzer Procedures (1973T) \$1.75

Angeles Machine, Method of Test for (1970) ASTM C131-

Angle Valves, Manual and Power Operated (3-72)

Angle-Beam Examination of Steel Plates, Specification

Anion Exchange Materials for Strong Acid Removal (1972)

Annealing of Water Cooled Nuclear Reactor Vessels (1974

Annealing of Water Cooled Nuclear Reactor Vessels (1974

Annual Doses to Man from Routine Releases of Reactor Ef

Annunciators for Control Systems (10-72) Amendment 1 (

Anticipated Transients Without Trip on Pressurized Wate

Antitrust Matters (12/73)

Antitrust Review of Construction Permit Applications Fo

Antitrust Review of Operating License Applications for

Apparatus Bushings, Requirements and Test Code for (196

Apparatus, Safety Standard for (1972) $\$ 4.00$

Apparent Density of Activated Carbon, Test for (1970) $\$$

Appendices to Sec. III Div. 1, Nuclear Power Plant Comp

Application at High Temperatures, Specification for ( 19
ANSI $\quad$ N140

NRC RG 3.26

NRC RG 1.70

NRC RG 3.25

NRC RG 1.70 .13

NRC RG 1.70 .36

NRC RG 1.70 .14

NRC RG 1.70 .24

NRC RG 1.70 .34

NRC RG 1.70 .17

NRC RG 1.70.15

NRC RG 1.70 .33

NRC RG 1.70 .25

NRC RG 1.70 .22

NRC RG 1.70.35

NRC RG 1.70 .18

RG 1.70 .26

NRC RG 1.70 .29

NRC RG 1.70 .16

NRC RG 1.70.31

NRC RG 1.70 .37

NRC RG 1.70 .30

NRC RG I.70.11

NRC RG 1.70 .27

NRC RG 1.70 .20

NRC RG 1.70 .12

NRC RG 1.70.21

NRC RG 1.70 .32

NRC RG 1.70 .23

RG 1.70 .28

NRC RG 1.70 .38

RG 1.70 .38
RG 1.92

C715

RDT F2-6T

RDT F2-8T

RDT F2-8T

RDT F2-6T

RDT F11-2T

RDT F11-3T

RDT F11-1T

RG 5.4

N15.7

N15.6

E498

D 3249

A 37.7

RDT E1-21T

A5 577

D 3087

N577

E509

RG 1.109

NRC

ERDA

ANSI

NRC

NRC

NRC

ANSI

ANSI

ASTM

A SME

ANSI 
72) Amendment $1(11-74)$

power Generating Station Protection Syste/

Preparation and

Draft Standard

Power Plant Protection Systems (6/73)

7) Calculation of Neutron Dose to Polymeric Materials and d Accounting Section of a Special Nuclear Material License

Pipe Hangers and Supports-Selection and rconium and Zirconium Alloy Bars, Rod and Wire for Nuclear rements for Bolting Material for Nuclear and Other Special 176) Guide for the Preparation of Construction Permit Connection with Its Antitrust Review of Operating License ion Plants $(1 / 76) \quad$ Standard Format and Content of License ess Than Critical Mass Quan/ Guide for the Preparation of
uel and Associate/ Standard Format and Content of License Guide to the Contents of

) (2-75) Super/Alloy Steel Bolting Material for Special irements for Materials Used in Reactor Coolant System Wear nt of Neutron Flux and Spectra for Physical and Biological ioactivity Procedures (A) Stds. (B) Medical and Biological ication for Alumina Ceramics for Electrical and Electronic irements for Pipe and Tubing for Nuclear and Other Special uirements for Steel Castings for Nuclear and Other Special ec. for Homogeneous Tool Resisting Steel Bars for Security spec. for Tool Resisting Composite Steel Bars for Security for Tool Resisting Steel Flat Bars and Shapes for Security equirements for Steel Plates for Nuclear and Other Specia ought Steel Welding Fittings for Nuclear and Other Specia ements for Forgings and Bars for Nuclear and Other Special Spec. for Copper Alloy Sand Castings for General ifications for Thermoluminescence Dosimetry-Environmental of Radioisotopic Power Generators for Certain Land and Sea Elastomeric Materials for Automotive r (1973/ Steel Castings for the Nuclear and Other Special r (1973) / Bolting Material for Nuclear and Other Special r (1973) \$1.7/ Steel Plates for Nuclear and Other Special ought Steel Welding Fittings for Nuclear and Other Special r (1973)/ Forgings and Bars for Nuclear and Other Special sheathed, Type $\mathrm{K}$ for Nuclear or for Other High Reliability Alloy Steel Bolting Materials for Special

plementary Requirements for Nickel Alloy Plate for Nuclea ements for Nickel Alloy Seamless Pipe and Tube for Nuclea nic Examination of Plain and Clad Steel Plates for Special heathed, Type K, for Nuclear or for Other High Reliability Zirconium and Zirconium-Alloy Ingots for Nuclea irements for Pipe and Tubing for Nuclear and Other Special

(1970) $\$ 1.75$ (1970) $\$ 1.75$ (1970) $\$$ Nickel Alloy Plate for Nuclea Nickel Alloy Rod and Bar for Nuclear Nickel Alloy Seamless Pipe and Tube for Nuclea fer Reprocessing Plants (6/75) Seltion, n Independent Spent Fuel Storage/ Guidance on the License um and Zirconium Alloy Sheet, Strip, and Plate for Nuclear rconium and Zirconium Alloy Bars, Rod and Wire for Nuclear um and Zirconium Alloy Sheet, Strip, and Plate for Nuclear rconium Sponge and Other Forms of Virgin Metal for Nuclea 1.75 Zirconium and Zirconium Alloy Ingots for Nuclea rconium Sponge and Other Forms of Virgin Metal for Nuclear tice for (1973) ASTM G16.1971 \$1.75

tine Reactor Releases for the Purpose of Impl/ irconium Alloys, Practice for (1974) \$1.75

Estimating Colorimetric Determination of Uranium in

Method for Colorimetric Determination of Uranium in ommended Practices for Volatile Organic Matter in Water by 1972) ASTM E40/ Uranium Oxide by Gallium Oxide Carrier DC 1970) $\$ 1.75$

Uranium Oxide by Gallium Oxide Carrier D-C

$1-1969 \$ 3.50$

$5-1969 \$ 3.50$

.6-1969\$2.50

ts) (7.75) Supers/ s) $(3-75)$ Mide Mild Steel Electrodes for Flux-Cored cent-Molybdenum Alloy Electrodes and Fluxes for Submerged $2.50 \quad$ Bare Mild Steel Electrodes and Fluxes for Submerged 2.50

2.50 Mild Steel Electrodes for Gas Metal Mild Steel Electrodes and Fluxes for Submerged Mild Steel Electrodes for Gas Meta specification for (1974) $\$ 1.75$ Mild Steel Electrodes for Flux-Cored Instrument Purging for Reduction of Hazardous Selection of Material Balance
Application of RDT Stds. (12-73) Supersedes F1-1, (7Application of the Single Failure Criterion to Nuclear Application of the Single-Failure Criterion to Nuclear Application of Threshold-Foil Measurements (1968) (R19 Application (Including That for a Uranium Enrichment Fa Application (1966) $\$ 4.00$ Application (1973) \$1.75

Rolled and Cold Finish Applications ASTM A614-73 (1974) \$1.75 Applications for Licenses to Process Source Material Applications for Nuclear Power Plants (Revision 1, 6/76 Applications for Nuclear Power Plants (10/74)

Applications for Plutonium Processing and Fuel Fabricat Applications for Special Nuclear Material Licenses of $L$ Applications for Storage Only of Unirradiated Reactor F Applications for Uranium Milling Licenses (2/73)

Applications of Bioassay for Uranium $(6 / 74)$

Applications (ASME SA-540 with Additional Requirements Applications (10-67)

Applications (1960) $\$ 2.00$ Inspection Requ Measureme Applications (1961) $\$ 3.00$ a Manual of Rad NCRP Applications (1972) $\$ 1.75$ Applications (1973) \$1.75 Applications (1974) ASTM A613-73 \$1.7 Applications (1974) ASTM A627-1968 \$1.75 Applications (1974) ASTM A628-1973 \$1.75 Applications (1974) ASTM A629-1971 \$1.75 Applications (1974) ASTM A647-1973 \$1.75 Applications (1974) ASTM A652-1973 \$1.75 Applications (1974) ASTM A654-73 \$1.75

Applications (1974) \$1.75

Applications (1975) $\$ 4.00$

Applications (3/74) /Esting, and Procedural Spec
Design, Construction, and Use

Applications, Classification System for (1975) \$1.75 Applications, Specification for Special Requirements Fo Applications, Specification for Special Requirements Fo Applications, Specification for Special Requirements Fo Applications, Specification for Special Requirements Fo Applications, Specification for (1967) \$1.75 Applications, Specification for (1970) \$1.75

Applications, Specification for (1971) ASTM B509-1970) Applications, Specification for (1971) \$1.75 ASTM B513. Applications, Specification for (1973) ASTM A578-1971 B Applications, Specification for (1973) ASTM E235-1973 Applications, Specification for (1973) \$1.75

Applications, Specification for (1974) ASTM A655-1973 Applications, Spec. for Supplementary Requirements for Applications, Spec. for Supplementary Requirements for Applications, Spec, for Supplementary Requirements for Application, and Inspection of Protective Coatings (Pai Application, Siting, Design, and Plant Protection for a Application, Specification for (1967) $\$ 1.75$ Application, Specification for (1973) ASTM B351-1967\$ Application, Specification for (1973) ASTM B352-1967 \$ Application, Specification for (1973) (ASTM B349-1967) Application, Specification for (1974) ASTM B350-1973\$ Application, Spec. for (1973) \$1.75

Applying for Specific Byproduct Material Licenses (3/76 Applying Statistics to Analysis of Corrosion Data, Prac

Aquatic Dispersion of Effluents from Accidental and Rou Aqueous Corrosion Testing of Samples of Zirconium and Z Aqueous Solutions Standard Method for (1975) \$1.75 Aqueous Solutions (1973) ASTM E318-1969 \$1.75 Aqueous-Injection Gas Chromatography (1974) \$1.75 Arc Technique, Method for Spectrochemical Analysis of ( Arc Technique, Method for Spectrochemical Analysis of ( Arc Welding Electrodes (1969) $\$ 2.00$

Arc Welding Electrodes, Specification for (1973) AWS A5 Arc Welding Electrodes, Specification for (1973) AWS A5 Arc Welding Electrodes, Specification for (1973) AWS A5 Arc Welding Electrodes, Specification for (1974)

Arc Welding Electrodes, Specification for (1974)

Arc Welding Electrodes, Specification for (1974)

Arc Welding (ASME SFA -5.20 with Additional Requiremen Arc Welding (ASME SFA-5.17 with Additional Requirement Arc Welding (ASME SFA-5.18 with Additional Requirement Arc Welding (9-75) 2-1/4-Percent-Chromium, 1-Per Arc Welding, Specification for (1973) AWS A5.17-1969 \$ Arc Welding, Specification for (1973) AWS A5.18-1969 \$ Arc Welding, Specification for (1973) AWS A5.20-1969 \$ Arc Welding, Specification for (1974)

Arc Welding, Specification for (1974)

Arc Welding, Specification for (1974)

(Arc)-Welded Steel Plate Pipe (Sizes 16 in. and Over),

Area Classification (1970) $\$ 3.00$

Areas and Item Control Areas (Revision 1, 4/75) Specif ASTM
Requ ASTM

ERDA

ANS

NRC

ASTM

NRC

MSS

ASTM

ANSI

NRC

Taff in NRC

NRC

NRC

ERDA

ERDA

RP
R ANS1

Std. ANSI

Std. Spec. ANS1

Special R ANSI

ANSI

ANS1

ANSI

NRC

ASTM

ASTM

ASTM

ASTM

ASTM

Ouples, ASTM

ASTM

ANSI

ANSI

ANSI

ANSI

ASTM

ANSI

ASTM

ASTM

ASTM

NRC

NRC

ASTM

ANSI

ANSI

ANSI

Zi ASTM

NRC

ANSI

NRC

ASTM

ASTM

ANSI

/Ec ASTM

ANSI

ASTM

AWS

ANSI

ANSI

ANSI

ASME

ASME

ASME

ERDA

ANSI

ANSI

ANSI

ASME

ASME

ASME

ASTM

ISA

NRC

RDT Fl-1

N41.2

RG 1.53

D2365

RG 5.45

SP-69

B351

N265

RG 10.4

RG 9.2

RG 9.3

RG 3.39

RG 10.3

RG 3.5

RG 8.11

RDT M6-5T

RDT F3-7T

R23

R28

D2442

A 655

N558

G24.45

G24.46

G24.47 
$\mathrm{nts}$ and in Plutonium/

Welder Qualification for Welding in Welder Qualification for

Selection of Material Balance Areas and ltem Control Visual Surveillance of Individuals in Material Access ccess to Protected Areas, Vital Areas, and Material Access Control of Personnel Access to Protected Areas, Vita Control of Personnel Access to Protected Specially Designed Vehicle and

ial (Revision I, 4/75) Test for Hydrolyzable Chlorine Compounds in Chlorinated sels (Ships and Barges) (1975) \$1./ Special Construction, t Components (1975) $\$ 4.40$

els (Ships and Barges) (1975) \$2./

Storage of Explosives or Other Da/

articles as Ships, Stores and Supp/

Vessels (Ships and Barges) (1975)/ Alternating Current Power Circuits, Surge

Transportation of Dangerous

Matter Nonmailable

on, Arrangement, and Other Provisions for Use of Dangerou electrical Resistivity of Manufactured Carbon and Graphite

1973)/Density in Air of Manufactured Carbon and Graphite transportation or Storage of Explosives or Other Dangerous

transportation or Storage of Explosives or Other Dangerous

uctions Assisted by Grants from National Endowment for the

e Chlorine Compounds in Chlorinated Aromatic Hydrocarbon Administrative Guide for Liability Insurance Nondestructive Uranium-235 Enrichment

ssion Detection (6/74)

ray Spectrometry $(9 / 74)$

Nondestructive

In situ

\section{In situ}

Calorimetric

Calorimetric

aterials Control, Calibration Techniques Fo/ d Waste $(10 / 73)$

struc tive

Nondestructive

1 Methods for the Analysis of Uranyl Nitrate Solutions fo -196/ Providing High Quality Zinc Coatings (Hot-Dip) on A386-1973\$1.75

ors $(12 / 20 / 72)$

mendment $\mid(4-72)$, Amendment 2 (/

inc-Coating (Hot-Dip) on

Serial Numbering of Fue -74)

Electrical Penetration Simulated Core

Orifice

ment 1 (5-72)

3), Amendment 2 (1-74)

Power Generating Stations (1973)/

uclear Power Plants (10/73)

ainless Steel Hexagonal Duct Tubes for Core Components and Welding of Reactor Core Components and Test dated Edition (Includes ANSI C37.20A-1970, C/ Switchgear Sheathed $(1-72)$

Thermocouple

Surveillance Program for New Fuel

Open Test

dment $2(1-74)$ FFTF Closed Loop in Reacto des E6-33T, (11-71) Amendment 1 (12-73), / Control Rod (5-72) Supersedes E5-2T/ Electric Heater and Connecto sedes E4-5T, (12.70)

Forced Circulation Cold Trap Plugging Temperature Indicato

Fuel and Control

ent I (8-73, Amend/ Gamma Compensated Ionization Chambe Fission Type Neutron Detecto Driver Fue

response Test for Sheathed, Mineral Insulated Thermocouple athed, Magnesium / Thermocouple Material and Thermocouple mentation for Light-Water-Cooled Nuclear Power Plants to dividual Observed Values) (1974) $\$ 4.00$

dividual Observed Values) (4/74)

nuclear Power Plants (1973/

Cleaning of Fluid Systems and lity Assurance Requirements for Cleaning Fluid Systems and 7-73) Visual in Service Inspection System and ications for Storage Only of Unirradiated Reactor Fuel and values) (1974) $\$ 4.00$

values) $(4 / 74)$

essment of the

Acceptable Concepts, Models, Equations, and

power Plant Control Room During a Postulated Hazardous C/ accident for Pressurized Water Reactors (5/74)

cal Consequences of a Pressurized Water Reactor Radioact/ cal Consequences of a Fuel Handling Accident in the Fuel/ cal Consequences of a Loss of Coolant Accident for Boili/ cal Consequences of a Loss of Coolant Accident for Press/ cal Consequences of a Steam Line Break Accident for Boil/ cal Consequences of a Radioactive Offgas System Failure Additional Information: Quality Information for Safety Analysis Reports: Quality cilities (1972) $\$ 3.00$ ants and for Plutonium Processing and Fuel Fabri/
Areas of Limited Accessibility in Fuel Reprocessing Pla Areas of Limited Accessibility (12/73)

Areas (Revision 1, 4/75)

Areas $(11 / 73)$

Areas $(6 / 73)$

Areas, and Material Access Areas (6/73)

Areas, Vital Areas, and Material Access Areas (6/73)

Armed Guards for Road Shipment of Special Nuclear Mate

Aromatic Hydrocarbons (Askarels) by Refluxing (1972) \$1

Arrangement, and Other Provisions for Nuclear Cargo Ves Arrangement, and Other Provisions for Nuclear Powerplan

Arrangement, and Other Provisions for Nuclear Tank Vess Arrangement, and Other Provisions for Transportation or Arrangement, and Other Provisions for Use of Dangerous Arrangenent, and Other Provisions for Nuclear Passenger Arresters for (1975) IEEE 28-1974\$5.00

Articles and Magnetized Materials (1975) $\$ 5.00$

Articles and Substances Under Special Rules (1975)

Articles as Ships. Stores and Supplies on Board Vessels

Articles at Room Temperature, Method of Test for (1973)

Articles by Physical Measurements, Method of Test for (

Articles or Substances and Combustible Liquids on Board

Articles or Substances and Combustible Liquids on Board ND Health Stds. on Projects or Prod

Askarels) by Refluxing (1972) $\$ 1.75$

Aspects of Shipping Nuclear Materials (1973) \$3.50

Assay by Gamma-Ray Spectrometry (4/74)

Assay for Plutonium in Scrap Material by Spontaneous F

Assay of Enriched Uranium Residual Holdup (8/74)

Assay of High Enrichment Uranium Fuel Plates by Gamma-

Assay of Plutonium Residual Holdup (5/74)

Assay of Plutonium (6/74)

Assay of Plutonium-Bearing Solids Applied to Nuclear M

Assay of Special Nuclear Material Contained in Scrap an

Assay Systems, Guide to Calibrating (1975) \$5.75

Assay, Isotopic Distribution, and Impurity Determinatio

Assembled Products, Specification for (R1973) ASTM A385

Assembled Steel Products, Specification for (1974) ASTM

Assemblies for Light-Water-Cooled Nuclear Power React

Assemblies for Nuclear Reactor Containment Structures a

Assemblies for Nuclear Reactors (3-73) Amendment 1 (12

Assemblies for Nuclear Systems (8-73)

Assemblies for Pressurized Water Reactors (7-71) Amend

Assemblies for Sodium Service (4-72) Amendment 1 (5-7

Assemblies in Containment Structures for Nuclear Fueled

Assemblies in Containment Structures for Water Cooled $\mathrm{N}$

Assemblies (5-76) Supersedes E6-20T, (12-71)

Assemblies (7.73)

Assemblies, Including Metal Enclosed Bus (1974) Consoli

Assemblies, Magnesium-Oxide Insulated, Stainless Steel

Assembly Designs $(6 / 76)$

Assembly Fabrication (10-73)

Assembly Fabrication (12-71) Amendment 1 (5-72), Amen

Assembly for Liquid Metal Fast Reactors (5-73) Superse

Assembly for Pressurizer for Pressurized Water Reactors

Assembly for Removal of Sodium Impurities (1.76) Super

Assembly for Sodium Service Supersedes E4-19T, (8.71)

Assembly Identification (1972) ANS-13.8\$5.00

Assembly Tag Gas (10.72)

Assembly (Fixed Electrical Compensation) (7-71) Amendm

Assembly (12-71) Amendment 1 (10-73)

Assembly (4-73)

Assembly (6-72)

Assembly, Chromel-P Versus Alumel, Stainless Steel She

Assess Plant Conditions During and Following an Acciden

Assessment of the Assumption of Normality (Employing in Assessment of the Assumption of Normality (Employing in

Associated Components During the Construction Phase of

Associated Components of Water-Cooled Nuclear Power Pl

Associated Equipment for the Reactor Enclosure System (

Associated Radioactive Material (10/73)

Assumption of Normality (Employing Individual Observed

Assumption of Normality (Employing Individual Observed

Assumptions for a Bioassay Program (9/73)

Assumptions for Evaluating the Habitability of Nuclear Assumptions Used for Evaluating a Control Rod Ejection Assumptions Used for Evaluating the Potential Radiologi Assumptions Used for Evaluating the Potential Radiologi Assumptions Used for Evaluating the Potential Radiologi Assumptions Used for Evaluating the Potential Radiologi Assumptions Used for Evaluating the Potential Radiolog Assumptions Used for Evaluating the Potential Radiologi Assurance During Design and Construction (7/74)

Assurance During Operations Phase (12/74)

Assurance for Protective Coatings Applied to Nuclear Fa Assurance Program Requirements for Fuel Reprocessing PI
NRC

NRC

NRC

NRC

NRC

NRC

ASTM

USCG

USCG

USCG

USCG

USCG

USCG

ANS

DOT

USPS

USCG

ANSI

NSI

USCC

DOL

ASTM

ANSI

NRC

NRC

NRC

NRC

NRC

NRC

ANSI

ANS

NRC

ANSI

ANSI

NRC

ERDA

ERDA

ERDA

ERDA

ERDA

ANSI

NRC

1c St ERDA

ERDA

ANSI

ERDA

NRC

ERDA

ERDA

ERDA

ERDA

ERDA

ERDA

ANSI

ERDA

ERDA

ERDA

ERDA

Time ERDA

ERDA

NRC

ANSI

NRC

ANSI

ERDA

NRC

ANS

NRC

NRC

NRC

NRC

NRC

NRC

NRC

NRC

NRC

NRC

NRC

ANSI

NRC

R 3.28

RG 1.71

RG 5.26

G 5.14

RG 5.7

G 5.7

RG 5.7

5.31

2441

6CFR 99

46 CFR 55

46 CFR 37

46CFR 146

46 CFR I 47

46CFR 79

C62.I

14CFR 103 
(1971) $\$ 4.00$

r Power Plants (Revision 2, (6/76)

) (Safety Guide $28,6 / 7 / 72$ )

e $33,11 / 3 / 72$ )

73), Amendment 2 (3-74), Amendment 3 (7-75), /

$n$, Storage, and Maintenance of Nuclear Power Plant Quality ssociated Components of Water-Cooled Nuclear Po/

Testing of Structural Concrete and Structural S/

d Testing of Structural Concrete A/

Mechanical Equipment and Systems (6/

ng, Storage, and Handling of Items for Water Coo/

to Water Cooled Nuclear Power Plants (6/73)

to Fuel Reprocessing Plants and to Plutonium Pro/ plants (1974) $\$ 5.50$

g of Instrumentation and Electric Equipment (Saf/

ction Phase of Nuclear Power Plants, Supplementary Quality

Quality

Quality

Reliability

ontrol Technology (1975) $\$ 4.00$

Krypton- 85 in the

Units of /

Design, Testing

Test for Particulate Matter in the

Test for Content of Oxidizing Substances in the

Rec. Practice for Planning the Sampling of the

75

Rec. Practice for Sampling Electrical Instruments in Hazardous

Specification for Electric-Fusion-Welded Steel Pipe for Air Sampling Instruments Manual for Evaluation of ts in Routine Releases from Light/

Methods for Estimatin

s Spectrometric Method), Method of Test for (1973) ASTM ) s Spectrometric Method) (1974) $\$ 1.75$

Test for dymium-148 Method) (1973) ASTM E321/ Methód of Test fo

dymium 148 Method), Standard Method of Test for (1974) \$ hod), Method of Test for (1973) ASTM E219-1969 \$1.75

hod), Standard Method of Test for (1974) $\$ 1.75$

Metals in Water and Waste Water by

1.75

Detecting Susceptibility to Intergranula

s, Method of (/ Detecting Susceptibility to Intergranular
adiological Factors Affecting Decision Making in a Nuclear

Method for Soil Investigation and Sampling by $r$, and Heat Exchanger Tubes, Speci/ Seamless Ferritic and al Fins, Speci/ Seamless and Welded Carbon, Ferritic, and 75
al Fins, Speci/ Specification for Seamless Ferritic Requirements for (1974A) \$1./ Carbon, Ferritic Alloy and ve or High Tem/ Welded Large Outside Diameter Light-Wal emperature Service, Specificati/ Electric-Fusion-Welded 73) Amendment 1 (4-74)

additional Requirements) (11-74) Supersedes M4-2T, (6-/ $r$ Avoiding Intergranular Corrosion and Stress Corrosion in

e Components and Assemblies (5-76) Supersedes E6-20T, 4) $\$ 1.75$ tional Requirements) (3-75) Supersedes M3-6T, (11-73)

core Components (3-73)

with Additional Requirements) (11-74) Supersedes M3-3T/ specification for (1974) $\$ 1.75$

ents (5-72)

tional Requirements) / Seamless and Welded Small Diameter General Service (/ Specification for Seamless and Welded netic Instruments to Measure the Delta Ferritic Content of asme SA-358 with Additional Pequirements) (4-75) Super/ with Additional Requirements) (7-75) Supersedes M3-5T, 03 with Additional Requirements) (1-75) Supersedes M2-/

73)

t Requirements for Thermal Insulating Materials for Use on Nonmetallic Thermal Insulation for nd Condenser Tubes, Specification for (1974A) \$1./ Welded ture Service, Specification for (1975) \$1.75

ion Service, Specification for (1974) $\$ 1.75$

cification for (1975) $\$ 1.75$

and Duties for (1975) $\$ 3.00$

Seamless

ts $(1966)(\mathrm{R} 1972) \$ 4.75$

Centrifugally Cast

$1(1.73)$

5) $\$ 1.75$

Qualifications and Duties for

Std. Spec. for

Elastomeric Materials for

Determination of Fuel Pellet Homogeneity by Alpha-

y Radioactivation Techniques,

Neutron-Flux Density and dioactivatio/ Method of Test for Neutron Flux Density and eability (1972) $\$ 1.75$ ) $\$ 1.75$ Estimating the Test for

1.75
n Austenitic Stainless Steel Components of / Tuidance for

Choice of Sample Size to Estimate the Recommended Practice for Constant Amplitude
Assurance Program Requirements for Nuclear Power Plants Assurance Program Requirements for the Design of Nuclea Assurance Program Requirements (Design and Construction Assurance Program Requirements (Operation) (Safety Guid Assurance Program Requirements (8-73) Amendment 1 ( 12 Assurance Records for Nuclear Power Plants (1974) $\$ 4.00$ Assurance Records (Revision 1, 12/75)

Assurance Requirements for Cleaning Fluid Systems and a

Assurance Requirements for Installation Inspection, and Assurance Requirements for Installation, Inspection, an Assurance Requirements for Installation, Inspection, an Assurance Requirements for Packaging, Shipping, Receiv Assurance Requirements for Protective Coatings Applied Assurance Requirements for Protective Coatings Applied Assurance Requirements for the Design of Nuclear Power Assurance Requirements for the Installation, and Testin Assurance Requirements for (1975) $\$ 4.00$ Assurance Terms and Definitions (1973) $\$ 3.00$ /R the Constru Assurance Terms and Definitions (2/74)

Assurance (6-74)

Atmosphere Accumulation, Biological Significance, and C Atmosphere Cleanup System Air Filtration and Adsorption Atmosphere (Optical Density of Filtered Deposit) (1969) Atmosphere (1970) $\$ 1.75$

Atmosphere (1973) ASTM D1357-1967\$1.75

Atmospheres for Analysis of Gases and Vapors (1973) $\$ 1$ Atmospheres (1960) $\$ 3.00$

Atmospheric and Lower Temperatures (1974) ASTM A671-19 Atmospheric Contaminents, 4 th Edition (1972) $\$ 12.50$

Atmospheric Transport and Dispersion of Gaseous Effluen

Atom Percent Fission in Uranium and Plutonium Fuel (Mas

Atom Percent Fission in Uranium and Plutonium Fuel (Mas

Atom Percent Fission in Uranium and Plutonium Fuel (Neo

Atom Percent Fission in Uranium and Plutonium Fuel (Neo

Atom Percent Fission in Uranium Fuel ( $R$ adiochemical Met

Atom Percent Fission in Uranium Fuel (Radiochemical Met

Atomic Absorption Spectrophotometry (1970) \$1.75

Attack in Stainless Steels, Rec. Practices for (1975) \$

Attack in Wrought Nickel-Rich, Chromium-Bearing Alloy

Attack (1974) $\$ 4.00$

Auditing Nuclear Materials Statements (1973) $\$ 3.50$

Auger Borings (1972) (ASTM D1452-1966) \$1.75

Austenitic Alloy Steel Boiler, (1974B) \$1.75 Superheate

Austenitic Alloy Steel Heat Exchanger Tubes with Integr

Austenitic Alloy Steel Tubes (1974) ASTM A669-1972 \$1

Austenitic Alloy Steel Tubes, Specification for General

Austenitic Chromium Nickel Alloy Steel Pipe for Corrosi

Austenitic Chromium-Nickel Alloy Steel Pipe for High T

Austenitic Stainless Steel Bar for Core Components (3-

Austenitic Stainless Steel Castings (ASME SA-351 with

Austenitic Stainless Steel Components of Fuel Reprocess

Austenitic Stainless Steel Hexagonal Duct Tubes for Cor

Austenitic Stainless Steel Pipe (ASME SA-312 with Addi

Austenitic Stainless Steel Pipe, Specification for (197

Austenitic Stainless Steel Plate, Sheet, and Strip for

Austenitic Stainless Steel Seamless Pipe (ASME SA-376

Austenitic Stainless Steel Tubing for General Service,

Austenitic Stainless Steel Tubing for LMFBR Core Compon

Austenitic Stainless Steel Tubing (ASTM a 632 with Addi

Austenitic Stainless Steel Tubing (Small-Diameter) for

Austenitic Stainless Steel Weld Metal (1974) $\$ 3.00$

Austenitic Stainless Steel Welded Pipe Large Diameter (

Austenitic Stainless Stee! Welded Tubing (ASME SA-249

Austenitic Stainless Steel Welding Fittings (ASME SA-4

Austenitic Stainless Steel Wire for Core Components (3-

Austenitic Stainless Steel (10-72) Supersedes M12-1T,

Austenitic Stainless Steel (2/23/73)

Austenitic Steel Boiler, Superheater, Heat Exchanger, a

Austenitic Steel Forged and Bored Pipe for High Tempera

Austenitic Steel Pipe for High Temperature Central Stat

Austenitic Steel Pipe for High Temperature Service, Spe

Authorized Nuclear Inservice Inspection, Qualifications

Authorized Nuclear Inspection (1974) \$3.50

Automatic Null Balancing Electrical Measuring Instrumen Automatic Spring Loaded Safety Valves (3-72) Amendment

Automotive Applications, Classification System for (197 Autoradiography (5-75)

Availability of Electric Power Sources (12/74)

Average Energy from ${ }^{3} \mathrm{H}(\mathrm{d}, \mathrm{n})^{4} \mathrm{He}$ Neutron Generators

Average Energy from $3 \mathrm{H}(\mathrm{D}, \mathrm{N}) 4 \mathrm{He}$ Neutron Generators by $\mathrm{Ra}$

Average Grain Size of Metals, Methods for (1974) $\$ 1.75$

Average Particle Size of Alumina and Silica by Air Perm

Average Quality of a Lot or Process, Practice for (1972

Average Velocity in a Duct (Pitot Tube Method) (1972) \$

Avoiding Intergranular Corrosion and Stress Corrosion I
ANSI

NRC

NRC

NRC

ERDA

ANSI

NRC

NRC

ANS1

NRC

NRC

NRC

NRC

ANSI

NRC

ANSI
NRC

ERDA

NCR P

NRC

ASTM

ASTM

ANSI

ASTM

ISA

ANSI

ACGlH

NRC

ANS!

ASTM

ANSI

ASTM

ANS1

ASTM

ASTM

ASTM

ANSI

NCRP

ANSI

ANSI

ASTM

ASTM

ANSI

ASTM

ASTM

ASTM

ERDA

ERDA

NRC

ERDA

ERDA

ASTM

ERDA

ERDA

ASTM

ERDA

ERDA

ANS!

IAg AWS

ERDA

ERDA

ERDA

ERDA

NRC

ASTM

ASTM

ASTM

ASTM

ANSI

ANSI

NS1

ERDA

ASTM

ERDA

NRC

ASTM

ANS1

ASTM

ASTM

ASTM

ASTM

NRC

ASTM

N45.2

RG 1.64

RG I 28

RG 1.33

RDT F2-2

N45.2.9

RG 1.88

RG 1.37

RG 1.94

N45.2.5

RG 1.116

RG 1.38

RG 1.54

RG 3.21

N45.2.11

RG 1.30

N452.8

N45.2.10

RG 1.74

RDT F2

R44

RG 1.52 
nt Relationship for Individual Vertical Piles Under Static t (Safety Guide 7,3/10/71) Supplement to (Safety Guide 7 tion Stds. (1960) tion Std. (1961)

964)

Natural
Film
Film
ance Std. (lonizing Radiation Emitting Products) for X-Ray

Selection of Materia

2) $\$ 4.75$ Std. Spec. for Automatic Nul of Extreme Pressure Properties of Lubricating Grease (Fou hod of Test for (1964) (RI969) ASTM C360-1963 \$1.75

General Purpose

equirements for $(1970) \$ 1.75$

Austenitic Stainless Stee Nickel Alloy Rod and

kali Reactivity of CementSupersedes M7-4T, Nickel-Chromium-Iron Alloy Rod and Supersedes M/ Nickel-Molybdenum-Chromium Alloy Rod and Supersedes M7-10T/ Nickel-Iron-Chromium Alloy Rod and ents) (3-75) Supersede/ Stainless Steel Welding Rods and $69 \$ 2.50 \quad$ Aluminum and Aluminum Alloy Welding Rods and sting Chromium and Chromium-Nickel Steel Welding Rods and Aluminum and Aluminum Alloy Welding Rods and

sting Chromium and Chromium-Nickel Steel Welding Rods and

Welding Specification for (1973) AWS A5 17-1969\$2.50 dditional Requirements) (3-75)/

Nickel and Nickel-Alloy Titanium and Titanium-Alloy

$19 \mathrm{~T},(3-75)$ Nickel-Chromium-Molybdenum-Columbium 15T, (1-72) Amendme/ Nickel-Molybdenum-Chromium Alloy 2-1/4-Percent-Chromium, 1-Percent-Molybdenum Alloy 73) AWS A5.14-1969 $\$ 2.50$ 74) Nickel and Nickel-Alloy Nickel and Nickel-Alloy

nts) (1-72) Supersedes M1/

Zirconium and Zirconium Alloy ermocouple Material, Iron and Constantan, Solid Conductor mocouple Material, Copper and Constantan, Solid Conductor mocouple Material, Chromel-P and Alumel, Solid Conductor and Other Provisions for Nuclear Cargo Vessels (Ships and Other Provisions for Nuclear Passenger Vessels (Ships and and Other Provisions for Nuclear Tank Vessels (Ships and method of Test for (1973) ASTM D2038-1968 \$/ Radioactive test for (1974) $\$ 1.75$

E393-1973 \$/ Method for Measuring Fast Neutron Flux for g (1973) \$1.75 Fast Neutron Flux by Analysis of Information for Safety Analysis Reports: Missile

Recommended Practice for Selection of Vapor destructive Examination of Welds in the Liners of Concrete 629-1971 \$1.75 Std. Spec. for Tool Resisting Steel Flat ess/ Specification for Stainless and Heat Resisting Steel nts) (11-74) Supersedes M7-3T, (10-73/ Stainless Steel finished Age-Hardening Stainless and Heat Resisting Steel Cobalt-Chromium Alloy cts Fabricated/ Pressed, and Forged Steel Shapes, Plates, $/ 28 / 72$ )

Specification for Deformed and Plain Billet-Steel astm A65/ Spec. for Special Requirements for Forgings and ication for Special Requirements for (1973)/ Forgings and

1.75

.75

Std. Spec. for Homogeneous Tool Resisting Steel 173 Safety G/ Mechanical (Cadweld) Splices in Reinforcing supersedes M7-1T/ Martensitic Stainless Steel (Type 403) Specification for Hot Rolled Alloy Stee Std. Spec. for Precipitation Hardening Nickel Alloy td. Spec. for Precipitation Hardening Iron Base Superalloy
Spec. for Precipitation Hardening Cobalt Containing Alloy service (ASTM a 637/ Precipitation Hardening Nickel Alloy itional Requirements) (4-76) Sup/ Nickel-Chromium Alloy Nickel Base-19Cr-3.1Mo-5.I ( $\mathrm{Cb}+\mathrm{Ta})-/ \quad$ Spec. for Alloy

.I ( $\mathrm{Cb}+\mathrm{Ta}) 0.90 \mathrm{Ti}-0.50 \mathrm{~A} 1$ Consumable Electrode or Vacuum/ hot Rolled and Cold Finished Zirconium and Zirconium Alloy hot Rolled and Cold Finished Zirconium and Zirconium Alloy ents) (1.72) Supersedes M/ Zirconium and Zirconium Alloy Specification for Aluminum-Alloy 5 Specification for Aluminum-Alloy Extruded Precipitation-Hardening Stanless Stee Spec. for Copper and Copper Alloy Forging Rod, Specification for Aluminum Bronze Rod, Copper, Sheet, Strip, Plate, and Rolled

Specification for Nickel-Iron-Chromium Alloy Rod and tion for Nickel-Iron-Chromium Alloy (UNS N08800) Rod and $\$ 1.75$ Nickel and Nickel-
Axial Load (1974) $\$ 1.75$

Backfitting Considerations, 10/27/71

Test for Load Settleme ASTM Coolant Acciden Background Material for Development of Radiation Protec Background Material for Development of Radiation Protec Background Material for the Development of Radiation (1 Background Radiation in the United States (1975) $\$ 5.00$

Badge Performance Criteria (2/2/73)

Badge Performance, Criteria for (1972) $\$ 4.25$

Baggage Inspection Systems (1975) $\$ 2.95$

Bags, Drop Test for (1973) $\$ 1.75$

Balance Areas and Item Control Areas (Revision 1, 4/75)
Balancing Electrical Measuring Instruments (1966) (R 197 Ball Method) (1974) $\$ 1.75$

Measu

Ball Valves $(1970) \$ 4.00$

Bar for Core Components (3-73) Amendment 1 (4-74)

Bar for Nuclear Applications, Spec. for Supplementary R

Bar Impact Testing of Metallic Materials (1972) $\$ 1.75$

Bar Method), Test for (1971) $\$ 1.75$

Bar (ASME SB-166 with Additional Requirements) (3-75

Bar (ASME SB-336 with Additional Requirements) (9-75)

Bar (ASME SB-408 with Additional Requirements) (9-75)

Bare Electrodes (ASME SFA-5.9 with Additional Requirem

Bare Electrodes, Specification for (1973) AWS A5.10-19

Bare Electrodes, Specification for (1973) AWS A5.9-196

Bare Electrodes, Specification for (1974)

Bare Electrodes, Specification for (1974)

Bare Mild Steel Electrodes and Fluxes for Submerged A

Bare Welding Rods and Electrodes (ASME SFA-5.14 with a

Bare Welding Rods and Electrodes (1970) $\$ 3.00$

Bare Welding Rods and Electrodes (6-75) Supersedes MI-

Bare Welding Rods and Electrodes (7-75) Supersedes M1-

Bare Welding Rods and Electrodes (9-75) Amendment 1 (1

Bare Welding Rods and Electrodes, Specification for (19

Bare Welding Rods and Electrodes, Specification for (19

Bare Welding Rods (ASTM B 351 with Additional Requireme

(Bare, Fiberglass Insulated, and Sheathed Over Fiberglas

(Bare, Fiberglass Insulated, and Sheathed Over Fiberglas

(Bare, Fiberglass Insulated, and Sheathed Over Fiberglas

Barges) (1975) $\$ 1.95 \quad$ /Ecial Construction, Arrangement,

Barges) (1975)

Barges) (1975) $\$ 2.15$

/L Construction, A rrangenent, and

Barium in Industrial Water and Industrial Waste Water,

Barium in Industrial Water and Industrial Waste Water,

Barium 140 Produced by Uranium-288 Fission (1974) ASTM

Barium-140 Produced by Uranium-238 Fission, Measurin

Barrier Design Procedures (12/74)

Barriers and Systems for Fuel Reprocessing Plants (2/74

Barriers for Thermal Insulations (1973) $\$ 1.75$

Barriers in Fuel Reprocessing Plants (5/75)

Bars and Rods, Tantalum (90Ta-10W) (1975) $\$ 3.00$

Bars and Shapes for Security Applications (1974) ASTM a

Bars and Shapes for Use in Boilers and Other Pressure V

Bars and Shapes (ASME SA-479 with Additional Requireme

Bars and Shapes (1974) \$1.75

for Hot Rolled and Cold

Bars and Shapes (4-75) Supersedes M7-7T, (7-71)

Bars and Strip, Zinc (Hot Galvanized) Coatings on Produ

Bars for Category 1 Concrete Structures (Revision 1, 12

Bars for Concrete Reinforcement (1975) \$1.75

Bars for Nuclear and Other Special Applications (1974)

Bars for Nuclear and Other Special Applications, Specif

Bars for Security Applications (1974) ASTM A627-1968 \$

Bars for Security Applications (1974) ASTM A628-1973

Bars of Category 1 Concrete Structures (Revision 1, 1/2

Bars (ASTM a 276 with Additional Requirements) (4-75)

Bars (1976) ASTM A322-1975 \$1.75

Bars, Forgings, and Forging Stock for High Temperature

Bars, Forgings, and Forging Stock for High Temperature

Bars, Forgings, and Forging Stock for High Temperature

Bars, Forgings, and Forging Stock for High Temperature

Bars, Forgings, and Forging Stock (ASME SA 637 with Add

Bars, Forgings, and Rings, Corrosion and Heat Resistant

Bars, Forgings, and Rings, Nickel-19Cr-19Fe-3.1 Mo-5

Bars, Rod and Wire for Nuclear Application (1973) $\$ 1.75$

Bars, Rod and Wire for Nuclear Application, Specificati

Bars, Rod and Wire (ASTM B 351 with Additional Requirem

Bars, Rods, and Wire (1974) ASTM B2 $11-1973 \$ 1.75$

Bars, Rods, Shapes, and Tubes (1974) ASTM B221-73 \$1.7

Bars, Shapes, and Forgings (ASME SA-564 with Additiona

Bar, and Shapes (1974A) \$1.75

Bar, and Shapes (1974) \$1.75

Bar, and Shapes (1974) $\$ 1.75$

Bar, Specification for (1974A) $\$ 1.75$

Bar, (1974) ASTM B408-1973 \$1.75

Bar, (1974) $\$ 1.75$

Base Alloy Clad Steel Plate, Specification for (1974A)
EPA

EPA

EPA

NCRP

NRC

ANS1

BRH

ASTM

NRC

ANSI

ASTM

ANS1

MSS

ERDA

ASTM

ASTM

ASTM

ERDA

ERDA

ERDA

ERDA

ANSI

ANSI

ASME

ASME

ANSI

ERDA

AWS

ERDA

ERDA

ERDA

ANSI

ASME

ERDA

ERDA

ERDA

USCG

USCG

ANS1

ASTM

NRC

NRC

ASTM

Non NRC

SAE

ANSI

ASTM

ERDA

ASTM

ERDA

ANSI

NRC

ASTM

ANSI

ASTM

ANSI

ANSI

NRC

ERDA

ANSI

NSI

ANSI

ANSI

ERDA

ERDA

ANS

SAE

ASTM

ANSI

ERDA

ANSI

ANSI

ERDA

ASTM

ASTM

ASTM

ASTM

ANSI

Specifica ASTM

ASTM

D 1143

17

FRC1

FRC2

FRC5

R45

RG 8.3

N13.7

2 ICFR $1020 \mathrm{G}$

D959

RG 5.26

C 39.4

D2596

A 37.92

SP-72

RDT M7-23T

B5 10

E23

C227

RDT M7-4T

RDT M7-11T

RDT M7-10T

RDT M1-2T

W3.10

W3.9

SFA-5.10

SFA-5.9

W3.17

RDT M1-11T

A5. 16 
ometric Methods for Chemical Analysis of Copper and Copper cal, Magnetic, and Other Similar Iron Nickel, and CobaltZirconium and Zirconiumigh Temperat/ 6 Are Contained in One Booklet Priced at $\$ 3.00$ Std. Spec. for Precipitation Hardening Iron

(1065.6C) Solution Treat eet, Strip, and Plate, Corrosion and Heat Resistant Nicke eet, Strip, and Plate, Corrosion and Heat Resistant Nicke

lloy Tubing, Seamless, Corrosion and Heat Resistant Nicke

, Forgings, and Rings, Corrosion and Heat Resistant Nickel

) $\begin{array}{ll}\text { o Shock and Vibration in Truck Transport (2-75) } & \text { Design } \\ \text { fects of Postulated Pipe Ruptu/ } & \text { Draft Standard for Design }\end{array}$ Fuel Storage Facility Design $\$ 1.75$

ge Stationary Type Power Plant and Substation Lead Storage 73) $\$ 1.75$

tes for Special Applications, Specification Fo/ 1 Castings, Specification for (1973) ASTM /

Ulanket-Type or Straight6) (R1973) A/

75 Flexural Strength of Concrete (Using Simple Obtaining and Testing Drilled Cores and Sawed

to Intergranular Attack in Wrought Nickel-Rich, Chromiumings (1972) (ASTM D1 194-1972) \$1.75 Method of Test for Proximity Measurement System (1-76) Liquid Sodium libration Techniques Fo/ Calorimetric Assay of Plutonium(2/76)

holdup of Special Nuclear Material in Drying and Fluidized tm E290-1968 $\$ 1.75$ Guidance on $\$ 1.75$

-Cooled Nuclear Power Reactors (3/76) Methods for Semi-Guided Method for Guided CostSpecification for Nuclear Grade Specification for Nuclear Grade and Spectrochemical Analysis Of, and Physical Tests on (/ and Spectrochemical Analysis Of, and Physical Tests on (/ r (1973) ASTM D 1890-1966 (1971) \$1.75 r1971) $\$ 1.75$ .00 75

Protection Against Specification for Deformed and Plain Applications of

eptable Concepts, Models, Equations, and Assumptions for A Measurement of Neutron Flux and Spectra for Physical and nual of Radioactivity Procedures (A) Stds. (B) Medical and packaging and Transportation of Radioactively Contaminated

packaging and Transportation of Radioactively Contaminated or (1972) ANS-6.3\$5.00 Testing (5/73) Shield Test Program for Evaluation of Installed $\$ 4.00 \quad$ Krypton-85 in the Atmosphere Accumulation $r$ Inspection and Testing Agencies for Concrete, Steel, and stm D1603-1968 \$1.75

s, Test for (1970) $\$ 1.75$

Carbon tional Requirements) (6-71) Amendment / Spec. for Mineral Fiber 972) $\$ 1.75$

Calcium Silicate

(R1973) ASTM CI65-1/ Compressive Strength of Preformed reaking Load and Calculated Flexural Strength of Preformed Density of Preformed ed Practice for Fabrication and Control of Steel Reference

Fans,

Spec. for Mineral Fiber Block and use of Dangerous Articles as Ships, Stores and Supplies on angerous Articles or Substances and Combustible Liquids on angerous Articles or Substances and Combustible Liquids on ted to Predict Heated Effluent Dispersion in Natural Water radionuclides in Air and in Water Fo/ Maximum Permissible Price for All Sections: Bound Edition \$1200.00: Lo/ Asme n/ (NB-T) Class I Nuclear Components (Supplement to Asme n) (NC-T) Class 2 Nuclear Components (Supplement to Asme n/ (ND-T) Class 3 Nuclear Components (Supplement to Asme (NE-T) Class MC Nuclear Components (Supplement to Asme $\mathrm{p} / \quad$ Welding and Brazing Qualifications (Supplement to Asme persedes / Nondestructive Examination (Supplement to Asme nal Requirements) (7-75) S/ Seamless Medium Carbon Steel $\$ 1.75$ Seamless Medium-Carbon Steel Electric-Resistance-Welded Carbon Steel inless and Heat Resisting Steel Bars and Shapes for Use in loose-Leaf $(\$ 55.00)$ Power Recommended Rules for Care and Operation of Heating Recommended Rules for Care of Powe s, Specification for (1974A) $\$ 1 . / \quad$ Welded Austenitic Steel
ubes, Speci/ Seamless Ferritic and Austenitic Alloy Steel
Base Alloys (1975) \$1.75

Base Alloys, Chemical Analysis of (1971) $\$ 1.75$

Base Alloys, Chemical Analysis of (1973) \$1.75

Base Alloys, Chemical Analysis of (1974) $\$ 1.75$

Base Superalloy Bars, Forgings, and Forging Stock for $\mathbf{H}$

Bases for GM Counter Tubes (1965) (R1971) $\$ 3.00$ and N

Bases for Systems That Perform Protective Functions in

Base-19Cr-3.1Mo-5.1 (Cb \& Ta)-0.90Ti-0.50A l

Base-19Cr-3.1 Mo-5.1 (Cb \& Ta)-0.90Ti-0.50A I Consum

Base-19Cr-3.1Mo-5.1 (Cb \& Ta)-0.90Ti-0.50A I Consum

Base-19Cr-3.1 Mo-5.1 (Cb \& Ta)-0.90Ti-0.50A I Soluti

Base-19Cr-3.1 Mo-5.1 (Cb+Ta)-0.90Ti-0.50Al-19-Fe

Basic Radiation Protection Criteria (1971) $\$ 4.00$

Basis Floods for Nuclear Power Plants (Revision 1, 4/76

Basis for Fuel and Irradiations Experiment Resistance $T$

Basis for Protection of Nuclear Power Plants Against Ef

Basis Tornado for Nuclear Power Plants (4/74)

Basis (Revision 1, 12/75)

Batteries, Rec. Practice for (1972) $\$ 5.40$

Batt-Type Thermal lnsulating Materials, Test for (1970

Beam Examination of Steel Plates, Specification for (19

Beam Ultrasonic Examination of Plain and Clad Steel Pla

Beam Ultrasonic Inspection of Carbon and Low Alloy Stee

Beam with Third Point Loading), Method of Test for (196

Beams of Concrete, Method of (1969) ASTM C42-1968 \$1.

Bearing Alloys, Method of (1973) ASTM G28-1972 \$1.75

Bearing Capacity of Soil for Static Load on Spread Foot

Bearing Film Thickness, Variable Reluctance Transducer,

Bearing Solids Applied to Nuclear Materials Control, $\mathrm{Ca}$

Bed Operations (Revision 1, 5/74) /Inimizing Residual

Being Operator at the Controls of a Nuclear Power Plant

Bend Test for Ductility of Metallic Materials (1969) as

Bend Test for Ductility of Welds (1973) ASTM E190-1971

Benefit Analysis for Radwaste Systems for Light-Water

Beryllium Oxide Powder ASTM C708-72a (1973) \$1.75

Beryllium Oxide Powder (1972A) $\$ 1.75$

Beryllium Oxide Powders, Chemical, Mass Spectrometric

Beryllium Oxide Powders, Chemical, Mass Spectrometric,

Beta Particle Radioactivity of Water, Method of Test Fo

Beta Particle Radioactivity of Water, Test for (1966) (

Betatron-Synchrotron Radiation Up to $100 \mathrm{MeV}$ (1954) $\$ 2$

Billet-Steel Bars for Concrete Reinforcement (1975) \$1

Bioassay for Uranium (6/74)

Bioassay Program (9/73)

Biological Applications (1960) $\$ 2.00$

Biological Applications (1961) $\$ 3.00$

Biological Materials (1973) $\$ 3.50$

Biological Materials (6/74)

Biological Sheilding in Nuclear Power Plants, Program F

Biological Shielding in Research and Training Reactors

Biological Significance, and Control Technology (1975)

Bituminous Materials as Used in Construction (1973) Ast

Black in Ethylene Plastics, Method of Test for (1971) a

Blanket-Type or Batt-Type Thermal Insulating Material

Block and Board Thermal lnsulation (1970) $\$ 1.75$

Block and Pipe Thermal lnsulation (ASTM C 533 with Addi

Block and Pipe Thermal Insulation, Specification for (I

Block Type Thermal Insulation, Method of Test for ( 1963

Block Type Thermal Insulation, Test for (1972) \$1.75

Block Type Thermal Insulation, Test for (1972) $\$ 1.75$

Blocks Used in Ultrasonic Inspection (1975) \$1.75

Blowdown Suppression Tank (5-72)

Blowers, and Compressors for Dry Gas Circulation (4-73

Board Thermal Insulation (1970) $\$ 1.75$

Board Vessels (1975) $\$ 7.50$

Board Vessels (1975) $\$ 7.50$

Board Vessels (1975) $\$ 7.50$

/ and Other Provisions for USCG

Bodies (5/74) /Procedure for Mathematical Models Selec

Body Burdens and Maximum Permissible Concentrations of

Boiler and Pressure Vessel Code-1977 Edition; Special

Boiler and Pressure Vessel Code, Section lii, Subsectio

Boiler and Pressure Vessel Code, Section Iii, Subsectio

Boiler and Pressure Vessel Code, Section Iii, Subsectio

Boiler and Pressure Vessel Code, Section lii, Subsectio

Boiler and Pressure Vessel Code, Section IX) (8-74) Su

Boiler and Pressure Vessel Code, Section V) (10-75) Su

Boiler and Superheater Tubes (ASME SA-210 with Additio

Boiler and Superheater Tubes, Specification for (1973)

Boiler Tubes, Specification for (1973) $\$ 1.75$

Boilers and Other Pressure Vessels (1975) \$1.75

Boilers Material Specifications (1977) Bound (\$40.00),

Boilers (1977) bd $(\$ 25.00)$, ll $(\$ 30.00)$

Boilers (1977) bd $(\$ 25.00), 11(\$ 30.00)$

Boilers $(1977)$ bd $(\$ 50.00), 11(\$ 70.00)$

Boiler, Superheater, Heat Exchanger, and Condenser Tube

Boiler, (1974B) \$1.75 Superheater, and Heat Exchanger T
Phot ASTM

ASTM

ectri ASTM

ASTM El 46

ANSI N18.8

$10 \mathrm{~F}$ ANSI

ANSI

ANSI

ANSI

NCRP

NRC

ERDA

NRC

NRC

IEEE

ASTM

ANSI

ANS

ANSI

ANSI

ANSI

ERDA

ANSI

NRC

ANSI

ANSI

NRC

ANSI

ASTM

ANS1

ASTM

ANSI

ASTM

NCRP

ASTM

NRC

Acc NRC

NCRP

a Ma NCRP

ANSI

NRC

ANSI

NRC

NCRP

ANS1

ASTM

ASTM

ERDA

ASTM

ANS1

ASTM

ASTM

End ASTM

ERDA

ERDA

ASTM

DOT

USCG

NRC
NCRP

ASME

ERDA

ERDA

ERDA

ERDA

ERDA

ERDA

ERDA

ASTM

ASTM

/R Sta ASTM

ASME

ASME

ASME

ASME

ASTM

ASTM

G81.45

N18.8

G87.78

887.84

G87.85

R39

N176

450

$\mathrm{C} 167$

A577

G35.25

G52.7

A 37.22

A 37.20

G80.4

G87.77

G87.146

RG 1.59

RDT F8-9T

RG 1.76

RG 1.13

A 37.158

RDT C8-2T 
ing Accident in the Fuel Handling and Storage Facility for of Main Steam lsolation Valve Leakage Control Systems for d for Nuclear Safety Criteria for the Design of Stationary al Startup Testing of Feedwater and Condensate Systems for 1 Consequences of a Radioactive Offgas System Failure in A adiological Consequences of a Loss of Coolant Accident for diological Consequences of a Steam Line Break Accident for Maintenance of Water Purity in (ASME SA-194 with Additional Requi/ Alloy Steel Nuts for 193 with Additional Requirements) $(2-75)$ S/ Alloy Steel 320 with Additional Requirements) (2-75) Su/ Alloy Steel ions ASTM A61/ Specification for Special Requirements for ions, Specification for Special Requirements for (I973)/ with Additional Requirements) (2-75) Super/ Alloy Steel on for $(1970) \$ 1.75$ ments) (8-75) Supersede/ High Strength, High Temperature uts and Plain Hardened Washers, Specificat/ High Strength 975) $\$ 1.75$ Quenched and Tempered Alloy Steel pecification for Structural Joints Using ASTM A325 or A490 Steel Sheet, Corrosion Resistant, Laminated Surface Practice for Preparation of Metal Surfaces for Adhesive for (1975) $\$ 1.75$ Peel or Stripping Strength of Adhesive Ferritic Alloy Steel Forged and for $(1975) \$ 1.75$ Austenitic Steel Forged and Method for Soil Investigation and Sampling by Auger Analytical Chemistry Methods for Absorber Pin Specification for Nuclear Grade ochemical Analysis of (1975) \$I.75 Nuclear Grade in Solutions of Fissile Material (1971) ANS-8.3 / Use of in Solutions of Fissile Material (1/73) Use of essel Code-1977 Edition; Special Price for All Sections: Power Boilers Material Specifications (1977) reports: Code Cases Applicable to Reactor Coolant Pressure Reactor Coolant Pressure tion for Safety Analysis Reports: Reactor Coolant Pressure mittance of Built-Up Sections by Means of the Guarded Hot Leak Testing Radioactive Integrity and Test Specifications for Selected Integrity and Test Specifications for Selected Leak Testing Radioactive Spec. of Gamma Ray Protection Against Radiation from uirements) (7-75) Supersedes MI-9T, (7-71)

$$
\text { Test for Strontium lon }
$$

$-1969 \$ 2.50$

gs (1970) $\$ 3.00$

ressure Vessel Code, Section IX) (8-74) Sup/ Welding and Welding and

ng the Potential Radiological Consequences of a Steam Line rmed Block Type Thermal Insulation, Test for (1972) \$1.7/ ardness Conversion Tables for Metals (Relationship Between

Test for Strontium Ion Brackish Water, Sea Water, and

(1973) $\$ 3.50$ Specification for Aluminum Testing for Leaks Using Test for
PPS

luding Supp. A89.1A-1975 \$13.50

Reinforced Concrete Definition of Terms Relating to Acoustical Tests of e Design, Fabrication and Erection of Structural Steel for Airborne Sound Insulation in Structural Concrete for
ce and Transmittance of -1974 (ACI 301-1972) \$3.50 hod of Test For/ Thermal Conductance and Transmittance of
art Amendment 1/ Metal Sheathed, MineraI Insulated Cable nuclides in Air and in Water Fo/ Maximum Permissible Body 1970, C/ Switchgear Assemblies, Including Metal Enclosed IEEE 21-1964\$4.00

Outdoor Apparatus

Factory Made Wrought Steel Wrought Stainless Steel

dment I (5-74) Valve, Isolation,

ower Plant Safety Systems (5/73)

Std. for

Guidance to Academic Institutions Applying for Specific dures for Exempted and Generally Licensed ltems Containing erformance Std. (Ionizing Radiation Emitting Products) for in Part Amendment $1 /$ Metal Sheathed, Mineral Insulated Testing of High Temperature Foil Shielded Instrumentation

r Generating Stations (19/ Type Test of Class IE Electric Specification for Nuclear Grade Silver-IndiumSpecification for Nuclear Grade Silver-IndiumSpectrochemical Analysis of Nuclear Grade Silver-Indium-
Boiling and Pressurized Water Reactors (Safety Guide 25

Boiling Water Reactor Nuclear Power Plants (Revision 1 , Boiling Water Reactor Plants: Issued for Trial Use and

Boiling Water Reactor Power Plants ( $12 / 75)$
Boiling Water Reactor (3/76) Boiling Water Reactors (Revision 2,6/74)

Boiling Water Reactors (Safety Guide 5, 3/10/71) Boiling Water Reactors (6/73)

Bolting for High Pressure and High Temperature Service Bolting Material for High Temperature Service (ASME SABolting Material for Low Temperature Service (ASME SABolting Material for Nuclear and Other Special Applicat Bolting Material for Nuclear and Other Special Applicat Bolting Material for Special Applications (ASME SA-540 Bolting Materials for Special Applications, Specificati Bolting Materials (ASME SA-453 with Additional Require Bolts for Structural Steel Joints, Including Suitable N Bolts for Structural Steel Joints, Specification for ( 1 Bolts (Approved February 1976) \$1.50

Bonded (I973) SAE AMS5500A-1969\$3.00

Bonding (1973) ASTM D265 I-1973 \$1.75

Bonds, Standard Method of Test for (I972) $\$ 1.75$

Bored Pipe for High Temperature Service, Specification

Bored Pipe for High Temperature Service, Specification

Borings (1972) (ASTM D 1452-I966) \$1.75

Boron Carbide Absorber Material (7-73)

Boron Carbide Pellet (5-73) Supersedes E6-30T, (8-7

Boron Carbide Powder (1974) \$1.75

Boron Carbide, Chemical, Mass Spectrometric, and Spectr

Borosilicate Glass Raschig Rings as a Neutron Absorber

Borosilicate-Glass Raschig Rings as a Neutron Absorber

Bound Edition \$1200.00: Loose-Leaf Edition \$1700.00 (1

Bound ( $\$ 40.00)$, Loose-Leaf $(\$ 55.00)$

Boundary Components ( $12 / 74)$

Tion for Safety Analysis

Boundary Leakage Detection Systems (5/73)

Boundary Materials and Inservice Inspection (1/75)

Box, Method of Test for (1967) (R1973) ASTM C236-1966

Brachytherapy Sources (Revision 1, 7/74)

Brachytherapy Sources (Revision 1,7/74)

Brachytherapy Sources (I973) $\$ 3.50$

Brachytherapy Sources (I973) $\$ 3.50$

Brachytherapy Sources (I974) $\$ 3.00$

Brachythreapy Sources ( I972) $\$ 4.00$

Brackish Water, Sea Water, and Brines (I974) $\$ 1.75$

Brazing Filler Metal (ASME SFA-5.8 with Additional Req

Brazing Filler Metal, Specification for (1973) AWS A5.8

Brazing Filler Metal, Specification for (1974)

Brazing Joints for Cast and Wrought Solder Joint Fittin

Brazing Qualifications (Supplement to ASME Boiler and P

Brazing Qualifications ( 1977$)$ bd $(\$ 40.00)$, ll $(\$ 55.00)$

Break Accident for Boiling Water Reactors (Safety Guide

Breaking Load and Calculated Flexural Strength of Prefo

Brinell Hardness, Vickers Hardness, Rockwell Hardness,

Brines ( I 974) $\$ 1.75$

Bronze Rod, Bar, and Shapes (1974) SI.75

Bronze Solder Joint Fittings for Sovent Drainage System

Bubble Emission Techniques (1974) \$1.75

Buffering Action of Metal Cleaners (1971) \$1.75

Buffers (10-71) Amendment I (12-71)

Building Code Requirements for (1972) ACI 318-1971, in

Building Constructions and Materials (1973) $\$ 1.75$

Buildings (Adopted February 12, 1969) $\$ 5.00$

Buildings, Rec. Practice for Measurement (1971) $\$ 1.75$

Buildings, Specification For, Including Addenda A I38.1 a

Built-Up Sections by Means of the Guarded Hot Box, Met

Bulk Material (2-73) Supersedes C7-14T, (3-70), in P

Burdens and Maximum Permissible Concentrations of $R$ adio

Bus (1974) Consolidated Edition (Includes ANSI C37.20A-

Bushings, Requirements and Test Code for (1964) (R 1970)

Butt Welding Ends (1972) $\$ 4.00$

Butt Welding Fittings (1971) $\$ 4.00$

Butt Welding Fittings (1971) $\$ 4.00$

Butterfly Type (8-72)supersedes E1-13T, (12-70) Amen

Butterfly Valves (1970) $\$ 3.00$

Bypass and Drain Connection (1971) $\$ 3.00$

Bypassed and Inoperable Status Indication for Nuclear $\mathbf{P}$

Byproduct Material Licenses (3/76)

Byproduct Material (6/74)

Cabinet X-Ray Systems (1975) $\$ 2.95$

Cable Bulk MateriaI (2-73) Supersedes C7-14T, (3-70

Cable for Nuclear Detectors (8-71)

Cable (6-74)

Cables, FieId Splices, and Connections for Nuclear Powe

Cadmium Alloy (1973) \$1.75

Cadmium Alloy (1974) ASTM C752-1973 \$1.75

Cadmium Alloys (1974) \$1.75 Radiologica NRC

NRC

NRC

ANS

ntial R NR

NRC

ERDA

ERDA

ERDA

ANSI

ASTM

ERDA

ASTM

ERDA

ASTM

ASTM

AISC

ANSI

ANSI

ASTM

ASTM

ANSI

ERDA

ERDA

ASTM

ASTM

ANSI

NRC

ASME

NRC

NRC

ANSI

NRC

NRC

ANSI

ANSI

NCRP

NCRP

ASTM

ERDA

ANS1

ASME

MSS

ERDA

ASME

NRC

ASTM

ANSI

ASTM

ASTM

ANSI

ASTM

ASTM

ERDA

ANSI

ASTM

AISC

ASTM

ANS

ANSI

ERDA

NCRP

ANSI

ANSI

ANSI

ANSI

MSS

ERDA

MSS

MSS

NRC

NRC

NRC

BRH

ERDA

ERDA

ERDA

ANSI

ASTM

ANSI

Chemical and ASTM

RG 1.25

RG 1.96

N21 2

RG 1.68 .

RG 1.98

RG 1.3

RG 1.5

RG 1.56

RDT M6-4T

RDT M6-3T

RDT M6-1T

N265

A6 I 4

RDT M6-5T

A540

RDT M6-6T

A 325

A490

S314

G87.1

Z197.28

D903

A369

A430

A 37.147 
cal and Spectrochemical Analysis of Nuclear Grade Silver rete Structures (Revision 1, 1/2/73 Safety G/

Mechanical oncrete (1973) ASTM/ Specification for Fly Ash and Raw or m C 533 with Additional Requirements) (6-71) Amendment / cification for (1972) $\$ 1.75$

ermal Insulation, Test for (1972) \$1.7/

Breaking Load and Limit of Error Concepts and Principles of Limit of Error Concepts and Principles of

) ASTM D2568-1970\$1.75

Rec. Practice for

s of Reactor Effluents for the Purpose of Evaluating Com/ application of Threshold-Foil Measurements (1968) (R197/ eous and Liquid Effluents from Light-Water-Cooled Powe/ 975) ANS-8.11

Validation of 176) Validation of
Nuclear Data Sets for Reactor Design

erritic Content of Austenitic St/ Nondestructive Assay Systems, Guide to Recommended Practice for Standard optical Pyrometer (1973) ASTM E452-1972 \$1.7/ Method for nsulating Materials Testing (19/ Recommended Practice for 1972) $\$ 1.75$

$2 \mathrm{~T},(2-69)$

975) $\$ 5.50$

Volume

nium-Bearing Solids Applied to Nuclear Materials Control, Nuclear Material Control, Mass Recommended Practice for Rotameter

to Nuclear Materials Control, Calibration Techniques Fo/ p (6-72) Amendment I (5-74) amendment I (1-74) 10/71) Vertical, 72) (ASTM D1194-1972) Selection of Diesel Generator Set Method of Test for Bearing Analytical Chemistry Methods for Boron A bsorber Pin Boron Specification for Nuclear Grade Boron cal Analysis of (1975) \$1.75 Nuclear Grade Boron 974A/ Std. Spec. for Quenched and Tempered Vacuum Treated tional Requirements) (7-75) Supersedes M2-8T, (7-71) a-508 with Additional Requirements) (4-76) Supersedes / al Requirements) (4-76) Supersedes M3-16T, (8-75) $\begin{array}{rr}\text { e, Specification for (1974) } \$ 1.75 & \text { Specification for Specialized } \\ \text { Seamless and Welded }\end{array}$ ith Additional Requirements) (5-75) Supersedes M2-3T, / vessel Components (197/ $\mathrm{d}$ of Test for (19/ Electrical Resistivity of Manufactured Specification for Steel Forgings, method of Test for (1973)/ Density in Air of Manufactured
f Test for (1973) ASTM C7/4.1972/ Thermal Diffusivity of (1972) $\$ 1.75$

Thermal Diffusivity of

\$1./ Moduli of Elasticity and Fundamental Frequencies of Standard Definitions and Terms Relating to Manufactured $\$ 1.75$ Chemical Analysis of

(1973) ASTM / Longitudinal-Beam Ultrasonic Inspection of th Additional Requirements) (5-75) Supersedes M 3-1 IT,/
Specification for Forgings, esting for Piping Components/

1971) ASTM D 1603-1968 $\$ 1.75$
ASTM C565-1971 $\$ 1.75$ Sodium $(1-72)$

e (1975) \$1.75

Std. Spec. for Piping Fituings of Std. Spec. for Piping Fittings of Wrought with Additional Requirements) (7-75) S/

$\mathrm{n}$ for $(1973) \$ 1.75$

uirements) (8-75) Supersedes M4-1T, (7-7I)

for $(1975) \$ 1.75$

service, Specification for (1974/

Specification for (1974A) \$1.7 her Pressure Vessel Components (1970) Ast/ Std. Spec. for ication for (1973) $\$ 1.75$

4)

n for (1975) \$1.75 Low and Intermediate Tensile Strength rements) (8-75) Supersedes M5-2T, (5-73)

1 Requirements) (7-75) Supersedes M3-1T, (5-73)

$14.1971 \$ 1.75$

for (1972) \$1.75

al Killed, Specification for (1975) \$1.75

tion for (1974A) $\$ 1.75$

specification for (1974A) $\$ 1.75$

74 A) $\$ 1.75$

ommended Practice for Liquid Phase Evaluation of Activated

3)

.75

$6-1972 \$ 1.75$
Cadmium Alloys, Methods for (1974) ASTM C760-1974 \$1.7

Cadweld) Splices in Reinforcing Bars of Category I Conc Calcined Natural Pozzolans for Use in Portland Cement C Calcium Silicate Block and Pipe Thermal Insulation (Ast Calcium Silicate Block and Pipe Thermal Insulation, Spe Calculated Flexural Strength of Preformed Block Type th Calculation in Nuclear Materials Control (1974) $\$ 3.00$ Calculation in Nuclear Materials Control (1.74)

Calculation of Absorbed Dose from Gamma Radiation ( 1971 Calculation of Annual Doses to Man from Routine Release Calculation of Neutron Dose to Polymeric Materials and Calculation of Releases of Radioactive Materials in Gas Calculational Methods for Nuclear Criticality Safety (I Calculational Methods for Nuclear Criticality Safety (6 Calculations (1975) ANS-19.I \$12.50

Calibrating Magnetic Instruments to Measure the Delta F Calibrating (1975) $\$ 5.75$

Calibration and Format for Nuclear Logs (1974) \$1.00 Calibration of Refractory Metal Thermocouples Using an Calibration of Standards and Equipment for Electrical I Calibration of Thermocouples by Comparison Techniques Calibration Program Requirements (2-73) Supersedes F3 Calibration Techniques for Nuclear Materials Control ( 1 Calibration Techniques for the (1975) \$5.75

Calibration Techniques for (1975) $\$ 5.50$

Calibration (1973) \$1.75

Calorimetric Assay of Plutonium (6/74)

Calorimetric Assay of Plutonium-Bearing Solids Applied

Canned or Wet Motor Driven Single Stage Centrifugal Pum

Cap for Penetrations LMFBR Reactor Vessel Head (4-73)

Capacity for Standby Power Supplies (Safety Guide 9, 3)

Capacity of Soil for Static Load on Spread Footings (19

Caps (6-71)

Carbide Absorber Material (7-73)

Carbide Pellet (5-73) Supersedes E6-30T, (8-71)

Carbide Powder (1974) \$1.75

Carbide, Chemical, Mass Spectrometric, and Spectrochemi

Carbon and Alloy Steel Forgings for Pressure Vessels (1

Carbon and Alloy Steel Forgings (ASME SA-54I with Addi

Carbon and Alloy Steel Forgings, Vacuum Treated (ASME S

Carbon and Alloy Steel Pipe (ASME SA-333 with Addition

Carbon and Alloy Steel Pipe (1975) \$1.75

Carbon and Alloy Steel Tubes for Low Temperature Servic

Carbon and Alloy Steel Welding Fittings (ASME SA-234 W

Carbon and Alloy, Quenched and Tempered, for Pressure

Carbon and Graphite Articles at Room Temperature, Metho

Carbon and Graphite Articles by Physical Measurements,

Carbon and Graphite by a Thermal Pulse Method, Method O

Carbon and Graphite by a Thermal Pulse Method, Test for

Carbon and Graphite Materials by Sonic Resonance (1974)

Carbon and Graphite (1975) \$1.75

Carbon and Graphite, Methods for (1973) ASTM C560-1969

Carbon and Low Alloy Steel Castings, Specification for

Carbon and Low Alloy Steel Welded Pipe (ASME SA-155 W

Carbon and Low Alloy Steel, Requiring Notch Toughness T

Carbon Black in Ethylene Plastics, Method of Test for

Carbon Graphite Mechanical Materials, Methods of (1973)

Carbon Meter Equilibration Module for Service in Liquid

Carbon Meter for Service in Liquid Sodium (1-72)

Carbon Steel and Alloy Steel for Low Temperature Servic

Carbon Steel Boiler and Superheater Tubes (ASME SA-210

Carbon Steel Boiler and Superheater Tubes, Specificatio

Carbon Steel Boiler Tubes, Specification for (1973) $\$ 1$

Carbon Steel Castings (ASME SA-2I6 with Additional Req

Carbon Steel for High Temperature Service Specification

Carbon Steel for Intermediate-and Higher-Temperature

Carbon Steel for Moderate and Lower Temperature Service

Carbon Steel Forgings for Piping Components (ASME SA-1

Carbon Steel Forgings for Seamless Drums, Heads, and Ot

Carbon Steel Heat Exchanger and Condenser Tubes, Specif

Carbon Steel Isolation Valves (4-73) Amendment 1 (5-7

Carbon Steel Plates of Structural Quality, Specificatio

Carbon Steel Plates (ASME SA-5I6 with Additional Requi

Carbon Steel Seamless Pipe (ASME SA-106 with Additiona

Carbon Steel Sheets for Pressure Vessels (1972) ASTM A4

Carbon Steel Sheets, Commercial Quality, Specification

Carbon Steel Sheet, Cold Rolled, Drawing Quality, Sceci

Carbon Steel, Improved Transition Properties, Specifica

Carbon Steel, Low and Intermediate-Tensile Strength,

Carbon Steel, Manganese-Silicon, Specification for (19

Carbon (1970) $\$ 1.75$

Carbonate, Low Chloride Fire Extinguishing Agent (12-7

Carbons and Graphite (1974) ASTM C749-75 $\$ 1.75$

Carbon-Manganese-Silicon, Specification for (1975) \$1

Carbon-14 Wastes (1953) \$2.00

Carbon, Cold Rolled, Commercial Quality (1974) ASTM A36
ANSI

NRC

ANSI

ERDA

ASTM

ASTM

ANSI

NRC

ANSI

NRC

ASTM

NRC

ANSI

NRC

ANSI

AWS

ANSI

API

ANSI

ASTM

ASTM

ERDA

ANSI

ANSI

ANSI

ASTM

NRC

ANSI

ERDA

ERDA

NRC

ANSI

ERDA

ERDA

ERDA

ASTM

ASTM

ASTM

ERDA

ERDA

ERDA

ASTM

ASTM

ERDA

ASTM

ANSI

ANSI

ANS!

ASTM

ASTM

ASTM

ANSI

ANSI

ERDA

ASTM

ANSI

ANSI

ERDA

ERDA

ASTM

ERDA

ASTM

ERDA

ASTM

ASTM

ASTM

ERDA

ANSI

ASTM

ERDA

ASTM

ERDA

ERDA

ANSI

ASTM

ASTM

ASTM

ASTM

ASTM

Rec ASTM

ERDA

ANSI

ASTM

NCRP

ANSI

574

G 110

A 37.122

RDT M 12-2T

C533

II 5.16

RG 5.18

K65.218

RG 1.109

D2365

RG 1.112

N1 6.9

RG 3.41

N4I

A4. 2

N 15.20

RP33

N 144

D2865

E220

RDT F3-2T

N15.19

N15.22

N15.18

D3 195 


\section{KWIC Index of U.S. Nuclear Standards}

Activated Specification for General Requirements for (1974A) \$1 nger Tubes with Integral Fins, Speci/ Seamless and Welded Apparent Density of Activated Particle Size Distribution of Granular Activated Total Ash Content of Activated Moisture in Activated Recommended Rules for Recommended Rules for ), ll $(\$ 30.00)$ onstruction, Arrangement, and Other Provisions for Nuclear $\begin{array}{ll}\text { alysis of (1972) ASTM E40/ } & \text { Uranium Oxide by Gallium Oxide } \\ \text { analysis of (1970) } \$ 1.75 & \text { Uranium Oxide by Gallium Oxide } \\ \text { Rail Freight }\end{array}$ Rail Express Code
Code tion (Revision 6, 5/76) n L, 5/76) Large Shippin omponents / Information for Safety Analysis Reports: Code mponents at Elevated Temperatures (Supplement to ASME Code

Temperature Reactors (Supplement to ASME Section III Code $1(11-73)$ Shielded Shipping Silver Brazing Joints for Centrifugally

Specification for (1975) \$1.7 ystems (1973) $\$ 3.50$

vice, Specification for (1975) $\$ 1.75$

Centrifugally

150 lb. Corrosion Resistan

$\$ 4.00$

(1970) $\$ 3.00$

ure Application at High Temperatures, Spec/

Centrifugally

4-76) Supersedes M3-31T,

Chemical Analysis of Steel

Stainless Steel Centrifugally Spec. for Copper Alloy Sand

74) Ast/ Specification for Special Requirements for Steel Specification for Special Requirements for (1973/

aphs for (1973) $\$ 1.75$

-75) Supersedes M4-1T, (7-71)

1-74) Supersedes M4-2T, (6-/

Steel

Carbon Steel Supersedes M4-5/ Nickel-Molybdenum-Chromium Alloy radiographic Inspection Method, Quality Standard for Stee cle Magnetic Inspection Method, Quality Standard for Steel Visual Method, Quality Standard for Steel ence Radiographs for Heavy Walled (4-1/2 to 12 in.) Stee rence Radiographs for Heavy Walled (2 to 4-1/2 in.) Stee

Depleted Uranium Cobalt-Chromium Alloy

E125-1963 \$1./ Magnetic Particle Indications on Ferrous -Beam Ultrasonic Inspection of Carbon and Low Alloy Steel

Titanium and Titanium Alloy Radioactive Waste

Testing of Reinforcing Bars for

ty $G /$ Mechanical (Cadweld) Splices in Reinforcing Bars o Design Limits and Loading Combinations fr Additional lnformation: Design of Seismic Concrete Placement in ance Std. (lonizing Radiation Emitting Products) for ColdStopping Powers for Use with High Efficiency Gas Phase Adsorbe Sponge and Expanded Fineness of Portland

Time of Setting of Hydraulic 5 and Raw or Calcined Natural Pozzolans for Use in Portland C360-1963 \$1.75 Ball Penetration in Fresh Portland Slump of Portland Qualifications for

Structures (11/75) est for (1973) $\$ 1.75$

Fiber Hydraulic-Setting Thermal Insulating and Finishing st for (1971) $\$ 1.75$

Porential Alkali Reactivity of

Fiber Hydraulic-Setting Thermal Insulating and Finishing Seamless Austenitic Steel Pipe for High Temperature rive (5-71) Amendment 1 (2-72), Amendment 2 (6-74) Horizontal, Electric Motor Driven, Single Stage Vertical, Canned or Wet Motor Driven Single Stage Vertical, Shaft Sealed, Motor Driven, Single Stage Performance Test Code for rature Service, Specification for (1975) $\$ 1.75$

emperature Service, Specification for (1975) $\$ 1.75$

bing for Pressure Application at High Temperatures, Spec/ equirements) (4-76) Supersedes M3-31T,/ Stainless Steel t, $(7-70)$

74)

Fast Flux Test Facility

72) $\$ 1.75$

Determination of lnsulation Compaction in Specification for Alumina
Carbon, Definition of Terms Relating to (1974) \$1.75

Carbon, Ferritic Alloy and Austenitic Alloy Steel Tubes

Carbon, Ferritic, and Austenitic Alloy Steel Heat Excha

Carbon, Test for (1970) $\$ 1.75$

Carbon, Test for $(1970) \$ 1.75$

Carbon, Test for $(1970) \$ 1.75$

Carbon, Test for (1970) $\$ 1.75$

Care and Operation of Heating Boilers (1977) bd $(\$ 25.00$

Care of Power Boilers (1977) bd $(\$ 25.00)$, ll $(\$ 30.00)$

Cargo Vessels (Ships and Barges) (1975) \$1.95

Carrier DC Arc Technique, Method for Spectroc c"

Carrier D-C Arc Technique, Method for Spectroc.se i - I

Carriers Regulations (1975) $\$ 6.80$

Carriers Regulations (1975) $\$ 6.80$

Case Acceptability: ASME Section IIl Design and Fabrica

Case Acceptability: ASME Section I11 Materials (Revisio

Cases and Crates, Testing (1973) $\$ 1.75$

Cases Applicable to Reactor Coolant Pressure Boundary C

Cases $1592,1593,1594,1595$, and 1596) Supersedes F9

Cases 1592, 1593, 1594, 1595, and 1596) (Revision 1,6/

Cask for Spent Reactor Fuel Elements (8-73) Amendment Cast and Wrought Solder Joint Fittings (1970) $\$ 3.00$

Cast Austenitic Steel Pipe for High Temperature Service

Cast Bronze Solder Joint Fittings for Sovent Drainage S

Cast Ferritic Alloy Steel Pipe for High Temperature Ser

Cast Flanged Valves (1959) $\$ 3.00$

Cast Flanges and Flanged Fittings (1965) $\$ 3.00$

Cast Iron Gate Valves, Flanged and Threaded Ends (1970)

Cast Iron Swing Check Valves, Flanged and Threaded Ends

Cast Iron-Chromium-Nickel High Alloy Tubing for Press

Cast Iron, Open-Hearth Iron, and Wrought Iron (1975) \$

Cast Pipe (ASME SA-451 with Additional Requirements) (

Castings for General Applications (1974) \$1.75

Castings for Nuclear and Other Special Applications ( 19

Castings for the Nuclear and Other Special Applications

Castings Up to 2 Inches in Thickness, Reference Radiogr

Castings (ASME SA-216 with Additional Requirements) (8

Castings (ASME SA-351 with Additional Requirements) (1

Castings (ASTM a 494 with Additional Requirements) (10-

Castings (1971) $\$ 2.00$

Castings (1971) $\$ 3.00$

Castings (1971) $\$ 8.00$

Castings (1973) ASTM E280-1972 \$1.75

Castings (1974) ASTM E186-1973 \$1.75

Castings (1975) $\$ 3.00$

Castings (7-75) Supersedes M4-3T, (6-72)

Castings, Reference Photographs for (1969) (R1973) ASTM

Castings, Specification for (1973) ASTM A609-1970 \$1.7

Castings, Spec. for (1969) $\$ 1.75$

Categories, Definition of (1967) $\$ 3.00$

Category 1 Concrete Structures (Revision 1, 12/28/72)

Category I Concrete Structures (Revision 1, 1/2/73 Safe

Category 1 Fluid System Components (5/73)

Category I Structures (11/74)

Category 1 Structures (6/73)

Cathode Gas Discharge Tubes (1975) \$2.95

Cavity Chambers (1961) $\$ 2.00$

Cells-Including Amendment 1973 (1972) $\$ 2.00$

Cellular Rubber Products, Specification for (1973) $\$ 1.7$

Cement by the Turbidimeter, Test for (1974) $\$ 1.75$

Cement by Vicat Needle, Test for (1974) $\$ 1.75$

Cement Concrete (1973) ASTM C618-1972 \$1.75

Cement Concrete (1974) $\$ 1.75$

Cement Concrete, Method of Test for (1964) (R1969) ASTM

Cement Concrete, Method of Test for (1974) $\$ 1.75$

Cement Grouting for Prestressing Tendons in Containment

Cement Mortars (Using 2-in (50-mm) Cube Specimens), T

Cement (ASTM C 449 with Additional Requirements) (10-7

Cement-Aggregate Combinations (Mortar-Bar Method), Te

Cement, Methods for (1970) ASTM C114-1969 \$1.75

Cement, Specification for (1970) $\$ 1.75$

Central Station Service, Specification for (1974) \$1.75

Centrifugal Free Surface, Sodium Pump with Electrical D

Centrifugal Pump (2-72) Amendment 1 (5-74)

Centrifugal Pump (6-72) Amendment 1 (5-74)

Centrifugal Pump (7-72) Supersedes E3-3T, (10-70), a

Centrifugal Pumps (1965) $\$ 5.00$

Centrifugally Cast Austenitic Steel Pipe for High Temp

Centrifugally Cast Ferritic Alloy Steel Pipe for High T

Centrifugally Cast Iron-Chromium-Nickel High Alloy Tu

Centrifugally Cast Pipe (ASME SA-451 with Additional R

Ceramic Electrical Insulators (8-74) Supersedes C18-1

Ceramic Grade Plutonium Dioxide (6-71)

Ceramic Grade Uranium Dioxide (6-71) Amendment 1 (12.

Ceramic Insulated Conductors (8/70) Amendment 1 (9/73)

Ceramics for Electrical and Electronic Applications ( 19
ASTM

ASTM

ASTM

ASTM

ASTM

ASTM

ASTM

ASME

ASME

Ecial C USCG

ANS1

ASTM

DOT

DOT

NRC

NRC

ASTM

NRC

ERDA

NRC

ERDA

MSS

ASTM

ANS1

ASTM

MSS

MSS

MSS

ANSI

ASTM

ERDA

ASTM

ANS!

ASTM

ASTM

ERDA

ERDA

ERDA

MSS

MSS

MSS

Refer ANSI

Refe ANS

SAE

ERDA

ANS

ANS1

ASTM

ANSI

NRC

NRC

NRC

NRC

NRC

Perform BRH

NCRP

1ES

ASTM

ASTM

ASTM

ly Ash ANSI

ASTM

ANSI

ASTM

NRC

ASTM

ERDA

ASTM

ANSI

Mineral ASTM

ASTM

ERDA

ERDA

ERDA

ERDA

ASME

ASTM

ASTM

ANS1

ERDA

ERDA

ERDA

ERDA

ERDA

ASTM

D2652

A498

D2854

D2862

2866

D2867

SEC-VI

SEC-VII

46CFR99

$\mathrm{Z} 128.27$

E402

49CFR 174

49CFR 175

RG 1.84

RG 1.85 
1-73)

m D3/ Absorbed Gamma and Electron Radiation Dose with the ment Properties of Sealed Radioactive Sources Contained in onstruction, and Use of Radioisotopic Power Generators for ments/ Administrative Guide for Obtaining Exemptions from Testing and

$1969 \$ 1.75$ Nondestructive Testing Personnel Qualification and Radioactive Radioactive

$1970 \$ 1.75$ for $(1970) \$ 1.75$ aining (1974) $\$ 3.50$ Methods for Radiochemical Determination of Radiochemical Determination of Cobalt -60 and Std. Specifications for Electric Std. Specifications for Hand Operated Std. Specifications for Manually Lever Operated
(8-73, Amend/ Gamma Compensated lonization ) Amendment 1 (8-73, Amend/ Gamma Compensated lonization
Stopping Powers for Use with Cavity
posed to High Energy Radiation, Rec. Practice for Determ/ posed to High Energy Radiation, Rec. Practice for Determ/ Wide Range (10 Decade) Neutron Flux Monitoring s (1969) ASTM E317-/ Practice for Evaluating Performance Requirements for Inspection of Dimensional
fiber Electrometer Type Dosimeters and Companion Dosimeter Stainless Steel 1973) ASTM C560-1969 \$1.75 Cast Iron Swing

5) $\$ 1.75$

0) ASTM C 114-1969 \$1.75

ions $(1971) \$ 1.75$

1974) $\$ 1.75$

Photometric Methods for

Photometric Methods for

ium-Iron Alloys ( 1973) \$1.75

1974) $\$ 1.75$

methods for (1973) (ASTM E195-1968) \$1.75

$n$, and Wrought lron (1975) $\$ 1.75$

Titanium and Titanium-Base Alloys, , and Other Similar Iron, Nickel, and Cobalt-Base Alloys, Zirconium and Zirconium-Base Alloys, silver-Cadmium Alloys, Methods for (1974) ASTM C760-1 silver-Indium-Cadmium Alloys (1974) \$1.75

Wrought Nonferrous Metals and Alloys for Determination of th Lens Gaskets (1968) $\$ 4.00$ $1971 \$ 1.75$

(1973) \$1.75 ASTM D2187/ Methods of Test for Physical and (1974) $\$ 1.75$

High Pressure

Energy Radiation, Rec. Practice for Determ/ Changes in ear Power Plant Control Room During a Postulated Hazardous Environment with Intended $\mathrm{Ch} /$ Threshold Limit Values for Hygienic Guides (For Hazard Evaluation of Industria sis of / Uranium Dioxide Powders and Pellets, Methods for sis $\mathrm{O} /$ Plutonium Dioxide Powders and Pellets, Methods for sis/ Nuclear Grade Mixed Oxides ( $\left.(\mathrm{U}, \mathrm{Pu}) \mathrm{O}\left({ }_{2}\right)\right)$, Methods for sis Of, and Physical Tests on (/ Beryllium Oxide Powders, sis $\mathrm{O} /$ Nuclear Grade Uranium Dioxide Powders and Pellets, sis/ Nuclear Grade Plutonium Dioxide Powders and Pellets, sis of (1974) \$/ Nuclear Grade Mixed Oxides ( (U,Pu)O( $\left.{ }_{2}\right)$ ) sis Of, and Physical Tests on (/ sis of (1975) $\$ 1.75$ Beryllium Oxide Powders, sis of Nuclear Grade Uranium Dioxid/ Standard Methods fo sis of Nuclear Grade Plutonium Diox/Standard Methods for nd Radiochemical Analysis of Nuclear Grade Plutonium Nit/ and Radiochemical Analysis of Nuclear Grade Plutonium Me/ grade Plutonium Nitrate Solutions, Methods for (1974) As/ and Radiochemical Analysis of Uranium Hexafluoride, Meth/ and Radiochemical Analysi/ Nuclear Grade Plutonium Metal, and Radiochemical, Analysis of (19/ Uranium Hexafluoride, nitrate Solutions and Plutonium Metal Standard Methods for 1 Analysis (7-7) -73) Qualification and Control of Analytical Qualification and Control of Analytical 7.73 ) Analytical Analytica

1 ( $12-74)$

Analytical

ive Substances and Ionizing Radiations (1971) $\$ 6.85$

Sodium Carbonate, Low Water and Waste Water, Tests for ixes, Method of Test for (1975) $\$ 1.75$ Water Soluble ng (1972) \$1/ Test for Hydrolyzable Chlorine Compounds in (Askarels) by Refluxing (1972) \$1/ Test for Hydrolyzable Test for Residual Tests for Residual

r Power Plant Control Room Operators Against an Accidental a Lot or Process, Practice for (1972) \$1.75

73) $\$ 1.75$

General Gas volatile Organic Matter in Water by Aqueous-Injection Gas
Ceramic-Insulated Magnet Wire (7-70)

Ceramographic Preparation Cf Mixed Oxide Fuel Pellets (

Ceric Sulfate Dosimeter, Method of Test for (1973) (Ast

Certain Devices to Be Distributed for Use Under General

Certain Land and Sea Applications (3/74)

Certain NRC Requirements Over Radioactive Material Ship

Certification of Particulate Clean Rooms (1970) $\$ 5.00$

Certification, Recommended Practice for $\$ 10.50$

Cesium in Water, Method of Test for (1973) ASTM D2577.

Cesium in Water, Test for (1972) $\$ 1.75$

Cesium-137 in Nuclear Fuel Solutions (1973) ASTM E320-

Cesium-137 in Nuclear Fuel Solutions, Standard Method

Cesium-137 Teletherapy Equipment, Guidelines for Maint

Chain Hoists (1971) $\$ 0.50$

Chain Hoists (1974) $\$ 0.50$

Chain Hoists (1974) \$0.50

Chamber Assembly (Fixed Electrical Compensation) (7-71

Chambers (1961) $\$ 2.00$

Changes in Chemical Reactivity of Inorganic Material Ex

Changes (1975) \$.75 /Alues for Chemical Substances and

Channel (2-71)

Characteristics of Pulse Echo Ultrasonic Testing System

Characteristics (8-73)

Chargers (1965) (R1971) $\$ 3.00$

Check Valves (3-72) Amendment 1 (5-74)

Check Valves, Flanged and Threaded Ends (1970) $\$ 3.00$

Chemical Analysis of Carbon and Graphite, Methods for (

Chemical Analysis of Copper and Copper Base Alloys (197

Chemical Analysis of Hydraulic Cement, Methods for (197

Chemical Analysis of Industrial Metal Cleaning Composit

Chemical Analysis of Metals, Recommended Practice for (

Chemical Analysis of Nickel (1975) \$1.75

Chemical Analysis of Nickel-Chromium and Nickel-Chrom

Chemical Analysis of Reactor and Commercial Columbium

Chemical Analysis of Reactor and Commercial Columbium,

Chemical Analysis of Steel, Cast lron, Open-Hearth Iro

Chemical Analysis of (1971) $\$ 1.75$

Chemical Analysis of (1973) \$1.75

Chemical Analysis of (1974) $\$ 1.75$

/Lectrical, Magnetic

Chemical and Spectrochemical Analysis of Nuclear Grade

Chemical and Spectrochemical Analysis of Nuclear Grade

Chemical Composition (1972) $\$ 1.75$

Chemical Industry Flanges and Threaded Stubs for Use Wi

(Chemical Method), Method of Test for (1973) ASTM C289.

Chemical Properties of Particulate Ion Exchange Resins

Chemical Properties of Particulate Ion Exchange Resins

Chemical Reactivity of Inorganic Material Exposed to $\mathrm{Hi}$

Chemical Release (6/74)

Ting the Habitability of

Chemical Substances and Physical Agents in the Workroom

Chemicals and Materials) (1955-1975) \$1.00 ea.

Chemical, Mass Spectrometric, and Spectrochemical Analy

Chemical, Mass Spectrometric, and Spectrochemical Analy

Chemical, Mass Spectrometric, and Spectrochemical Analy

Chemical, Mass Spectrometric, and Spectrochemical Analy

Chemical, Mass Spectrometric, and Spectrochemical Analy

Chemical, Mass Spectrometric, and Spectrochemical Analy

Chemical, Mass Spectrometric, and Spectrochemical Analy

Chemical, Mass Spectrometric, and Spectrochemical Analy

Chemical, Mass Spectrometric, and Spectrochemical Analy

Chemical, Mass Spectrometric, and Spectrochemical Analy

Chemical, Mass Spectrometric, and Spectrochemical Analy

Chemical, Mass Spectrometric, Spectrochemical Nuclear a

Chemical, Mass Spectrometric, Spectrochemical, Nuclear

Chemical, Mass Spectrometric, Spectrochemical, Nuclear

Chemical, Mass Spectrometric, Spectrochemical, Nuclear

Chemical, Mass Spectrometric, Spectrochemical, Nuclear

Chemical, Mass Spectrometric, Spectrochemical, Nuclear

Chemical, Mass Spectrometric, Spectrochemical, Nuclear

Chemistry Laboratories for Control Rod Absorber Materia

Chemistry Laboratories for Mixed Oxide Fuel Analysis ( 7

Chemistry Methods for Boron Carbide Absorber Material (

Chemistry Methods for Metallic Core Components (9-75)

Chemistry Methods for Mixed Oxide Fuel (7.73) Amendmen

Child Labor Regulations Section 57 Exposure to Radioact

Chloride Fire Extinguishing Agent (12.73)

Chloride lon in (1974) $\$ 1.75$

Chlorides Present as Admixes in Graded Aggregate Road M

Chlorinated Aromatic Hydrocarbons (Askarels) by Refluxi

Chlorine Compounds in Chlorinated Aromatic Hydrocarbons

Chlorine in Waste Water (1974) $\$ 1.75$

Chlorine in Water (1974) $\$ 1.75$

Chlorine Release (2/75)

Choice of Sample Size to Estimate the Average Quality

Chromatoraphy Procedures, Recommended Quality $O$

Chromatography (I974)

Chromel-P and Alumel, Solid Conductor (Bare, Fiberglas
ERDA

ERDA

ANS1

NRC

NRC

NRC

IES

ASNT

ANS1

ASTM

ANSI

ANS1

HMI

HM

HMI

ERDA

NCRP

ASTM

ACGlH

ANS1

ERDA

ANSI

MSS

ANS1

ASTM

ANSI

ASTM

ASTM

ASTM

ASTM

ANSI

ASTM

ASTM

ASTM

ASTM

ANSI

ASTM

ASTM

MSS

ANSI

ANSI

ASTM

ASTM

NRC

ACGlH

AIHA

NSI

ANSI

ANSI

ASTM

ASTM

ASTM

ASTM

ASTM

NRC

NRC

ASTM

ANSI

ANSI

ANSI

ASTM

ASTM

NRC

ERDA

ERDA

ERDA

ERDA

ERDA

ERDA

ASTN

ASTM

ASTM

ASTM

ASTM

ASTM

NRC

ASTM

ASTM

ASTM

ERDA

RDT M7.13T

RDT F11-6T

65.230

RG 6.4

RG 6.3

RG 7.5

CS.6T

NT-TC-1A

N165

D2577

N 117

E320

N449

400

200

300

RDT C15-7T 
nesium / Thermocouple Material and Thermocouple Assembly, Supersedes M1-15T, (1-72) Amendme/ Nickel-Molybdenumt, (7-71) uirements) (10-75) Supersedes M4-5/ (4-76) Nickel-Molybdenum72)

equirements) (7-75) Supersedes M2-/ th Additional Requirements) (9-75) Supers/ or (1974) ASTM B409-1973 \$1.75

I Requirements) (9-75) Supersedes M/ Requirements) (9-75) Supersedes M7-10T 5 th Additional Requirements) (7-75) / ith Additional Requirements) (7-75) Super/ ional Requirements) (4-76) Supersed/ tional Requirements) (1/-75) Supers/ 1 Requirements) (7-75) Supersedes M/ 4) $\$ 1.75$ ctrodes, Specification for (1973) A/ ctrodes, Specification for (1974) 3.50 re Electrodes, Specification for (1/ re Electrodes, Specification for (1)

\section{Flux Core} Corrosion-Resistin Corrosion-Resisting Corrosion-Resisting Corrosion-Resisting Chemical Analysis of Nickeltem/ Welded Large Outside Diameter Light-Wall Austenitic on for (1974A) $\$ 1.75$

or $(1975) \$ 1.75$

Corrosion-Resisting

Stainless and Heat Resisting ptibility to Intergranular Attack in Wrought Nickel-Rich, 168 with Additional Requirements) (1-75) Supers/ Nickeltion for (1973) ASTM B 168-1970 \$1.75

itional Requirements) (3-75) Supersedes M7-4T,/

Nickel-

B167-1970\$1.75

(1973) ASTM B434-1971 \$1.75

Specification (2-73) Chemical Analysis of Nickel-C -Hardenable NickeStrip, Specification for (1973) (ASTM B443-197)

Strip 5597 with Additional Requirements) (8-75/ Strip (AMS 5596 with Additional Requirements) (/ ms 5589 with Additionil Requirements) (7-75) Su/ ms 5590 with Additional Requirements) (8-75) Su lectrodes (6-75) Supersedes M 1-19T, (3-75) Pressure Vessel Plates, Alloy Steel

pressure Vessel Plates, Alloy Steel, Quenched and Tempered service, Specificati/ Electric-Fusion-Welded Austenitic tion at High Temperatures, Spec/ Centrifugally Cast Iron$p$ for Fusion-Welded Unfired Pressure Ves/ Heat Resisting ecification for (1974A) \$1.75

ification for (1973) A/ Corrosion-Resisting Chromium and ification for (1974) Corrosion-Resisting Chromium and Flux Core Corrosion-Resisting Chromium and cation for (1974) $\$ 1.75$

Specification for ( $1 /$ Stainless and Heat Resisting

Corrosion-Resisting Chromium and Corrosion-Resisting Chromium and Steel, Quenched and Tempered, Nickel-Cobalt-Molybdenum72A) A/ Pressure Vessel Plates, Alloy Steel, Five Percent $s$ and Electrodes (9-75) Amendment 1 (1/ luxes for Submerged Arc Welding (9-75) me SA-387 with Additional Requirements/ ubes (ASME SA-213 with Additional Requ/ forgings (ASME SA-336 with Additional /

2-1/4-Percent2-1/4-Percent2-1/4-Percent2-1/4-Percent2-1/4-Percent0 Alternating Current Power standard Criteria for Separation of Class IE Equipment and purities (1-76) Supersedes E4-5T, (12-70) Forced

$\$ 1.75$

$\$ 1.75$

on Fo/ Fans, Blowers, and Compressors for Dry Gas Corrosion-Resisting Chromium Stee Stainless Chromium-Nickel Stee Practice for Examination of Fuel Elemen Properties, Rec. Practice for Examination O/ Fuel Elemen Control of Stainless Steel Weld $\$ 55.00), 11(\$ 85.00)$ Fast Flux Test Facility Driver Fuel Pin Seamless and Pressure Vessel Code, Section Iii, Subsectio/

(NE-T) Classification for Determination of Sound Transmission $55.00)$, II ( $\$ 85.00)$ upplement to ASME Section I/ nerating Stations, Trial Use/ ear Power Generating Stati/

Guidance for Construction of Draft Standard Type Test of nd Pressure Vessel Code, Section Iii, Subsection/ des E1-18T, (2-71)

ing Stations, (Trial Guide Issued for Use/ s for Nuclear Power Generating Stations (19/

Draft Std. for Use and Comme/
Draft Standard Criteria for Separation of
Chromel-P Versus Alumel, Stainless Steel Sheathed, Mag Chromium Alloy Bare Welding Rods and Electrodes (7-75) Chromium Alloy Bars and Shapes (4-75) Supersedes M7-7 Chromium Alloy Bars, Forgings, and Forging Stock (ASME Chromium Alloy Castings (ASTM a 494 with Additional Req Chromium Alloy Castings (7-75) Supersedes M4-3T, (6Chromium Alloy Forgings (ASME SA-182 with Additional R Chromium Alloy Plate, Sheet, and Strip (ASME SB-409 Wi Chromium Alloy Plate, Sheet, and Strip, Specification F Chromium Alloy Rod and Bar (ASME SB-336 with Additiona Chromium Alloy Rod and Bar (ASME SB-408 with Additiona Chromium Alloy Rod and Bar, (1974) ASTM B408-1973 \$1.7 Chromium Alloy Seamless Pipe and Tubes (ASME SB-167 W Chromium Alloy Seamless Pipe and Tubing (ASME SB-407 W Chromium Alloy Seamless Tubes (ASME SB - 163 with Addit Chromium Alloy Sheet and Plate (ASME SB -434 with Addi Chromium Alloy Welded Pipe (ASME SA-358 with Additiona Chromium Alloy (UNS N08800) Rod and Bar, (1974) $\$ 1.75$ Chromium Alloy (UNS N08800) Seamless Pipe and Tube (197 Chromium and Chromium-Nickel Steel Covered Welding Ele Chromium and Chromium-Nickel Steel Covered Welding Ele Chromium and Chromium-Nickel Steel Electrodes (1974) \$ Chromium and Chromium-Nickel Steel Welding Rods and Ba Chromium and Chromium-Nickel Steel Welding Rods and Ba Chromium and Nickel-Chromium-Iron Alloys (1973) \$1.75 Chromium Nickel Alloy Steel Pipe for Corrosive or High Chromium Steel Clad Plate, Sheet and Strip, Specificat Chromium Steel Plate, Sheet, and Strip, Specification $F$ Chromium-Bearing Alloys, Method of (1973) ASTM G28-19 Chromium-lron Alloy Plate, Sheet, and Strip (ASME SBChromium-1ron Alloy Plate, Sheet, and Strip, Specifica Chromium-lron Alloy Rod and Bar (ASME SB-166 with Add Chromium-1ron Alloy Seamless Pipe and Tube (1973) ASTM Chromium-1ron Alloy Sheet and Plate, Specification for Chromium-1ron Alloy Springs (5-75) Supersedes M8-IT, Chromium-1ron Alloys (1973) $\$ 1.75$

Chromium-Molybdenum-Columbium Alloy Plate, Sheet, and Chromium-Molybdenum-Columbium Alloy Plate, Sheet, and Chromium-Molybdenum-Columbium Alloy Plate, Sheet, and Chromium-Molybdenum-Columbium Alloy Seamless Tubes (A Chromium-Molybdenum-Columbium Alloy Seamless Tubes (A Chromium-Molybdenum-Columbium Bare Welding Rods and $\mathrm{E}$ Chromium-Molybdenum, Specification for (1974A) $\$ 1.75$ Chromium-Molybdenum, Specification for (1974) \$1.75 Chromium-Nickel Alloy Steel Pipe for High Temperature Chromium-Nickel High Alloy Tubing for Pressure Applica Chromium-Nickel Stainless Steel Plate, Sheet, and Stri Chromium-Nickel Steel Clad Plate, Sheet, and Strip, Sp Chromium-Nickel Steel Covered Welding Electrodes, Spec Chromium-Nickel Steel Covered Welding Electrodes, Spec Chromium-Nickel Steel Electrodes (1974) $\$ 3.50$ Chromium-Nickel Steel Plate, Sheet, and Strip, Specifi Chromium-Nickel Steel Welding Rods and Bare Electrodes Chromium-Nickel Steel Welding Rods and Bare Electrodes Chromium, Specification for (1973) ASTM A605-1972 \$1.7 Chromium, 0.5 Percent Molybdenum, Specification for (19 Chromium, 1-Percent-Molybdenum Alloy Bare Welding Rod Chromium, 1-Percent-Molybdenum Alloy Electrodes and F Chromium, 1-Percent-Molybdenum Alloy Steel Plates (As Chromium, 1-Percent-Molybdenum Alloy Steel Seamless T Chromium, 1-Percent-Molybdenum Alloy Steel Tubesheet Circuits, Surge Arresters for (1975) IEEE 28-1974\$5.0

Circuits, (Trial Std. Issued for Use and Comment) (1974 Circulation Cold Trap Assembly for Removal of Sodium Im Circulation (4-73)

Clad Plate, Sheet and Strip, Specification for (1974A)

Clad Plate, Sheet, and Strip, Specification for (1974A)

Clad Steel Plates for Special Applications, Specificati

Clad Steel Plate, Specification for (1974A) \$1.75

Cladding Including the Determination of the Mechanical Cladding lncluding the Determination of the Mechanical Cladding of Low Alloy Steel Components (5/73) Cladding Tube (6-71)

Class MC Components for Nuclear Power Plant (1977) bd ( Class MC Nuclear

Class 1 Components for Nuclear Power Plant (I977) bd ( $\$$ Class 1 Components in Elevated-Temperature Reactors ( $S$ Class 1 Electrical Valve Operators for Nuclear Power Ge Class 1 Motors Installed Inside the Containment of $\mathrm{Nucl}$ Class 1 Nuclear Components (Supplement to ASME Boiler a Class 1 Valves for Liquid Metal Service (5-75) Superse Class $1 \mathrm{E}$ Control Switchboards for Nuclear Power Genera Class 1 E Electric Cables, Field Splices, and Connection Class 1E Equipment and Circuits, (Trial Std. lssued for Class 1E Equipment for Nuclear Power Plants (11/74)
ERDA

ERDA

ERDA

ERDA

ERDA

ERDA

ERDA

ERDA

ANS1

ERDA

ERDA

ANSI

ERDA

ERDA

ERDA

ERDA

ASTM

ANSI

ASME

AWS

ANSI

ASME

ASTM

ASTM

ASTM

ANSI

ERDA

ANSI

ANSI

ANSI

ERDA

ANSI

ERDA

ERDA

ERDA

RDA

ERDA

ASTM

ASTM

STM

ANSI

ASTM

ASTM

NS

ASME

AWS

ASTM

ASME

ANSI

ANSI

ERDA

ERDA

ERDA

RDA

ANSI

ANSI

ERDA

ERDA

ASTM

ANSI

ASTM

ANS1

ASTM

NRC

ERDA

ASME

ASTM

ASME

NRC

ANSI

ANSI

ERDA

ERDA

ANS

ANSI

ANSI

NRC

RDT C7.6T

DT Ml-15T

RDT M7-7T

RDT M2-15T

RDT M4-5T 
tions, Criteria for (1975) IEEE Std. 308-1974 \$4.00

Heat Exchanger,

safety Analysis Reports: Inservice Inspection of ASME Code $55.00),(\$ 85.00)$

nd Pressure Vessel Code, Section lii, Subsection/

(NC-T)

des E1-19T, (9/70)

Accumulators,

$55.00), 11(\$ 85.00)$

nd Pressure Vessel Code, Section lii, Subsection/

Heat Exchanger,

class (1973) \$1.75

(ND-T)

ation Plants (I0/73)

Seismic Design

1.00

(ASTM D2487-1969) $\$ 1.75$

rap (I $2 / 20 / 72)$

7)

Unirradiated Uranium Scrap,

Unirradiated Plutonium Scrap,

Radioactive Self-Luminous Light Sources,

7 Polymeric Materials for Service in Ionizing Radiation, Polymeric Materials for Service in Ionizing Radiation,

Elastomeric Materials for Automotive Applications, Seismic Design

Instrument Purging for Reduction of Hazardous Area Tornado Design

Radioactive-Waste-Containing Components/

Quality Group

Radioactive-Waste-Containing Components/
of Test for (I973) ASTM C142-1971 \$1.75

Laminar-Flow

Testing and Certification of Particulate

Method of Test for the Test for Buffering Action of Metal

Total Immersion Corrosion Test for Soak Tank Metal

Test for Rinsing Properties of Metal

nents (2-72) Supersedes F5-1T, (3-69) Amendment I (4-1

er-Cooled Nuclear Po/ Quality Assurance Requirements for ing the Construction Phase of Nuclear Power Plants (1973/ icles $(1972) \$ 2.50$

icles $(I / 73)$

Efficiency Testing of Air Efficiency Testing of Air

Nuclear Air

ctice for (1974) $\$ 1.75$

Descaling and

Supersedes F5-IT, (3-69) Amendment 1 (4-/ Cleaning and

Design, Testing, and Maintenance Criteria for Atmosphere Information for Safety Analysis Reports: Reactor Water endment 1 (5-72), Amendment 2-(1-74)

(4-73) Amendment I (1-74)

FFTF

Materials and Inspection for Reactor Vessel Preloading Threaded Fasteners and Std. Spec. for High Temperature Glass
Wire973) ASTM E1 I-1970 $\$ 1.75$ hod of Test for (19/

1.75

Resistance to Abrasion of Small Size Scratch Hardness of $1971 \$ 1.75$ Method of Test for Specific Gravity and Absorption of Sieve or Screen Analysis of Fine and (1969) (RI97) Std. Spec. for Fully Cured Silicone Rubber electromagnetic) Test/ Recommended Practice for Measuring cation for (1974) ASTM A386-1973 \$1.75 Zincation for (1973) \$1.75

Zinc tonium Pro/ Quality Assurance Requirements for Protective 6/73) Quality Assurance Requirements for Protective ng (R1973) ASTM C536-I/ Method of Test for Continuity of $1971 \$ 1.75$

Itage ASTM C537-/ Method of Test for Reliability of Glass teel Shapes, Plates, Bars and Strip, Zinc (Hot Galvanized) n for (R1973) ASTM A385-196/ Providing High Quality Zinc Selection, Application, and Inspection of Protective inment Facilities ( I972) $\$ 3.00$

Protective

0

Test for Adhesion or Cohesive Strength of Flame-Sprayed Measuring Neutron Flux Density by Radioactivation of ck for High Tempe/ Std. Spec. for Precipitation Hardening Electrical, Magnetic, and Other Similar Iron, Nickel, and es M7-7T, (7-7I)

$3 \mathrm{~T},(6-72)$

vessel Plates, Alloy Steel, Quenched and Tempered, Nickellines for Maintaining (1974) $\$ 3.50$

brication (Revision 6, 5/76)

vision $L, 5 / 76$ )

ary Components / Information for Safety Analysis Reports:

em Components at Elevated Temperatures (Supplement to Asme ated-Temperature Reactors (Supplement to ASME Section lii for Safety Analysis Reports: Inservice Inspection of Asme

7) bd $(\$ 75.00)$, II ( $\$ 100.00)$
Class IE Power Systems for Nuclear Power Generating Sta

Class 1, Water to Water, Straight or U Tube (6-73)

Class 2 and 3 Components $(2 / 75)$

Class 2 Components for Nuclear Power Plant (1977) bd ( $\$$

Class 2 Nuclear Components (Supplement to ASME Boiler a

Class 2 Pressure Vessel (3-73)

Class 2 Valves for Liquid Metal Service (6-74) Superse

Class 2, Water to Water, Straight or U Tube (7-7I)

Class 3 Components for Nuclear Power Plant (1977) bd (\$

Class 3 Nuclear Components (Supplement to ASME Boiler a

Classification for Determination of Sound Transmission

Classification for Plutonium Processing and Fuel Fabric

Classification of Containment Properties of Sealed Radi

Classification of Nuclear Ships, Guide for the (1962) \$

Classification of Soils for Engineering Purposes (1972)

Classification of Unirradiated Plutonium and Uranium Sc

Classification of (1970) $\$ 3.25$

Classification of (1972) \$4.25

Classification of (1975) NBS Handbook $116 \$ 2.00$

Classification System for (ASTM D2953-1971) (1973) \$I

Classification System for (197I) \$1.75

Classification System for (1975) \$1.75

Classification (Revision 2, 2/76)

Classification (1970) $\$ 3.00$

Classification $(6 / 76)$

Classifications and Standards for Water-, Steam-, and

Clay Lumps and Friable Particles in Aggregates, Method

Clean Air Devices (1968) $\$ 1.50$

Clean Rooms (1970) $\$ 5.00$

Cleanability of Surface Finishes (1973) \$1.75

Cleaners (197I) \$1.75

Cleaners (1972) $\$ 1.75$

Cleaners (1972) $\$ 1.75$

Cleaning and Cleanliness Requirements for Nuclear Compo

Cleaning Compositions ( 1971 ) $\$ 1.75$

Cleaning Fluid Systems and Associated Components of Wat Cleaning of Fluid Systems and Associated Components Dur Cleaning Systems Containing Devices for Removal of Part

Cleaning Systems Containing Devices for Removal of Part

Cleaning Systems, Testing of (1975) $\$ 5.00$

Cleaning Titanium and Titanium Alloy Surfaces, Rec. Pra

Cleanliness Requirements for Nuclear Components (2-72)

Cleanup System Air Filtration and Adsorption Units of $\mathrm{L}$

Cleanup System (5/75)

Closed Loop in Reactor Assembly Fabrication (12-71) Am

Closure Cap for Penetrations LMFBR Reactor Vessel Head

Closure Studs ( $10 / 73)$

Closures (2-69) Amendment I (10-71)

Cloth Pressure Sensitive Electrical Tape (1973) \$1.75

Cloth Sieves for Testing Purposes, Specification for (1

Coarse Aggregate by Use of the Los Angeles Machine, Met

Coarse Aggregate Particles, Method of Test for (I968) \$

Coarse Aggregate (1974) ASTM C127-1973 \$1.75

Coarse Aggregates, Method of Test for (1973) ASTM C1 36 Coated Fabrics (1973) $\$ 1.75$

Coated Glass Fabric and Tapes for Electrical Insulation

Coating Thickness by Magnetic-Field or Eddy-Current (

Coating (Hot-Dip) on Assembled Steel Products, Specif

Coating (Hot-Dip) on Iron and Steel Hardware, Specific

Coatings Applied to Fuel Reprocessing Plants and to PIu

Coatings Applied to Nuclear Facilities ( I972) \$3.00

Coatings Applied to Water Cooled Nuclear Power Plants

Coatings in Glassed Steel Equipment by Electrical Testi

Coatings of Zinc on Steel, Specification for ASTM A 164.

Coatings on Glassed Steel Reaction Equipment by High Vo

Coatings on Products Fabricated from Rolled, Specificat

Coatings (Hot-Dip) on Assembled Products, Specificatio

Coatings (Paints) for Fuel Reprocessing Plants (6/75)

Coatings (Paints) for Light Water Nuclear Reactor Conta

Coatings (Paints) for the Nuclear Industry (1974) \$14.0

Coatings (1974) \$I.75

Cobalt and Silver (1973T)

Cobalt Containing Alloy Bars, Forgings, and Forging Sto

Cobalt-Base Alloys, Chemical Analysis of (1973) \$1.75

Cobalt-Chromium Alloy Bars and Shapes (4-75) Supersed

Cobalt-Chromium Alloy Castings (7-75) Supersedes M4-

Cobalt-Molybdenum-Chromium, Specification for (1973)

Cobalt-60 and Cesium-137 Teletherapy Equipment, Guide

Code Case Acceptability: ASME Section III Design and Fa

Code Case Acceptability: ASME Section III Materials (Re

Code Cases Applicable to Reactor Coolant Pressure Bound

Code Cases 1592, 1593, 1594, 1595, and 1596) Supersedes

Code Cases 1592, I 593, 1594, 1595, and I 596) (Revision

Code Class 2 and 3 Components (2/75)

Code for Centrifugal Pumps (I965) $\$ 5.00$

Information

Code for Concrete Reactor Vessels and Containments (197
ANSI

ERDA

ASME

ERDA

ERDA

ERDA

ERDA

ASME

ERDA

ASTM

NRC

NRC

ABS

ANSI

NRC

ANSI

ANS

ANS

ANSI

ASTM

ASTM

NRC

ISA

NRC

NRC

ANSI

IES

IES

ASTM

ASTM

ASTM

ASTM

ERDA

ASTM

NRC

ANSI

ANS

NRC

ANSI

ASTM

ERDA

NRC

NRC

ERDA

ERDA

NRC

ERDA

ASTM

ANSI

ANSI

ASTM

ANSI

ANSI

ASTM

ANSI

ASTM

ANSI

ASTM

NRC

ANS

NRC

ANSI

ANSI

ANSI

ANSI

ANSI

NRC

ANSI

ANSI

ASTM

ASTM

ANSI

ASTM

ERDA

ERDA

ANSI

ANSI

NRC

NRC

NRC

ERDA

NRC

NRC

ASME

N41. 12

RDT E4-2T

RG 1.70.25

SEC-IIINC

RDT E15-2C

RDT E10-4T

RDT E1-I9T

RDT E4-17T

EC-IIIND

RDT E15-2D

E413

RG 3.14

RG 6.4

AG 5.2

N15.1

N15.10

N540

N4.1

D2953 
Performance Test Safe ty Colo

Outdoor Apparatus Bushings, Requirements and Test up/ Distribution, Power and Regulating Transformers, Test upp. A89.1 A-1975\$13.50 Reinforced Concrete, Building und Edition \$1200.00: Lo/ ASME Boiler and Pressure Vesse Structural Wcldin National Electrical

Components (Supplement to ASME Boiler and Pressure Vesse Components (Supplement to ASME Boiler and Pressure Vessel Components (Supplement to ASME Boiler and Pressure Vesse Components (Supplement to ASME Boiler and Pressure Vcsscl lifications (Supplement to ASME Boiler and Pressure Vessel examination (Supplement to ASME Boiler and Pressure Vcsse Identification of Piping Systems by Colo Test for Relative Density of

Tests for Unconfined Compressive Strength of Method of Test for Unconsolidated, Undrained Strength of Test for Adhesion or r Tubes, Specification for (1973) $\$ 1.75$ Seamless ng Steel Bars and Shape/ Specification for Hot Rolled and nd Wire for Nuclear Application, Specific/ Hot Rolled and nd Wire for Nuclear App/ Specification for Hot Rolled and ecification for (1972) $\$ 1.75$

$\$ 1.75$

tion for (1975) \$1.75

vanadium, Specific/

Std. Spec. for Steel, Carbon, Carbon Steel Sheet

76) Supersedes E4-5T, (12-70)

1966) $\$ 1.50$

erformance Std. (Ionizing Radiation Emitting Products) for sm for Sodium Service (3-71) Amendment 1 (12-72), Amen/ lant Quality Assurance Records (Revision 1, 12/75)

ce Records for Nuclear Power Plants (19/ Requirements for Safety

Identification of Piping Systems ons (1973) ASTM E318-1969\$1.75

ons Standard Method for (1975) $\$ 1.75$

Method for

Specification for Columbium and

Columbium and

additional Requirements) (/

ional Requirements) (8-75/

Nickel-Chromium-Molybdenum Nickel-Chromium-Molybdenum-
Nickel-Chromium-Molybdenumfor (1973) (ASTM B443-197/ for (1973) ASTM B394-1970 \$1.75

Columbium and l Requirements) (7-75) Su/ Nickel-Chromium-Molybdenumi Requirements) (8-75) Su/ Nickel-Chromium-Molybdenumation for (1973) ASTM B393-1964 \$1.75 $64 \$ 1.75$

Columbium and (1964) $\$ 1.75$

Specification for (1973) ASTM B394-1970\$1.75 late, Specification for (1973) ASTM B393-1964 \$1.75 trip, Hot Rolled and Cold Rolled, High Strength, Low Alloy (3-75)

Nickel-Chromium-Molybdenum$964 \$ 1.75$

Chemical Analysis of Reactor and Commercial Chemical Analysis of Reactor and Commercial em Components (6/73) ents $(5 / 73)$ Design Limits and Loading Design Limits and Loading smic Response Analysis (Revision 1, 2/76) a Loss of Coolant Accident (Safety Guide 7,I d Fuel Fabrication Plants (3/73) f Explosives or Other Dangerous Articles or Substances and f Explosives or Other Dangerous Articles or Substances and Chemical Analysis of Reactor and

$68) \$ 1.75$

$0 / 75)$ for Steel, Carbon, Cold Rolled, Cold Rolled Carbon Steel Sheets, Preparation of Environmental Reports for Ireversible and Irretrievable

ment $1(9 / 73)$

Determination of Insulation tionship of Quartz-Fiber Electrometer Type Dosimeters and Protection Systcm Calibration of Thermocouples by al Compensation) (7-71) Amendment I (8-73, Amend/ Gamma Compensated Ionization Chamber Assembly (Fixed Electrical Radioactive Material/

Administrative Guide for Verifying eleases of Reactor Effluents for the Purpose of Evaluating ect to NRC Regulations (Revision 2, 8/75)

Food and Drugs: Notification of Defects or Failure to dment 1 (12-73), A mendment 2 (6-74) t $1(3-74)$

Austenitic Stainless Steel Hexagonal Duct Tubes for Core Transportation of Critical Marking of
Code for Displacemcnt Pumps (1962) $\$ 4.00$

Code for Marking Physical Hazards (1971) $\$ 3.00$

Code for (1964) (R 1970) IEEE 21-1964\$4.00

Code for (1973) (IEEE Std 262-1973), Including Draft S

Code Requirements for (1972) ACI 318-1971, Including S

Code- 1977 Edition; Special Price for All Sections: Bo

Codc (1975) $\$ 24.00$

Code (1975) $\$ 5.50$

Code, Section lii, Subsection NA and Nb) Supersedes E15

Code, Section lii, Subsection NA and Nc) Superscdes E 15

Code, Section Iii, Subsections NA and Nd) (3-75) Super

Code, Section Iii, Subsections NA Ne) (8-75) Supersede

Code, Section IX) (8-74) Supersedes F6-5T, (7-71) Am

Code, Section V) (10-75) Supersedes F3-6T, (12-74) a

Coding, Scheme for the (1975) $\$ 3.00$

Cohesionless Soils (1972) (ASTM D2049-1969) \$1.75

Cohesive Soil (1972) (ASTM DI266-1972) \$1.75

Cohesive Soils in Triaxial Compression (1972) (ASTM D28

Cohesive Strength of Flame-Sprayed Coatings (1974) \$1.

Cold Drawn Low Carbon Steel Heat Exchanger and Condense

Cold Finished Age-Hardening Stainless and Heat Resisti

Cold Finished Zirconium and Zirconium Alloy Bars, Rod a

Cold Finished Zirconium and Zirconium Alloy Bars, Rod a

Cold Rolled Carbon Steel Sheets, Commercial Quality, $S_{p}$

Cold Rolled, Commercial Quality (1974) ASTM A366-1972

Cold Rolled, Drawing Quality, Special Killed, Specifica

Cold Rolled, High Strength, Low Alloy Columbium and/or

Cold Trap Assembly for Removal of Sodium Impurities ( 1

Cold Weather Concreting, Practice for (1968) (ACI 306-

Cold-Cathode Gas Discharge Tubes (1975) \$2.95

Collapsible Rotor, Roller Nut Control Rod Drive Mechani

Collection, Storage, and Maintenance of Nuclear Power P

Collection, Storage, and Maintenance of Quality Assuran

Color Code for Marking Physical Hazards (1971) $\$ 3.00$

Color Coding, Scheme for the (1975) $\$ 3.00$

Colorimetric Determination of Uranium in Aqueous Soluti Colorimetric Determination of Uranium in Aqueous Soluti Columbium Alloy Ingots (1973) ASTM B 391-64 \$1.75

Columbium Alloy Ingots, Specification for (1964) $\$ 1.75$

Columbium Alloy Plate, Sheet, and Strip (AMS 5596 with

Columbium Alloy Plate, Sheet, and Strip 5597 with Addit

Columbium Alloy Plate, Sheet, and Strip, Specification

Columbium Alloy Seamless and Welded Tubes, Specificatio

Columbium Alloy Seamless Tubes (AMS 5589 with Additiona

Columbium Alloy Seamless Tubes (AMS 5590 with Additiona

Columbium Alloy Strip, Sheet, Foil, and Plate, Specific

Columbium and Columbium Alloy Ingots (1973) ASTM B391-

Columbium and Columbium Alloy Ingots, Specification for

Columbium and Columbium Alloy Seamless and Welded Tubes

Columbium and Columbium Alloy Strip, Sheet, Foil, and $\mathbf{P}$

Columbium and/or Vanadium, Specification for (1973) Ast

Columbium Bare Welding Rods and Electrodes (6-75) Supe

Columbium Metal, Specification for (1973) ASTM B383-1

Columbium (1974) \$1.75

Columbium, Methods for (1973) (ASTM E195-1968) $\$ 1.75$

Combinations for Metal Primary Reactor Containment Syst

Combinations for Seismic Category 1 Fluid System Compon

Combinations (Mortar-Bar Method), Test for (1971) $\$ 1.7$

Combining Modal Responses and Spatial Components in Sei

Combustible Gas Concentrations in Containment Following

Combustible Gases and Vapors in Plutonium Processing an

Combustible Liquids on Board Vessels (1975) $\$ 7.50$

Combustible Liquids on Board Vessels (1975) $\$ 7.50$

Commercial Columbium (1974) $\$ 1.75$

Commercial Columbium, Methods for (1973) (ASTM E195-19

Commercial Quality (1974) ASTM A366-1972 \$1.75

Commercial Quality, Specification for (1972) $\$ 1.75$

Commercial Uranium Enrichment Facilities (Revision 1, 1

Commitments of Material Resources (Revision 1, 6/76)

Commodity List of Hazardous Materials (1975) $\$ 6.80$

Communication with Transport Vehicles (Revision 1, 5/75

Compaction in Ceramic Insulated Conductors (8/70) Amend

Companion Dosimeter Chargers (1965) (R 1971) \$3.00

Comparator (4-72) Amendment 1 (6-73)

Comparison Techniques (1972) $\$ 1.75$

Compensated Ionization Chamber Assembly (Fixed Electric

Compensation) (7-71) Amendinent 1 (8-73, Amendment 2

Compliance with Packaging Requirements for Shipments of

Compliance with 10 CFR Part 50, Appendix I (3/76)

Complication of Reporting Requirements for Persons Subj

Comply (1975) $\$ 2.95$

Component for Liquid Metal Piping Systems (11-71) Amen

Component Pot for Liquid Metal Service (3-72) Amendmen

Components and Assemblies (5-76) Supersedes E6-20T, (

Components and Equipment (1-76)

Components and Parts (6-75) (Supersedes F7-3T, (1 1-7
ASME

ANSI

ANSI

ANSI

ASME

AWS

NFPA

ERDA

ERDA

ERDA

ERDA

RDA

ERDA

ANSI

ANSI

NSI

ANS

ASTM

ASTM

ASTM

ASI

ASTM

ASTM

ANS1

STM

ANSI

ERDA

ANS1

RDA

NRC

NS

NS1

ANS

ANS1

ASTM

ANSI

STM

ERDA

ERDA

ANSI

ANS1

ERDA

ERDA

ANS1

ANS1

ASTM

ANS1

NS1

ANS1

NSI

ASTM

ANSI

NRC

NRC

NRC

IE O DOT

USCG

ASTM

ANSI

ANS1

ASTM

NRC

NRC

NRC

ERDA

ANSI

ERDA

ASTM

ERDA

ERDA

ANSI

IE R NRC

NRC

BRH

ERDA

ERDA

ERDA

ERDA

ERDA

PTC7.

Z53.1

C76.1

C57.12.90

A 89.1

CODE-77

DI.1

RDT E15-2B

RDT E15-2C

RDT E15-2D

RDT E15-2E

RDT F6-5T

RDT F3-6T 
0-72), Amendment 2 (7-)

Hoisting and Rigging of Critical Welding of Reactor Core

9/ Guidelines and Procedures for Design of Nuclear System Code $\mathrm{Ca} /$ Requirements for Construction of Nuclear System 5.00) General Requirements for Nuclear Power Plant er Plants (1973/ Cleaning of Fluid Systems and Associated

$11(\$ 85.00)$

$(\$ 85.00)$

II $(\$ 85.00)$

II $(\$ 85.00)$

77-2T, (2-69) Amend/

to ASME Section I/

$76)$ Piston Rings of High Strength Alloys for Core

Class

Class 2

Class 3

Class $\mathrm{Mc}$

Packaging, Packing, and Marking of Guidance for Construction of Class Combining Modal Responses and Spatial rrosion and Stress Corrosion in Austenitic Stainless Stee $s$ for Water-, Steam-, and Radioactive-Waste-Containing nce Requirements for Cleaning Fluid Systems and Associated

(7-75) Supersedes M2-I

73) Nuclear Power Plant el Code, Section Iii, Subsection/ el Code, Section Iii, Subsection/ el Code, Section Iii, Subsection el Code, Section Iii, Subsectio/ Guard Vessel for Primary Sodium Containing code Cases Applicable to Reactor Coolant Pressure Boundary gings for Seamless Drums, Heads, and Other Pressure Vesse bon and Alloy, Quenched and Tempered, for Pressure Vessel Alloy Steel, Requiring Notch Toughness Testing for Piping ing Products) for Diagnostic X-Ray Systems and Their Major Arrangement, and Other Provisions for Nuclear Powerplant Rules for Inservice Inspection of Nuclear Power Plant Appendices to Sec. III Div. 1, Nuclear Power Plant mation for Safety Analysis Reports: Mechanical Systems and ectrometer Helium Leak Detection for Instruments and Small 1 4-/ Cleaning and Cleanliness Requirements for Nuclear Threaded Fasteners for Nuclear

s Reports: Inservice Inspection of ASME Code Class 2 and 3 ustenitic Stainless Steel Plate, Sheet, and Strip for Core Austenitic Stainless Steel Wire for Core Austenitic Stainless Steel Bar for Core Austenitic Stainless Steel Tubing for LMFBR Core Low Friction Hard Surface for Core

ontrol of Stainless Steel Weld Cladding of Low Alloy Steel d Loading Combinations for Seismic Category 1 Fluid System Combinations for Metal Primary Reactor Containment System Analytical Chemistry Methods for Metallic Core stm A628-1973\$1.75 $\$ 2.50$ Std. Spec. for Tool Resisting

Coolant

nonferrous Metals and Alloys for Determination of Chemical Chemical Analysis of Industrial Metal Cleaning s) by Refluxing (1972) \$1/ Test for Hydrolyzable Chlorine 1674-1967) \$/ Methods of Testing Polymerizable Embedding hase Adsorbents for Trapping Radioactive lodine and lodine ained, Method of Marking (1954) (R1971) CGA C4 / Portable ons (1965) CGA V-1-1965\$7.00

tatic Young's Modulus of Elasticity and Poisson's Ratio in osure to High Energy Nuclear Radiation, Methods of Test osure to High Energy Nuclear Radiation, Testing (1968) (/ r (1968) ACI 214-1965 \$1.75

ce for (1968) (ACI 214-1965) \$1.75 Evaluation of hod of Tests for Stress Relaxation of Vulcanized Rubber in test for Elastic Moduli of Rock Core Specimens in Uniaxial olidated, Undrained Strength of Cohesive Soils in Triaxial Creep of Concrete in

Field, Method of (1970) ASTM/ Making and Curing Concrete $6-1972) \$ 1.75$

Method of Test for (1974) ASTM C39-1972 \$1.75

2 -in (50-mm) Cube Specimens), Test for (1973) $\$ 1.75$

sulation, Method of Test for (1963) (R1973) ASTM C165-1/ m D2938-1971A) \$1.75

Method of Test for Unconfined ithout Pore Pressure Measurements (197/ test for (1973) ASTM C695-1971T \$1.75 1975) $\$ 1.75$

66 (1972) $\$ 1.75$ Rpectrochemical programming Practices to Facilitate Interchange of Digital Guidelines for the Documentation of Digital for (1973) ASTM E267-1970\$1.75 Uranium and Plutonium for $(1970) \$ 1.75$ Uranium and Plutonium nt Accident (Safety Guide 7,/ Control of Combustible Gas

Maximum Permissible Body Burdens and Maximum Permissible Differences in the Transfer of Special Nuclear Materials, ials Control (1974) $\$ 3.00$
Components and Related Equipment (8-72) Amendment 1 ( 1 Components and Test Assemblies (7-73)

Components at Elevated Temperature (9-74) Supersedes F Components at Elevated Temperatures (Supplement to ASME Components Div. 1 and Div. 2 (1977) bd $(\$ 40.00), 11(\$ 6$ Components During the Construction Phase of Nuclear Pow Components for Liquid Metal Service (5-74)

Components for Nuclear Power Plant (1977) bd $(\$ 55.00)$, Components for Nuclear Power Plant $(1977)$ bd $(\$ 55.00)$, Components for Nuclear Power Plant (1977) bd $(\$ 55.00)$, Components for Nuclear Power Plant $(1977)$ bd $(\$ 55.00)$, Components for Shipment and Storage (9-75) Supersedes Components in Elevated-Temperature Reactors (Supplemen Components in Seismic Response Analysis (Revision 1, 2 / Components of Fuel Reprocessing Plants $(9 / 75)$

Components of Nuclear Power Plants (Revision 3, 2/76) Components of Water-Cooled Nuclear Power Plants (3/16/ Components Supports (1977) bd $(\$ 30.00)$, $11(\$ 40.00)$

Components (ASME SA-105 with Additional Requirements) Components (AWS D1.1 with Additional Requirements) (6Components (Supplement to ASME Boiler and Pressure Vess Components (Supplement to ASME Boiler and Pressure Vess Components (Supplement to ASME Boiler and Pressure Vess Components (Supplement to ASME Boiler and Pressure Vess Components (11-70) Amendment 1 (7-70)

Tion for Safety Analysis Reports: NRC

Components (1970) ASTM A266-1969 \$1.75 /on Steel for ANS

Components (1973) $\$ 1.75$

Components (1974) $\$ 1.75$

Components (1975) $\$ 2.95$

Components (1975) $\$ 4.40$

/Ation for Steel Forgings, Car

for Forgings, Carbon and Low

Td. (lonizing Radiation Emitt

Components (1977) bd (\$60.00); $11(\$ 90.00)$

Components $(1977)$ bd $(\$ 70.00)$ ll $(\$ 90.00)$

Components $(1 / 75)$

Components $(2-72)$

Components (2-75) Supersedes E8-18T, (10-71)

Components $(2 / 75)$

Components $(3-73)$

Components $(3-73)$

Components (3-73) Amendment 1 (4-74)

Components (5-72)

Components (5-73) Amendment 1 (9-73)

Components $(5 / 73)$

Components $(5 / 73)$

Components $(6 / 73)$

Components (9-75)

Composite Steel Bars

Composite Surfacing Welding Rods and Electrodes (1970)

Composition in Pressurized Water Reactors (10/71)

Composition (1972) $\$ 1.75$

Compositions (1971) $\$ 1.75$

Compounds in Chlorinated Aromatic Hydrocarbons (Askare

Compounds Used for Electrical Insulation (1970) (ASTM D

Compounds (10-73) Supersedes M16-1T, (6-72)

Design Limits an

Compressed Gas Containers to Identify the Material Cont

Compressed Gas Cylinder Valve Outlet and Inlet Connecti

Compression of Cylindrical Concrete Specimens, Method O

Compression Set Induced in Vulcanized Rubber During Exp

Compression Set Induced in Vulcanized Rubber During Exp

Compression Test Results of Field Concrete, Practice Fo

Compression Test Results of F 13901968 \$1.75

Compression (1972) $\$ 1.75$

Compression (1972) (ASTM D2850-1970) \$1.75

Compression, Test for (1974) $\$ 1.75$

Compressive and Flexural Strength Test Specimens in the

Compressive Strength of Cohesive Soil (1972) (ASTM D126

Compressive Strength of Cylindrical Concrete Specimens,

Compressive Strength of Hydraulic Cement Mortars (Using

Compressive Strength of Preformed Block Type Thermal in

Compressive Strength of Rock Core Specimens (1972) (Ast

Compressive Strength of Undrained Rock Core Specimens W

Compressive (Crushing) Strength of Graphite, Method of

Compressive (Crushing) Strength of Graphite, Test for

Compressors for Dry Gas Circulation (4-73)

Compressors (8-73)

Computations, Practice for (1968) (R 1973) ASTM E158-19

Computer Programs (1971) $\$ 7.50$

Recommended

Computer Programs (1974) ANS $10.3 \$ 8.50$

Concentrations and Isotopic Abundances, Method of Test

Concentrations and Isotopic Abundances, Method of Test

Concentrations in Containment Following a Loss of Coola

Concentrations of Radionuclides in Air and in Water for

Concepts and Principles for the (1975) $\$ 2.75$

Concepts and Principles of Calculation in Nuclear Mater
BRH

ASME

ASME

ERDA

ERDA

ERDA

SME

ANSI

ASME

A

ASME

ERA

NRC

NRC

ERDA

ERDA

RDA

NSI

STM NRC

ERDA
ERDA

ERDA

NRC

ERDA

ERDA

ERDA

ERDA

ERDA
NRC

NRC

ERDA

ANSI

AWS

ERDA

ASTM

ASTM

ERDA

ANS

ANS

ANSI

ASTM

ANSI

ANS

Met ANSI

ASTM

ANSI

ASTM

ANS

ANS

ANSI

ASTM

ANS1

ANS1

ASTM

ANS1

ASTM

ERDA

ERDA

ANSI

ANS

ANS1

ASTM

NRC

NCRP

ANS1

RDT F8-6T

RDT F6-2T

RDT F9-5T

RDT F9-4T

SEC-1II-R

N45.2.1

RDT E6-40T

SEC-IIINB

SEC-IIINC

SEC-111ND

SEC-111NE

RDT F7-2T

RG 1.87

RG 1.92

RG 3.37

RG 1.26

RG 1.37

SEC-IIINF

RDT M2-1T

RDT F6-6T

RDT E15-2B

RDT E15-2C

RDT E15-2D

RDT E15-2E

RDT E 10-2T

RG 1.70.13 
75) $\$ 1.75$

1975) $\$ 1.75$

Air Content of Freshly Mixed

in the Fie

$1 / 74$ )

Air Content of Freshly Mixed (138. $\$ 2.50$

.50

Creep of

$8 / 72)$

73)

Structural Acceptance Test for

$5.00), 11(\$ 100.00)$

Post-Tensioned Prestressing Systems for Code for pecification for Deformed and Plain Billet-Steel Bars for $1971 \$ 1.75$

Splitting Tensile Strength of Cylindrical asticity and Poisson's Ratio in Compression of Cylindrical Testing of Reinforcing Bars for Category 1

anical (Cadweld) Splices in Reinforcing Bars of Category I 973) ASTM C192-1969 \$1.75

method of Test for (1966) (R1973) A/ Flexural Strength of Recommended Practice for Consolidation of $w$ or Calcined Natural Pozzolans for Use in Portland Cement Specification for Air Entraining Admixtures for testing Fly Ash for Use as an Admixture in Portland Cement

$t$ for Unit Weight, Yield, and Air Content (Gravimetric) of Obtaining and Testing Drilled Cores and Sawed Beams of -1971 , Including Supp. A89.1A-1975\$13.50 Reinforced Constituents of Aggregates for Radiation-Sheilding $197 /$ Constituents of Aggregates for Radiation-Shielding $1963 \$ 1.75 \quad$ Ball Penetration in Fresh Portland Cement Slump of Portland Cement Sampling Fresh $\$ 2.75$

Proportions for Normal and Heavy Weight Evaluation of Compression Test Results of Field Selecting Proportions for Structural Lightweight Measuring, Mixing, Transporting and Placing of Selecting Proportions for No-Slump 5 Evaluation of Compression Test Results of Field Petrographic Examimation of Aggregates for Lightweight Aggregates for Structural Aggregates for Radiation-Shielding $1969(1975) \$ 1.75$ Sheet Materials for Curing Aggregates for Radiation-Sheilding

nstruct/ Practice for Inspection and Testing Agencies for Organic Impurities in Sand for Air Entraining Admixtures for Cold Weather Hot Weather

reoperational and Initial Startup Testing of Feedwater and 1974) $\$ 1.75$ Seamless Nickel and Nickel Alloy 974A) $\$ 1.75$ Copper and Copper-Alloy Seam less Seamless Cold Drawn Low Carbon Steel Heat Exchanger and Austenitic Steel Boiler, Superheater, Heat Exchanger, and ASTM B234 197/ Aluminum-Alloy Drawn Seamless Tubes for Seamless and Welded Titanium and Titanium Alloy Tubes for Eddy Current Flowmeter Power Supply and Signal

Light-Water-Cooled Nuclear Power Plants to Assess Plant

for Direct Shear Test of Soils Under Consolidated Drained

means of the Guarded Hot Box, Method of Test For/ Thermal uations of Fallout in the United States from Weapons Test. y Transition Temperature of Ferritic Steels (1970) ASTM in in Situ, Safety in (1975) ANS-8.6 \$6.50

late, Method of Test for (1975) ASTM C177-1971/ Thermal late, Test for (1971) $\$ 1.75$

er, Test for $(1970) \$ 1.75$

67) (R1969) ASTM C335-1969 \$1.75

Thermal

Thermal

Thermal

rmal Insulation, Flexible or Molded, High Temperature, Low r Fibe/ Thermocouple Material, Iron and Constantan, Solid r Fi/ Thermocouple Material, Copper and Constantan, Solid r Fi/ Thermocouple Material, Chromel-P and Alumel, Solid etermination of Insulation Compaction in Ceramic Insulated plants $(2 / 74)$

1974) $\$ 2$.

Finishes for Contact Faces of Pipe Flanges and ping Valves (1969) $\$ 2.00$

rmit Applications/ Information Needed by the NRC Staff in
Concepts and Principles of Calculation in Nuclear Mater Concepts, Models, Equations, and Assumptions for a Bioa Concrete and Structural Steel During the Construction $\mathrm{P}$ Concrete and Structural Steel During the Construction $\mathbf{P}$ Concrete Barriers in Fuel Reprocessing Plants (5/75)

Concrete by the Pressure Method, Method of Test for (19

Concrete by the Volumetric Method, Method of Test for ( Concrete Compressive and Flexural Strength Test Specime Concrete Containment Structures with Grouted Tendons (1 Concrete Containment Structures (Revision 2, 1/76)

Concrete for Buildings, Specification For, Including Ad

Concrete Form Work, Practice for (1968) (ACI 347-1968

Concrete in Compression, Test for (1974) \$1.75

Concrete Inspection, Recommended Practice for (1975) \$7

Concrete Placement in Category 1 Structures (6/73)

Concrete Primary Reactor Containments (Revision 1, 12/2

Concrete Radiation Shields for Nuclear Power Plants (12

Concrete Radiation Shields (1972) ANS-11.13\$10.00

Concrete Radiation Shields (6/73)

Concrete Reactor Vessels and Containments (11/75)

Concrete Reactor Vessels and Containments (1977) bd (\$7

Concrete Reinforcement (1975) \$1.75

Concrete Specimens, Method of Test for (1973) ASTM C496

Concrete Specimens, Method of Test for (1974) ASTM C39-

Concrete Specimens, Method of Test (1967) (R1973) ASTM

Concrete Structures (Revision 1, 12/28/72)

Concrete Structures (Revision 1, 1/2/73 Safety Guide 10

Concrete Test Specimens in the Laboratory, Method of ( 1

Concrete (Using Simple Beam with Third Point Loading),

Concrete (1972) $\$ 9.50$

Concrete (1973) ASTM C618-1972 \$1.75 /Fly Ash and Ra

Concrete (1974) $\$ 1.75$

Concrete (1974) $\$ 1.75$

Concrete (1975) $\$ 1.75$

Concrete, Method of (1969) ASTM C42-1968 \$1.75

Sampling and ASTM

Concrete, Building Code Requirements for (1972) ACI 318

Concrete, Descriptive Nomenclature of (1973)

Concrete, Descriptive Nomenclature of (1975) ASTM C638

Concrete, Method of Test for (1964) (R1969) ASTM C360-

Concrete, Method of 'Test for (1974) $\$ 1.75$

Concrete, Method of (1973) ASTM C 172-1971 \$1.75

Concrete, Practice for Selecting (1974) ACI $211.1-1974$

Concrete, Practice for (1968) ACI 214-1965 \$1.75

Concrete, Practice for (1971) ACl 211.2-1969 \$2.75

Concrete, Practice for (1973) ACI 304-1973 $\$ 2.75$

Concrete, Recommended Practice for (1975) $\$ 9.50$

Concrete, Rec. Practice for (1968) (ACI 214-1965) \$1.7

Concrete, Rec. Practice for (1973) \$1.75

Concrete, Specification for (1970) ASTM C330-1969 \$1.7

Concrete, Specification for (1975) ASTM C637-1973 \$1.7

Concrete, Specifications for (1970) (R 1975) ASTM C171-

Concrete, Spec. for (1973) \$1.75

Concrete, Steel, and Bituminous Materials as Used in Co

Concrete, Test for (1973) $\$ 1.75$

Concrete, Testing (1973) $\$ 1.75$

Concreting, Practice for (1968) (ACI 306-1966) $\$ 1.50$

Concreting, Practice for (1972) ACI 305-1972 \$2.50

Condensate Systems for Boiling Water Reactor Power Plan

Condenser and Heat Exchanger Tubes, Specification for (

Condenser Tubes and Ferrule Stock, Specification for ( 1

Condenser Tubes, Specification for (i973) $\$ 1.75$

Condenser Tubes, Specification for (1974A) \$1.75

Condensers and Heat Exchangers, Specification for (1974

Condensers and Heat Exchangers, Specification for (1974

Conditioning Electronics (2-73)

Conditions During and Following an Accident (12/75)

Conditions (1973) (ASTM D3080-1972) \$1.75 /Od

Conduct of Nuclear Material Physical Inventories (11/73

Conductance and Transmittance of Built-Up Sections by

Conducted Through 1962 (1963)

Conducting Drop-Weight Test to Determine Nil-Ductilit

Conducting Subcritical Neutron Multiplication Measureme

Conductivity of Materials by Means of the Guarded Hot P

Conductivity of Materials by Means of the Guarded Hot P

Conductivity of Materials by Means of the Heat Flow Met

Conductivity of Pipe Insulation, Method of Test for (19

Conductivity of Water, Tests for (1971) \$1.75

Conductivity (5-72) Amendment 1 (4-73)

Conductor (Bare, Fiberglass Insulated, and Sheathed Ove

Conductor (Bare, Fiberglass Insulated, and Sheathed Ove

Conductor (Bare, Fiberglass Insulated, and Sheathed Ove

Conductors $(8 / 70)$ Amendment $1(9 / 73)$

Confinement Barriers and Systems for Fuel Reprocessing

Connecting End Flanges of Ferrous Valves and Fittings (

Connecting Flange Joint Between Tapping Sleeves and Tap

Connection with Its Antitrust Review of Construction Pe
NRC

NRC

ANS

NRC

ASTM

ASTM

ANSI

NRC

ANSI

ANSI

ASTM

NRC

NRC

ANS

NRC

NRC

ASME

ASTM

ANSI

NRC

NRC

ANS

ANS

$\mathrm{ACl}$

ANSI

ASTM

ANSI

ANSI

ASTM

ANS1

ANS

ASTM

ANSI

ANS

ANS

ANSI

ANSI

ACI

ANSI

ASTM

ANSI

ANSI

ANSI

ASTM

ANSI

ASTM

ASTM

ANSI

ANSI

NRC

ASTM

ASTM

ASTM

/Lded ASTM

ANSI

ASTM

ERDA

/R NRC

of Test ANS

NRC

ANSI

EPA

ANSI

ANSI

ANSI

ASTM

ASTM

ANSI

ASTM

the ERDA

ERDA

ERDA

ERDA

ERDA

NRC

MSS

MSS

NRC

RG 5.18

RG 8.9

N45.2.5

RG 1.94

RG 3.27

C23

C 173

A 37.17

RG 1.90

RG 1.35

Al 38.1

A 145 .

C 512

311

RG 1.55

RG 1.18

RG 1.69

N101.6

RG 3.9

RG 1.103

SEC-1II/2

A615 
se App/ Information Needed by the AEC Regulatory Staff in Std. for Bypass and Drain

Type Test of Class IE Electric Cables, Field Splices, and Compressed Gas Cylinder Valve Outlet and Inlet upersedes E5-2T Electric Heater and Thermocouple Connectors and Thermocouple High Temperature Electrical

Thermocouple

High Voltage

endment $1(1-73)$ assumptions Used for Evaluating the Potential Radiological assumptions Used for Evaluating the Potential Radiological assumptions Used for Evaluating the Potential Radiological assumption's Used for Evaluating the Potential Radiological assumptions Used for Evaluating the Potential Radiological

I Nuclear Materials in Equipment for Wet Process /

1 Nuclear Material in Equipment for Dry Process O/

1 Nuclear Material in Drying and Fluidized Bed Op/ ps (1965) $\$ 7.50$

75)

Design

Design

Safety

Additional Information: Hydrological Additional Information: Fire Protection
Additional Information: Geography and Demography ds $(2 / 75)$ Design ide 7,3/10/71) Supplement to (Safety Guide 7, Backfitting

clear Tank Vessels (Ships and Barges) (1975) \$2./ Special
2) $\$ 1 \quad$ Method of Test for Direct Shear Test of Soils Under switchgear Assemblies, Including Metal Enclosed Bus (1974)

970) $\$ 1.75$

rials $(1972 \mathrm{~T}) \$ 1.75$

terials (1972T)

terials (1972T)/ Recom
upersedes C7-14T, (3-70), I
supersedes C7-14T, (3-7)

and Sheathed Over Fibe/

, and Sheathed Over Fi/ crete, Descriptive Nomenclature of (1973)

crete, Descriptive Nomenclature of (1975) ASTM C638-197/ ture Reactors (Supplement to ASME Section I/ Guidance for ks (1973) $\$ 4.00 \quad$ Recommended Rules for Design and allati/ Instrumentation and Electric Equipment During the emperatures (Supplement to ASME Code $\mathrm{Ca} /$ Requirements for $y$ the NRC Staff in Connection with Its Antitrust Review of ing of Structural Concrete and Structural Steel During the ning of Fluid Systems and Associated Components During the Housekeeping During the s of Inspection, Examination and Testing Personnel for the ing of Structural Concrete and Structural Steel During the $n$, and Testing of Mechanical Equipment and Systems for the and Handling of Items for Nuclear Power Plants (During the $s$ for Concrete, Steel, and Bituminous Materials as Used in Manual of Steel

dditional Information: Quality Assurance During Design and finition of Terms Relating to Acoustical Tests of Building Quality Assurance Program Requirements (Design and for Certain Land and Sea Applications (3/74) lear Powerplant Components (1975) $\$ 4.40$

lear Cargo Vessels (Ships and Barges) (1975) \$1./ nsportation or Storage of Explosives or Other Da/ of Dangerous Articles as Ships, Stores and Supp/ lear Passenger Vessels (Ships and Barges) (1975)/ ngs, Nickel-19Cr-19Fe-3.1 Mo-5.1 (Cb+Ta) 0.90Ti-0.50A 1 kel Base-19Cr-3.1 Mo-5.1 (Cb+Ta)-0.90Ti-0.50Al-19-Fe nt Nickel Base-19Cr-3.1 Mo-5.1 (Cb \& Ta)-0.90Ti-0.50Al 954.4C) Alloy Tubing, Seamless, Corrosion and Heat Resis/ lloy Tubing (Seamless, Corrosion and Heat Resistant Nickel nt Nickel Base-19Cr-3.1Mo-5.1 (Cb \& Ta)-0.90Ti-0.50 A 1 (4-74) Amendment 1 (5-75)

deuterium Oxide, Method of Test for (1973) ASTM D2033-1/ deuterium Oxide (1973) $\$ 1.75$

Test for 75

s of Ferrous Valves and Fittings (1974) $\$ 2 . /$
Method, Using Pulsed Longitudinal Waves Induced by Direct

Fuel Shipping

Water Vapor Transmission of Shipping als (7/ Selection and Use of Pressure-Sensitive Seals on f Marking (1954) (R1971) CGA C4 / Portable Compressed Gas Inspection and Preventive Maintenance of Fuel Shipping ded Practice for Controlled Shock Input Tests for Shipping Shipping

Cylindrical Shipping Shipping
Connection with lts Antitrust Review of Operating Licen

Connection (1971) $\$ 3.00$

Connections for Nuclear Power Generating Stations (1975

Connections (1965) CGA V-1-1965\$7.00

Connector Assembly for Pressurizer for Pressurized Wate

Connector Panels (1-72) Amendment 1 (1-73)

Connectors and Hermetic Seals (3-70)

Connectors and Thermocouple Connector Panels (1-72) Am

Connectors for Nuclear Instruments (1968) (R1973) \$2.50

Connectors for Nuclear Instruments (1971) $\$ 3.00$

Consequences of a Fuel Handling Accident in the Fuel $\mathrm{Ha}$

Consequences of a Loss of Coolant Accident for Boiling

Consequences of a Loss of Coolant Accident for Pressuri

Consequences of a Pressurized Water Reactor Radioactive

Consequences of a Radioactive Offgas System Failure in

Consequences of a Steam Line Break Accident for Boiling

Considerations for Minimizing Residual Holdup of Specia

Considerations for Minimizing Residual Holdup of Specia

Considerations for Minimizing Residual Holdup of Specia

Considerations for Nuclear Power Plants on Merchant Shi

Considerations for Nuclear Power Plants (Revision 1, 1/

Considerations for Nuclear Power Plants (2/74)

Considerations for Nuclear Power Plants (8/74)

Considerations: Systems for Measuring the Mass of Liqui

Considerations, $10 / 27 / 71$ Coolant Accident (Safe

Consideration, Arrangement, and Other Provisions for $\mathrm{Nu}$

Consolidated Drained Conditions (1973) (ASTM D 3080-197

Consolidated Edition (Includes ANSI C37.20A-1970, C27.

Consolidation of Concrete (1972) $\$ 9.50$

Consolidation Properties of Soils (1972) (ASTM D2435-1

Constant Amplitude Axial Fatigue Tests of Metallic Mate

Constant Amplitude Fatigue Test Results for Metallic Ma

Constantan, Mineral Oxide Insulated, Sheathed (4-70) S

Constantan, Mineral-Oxide Insulated, Sheathed (4-70)

Constantan, Solid Conductor (Bare, Fiberglass Insulated

Constantan, Solid Conductor (Bare, Fiberglass Insulated

Constants of Rock (1972) (ASTM D2845-1969) \$1.75

Constituents of Aggregates for Radiation-Sheilding Con

Constituents of Aggregates for Radiation-Shielding Con

Construction of Class 1 Components in Elevated-Tempera

Construction of Large, Welded, Low Pressure Storage Tan

Construction of Nonmetallic Gaskets for Corrosive Servi

Construction of Nuclear Power Generating Stations, Inst

Construction of Nuclear System Components at Elevated T

Construction Permit Applications for Nuclear Power Plan

Construction Phase of Nuclear Power Plants (Revision 1 ,

Construction Phase of Nuclear Power Plants (1973) \$4.00

Construction Phase of Nuclear Power Plants (1973) $\$ 4.00$

Construction Phase of Nuclear Power Plants (1973) \$4.00

Construction Phase of Nuclear Power Plants (1974) \$4.50

Construction Phase of Nuclear Power Plants, Supplementa

Construction Phase) (1972) $\$ 4.50$ / Receiving, Storage

Construction (1973) $\$ 20.00$

Construction (7/74)

Constructions and Materials (1973) $\$ 1.75$

Construction) (Safety Guide 28,6/7/72)

Construction, and Use of Radioisotopic Power Generators

Construction, Arrangement, and Other Provisions for Nuc

Construction, Arrangement, and Other Provisions for Nuc

Construction, Arrangement, and Other Provisions for Tra

Construction, Arrangement, and Other Provisions for Use

Construction, Arrangenent, and Other Provisions for Nuc

Consumable Electrode or Vacuum Induction Melted Solutio

Consumable Electrode or Vacuum Induction Melted $1750 \mathrm{~F}$

Consumable Electrode or Vacuum Induction Melted $1750 \mathrm{~F}$

Consumable Electrode or Vacuum Induction Melted 1750F (

Consumable Electrode or Vacuum Induction Melted $1950 \mathrm{~F}$

Consumable Electrode or Vacuum Induction Melted $1950 \mathrm{~F}$

Consumable Welding Inserts (3-75) Supersedes M1-21T,

Consumption of Potassium Permanganate by Impurities in

Consumption of Potassium Permanganate by Impurities in

Contact Examination of Weldments, Method for (1974) \$1.

Contact Faces of Pipe Flanges and Connecting End Flange

Contact, Practice for (1969) (R 1973) ASTM E1 14-1963 (1

Container Packaging Spec. (1975) $\$ 6.80$

Container Tiedown for Truck Transport (1-75)

Containers by Cycle Method, of Test for (1973) $\$ 1.75$

Containers for Onsite Storage of Special Nuclear Materi

Containers to Identify the Material Contained, Method O

Containers $(1-75)$

Containers (1-75)

Containers (1971) $\$ 1.75$

Containers, Drop Test for (1973) $\$ 1.75$

Containers, Drop Test for (1973) $\$ 1.75$

Containers, Incline Impact Test for (1973) $\$ 1.75$
NRC

MSS

ANSI

ANSI

ERDA

ERDA

ERDA

ERDA

ANSI

ANSI

NRC

NRC

NRC

NRC

NRC

NRC

NRC

NRC

NRC

SNAME

NRC

NRC

NRC

NRC

USCG

ANS

$\mathrm{ACl}$

ANSI

ASTM

ASTM

ERDA

ERDA

ERDA

ERDA

/Tor ANSI

ASTM

ANSI

NRC

API

ASTM

ANS1

ERDA

NRC

NRC

ANSI

ANSI

ANSI

ANSI

ANS1

ANSI

ANS1

AISC

NRC

De ASTM

NRC

USCG

USCG

USCG

USCG

USCG

SAE

ANSI

ANSI

ANSI

ANSI

ANSI

ERDA

ANSI

ASTM

ASTM

MSS

ANS

DOT

ERDA

ASTM

NRC

ANSI

ERDA

ERDA

Recommen ASTM

ASTM

ASTM

ASTM

93

P-45

N41. 10

(4)

RDT E5-2T

RDT C7-15T

RDT C17-1T

RDT C7-15T

N544

N42. 4

RG 1.25

RG 1.3

RG 1.4

RG 1.24

RG 1.98

RG 1.5

RG 5.25

RG 5.42

RG 5.8

3-18

RG 1.70.1

R 1.70 .4

RG 1.70 .7

RG 5.48

RG 1.7

$46 \mathrm{CFR} 37$

A 37.185 
Net Positive Suction Head for Emergency Core Cooling and

Guide 19) Nondestructive Examination of Primary sts of Continuous Duty Class 1 Motors Installed Inside the ion Tests of Electric Valve Operators Installed Inside the tion Tests of Continuous-Duty Motors Installed Inside the ntained in Certain Devices to Be Distr/ Classification of Sumps for Emergency Core Cooling and (/ Electrical Penetration Assemblies for Nuclear Reactor ing Stations (1973)/ Electrical Penetration Assemblies in

$7.60 \$ 7.50$

lants (10/73) Leakage-Rate Testing of

Electric Penetration Assemblies in

ce Inspectionservice Inspection of Prestressed Concrete ifications for Ungrouted Tendons in Prestressed Concrete Additional Information: Air Filtration Systems and

Limits and Loading Combinations for Metal Primary Reactor Expansion Joint Gaskets Steel

Instrument Lines Penetrating Primary Reactor Protection Against Pipe Whip Inside

Structural Acceptance Test for Concrete Primary Reactor oned Prestressing Systems for Concrete Reactor Vessels and Code for Concrete Reactor Vessels and Packaging and Transportation of Radioactively Packaging and Transportation of Radioactively Control and Removal of Radioactive ction Guides for Environmental Sr-89, Sr-90, and Cs-137 Sampling Instruments Manual for Evaluation of Atmospheric counting Section of a Special Nuclea/ Standard Format and Total Ash

brating Magnetic Instruments to Measure the Delta Ferritic 75 Acid insoluble

d. Method of Test for (1975) $\$ 1.75$ hod, Method of Test for (1975) $\$ 1.75$ $\mathrm{g}$ and Fuel Fabrication Plants (1/76) rradiated Reactor Fuel and Associate/ ) $\$ 1.75$

g Plants (2/75)

ants (Revision 2, (9/75)

nt Facilities (12/74) mcthods (Shallow Depths) ng Plants (4/73)

ounting Technique, Method of Test for (1974) ASTM/ Oxygen ounting Technique, Method of Test for (1973) \$1.7/ Oxygen

2/73)

ufacturing Plants $(6 / 74)$

ectrical Testing (R1973) ASTM C536-1/

ndment 1 (6-73)

ctive Electrode (1973) $\$ 1.75$

tainment of Nuclear Power Generating Stati/

cification and Performance / $t$ of Water Cooled Nuclear Power P/ Qualification Tests of Safety and Health Stds. for Federal Supply al (2/75)

cal Terminology and Notation for Special Nuclear Materials

andard Format and Content for the Special Nuclear Material oratories (1951) $\$ 2.00$

Selection of Material Balance Areas and Item

Fuel and

73) Amendment $1(1 / 75)$

(1974) ANS $15.2 \$ 8.50$

uel Reprocessing Plant/

amendment 1 (12-74)

1 Rod Absorber Material Analysis (7-7/ Qualification and

oxide Fuel Analysis (7-73)

Qualification and t Following a Loss of Coolant Accident (Safety Guide 7,/

173)

General Use of Locks in the Protection and reas, and Material Access Areas (6/73)
Containers, Test for (1973) $\$ 1.75$

Containers, Vibration Test for (1975) $\$ 1.75$

ASTM

Containing Alloy Bars, Forgings, and Forging Stock for

Containing Byproduct Material (6/74)

Containing Components of Nuclear Power Plants (Reptance

Containing Components (1 1-70) Amendment 1 (7-7O)

Containing Devices for Removal of Particles (1972) \$2.5

Containing Devices for Removal of Particles (1/73)

Containing Product (Revision 1, 6/76)

Containing Sodium (8-74)

/O S

Containment Facilities (1972) $\$ 3.00$

Containment Following a Loss of Coolant Accident (Safet

Containment Heat Removal System Pumps (Safety Guide 1

Containment Liner Welds (Revision 1, 8/11/72, of Safety

Containment of Nuclear Power Generating Stations, Guide
Containment of Nuclear Power Plants $(1 / 74)$

Containment of Water Cooled Nuclear Power Plants (3/16

Containment Properties of Sealed Radioactive Sources Co

Containment Spray Systems (6/74)

Containment Structures A mendment 1 (4-72), Amendment 2

Containment Structures for Nuclear Fueled Power Generat

Containment Structures for Nuclear Reactors (197I) ANS-

Containment Structures for Water Cooled Nuclear Power P

Containment Structures with Grouted Tendons (11/74)

Containment Structures (Revision 2, 1/76)

Containment Structures (11/75)

Containment Sumps for Nuclear Power Plants (12/73)

Containment System Components $(6 / 73)$

Containment Vessel Airlock (3-72) Amendment 1 (8-73)

Containment Vessel Airlock (6-72)

Containment Vessel Airlock (6-72)

Containment Vessel (12-73)

Containment (Safety Guide 11, 3/10/71

Containment $(5 / 73)$

Containments (Revision 1, 12/28/72)

Containments (11/75)

Containments $(1977)$ bd $(\$ 75.00), 11(\$ 100.00)$

Contaminated Biological Materials (1973) $\$ 3.50$

Contaminated Biological Materials (6/74)

Contamination in Laboratories (1951) $\$ 2.00$

Contamination (1965).

Contaminents, 4th Edition (1972) $\$ 12.50$

Content for the Special Nuclear Material Control and Ac

Content of Áctivated Carbon, Test for (1970) $\$ 1.75$

Content of Austenitic Stainless Steel Weld Metal (1974)

Content of Copper and Iron Powders, Test for (1974) \$1.

Content of Freshly Mixed Concrete by the Pressure Metho

Content of Freshly Mixed Concrete by the Volumetric Met

Content of License Applications for Plutonium Processin

Content of License Applications for Storage Only of Uni

Content of Oxidizing Substances in the A tmosphere (1970

Content of Safety Analysis Reports for Fuel Reprocessin

Content of Safety Analysis Reports for Nuclear Power Pl

Content of Safety Analysis Reports for Uranium Enrichme

Content of Soil and'Soil Aggregate in Place by Nuclear

Content of Soil and Soil Aggregate in Place by Nuclear

Content of Steel, Recommended Practice for (1974) \$1.75

Content of Technical Specifications for Fuel Reprocessi

Content Using a 14-MeV Neutron Activation and Direct $\mathrm{C}$

Content Using a 14-MeV Neutron Activation and Direct $C$

Content (Gravimetric) of Concrete (1975) \$1.75

Contents of Applications for Uranium Milling Licenses

Contingency Measures for Uranium and Plutonium Fuel Man

Continuity of Coatings in Glassed Steel Equipmení by El

Continuity Type Liquid Metal Leak Detector (10-72) Ame

Continuous Determination of Sodium in Water by Ion Sele

Continuous Duty Class 1 Motors Installed Inside the Con

Continuously Monitoring Radioactivity in Effluents, Spe

Continuous-Duty Motors Installed Inside the Containmen

Contracts (1975) $\$ 3.25$

Control Accountability (2/2/73)

Control and Accountability of Plutonium in Waste Materi

Control and Accounting Section of a Special Nuclear Mat

Control and Removal of Radioactive Contamination in Lab

Control Areas (Revision 1, 4/75)

Control Assembly Tag Gas (10-72)

Control Equipment Grounding and Sheilding Practices (1)

Control for Plate-Type Uranium-Aluminum Fuel Elements

Control for the Welding of Low Alloy Steel for Use in $\mathbf{F}$

Control Monitor, Port Plug (Fabrication Only) (10-73)

Control of Analytical Chemistry Laboratories for Contro

Control of Analytical Chemistry Laboratories for Mixed

Control of Combustible Gas Concentrations in Containmen

Control of Electroslag Weld Properties (12/28/72)

Control of Facilities and Special Nuclear Materials (11

Control of Personnel Access to Protected Areas, Vital a
ASTM

ANSI

ANSI

NRC

ERDA

ANSI

NRC

NRC

Pr ANSI

NRC

NRC

NRC

ANSI

NRC

NRC

NRC

ERDA

ANSI

ANSI

NRC

NRC

NRervi NRC

NRC

NRC

Design NRC

ERDA

ERDA

ERDA

ERDA

NRC

NRC

NRC

NRC

ASME

ANSI

NRC

NCRP

Air

ACA

NRC

ASTM

AWS

ASTM

ASTM

ASTM

NRC

NRC

ASTM

NRC

NRC

NRC

ANSI

ASTM

ASTM

NRC

ANSI

ASTM

ASTM

NRC

NRC

ANSI

ERDA

A STM

ANSI

ANSI

NRC

DOI

NRC

NRC

NCRP

NRC

ERDA

ERDA

ANS

NRC

ERDA

ERDA

ERDA

NRC

NRC

NRC

NRC

D998

D999

G81.46

RG 6.6

RG 1.26

RDT E10-2T

N101.1

RG 3.2

RG 6.7

RDT E 16-1T

N101.2

RG 1.7

RG 1.1

RG 1.19

N41.9

RG 1.73

RG 1.40

RG 6.4

RG 1.82

RDT P3-1T

N45.3

N45.4

RG 1.63

RG 1.90

RG 1.35

RG 1.107

RG 1.70 .2

RG 1.57

RDT E10-5T

RDT E14-5T 
Control of Preheat Temperature for Welding of Low Alloy Control of Radiation Hazards in Uranium Mining (1967) Control of Special Nuclear Material (1/74) Control of Stainless Steel Weld Cladding of Low Alloy S Control of Stainless Steel Welding (Revision 1, 6/73)

Control of Steel Reference Blocks Used in Ultrasonic in Control of the Use of Sensitized Stainless Steel (5/73)

Control Rod Absorber Material Analysis (7-73) Control Rod Absorber Pin for Liquid Metal Fast Reactors Control Rod Assembly for Liquid Metal Fast Reactors (5 Control Rod Drive Mechanism for Sodium Service (3-71) Control Rod Driveline for Sodium Cooled Reactors (4-73 Control Rod Ejection Accident for Pressurized Water Rea Control Room During a Postulated Hazardous Chemical Re Control Room Operators Against an Accidental Chlorine R Control Switchboards for Nuclear Power Generating Stati Control Systems for Boiling Water Reactor Nuclear Power Control Systems for Conversion Facilities, Guide to Pra Control Systems for Fuel Fabrication Facilities (A Guid Control Systems for Nuclear Power Plants (Revision 1, 6 Control Systems for (1974) $\$ 3.50$

Control Systems (A Guide to Practice) (1974) $\$ 3.00$ Control Systems (10-72) Amendment 1 (8-73)

Control Technology (1975) $\$ 4.00$

Control (1968) $\$ 5.15$

Control (1971) $\$ 3.25$

Control (1974) $\$ 3.00$

Control (1975) $\$ 5.50$ oncepts and Principles of Calculation in Nuclear Materials

70) $\$ 1.75$

\section{1) $\$ 1.75$
973) ASTM E217-1970 $\$ 1.75$}

(1973) ASTM E142-1972 \$1.75

0

el (1975) ANS 8./ Uranium by
Recommended Practice for Uranium by

Industrial Administrative Criteria for Nuclear Criticality Safety
Guidance on Being Operator at the formation for Safety Analysis Reports: Instrumentation and of Plutonium-Bearing Solids Applied to Nuclear Materials Nuclear Material gnetic Resonance (NMR) Spectroscopy, Definitions, Symbols, Nuclear Material Control Systems for ell Hardness, Vickers Hardness, Rockwe/ Standard Hardness ating the Potential Radiological Consequences of a Loss of ating the Potential Radiological Consequences of a Loss of ible Gas Concentrations in Containment Following a Loss of

1)

Safety Analysis Reports: Code Cases Applicable to Reactor 73) Reactor tion (1/ Information for Safety Analysis Reports: Reactor

Inspection Requirements for Materials Used in Reactor ayed Neutron-Emitting Fission Products in Nuclear Reactor layed Neutron Emitting Fission Products in Nuclear Reactor safety Related Systems, Structures and Equipment for Water stures (3-71)

during and Following A/ Instrumentation for Light-Waterterials in Liquid and Gaseous Effluents from Light-Waterystem Air Filtration and Adsorption Units of Light-Water penetration Assemblies in Containment Structures for Water Housekeeping Requirements for Water pping, Receiving, Storage, and Handling of ltems for Water ous-Duty Motors Installed Inside the Containment of Water cleaning Fluid Systems and Associated Components of Waterance Requirements for Protective Coatings Applied to Water Serial Numbering of Fuel Assemblies for Light-Water-Benefit Analysis for Radwaste Systems for Light-Water

Guide for in Service Annealing of $W$ ater

Recommended Guide for in Service Annealing of Water preoperational and Initial Startup Test Programs for Water terials in Gaseous and Liquid Effluents from Light-WaterAmendment 2 (3-74)

(12.72), Amendment $2 /$

(3-74)

(4-73) Instrument Tree for Sodium Core Radial Shield for Sodium

f Gaseous Effluents in Routine Releases from Light-WaterFabrication of Control Rod Driveline for Sodium Heat Exchanger for Gas ty Guide 1,/ Net Positive Suction Head for Emergency Core n $1,1 / 75)$ Preoperational Testing of Emergency Core Std. Spec. for Copper and Spec. for Copper and

74) $\$ 1.75$ Spec. for
Control (1.74)

Controlled Potential Coulometry, Method of Test for ( 19
Controlled Shock Input Tests for Shipping Containers (1 Controlled-Potential Coulometry, Method of Test for (I

Controlling Quality of Radiographic Testing, Method for Controls and Systems (1970) \$16.00

Controls for Nuclear Power Plants (1972) ANS-3.2 \$10.0 Controls in Operations Where Shielding Protects Personn Controls of a Nuclear Power Plant (2/76)

Controls $(2 / 75)$

Control, Calibration Techniques for the (1975) $\$ 5.75$ Control, Mass Calibration Techniques for (1975) $\$ 5.50$ Conventions, and References Relating to (1974) $\$ 1.75$ Conversion Facilities, Guide to Practice (1971) \$4.50 Conversion Tables for Metals (Relationship Between Brin Coolant Accident for Boiling Water Reactors (Revision 2 Coolant Accident for Pressurized Water Reactors (Revisi Coolant Accident (Safety Guide 7, 3/10/71) Supplement T Coolant Composition in Pressurized Water Reactors (10/7

Coolant Pressure Boundary Components (12/74) Coolant Pressure Boundary Leakage Detection Systems ( 5 Coolant Pump Flywheel Integrity (Revision 1, 8/75)

Coolant System Wear Applications (10-67)

Coolant Water During Reactor Operation, Measurement of Coolant Water During Reactor Operation, Method for Meas Cooled and Moderated Nuclear Power Generating Plants, F Cooled Heat Exchanger for Nuclear Steam Supplied System Cooled Nuclear Power Plants to Assess Plant Conditions Cooled Nuclear Power Plants (Revision 1, 6/74) Cooled Nuclear Power Plants (Revision 1, 7/76) Cooled Nuclear Power Plants (10/73)

Cooled Nuclear Power Plants $(3 / 16 / 73)$

Cooled Nuclear Power Plants $(3 / 16 / 73)$ Cooled Nuclear Power Plants $(3 / 16 / 73)$ Cooled Nuclear Power Plants $(3 / 16 / 73)$ Cooled Nuclear Power Plants (6/73)

Cooled Nuclear Power Reactors (12/20/72) Cooled Nuclear Power Reactors (3/76)

Cooled Nuclear Reactor Vessels (1974) ASTM E509-74\$1. Cost

Cooled Nuclear Reactor Vessels (1974) \$1.75

Cooled Power Reactors (11/73)

Cooled Power Reactors (4/76) /Leases of Radioactive $\mathrm{Ma}$

Cooled Reactors (Fabrication Only) Amendment 1 (8-73),

Cooled Reactors (Fabrication Only) (1-72) Amendment I

Cooled Reactors (Fabrication Only) (10-72) Amendment 1

Cooled Reactors (Fabrication Only) (8-72) Amendment 1 Cooled Reactors (12-71) Amendment 1 (4-72), Amendment Cooled Reactors (3/76) Ric Transport and Dispersion O Cooled Reactors (4-73) Amendment 1 (3-74)

Cooler (5-72) Amendment 1 (3-73, Amendment 2 (10-73) Cooling and Containment Heat Removal System Pumps (Safe Cooling and Containment Spray Systems (6/74)

Cooling Systems for Pressurized Water Reactors (Revisio Copper Alloy Die Forgings (Hot Pressed) (1974) $\$ 1.75$ Copper Alloy Forging Rod, Bar, and Shapes (1974) \$1.75 Copper Alloy Sand Castings for General Applications (19 Copper Alloy (UNS N04400) Plate, Sheet and Strip, Speci
NRC

EPA

NRC

NRC

NRC

ASTM

NRC

Alific ERDA

ERDA

ERDA

ERDA

ERDA

NRC

NRC

ANS ]

NRC

ANS!

ANS I

NRC

ANSI

ANSI

ERDA

NCRP

USCG

ANSI

ANSI

NRC

ASTM

ASTM

ANS!

ANSI

NEMA

ANSI

ANSI

NRC

in NRC

ANSI

ANSI

ASTM

ANSI

NRC

NRC

ERDA

ion for NRC

NRC

NRC

ERDA

ASTM

ANSI

ANSI

ERDA

NRC

Ive Ma NRC Anup S NRC

Electric NRC

NRC

NRC

Ests of Continu NRC irements for NRC

NRC

NRC

ANSI

ASTM

NRC

NRC

ERDA

ERDA

ERDA

ERDA

ERDA

ERDA

NRC

NRC

NRC

ASTM

ASTM

ASTM

ASTM

RG 1.50

FRC 8

RG 5.15

RG 1.43

RG 1.31

E428

RG 1.44

RDT F2-8T

RDT E6-25T

RDT E6-33T

RDT E6-5T

RDT E6-26T

RG 1.77

RG 1.78

RG 1.95

N41.17

RG 1.96

N 15.4

N15.9

RG 5.29

N15.8

N 15.13

RDT C $17-8 \mathrm{~T}$

R44

42CFR 78

N15.2

N15.16

N15.19

RG 5.18

E2 17

D2956

N 106

Z166.7

ICS

N 18.7

N16.8

RG 1.114

RG 1.70 .22

N 15.22

N15.18

E386

N 15.4

Z76.4

RG 1.3

RG 1.4

RG 1.7

RDT Al-1T

RG 1.70 .13

RG 1.45

RG 1.70 .20

RG 1.14

RDT F3-7T

D2470 
$\$ 1.75$

s Insulated, and Sheathed Over Fi/ 4) $\$ 1.75$

974) $\$ 1.75$

Specification for Nickel. Thermocouple Material, Std. Spec. for Spec. for ication for (1973) AWS A5.6-1969 \$2.50

ication for (1974)

errule Stock, Specification for (1974A) \$1.75

r (1973) AWS A5.7-1969 \$2.50

r (1974)

Acid Insoluble Content of

Photometric Methods for Chemical Analysis of Copper and Specification for Standard Sizes of Seamless (1973) AWS A5.6-1969\$2.50 (1974)

k, Specification for (1974A) $\$ 1.75$

s A5.7-1969 \$2.50

(4-70) Supersedes C7-14T, (3-7)

Is, Specification for (1975A) \$1.75

ion for (1974A) $\$ 1.75$

l (12-74)

ndment 1 (3-74)

Copper and

Copper and

Copper and

Copper and

Copper and

Thermocouple Material,

Specification for Seamless

Specification for

Fabrication of

Austenitic Stainless Steel Hexagonal Duct Tubes for

Piston Rings of High Strength Alloys for Austenitic Stainless Steel Plate, Sheet, and Strip for Austenitic Stainless Steel Wire for Austenitic Stainless Steel Bar for Austenitic Stainless Steel Tubing for LMFBR Low Friction Hard Surface for Analytical Chemistry Methods for Metallic $\begin{array}{rr}\text { (Safety Guide 1, } & \text { Net Positive Suction Head for Emergency } \\ \text { Sumps for Emergency } \\ \text { vision } 1,1 / 75) & \text { Preoperational Testing of Emergency }\end{array}$ $\begin{array}{rr}\text { (Safety Guide 1, } & \text { Net Positive Suction Head for Emergency } \\ \text { Sumps for Emergency } \\ \text { vision } 1,1 / 75) & \text { Preoperational Testing of Emergency }\end{array}$ vision $1,1 / 75)$
Steel Electrodes (1974) $\$ 3.50$ iquid Metal Service (4.73)

cation Only) (8-72) Amendment 1 (4-73)

amendment 1 (4-72), Amendment 2 (7-73), Amendment 3 (3/ brication Only) (10-72) Amendment 1 (3-74)

Recommended Practice for Test for Elastic Moduli of Rock Test for Triaxial Compressive Strength of Undrained Rock Method of Test for Direct Tensile Strength of Rock method of Test for Unconfined Compressive Strength of Rock ication Only) (1-72) Amendment l (12-72), Amendment 2 /

irements) (7-75) Supers/ $1969 \$ 2.50$

tm $\mathrm{C} 42-1968 \$ 1.75$

Obtaining and Testing Drilled
$5.1(\mathrm{Cb}+\mathrm{Ta})-1$ um Induction Melted 1750F ( $954.4 \mathrm{C}$ ) Alloy Tubing, Seamless, 5.I ( Cb \& Ta) -0.90Ti-0.)

5.

e or Vacuum Induction Melted 195/

steel Components of / Coy Sheet, Strip, and Plate, Alloy Sheet, Strip, and Plate, Guidance for Avoiding intergranular Applying Statistics to Analysis of n Stainless Steel (1971) \$1.75 Evaluating Stress Guidance for Avoiding Intergranular Corrosion and Stress

1965) $\$ 3.00$

e AMS5500A-1969 \$3.00

$150 \mathrm{lb}$

Steel Sheet,

Alloys, Practice for (1974) \$1.75

I Covered Welding Electrodes, Specification for (19) Aqueous

I Welding Rods and Bare Electrodes, Specification for (I/

1 Covered Welding Electrodes, Specification for (1974)

1 Welding Rods and Bare Electrodes, Specification for (1/ I Electrodes (1974) $\$ 3.50$

nd Strip, Specification for (1974A) $\$ 1.75$

ight-Wall Austenitic Chromium Nickel Alloy Steel Pipe for Design and Construction of Nonmetallic Gaskets for Recommended Practice for Determination of water-Cooled Nuclear Power Reactors (3/76) Uranium by Controlled Potential $(7-71)$ ned in One Booklet Priced at $\$ 3.00$ Logarithmic iple Input Preamplifier/Discriminator for Use with Neutron Standard Test Procedure for Geiger-Muller 74) Current Pulse Preamplifiers for Use with Fission
G01-1970\$3.00 d Test Procedures for Photo-Multipliers for Scintillation
Copper Alloy (UNS N04400) Seamless Pipe and Tube (1971) Copper and Constantan, Solid Conductor (Bare, Fiberglas Copper and Copper Alloy Die Forgings (Hot Pressed) (197 Copper and Copper Alloy Forging Rod, Bar, and Shapes (1 Copper and Copper Base Alloys (1975) \$1.75

Copper and Copper-Alloy Arc Welding Electrodes, Specif Copper and Copper-Alloy Arc Welding Electrodes, Specif Copper and Copper-Alloy Seamless Condenser Tubes and F Copper and Copper-Alloy Welding Rods, Specification Fo Copper and Copper-Alloy Welding Rods, Specification Fo Copper and Iron Powders, Test for (1974) \$1.75 Copper Base Alloys (1975) \$1.75

Copper Pipe (1975) \$1.75

Copper-Alloy Arc Welding Electrodes, Specification for Copper-Alloy Arc Welding Electrodes, Specification for Copper-Alloy Seamless Condenser Tubes and Ferrule Stoc Copper-Alloy Welding Rods, Specification for (1973) Aw

Copper-Alloy Welding Rods, Specification for (1974) Copper-Constantan, Mineral-Oxide Insulated, Sheathed Copper-Nickel Alloy Plate and Sheet for Pressure Vesse Copper-Nickel Pipe and Tube (1975) \$ T.75

Copper-Silicon Alloy Rod, Bar, and Shapes (1974A) \$1.7 Copper, Sheet, Strip, Plate, and Rolled Bar, Specificat

Core Assemblies for Nuclear Reactors (3-73) Amendment Core Component Pot for Liquid Metal Service (3-72) Ame Core Components and Assemblies (5-76) Supersedes E6-2 Core Components and Test Assemblies (7-73)

Core Components for Liquid Metal Service (5-74)

Core Components (3-73)

Core Components (3-73)

Core Components (3-73) Amendment 1 (4-74)

Core Components (5-72)

Core Components (5-73) Amendment 1 (9-73)

Core Components (9-75)

Core Cooling and Containment Heat Removal System Pumps

Core Cooling and Containment Spray Systems (6/74)

Core Cooling Systems for Pressurized Water Reactors (Re

Core Corrosion-Resisting Chromium and Chromium-Nickel

Core Permanent Magnet Flow Through Type Flowmeter for L

Core Radial Reflector for Sodium Cooled Reactors (Fabri

Core Radial Shield for Sodium Cooled Reactors (12-71)

Core Restraint Mechanism for Sodium Cooled Reactors (Fa

Core Sampling of Graphite Electrodes, (1974) $\$ 1.75$

Core Specimens in Uniaxial Compression (1972) \$1.75

Core Specimens Without Pore Pressure Measurements (1974

Core Specimens (1972) (ASTM D2936-1971) \$1.75

Core Specimens (1972) (ASTM D2938-1971A) \$1.75

Core Support Structure for Sodium Cooled Reactors (Fabr

Core Support Structures $(1977)$ bd $(\$ 40.00)$, Il $(\$ 70.00)$

Cored Arc Welding (ASME SFA -5.20 with Additional Requ

Cored Arc Welding, Specification for (1973) AWS A5.20-

Cored Arc Welding, Specification for (1974)

Cores and Sawed Beams of Concrete, Method of (1969) as

Corrosion and Heat Resistant Nickel Base-19Cr-3.1Mo-

Corrosion and Heat Resistant Nickel Base-19Cr-3.1Mo-

Corrosion and Heat Resistant Nickel Base-19Cr-3.1Mo-

Corrosion and Heat Resistant Nickel Base-19Cr-3.1Mo-

Corrosion and Heat Resistant Nickel Consumable Electrod

Corrosion and Stress Corrosion in Austenitic Stainless

Corrosion Data, Practice for (1973) ASTM G I6-197I \$1.7

Corrosion Effect of Wicking-Type Thermal Insulations $\mathrm{O}$

Corrosion in Austenitic Stainless Steel Components of $\mathrm{F}$

Corrosion Resistant Cast Flanged Valves (1959) $\$ 3.00$

Corrosion Resistant Cast Flanges and Flanged Fittings (

Corrosion Resistant, Laminated Surface Bonded (1973) SA

Corrosion Test for Soak Tank Metal Cleaners (1972) \$1.7

Corrosion Testing of Samples of Zirconium and Zirconium

Corrosion-Resisting Chromium and Chromium-Nickel Stee

Corrosion-Resisting Chromium and Chromium-Nickel Stee

Corrosion-Resisting Chromium and Chromium-Nickel Stee

Corrosion-Resisting Chromium and Chromium-Nickel Stee

Corrosion-Resisting Chromium and Chromium-Nickel Stee

Corrosion-Resisting Chromium Steel Clad Plate, Sheet a

Corrosive or High Temperature Service, Specification Fo

Corrosive Service, Practice for (1971) $\$ 1.75$

Corrosivity of Adhesive Materials (1974) $\$ 1.75$

Cost-Benefit Analysis for Radwaste Systems for Light-

Coulometry, Method of Test for (1970) \$1.75

Coulometry, Method of Test for (1973) ASTM E217-1970 \$

Count Rate Source Range Neutron Flux Monitoring System

Counter Tubes (1965) (R 1971) $\$ 3.00$ and N42.6 Are Contai

Counters (12-75) Supersedes C10-3T, (3-72)

Counters $(5 / 73)$

Counters (8-71) Amendment 1 (6-73), Amendment 2 ( 10

Counters, Test Procedures for (1969) (R 1974) IEEE Std.

Counting and Glossary for Scintillation Counting Field
ASTM

ERDA

ASTM

ASTM

ASTM

ANSI

ASME

ASTM

ANSI

ASME

ASTM

ASTM

ASTM

ANSI

ASME

ASTM

ANSI

ASME

ERDA

ASTM

ASTM

ASTM

ASTM

ERDA

ERDA

ERDA

ERDA

ERDA

ERDA

ERDA

ERDA

ERDA

ERDA

ERDA

NRC

NRC

NRC

AWS

ERDA

ERDA

ERDA

ERDA

ASTM

ASTM

ASTM

ANSI

ANSI

ERDA

ASME

ERDA

ANSl

ASME

ANS1

ANSI

ANS1

ANS1

ANSI

ANSI

NRC

ANS1

ASTM

NRC

MSS

MSS

ANSI

ASTM

ASTM

ANSI

ANSI

ASME

ASME

AWS

ASTM

ASTM

ASTM

ASTM

NRC

A STM

ANSI

ERDA
ANSI

Mult ERDA

NRC

ERDA

ANSI

ANS1

B 165

RDT C7-3T

B283

B! 24

SFA-5.6

B 1 I ]

W 3.7

SFA-5.7

E194

E62

B42

3.6

SFA-5.6

B 111

W3.7

SFA-5.7 
for Scintillation Counting and Glossary for Scintillation ygen Content Using a $14-\mathrm{MeV}$ Neutron Activation and Direct $1-75)$ ygen Content Using a $14-\mathrm{MeV}$ Neutron Activation and Direct $1(5-76)$ Sodium AWS A5.1-1969 \$3.50

Methods for the Analysis of Sodium and Mild Steel

AWS A5.5-1969 \$3.50

Low Alloy Steel Mild Steel ) al Requirements) (3-75) Supersedes M1-3T, (/ Low Alloy Steel Mild Steel nal Requirements) (3-75) Supers/ al Requirements) (3-75) Supersedes M1-/ al Requirements) (3-75) Supersedes M 1-/ s A5.11-1969\$2.50

Nickel and Nickel Allo Stainless Stee Low Alloy Stee Nickel and Nickel-Alloy Corrosion-Resisting Chromium and Chromium-Nickel Stee Nickel and Nickel-Alloy Corrosion-Resisting Chromium and Chromium-Nickel Steel Density of Preformed Pipe Environmental Stress ) ASTM D1693-1970\$1.75 1.75

\section{Method of Test for Accelerated Ozone}

Specifications for Electric Overhead Traveling nd Under Running Single Girder Electric Overhead Traveling

Large Shipping Cases and

ion Systems ( 1 2-69)

Supplementary nd Adsorption Units of Design, Testing, and Maintenance rations Where Shielding Protects Personnel (1975) ANS 8./

Earthquake Instrumentation General Site Suitability

Nuclear Power Plants (Revision 1, 6/73)

its, (Trial Std. Issued for Use and Comme/

Draft Standard ctor Plants: Issued Fo/ Draft Standard for Nuclear Safety Reactor Plants (1973) ANS-51.1 \$30.50 Nuclear Safety Reactor Plants (1975) \$5.50 Standard Nuclear Safety ng of Nuclear Power Generating Station Protection Systems, Protection Systems for Nuclear Power Generating Stations,

Film Badge Performance, ar Fuel Reprocessing Facilities, Guide to Principle Design ss 1E Power Systems for Nuclear Power Generating Stations, moderated Nuclear Power Generating Plants, Fire Protection

Supplies for Nuclear Power Generating Stations, Trial Use protective Functions in Nuclear Power Generating Stations, Basic Radiation Protection Film Badge Performance

n Syste/ 73) Draft Standard Application of the Single Failure Application of the Single-Failure Transportation of ment 1 (10-72), Amendment 2 (7-) of (1975) ANS-1 $\$ 8.00$

cations for Special Nuclear Material Licenses of Less Than

ng Protects Personnel (1975) ANS 8./

Dosimetry for ials Outside Reactors (1975) ANS-8. I $\$ 10.00$ ials Outside Reactors (1/73)

Guide for ( 1975) ANS-8.7\$12.00 Validation of Calculational Methods for Nuclear Validation of Calculational Methods for Nuclear

) $\$ 1.75$ Thermal Neutron Absorption stm C626-1971/ Estimating the Thermal Neutron Absorption 3) ASTM C695-1971T \$1.75 Compressive strength of Hydraulic Cement Mortars (Using 2-in ( $50-\mathrm{mm}$ ) amma and Electron Radiation Dose with the Ferrous Sulfateamma and Electron Radiation Dose with the Ferrous SulfateElectrical Insulation (1969) (R 197) Std. Spec. for Fully specimens in the Field, Method of (1970) ASTM/ Making and d of (1973) ASTM C 192-1969\$1.75 C171-1969 (1975) $\$ 1.75$

electronics (2-73)

$28-1974 \$ 5.00$

Making and 71) Sheet Materials for Eddy (6-73)

Alternating Direct rs (8-71) Amendment 1 (6-73), Amendment 2 (10-74) (c)

$\$ 3.00$

Review of the

Saturation, Practice for (1973) ASTM E309-1971 \$/ Eddyuid Metal Pressure Measurement System, Flush Mounted, Eddy or Measuring Coating Thickness by Magnetic-Field or EddyWelding and

Water Vapor Transmission of Shipping Containers by Method of Test for Density of Soil in Place by the Drive v- $1-1965 \$ 7.00$ Compressed Gas

3) ASTM C496-197I \$1.75

4) ASTM C 39-1972\$1.75
Counting Field (1972) IEEE Std. 398-1972 \$5.40 Counting Technique, Method of Test for (1973) $\$ 1.75$

Counting Technique, Method of Test for (1974) ASTM E38

Cover Gas Purchase Specifications (7-72) Amendment 1 Cover Gas ( 1-76) Supersedes F3-40T, (1-73) Amendment Covered Arc Welding Electrodes, Specification for ( 1973 Covered Arc Welding Electrodes, Specification for (1973 Covered Arc Welding Electrodes, Specification for (1974 Covered Arc Welding Electrodes, Specification for ( 1974 Covered Welding Electrodes (ASME SFA-5.1 with Addition Covered Welding Electrodes (ASME SFA-5.11 with Additio Covered Welding Electrodes (ASME SFA-5.4 with Addition Covered Welding Electrodes (ASME SFA-5.5 with Addition Covered Welding Electrodes, Specification for (1973) Aw Covered Welding Electrodes, Specification for (1973) Aw Covered Welding Electrodes, Specification for (1974) Covered Welding Electrodes, Specification for (1974) Covering Type Thermal Insulation, Test for (1972) \$1.75 Cracking of Ethylene Plastics, Method of Test for (1971 Cracking of Vulcanized Rubber (1971) ASTM D1 149-1970 \$ Crane Handling Systems for Nuclear Power Plants (2/76) Crane (1971) \$3.00 Cranes (1974) $\$ 3.00$

Crates, Testing (1973) $\$ 1.75$

Creep of Concrete in Compression, Test for (1974) $\$ 1.75$ Criteria and Requirements for RDT Reactor Plant Protect Criteria for Atmosphere Cleanup System Air Filtration a Criteria for Nuclear Criticality Safety Controls in Ope Criteria for Nuclear Power Plants (1974) ANS $2.2 \$ 10.00$ Criteria for Nuclear Power Stations (Revision 1, 11/75) Criteria for Safety-Related Electric Power Systems for Criteria for Separation of Class $1 \mathrm{E}$ Equipment and Circu Criteria for the Design of Stationary Boiling Water Rea Criteria for the Design of Stationary Pressurized Water Criteria for the Design of Stationary Pressurized Water Criteria for the (1975) $\$ 5.00$

Criteria for (1972) IEEE Std. 279-1971 \$4.00

Criteria for (1972) $\$ 4.25$

Criteria for (1973) $\$ 5.00$

Criteria for (1975) IEEE Std. 308-1974\$4.00

Criteria For, Issued for Trial Use and Comment (ANS-59 Criteria (Issued for Trial Use and Comment) IEEE 387-1

Criteria (Issued for Trial Use and Comment) (ANS 4.1) \$ Criteria (1971) $\$ 4.00$

Criteria (2/2/73)

Criterion to Nuclear Power Generating Station Protectio Criterion to Nuclear Power Plant Protection Systems (6) Critical Components and Equipment (1-76)

Critical Components and Related Equipment (8-72) Amend Critical Experiments, Safety Guide for the Performance Critical Mass Quantities (7/76) / Preparation Criticality Accident Alarm System ( 1969) ANS-8.5 $\$ 3.00$ Criticality Accident Alarm Systems (12/74)

Criticality Accidents (1969) \$4.25

Criticality Safety Controls in Operations Where Shield Criticality Safety in Operations with Fissionable Mater Criticality Safety in Operations with Fissionable Mater Criticality Safety in the Storage of Fissile Materials,

Criticality Safety (1975) ANS-8.11

Criticality Safety $(6 / 76)$

Cross Section of Nuclear Graphite, Estimating the (197] Cross Section of Nuclear Graphite, Methods for (1973) a (Crushing) Strength of Graphite, Method of Test for (197 Crushing) Strength of Graphite, Test for (1975) $\$ 1.75$

Cube Specimens), Test for (1973) \$1.75

Cupric Sulfate Dosimeter, Method of Test for (1973) (A Cupric Sulfate Dosimeter, Test for (1971)

Cured Silicone Rubber Coated Glass Fabric and Tapes for Curing Concrete Compressive and Flexural Strength Test Curing Concrete Test Specimens in the Laboratory, Metho Curing Concrete, Specifications for (1970) (R1975) ASTM Current Flowmeter Power Supply and Signal Conditioning Current Power Circuits, Surge Arresters for (1975) IEEE Current Power Range Neutron Flux Monitoring System ( 7 Current Probe Type Flow Sensor for Liquid Metal Service Current Pulse Preamplifiers for Use with Fission Counte Current State of Radiation Protection Philosophy (1975) Current Testing of Steel Tubular Products with Magnetic Current Type, Inductive, Absolute or Gage (10-70) Amen Current (Electromagnetic) Test Methods (1974) \$1.75 Cutting, Safety in (1973) $\$ 5.00$

Cycle Method, of Test for (1973) $\$ 1.75$

Cylinder Method (1972) (ASTM D2937-1971) \$1.75 Cylinder Valve Outlet and Inlet Connections (1965) CGA Cylindrical Concrete Specimens, Method of Test for (197 Cylindrical Concrete Specimens, Method of Test for (197
/Liers ANSI

IX ASTM

ANSI

ERDA

ERDA

ANS1

ANSI

ASME

ASME

ERDA

ERDA

ERDA

ERDA

ANSI

ANSI

ASME

ASME

ASTM

ANSI

ANSI

NRC

CMAA

CMAA

ASTM

ASTM

ERDA

NRC

ANSI

ANSI

NRC

NRC

ANSI

ANSI

ANSI

ANSI

IEEE

ANSI

ANSI

Nucle ANS

Cla ANSI

ANSI

ANSI

ANSI

NCRP

NRC

ANSI

NRC

ERDA

ERDA

ANSI

NRC

ANSI

NRC

ANSI

ANSI

NRC

ANSI

NRC

ASTM

ANSI

ANSI

ASTM

ASTM ANSI ASTM

ANS

ANSI

ANSI

ANSI

ERDA

ANSI

ERDA

ERDA

ERDA

ANSI

ERDA

F ASTM

ANSI

ASTM

ANSI

ANSI

ANSI

ANSI

N42.9

E385

N637

RDT M 14-1T

RDT F3-40T

W3.1

3.5

SFA-5. 1 
odulus of Elasticity and Poisson's Ratio in Compression of Preferred Limits and Fits for

\subsection{5 \\ Effects of Residual Elements on Predictcd Radiation \\ ts $(10 / 73)$ \\ Transportation of \\ construction, Arrangement, and Other Provisions for Use of $\mathrm{S}$ on Bo/ Transportation or Storage of Explosives or Other sions for Transportation or Storage of Explosives or Other 9.1) $\$ 12.50$ copy Systems for Material Protection Measurements, Part I: Analysis and Use of Process to Fatigue Testing and the Statistical Analysis of Fatigue Applying Statistics to Analysis of Corrosion \\ Recommended Practice for Wide Range ( 10 \\ Radiological Factors Affecting Food and Drugs: Notification of} Iding Constructions and Materials (1973) \$1.75

Dosimetry,

Thermal Insulating $M$ aterials, Activated Carbon,

Radioactive Waste Categories, Terms and Symbols Relating to Emission Spectroscopy, nd Graphite (1975) \$1.75 975A) $\$ 1.75$

e $170-1963$ (1968) $\$ 1.75$

975B) \$1.75 ANSI C 59.75 (1973)

g (1974) ASTM E268 $1968 \$ 1.75$

e Statistical Analysis of Fatigue Data (1973) (ASTM E206/ ction (1974) $\$ 1.75$

ection (1974) $\$ 1.75$

Materials (1975A) $\$ 1.75$

t (1974) $\$ 1.75$

74) $\$ 1.75$

power Generating Stations (1972) $\$ 4.00$

Terms Relating to Leak Testing, Quality Assurance Terms and Quality Assurance Terms and

Food and Drugs: Subpart A, General Provisions ing to (1) Nuclear Magnetic Resonance (NMR) Spectroscopy, forcement (1975) $\$ 1.75$ Specification for actor Coolant Water During Reactor Operatıon, Method For/ eactor Coolant Water During Reactor Operation, Measureme/ edures for Calibrating Magnetic Instruments to Measure the od of Test for (1973) ASTM C624-1971 \$1.75 for $(1971) \$ 1.75$

4)

Additional Information: Geography and generators by Radioactivation Techniques, / Neutron-Flux rators by Radioactivatio/ Method of Test for Neutron Flux Measuring Neutron Flux

cles by Physical Measurements, Method of Test for (1973)/

ng Materials, Test for (1970) $\$ 1.75$ Apparent $\$ 1.75$ Thickness and Test for Particulate Matter in the Atmosphere (Optical $t$ for $(1972) \$ 1.75$

ion, Test for (1972) $\$ 1.75$

Methods (Shallow Depth), Tests for (1971) $\$ 1.75$

1972) (ASTM D2937-1971) \$1.75

Method of Test for and $18(457 \mathrm{~mm}) \mathrm{l} / \quad$ Standard Methods of Test for Moisture mmer and 12-in. (304.8-mm) Drop, Tests for (/ Moisturective Materials Shipments, Administrative Guid/ $\quad \begin{array}{r}\text { X-Ray Protection in } \\ \text { Obtaining }\end{array}$

Sodium and Potassium in Water and Water Formed late Matter in the Atmosphere (Optical Density of Filtered il and Soil Aggregate in Place by Nuclear Methods (Shallow il and Soil Aggregate in Place by Nuclear Methods (Shallow

1 and Soil-Aggregate in Place by Nuclear Methods (Shallow aces, Rec. Practice for (1974) \$1.75

Preparation of System Design stituents of Aggregates for Radiation-Sheilding Concrete, stituents of Aggregates for Radiation-Shielding Concrete, nt ANS $58.1 \$ 12.00$

storage Tanks (1973) $\$ 4.00$

osive Service, Practice for (1971) $\$ 1.75$

Draft Standard for Plant

Additional lnformation: Quality Assurance During Quality Assurance Program Requirements

Protection for Energies Up to $10 \mathrm{MeV}$ Structural Sheilding Code Case Acceptability: ASME Section lii Pipe Hangers and Supports-Material,

s Handbook $107 \$ 3.00$ Radiological Safety in the $s$ for Type a Quantities of Radioactive Materials, Guide to Gamma Ray Protection for Energies Up to $10 \mathrm{Mev}$ : Equipment
Cylindrical Concrete Specimens, Method of Test (1967) ( Cylindrical Parts (1967) (R1974) \$4.00

Cylindrical Shipping Containers, Drop Test for (1973) \$

Damage to Reactor Vessel Materials (7/75)

Damping Values for Seismic Design of Nuclear Power Plan Dangerous Articles and Magnetized Materials (1975) $\$ 5.0$

Dangerous Articles as Ships, Stores and Supplics on Boa

Dangerous Articles or Substances and Combustible Liquid

Dangerous Articles or Substances and Combustible Liquid

Data Acquisition Systems (Revision 1, 5/74)

Data for the Protection of Special Nuclear Material (6/

Data Sets for Reactor Design Calculations (1975) ANS-I

Data (1973) (ASTM E206-1972) \$1.75

Data, Practice for (1973) ASTM G $16-197$

Dealing with Outlying Observations (6/74)

Decade) Neutron Flux Monitoring Channel (2-71)

Decision Making in a Nuclear Attack (1974) $\$ 4.00$

Defects or Failure to Comply (1975) $\$ 2.95$

Definition of Terms Relating to Acoustical Tests of Bui

Definition of Terms Relating to Water (1974) \$1.75

Definition of Terms Relating to (i963) (R 1968) \$1.75

Definition of Terms Relating to (1967) \$1.75

Definition of Terms Relating to (1974) \$1.75

Definition of (1967) $\$ 3.00$

Definition of (1975A) $\$ 1.75$

Definitions and Terms Relating to Manufactured Carbon a

Definitions for Mechanical Testing of Steel Products (1

Definitions of Terms Relating to Dosimetry (1973) ASTM

Definitions of Terms Relating to Electric Insulation (1

Definitions of Terms Relating to Electromagnetic Testin

Definitions of Terms Relating to Fatigue Testing and th

Definitions of Terms Relating to Liquid Penetrant lnspe

Definitions of Terms Relating to Magnetic Particle Insp

Definitions of Terms Relating to Rubber and Rubber Like

Definitions of Terms Relating to Temperature Measuremen

Definitions of Terms Relating to Ultrasonic Testing (19

Definitions of Terms Used in IEEE Standards on Nuclear

Definitions of (1973) ASTM E425-1971 \$1.75

Definitions (1973) $\$ 3.00$

Definitions (2/74)

Definitions) (1975) $\$ 2.95$

Definitions, Symbols, Conventions, and References Relat

Deformed and Plain Billet-Steel Bars for Concrete Rein

Delayed Neutron Emitting Fission Products in Nuclear Re

Delayed Neutron-Emitting Fission Products in Nuclear $\mathbf{R}$

Delta Ferritic Content of Austenitic Stainless Steel We

Delta-In-Hours (DIH) Purity of Nuclear Graphite, Meth

Delta-In-Hours (DIH) Purity of Nuclear Graphite, Test

Demography Considerations for Nuclear Power Plants (8/7

Density and Average Energy from ${ }^{3} \mathrm{H}(\mathrm{d}, \mathrm{n}){ }^{4} \mathrm{He}$ Neutron

Density and Average Energy from $3 \mathrm{H}(\mathrm{D}, \mathrm{N}) 4 \mathrm{He}$ Neutron Gene

Density by Radioactivation of Cobalt and Silver (1973T)

Density in Air of Manufactured Carbon and Graphite Arti

Density of Activated Carbon, Test for (1970) $\$ 1.75$

Density of Blanket-Type or Batt-Type Thermal lnsulati

Density of Cohesionless Soils (1972) (ASTM D2049-1969)

Density of Filtered Deposit) (1969) $\$ 1.75$

Density of Preformed Block Type Thermal Insulation, Tes

Density of Preformed Pipe Covering Type Thermal Insulat

Density of Soil and Soil-Aggregate in Place by Nuclear

Density of Soil in Place by the Drive Cylinder Method (

Density Relations of Soils Using $10 \mathrm{lb}$. (4.5 mg) Rammer

Density Relations of Soils, Using 5.5-lb. (2.5-kg) Ra

Dental Offices (1970) $\$ 4.00$

Department of Transportation Special Permits for Radioa

Depleted Uranium Castings (1975) $\$ 3.00$

Deposits by Flame Photometry, Tests for (1971) $\$ 1.75$

Deposit) (1969) $\$ 1.75$

Depths), Test for (1972) $\$ 1.75$

ASTM
Test for Particu ASTM

Depth) (1972) $\$ 1.75$ (ASTM

Moisture Content of So ASTM

Depth), Tests for (1971) $\$ 1.75$

Density of Soi ASTM

Descaling and Cleaning Titanium and Titanium Alloy Surf ASTM

Descriptions (12-75) Supersedes (3-72)

Descriptive Nomenclature of (1973)

Descriptive Nomenclature of (1975) ASTM C638-1973 \$1.7

Design Against Missiles-lssued for Trial Use and Comme

Design and Construction of Large, Welded, Low Pressure

Design and Construction of Nonmetallic Gaskets for Corr

Design and Construction ( $7 / 74)$

(Design and Construction) (Safety Guide 28, 6/7/72)

Design and Evaluation (1970) $\$ 4.00$ /-Ray and Gamma Ray

Design and Fabrication (Revision 6, 5/76)

Design and Manufacture (1967) $\$ 4.00$

Design and Operation of Particle Accelerators (1969) NB ANSI

Design and Use of (1975) $\$ 5.00$

Design and Use (1968) $\$ 3.00$
ANS1

ANS1

ASTM

NRC
NRC

DOT

USCG

USCG

NRC

ANSI

ANSI

ANSI

ERDA

NCRP

BRH

ASTM

ASTM

ASTM

ANSI

ASTM

ASTM

ANSI

ASTM

ANSI

ASTM

ASTM

ASTM

ASTM

IEEE

ANS1

ANS1

BRH

ASTM

ASTM

ANSI

AWS

ASTM

NRC

ASTM

ANSI

ANSI

ASTM

ASTM

ANSI

ASTM

ASTM

ASTM

ANSI

ASTM

ASTM

NCRP

ANS1

ERDA

ANSI

ANSI

ANS

A PI

NRC

NRC

NCRP

NRC

MSS

Shipping Package ANSI Medical X-Ray a.sd NCRP

A 37.94

B4. 1

D997

RG 1.99

RG 1.61

4CFR 103

46CFR 147

46CFR 146

46CFR I 46

RG 5.9

RG 5.24

N4I 1

Z92.2

G80.3

RG 5.36

RDT C15-2T

R42

2 ] CFR 1003

C634

D1129

E170

C 168

D2652

N5.8

E135

C709

A 370

N105

D 1711

Z166.31

Z92.2

E270

E269

D 1566

E344

E500

380

Z166.25

N45.2.10

RG 1.74

21CFR I000A

E386

A615 
ons in Nuclear Power G/

Draft Standard for Preparation of $1,4 / 76)$ tance to Shock and Vibration in Truck Transport (2-75) inst Effects of Postulated Pipe Ruptu/

Draft Standard for

Fuel Storage Facility

Fabrication Plants (10/73)

Nuclear Data Sets for Reactor Seismic Seismic

Tornado

Special Nuclear Materials in Equipment for Wet Process / Special Nuclear Material in Equipment for Dry Process O/ Special Nuclear Material in Drying and Fluidized Bed Op/ Liquids $(2 / 75)$

Nuclear Fuel Reprocessing Facilities, Guide to Principle Preparation of System

ion Plants $(6 / 73)$ Additional Information: Water Level (Flood)

ing Systems $(9 / 75)$

Liquid Waste Treatment System

ssing and Fuel Fabrication Plants (8/73)

y Reactor Containment System Components (6/73)

gory 1 Fluid System Components (5/73)

Handling and Storage Facilities in a Reprocessing Plant/

stems for Boiling Water Reactor Nuclear Power Plants ( Re/
Information for Safety Analysis Reports: Environmental 74) Seismic Requirements for Design Response Spectra for Seismic Quality Assurance Program Requirements for the Damping Values for Seismic Quality Assurance Requirements for the ture (9-74) Supersedes F9/ Guidelines and Procedures for
Additional Information: ed Fo/ Draft Standard for Nuclear Safety Criteria for the 1973 ) ANS-51.1 $\$ 30.50 \quad$ Nuclear Safety Criteria for the 1975) $\$ 5.50 \quad$ Standard Nuclear Safety Criteria for the Information for Safety Analysis Reports: Missile Barrier ower Plants (Revision 1, 12/73)

anium Mills (6/73)

Information for Safety Analysis Reports: Fuel System

Method of Test for (1973) ASTM D2295-1972 (Revision and

Electrical and Electronics Parts and Equipment, Reference special Nuclear Material (Revision I, 4/75) Specially Surveillance Program for New Fuel Assembly uel Storage/ Surveillance Program for New Fuel Assembly nerators for Certain Land and Sea Applications (3/74)

r Buildings (Adopted February 12,/ Specification for the e Cleanup System Air Filtration and Adsorption Units of / dip Galvanized Structural Steel Products and Procedure for inless Steels, Rec. Practices for (1975) \$1.75

ught Nickel-Rich, Chromium-Bearing Alloys, Method of Mass Spectrometer Helium Leak Reactor Coolant Pressure Boundary Leakage say for Plutonium in Scrap Material by Spontaneous Fission Fission Type Neutron

Testing for Leaks Using the Mass Spectrometer Leak Tests for Leaks Using the Mass Spectrometer Leak Neutron Activation .75 Selection of Neutron Activation ode (/ Testing for Leaks Using the Mass Spectrometer Leak for Leaks Using the Mass Spectrometer Leak Detector in the BF3 Gamma Tolerant Neutron Electrical Continuity Type Liquid Metal Leak nded Practice for Testing for Leaks Using the Halogen Leak Testing of High Temperature Cable for Nuclear
(Agrees with IEC 333)/ Semiconductor Radiation $71 \$ 4.00$ Amplifiers and Preamplifiers for Semiconductor Radiation ellet Homoneity by Use of an Electronium Gamma-Ray (1973) ASTM E320-1970 \$1.75 Methods for Radiochemical Standard Method for (1970) $\$ 1.75$ Radiochemical Sampling Wrought Nonferrous Metals and Alloys for

4) $\$ 1.75$ Recommended Practice for r Fuels (1973T) \$1/ Method of Test for Spectrophotometric radiography $(5-75)$

ated Conductors (8/70) Amendment $1(9 / 73)$

9 on Water (1972) \$1.75 Recommended Practice fór c Constants of Rock (1972) (ASTM D2845-1969)/ Laboratory rode $(1973) \$ 1.75$ Continuous Classification for

ice for Examination of Fuel Element Cladding Including the ce for Examination $\mathrm{O} / \quad$ Fuel Element Cladding Including the method for (1975) $\$ 1.75$

tm E318-1969 \$1.75 Colorimetric ion Rate Distributions and Reactivity of Nuclear Reactors, e Solutions for Assay, 1sotopic Distribution, and Impurity itic Steels (1970) ASTM / Conducting Drop-Weight Test to
Design Bases for Systems That Perform Protective Functi Design Basis Floods for Nuclear Power Plants (Revision Design Basis for Fuel and Irradiations Experiment Resis Design Basis for Protection of Nuclear Power Plants Aga Design Basis Tornado for Nuclear Power Plants (4/74) Design Basis (Revision 1, 12/75)

Design Calculations (1975) ANS-19.1 \$12.50

Design Classification for Plutonium Processing and Fuel Design Classification (Revision 2, 2/76)

Design Classification (6/76)

Design Considerations for Minimizing Residual Holdup of Design Considerations for Minimizing Residual Holdup of Design Considerations for Minimizing Residual Holdup of Design Considerations: Systems for Measuring the Mass $\mathrm{O}$ Design Criteria for (1973) $\$ 5.00$

Design Descriptions (12-75) Supersedes (3-72)

Design for Nuclear Power Plants (5/74)

Design Guide for Plutonium Processing and Fuel Fabricat Design Guide for Ventilation Systems for Fuel Reprocess Design Guide for Ventilation Systems of Plutonium Proce Design Limits and Loading Combinations for Metal Primar Design Limits and Loading Combinations for Seismic Cate Design Objectives for Highly Radioactive Solid Material

Design of Main Steam 1solation Valve Leakage Control Sy Design of Mechanical and Electrical Equipment Qualifica Design of Nuclear Power Plants and Test Facilities ( 1 -

Design of Nuclear Power Plants (Revision I, 12/73)

Design of Nuclear Power Plants (Revision 2, (6/76)

Design of Nuclear Power Plants (10/73)

Design of Nuclear Power Plants (1974) $\$ 5.50$

Design of Nuclear System Components at Elevated Tempera

Design of Seismic Category 1 Structures (11/74)

Design of Stationary Boiling Water Reactor Plants: Issu

Design of Stationary Pressurized Water Reactor Plants (

Design of Stationary Pressurized Water Reactor Plants (

Design Procedures (12/74)

Design Response Spectra for Seismic Design of Nuclear P

Design Stability of Embankment Retention Systems for Ur

Design (5/75)

Designation of Z208.1-1970) \$1.75

Designations for (1975) IEEE $200 \$ 6.00$

Designed Vehicle and Armed Guards for Road Shipment of

Designs (6/76)

Design, and Plant Protection for an Independent Spent F

Design, Construction, and Use of Radioisotopic Power Ge

Design, Fabrication and Erection of Structural Steel Fo

Design, Testing, and Maintenance Criteria for Atmospher

Detecting Embrittlement, Rec. Practice for (1974) \$1.75

Detecting Susceptibility to Intergranular Attack in Sta

Detecting Susceptibility to Intergranular Attack in Wro

Detection for Instruments and Small Components (2-72)

Detection Systems (5/73)

Detection (6/74)

Detector Assembly (12-71) Amendment 1 (10-73)

Detector in the Detector Probe Mode (1973) \$1.75

Detector in the Inside-Out Testing Mode (1973) \$1.75

Detector Materials, Guide for Selection of (1973) $\$ 1.75$

Detector Materials, Guide for (1974) ASTM E419-1973 \$1

Detector or Residual Gas Analyzer in the Tracer Probe M

Detector Probe Mode (1973) \$1.75

Detector Tubes (12-75) Supersedes CI5-11T, (8-72)

Detector (10-72) Amendment 1 (6-73)

Detectors (Alkali-Ion Diode) ( 1971 ) $\$ 1.75$

Detectors (8-71)

Detectors, Test Procedures for (1968) (R1974) IEEE Std.

Detectors, Test Procedures for (1969) IEEE Std. 301-19

Detectors, Test Procedures for (1972) IEEE Std. 325-I9

Determination of a Figure of Merit for $\mathrm{PuO}_{2}-\mathrm{UO}_{2}$ Fuel $\mathrm{P}$

Determination of Cesium-137 in Nuclear Fuel Solutions

Determination of Cesium-137 in Nuclear Fuel Solutions

Determination of Chemical Composition (1972) $\$ 1.75$

Determination of Corrosivity of Adhesive Materials ( 197

Determination of Fission Zirconium in lrradiated Nuclea

Determination of Fuel Pellet Homogeneity by Alpha-Auto

Determination of Insulation Compaction in Ceramic Insul

Determination of Precision of Methods of Committee D-

Determination of Pulse Velocities and Ultrasonic Elasti

Determination of Sodium in Water by lon Selective Elect

Determination of Sound Transmission Class (1973) \$1.75

Determination of the Mechanical Properties (1973) ASTM

Determination of the Mechanical Properties, Rec. Practi

Determination of Uranium in Aqueous Solutions Standard

Determination of Uranium in Aqueous Solutions (1973) as

Determination of (1975) ANS $19.3 \$ 7.50$

Determinations (12/74) / the Analysis of Uranyl Nitrat NRC

Determine Nil-Ductility Transition Temperature of Ferr
ANS

NRC

ERD

ANS 1

NRC

ANS1

NRC

NRC

NRC

NRC
NRC

NRC

ANS1

ERDA

NRC

NRC

NRC

NRC

NRC

ANSI

NRC

NRC

ERDA
NRC

NRC

NRC

ANS1

ERDA

ANSI

ANS1

ANS1

NRC

NRC

NRC

ANS1

ANS1

NRC

NRC

NRC

AISC

NRC

ASTM

ASTM

ANS

ERDA

NRC

ERDA

ASTM

ASTM

ASTM

ASTM

ASTM
ERDA

ERDA

ASTM

ERDA

ANSI

ANSI

ANDA

ASTM

ASTM

ASTM

ASTM

ERDA

ERDA

ASTM

ANSI

ASTM

ANSI

ASTM

ASTM

ANSI

ANSI

N18.8

RG 1.59

RDT F8-9T

N176

RG 1.76

RG 1.13

N41 I

RG 3.14

RG 1.29

RG 1.117

RG 5.25

RG 5.42

RG 5.8

RG 5.48

N101.3

RDT F I-2T

RG 1.70 .5

RG 3.10

RG 3.32

RG 3.12

RG 1.57

RG 1.48

N305

RG 1.96

RG 1.70 .24

RDT F9-2T

RG 1.60

RG 1.64

RG 1.61

N45.2.11

RDT F9-5T

RG 1.70 .9

N212

N18.2 
ctice for (1974) \$1.75

sulation (1973) ASTM C447-1971\$1.75 Method of Test for terial Exposed to High Energy Radiation, Rec. Practice for

for Consumption of Potassium Permanganate by Impurities in 1) Consumption of Potassium Permanganate by Impurities in $968 \$ 1.75$ $968 \$ 1.75$

Testing

Background Material fo Background Material for

in Research Reactors (11/73) $15.1 \$ 12.00$

nmetals in Liquid Sodium (1-72) / Background Material for the

Research Reactors

Specimen Equilibration Efficiency Testing of Air Cleaning Systems Containing Efficiency Testing of Air Cleaning Systems Containing perties of Sealed Radioactive Sources Contained in Certain Installation of Overpressure Protection

Laminar-Flow Clean Ai Mechanical Locking

Logic Diagrams (Two State

erformance Std. (lonizing Radiation Emitting Products) for t to ANSI Y 14.15-1966 (R1970), Electrical and Electronics IEEE $91-1973 \$ 6.00$ b $\$ 8.00$

Logic

b $\$ 8$

aboratory Use, Test for (1969) $\$ 1.75$ with Additional Requirements) / teel Pipe for Corrosive or High Tem/

Electrical and Electronics Electrical and Electronics Maximum Pore Welded Large Outside -75) Super/ Austenitic Stainless Steel Welded Pipe Large mless and Welded Austenitic Stainless Steel Tubing (SmallTest for Evaluating Inhibitory Toxicity of Waters to Specification for Aluminum-Alloy Aluminum-Alloy

$1969 \$ 5.00$

Std. Spec. for Copper and Copper Alloy

s (Safety Guide 9, 3/10/71)

s for Nuclear Power Generating Stations, /

Selection of s $(6 / 74)$

c Output Signal (4-74)

nbs Handbook $111 \$ 3.00$

Evaluation of Shipper-Receiver

72)

Radiation Safety for X-Ray

ethod, Method of Test for (1973) ASTM C714-1972/ Thermal ethod, Test for (1972) \$1.75

mmended Programming Practices to Facilitate Interchange of Guidelines for the Documentation of Requirements for Inspection of

stm D2435-1970) $\$ 1.75$

1973) $\$ 10.00$ Method of Test for One

(R1973) $\$ 1.75$

Face-to-Face and End-to-End

Unfired Pressure Vessel Flange Methods for the Accountability of Plutonium Specification for Nuclear Grade Sinterable Uranium Specification for Nuclear Grade Sinterable Plutonium Specification for Nuclear Grade, Sinterable Uranium Specification for Nuclear Grade, Sinterable Uranium c, and Spectrochemical Analysis of Nuclear Grade Plutonium ric, and Spectrochemical Analysis of Nuclear Grade Uranium ic, and Spectrochemical Analysis $\mathrm{O} / \quad$ Nuclear Grade Uranium ic, and Spectrochemical Analysis/ Nuclear Grade Plutonium Spectrometric, and Spectrochemical Analysis of / Uranium Spectrometric, and Spectrochemical Analysis O/ Plutonium Fast Flux Test Facility Ceramic Grade Plutonium

Safeguarding Against Ceramic Grade Uranium stm A385-196/ Providing High Quality Zinc Coatings (Hot74) ASTM A386-1973\$1.75 3) $\$ 1.75$

Zinc-Coating (HotZinc Coating (Hotlection Method, Using Pulsed Longitudinal Waves Induced by .7/ Oxygen Content Using a 14-MeV Neutron Activation and $\mathrm{tm} /$ Oxygen Content Using a 14-MeV Neutron Activation and em (7-71)

or X and Gamma Radiation, Performance, Specification For/ onditions (1973) (ASTM D3080-1972) \$/ Method of Test for astm D2936-1971) \$1.75 $(2 / 26 / 73)$ Method of Test for

nformation for Safety Analysis Reports: Pressurizer Relief onizing Radiation Emitting Products) for Cold-Cathode Gas

sonic Inspection of Metal Pipe and Tubing for Longitudinal or Mathematical Models Selected to Predict Heated Effluent ctor Releases for the Purpose of Impl/ Estimating Aquatic m Light/ Methods for Estimating Atmospheric Transport and
Determining Inclusion Content of Steel, Recommended Pra

ASTM

Determining the Maximum Use Temperature of Preformed in

ANSI

Determining (1962) (R1968) \$1.75 /Vity of Inorganic Ma ASTM

Deuterium Oxide (1973) $\$ 1.75$

Test ASTM

ANSI

Deuterium Oxide, Method of Test for (1973) ASTM D2033

Deuterium Oxide, Method of Testing (1973) ASTM D2184-

Deuterium Oxide, Specification for (1973) ASTM D2032-1

Deuterium Oxide, Spec. for (1968) (R1975) \$1.75

Deuterium Oxide, Standard Method of (1972) $\$ 1.75$

Development of Radiation Protection Stds. (1960)

Development of Radiation Protection Std. (1961)

Development of Radiation ( 1964)

Development of Technical Specifications for Experiments

Development of Technical Specifications for (1974) ANS-

Device (Or Multipurpose Sampler) for the Analysis of No

Devices for Removal of Particles (1972) $\$ 2.50$

Devices for Removal of Particles (1/73)

Devices to Be Distributed for Use Under General License

Devices (10/73)

Devices (1968) $\$ 1.50$

Devices (3-69) Amendment 1 (10-71)

Devices), Graphic Symbols for (1973) IEEE 91-1973\$6.0

Diagnostic X-Ray Systems and Their Major Components (19

Diagrams Sold Separately $\$ 1.75$

Diagrams (Two State Devices), Graphic Symbols for (1973

Diagrams (1966) lncludes Supplements Y 14.15 a and $Y 14.15$

Diagrams, Graphic Symbols for (1975) IEEE 315-1975 \$8.

Diameter and Permeability of Rigid Porous Filters for $\mathrm{L}$

Diameter Austenitic Stainless Steel Tubing (ASTM a 632

Diameter Light-Wall Austenitic Chromium Nickel Alloy S

Diameter (ASME-SA-358 with Additional Requirements) (4

Diameter) for General Service (1974) ASTM A632-1969 \$1

Diatoms (1973) \$1.75

Die and Hand Forgings (1974) ASTM B247-1973 \$1.75

Die and Hand Forgings, Specification for (1974) $\$ 1.75$

Die Forgings (Hot Pressed) (1974) \$1.75

Dielectric Tests, Techniques for (1968) (R1973) IEEE 4 -

Diesel Generator Set Capacity for Standby Power Supplie

Diesel Generator Units Applied as Standby Power Supplie

Differences in the Transfer of Special Nuclear Material

Differences in the Transfer of Special Nuclear Material

Differential Pressure Transmitter, Pneumatic or Electri

Diffraction and Fluorescence Analysis Equipment (1971)

Diffusion Carbon Meter for Service in Liquid Sodium (1-

Diffusivity of Carbon and Graphite by a Thermal Pulse M

Diffusivity of Carbon and Graphite by a Thermal Pulse M

Digital Computer Programs (1971) $\$ 7.50$

Digital Computer Programs (1974) ANS 10.3\$8.50

Dimensional Characteristics (8-73)

Dimensional Consolidation Properties of Soils (1972) (A

Dimensioning and Tolerancing for Engineering Drawings (

Dimensions of Ferrous Valves (1973) \$4.00

Dimensions of Plastic Pipe Fittings, Symbols for (1968)

Dimensions (1969) $\$ 4.00$

Diode) (1971) $\$ 1.75$

Dioxide Powder (12/74)

Recommended Practice for Testi

Dioxide Powder (1973) \$1.75

Dioxide Powder (1974A) \$1.75

Dioxide Powder (1974) ASTM C753-1973 \$1.75

Dioxide Powder (1975) ASTM C757-1974a \$1.75

Dioxide Powders and Pellets and Nuclear Grade Mixed Oxi

Dioxide Powders and Pellets $(2 / 9 / 73)$

Dioxide Powders and Pellets, Chemical, Mass Spectrometr

Dioxide Powders and Pellets, Chemical, Mass Spectrometr

Dioxide Powders and Pellets, Methods for Chemical, Mass

Dioxide Powders and Pellets, Methods for Chemical, Mass

Dioxide (6-71)

Dioxide (6-71) Amendment 1 (12-74)

Dip Galvanized Structural Steel Products and Procedure

Dip) on Assembled Products, Specification for (R1973) a

Dip) on Assembled Steel Products, Specification for ( 19

Dip) on Iron and Steel Hardware, Specification for ( 197

Direct Contact, Practice for (1969) (R1973) ASTM El 14.

Direct Counting Technique, Method of Test for (1973) \$1

Direct Counting Technique, Method of Test for (1974) as

Direct Current Power Range Neutron Flux Monitoring Syst

Direct Reading and Indirect Reading Pocket Dosimeters F

Direct Shear Test of Soils Under Consolidated Drained C

Direct Tensile Strength of Rock Core Specimens (1972) (

Direct-Reading and Indirect-Reading Pocket Dosimeters

Discharge System (6/75)

Discharge Tubes (1975) \$2.95

Discontinuities, Method for (1974) $\$ 1.75$

Dispersion in Natural Water Bodies $(5 / 74)$

Performance Std. (I BRH

$\begin{array}{ll}\text { /Procedure F } & \text { NRC } \\ \text { Rea } & \text { NRC }\end{array}$

Dispersion of Effluents from Accidental and Routine Rea
Dispersion of Gaseous Effluents in Routine Releases Fro
ANS

ANSI

ASTM

ASTM

EPA

EPA

EPA

NRC
ANSl

ERDA

ANSI

NRC

NRC

NRC

ERDA

BRH

ANSI

ANS1

ANSI

ANSl

ERDA

ASTM

ERDA

ANS!

ASTM

ASTM

ASTM

ANSI

ANS

ANS!

NRC

ANSI

ERDA

ANSI

ASTM

ANS

ANSI
ERDA

ANSI

ANSl

ANS1

ASTM

ANSI

ASTM

NRC
ASTM

ASTM

ANSI

ANS

NRC

NRC

ASTM

ANSI

ERDA

ERDA

ASTM

ANSI

ANSI

ASTM

ANSI

ASTM

ANSI

ERDA

ANSI

ANS

NRC
NRC

E45

Z98.28

E183

D2033

N157

D2032

D2 184

FRCl

FRC2

FRC5

RG 2.2

N378

RDT C8-8T

N101.1

RG 3.2

RG 6.4

RG 1.67

S-2T

RDT M6-2T

Y32. 14

21 CFR1020C

Y14.15A

Y32.14 
Reciprocating Positive Performance Test Code for

Radioactive Waste

use (1951) $\$ 2.00$

$\mathrm{d}$ of Tests for $(1974) \$ 1.75$

Particulate and Tests for

led Radioactive Sources Contained in Certain Devices to Be 70) $\$ 1.75$

Particle Size

redundant Standby (Onsite) Power Sources and Between Thei mination of (1975) ANS $19.3 \$ 7.50$ Neutron Reaction Rate e Analysis of Uranyl Nitrate Solutions for Assay, Isotopic $0.3 \$ 8.50$

ode for (1973) (IEEE Std 262-1973), Including Draft Sup/ Guidelines for the Special Nuclear Material Rec. Practice for Calculation of Absorbed Std Method of Test for Absorbed Gamma Radiation ys (1961) $\$ 2.00$

Measurement of Absorbed Calculation of Neutron d-Foil Measurements (1968) (R197/ or (1973) (ASTM D3/ Absorbed Gamma and Electron Radiation Test for (1971) Absorbed Gamma and Electron Radiation for the Purpose of Evaluating Com/ Calculation of Annual f Quartz-Fiber Electrometer Type Dosimeters and Companion Std. Relating to Personne od of Test for Absorbed Gamma Radiation Dose in the Fricke 71)/ Interrelationship of Quartz-Fiber Electrometer Type ification For/ Direct Reading and Indirect Reading Pocket 3.50 Personnel Neutron

Direct-Reading and Indirect-Reading Pocket Personnel Neutron on Radiation Dose with the Ferrous Sulfate-Cupric Sulfate d Gamma and Electron Radiation Dose with the Ceric Sulfate on Radiation Dose with the Ferrous Sulfate-Cupric Sulfate

r Reporting (1974) \$1.75

8) $\$ 1.75$

Definitions of Terms Relating to

ing, and Procedural Specifications for Thermoluminescence

Std. for Bypass and

Cast Bronze Solder Joint Fittings for Sovent 5) $\$ 1.75$ of Test for Direct Shear Test of Soils Under Consolidated Sheet, Cold Rolled, Abbreviations for Use in Dimensioning and Tolerancing for Engineering es, Specification for (1973) $\$ 1.75$ , Specification for (1974) ASTM B234 197/ Seamless Cold Aluminum-Alloy Aluminum-Alloy 1969) ASTM C42-1968 \$1.75 Obtaining and Testing Method of Test for Density of Soil in Place by the (12-72), Amen/ Collapsible Rotor, Roller Nut Control Rod

$1(3-74)$

I $(5-74)$

$1(5-74)$

s E3-3T, (10-70), Amendm/

Fabrication of Control Rod

Vertical, Canned or Wet Motor Horizontal, Electric Motor Vertical, Shaft Sealed, Motor

Fast Flux Facility

nt $1(12-74)$

Fast Flux Test Facility Fast Flux Test Facility Fast Flux Test Facility

Fast Flux Test Facility Fast Flux Test Facility Fast Flux Test Facility Fast Flux Test Facility

Fast Flux Facility

Shipping Containers, Bags,

Cylindrical Shipping Containers, of Soils Using $10 \mathrm{lb}$. (4.5 mg) Rammer and $18(457 \mathrm{~mm})$ in (1974) $\$ 1.75$

n Temperature of Ferritic Steels (1970) ASTM / Conducting 75) $\$ 2.95$ s, Using 5.5-lb. (2.5-kg) Rammer and 12-in. (304.8-m m)

5) $\$ 2.95$

Food and

Food and

on $(1975) \$ 2.95$

Food and

0) Ast/ Std. Spec. for Carbon Steel Forgings for Seamless rd for Steel Castings (1971) $\$ 3.00$

Fans, Blowers, and Compressors for

69) (R 1973) ASTM E109-1963 (1971) $\$ 1.75$

sidual Holdup of Special Nuclear Material in Equipment for er Vapor Transmission of Flexible Heat Sealed Packages for Minimizing Residual Holdup of Special Nuclear Material in
Displacement Pump (3-72) Amendment 1 (5-74)

Displacement Pumps (1962) $\$ 4.00$

Disposal in the Ocean (1954) $\$ 2.00$

Disposal of Carbon-14 Wastes (1953) $\$ 2.00$

Disposal of Phosphorus-32 and lodine-131 for Medical

Dissolved and Gaseous Hydrogen in Water, Standard Metho

Dissolved Matter in Water, Tests for (1974) $\$ 1.75$

Dissolved Oxygen in Waste Water (1974) $\$ 1.75$

Dissolved Oxygen in Water, Tests for (1971) $\$ 1.75$

Distributed for Use Under General License (Revision I,

Distribution of Granular Activated Carbon, Test for ( 19

Distribution Systems (Safety Guide 6, 3/10/71)

Distributions and Reactivity of Nuclear Reactors, Deter

Distribution, and Impurity Determinations (12/74)

Distribution, Power and Regulating Transformers, Test C

Documentation of Digital Computer Programs (1974) ANS

Doorway Monitors (6/74)

Dose from Gamma Radiation (1971) ASTM D2568-1970 \$1.75

Dose in the Fricke Dosimeter (1972) $\$ 1.75$

Dose of Neutrons, and Mixtures of Neutrons and Gamma Ra

Dose to Polymeric Materials and Application of Threshol

Dose with the Ceric Sulfate Dosimeter, Method of Test F

Dose with the Ferrous Sulfate-Cupric Sulfate Dosimeter

Dose with the Ferrous Sulfate-Cupric Sulfate Dosimeter

Doses to Man from Routine Releases of Reactor Effluents

Dosimeter Chargers (1965) (R1971) \$3.00

Dosimeter Service (1971) \$0.50

Dosimeter (1972) \$1.75

/Elationship O

Dosimeters and Companion Dosimeter Chargers (1965) (RI9

Dosimeters for $X$ and Gamma Radiation, Performance, Spec

Dosimeters (Neutron Energies) Less Than $20 \mathrm{MeV}$ (1976) \$

Dosimeters $(2 / 26 / 73)$

Dosimeters $(6 / 76)$

Dosimeter, Method of Test for (1973) (ASTM D2954-1971)

Dosimeter, Method of Test for (1973) (ASTM D3001-1971)

Dosimeter, Test for (1971)

Absorbed Gamma and Electr

Dosimetry for Criticality Accidents (1969) \$4.25

Dosimetry Results on Nuclear Graphite, Rec. Practice Fo

Dosimetry (1973) ASTM E 170-1963 (1968) \$1.75

Dosimetry-Environmental Applications (1975) $\$ 4.00$

Dosimetry, Definition of Terms Relating to (1963) (R196

Drain Connection (1971) $\$ 3.00$

Drainage Systems (1973) \$3.50

Drained Conditions (1973) (ASTM D3080-1972) $\$ 1.75$

Drawing Quality, Special Killed, Specification for (197

Drawings and in Text (1972) $\$ 12.00$

Drawings (1973) $\$ 10.00$

Drawn Low Carbon Steel Heat Exchanger and Condenser Tub

Drawn Seamless Tubes for Condensers and Heat Exchangers

Drawn Seamless Tubes, Specification for (1975) \$1.75

Drilled Cores and Sawed Beams of Concrete, Method of (

Drive Cylinder Method (1972) (ASTM D2937-1971) \$1.75

Drive Mechanism for Sodium Service (3-71) Amendment

Drive (5-71) Amendment 1 (2-72), Amendment 2 (6-74)

Driveline for Sodium Cooled Reactors (4-73) Amendment

Driven Single Stage Centrifugal Pump (6-72) Amendment

Driven, Single Stage Centrifugal Pump (2-72) Amendment

Driven, Single Stage Centrifugal Pump (7-72) Supersede

Driver Fuel Assembly (4-73)

Driver Fuel Pin End Caps (6-71)

Driver Fuel Pin Insulator Pellet (6-71)

Driver Fuel Pin Mixed Oxide Fuel Pellet (6-71) Amendme

Driver Fuel Pin Plenum Spacer (6-71)

Driver Fuel Pin Plenum Spring (6-71)

Driver Fuel Pin Reflectors (6-71)

Driver Fuel Pin Seamless Cladding Tube (6-71)

Driver Fuel Pin Wrap Wire (6-71)

Driver Fuel Pin (6-71)

Drop Test for (1973) \$1.75

Drop Test for (1973) $\$ 1.75$

Drop Test for (1973) \$1.75

Drop (1970) \$1.75

/Test for Moisture Density Relations

Drop-Weight Tear Tests of Ferritic Steels, Method for

Drop-Weight Test to Determine Nil-Ductility Transitio

Drop, Tests for (1970) \$1.75 /Ensity Relations of Soil

Drugs: Notification of Defects or Failure to Comply ( 19

Drugs: Records and Reports (1975) \$2.95

Drugs: Subpart A, General Provisions (Definitions) (197

Drugs: Subpart B, Statements of Policy and Interpretati

Drums, Heads, and Other Pressure Vessel Components (197

Dry Gas Circulation (4-73)

Dry Particle Magnetic Inspection Method, Quality Standa

Dry Powder Magnetic Particle Inspection, Method for (19

Dry Process Operations (1/75)

Dry Products (1972) \$1.75 Test for Wa

Drying and Fluidized Bed Operations (Revision 1, 5/74)
ERDA

ASME

NCRP

NCRP

NCRP

ASTM

ASTM

ASTM

ASTM

NRC

ASTM

NRC

ANSI

th NRC

ANSI

ANSI

NRC

ANSI

ASTM

NCRP

ASTM

ANSI

ANSI

ASTM

NRC

ANSI

NSF

ANSI

ANS

ANSI

NRC

NRC

ANS1

ANS1

ASTM

ANSI

ASTM

ANSI

[Es ANSI

ASTM

MSS

ANS1

Od ANS1

ASTM

ANSI

ANSI

ASTM

ANSI

ASTM

ANSI

ANSI

ERDA

ERDA

ERDA

ERDA

ERDA

ERDA

ERDA

ERDA

ERDA

ERDA

ERDA

ERDA

ERDA

ERDA

ERDA

ASTM

ASTM

ASTM

ASTM

ANSI

ASTM

BRH

BRH

BRH

BRH

ANSI

ERDA

ANSI

NRC

ASTM

NRC

RDT E3-7T

RI 6

R 12

D1588

D 1888

D1589

D888

RG 6.4

D2862

RG 1.6 
Pipe Threads (Except oustical and Airflow Performance, Testing (I973) \$1.75 upersedes E6-20T, / Austenitic Stainless Steel Hexagona Test for Average Velocity in A $\$ 1.75$ Methods for Semi-Guided Bend Test for Method for Guided Bend Test for 70) ASTM / Conducting Drop-Weight Test to Determine NilQualifications an uthorized Nuclear Inservice Inspection, Qualifications and Plant Security Nuclear Power Generating Stati/ Type Tests of Continuous ooled Nuclear Power P/ Qualification Tests of Continuouslants (1974) ANS $2.2 \$ 10.00$ $(2 / 74)$

Instrumentation fo measuring Ground Resistance and Potential Gradients in the actice for Evaluating Performance Characteristics of Pulse ning Electronics (2-73)

rvice $(6-73)$

Liquid Metal Pressure Measurement System, Flush Mounted

gnetic Saturation, Practice for (1973) ASTM E309-1971 \$

tice for Measuring Coating Thickness by Magnetic-Field or \$1200.00: Lol ASME Boiler and Pressure Vessel Code-1977 Radiation Protection in

gth of Mortar, Method of Test for (1970) ASTM C87-1969/ s Steel (1971) \$1.75 Evaluating Stress Corrosion Supplement No. 2 to the AISC Specification ( 310 ) Supplement No. 3 to the AISC Specification (S310) Supplement No. 1 to the AISC Specification (S3 10)

erties of Metallic Materials, Practice for (1973) ASTM E/ erties of Metallic Materials, Rec. Practice for (1962) (/ esign Basis for Protection of Nuclear Power Plants Against age to Reactor Vessel Materials (7/75)

t 1973 (1972) $\$ 2.00$

evices for Removal of Particles (1972) \$2.50

High

evices for Removal of Particles (1/73)

ocedure for Mathematical Models Selected to Predict Heated

on of Annual Doses to Man from Routine Releases of Reacto for the Purpose of Impl/ Estimating Aquatic Dispersion of nd Releases of Radioactive Materials in Liquid and Gaseou

of Releases of Radioactive Materials in Gaseous and Liquid estimating Atmospheric Transport and Dispersion of Gaseous

strumentation for Continuously Monitoring Radioactivity in Assumptions Used for Evaluating a Control Rod

aboratory Determination of Pulse Velocities and Ultrasonic ession (1972) \$1.75

aphite Materials by Sonic Resonance (1974) \$1./ Moduli of rical Concrete Specimens, Meth/ Static Young's Modulus of sification System for (1975) \$1.75

lear Power Generating Stations (19/

ower Generating Stations, Installati/ s, Guide for (1975) $\$ 5.00$

Type Test of Class IE Std. Specifications for Instrumentation and Seismic Qualification of Seismic Qualification of $s$ for the Installation, and Testing of Instrumentation and for Pressurized Water Reactors (5-72) Supersedes E5-2T/

Electrical Grade Magnesium Oxide as Used in Sheathed Type 72) Amendment $1(5-74)$ Std. Definitions of Terms Relating to Horizontal Thermal Overload Protection for There Specifications for

Spec. for Top Running and Under Running Single Girde es for Water Cooled Nuclear Power Plants (10/73)

on $1,6 / 73$ )

\section{s (1973) $\$ 1.75$}

revision $1,1 / 75$

nt of Nuclear Power Plants (1/74) 75 Supplement to ANSI Y14.I5-1966 (R I970) plements Y $14.15 \mathrm{a}$ and $\mathrm{Y} 14.15 \mathrm{~B} \$ 8.00$

r (1975) IEEE $315-1975 \$ 8.00$

ce Designations for (1975) lEEE $200 \$ 6.00$

Nationa end/ Gamma Compensated lonization Chamber Assembly (Fixed 10-72) Amendment 1 (6-73)

High Temperature

$2(6-74)$

Centrifugal Free Surface, Sodium Pump with y Analysis Reports: Environmental Design of Mechanical and
ysis Reports: Seismic Oualification of Instrumentation and
Dryseal) ( 1968 ) $\$ 4.75$

Duct Liner Materials and Prefabricated Silencers for Ac Duct Tubes for Core Components and Assemblies (5-76) S Duct (Pitot Tube Method) (1972) \$1.75

Ductility of Metallic Materials (1969) ASTM E290-1968

Ductility of Welds (1973) ASTM E190-1971 \$1.75

Ductility Transition Temperature of Ferritic Steels (19

Duties for Authorized Nuclear Inspection (1974) \$3.50

Dutics for (1975) $\$ 3.00$

Duties $(1 / 75)$

Duty Class 1 Motors Installed Inside the Containment of Duty Motors Installed Inside the Containment of Water $C$ Earthquake Instrumentation Criteria for Nuclear Power P Earthquake Instrumentation for Fuel Reprocessing Plants Earthquakes (Revision 1, 4/74)

Earth, Guide for (1962) $\$ 3.60$

Echo Ultrasonic Testing Systems (1969) ASTM E317.1968 Eddy Current Flowmeter Power Supply and Signal Conditio

Eddy Current Probe Type Flow Sensor for Liquid Metal Se

Eddy Current Type, Inductive, Absolute or Gage (10-70)

Eddy-Current Testing of Steel Tubular Products with Ma

Eddy-Current (Electromagnetic) Test Methods (1974) \$1.

Edition; Special Price for All Sections: Bound Edition

Educational Institutions (1966) $\$ 3.00$

Effect of Organic 1mpurities in Fine Aggregate on Stren

Effect of Wicking-Type Thermal Insulations on Stainles

(Effective December 8, 1971 ) $\$ .75$

(Effective June 12, 1974) $\$ 1.00$

(Effective November 1, 1970) $\$ .75$

Effer of High Energy Radiation on the Mechanical Prop

Effecis uigh Energy Radiation on the Mechanical Prop

Effects of Postulated Pipe Rupture (Issued for Trial Us

Effects of Residual Elements on Predicted Radiation Dam

Efficiency Gas Phase Adsorber Cells-Including Amendmen

Efficiency Testing of Air Cleaning Systems Containing D

Efficiency Testing of Air Cleaning Systems Containing D

Effluent Dispersion in Natural Water Bodies (5/74)

Effluents for the Purpose of Evaluating Compliance with

Effluents from Accidental and Routine Reactor Releases

Effluents from Light-Water-Cooled Nuclear Power Plant

Effluents from Light-Water-Cooled Power Reactors (4/7

Effluents in Routine Releases from Light-Water-Cooled

Effluents, Specification and Performance of (1974) $\$ 5.0$

Ejection Accident for Pressurized Water Reactors (5/74)

Elastic Constants of Rock (1972) (ASTM D2845-I969) \$1

Elastic Moduli of Rock Core Specimens in Uniaxial Compr

Elasticity and Fundamental Frequencies of Carbon and $\mathrm{Gr}$

Elasticity and Poisson's Ratio in Compression of Cylind

Elastomeric Materials for Automotive Applications, Clas

Electric Cables, Field Splices, and Connections for Nuc

Electric Chain Hoists (197I) $\$ 0.50$

Electric Equipment During the Construction of Nuclear $\mathrm{P}$

Electric Equipment for Nuclear Power Generating Station

Electric Equipment for Nuclear Power Plants (3/76)

Electric Equipment (Safety Guide 30, 8/11/72)

Electric Heater and Connector Assembly for Pressurizer

Electric Heaters: Simulated LMFBR Fuel Pins (3-72)

Electric Heating Elements (1970) \$1.75

1973)

Electric Motor Driven, Single Stage Centrifugal Pump (2

Electric Motors on Motor Operated Valves (11/75)

Electric Output Signal $(4-74)$

Electric Overhead Traveling Crane (197I) $\$ 3.00$

Electric Overhead Traveling Cranes (1974) $\$ 3.00$

Electric Penetration Assemblies in Containment Structur

Electric Power Sources (12/74)

Electric Power Systems for Nuclear Power Plants (Revisi

Electric Power (6/75)

Electric Stress of Solid Electrical Insulating Material

Electric Systems for Multi-Unit Nuclear Power Plants (

Electric Systems (Revision 1, 1/75)

Electric Valve Operators Installed Inside the Containme

Electric Wire Rope Hoists (1974) $\$ 3.00$

Electrical and Electronic Applications (1972) \$1.75

Electrical and Electronics Diagrams Sold Separately $\$ 1$.

Electrical and Electronics Diagrams (1966) Includes Sup

Electrical and Electronics Diagrams, Graphic Symbols Fo

Electrical and Electronics Parts and Equipment, Referen

Electrical Code (1975) \$5.50

Electrical Compensation) (7-71) Amendment l (8-73, Am

Electrical Conductivity of Water, Tests for (I971) \$1.7

Electrical Connectors and Hermetic Seals (3.70)

Electrical Continuity Type Liquid Metal Leak Detector

Electrical Drive (5-71) Amendment 1 (2.72), Amendment

Electrical Equipment Qualification Tests and Analyses ( Formation for Safety Anal NRC
B2.1

ASTM E477

ERDA RDT E6-20T

ASTM D3154

ANSI Z168.11

ANSI Z115.4

Z178.5

ANSI

ANSI N626.

NRC RG 5.43

ANSI N41.9

NRC RG 1.40

ANSI

NRC RG 3.17

NRC RG I 12

IEEE 81

ERDA RDT C 10-5T

ERDA RDT C4-7T

ERDA RDT C6-3T

ANSI Z166.27

ASTM E376

ASME CODE-77

NCRP R32

ANSI A37.129

ASTM C692

AISC $\$ 320$

AISC \$32

AISC S319

ANSI N145

ASTM E184

ANSI N176

NRC RG 1.99

IES CS-8T

ANS] N101.1

NRC RG 3.2

/Pr NRC RG 4.4

NRC RG 1.109

NRC $\quad$ RG 1.113

NRC RG 1.21

NRC RG 1.112

NRC RG 1.111

ANSI NI3.10

RG 1.77

ANSI A37.176

ASTM D3148

ASTM C747

ANSI A37.94

ASTM D2000

ANSI N41.10

HMI 400

N45.2.4

IEEE 344

NRC RG 1.100

NRC RG 1.30

ERDA RDT E5-2T

RDT P4-1T

D2900

D 1711

RDT E3-6T

RG I.106

RDT C6-2T

70

74

RG 1.63

RG 1.93

RG 1.32

RG 1.70 .36

D3 I 5 I

RG 1.81

RG 1.75

RG 1.73

100

D2442

Y I 4.15A

Y I 4.15

Y 32.2

Y32.16

70

RDT C15-7T

DI 125

RDT C17-1T

RDT C8-4T

RDT E3-2T

RG 1.70 .24

RG 1.70 .23 
pe Electric Heating Elements (1/ $\$ 3.00$

Accelerated Life Test of

Intrinsically Safe and Non Incendive ed Practice for Calibration of Standards and Equipment for Test for Thermal Failure Under Electric Stress of Solid Testing Adhesives Relative to Their Use as

ly Cured Silicone Rubber Coated Glass Fabric and Tapes for 0)

hods of Testing Polymerizable Embedding Compounds Used for

Std. Spec. for Automatic Null Balancing ontainment Structures Amendment 1 (4-72), Amendment 2 (/ ures for Nuclear Fueled Power Generating Stations (1973)/ Periodic Testing of (2-74) Metal Sheathed, Mineral-Insulated cialized Service (1973) ASTM / Specification for Sheathed cialized Service, Specification for (1971) \$1.7/ Sheathed ite Articles at Room Temperature, Method of Test for (19/ Spec. for High Temperature Glass Cloth Pressure Sensitive 5) $\$ 5.00$

$\mathrm{t}$ for Continuity of Coatings in Glassed Steel Equipment by

Stations, Trial Use/ Draft Standard Type Test of Class I nd Cobalt-Base Alloys, Chemical Analy/ High Temperature, 16 in. and Over), Specification for (1974) $\$ 1.75$

loy Steel Pipe for High Temperature Service, Specificati/ Lower Temperatures (1974) ASTM A671-/ Specification for ervice, Specification for (1975) \$1.75

Specification for (1973) $\$ 1.75$

um (1-72)

Specification for

-19Cr-19Fe-3.1 Mo-5.1 (Cb+Ta) 0.90Ti-0.50A 1 Consumable 9Cr-3.1 Mo-5.1 (Cb+Ta)-0.90Ti-0.50Al-19-Fe Consumable ase-19Cr-3.1 Mo-5.1 ( $\mathrm{Cb} \& \mathrm{Ta}$ )-0.90Ti-0.50A 1 Consumable

oy Tubing, Seamless, Corrosion and Heat Resis/ Consumable ase-1 $9 \mathrm{Cr}-3.1 \mathrm{Mo}-5.1$ ( Cb \& Ta)-0.90Ti-0.50 Al Consumable

(Seamless, Corrosion and Heat Resistant Nickel Consumable

ntinuous Determination of Sodium in Water by Ion Selective on for ASTM A 164-1971 \$1.75

0.00 )

fa-5.17 with Additional Requirements) (3-75)

Part C-Welding Rods, ication for (1973) AWS A5.17-1969 \$2 50 ication for (1974)

with Additional Requirements) (7-75) Supers/ or (1973) AWS A5.20-1969 $\$ 2.50$

or (1974)

th Additional Requirements) (4-75) Supersede/

(1973) AWS A5.18-1969 \$2.50

(1974)

(3-75) Supersedes M1-3T, (

Mild Steel Covered Welding

(3-75) Supers/ Nickel and Nickel Alloy Covered Welding ) (3-75)/ Nickel and Nickel-Alloy Bare Welding Rods and (3-75) Supersedes M1-/

(3.75) Supersedes M1-/

(3-75) Supersede/

Stainless Steel Covered Welding Low Alloy Steel Covered Welding Stainless Steel Welding Rods and Bare Tungsten Arc Welding
Composite Surfacing Welding Rods and Titanium and Titanium-Alloy Bare Welding Rods and e Corrosion-Resisting Chromium and Chromium-Nickel Steel el-Chromium-Molybdenum-Columbium Bare Welding Rods and Nickel-Molybdenum-Chromium Alloy Bare Welding Rods and 50 romium, 1-Percent-Molybdenum Alloy Bare Welding Rods and Mild Steel Covered Arc Welding 50 Nickel and Nickel-Alloy Covered Welding 50
00 $.50 \quad$ Nickel and Nickel-Alloy Bare Welding Rods and isting Chromium and Chromium-Nickel Steel Covered Welding 50 Low Alloy Steel Covered Arc Welding Copper and Copper-Alloy Arc Welding
Chromium and Chromium-Nickel Sieel Welding Rods and Bare Mild Steel Covered Arc Welding

Aluminum and Aluminum Alloy Welding Rods and Bare Nickel and Nickel-Alloy Covered Welding Nicke! and Nickel-Alloy Bare Welding Rods and Low Alloy Steel Covered Arc Welding Copper and Copper-Alloy Arc Welding isting Chromium and Chromium-Nickel Steel Covered Welding Chromium and Chromium-Nickel Steel Welding Rods and Bare ements) (3-75) Supersedes M I-5T, (7-1 Welding Rods and

Recommended Practice for Core Sampling of Graphite Std. Spec. for Precision

mendment 1 (9-71), Amendment 2 (1-74), Amendment 3 (5-/ Definitions of Terms Relating to

ing Coating Thickness by Magnetic-Field or Eddy-Current argers (1965) (R1971)/

3) ASTM E230-1972 $\$ 3.00$
Electrical Grade Magnesium Oxide as Used in Sheathed Ty Electrical lnstruments in Hazardous Atmospheres (1960)

Electrical lnstruments (1965) \$5.00

Electrical lnsulating Materials Testing (1971) \$1.75

Electrical Insulating Materials (1973) \$1.75

Electrical Insulation (1969) \$1.75

Electrical Insulation (1969) (R1974) ASTM D 193I-1973

Electrical Insulation (1970) (ASTM D 1674-1967) \$1.75

Electrical Insulators (8-74) Supersedes C18-1T, (7-7

Electrical Measuring Instruments (1966) (R1972) \$4.75

Electrical Penetration Assemblies for Nuclear Reactor C

Electrical Penetration Assemblies in Containment Struct

Electrical Power and Protection Systems (6/76)

Electrical Resistance Heater (3-75) Supersedes P4-3T,

Electrical Resistance Heaters, for Nuclear or Other Spe

Electrical Resistance Heaters, for Nuclear or Other Spe

Electrical Resistivity of Manufactured Carbon and Graph

Electrical Tape (1973) $\$ 1.75$

Electrical Testing (R1973) ASTM C536-1972 \$1.75

Electrical Transducer Nomenclature and Terminology (197

Electrical Valve Operators for Nuclear Power Generating

Electrical, Magnetic, and Other Similar Iron, Nickel, a

Electric-Fusion (Arc)-Welded Steel Plate Pipe (Sizes

Electric-Fusion-Welded Austenitic Chromium-Nickel A

Electric-Fusion-WeIded Steel Pipe for Atmospheric and

Electric-Fusion-Welded Steel Pipe for High Pressure S

Electric-Resistance-Welded Carbon Steel Boiler Tubes,

Electric-Resistance-Welded Steel Pipe (1973A) \$1.75

Electrochemical Oxygen Meter for Service in Liquid Sodi

Electrode or Vacuum Induction Melted Solution Heat Trea

Electrode or Vacuum Induction Melted $1750 \mathrm{~F}(954.4 \mathrm{C}) \mathrm{S}$ Electrode or Vacuum Induction Melted $1750 \mathrm{~F}$ (954.4 C) S Electrode or Vacuum Induction Melted 1750F (954.4C) All Electrode or Vacuum Induction Melted 1950 F (1065.6 C) Electrode or Vacuum Induction Melted $1950 \mathrm{~F}(1065.6 \mathrm{C}) \mathrm{S}$ Electrode (1973) $\$ 1.75$

Electrodeposited Coatings of Zinc on Steel, Specificat

Electrodes and Filler Metals (1977) bd $(\$ 30.00)$, II ( $\$ 4$

Electrodes and Fluxes for Submerged Arc Welding (ASME S Electrodes and Fluxes for Submerged Arc Welding (9-75) Electrodes and Fluxes for Submerged Arc Welding, Specif Electrodes and Fluxes for Submerged Arc Welding, Specif Electrodes for Flux-Cored Arc Welding (ASME SFA -5.20 Electrodes for Flux-Cored Arc Welding, Specification F Electrodes for Flux-Cored Arc Welding, Specification F Electrodes for Gas Metal Arc Welding (ASME SFA-5.18 Wi Electrodes for Gas Metal Arc Welding, Specification for Electrodes for Gas Metal Arc Welding, Specification for Electrodes (ASME SFA-5.I with Additional Requirements) Electrodes (ASME SFA-5.11 with Additional Requirements Electrodes (ASME SFA-5.14 with Additional Requirements Electrodes (ASME SFA-5.4 with Additional Requirements) Electrodes (ASME SFA-5.5 with Additional Requirements) Electrodes (ASME SFA-5.9 with Additional Requirements) Electrodes (1969) $\$ 2.00$

Electrodes (1970) $\$ 2.50$

Electrodes (1970) $\$ 3.00$

Electrodes (1974) $\$ 3.50$

Electrodes (6-75) Supersedes M1-19T, (3-75)

Electrodes (7-75) Supersedes M I-15T, (1-72) Amendmen

Electrodes (9-75) Amendment 1 (10-75)
Electrodes, Specification for (1973) AWS A5.1-1969 \$3.

Electrodes, Specification for (1973) AWS A5.10-1969 \$2

Electrodes, Specification for (1973) AWS A5.11-1969 \$2

Electrodes, Specification for (1973) AWS A5.13-1970 \$3

Electrodes, Specification for (1973) AWS A5.14-1969 \$2

Electrodes, Specification for (19.73) AWS A5.4-1969 \$2

Electrodes, Specification for (1973) AWS A5.5-1969\$3.

Electrodes, Specification for (1973) AWS A5.6-1969 \$2.

Electrodes, Specification for (1973) AWS A5.9-1969 \$2.

Electrodes, Specification for (1974)

Electrodes, Specification for (1974)

Electrodes, Specification for (1974)

Electrodes, Specification for (1974)

Electrodes, Specification for (1974)

Electrodes, Specification for (1974)

Electrodes, Specification for (1974)

Electrodes, Specification for (1974)

Electrodes, Surfacing (A

Electrodes, (1974) \$1.75

Electroformed Sieves (1973) ASTM E161- 1970

Electromagnetic Pump for Liquid Metal Service (3-71) a

Electromagnetic Testing (1974) ASTM E268 $1968 \$ 1.75$

(Electromagnetic) Test Methods (1974) \$1.75

Electrometer Type Dosimeters and Conpanion Dosimetcr Ch

Electromotive Force (EMF) Tables for Thermocouples (197 /for Measu

ASTM

ISA

ISA

ASTM

ASTM

ANS1

ERDA

ANSI

ERDA

ANSI

NRC

ERDA

ANS1

ASTM

ANSI

Std. ASTM

Tes ANSI

!SA

ANS1

ASTM

ASTM

ASTM

ANSI

ASTM

ASTM

ERDA

SAE

ANSI

ANSI

ANS1

ANS

ANSI

Co ASTM

ANSI

ASME

ERDA

ERDA

ASME

ERDA

ANS1

ASME

ERDA

ANSI

ASME

ERDA

ERDA

ERDA

ERDA

ERDA

ERDA

AWS

AWS

AWS

Cor AWS

ERDA

ERDA

ANSI

ANSI

ANSI

ANSI

ANSI

ANS

ANSI

ANSI

ANSI

ASME

ASME

ASME

ASME

ASME

ASME

Corrosion-Res ASME /Osion-Resisting ASME

ERDA

ASTM

ANSI

ERDA ANSI

ASTM

ANSI

ANSI

D 2900 RP 12.1

RPI 2.2

D2865

D3151

404

$(-89$

C59.47

RDT C18-1 T

C39.4

RDT P3-1T

N45.3

RG 1.118

RDT P4-3T

N 143

E420

K.90.7

D2754

Z167.8

S37.

N41.6

E354

A 134

B 125.53

A 155
A 178 
Sheilding for High Energy f Merit for $\mathrm{PuO}_{2}-\mathrm{UO}_{2}$ Fuel Pellet Homogeneity by Use of an r, Method of Test for (1973) (ASTM D3/ Absorbed Gamma and c Sulfate Dosimeter, Method of Test F/ Absorbed Gamma and c Sulfate Dosimeter, Test for (1971) Absorbed Gamma and Specification for Alumina Ceramics for Electrical and

Repurchase, Repairs, or Replacement of Importation of Performance Stds. for

Supplement to ANSI Y 14.15-1966 (R 1970), Electrical and a and Y14.15B $\$ 8.00$

$15.1975 \$ 8.00$

for (1975) IEEE $200 \$ 6.00$

Electrical and

Electrical and

Electrical and

ddy Current Flowmeter Power Supply and Signal Conditioning

hanical Properties (197/

Practice for Examination of Fue hanical Properties, Rec. Practice for Examination O/

Fuel uality Verification for Plate-Type Uranium-Aluminum Fuel I Materials (7/75) Effects of Residual

Magnesium Oxide as Used in Sheathed Type Electric Heating Quality Control for Plate-Type Uranium-Aluminum Fuel Shielded Shipping Cask for Spent Reactor Fuel s, Practice for (1970) $\$ 1.75$

and Procedures for Design of Nuclear System Components at gth Properties of Adhesives in Shear by Tension Loading at

uirements for Construction of Nuclear System Components at ion I/ Design Stability of (ASTM D 674-1967) \$ Methods of Tafeguarding Against ized Structural Steel Products and Procedure for Detecting Nuclear Power Plants (Revision 1, 1/75) tem Pumps (Safety Guide 1, Net Positive Suction Head fo 174) actors (Revision 1, 1/75)

Sumps for

Information for Safety Analysis Reports: ants $(9 / 75)$

.00

Temperatures: Electromotive Force Terms and Symbols Relating to Testing for Leaks Using Bubble Internal

ter During Reactor Operation, Method For/ Delayed Neutron ter During Reactor Operation, Measureme/

Delayed NeutronAlpha

ation Emitting Products) for Microwave and Radio Frequency $95 \quad$ Performance Std. (Ionizing Radiation s (1975) \$2.95 Performance Std. (lonizing Radiation ir Major Components/ Performance Std. (lonizing Radiation 95 Performance Std. (lonizing Radiation itting Products (19/ Performance Std. (lonizing Radiation

Performance Std. (lonizing Radiation Performance Std. (lonizing Radiation Performance Std. (lonizing Radiation (1975) $\$ 2.95$ Assessment of the Assumption of Normality Assessment of the Assumption of Normality C37.20A-1970, C/ Switchgear Assemblies, Including Metal inspection System and Associated Equipment for the Reactor Fast Flux Facility Driver Fuel Pin Finishes for Contact Faces of Pipe Flanges and Connecting n Projects or Productions Assisted by Grants from National Cast Iron Swing Check Valves, Flanged and Threaded Cast 1ron Gate Valves, Flanged and Threaded

(1974) ASTM A255-1974 \$1.75

Butt Welding

valuation (19) Medical X-Ray and Gamma Ray Protection for $\$ 3.00$ Medical X-Ray and Gamma Ray Protection for ons Using Non-Medical X-Ray and Sealed Gamma Ray Sources, Personnel Neutron Dosimeters (Neutron Sheilding for High

ctivation Techniques, / Neutron-Flux Density and Average atio/ Method of Test for Neutron Flux Density and Average $\mathrm{n}$ Set lnduced in Vulcanized Rubber During Exposure to High $n$ Set lnduced in Vulcanized Rubber During Exposure to High ic Materials, Practice for (1973) ASTM E/

ic Materials, Rec. Practice for (1962) (/

Effects of High

Effects of High

$\$ 1.75$

Exposure of Polymeric Materials to $\mathrm{High}$ Exposure of Adhesive Specimens to High
Chemical Reactivity of Inorganic Material Exposed to $\mathrm{High}$ Exposure of Polymeric Materials to High Exposure of Adhesive Specimens to High mation for Safety Analysis Reports: Metallic Materials for Dimensioning and Tolerancing for Classification of Soils for
Electron Accelerator Installations (1964) $\$ 2.00$

Electron Microprobe (9-72)

Termination of a Figure O ERDA

Electron Radiation Dose with the Ceric Sulfate Dosimete

Electron Radiation Dose with the Ferrous Sulfate-Cupri

Electron Radiation Dose with the Ferrous Sulfate-Cupri

Electronic Applications (1972) \$1.75

Electronic Product Radiation Control (1968) \$5.15

Electronic Products (1975) $\$ 2.95$

Electronic Products (1975) \$2.95

Electronic Products: General (1975) $\$ 2.95$

Electronics Diagrams Sold Separately $\$ 1.75$

Electronics Diagrams (1966) Includes Supplements Y 14.15

Electronics Diagrams, Graphic Symbols for (1975) IEEE 3

Electronics Parts and Equipment, Reference Designations

Electronics (2-73)

Electroslag Weld Properties (12/28/72)

Element Cladding Including the Determination of the $\mathrm{Mec}$

Element Cladding Including the Determination of the Mec

Elements for Use in Research Reactors (Revision 1, 7/76

Elements on Predicted Radiation Damage to Reactor Vesse

Elements (1970) $\$ 1.75$

Elements (1974) ANS $15.2 \$ 8.50$

Elcments (8-73) Amendment I (II-73)

Elevated Temperature Tension Tests of Metallic Material

Elevated Temperature (9-74) Supersedes F9-5T, (3-74)

Elevated Temperatures (Metal-10-Metal) Method of Te

Elevated Temperatures (Supplement to ASME Code Cases 15

Elevated-Temperature Reactors (Supplement to ASME Sect

Embankment Retention Systems for Uranium Mills (6/73)

Embrittlement of Hot Dip Galvanized Structural Steel $\mathrm{Pr}$

Embrittlement, Rec. Practice for (1974) \$1.75

Emergency and Shutdown Electric Systems for Multi-Unit / Galvan

Emergency Core Cooling and Containment Heat Removal Sys

Emergency Core Cooling and Containment Spray Systems ( 6

Emergency Core Cooling Systems for Pressurized Water Re

Emergency Planning for Nuclear Power Plants (11/75)

Emergency Planning (12/74)

Emergency Water Supply Systems for Fuel Reprocessing P

(EMF) Tables for Thermocouples (1973) ASTM E230-1972 \$3

Emission Spectroscopy, Definition of (1975A) $\$ 1.75$

Emission Techniques (1974) $\$ 1.75$

Emitters (1961) Free

Emitting Fission Products in Nuclear Reactor Coolant Wa

Emitting Fission Products in Nuclear Reactor Coolant Wa

Emitting Particles in Lungs (1975) $\$ 3.00$

Emiuing Products) for Cabinet X-Ray Systen

Emitting Products) for Cold-Cathode Gas Discharge Tube

Emitting Products) for Diagnostic X-Ray Systems and the

Eminting Products) for Fluoroscopic Equipment (1975) \$2

Emitting Products) for Microwave and Radio Frequency Em

Emitting Products) for Radiographic Equipment (1975) $\$ 2$

Emitting Products) for Television Receivers (1975) $\$ 2.9$

Emitting Products) for X-Ray Baggage Inspection Systems

(Employing Individual Observed Values) (1974) \$4.00

Employing lndividual Observed Values) (4/74)

Enclosed Bus (1974) Consolidated Edition (Includes ANSI

Enclosure System (7-73)

End Caps (6-71)

End Flanges of Ferrous Valves and Fittings (1974) $\$ 2.00$

Endowment for the Arts (1975) $\$ 6.85$

Ends (1970) $\$ 3.00$

Ends $(1970) \$ 4.00$

Ends (1972) $\$ 4.00$

End-Quench Test for Hardenability of Steel, Method of

End-to-End Dimensions of Ferrous Valves (1973) $\$ 4.00$

Energies Up to I0 MeV Structural Sheilding Design and E

Energies Up to $10 \mathrm{Mev}$ : Equipment Design and Use (1968)

Energies Up to 10-Mev, General Safety Standard for (19

Energies) Less Than $20 \mathrm{MeV}$ (1976) $\$ 3.50$

Energy Electron Accelerator Installations (1964) $\$ 2.00$

Energy from ${ }^{3} \mathrm{H}(d, n){ }^{4} \mathrm{He}$ Neutron Generators by Radioa

Energy from $3 \mathrm{H}(\mathrm{D}, \mathrm{N}) 4 \mathrm{He}$ Neutron Generators by Radioactiv

Energy Nuclear Radiation, Methods of Test for (1971) as

Energy Nuclear Radiation, Testing (1968) (R1974) \$1.75

Energy Radiation on the Mechanical Properties of Metal

Energy Radiation on the Mechanical Properties of Metall

Energy Radiation, Practice for (1968) (R1973) ASTM D167

Energy Radiation, Practice for (1973) ASTM D 1879-1970

Energy Radiation, Rec. Practice for (1966) (R1971) \$1.7

Energy Radiation, Rec. Practice for (1970) \$1.75

Engineered Safety Features (2/75)

Engineering Drawings (1973) $\$ 10.00$

Engineering Purposes (1972) (ASTM D2487-1969) \$1.75
ANSI

ANSI

ASTM

ASTM

USCG

BRH

BRH

ANSI

ANSI

ANS

ANSI

ERDA

NRC

ANSI

ASTM

NRC

NRC

ASTM

ANSI

ERDA

ASTM

ERDA

ANSI

ERDA

NRC

NRC

ANSI

ASTM

ASTM

NRC

NRC

NRC

NRC

NRC

NRC

NRC

ANSI

ASTM

ASTM

NAS

ANSI

ASTM

NCRP

BRH

BRH

BRH

BRH

BRH

BRH

BRH

BRH

BRH

ANS1

NRC

ANS1

ERDA

ERDA

MSS

DOL

MSS

MSS

ANS I

ANS1

ANSI

NCRP

NCRP

ANSI

ANSI

NCRP

ASTM

ANSI

ANSI

ASTM

ANSI

ASTM

ANSI

ANSI

ASTM

ASTM

ASTM

Infor NRC

ANSI

ANSI

R3I

RDT F1 1-4T

K65.230

K65.229

D2954

D2442

42 CFR 78

21CFRI004

2ICFRIO0S

ICFR 1010

Y14.15A

Y 14.15

Y 32.2

Y 32.16

RDT C 10-5T

RG 1.34

N147

$\mathrm{E} 453$

RG 2.3

RG 1.99

D2900

N398

RDT E1 2-4T 
Information for Safety Analysis Reports: Hydrologic In Situ Assay of Nondestructive Uranium-235 reparation of Environmental Reports for Commercial Uranium Format and Content of Safety Analysis Reports for Uranium material License Application (Including That for a Uranium ry $(9 / 74)$ Nondestructive Assay of High Specification for Air

Sealability of

5

or Chemical Substances and Physical Agents in the Workroom rocedural Specifications for Thermoluminescence Dosimetryment Qualificat/ Information for Safety Analysis Reports: seeking an Exemption for a Radionuclid/

Facilities (Revision 1, 10/75) ion $1,1 / 75$ )

Preparation of an Preparation of Preparation of Preparation of

(1965) Protective Action Guides for thod of Test for (1971) ASTM D1693-1970 \$1.75

Terrestrial r Plants (12/75)

$(5 / 74)$

$5 / 74)$

Measurements of Radionuclides in the Measurements of Radionuclides in the Measurements of Radionuclides in the Programs for Monitoring Radioactivity in the Acceptable Concepts, Models,
analysis of Nonmetals in Liquid Sodium (1-72)/ Specimen 2)

Carbon Meter comme/ Draft Standard Criteria for Separation of Class IE actice for Prefabricated Reflective Insulation Systems for actice for Prefabricated Reflective Insulation Systems for

lear/ Installation, Inspection, and Testing of Mechanical ts for Installation, Inspection, and Testing of Mechanical method of Test for Continuity of Coatings in Glassed Steel or Reliability of Glass Coatings on Glassed Steel Reaction $\mathrm{X}-\mathrm{R}$ ay and Gamma Ray Protection for Energies Up to $10 \mathrm{Mev}$ : rating Stations, Installati/ nstrumentation and Electric

Minimizing Residual Holdup of Special Nuclear Material in 19/ Recommended Practice for Calibration of Standards and for (1975) $\$ 5.00 \quad$ Seismic Qualification of Electric Qualification of Class IE Seismic Qualification of Electric

Visual in Service Inspection System and Associated ge/ Draft Standard Safety Related Systems, Structures and minimizing Residual Holdup of Special Nuclear Materials in dment $1(1 / 75)$ reports: Environmental Design of Mechanical and Electrical Installation, and Testing of Instrumentation and Electric Transportation of Critical Components and ion Safety for X-Ray Diffraction and Fluorescence Analysis d. (Ionizing Radiation Emitting Products) for Radiographic d. (Ionizing Radiation Emitting Products) for Fluoroscopic s: Seismic Qualification of Instrumentation and Electrical Hoisting and Rigging of Critical Components and Related 6.00 Cobalt-60 and Cesium-137 Teletherapy Electrical and Electronics Parts and

ruary 12,1 Specification for the Design, Fabrication and Materials Control (1974) $\$ 3.00$

Materials Control (1.74)

ice for (1972) $\$ 1.75$ Limit of

ctions ( 1964 ) ous Effluents in Routine Releases from Light/ Methods for r (1974) $\$ 1.75$

of Nuclear Graphite, Methods for (1973) ASTM C626-1971/ rmal Neutron Absorption Cross Section of Nuclear Graphite, Fast Neutron Flux Measurements by TrackFast Neutron Flux Measurements by Track-

$-1968 \$ 1.75$ Carbon Black in $-1970 \$ 1.75$ Environmental Stress-Cracking of here Radiation Exposure May Occur (1967) \$3.25 Immediate zed Water Reactors (5/74) s (1970) \$1.75 Routine Releases of Reactor Effluents for the $P$ 73) $\$ 1.75$ trasonic Testing Systems (1969) ASTM E317bber-Like Materials (1974) \$1.75 rmal Insulations on Stainless Steel (1971) \$1.75 rol Room During a Postulated Hazardous C/ Pressurized Water Reactor Radioact/ Fuel Handling Accident in the Fuel/ Loss of Coolant Accident for Boili/ Loss of Coolant Accident for Press/
Engineering (1/75)

Enriched Uranium Residual Holdup (8/74)

Enrichment Assay by Gamma-Ray Spectrometry (4/74) Enrichment Facilities (Revision 1, 10/75)

Enrichment Facilities (12/74)

Enrichment Facility) (12/74)

Enrichment I on of a Special Nuclear

Entraining Admixtures for Concrete (I974) \$1.75

Entraining Admixtures for Concrete, Testing (1973) $\$ 1.7$

Enveloped Gaskets, Test for (1974) $\$ 1.75$

Environment with Intended Changes (1975) \$.75

Environmental Applications (1975) $\$ 4.00 \quad /$ Esting, and P
Environmental Design of Mechanical and Electrical Equip

Environmental Report to Support a Rule Making Petition

Environmental Reports for Commercial Uranium Enrichment

Environmental Reports for Nuclear Power Stations (Revis

Environmental Reports for Uranium Mills (4/73)

Environmental Sr-89, Sr-90, and Cs-137 Contamination

Environmental Stress-Cracking of Ethylene Plastics, Me

Environmental Studies for Nuclear Power Stations (7/76)

Environmental Technical Specifications for Nuclear Powe

Environment-Analysis of I-131 in Milk (9/73)

Environment: Sampling and Analysis of Plutonium in Soil

Environment: Strontium-89 and Strontium-90 Analyses

Environs of Nuclear Power Plants (Revision 1, 2/75)

Equations, and Assumptions for a Bioassay Program (9/73

Equilibration Device (Or Multipurpose Sampler) for the

Equilibration Module for Service in Liquid Sodium (1-7

Equipment and Circuits, (Trial Std. Issued for Use and

Equipment and Pipe Operating at Temperatures Above Ambi

Equipment and Pipe Operating at Temperatures Above Ambi

Equipment and Systems for the Construction Phase of Nuc

Equipment and Systems (6/76) /Ity Assurance Requiremen

Equipment by Electrical Testing (R1973) ASTM C536-1972

Equipment by High Voltage ASTM C537-72 (I973) $\$ 1.75$

Equipment Design and Use (1968)

Equipment During the Construction of Nuclear Power Gene

Equipment for Dry Process Operations (1/75)

Equipment for Electrical Insulatirg Materials Testing (

Equipment for Nuclear Power Generating Stations, Guide

Equipment for Nuclear Power Plants (11/74)

Equipment for Nuclear Power Plants (3/76)

Equipment for the Reactor Enclosure System (7-73)

Equipment for Water Cooled and Moderated Nuclear Powe

Equipment for Wet Process Operations (6/74)

Equipment Grounding and Sheilding Practices (1/73) Amen

Equipment Qualification Tests and Analyses $(2 / 75)$

Equipment (Safety Guide $30,8 / 11 / 72$ )

Equipment (1-76)

Equipment (1971) NBS Handbook $111 \$ 3.00$

Equipment (1975) $\$ 2.95$

Equipment (1975) $\$ 2.95$

Equipment (2/75)

/Formation for Safety Analysis Report

Equipment (8-72) Amendment 1 (10-72), Amendment 2 (7-

Equipment, Guidelines for Maintaining (1974) $\$ 3.50$

Equipment, Reference Designations for (1975) IEEE $200 \$$

Equipping, and Qualifying of Guards and Watchmen (1/74)

Erection of Structural Steel for Buildings (Adopted Feb

Error Concepts and Principles of Calculation in Nuclear

Error Concepts and Principles of Calculation in Nuclear

Estimate the Average Quality of a Lot or Process, Pract

Estimates and Evaluations of Fallout in the United Stat

Estimates for 1964-1965 and Verification of 1963 Predi

Estimating Aquatic Dispersion of Effluents from Acciden

Estimating Atmospheric Transport and Dispersion of Gase

Estimating the Average Grain Size of Metals, Methods Fo

Estimating the Thermal Neutron Absorption Cross Section

Estimating the (1971) \$1.75

Etch Technique (1973) \$1.75

Etch Technique, Method for (1974) ASTM E418-1973 \$1.75

Ethylene Plastics, Method of Test for (1971) ASTM D1603

Ethylene Plastics, Method of Test for (1971) ASTM DI693

Evacuation Signal for Use in Industrial Installations W

Evacuation Signal (2/16/73)

Evaluating a Control Rod Ejection Accident for Pressuri

Evaluating Acute Toxicity of Water to Fresh Water Fishe

Evaluating Compliance with 10 CFR Part 50, Appendix 1 (

Evaluating Inhibitory Toxicity of Waters to Diatoms ( 19

Evaluating Performance Characteristics of Pulse Echo UI

Evaluating Pressure Sealing Properties of Rubber and Ru

Evaluating Stress Corrosion Effect of Wicking-Type the

Evaluating the Habitability of Nuclear Power Plant Cont

Evaluating the Potential Radiological Consequences of a

Evaluating the Potential Radiological Consequences of a

Evaluating the Potential Radiological Consequences of a

Evaluating the Potential Radiological Consequences of a
NRC

NRC

NRC

NRC

NRC

NRC

ASTM

ASTM

ASTM

ACGlH

ANSI

NRC

NRC

NRC

NRC

NRC

EPA

ANSI

NRC

NRC

NRC

NRC

NRC

NRC

NRC

ERDA

ANSI

ANS1

ASTM

ANSI

ANSI

ANSI

NCRP

ANSI

ASTM

IEEE

ERDA

ANSI

NRC

ERDA

Is NRC

NRC

ERDA

Radiat ANSI

BRH

BRH

ERDA

ANS

ANSI

NRC

AISC

ANS

NRC

ASTM

EPA

EPA

NRC

NRC

ASTM

ANSI

the ASTM

ASTM

ANSI

ANSI

ANSI

NRC

NRC

ASTM

NRC

ASTM

ANSI

ASTM

NRC

NRC

NRC

NRC

NRC

RG 1.70 .17

RG 5.37

RG 5.21

RG 4.9

RG 3.25

RG 5.45

RG 5.38

C260

C 233

F I I 2

*1 1

N545

RG 1.70 .24

RG 6.7

RG 49

RG 4.2

RG 3.8

FRC 7 
KWIC Index of U.S. Nuclear Standards

Steam Line Break Accident for Boil/ Radioactive Offgas System Failure !

Assumptions Used for Assumptions Used for and Releases of Radioactive Materials in Liq/ Recommended Practice for Liquid Phase essurized Water Reactor Plants (Issued Fo/ Draft Standard 72) $\$ 12.50 \quad$ Air Sampling Instruments Manual for e, Rec. Practice for (1968) (ACI 214-1965) \$1.75

e, Practice for (1968) ACI 214-1965 \$1.75

rtation Routes Near Nuclear Power Plant Sites (1/75)

-1975) \$1.00 ea.

$h$ and Training Reactors (5/73)

Hygienic Guides (For Hazard Shield Test Program for Statistical

sfer of Special Nuclear Materials, Concepts / Statistica sfer of Special Nuclear Materials (6/74)

for Energies Up to $10 \mathrm{MeV}$ Structural Sheilding Design and s Test. Conducted Through 1962 (1963) or (1973) $\$ 1.75$

phase of Nuclear Power Pla/

Estimates and rmination of the Mechanical Petrographic ASTM A388-1971\$1.75

applications, Specification Fo/

n $1,8 / 11 / 72$, of Safety Guide 19)

Qualifications of Inspection

Practice fo Ultrasonic

1.75

ssing Plants and in Plutonium Processing /

Straight-Beam Ultrasonic Nondestructive

Magnetic Particle Ultrasonic Angle-Beam Nondestructive Nondestructive

in Fuel Reprocessing Plants (5/75) ermination of the Mechanical Properties, Rec. Practice for sel Code, Section V) (10-75) Supersedes /

Nondestructive Nondestructive

Qualification of Nuclear Power Plant Inspection, Operating Performance of Anion Methods of Sampling of Particulate Ion st for Physical and Chemical Properties of Particulate Ion ts for Physical and Chemical Properties of Particulate Ion $\$ 1.75$ Seamless Cold Drawn Low Carbon Steel Heat endment 2 (10-73)

4-6T, (1-72), Amendment 1 (1-72)

Heat

Intermediate Hea

d Welded Carbon, Ferritic, and Austenitic Alloy Steel Heat

ic Alloy Steel Boiler, (1974B) 1.75 Superheater, and Heat Seamless Nickel and Nickel Alloy Condenser and Heat 2-72), Amendment 3 (11-73), Amendme/ Sodium to Air Heat uminum-Alloy Drawn Seamless Tubes for Condensers and Heat

Titanium and Titanium Alloy Tubes for Condensers and Heat a) $\$ 1 . / \quad$ Welded Austenitic Steel Boiler, Superheater, Heat

$(7-71)$

Heat

uct Material (6/74) Acceptance Sampling Procedures for

mental Report to Support a Rule Making Petition Seeking an ve Material Shipments/Administrative Guide for Obtaining 973) $\$ 1.75$

dment $1(8-73)$

ransport $(2-75)$

Sponge and

Design Basis for Fuel and Irradiation

Review of

Research Reactors, Review of Development of Technical Specifications for

ANS- $1 \$ 8.00$ Critical

Near Nuclear Power Plant Sites (1/75)

Evaluation of

d Combustible Liquids on Bo/ Transportation or Storage of ent, and Other Provisions for Transportation or Storage of

erm/ Changes in Chemical Reactivity of Inorganic Material perating Philosophy for Maintaining Occupational Radiation signal for Use in Industrial Installations Where Radiation Practice for (1973) ASTM D 1879-1970 \$1.75

Rec. Practice for (1970) $\$ 1.75$

n, Practice for (1968) (R 1973) ASTM D1672-1966 (1971) \$/ n, Rec. Practice for (1966) (R1971) \$1.75 nd Redesignation of N2.2-1966) (/ Occupational Radiation est / Compression Set Induced in Vulcanized Rubber During 8) (/ Compression Set Induced in Vulcanized Rubber During ons (1971) $\$ 6.85$ Child Labor Regulations Section 57 Instruction Concerning Prenatal Radiation ions of Radionuclides in Air and in Water for Occupational Rail Ball Method) (1974) $\$ 1.75$ Sodium Carbonate, Low Chloride Fire Measurement of $73 \$ 1.75$

Specification for Aluminum-Alloy ecification for Aluminum-Alloy Seamless Pipe and Seamless for Aluminum-Alloy Standard Structural Shapes, Rolled or
Evaluating the Potential Radiological Consequences of a Evaluating the Potential Radiological Consequences of a Evaluating, and Reporting Radioactivity in Solid Wastes Evaluation of Activated Carbon (1970) $\$ 1.75$

Evaluation of Anticipated Transients Without Trip on $\mathrm{Pr}$ Evaluation of Atmospheric Contaminents, 4th Edition (19 Evaluation of Compression Test Results of Field Concret Evaluation of Compression Test Results of Field Concret Evaluation of Explosions Postulated to Occur on Transpo Evaluation of Industrial Chemicals and Materials) (1955

Evaluation of Installed Biological Shielding in Researc Evaluation of Material Unaccounted for $(6 / 74)$

Evaluation of Shipper-Receiver Differences in the Tran

Evaluation of Shipper-Receiver Differences in the Tran

Evaluation (1970) $\$ 4.00 \quad$ /-Ray and Gamma Ray P

Evaluations of Fallout in the United States from Weapon

Examimation of Aggregates for Concrete, Rec. Practice F

Examination and Testing Personnel for the Construction

Examination of Fuel Element Cladding Including the Dete

Examination of Heavy Steel Forgings, Practice for (1973

Examination of Plain and Clad Steel Plates for Special

Examination of Primary Containment Liner Welds (Revisio

Examination of Steel Forgings, Method for (1974) \$1.75

Examination of Steel Plates, Specification for (1973) \$

Examination of Tubular Products for Use in Fuel Reproce

Examination of Tubular Products (10/73)

Examination of Weldments, Method for (1974) $\$ 1.75$

Examination of Welds in the Liners of Concrete Barriers

Examination of (1972) \$1.75/Ladding Including the Det

Examination (Supplement to ASME Boiler and Pressure Ves

Examination (1977) bd $(\$ 50.00)$, II $(\$ 70.00)$

Examination, and Testing Personnel (8/73)

Exchange Materials for Strong Acid Removal (1972) $\$ 1.75$

Exchange Materials (1973) ASTM D2687-1972 \$1.75

Exchange Resins (1973) \$1.75 ASTM D2187-1972 \$1.75

Exchange Resins (1974) $\$ 1.75$

Exchanger and Condenser Tubes, Specification for (1973)

Exchanger for Gas Cooler (5-72) Amendment 1 (3-73, Am

Exchanger for Liquid Metal Systems (5-74) Supersedes E

Exchanger for Nuclear Steam Supplied Systems (3-71)

Exchanger Tubes with Integral Fins, Specification for

Exchanger Tubes, Specification

Exchanger Tubes, Specification for (1974) $\$ 1.75$

Ritic and Austenit

Exchanger (6-71), Amendment 1 (10-71), Amendment 2 (1

Exchangers, Specification for (1974) ASTM B234 1973 \$1.

Exchangers, Specification for (1974) $\$ 1.75$ land Welded

Exchanger, and Condenser Tubes, Specification for (1974

Exchanger, Class 1, Water to Water, Straight or U Tube

Exchanger, Class 2, Water to Water, Straight or U Tube

Exchanger, Non Regenerative Type (5-72)

Exempted and Generally Licensed Items Containing Byprod

Exemption for a Radionuclide-Containing Product (Revis

Exemptions from Certain NRC Requirements Over Radioacti

Expanded Cellular Rubber Products, Specification for ( 1

Expansion Joint Containment Vessel Airlock (3-72) Amen

Experiment Resistance to Shock and Vibration in Truck T

Experiments Containing Sodium (8.74)

Experiments for Research Reactors (7/76)

Experiments for (1974) ANS $15.6 \$ 8.50$

Experiments in Research Reactors (11/73)

Experiments, Safety Guide for the Performance of (1975)

Explosions Postulated to Occur on Transportation Routes

Explosives or Other Dangerous Articles or Substances an

Explosives or Other Dangerous Articles or Substances an

Exposed to High Energy Radiation, Rec. Practice for Det

Exposure as Low as Is Reasonably Achievable (Nuclear Po

Exposure as Low as Is Reasonably Achievable (Revision 1

Exposure May Occur (1967) \$3.25 Immediate Evacuation Exposure of Adhesive Specimens to High Energy Radiation Exposure of Adhesive Specimens to High Energy Radiation

Exposure of Polymeric Materials to High Energy Radiatio

Exposure of Polymeric Materials to High Energy Radiatio

Exposure Records Systems (5/73)

Exposure Records Systems, Practice for (Reaffirmation a

Exposure to High Energy Nuclear Radiation, Methods of T

Exposure to High Energy Nuclear Radiation, Testing (196

Exposure to Radioactive Substances and Ionizing Radiati

Exposure (Revision 1, 11/75)

Exposure (1959) $\$ 2.00$ / Maximum Permissible Concentrat

Express Carriers Regulations (1975) $\$ 6.80$

Extinguishing Agent (12-73)

Extreme Pressure Properties of Lubricating Grease (Four

Extruded Bars, Rods, Shapes, and Tubes (1974) ASTM B221

Extruded Tube (1974) ASTM B241 $1973 \$ 1.75$

Extruded (1974) ASTM B308-1973 \$1.75

Extrusion Materials, Specification for (1973) $\$ 1.75$

Specification
NRC

NRC

NRC

ASTM

ANSI

ACGIH

ANSI

ANSI

NRC

AlHA

NRC

NRC

ANS

NRC

NCRP

EPA

ASTM

ANS

ANS

ANSI

ANSI

NRC

ASTM

ASTM

NRC

NRC

ASTM

NRC

ASTM

ERDA

ASME

NRC

ASTM

ANSI

ANSI

Tes ASTM

ASTM

ERDA

ERDA

ERDA

ASTM

ASTM

ASTM

ERDA

ANSI

ASTM

ASTM

ERDA

ERDA

ERDA

NRC

NRC

NRC

ASTM

ERDA

ERDA

ERDA

NRC

ANSl

NRC

ANSI

NRC

DOT

USCG

ASTM

NRC

NRC

ANSI

ANSI

ASTM

ANSI

ASTM

NRC

ANSI

ANSI

ASTM

DOL

NRC

NCRP

DOT

ERDA

ASTM

ANSI

ANSI

ANSI

RG 1.5

RG 1.98

RG 1.21

D2355

N66

A 146.1

B I 46. 1

RG 1.91 
Polyethylene Plastics Molding and Measuring Flow Rates of Thermoplastics by 72) Superse/ Zirconium and Zirconium Alloy Forgings and Std. Spec. for Fully Cured Silicone Rubber Coated Glass bars and Strip, Zinc (Hot Galvanized) Coatings on Products in Ultrasonic Inspection (1975)/ Recommended Practice for ngs (Adopted February 12,/ Specification for the Design, r Liquid Metal Service (8-71) Amendment 1 (11-72), Ame/ 00 Nuclear Material Control Systems for Fuel reactors (4-73) Amendment 1 (3-74)

ice (3-72) Amendment 1 (3-74)

74)

Instrument Tree for Sodium Cooled Reactors nt 2 /

Core Support Structure for Sodium Cooled Reactors Core Restraint Mechanism for Sodium Cooled Reactors

Temperature and Liquid Level Control Monitor, Port Plug 1 Flux Monitor Mechanical System for Liquid Metal Service Core Radial Reflector for Sodium Cooled Reactors Reprocessing Plants and for Plutonium Processing and Fuel ic Design Classification for Plutonium Processing and Fuel Radiation Protection in Nuclear Reactor Fuel al Fire Protection Guide for Plutonium Processing and Fuel of License Applications for Plutonium Processing and Fuel bustible Gases and Vapors in Plutonium Processing and Fuel

1 Reprocessing Plants and to Plutonium Processing and Fuel

1 Reprocessing Plants and in Plutonium Processing and Fuel

1 Reprocessing Plants and in Plutonium Processing and Fuel ment System Design Guide for Plutonium Processing and Fuel

e for Ventilation Systems of Plutonium Processing and Fuel 1 Reprocessing Plants and in Plutonium Processing and Fuel Code Case Acceptability: ASME Section 111 Design and Open Test Assembly FFTF Closed Loop in Reactor Assembly Test for Hydrogen Permeability of Rubber Coated rous Valves and Fittings (1974) \$2.J Finishes for Contact s (1973) $\$ 4.00$

71) $\$ 7.50$

Recommended Programming Practices to General Use of Locks in the Protection and Control of fire Protection Practice for (1975) $\$ 2.50$

for Highly Radioactive Solid Material Handling and Storage Nuclear Material Control Systems for Fuel Fabrication

of Environmental Reports for Commercial Uranium Enrichment c Requirements for Design of Nuclear Power Plants and Test Content of Safety Analysis Reports for Uranium Enrichment ality Assurance for Protective Coatings Applied to Nuclear tings (Paints) for Light Water Nuclear Reactor Containment

formation: Nearby Industrial, Transportation, and Military Nuclear Material Control Systems for Conversion

3) $\$ 5.00$ Nuclear Fuel Reprocessing Sampling Airborne Radioactive Materials in Nuclear o Practice) (1974) $\$ 3.00$ Fuel Reprocessing Fast Flux Test Fuel Storage Fast Flux Fast Flux Test Fast Flux Test Fast Flux Test Fast Flux Test Fast Flux Test Fast Flux Test Fast Flux Test Fast Flux a Fuel Handling Accident in the Fuel Handling and Storage Fast Flux

Fast Flux Test

Test Vehicles for Transient Reactor Test cense Application (Including That for a Uranium Enrichment

1974) $\$ 4.00$ g Fittings, Spec. for (1973) $\$ 1.75$ Spot $\$ 4.00$

fittings, Specification for (1973) (ASTM B366-1972) \$1./ rotection Syste/ tems $(6 / 73)$

Draft Standard Application of the Single Application of the Single-

1 Radiological Consequences of a Radioactive Offgas System Food and Drugs: Notification of Defects or ating Materials (1973) $\$ 1.75$ Test for Thermal

f Pressurized Water Reactor Radioactive Gas Storage Tank 63 Predictions (1964)

Revised

ed Through 1962 (1963)

Health Implications of (4-73)

Estimates and Evaluations of

$(6-71)$

t $(6-71)$
Extrusion Materials, Specification for (1974) \$1.75 ASTM

Extrusion Plastometer (1973) \$1.75

Extrusions (ASTM B 356 with Additional Requirements) (1

Fabric and Tapes for Electrical Insulation (1969) (R197

Fabricated from Rolled, Specification for (1974) ASTM a

Fabrication and Control of Steel Reference Blocks Used

Fabrication and Erection of Structural Steel for Buildi

Fabrication and Installation of Piping Subassemblies Fo

Fabrication Facilities (A Guide to Practice) (1975) \$3.

Fabrication of Control Rod Driveline for Sodium Cooled

Fabrication of Core Component Pot for Liquid Metal Serv

Fabrication Only) Amendment 1 (8-73), Amendment 2 (3-

(Fabrication Only) (1-72) Amendment 1 (12-72), Amendme

(Fabrication Only) (10-72) Amendment 1 (3-74)

Fabrication Only) (10-73) Amendment 1 (12-74)

Fabrication Only) (7-72) Amendment 1 (7-73), Amendmen

(Fabrication Only) (8-72) Amendment 1 (4-73)

Fabrication Plants (Revision 1, 3/74)

Fabrication Plants (10/73)

Fabrication Plants (1963) $\$ 5.50$

Fabrication Plants (1/74)

Fabrication Plants $(1 / 76)$

Fabrication Plants (3/73)

Fabrication Plants $(3 / 74)$

Fabrication Plants $(5 / 75)$

Fabrication Plants (5/75)

Fabrication Plants $(6 / 73)$

Fabrication Plants $(8 / 73)$

Fabrication Plants $(8 / 75)$

Fabrication (Revision 6, 5/76)

Fabrication (10-73)

Fabrication (12-71) Amendment 1 (5-72), Amendment 2 (

Fabrics (1973) $\$ 1.75$

Faces of Pipe Flanges and Connecting End Flanges of Fer

Face-to-Face and End-to-End Dimensions of Ferrous Valve

Facilitate Interchange of Digital Computer Programs (19

Facilities and Special Nuclear Materials (11/73)

Facilities Handling Radioactive Materials, Recommended

Facilities in a Reprocessing Plant (1975) $\$ 7.50$

Facilities (A Guide to Practice) (1975) $\$ 3.00$

Facilities (Revision 1, 10/75)

Facilities (1-74)

Facilities (12/74)

Facilities (1972) $\$ 3.00$

Facilities (1972) $\$ 3.00$

Facilities (9/74)

Facilities, Guide to Practice (1971) \$4.50

Facilities, Guide to Principle Design Criteria for (197
Facilities, Guide to (1969) ISO $2889 \$ 7.00$

Facilities, Nuclear Material Control Systems (A Guide T

Facility Ceramic Grade Plutonium Dioxide (6-71)

Facility Design Basis (Revision 1, 12/75)

Facility Driver Fuel Pin End Caps (6-71)

Facility Driver Fuel Pin Insulator Pellet (6.71)

Facility Driver Fuel Pin Mixed Oxide Fuel Pellet (6-71

Facility Driver Fuel Pin Plenum Spacer (6-71)

Facility Driver Fuel Pin Plenum Spring (6-71)

Facility Driver Fuel Pin Reflectors (6-71)

Facility Driver Fuel Pin Seamless Cladding Tube (6-71)

Facility Driver Fuel Pin Wrap Wire (6-71)

Facility Driver Fuel Pin (6-71)

Facility for Boiling and Pressurized Water Reactors (SA

Facility Plutonium Nitrate Solution (6-71)

Facility Uranyl Nitrate Solution (6-71)

Facility (Treat) Experiments Containing Sodium (8-74)

Facility) (12/74)

Facing Std. (1970) $\$ 2.00$

Factors Affecting Decision Making in a Nuclear Attack

Factory Made Wrought Aluminum and Aluminum Alloy Weldin

Factory Made Wrought Steel Butt Welding Fittings (1971)

Factory-Made Wrought Nickel and Nickel-Alloy Welding

Failure Criterion to Nuclear Power Generating Station P

Failure Criterion to Nuclear Power Plant Protection Sys

Failure in a Boiling Water Reactor (3/76)

/He Potentia

Failure to Comply (1975) $\$ 2.95$

Failure Under Electric Stress of Solid Electrical Insul

Failure (Safety Guide 24,3/23/72)

Cal Conseq

Fallout Estimates for 1964-1965 and Verification of 19

Fallout from Nuclear Weapons Test. Through 1961 (1962)

Fallout in the United States from Weapons Test. Conduct

Fans, Blowers, and Compressors for Dry Gas Circulation

Fast Flux Facility Driver Fuel Pin End Caps (6-71)

Fast Flux Facility Driver Fuel Pin (6-71)

Fast Flux Facility Plutonium Nitrate Solution (6-71)

Fast Flux Test Facility Ceramic Grade Plutonium Dioxide

Fast Flux Test Facility Driver Fuel Pin Insulator Pelle
ASTM

ERDA

ANS

ANSI

ASTM

AISC

ERDA

ANSI

ERDA

ERDA

ERDA

ERDA

ERDA

ERDA

ERDA

Fuel

Seism NRC

ANSI

Gener NRC

NRC

NRC

RC

NRC

NRC

NRC

NRC

NRC

ERDA

ASTM

MSS

ANS!

ANS

NRC

NFPA

/lves ANSI

ANSI

Seismi ERDA

and NRC

Qu ANSI

Coa ANS

NRC

ANSI

ANSI

ANSI

ERDA

NRC

ERDA

ERDA

ERDA

ERDA

ERDA

ERDA

ERDA

ERDA

ERDA

NRC

ERDA

ERDA

ERDA

NRC

MSS

NCRP

ASTM

ANSI

ANSI

ANSI

NRC

NRC

BRH

NRC

EPA

EPA

EPA

ERDA

ERDA

ERDA

ERDA

ERDA

ERDA

D 1248

1238

RDT M2-9T

C59.89

G8.1

E428

S310

RDT F6-11T

N15.9

RDT E6-26T

RDT E6-34T

RDT E6-18T

RDT E6-13T

RDT E6-17T

RDT E6-10T

RDT E6-36T

RDT E6-19T

RG 3.3

RG 3.14

N7. 2

RG 3.16

RG 3.39

RG 3.7

RG 3.21

RG 3.29

RG 3.28

RG 3.10 
1 Pellet (6-71) Amendment 1 (12-74)

6-71)

6.71)

$71)$

ng Tube (6-71)

1)

y Uranium-238 Fission, Measuring (1973) $\$ 1.75$

$y$ from Uranium-238 Fission (1974) As/

y from Uranium-238 Fission, Test for (1972) \$1.75

ASTM E266-1970 \$1.75

ring $(1970) \$ 1.75$

(1970) $\$ 1.75$

m E263-1970 \$1.75

1.75

stm E264-1970 \$1.75

$\mathrm{ng}(1970) \$ 1.75$

stm E265.1970 \$1.75

astm E262.70 \$1.75

88 Fission (1974) ASTM E393-1973 \$/ Method for Measuring Method for (1974) ASTM E418-1973\$1.75

(1973) $\$ 1.75$

Operation of dment 1 (12-73), / Control Rod Assembly for Liquid Metal

$18 \mathrm{~T},(10-71)$ Preloading Threaded elating to Fatigue Testing and the Statistical Analysis of ding (1973) $\$ 1.75$ ecommended Practice for Presentation of Constant Amplitude Data (1973) (ASTM E206/ Definitions of Terms P.elating to Recommended Practice for Constant Amplitude Axial analysis Reports: Metallic Materials for Engineered Safety Safety and Health Stds. for

tor Power / Preoperational and Initial Startup Testing of Information for Safety Analysis Reports: Steam and ication for General Requirements for (1974A) \$1./ Carbon, perature Service, Specification for (1975) $\$ 1.75$

Specification for (1974A) $\$ 1.75$ Specification for (1975) $\$ 1.75 \quad$ Centrifugally Cast

SeamlessRequirements) (4-76) Supersedes M3-12T, (12-/ Seamless 75 Superheater, and Heat Exchanger Tubes, Speci/ Seamless for Calibrating Magnetic Instruments to Measure the Delta test to Determine Nil-Ductility Transition Temperature of

$-1972 \$ 1.75$

es with Integral Fins, Speci/

73 ) ASTM E125-1963\$1./
Drop-Weight Tear Tests of Specification for Seamless Seamless and Welded Carbon,

Magnetic Particle Indications on Part A:

st F/ Absorbed Gamma and Electron Radiation Dose with the 71) Absorbed Gamma and Electron Radiation Dose with the ontact Faces of Pipe Flanges and Connecting End Flanges of Face-to-Face and End-to-End Dimensions of

Copper and Copper-Alloy Seamless Condenser Tubes and 1) Amendment 1 (5-72), Amendment 2 (1-74)

ter Chargers (1965) (R1971)/

Spec. for Mineral ng Cement, Specification for (1970) $\$ 1.75$ ng Cement (ASTM C 449 with Additional Requiremen/ Mineral ible and Loose Fill (ASTM C 612 with Additional / Mineral requirements) (3-74) HEPA Filter Medium, Glass uple Material, Iron and Constantan, Solid Conductor (Bare, le Material, Copper and Constantan, Solid Conductor (Bare, le Material, Chromel-P and Alumel, Solid Conductor (Bare, d Conductor (Bare, Fiberglass Insulated, and Sheathed Over d Conductor (Bare, Fiberglass Insulated, and Sheathed Over

d Conductor (Bare, Fiberglass Insulated, and Sheathed Over bd $(\$ 40.00), 11(\$ 60.00)$

) $\$ 1.75$

Evaluation of Compression Test Results of ting Stations (19/ Type Test of Class IE Electric Cables, tillation Counting and Glossary for Scintillation Counting

te Compressive and Flexural Strength Test Specimens in the v Use of an Electron Microprobe (9-7) Determination of A imiting Values, Recommended P/ Indicating Which Places of al Insulation, High Temperature, Rigid, Flexible and Loose s) (7-75) Supersedes M 1-9T, (7-71) Brazing $\$ 2.50$ Part C-Welding Rods, Electrodes and
Brazing Brazing

Fast Flux Test Facility Driver Fuel Pin Mixed Oxide Fue Fast Flux Test Facility Driver Fuel Pin Plenum Spacer ( Fast Flux Test Facility Driver Fuel Pin Plenum Spring ( Fast Flux Test Facility Driver Fuel Pin Reflectors (6Fast Flux Test Facility Driver Fuel Pin Seamless Claddi Fast Flux Test Facility Driver Fuel Pin Wrap Wire (6-7 Fas: Flux Test Facility Uranyl Nitrate Solution (6-71) Fast Neutron Flux by Analysis of Barium-140 Produced B Fast Neutron Flux by Analysis of Molybdenum-99 Activit Fast Neutron Flux by Analysis of Molybdenum-99 Activit Fast Neutron Flux by Radioactivation of Aluminum (1973) Fast Neutron Flux by Radioactivation of Aluminum, Measu Fast Neutron Flux by Radioactivation of Iron Measuring Fast Neutron Flux by Radioactivation of Iron (1973) Ast Fast Neutron Flux by Radioactivation of Nickel (1970) \$ Fast Neutron Flux by Radioactivation of Nickel (1973) a Fast Neutron Flux by Radioactivation of Nickel, Measuri Fast Neutron Flux by Radioactivation of Sulfur (1973) a Fast Neutron Flux by Radioactivation Techniques (1973) Fast Neutron Flux for Barium 140 Produced by Uranium-2 Fast Neutron Flux Measurements by Track-Etch Technique Fast Neutron Flux Measurements by Track-Etch Technique Fast Pulse Reactors (1975) ANS 14.1 \$7.50

Fast Reactors (5-73) Supersedes E6-25T, (11-71)

Fast Reactors (5-73) Supersedes E6-33T, (11-71) Amen Fasteners and Closures (2-69) Amendment 1 (10-71) Fasteners for Nuclear Components (2-75) Supersedes E8Fatigue Data (1973) (ASTM E206-1972) $\$ 1.75$ /F
Fatigue Properties of Adhesives in Shear by Tension Loa Fatigue Properties of Adhesives in Shear by Tension Loa Fatigue Testing and the Statistical Analysis of Fatigue Fatigue Tests of Metallic Materials (1972T) \$1.75 Features (2/75) Federal Supply Contracts (1975) $\$ 3.25$

Feedwater and Condensate Systems for Boiling Water Reac Feedwater System Materials (4/75)

Ferritic Alloy and Austenitic Alloy Steel Tubes, Specif Ferritic Alloy Steel Forged and Bored Pipe for High Tem Ferritic Alloy Steel Pipe for High Temperature Service, Ferritic Alloy Steel Pipe for High Temperature Service, Ferritic Alloy Steel Pipe (ASME SA-335 with Additional Ferritic and Austenitic Alloy Steel Boiler, (1974B) \$1. Ferritic Content of Austenitic Stainless Steel Weld Met Ferritic Steels (1970) ASTM E208-1969 \$1.75

Ferritic Steels, Method for (1974) \$1.75

Ferritic-Austenitic Alloy Steel Tubes (1974) ASTM A669 Ferritic, and Austenitic Alloy Steel Heat Exchanger Tub Ferrous Castings, Reference Photographs for (1969) (R19 Ferrous Materials (1977) bd (\$90.00), Il (\$125.00) Ferrous Sulfate-Cupric Sulfate Dosimeter, Method of Te Ferrous Sulfate-Cupric Sulfate Dosimeter, Test for (19 Ferrous Valves and Fittings (1974) $\$ 2.00$

Ferrous Valves (1973) $\$ 4.00$

Ferrule Stock, Specification for (1974A) \$1.75

FFTF Closed Loop in Reactor Assembly Fabrication (12-7 Fiber Block and Board Thermal Insulation (1970) \$1.75

Fiber Electrometer Type Dosimeters and Companion Dosime

Fiber Hydraulic-Setting Thermal Insulating and Finishi Fiber Hydraulic-Setting Thermal Insulating and Finishi Fiber Thermal Insulation, High Temperature, Rigid, Flex Fiber (MIL-F-51079 with Modifications and Additional Fiberglass Insulated, and Sheathed Over Fiberglass Insu Fiberglass Insulated, and Sheathed Over Fiberglass Insu Fiberglass Insulated, and Sheathed Over Fiberglass Insu

Fiberglass Insulation) (1-73)

Fiberglass Insulation) (4-70)

Fiberglass Insulation) (4/70) /Er and Co
Fiberglass-Reinforced Plastic Pressure Vessels (1977)

El-P and Alumel, So

IN and Constantan, Soli

Field or Eddy-Current (Electromagnetic) Test Methods (

Field Splices, and Connections for Nuclear Power Genera

Field (1972) IEEE Std. 398.1972

Field Method of (1970) ASTM C31-1969\$1.75

Liers for Scin

Figure of Merit for $\mathrm{PuO}_{2}-\mathrm{UO}_{2}$ Fuel Pellet Homogeneity B

Figures Are to Be Considered Significant in Specified $\mathrm{L}$

Fill (ASTM C 612 with Additional Requirements) (3-73)

Filler Metal (ASME SFA-5.8 with Additional Requirement

Filler Metals (1977) bd $(\$ 30.00)$, ll $(\$ 40.00)$

Filler Metal, Specification for (1973) AWS A5.8-1969

Filler Metal, Specification for (1974)

Film Badge Performance Criteria (2/2/73)

Film Badge Performance, Criteria for (1972) $\$ 4.25$

Film Thickness, Variable Reluctance Transducer, Proxim Filter for Sodium Service (1-73)

Filter Medium, Glass Fiber (MlL-F-51079 with Modifica
ERDA

ERDA

ERDA

ERDA

ERDA

ERDA

ERDA

ASTM

ANSI

ASTM

ANSI

ASTM

ASTM

ANSI

A STM

ANSI

ASTM

ANSI

ANSI

ANSI

ANSI

ASTM

ANS1

ERDA

ERDA

ERDA

ERDA

Terms R ANSI

ASTM

ASTM

ANS1

ASTM

NRC

DOL

NRC

ASTM

ASTM

ASTM

ASTM

ERDA

ASTM

AWS

Weight ANS

ASTM

ANSI

ASTM

ASME

ANS1

ASTM

MSS

ANSI

ASTM

ERDA

ASTM

ANSI

ASTM

ERDA

ERDA

ERDA

ERDA

ERDA

ERDA

ERDA

ERDA

ERDA

ASME

ANSI

ANS

A STM

ANS1

ANS

ANS1

ERDA

ASTM

ERDA

ERDA

ASME

ANSI

ASME

ANSI

ERDA

ERDA

ERDA

RDT E13-6T

RDT E 13-11

RDT E13-12

RDT E13-10

E13-8T

RDT E13-13

RDT E13-3T

E393

N636

N114

E266

E263

N111

E265

N11 2

E264

N113

N110

N638

N639 
r Particulate Matter in the Atmosphere (Optical Density of Maximum Pore Diameter and Permeability of Rigid Porous Hepa and Maintenance Criteria for Atmosphere Cleanup System Air wer Plants $(12 / 73)$ Effect of Organic Impurities in Method of Test for Specific Gravity and Absorption of stm C136-1971 \$1.75 Method of Test for Rockwell Hardness of or $(1974) \$ 1.75$

ng, Method of Test for (1970) ASTM C117-1969/ Materials of Test for Moisture-Penetration Resistance Relations of eel Bars and Shape/ Specification for Hot Rolled and Cold re for Nuclear Application, Specific/ Hot Rolled and Cold re for Nuclear App/ Specification for Hot Rolled and Cold ng End Flanges of Ferrous Valves and Fittings (I974) \$2 Method of Test for the Cleanability of Surface Mineral Fiber Hydraulic-Setting Thermal Insulating and Mineral Fiber Hydraulic-Setting Thermal Insulating and Austenitic Alloy Steel Heat Exchanger Tubes with Integral Sodium Carbonate, Low Chloride ater Cooled and Moderated Nuclear Power Generating Plants, 6) Fabrication Plants (1/74) 76)

General

Nuclear Reactors, Recommended Facilities Handling Radioactive Materials, Recommended test for Evaluating Acute Toxicity of Water to Fresh Water

Glass Raschig Rings as a Neutron Absorber in Solutions of Glass Raschig Rings as a Neutron Absorber in Solutions of Nuclear Criticality Safety in the Storage of $2(10-74)$ Current Pulse Preamplifiers for Use with

tive Assay for Plutonium in Scrap Material by Spontaneous ic Method), Method of Test for (1973) ASTM / Atom Percent ic Method) (1974) $\$ 1.75$ Test for Atom Percent thod), Standard Method of Test for (1974) \$/ Atom Percent ethod) (1973) ASTM E321/ Method of Test for Atom Percent of Test for (1973) ASTM E219-1969 \$1.75 Atom Percent d Method of Test for (1974) $\$ 1.75$ g Reactor Operation, Method For/ Reactor Operation, Measureme nt $1(10-73)$

// Method of Test for Spectrophotometric Determination of $x$ by Analysis of Molybdenum-99 Activity from Uranium-238 Fast Neutron Flux for Barium 140 Produced by Uranium-288 $\$ 10.00$

Nuclear Criticality Safety in Operations with Nuclear Criticality Safety in Operations with Flux by Analysis of Barium-140 Produced by Uranium-238 $x$ by Analysis of Molybdenum-99 Activity from Uranium-238 Preferred Limits and

74) ASTM A652-1/ Specification for Wrought Steel Welding ecification 'for Special Requiremen/ Wrought Steel Welding $\begin{array}{rr}\text { w Temperature Service (1975) } \$ 1.75 & \text { Cast Bronze Solder Joint } \\ \text { Std. Spec. for Piping }\end{array}$ -75) Supersedes M2-3T, Carbon and Alloy Steel Welding -75) Supersedes M2-/ Austenitic Stainless Steel Welding $150 \mathrm{lb}$. Corrosion Resistant Cast Flanges and Flanged Silver Brazing Joints for Cast and Wrought Solder Joint Factory Made Wrought Steel Butt Welding Wrought Stainless Steel Butt Welding Steel Pipe Flanges, Flanged Valves and e Flanges and Connecting End Flanges of Ferrous Valves and Standard Marking System for Valves, Forged Steel High Test Wrought Welding Factory-Made Wrought Nickel and Nickel-Alloy Welding Factory Made Wrought Aluminum and Aluminum Alloy Welding Dimensions of Plastic Pipe 73. Amend/ Gamma Compensated Ionization Chamber Assembly Requirements for

sodium and Potassium in Water and Water Formed Deposits by 74) $\$ 1.75$

Test for Adhesion or Cohesive Strength of

(1969) $\$ 2.00$

Unfired Pressure Vessel Connecting Cast Iron Swing Check Valves, Cast Iron Gate Valves, $150 \mathrm{lb}$. Corrosion Resistant Cast Flanges and $150 \mathrm{lb}$. Corrosion Resistant Cast d Fittings ( 1974 ) \$2./
Filtered Deposit) (1969) $\$ 1.75$

Filters for Laboratory Use, Test for (1969) $\$ 1.75$

Test Fo ASTM ASTM Filters (AACC CS1 with Additional Requirements) (8-74) Filters (1968) $\$ 1.50$

Filtration and Adsorption Units of Light-Water Cooled Filtration Systems and Containment Sumps for Nuclear Po Fine Aggregate on Strength of Mortar, Method of Test Fo Fine Aggregate (1973) \$1.75

Fine and Coarse Aggregates, Method of Test for (1973) a Fine Grained Graphite Materials (1974) ASTM C748-73 \$1 Fineness of Portland Cement by the Turbidimeter, Test F Finer Than No. 200 Sieve in Mineral Aggregates by Washi Fine-Grained Soils (1972) (ASTM D 1558-1971) \$1.75 Finished Age-Hardening Stainless and Heat Resisting St Finished Zirconium and Zirconium Alloy Bars, Rod and Wi Finished Zirconium and Zirconium Alloy Bars, Rod and Wi Finishes for Contact Faces of Pipe Flanges and Connecti Finishes (1973) \$1.75

Finishing Cement (ASTM C 449 with Additional Requiremen Finishing Cement, Specification for (1970) $\$ 1.75$ Fins, Specification for (1973) \$1.75

Fire Extinguishing Agent (12-73)

Fire Protection Considerations for Nuclear Power Plants Fire Protection Criteria For, Issued for Trial Use and Fire Protection Guide for Fuel Reprocessing Plants (6/7 Fire Protection Guide for Plutonium Processing and Fue Fire Protection Guidelines for Nuclear Power Plants (6/

Fire Protection Practice for (1974) \$3.50

Fire Protection Practice for (1975) $\$ 2.50$

Fishes (1970) $\$ 1.75$

Fissile Material Symbol (1971) \$2.75

Fissile Material (1971) ANS-8.3 \$7.50

Fissile Material ( $1 / 73$ )
Fissile Materials, Guide for (1975) ANS-8.7 $\$ 12.00$

Fission Detection $(6 / 74)$

Fission in Uranium and Plutonium Fuel (Mass Spectrometr

Fission in Uranium and Plutonium Fuel (Neodymium $148 \mathrm{Me}$

Fission in Uranium and Plutonium Fuel (Neodymium-148 M

Fission in Uranium Fuel (Radiochemical Method), Method

Fission in Uranium Fuel (Radiochemical Method), Standar

Fission Products in Nuclear Reactor Coolant Water Durin

Fission Products in Nuclear Reactor Coolant Water Durin

Fission Type Neutron Detector Assembly (12-71) Amendme

Fission Zirconium in Irradiated Nuclear Fuels (1973T) \$

Fission (1974) ASTM E343-1972 \$1.75

Fast Neutron Flu

Fission (1974) ASTM E393-1973 \$1.75

Od for Measuring

Fissionable Materials Outside Reactors (1975) ANS-8.1

Fissionable Materials Outside Reactors (1/73)

Fission, Measuring (1973) \$1.75

Fission, Test for (1972) $\$ 1.75$

Fast Neutron

(R1974) \$4.00

Fittings for Nuclear and Other Special Applications (19

Fittings for Nuclear and Other Special Applications, $S_{p}$

Fittings for Sovent Drainage Systems (1973) $\$ 3.50$

Fittings of Wrought Carbon Steel and Alloy Steel for Lo

Fittings (ASME SA-234 with Additional Requirements) (5

Fittings (ASME SA-403 with Additional Requirements) (1

Fittings (1965) $\$ 3.00$

Fittings ( 1970) $\$ 3.00$

Fittings (1971) $\$ 4.00$

Fittings (1971) $\$ 4.00$

Fittings (1973) $\$ 12.00$

Fittings (1974) $\$ 2.00$

Fittings, Flanges and Unions (1964) \$4.00

/Nishes for Contact Faces of Pip

Fitrings, Specification for $(1970) \$ 4.00$

Fittings, Specification for (1973) (ASTM B366-1972) $\$ 1$

Fittings, Spec. for (1973) \$1.75

Fittings, Symbols for (1968) (R1973) $\$ 1.75$

Fixed Electrical Compensation) (7-71) Amendment I (8-

Fixed Industrial Stairs (1968) \$2.75

Fixed Ladders, Safety Requirements for (1974) $\$ 5.50$

Flame Photometry, Tests for (1971) \$1.75

Flame-Sprayed Coatings (1974) $\$ 1.75$

Flammability of Self-Supporting Plastics, Test for (19

Flange Dimensions (1969) $\$ 4.00$

Flange Joint Between Tapping Sleeves and Tapping Valves

Flanged and Threaded Ends (1970) $\$ 3.00$

Flanged and Threaded Ends (1970) $\$ 4.00$

Flanged Fittings (1965) $\$ 3.00$

Flanged Valves and Fittings (1973) $\$ 12.00$

Flanged Valves (1959) $\$ 3.00$

Flanges and Connecting End Flanges of Ferrous Valves an

Flanges and Flanged Fittings (1965) $\$ 3.00$
D 1704

E 128

RDT E9-1T

CS- $1 \mathrm{~T}$

RG 1.52

RG 1.70 .2

A 37.129

C128

A 37.8

K90.14

C 115

A 37.4

A 37.157

A 564

N 122

B351

SP-6

C756

RDT M12-3T

C449

A 498

RDT M17-1T

RG 1.70 .4

N 18.10

RG 3.38

RG 3.16

RG 1.120

802

801

D 1345

N 12.1

N1 6.4

RG 3.1

N16.5

RDT C15-3T

RG 5.34

N108

E244

E321

N11 8

N 107

E219

N1 63

D2470

RDT C 15-5T

E495

N636

N638

N 16.1

RG 3.4

E393

E343

B4.1

N560

A652

B! 6.32

A420

RDT M2-3T

RDT M2-5T

SP-51

SP-73

B 16.9

SP-43

B I 6.5

SP-6

SP-25

B 16.11

SP-75

H34.15

B361

D2749

RDT C15-7T

A64.1

A 14.3

D 1428

C633

D635

B1 6.30

SP-60

SP-7 1

SP-70

SP-51

B 16.5

SP-42

SP-6

SP-5! 
High Pressure Chemical Industry ishes for Contact Faces of Pipe Flanges and Connecting End for (1976) $\$ 1.75$

stm A629-1971 \$1.75 $1970 \$ 1.75$

Forged or Rolled Steel Pipe Steel Pipe
Std. Spec. for Tool Resisting Steel Tantalum Ingots and Tantalum Ingots and

mineral Fiber Thermal Insulation, High Temperature, Rigid, 1.75 Test for Water Vapor Transmission of
(5-72) Amendment 1 (4-73) Thermal Insulation,

hird Point Loading), Method of Test for (1966) (R1973) A/ ation, Test for (1972) \$1.7/ Breaking Load and Calculated f (1970) ASTM/ Making and Curing Concrete Compressive and

Design Basis

Additional information: Water Level Requirements for (1973) $\$ 3.00$

r(6-72) Amendment 1 (9-73), Amendment 2 (6-74)

Thermal Conductivity of Materials by Means of the Heat ures, Measurement of (1973) \$1.75 1973) $\$ 1.75$

$-73)$

(1-71)

Measuring

sedes C4-5T, (8-71)

Eddy Current Probe Type in Core Permanent Magne Venturi

ics $(2-73)$ Permanent Magnet in Core Permanent Magnet Flow Through Type ign Limits and Loading Combinations for Seismic Category truction Phase of Nuclear Power Plants (1973/

Cleaning of d Nuclear Po/ Quality Assurance Requirements for Cleaning $\$ 3.00$ Residual Holdup of Special Nuclear Material in Drying and 72) $\$ 1.75$

adiation Safety for X-Ray Diffraction and

Microquantities of Uranium in Water by erformance Std. (lonizing Radiation Emitting Products) for r Gage (10-70/ Liquid Metal Pressure Measurement System, ns $(1960) \$ 2.00$

Measurement of Neutron 38 Fission, Measuring (1973) \$1.75 Fast Neutron $\mathrm{m}-238$ Fission (1974) As/ Method of Test for Fast Neutron m-238 Fission, Test for (1972) $\$ 1.75$ $970 \$ 1.75$ Fast Neutron

Method for Measuring Fast Neutron Fast Neutron

$\$ 1.75$ Fast Neutron

$0 \$ 1.75$

75

$0 \$ 1.75$

$70 \$ 1.75$

$\$ 1.75$

Methods for Measuring Fast Neutron Fast Neutron Method for Measuring Fast Neutron
Fast Neutron
Method for Measuring Fast Neutron Method of Measuring Neutron Method for Measuring Fast Neutron Thermal Neutron Neutron

ickel Steel Electrodes (1974) $\$ 3.50$

tron Generators by Radioactivation Techniques,

Neutron-

Generators by Radioactivatio/ Method of Test for Neutron 973T) Measuring Neutron Fast Fast

974) ASTM E393-1973 \$/ Method for Measuring Fast Neutron (1974) ASTM E418-1973\$1.75 Fast Neutron Fast Neutron (Fabrication Only) (7-72) Amendment 1 (7-73/ Low Level Wide Range ( 10 Decade) Neutron Logarithmic Count Rate Source Range Neutron Direct Current Power Range Neutron thmic Mean Square Voltage (MSV) Intermediate Range Neutron 71) let (6-71) Amendment $1(12-74)$

)

be $(6-71)$

Fast

Fast

Fast

Fast

Fast

Fast

dditional Requirements) (3-75/ Mild Steel Electrodes and ent-Chromium, 1-Percent-Molybdenum Alloy Electrodes and 73) AWS A 5.17-1969 \$2.50 74) Bare Mild Steel Electrodes and Mild Steel Electrodes and Mild Steel Electrodes for Requirements) (7-75) Supers/ Mild Steel Electrodes for
Mild Steel Electrodes for
Flanges and Threaded Stubs for Use with Lens Gaskets (1 Flanges and Unions (1964) $\$ 4.00$

Flanges of Ferrous Valves and Fittings (1974) $\$ 2.00$

Flanges, and Valves and Parts for General Service, Spec

Flanges. Flanged Valves and Fittings (1973) \$12.00

Flat Bars and Shapes for Security Applications (1974) a

Flat Mill Products, Specification for (1973) ASTM B364.

Flat Mill Products, Spec. for (1970) $\$ 1.75$

Flexible and Loose Fill (ASTM C 612 with Additional Req

Flexible Heat Sealed Packages for Dry Products (1972) \$

Flexible or Molded, High Temperature, Low Conductivity Flexible Packages (1972) \$1.75

Flexural Strength of Concrete (Using Simple Beam with T Flexural Strength of Preformed Block Type Thermal Insul Flexural Strength Test Specimens in the Field, Method $\mathrm{O}$ Flood Protection for Nuclear Power Plants (10/75

Floods for Nuclear Power Plants (Revision 1, 4/76)

(Flood) Design for Nuclear Power Plants (5/74)

Floor and Wall Openings, Railings and Toeboards, Säety

Floor Valve, Reactor Refueling and Maintenance for Lmfb Flow Clean Air Devices (1968) $\$ 1.50$

Flow Meter, Test for (1970) $\$ 1.75$

Flow Properties of Lubricating Greases at High Temperat

Flow Rates of Thermoplastics by Extrusion Plastometer (

Flow Sensor for Liquid Metal Service (6-73)

Flow Through Type Flowmeter for Liquid Metal Service (4

Flow Tube for Liquid Sodium (8-74) Supersedes C4-4T,

Flowmeter for Liquid Metal Piping Systems (4-74) Super

Flowmeter for Liquid Metal Service (4-73)

Flowmeter Power Supply and Signal Conditioning Electron

Fluid System Components (5/73)

Fluid Systems and Associated Components During the Con

Fluid Systems and Associated Components of Water-Coole

Fluidized Bed Operations (Revision 1, 5/74)

Fluorescence Analysis Equipment (1971) NBS Handbook 111

Fluoride lon in Water, Standard Method of Tests for (19

Fluorometry, Test for (1975) \$1.75

Fluoroscopic Equipment (1975) $\$ 2.95$

Flush Mounted, Eddy Current Type, Inductive, Absolute $\mathrm{O}$

Flux and Spectra for Physical and Biological Applicatio

Flux by Analysis of Barium-140 Produced by Uranium-2

Flux by Analysis of Molybdenum-99 Activity from Uraniu

Flux by Analysis of Molybdenum-99 Activity from Uraniu

Flux by Radioactivation of Aluminum (1973) ASTM E266-1

Flux by Radioactivation of Aluminum, Measuring (1970) $\$$

Flux by Radioactivation of Iron Measuring (1970) $\$ 1.75$

Flux by Radioactivation of Iron (1973) ASTM E263-1970

Flux by Radioactivation of Nickel (1970) $\$ 1.75$

Flux by Radioactivation of Nickel (1973) ASTM E264-197

Flux by Radioactivation of Nickel, Measuring (1970) $\$ 1$.

Flux by Radioactivation of Sulfur (1973) ASTM E265-197

Flux by Radioactivation Techniques (1973) ASTM E261-19

Flux by Radioactivation Techniques (1973) ASTM E262-70

Flux by Radioactivation Techniques, Measuring (1970) \$1

Flux by Radioactivation (1970) $\$ 1.75$

Flux Core Corrosion-Resisting Chromium and Chromium-N

Flux Density and Average Energy from ${ }^{3} \mathrm{H}(\mathrm{d}, \mathrm{n}){ }^{4} \mathrm{He} \mathrm{Neu}$

Flux Density and Average Energy from $3 \mathrm{H}(\mathrm{D}, \mathrm{N}) 4 \mathrm{He}$ Neutron

Flux Density by Radioactivation of Cobalt and Silver (1

Flux Facility Driver Fuel Pin End Caps (6-71)

Flux Facility Driver Fuel Pin (6-71)

Flux Facility Plutonium Nitrate Solution (6-71)

Flux for Barium 140 Produced by Uranium-288 Fission (

Flux Measurements by Track-Etch Technique (1973) $\$ 1.75$

Flux Measurements by Track-Etch Technique, Method for

Flux Monitor Mechanical System for Liquid Metal Service

Flux Monitoring Channel (2-71)

Flux Monitoring System (7-71)

Flux Monitoring System (7-71)

Flux Monitoring System (7-71)

Flux Test Facility Ceramic Grade Plutonium Dioxide (6-

Flux Test Facility Driver Fuel Pin Insulator Pellet (6.

Flux Test Facility Driver Fuel Pin Mixed Oxide Fuel Pel

Flux Test Facility Driver Fuel Pin Plenum Spacer (6-71

Flux Test Facility Driver Fuel Pin Plenum Spring (6-7

Flux Test Facility Driver Fuel Pin Reflectors (6-71)

Flux Test Facility Driver Fuel Pin Seamless Cladding Tu

Flux Test Facility Driver Fuel Pin Wrap Wire (6-71)

Flux Test Facility Uranyl Nitrate Solution (6-7i)

Fluxes for Submerged Arc Welding (ASME SFA-5.17 with

Fluxes for Submerged Arc Welding (9-75)

Fluxes for Submerged Arc Welding, Specification for (1

Fluxes for Submerged Arc Welding Specification for (19

Flux-Cored Arc Welding (ASME SFA -5.20 with Additiona

Flux-Cored Arc Welding, Specification for (1973) AWS a

Flux-Cored Arc Welding, Specification for (1974)
MSS

MSS

/N MSS

ASTM

ANSI

ANSI

ANSI

ASTM

ERDA

ASTM

ERDA

ASTM

ANSI

ASTM

ANSI

NRC

NRC

NRC

ANSI

ERDA

IES

ASTM

ASTM

ASTM

ERDA

ERDA

ERDA

ERDA

ERDA

Des NRC

ANSI

NRC

NRC

ANSI

ASTM

ASTM

BRH

ERDA

NCRP

ASTM

ANSI

ASTM

ANSI

ASTM

ASTM

ANSI

ASTM

ANS1

ASTM

ANSI

ANSI

ANSI

ASTM

ASTM

AWS

ASTM

ANSI

ASTM

ERDA

ERDA

ANSI

ASTM

ANSI

ERDA

ERDA

ERDA

ERDA

Logari ERDA

ERDA

ERDA

ERDA

ERDA

ERDA

ERDA

ERDA

ERDA

ERDA

ERDA

ERDA

ANSI

ASME

ERDA

ANSI

ASME

SP. 65

SP-25

SP. 6

A 181

B 16.5

G24.47

Z179.14 

n Portland Cement Concrete (1973) ASTM/ Specification for
rete (1974) $\$ 1.75$

\section{Reactor Coolant Pump}

Information for Safety Analysis Reports: Pum

Dose to Polymeric Materials and Application of Threshold-

$64 \$ 1.75$ Columbium and Columbium Alloy Strip, Sheet,
ces Intended for Use in the Production, Processing, and omply (1975) $\$ 2.95$

ons) (1975) \$2.95

erpretation (1975) $\$ 2.95$

ded for Use in the Production, Processing, and Handling of

$1972 \$ 3.00$

st for Bearing Capacity of Soil for Static Load on Spread dium Impurities ( $1-76)$ Supersedes E4-5T, (12-70)

cification for (1975) $\$ 1.75$

cification for $(1975) \$ 1.75$

ts for General Service, Spec. for (1976) $\$ 1.75$

73) $\$ 3.00$

galvanized) Coatings on Products Fabricated/ Spec for Copper and Sintered, and Precipitation Hardening Nickel Alloy Bars, Forgings, and r Precipitation Hardening Nickel Alloy Bars, Forgings, and itation Hardening Iron Base Superalloy Bars, Forgings, and tion Hardening Cobalt Containing Alloy Bars, Forgings, an ) (4-76) Sup/ Nickel-Chromium Alloy Bars, Forgings, and tions (1974) ASTM A65/ Spec. for Special Requirements for tions, Specification for Special Requirements for (1973)/ uirements) (1-72) Superse/ Zirconium and Zirconium Alloy ional Requirements) (7-75) Supersedes M2-/ Carbon Stee uenched and Tempered Vacuum Treated Carbon and Alloy Stee vessel Components (1970) Ast/ Std. Spec. for Carbon Steel -75) Supersedes / Martensitic Stainless Steel (Type 403 -76) Supersedes M2-2T, (/ Stainless and Low Alloy Stee -75) Supersedes M2-/ Nickel-Molybdenum-Chromium Alloy 1-74) Supersedes M2-4T, (4-72)

nt-Chromium, 1-Percent-Molybdenum Alloy Steel Tubesheet -75) Supersedes M2-8T, (7-71) Carbon and Alloy Stee precipitation-Hardening Stainless Steel Bars, Shapes, and Std. Spec. for Copper and Copper Alloy Die Specification for Titanium and Titanium Alloy Specification for Aluminum-Alloy Die and Hand Std. Spec. for Stainless and Heat Resisting Stee Spec. for Titanium and Titanium Alloy

Std. Spec. for Precipitation Hardening Nickel Alloy Bars, ec. for Precipitation Hardening Iron Base Superalloy Bars, for Precipitation Hardening Cobalt Containing Alloy Bars, e (ASTM a 637/ Precipitation Hardening Nickel Alloy Bars, I Requirements) (4-76) Sup/ Nickel-Chromium Alloy Bars, 1 Base-19Cr-3.1Mo-5.I (Cb+Ta)-/ Spec. for Alloy Bars, \&ta) $0.90 \mathrm{Ti}-0.50 \mathrm{Al}$ Consumable Electrode or Vacuum/ Bars, Pressure Vessel Components (197) Specification for Stee oughness Testing for Piping Components/ Specification for Magnetic Particle Examination of Stee Ultrasonic Examination of Heavy Stee requirements) (4-76) Supersedes/ Aluminum-Alloy Die and Hand

trol and Accounting Section of a Special Nuclea/ m Processing and Fuel Fabrication Plants (1/76) only of Unirradiated Reactor Fuel and Associate/ reprocessing Plants (2/75)

ar Power Plants (Revision 2, (9/75)

um Enrichment Facilities (12/74) 1.75 Sodium and Potassium in Water and W ate Analysis of Solvent Systems Used for Removal of Water ation for (1973) (ASTM B349-/ Zirconium Sponge and Othe r (1973) $\$ 1.75$

Zirconium Sponge and Othe Unified Screw Threads (UN and UNR Thread
Remelted Lithium Metal in Ingo ment of Extreme Pressure Properties of Lubricating Grease 74) $\$ 1.75$

$71)$, Amendment $2(12-71)$

Test for Plane-Strain

Rail

esonance (1974) \$1./ Moduli of Elasticity and Fundamental

izing Radiation Emitting Products) for Microwave and Radio

4) (R1969) ASTM C360-1963\$1.75 Ball Penetration in f Test for (1975) $\$ 1.75$ Test for Evaluating Acute Toxicity of Water to of Test for (1975) $\$ 1.75$ Air Content of Tungsten

Fly Ash and Raw or Calcined Natural Pozzolans for Use I Fly Ash for Use as an Admixture in Portland Cement Conc Flywheel Integrity (Revision 1,8/75) Flywheel Integrity (4/75)

Foil Measurements ( I968) (R 1973) \$1.75

Foil Shielded Instrumentation Cable (6-74)

Foil, and Plate, Specification for (1973) ASTM B393-19

Food Additives, Subpart G. Radiation and Radiation Sour Food and Drugs: Notification of Defects or Failure to C Food and Drugs: Records and Reports (1975) $\$ 2.95$

Food and Drugs: Subpart A, General Provisions (Definiti Food and Drugs: Subpart B, Statements of Policy and Int Food (1975) $\$ 6.75$ /Diation and Radiation Sour Footings (1972) (ASTM D1194-1972) \$1.75 Method of T Force (EMF) Tables for Thermocouples (1973) ASTM E230Forced Circulation Cold Trap Assembly for Removal of So Forced Vibration Testing of Vulcanizates (1971) $\$ 1.75$ Forged and Bored Pipe for High Temperature Service, Spe Forged and Bored Pipe for High Temperature Service, Spe Forged or Rolled Steel Pipe Flanges, and Valves and Par Forged Steel Fittings, Socket-Welding and Threaded ( 19 Forged Steel Shapes, Plates, Bars and Strip, Zinc (Hot Forged (1966) $\$ 3.00$

Forging Rod, Bar, and Shapes (1974) $\$ 1.75$

Forging Stock for High Temperature Service (ASTM a 637 Forging Stock for High Temperature Service (1973) ASTM Forging Stock for High Temperature Service (1973) ASTM Forging Stock for High Temperature Service (1973) ASTM Forging Stock (ASME SA 637 with Additional Requirements Forgings and Bars for Nuclear and Other Special Applica Forgings and Bars for Nuclear and Other Special Applica Forgings and Extrusions (ASTM B 356 with Additional Req Forgings for Piping Components (ASME SA-105 with Addit Forgings for Pressure Vessels (1974A) \$1.75 Forgings for Seamless Drums, Heads, and Other Pressure Forgings (ASME SA-182 with Additional Requirements) (3 Forgings (ASME SA-182 with Additional Requirements) (4 Forgings (ASME SA-182 with Additional Requirements) (7 Forgings (ASME SA-336 with Additional Requirements) (1 Forgings (ASME SA-336 with Additional Requirements) (2 Forgings (ASME SA-541 with Additional Requirements) (7 Forgings (ASME SA-564 with Additional Requirements) ( 5 Forgings (Hot Pressed) (1974) $\$ 1.75$

Forgings (1970) ASTM B381-1969\$1.75

Forgings (1974) ASTM B247-1973 \$1.75

Forgings (1975) \$1.75

Forgings (1975) $\$ 1.75$

Forgings-Pressed, Sintered, and Forged (1966) $\$ 3.00$ Forgings, and Forging Stock for High Temperature Servic Forgings, and Forging Stock for High Temperature Servic Forgings, and Forging Stock for High Temperature Servic Forgings, and Forging Stock for High Temperature Servic Forgings, and Forging Stock (ASME SA 637 with Additiona Forgings, and Rings, Corrosion and Heat Resistant Nicke Forgings, and Rings, Nickel-19Cr-19Fe-3.1Mo-5.1 (Cb Forgings, Carbon and Alloy, Quenched and Tempered, for Forgings, Carbon and Low Alloy Steel, Requiring Notch T Forgings, Method for (1974) \$1.75

Forgings, Practice for (1973) ASTM A388-1971 \$1.75 Forgings, Specification for (1974) $\$ 1.75$

Forgings, Vacuum Treated (ASME SA-508 with Additional Form Work, Practice for (1968) (ACI 347-1968 $\$ 2.50$ Format and Content for the Special Nuclear Material Con Format and Content of License Applications for Plutoniu Format and Content of License Applications for Storage Format and Content of Safety Analysis Reports for Fuel Format and Content of Safety Analysis Reports for Nucle Format and Content of Safety Analysis Reports for Urani Format for Nuclear Logs (1974) $\$ 1.00$

Formed Deposits by Flame Photometry, Tests for (1971) \$ Formed (1973) $\$ 1.75$

Forms of Virgin Metal for Nuclear Application, Specific

Forms of Virgin Metal for Nuclear Application, Spec. Fo

Form) (1974) \$15.00

Form, Specification for (1972) $\$ 1.75$

(Four Ball Method) (1974) $\$ 1.75$

Fracture Toughness of Metallic Materials, Method of (19

Freeze Vent for Sodium Service (2-71) Amendment 1 (9-

Freight Carriers Regulations (1975) $\$ 6.80$

Frequencies of Carbon and Graphite Materials by Sonic R Ce Std. (Ion

Frequency Emitting Products (1975) \$2.95

Fresh Concrete, Method of (1973) ASTM C172-197। $\$ 1.75$

Fresh Portland Cement Concrete, Method of Test for (196

Fresh Water Fishes (1970) $\$ 1.75$

Freshly Mixed Concrete by the Pressure Method, Method O
Freshly Mixed Concrete by the Volumetric Method, Method
ANSI

NRC

NRC

ASTM

ERDA

ANS

FDA

BRH

BRH

BRH

BRH

FDA

ANSI

ERDA

ASTM

ASTM

ANSI

ANSI

SAE

ASTM

ERDA

ANSI

ANSI

ANSI

ERDA

ANSI

ASTM

ERD

ERDA

ASTM

ANSI

ERDA

ERDA

ERA

ERDA

ERDA

ERDA

A STM

ANSI

ANSI

ASTM

A STM

SAE

ANSI

ANSI

ERDA

ERDA

ANSI

SAE

ASTM

ASTM

ASTM

ANSI

ASTM

ERDA

ANSI

NRC

NRC

NRC

NRC

NRC

API

ASTM

ASTM

ANSI

ANSI

ASTM

ASTM

ASTM

ERDA

DOT

ASTM

BRH

ANSI

ANSI

ASTM

ASTM

ASTM

A 37.122

C311

RG 1.14

RG 1.70 .30

D2365

RDT C17-9T

Z179.20

2ICFR 121

2 ICFR 1003

21CFR 1002

2ICFR 1000A

$21 \mathrm{CFR} 1000 \mathrm{~B}$

21CFR 121

A 37.158

C 96.2

RDT E4-5T

D223 I

A 369

A430

A 18

B 16.1

G8.1

AMS7897

B 124

RDT M2-I 8T

G81.44

G81.45

G81.46

RDT M2-15T 
Vibration in Truck Transport (2.75) reactors $(12 / 20 / 72)$ amendment $1(5-72)$

Design Basis for Serial Numbering of Surveillance Program for New

e Mechanical Properties (197/ Practice for Examination of e Mechanical Properties, Rec. Practice for Examination O/ Quality Verification for Plate-Type Uranium-Aluminum Quality Control for Plate-Type Uranium-Aluminum Shielded Shipping Cask for Spent Reactor

$\$ 3.00$ Nuclear Material Control Systems for Fuel Reprocessing Plants and for Plutonium Processing and seismic Design Classification for Plutonium Processing and Radiation Protection in Nuclear Reactor general Fire Protection Guide for Plutonium Processing and ntent of License Applications for Plutonium Processing and f Combustible Gases and Vapors in Plutonium Processing and o Fuel Reprocessing Plants and to Plutonium Processing and n Fuel Reprocessing Plants and in Plutonium Processing and n Fuel Reprocessing Plants and in Plutonium Processing and treatment System Design Guide for Plutonium Processing and

Guide for Ventilation Systems of Plutonium Processing and n Fuel Reprocessing Plants and in Plutonium Processing and or Evaluating the Potential Radiological Consequences of A diological Consequences of a Fuel Handling Accident in the 5) Protection Contingency Measures for Uranium and Plutonium Determination of Determination of a Figure of Merit for $\mathrm{PuO}_{2}-\mathrm{UO}_{2}$ Fast Flux Test Facility Driver Fuel Pin Mixed Oxide Ceramographic Preparation Cf Mixed Oxide Fast Flux Facility Driver Fast Flux Test Facility Driver Fast Flux Test Facility Driver Fast Flux Test Facility Driver Fast Flux Test Facility Driver Fast Flux Test Facility Driver Fast Flux Test Facility Driver Fast Flux Test Facility Driver Fast Flux Facility Driver Electric Heaters: Simulated LMFBR Nondestructive Assay of High Enrichment Uranium Criteria for (1973) $\$ 5.00$

systems (A Guide to Practice) (1974) $\$ 3.00$ ctions $(6 / 74)$ Nuclear nd Fuel Fabri/

Quality Assurance Program Requirements fo ification for Welding in Areas of Limited Accessibility in ture Control for the Welding of Low Alloy Steel for Use in

Nondestructive Examination of Tubular Products for Use in Assurance Requirements for Protective Coatings Applied to Earthquake Instrumentation for Confinement Barriers and Systems for Reporting of Operating Information for Process Offgas Systems for

standard Format and Content of Safety Analysis Reports for Content of Technical Specifications for examination of Welds in the Liners of Concrete Barriers in cation, and Inspection of Protective Coatings (Paints) for General Fire Protection Guide for

Emergency Water Supply Systems for ress Corrosion in Austenitic Stainless Steel Components of 75) General Design Guide for Ventilation Systems for

Inspection and Preventive Maintenance of Operating Manuals for

for Radiochemical Determination of Cesium-137 in Nuclear Radiochemical Determination of Cesium-137 in Nuclear

ing, Design, and Plant Protection for an Independent Spent Information for Safety Analysis Reports:

Test for Atom Percent Fission in Uranium and Plutonium 973) ASTM / Atom Percent Fission in Uranium and Plutonium r (1974) \$/ Atom Percent Fission in Uranium and Plutonium of Test for Atom Percent Fission in Uranium and Plutonium astm E219-1969 \$1.75 Atom Percent Fission in Uranium Atom Percent Fission in Uranium Analytical Chemistry Methods for Mixed Oxide netration Assemblies in Containment Structures for Nuclear

c Determination of Fission Zirconium in Irradiated Nuclear es for Electrical Insulation (1969) (R197/ Std. Spec. for
Friable Particles in Aggregates, Method of Test for (19 Fricke Dosimeter (1972) \$1.7\$

Friction Hard Surface for Core Components (5-73) Amend Fuel Analysis (7-73)

Fuel and Associated Radioactive Material (10/73)

Fuel and Control Assembly Tag Gas (10-72)

Fuel and Irradiations Experiment Resistance to Shock an

Fuel Assemblies for Light-Water-Cooled Nuclear Power

Fuel Assemblies for Pressurized Water Reactors (7-71)

Fuel Assembly Designs (6/76)

Fuel Assembly Identification (1972) ANS-13.8 $\$ 5.00$

Fuel Assembly (4-73)

Fuel Element Cladding Including the Determination of th

Fuel Element Cladding Including the Determination of th

Fuel Elements for Use in Research Reactors (Revision 1,

Fuel Elements (1974) ANS I5.2 $\$ 8.50$

Fuel Elements (8-73) Amendment 1 (1I-73)

Fuel Fabrication Facilities (A Guide to Practice) (1975

Fuel Fabrication Plants (Revision 1, 3/74)

Fuel Fabrication Plants (10/73)

Fuel Fabrication Plants (1963) $\$ 5.50$

Fuel Fabrication Plants (1/74)

Fuel Fabrication Plants $(1 / 76)$

Fuel Fabrication Plants $(3 / 73)$

Fuel Fabrication Plants (3/74)

Fuel Fabrication Plants $(5 / 75)$

Fuel Fabrication Plants $(5 / 75)$

Fuel Fabrication Plants $(6 / 73)$

Fuel Fabrication Plants $(8 / 73)$

Fuel Fabrication Plants ( $8 / 75)$

Fuel Handling Accident in the Fuel Handling Products for Use I

Fuel Handling and Storage Facility for Boiling and Pr

Fuel Manufacturing Plants (6/74)

Fuel Pellet Homogeneity by Alpha-Autoradiography (5-7

Fuel Pellet Homogeneity by Use of an Electron Microprob

Fuel Pellet (6-71) Amendment 1 (12-74)

Fuel Pellets (1.73)

Fuel Pin End Caps (6-71)

Fuel Pin Insulator Pellet (6-7I)

Fuel Pin Mixed Oxide Fuel Pelíet (6-71) Amendment 1 (1

Fuel Pin Plenum Spacer (6-71)

Fuel Pin Plenum Spring (6-71)

Fuel Pin Reflectors (6-71)

Fuel Pin Seamless Cladding Tube (6-71)

Fuel Pin Wrap Wire (6-71)

Fuel Pin (6-71)

Fuel Pins (3-72)

Fuel Plates by Gamma-R ay Spectrometry (9/74)

Fuel Reprocessing Facilities, Guide to Principle Design

Fuel Reprocessing Facilities, Nuclear Material Control

Fuel Reprocessing Plant Protection System Actuation Fun

Fuel Reprocessing Plants and for Plutonium Processing a

Fuel Reprocessing Plants and in Plutonium Processing an

Fuel Reprocessing Plants and in Plutonium Processing an

Fuel Reprocessing Plants and in Plutonium Processing an

Fuel Reprocessing Plants and to Plutonium Processing an

Fuel Reprocessing Plants $(2 / 74)$

Fuel Reprocessing Plants (2/74)

Fuel Reprocessing Plants (2/74)

Fuel Reprocessing Plants $(2 / 74)$

Fuel Reprocessing Plants $(2 / 75)$

Fuel Reprocessing Plants $(4 / 73)$

Fuel Reprocessing Plants (5/75)

Fuel Reprocessing Plants $(6 / 75)$

Fuel Reprocessing Plants $(6 / 76)$

Fuel Reprocessing Plants $(9 / 75)$

Fuel Reprocessing Plants (9/75)

Fuel Reprocessing Systems (9/75)

Fuel Shipping Container Tiedown

Fuel Shopping Containers (1-75)

Fuel Solutions (1973) ASTM E320-1970 \$1.75

Fuel Solutions, Standard Method for (1970) \$1.75

Fuel Storage Facility Design Basis (Revision 1, 12/75)

Fuel Storage Installation (12/74)

Se Application, Sit

Fuel System Design (5/75)

Fuel (Mass Spectrometric Method) (1974) $\$ 1.75$

Fuel (Mass Spectrometric Method), Method of Test for (1

Fuel (Neodymium 148 Method), Standard Method of Test Fo

Fuel (Neodymium-148 Method) (1973) ASTM E32I-1969) \$

Fuel (Radiochemical Method), Method of Test for (1973)

Fuel (Radiochemical Method), Standard Method of Test Fo

Fuel (7-73) Amendment 1 (12-74)

Fueled Power Generating Stations (1973) IEEE 317-1972

Fuels (1973T) $\$ 1.75$

/Hod of

Fully Cured Silicone Rubber Coated Glass Fabric and Tap
ANSI

St ASTM

ERDA

ERDA

Lic NRC

ERDA

ERDA

NRC

ERDA

NRC

ANSI

ERDA

ANSI

ASTM

NRC

ANSI

ERDA

ANSI

NRC

NRC

ANSI

NRC

NRC

nitoring $\mathrm{O}$ NRC

NRC

NRC

NRC

NRC

NRC

NRC

NRC

NRC

ERDA

ERDA

ERDA

ERDA

ERDA

ERDA

ERDA

ERDA

ERDA

ERDA

ERDA

ERDA

ERDA

ERDA

NRC

ANSI

ANSI

NRC

NRC

NRC

NRC

NRC

NRC

NRC

NRC

NRC

NRC

NRC

NRC

NRC

NRC

NRC

NRC

NRC

NRC

ERDA

ERDA

ERDA

ANSI

ASTM

NRC

NRC

NRC

ASTM

ANSI

ASTM

ANS

ANSI

ASTM

ERDA

ANSI

ASTM

ANSI

A 37.28

D 1671

RDT E6-38'

RDT F2-6T

RG 3.15

RDT M14-2T

RDT F8-9T

RG 5.1

RDT E13-15

RG 1.119

N1 8.3

RDT E13-16

N147

E453

RG 2.3

N398

RDT E 12-4 T

N15.9

RG 3.3

RG 3.14

N7. 2

RG 3.16

RG 3.39 
KWIC Index of U.S. Nuclear Standards

Self Operated and Power Operated Safety Related Valves ration of Design Bases for Systems That Perform Protective Periodic Testing of Protection System Actuation ing of Fuel Reprocessing Plant Protection System Actuation s by Sonic Resonance (1974) \$1./ Moduli of Elasticity and Reference Radiographs for Stee Over), Specification for (1974) $\$ 1.75$ pipe for High Temperature Service, Specificati/ peratures (1974) ASTM A671-1 Specification for Electricecification for (1975) $\$ 1.75$

Electricromium-Nickel Stainless Steel Plate, Sheet, and Strip for

Flush Mounted, Eddy Current Type, Inductive, Absolute or trochemical Analysis of (1972) ASTM E40/ Uranium Oxide by ectrochemical Analysis of (1970) $\$ 1.75$

Uranium Oxide by detecting / Safeguarding Against Embrittlement of Hot Dip and Forged Steel Shapes, Plates, Bars and Strip, Zinc (Ho e Dosimeter, Method of Test for (1973) (ASTM D3/ Absorbed ate-Cupric Sulfate Dosimeter, Method of Test F/ Absorbed ate-Cupric Sulfate Dosimeter, Test for (1971) Absorbed ectrical Compensation) (7-71) Amendment 1 (8-73, Amend 75 971) $\$ 4.40$ Std. Method of Test for Absorbed Portable X or Rec. Practice for Calculation of Absorbed Dose from

$t$ Reading and Indirect Reading Pocket Dosimeters for $X$ and waste Water, Method for Measurement of (1973) ASTM D1690/ Test for Measurement of Spec. of al Sheilding Design and Evaluation (19/ Medical X-Ray and nt Design and Use (1968) $\$ 3.00 \quad$ Medical X-Ray and ty Sta/ Installations Using Non-Medical X-Ray and Sealed of Absorbed Dose of Neutrons, and Mixtures of Neutrons and $459-1969 \$ 1.75$

es C15-11T, (8-72)

td. 325-1971 \$4.00 Nondestructive Uranium-235 Enrichment Assay by estructive Assay of High Enrichment Uranium Fuel Plates by eaks Using the Mass Spectrometer Leak Detector or Residual (1973) $\$ 1.75$

for Volatile Organic Matter in Water by Aqueous-Injection Fans, Blowers, and Compressors for Dry Radioactive oolant Accident (Safety Guide 7./

Control of Combustible od of Marking (1954) (R1971) CGA C4 / Portable Compressed 73) Heat Exchanger for cga V-1-1965 $\$ 7.00$ Compressed

(Ionizing Radiation Emitting Products) for Cold-Cathode equirements) (4-75) Supersede/ $18-1969 \$ 2.50$ Mild Steel Electrodes for Mild Steel Electrodes for Mild Steel Electrodes for dodine Compounds (10-73) Supersedes M 16-1T, (6-72) 2) $\$ 2.00$

High Efficiency Sodium Cover Tank for

al Consequences of a Pressurized Water Reactor Radioactive Iner 76) Iron and Stee Methods for the Analysis of Sodium and Cover Fuel and Control Assembly Tag

powe/ Calculation of Releases of Radioactive Materials in wastes and Releases of Radioactive Materials in Liquid and ods for Estimating Atmospheric Transport and Dispersion of (1974) $\$ 1.75$

cation Plants (3/73)

Dissolved and

Rec. Practice for Sampling Atmospheres for Analysis of

Design and Construction of Nonmetallic ical Industry Flanges and Threaded Stubs for Use with Lens Sealability of Enveloped Cast Iron

t $1(5-74)$ Stainless Stee

974) 1EEE Std. $301-1970 \$ 3.00$ Standard Test Procedure for

pec for Copper A eprocessing Systems (9/75) nts $(6 / 76)$

and Fuel Fabrication Plants (1/74)

tice for (1973) $\$ 1.75$

ntained in Certain Devices to Be Distributed for Use Under tm E181-1962 \$1.75 tions for Assay, Isotopic Distribution, and 1mpurity Det/
Functional Specification Standard (1975) $\$ 3.00$

Functions in Nuclear Power Generating Stations, Criteri

ANSI

Functions (Safety Guide 22, 2/17/72)

Functions (6/74)

Fundamental Frequencies of Carbon and Graphite Material

Fusion Welds (1973) ASTM E390-1969 \$1.75

Fusion (Arc)-Welded Steel Plate Pipe (Sizes 16 in. and

Fusion-Welded Austenitic Chromium-Nickel Alloy Steel

Fusion-Welded Steel Pipe for Atmospheric and Lower Tem

Fusion-Welded Steel Pipe for High Pressure Service, $\mathrm{Sp}$

Fusion-Welded Unfired Pressure Vessels, Specification

Gage (10-70) Amendment 1 (10-71) /Measurement System

Gallium Oxide Carrier DC Arc Technique, Method for Spec

Gallium Oxide Carrier D-C Arc Technique, Method for Sp

Galvanized Structural Steel Products and Procedure for

Galvanized) Coatings on Products Fabricated from Rolled

Gamma and Electron Radiation Dose with the Ceric Sulfat

Gamma and Electron Radiation Dose with the Ferrous Sulf

Gamma and Electron Radiation Dose with the Ferrous Sulf

Gamma Compensated Ionization Chamber Assembly (Fixed E

Gamma Radiation Dose in the Fricke Dosimeter (1972) \$1.

Gamma Radiation Survey Instruments, Specification of (1

Gamma Radiation (1971) ASTM D2568-1970 \$1.75

Gamma Radiation, Performance, Specification for (1972)

Gamma Radioactivity of Industrial Water and Industrial

Gamma Radioactivity of Water (1973) $\$ 1.75$

Gamma Ray Brachytherapy Sources (1974) $\$ 3.00$

Gamma Ray Protection for Energies Up to $10 \mathrm{MeV}$ Structur

Gamma Ray Protection for Energies Up to $10 \mathrm{Mev}$ : Equipme

Gamma Ray Sources, Energies Up to 10-Mev, General Safe

Gamma Rays (1961) $\$ 2.00$

Measurement

Gamma Spectrometry of Water, Method of Test for ASTM D2

Gamma Spectrometry of Water, Test for (1972) \$1.75

Gamma Tolerant Neutron Detector Tubes (12-75) Supersed

Gamma-Ray Detectors, Test Procedures for (1972) 1EEE S

Gamma-Ray Sources (6/74)

Gamma-Ray Spectrometry (4/74)

Gamma-Ray Spectrometry $(9 / 74)$

Nond NRC

Analyzer in the Tracer Probe Mode (1973) \$1 75

Gas Chromatography Procedures, Recom

Gas Chromatography (1974) \$1.75

Gas Circulation (4-73)

Gas Compressors (8-73)

Gas Concentrations in Containment Following a Loss of $\mathrm{C}$

Gas Containers to Identify the Material Contained, Meth

Gas Cooler (5-72) Amendment 1 (3-73, Amendment 2 (10

Gas Cylinder Valve Outlet and lnlet Connections (1965)

Gas Discharge Tubes (1975) \$2.95 Performance Std

Gas Metal Arc Welding (ASME SFA-5.18 with Additional R

Gas Metal Arc Welding, Specification for (1973) AWS A5.

Gas Metal Arc Welding, Specification for (1974)

Gas Phase Adsorbents for Trapping Radioactive lodine an

Gas Phase Adsorber Cells-Including Amendment 1973 (197

Gas Purchase Specifications (7-72) Amendment 1 (1-75)

Gas Service (11-72) Amendment 1 (1-74)

Gas Storage Tank Failure (Safety Guide 24, 3/23/72)

Gas Valves (5-72) Amendment $1(1-74)$

Gas Welding Rods (1969) \$2.50

Gas (1-76) Supersedes F 3-40T, (1-73) Amendment 1 (5Gas (10-72)

Gaseous and Liquid Effluents from Light-Water-Cooled

Gaseous Effluents from Light-IVater-Cooled Nuclear Pow

Gaseous Effluents in Routine Releases from Light-Water

Gaseous Hydrogen in Water, Standard Method of Tests for

Gases and Vapors in Plutonium Processing and Fuel Fabri

Gases and Vapors (1973) $\$ 1.75$

Gaskets Containment Vessel Airlock (6-72)

Gaskets for Corrosive Service, Practice for (1971) $\$ 1.7$

Gaskets (1968) $\$ 4.00$

Gaskets, Test for (1974) $\$ 1.75$

High Pressure Chem

Gate Valves, Flanged and Threaded Ends (1970) \$4.00

Gate Valves, Manual and Power Operated (3-72) Amendmen

Geiger-Muller Counters (5/73)

Geiger-Muller Counters, Test Procedures for (1969) (R

General Ambient Air Analyzer Procedures (1973T) \$1.75

General Applications (1974) \$1.75

General Design Guide for Ventilation Systems for Fuel R

General Design Guide for Ventilation Systems of Plutoni

General Fire Protection Guide for Fuel Reprocessing Pla

General Fire Protection Guide for Plutonium Processing

General Gas Chromatography Procedures, Recommended Prac

General Information and Regulations (1975) $\$ 6.80$

General Instrumentation (2-72) Amendment 1 (5-73)

General License (Revision 1, 5/75)

Oactive Sources Co

General Methods for Analysis of Radioisotopes (1973) as

General Methods for the Analysis of Uranyl Nitrate Solu
ANSI

ASTM

ASTM

ERDA

ANS1

ASTM

STM

ANSI

ERDA

ASTM

ANSI

ANSI

ANS1

ASTM

NCRP

NCRP

NCRP

ANS1

ANS1

ERDA

ASTM

ASTM

ERDA

ERDA

ANS1

ERDA

ANS

BRH

ERDA

ANS1

ASME

ERDA

IES

ERDA

ERDA

/C NRC

ERDA

AWS

ERDA

ERDA

NRC

NRC

NRC

ASTM

NRC

ASTM

ERDA

ASTM

MSS

ASTM

MSS

ERDA

NRC

ANS1

ASTM

ASTM

NRC

NRC

NRC

ASTM

DOT

ERDA

NRC

ANSI

NRC

N278.

N18.8

RG 1.22

RG 3.22

C747

Z 166.24

A 134

A358

B 125.53

A 155

A 240

RDT C6-3T

Z128.27

A 143

G8.1

K 65.230

K65.220

D2954

RDT C 15-7T

D 1671

N13.4

K65.218

N13.5

N150

D 1690 
Div. I and Div. 2 (1977) bd (\$40.00), Il (\$65.00)

Alloy and Austenitic Alloy Steel Tubes, Specification for Steel Plates for Pressure Vessels, Specification for cal Sealed Gamma-Ray Sources $(6 / 74)$

-Ray and Sealed Gamma Ray Sources, Energies Up to 10-Mev, ed Austenitic Stainless Steel Tubing (Small-Diameter) for Seamless and Welded Austenitic Stainless Steel Tubing for ged or Rolled Steel Pipe Flanges, and Valves and Parts for tions (Revision $1,11 / 75$ )

acilities and Special Nuclcar Materials ( $11 / 73)$

$(6 / 74)$

Performance Stds. for Electronic Products: Acceptance Sampling Procedures for Exempted and Information for Safety Analysis Reports: Internally and Equipment for Water Cooled and Moderated Nuclear Power 1975) $\$ 5.00$

Periodic Testing of Nuclear Power plication of the Single Failure Criterion to Nuclear Power

finitions of Terms Used in IEEE Standards on Nuclear Power

emblies in Containment Structures for Nuclear Fueled Power

c Cables, Field Splices, and Connections for Nuclear Power

$1971 \$ 4.00$ Protection Systems for Nuclear Power

$1974 \$ 4.00 \quad$ Class IE Power Systems for Nuclear Power

systems That Perform Protective Functions in Nuclear Power

smic Qualification of Electric Equipment for Nuclear Power

1 Motors Installed Inside the Containment of Nuclear Power

lectric Equipment During the Construction of Nuclear Power

Units Applied as Standby Power Supplies for Nuclear Power

st of Class I Electrical Valve Operators for Nuclear Power

t Std. for Class 1E Control Switchboards for Nuclear Power sedes E4-1T, (10-69)

ty Guide $9,3 / 10 / 71$ )

Itection of Pressurized W ater Reactor Steam Draft Standard Diesel Sodium Heated Steam on Flux Density and Average Energy from $3 \mathrm{H}(\mathrm{D}, \mathrm{N}) 4 \mathrm{He}$ Neutron lux Density and Average Energy from ${ }^{3} \mathrm{H}(\mathrm{d}, \mathrm{n})^{4} \mathrm{He}$ Neutron Design, Construction, and Use of Radioisotopic Power

Motors and Information for Safety Analysis Reports: Steam Polyphase Induction Motors and er Plants $(8 / 74)$

2) IEEE Std. 325-1971 \$4.00

surements, Part 1: Data Acquisition Sy/ Additional lnformation:

1.75 igh Voltage ASTM C537(R197) Std Spec, for Fully Cured Silicone Rubber Coated ional Requirements) (3-74)

of Fissile Material (1971) ANS-8.3

of Fissile Material (1/73) stm C536-1/ Method of Test for Continuity of Coatings in 537-1 Method of Test for Reliability of Glass Coatings on 2) ures for Photo-Multipliers for Scintillation Counting and 67) $\$ 7.95$

Specification for Nuclear Specification for Nuclear Specification for Nuclear spectrochemical Analysis of (1975) $\$ 1.75$
Heating Elements (1/ Nuccelear ar Grade Plutonium Dioxide Powders and Pellets and Nuclear metric, and Spectrochemical Analysis of (1974) \$/ Nuclear mass Spectrometric, and Spectrochemical Analysis/ Nuclear ass Spectrometric, and Spectrochemical Analysis of Nuclear mass Spectrometric, and Spectrochemical Analysis/ Nuclear Fast Flux Test Facility Ceramic ectrochemical, Nuclear and Radiochemical Analysi/ Nuclear trochemical, Nuclear and Radiochemical Analysis of Nuclear $01-1972 \$ 1.75$

Nuclear Nuclear

tandard Methods for Chemical, Mass Spectrometric, Spectr/ ctrochemical Nuclear and Radiochemical Analysis of Nuclear s/ Chemical, Mass Spectrometric, Spectrochemical, Nuclear c760-1/ Chemical and Spectrochemical Analysis of Nuclear $973 \$ 1.75$ Specification for Nuclear Specification for Nuclear Specification for Nuclear Specification for Nuclear ass Spectrometric, and Spectrochemical Analysis of Nuclear ss Spectrometric, and Spectrochemical Analysis O/ Nuclear Ceramic Nuclear al Analysis of (1975) $\$ 1.75$ ass Spectrometric, and Spectrochemical Analysis of Nuclear ass Spectrometric, and Spectrochemical Analysis of Nuclear
General Provisions (Definitions) (1975) $\$ 2.95$ General Purpose Ball Valves (1970) $\$ 4.00$ General Requirements for Nuclear Power Plant Components General Requirements for (1974A) $\$ 1.75$

General Requirements for (1975) \$1.75

General Safety Standard for Installations Using Nonmedi

General Safety Standard for (1974) NBS Handbook $114 \$ 2$ General Service (1974) ASTM A632-1969 \$1.75

General Service, Specification for (1974) $\$ 1.75$

General Service, Spec. for (1976) $\$ 1.75$

General Site Suitability Criteria for Nuclear Power Sta General Use of Locks in the Protection and Control of $F$ General (1975) \$2.95

Generally Licensed 1tems Containing Byproduct Material Generated Missiles (6/75)

Generating Plants, Fire Protection Criteria For, Issued

Generating Station Protection Systems, Criteria for the

Generating Station Protection Systems, Trial Use

Generating Stations (1972) \$4.00

Generating Stations (1973) IEEE 317-1972 $\$ 3.00$

Generating Stations (1975) IEEE Std. 383-1974 \$4.00

Generating Stations, Criteria for (1972) IEEE Std. 279.

Generating Stations, Criteria for (1975) IEEE Std. 308 -

Generating Stations, Criteria (Issued for Trial Use and

Generating Stations, Guide for (1975) $\$ 5.00$

Generating Stations, Guide For, (1976) 1EEE 334-1971 \$

Generating Stations, Installation, Inspection and Testi

Generating Stations, Trial Use Criteria (1ssued for Tri

Generating Stations, Trial Use Guide (lssued for Trial

Generating Stations, (Trial Guide Issued for Use and Co

Generator for Pressurized Water Reactors (12-71) Super

Generator Set Capacity for Standby Power Supplies (Safe Generator Tubes (Revision 1, 7/75)

Generator Units Applied as Standby Power Supplies for N Generator (2-74), Supersedes E4-16T, (5-72)

Generators by Radioactivation Techniques (1974) ASTM E4 Generators by Radioactivation Techniques, Test for (197 Generators for Certain Land and Sea Applications (3/74) Generators (1972) $\$ 22.50$

Generators (1/75)

Generators, Test Procedure for (1964) $\$ 3.80$

Geography and Demography Considerations for Nuclear Pow Geranium Gamma-Ray Detectors, Test Procedures for (197

Ge(Li) Spectroscopy Systems for Material Protection Mea

Girder Electric Overhead Traveling Cranes (1974) $\$ 3.00$ Glass Cloth Pressure Sensitive Electrical Tape (1973) \$

Glass Coatings on Glassed Steel Reaction Equipment by $\mathrm{H}$

Glass Fabric and Tapes for Electrical Insulation (1969)

Glass Fiber (MIL-F-51079 with Modifications and Addit

Glass Raschig Rings as a Neutron Absorber in Solutions

Glass Raschig Rings as a Neutron Absorber in Solutions

Glassed Steel Equipment by Electrical Testing (R1973) a

Glassed Steel Reaction Equipment by High Voltage ASTM C

Globe and Angle Valves, Manual and Power Operated (3-7

Glossary for Scintillation Counting Field (1972) IEEE S

Glossary of Terms in Nuclear Science and Technology (19

Grade Beryllium Oxide Powder ASTM C708-72a (1973) \$1.7

Grade Beryllium Oxide Powder (1972A) $\$ 1.75$

Grade Boron Carbide Powder (1974) $\$ 1.75$

Grade Boron Carbide, Chemical, Mass Spectrometric, and

Grade Magnesium Oxide as Used in Sheathed Type Electric

Grade Mixed Oxides ( (U, Pu $)$ O $)(5 / 73)$

Nalysis of

Grade Mixed Oxides ( (U,Pu)O(2)), Chemical, Mass Spectro

Grade Mixed Oxides ( $(\mathrm{U}, \mathrm{Pu}) \mathrm{O}(2)$ ), Methods for Chemical,

Grade Plutonium Dioxide Powders and Pellets and Nuclear

Grade Plutonium Dioxide Powders and Pellets, Chemical,

Grade Plutonium Dioxide (6-71)

Grade Plutonium Metal, Chemical, Mass Spectrometric, Sp

Grade Plutonium Metal, Methods for (1974) ASTM C758-19

Grade Plutonium Metal, Specification for (1973) ASTM C7

Grade Plutonium Metal, Spec. for (1972) \$1.75

Grade Plutonium Nitrate Solutions and Plutonium Metal S

Grade Plutonium Nitrate Solutions (1973) \$1.75

Grade Plutonium Nitrate Solutions, Methods for (1974) a

Grade Silver-Cadmium Alloys, Methods for (1974) ASTM

Grade Silver-Indium-Cadmium Alloy (1973) \$1.75

Grade Silver-Indium-Cadmium Alloy (1974) ASTM C752-1

Grade Silver-Indium-Cadmium Alloys (1974) \$1.75

Grade Sinterable Plutonium Dioxide Powder (1974A) $\$ 1.75$

Grade Sinterable Uranium Dioxide Powder (1973) \$1.75

Grade Uranium Dioxide Powders and Pellets (2/9/73)

Grade Uranium Dioxide Powders and Pellets, Chemical, Ma

Grade Uranium Dioxide (6-71) Amendment 1 (12.74)

Grade Uranyl Nitrate Solutions, Nuclear and Radiochemic

Grade (1973) ASTM C696-1972 \$2.00 /Ds for Chemical, M ANSI

Grade (1973) ASTM C697-1972 $\$ 2.00$ /Ds for Chemical, M ANSI
BRH

MSS

ASME

ASTM

ASTM

NRC

ANSI

ASTM

for ASTM

NRC

NRC

BRH

NRC

NRC
ANSI

Ap ANSI

De IEEE

N Ass ANSI

ANS1

ANSI

ANSI

Sei IEEE

ANS1

ANS1

ANS1

ANS1

ERDA

NRC

NRC

ANS1

ERDA

ANSI

ASTM

NRC

NEM

NRC

IEEE

ANSI

NRC

CMAA

ASTM

ANSI

ANSI

NRC

ANS

ANSI

ERDA

ANSI

ASTM

ASTM

ASTM

ASTM

ASTM

ANSI

ASTM

ERDA

ASTM

ANS1

NRC

Spe ASTM

ANSI

ANSI

ASTM

ANS1

ASTM

ASTM

ASTM

NRC

ICFR ! 000A

SP. 72

SEC-111-R

A450

A20

RG 6.5

N543

B 125.49

A269

A 181

RG 4.7

RG 5.12

21CFR 1010

RG 6.6

RG 1.70 .35

N18.10

338

N41.2

380

N45.3

N41.10

N42.7

N41.12

N18.8

344

N4 1.9

N45.2.4

N41.13

N41.6

N41.17

RDT E4-1T

RG 1.9

RG 1.83

N41.13 
$\$ 1.75$

and Platinum 10 Percent Rhodium Wires, Noninsulated, Std.

$53-1973 \$ 1.75$

$57-1974$ a $\$ 1.75$ Water Soluble Chlorides Present as Admixes in Specification for Nuclear Specification for Nuclear Measuring Ground Resistance and Potential Estimating the Average Method of Test for Rockwell Hardness of Fine st for Moisture-Penetration Resistance Relations of Finety and Health Stds. on Projects or Productions Assisted by Particle Size Distribution of Nonmailable Matter: Written, Printed and Logic Diagrams (Two State Devices),

Electrical and Electronics Diagrams, or (19/ Electrical Resistivity of Manufactured Carbon and est for (1973)/ Density in Air of Manufactured Carbon and (1973) ASTM C714-1972/ Thermal Diffusivity of Carbon and 75

Thermal Diffusivity of Carbon and Recommended Practice for Core Sampling of Ii of Elasticity and Fundamental Frequencies of Carbon and Method of Test for Rockwell Hardness of Fine Grained $565-1971 \$ 1.75$

Method of Test for Tensile Stress-Strain of Cor Carbon

Definitions and Terms Relating to Manufactured Carbon and Method of Test for Lubricating Qualities of Thermal Neutron Absorption Cross Section of Nuclear Lattice Spacing of Nuclear Measurement of Lattice Spacing of Nuclear Ash in

75

75
75

.75 Chemical Analysis of Carbon and ng the Thermal Neutron Absorption Cross Section of Nuclear Reporting lrradiation Results on Irradiation Results on Dosimetry Results on Nuclear Delta-In-Hours (DlH) Purity of Nuclear Compressive (Crushing) Strength of Test for Unit Weight, Yield, and Air Content Method of Test for Specific
Method of Test for Specific Method of Test for Specific
Pre Properties of Lubricating Measurement of Extreme Pressure Properties of Lubricating
Flow Properties of Lubricating
Measuring 75 175) for (1962) $\$ 3.60$ Instrumentation and Control Equipment , and Radioactive-Waste-Containing Components/ Quality ection of Prestressed Concrete Containment Structures with ures $(11 / 75)$

11-70) Amendment 1 (7-70)

Qualifications for Cement

ce and Transmittance of Built-Up Sections by Means of the $1971 /$ Thermal Conductivity of Materials by Means of the Thermal Conductivity of Materials by Means of the

evision 1, 4/75) Training, Equipping, and Qualifying of s Corrosion in Austenitic Stainless Steel Components of / ated-Temperature Reactors (Supplement to ASME Section I/ m Mining (1967)

Power Plant $(2 / 76)$

d Plant Protection for an Independent Spent Fuel Storage/ Byproduct Material Licenses (3/76)

ction Plants $(10 / 73)$

ing $(2 / 2 / 73)$

General Fire Protection

reactor Vessels (1974) ASTM E509-74 \$1.75 reactor Vessels (1974) $\$ 1.75$

ar Materials (1973) \$3.50

Administrative Practices in Radiation Monitoring (A

ments Over Radioactive Material Shipments/ al $(6 / 74)$

nts $(6 / 73)$

nts $(1 / 74)$

73) $\$ 1.75$

Liquid Waste Treatment Syste General Fire Protection Rec.

Neutron Activation Detector Materials,

Critical Experiments, Safety

to Process Source Material (7/76)

uclear Material Licenses of Less Than Critical Mass Quan/ Classification of Nuclear Ships, 90 (Published May, 1969) (IEEE Std. 93-1968) \$6.00

50

Administrative tems $(9 / 75)$

nd Fuel Fabrication Plants (8/73)

General Design

General Design

nts for Shipments of Radioactive Material,
ng Ground Resistance and Potential Gradients in the Earth, ng Ground Resistance and Potential Gradients in the Earth,
ermits for Radioactive Materials Shipments, Administrative Selection of Neutron Activation Detector Materials
Grade (8-72) Amendment 1 (11-74)

Graded Aggregate Road Mixes, Method of T Aterials, P Grade, Sinterable Uranium Dioxide Powder (1974) ASTM Grade, Sinterable Uranium Dioxide Powder (1975) ASTM C7 Gradients in the Earth, Guide for (1962) $\$ 3.60$

Grain Size of Metals, Methods for (1974) \$1.75

Grained Graphite Materials (1974) ASTM C748-73 \$1.75 Grained Soils (1972) (ASTM D1558-1971) \$1.75 /D

Grants from National Endowment for the Arts (1975)

Granular Activated Carbon, Test for (1970) \$1.75

Graphic Matter (1975)

Graphic Symbols for (1973) IEEE 91-1973 $\$ 6.00$

Graphic Symbols for (1975) IEEE 315-1975 $\$ 8.00$

Graphite Articles at Room Temperature, Method of Test F

Graphite Articles by Physical Measurements, Method of T

Graphite by a Thermal Pulse Method, Method of Test for

Graphite by a Thermal Pulse Method, Test for (1972) \$1.

Graphite Electrodes, (1974) \$1.75

Graphite Materials by Sonic Resonance (1974) $\$ 1.75$

Graphite Materials (1974) ASTM C748-73 \$1.75

Graphite Mechanical Materials, Methods of (1973) ASTM C

Graphite (1974) ASTM C749-75 \$1.75

Graphite (1975) $\$ 1.75$

Graphites (1964) (R1974) ASTM D1367-1964 (R1973) \$1.75

Graphite, Estimating the (1971) \$1.75

Graphite, Measurement of (1969) (R1975) \$1.75

Graphite, Method for (1973) ASTM C558-1969 \$1.75

Graphite, Method of Test for (1973) ASTM C561-1969 \$1.

Graphite, Method of Test for (1973) ASTM C562-1969 \$1.

Graphite, Method of Test for (1973) ASTM C624-1971 \$1.

Graphite, Method of Test for (1973) ASTM C695-1971T \$1

Graphite, Methods for (1973) ASTM C560-1969 \$1.75

Graphite, Methods for (1973) ASTM C626-1971 \$1.75

Graphite, Practice for (1973) ASTM C625-1972 \$1.75

Graphite, Rec. Practice for Reporting (1972) \$1.75

Graphite, Rec. Practice for Reporting (1974) \$1.75

Graphite, Test for (1971) \$1.75

Graphite, Test for (1975) \$1.75

(Gravimetric) of Concrete (1975) \$1.75

Gravity and Absorption of Coarse Aggregate (1974) ASTM

Gravity and Absorption of Fine Aggregate (1973) \$1.75

Grease (Four Ball Method) (1974) $\$ 1.75$

Greases at High Temperatures, Measurement of (1973) \$1

Ground Resistance and Potential Gradients in the Earth,

Grounding and Sheilding Practices (1/73) Amendment 1

Group Classifications and Standards for Water-, Steam-

Grouted Tendons (11/74) Inservice Insp

Grouting for Prestressing Tendons in Containment Struct

Guard Vessel for Primary Sodium Containing Components

Guarded Hot Box, Method of Test for (1967) (R1973) ASTM

Guarded Hot Plate, Method of Test for (1975) ASTM C177-

Guarded Hot Plate, Test for (1971) \$1.75

Guards and Watchmen (1/74)

Guards for Road Shipment of Special Nuclear Material ( $R$

Guidance for Avoiding Intergranular Corrosion and Stres

Guidance for Construction of Class 1 Components in Elev

Guidance for the Control of Radiation Hazards in Uraniu

Guidance on Being Operator at the Controls of a Nuclear

Guidance on the License Application, Siting, Design, an Guidance to Academic Institutions Applying for Specific Guide for Acceptable Waste Storage Methods at $\mathrm{UF}_{6}$ Produ Guide for Administration Practices in Radiation Monitor Guide for Fuel Reprocessing Plants (6/76)

Guide for in Service Annealing of Water Cooled Nuclear Guide for in Service Annealing of Water Cooled Nuclear Guide for Liability Insurance Aspects of Shipping Nucle Guide for Management) (1969) $\$ 4.25$

Guide for Obtaining Exemptions from Certain NRC Require Guide for Packaging and Transporting Radioactive Materi Guide for Plutonium Processing and Fuel Fabrication Pla Guide for Plutonium Processing and Fuel Fabrication Pla Guide for Preparation of Leak Testing Specification (19 Guide for Selection of (1973) \$1.75

Guide for the Performance of (1975) ANS-1 \$8.00

Guide for the Preparation of Applications for Licenses

Guide for the Preparation of Applications for Special N Guide for the (1962) $\$ 1.00$

Guide for the (1973) ASTM E432-1971 \$1.75

Guide for Transformer Impulse Tests, Appendix to C57.12

Guide for Transporting Radioactive Materials (1973) $\$ 4$

Guide for Ventilation Systems for Fuel Reprocessing Sys

Guide for Ventilation Systems of Plutonium Processing a

Guide for Verifying Compliance with Packaging Requireme

Guide for (1962) \$3.60

Guide for (1973) $\$ 3.00$

/Nt of Transportation Special P

Guide for (1974) ASTM E419-1973 \$1.75
ERDA

ASTM

ANSI

ANSI

IEEE

ASTM

ANS1

ANSI

ASTM

USPS

ANSI

ANSI

ANSI

ANS1

ANS1

ASTM

ASTM

Du ASTM

ANS1

ANSI

ANS1

ASTM

ANSI

ASTM

ANSI

ANSI

ANS1

ANS1

ANS1

ANS1

/Ti ANSI

ANSI

ASTM

ASTM

ASTM

ASTM

ASTM

ANSI

ASTM

ASTM

ASTM

ERDA

NRC

NRC

NRC

ERDA

ANSI

ANSI

ASTM

NRC

NRC

NRC

NRC

EPA

NRC

NRC

NRC

NRC

NRC

NRC

ANS1

ASTM

ANSl

ANS1

NRC

NRC

NRC

NRC

ASTM

ASTM

ANS1

NRC

NRC

ABS

ANSI

ANS1

ANS1

NRC

NRC

ANSI

IEEE

ANS1

RDT C7-7T

D 141

N567

N568

81

E112

K 90.14

A 37.157

29CFR 505

D2862

POSTL 123

Y 32.14

Y 32.2

K90.7

K90.2

K 90.12

C714

C783

C747

K90.14

K90.6 
ar Criticality Safety in the Storage of Fissile Materials Electric Equipment for Nuclear Power Generating Stations, side the Containment of Nuclear Power Generating Stations, switchboards for Nuclear Power Generating Stations, (Trial Nondestructive Assay Systems g Packages for Type a Quantities of Radioactive Materials, uclear Material Control Systems for Conversion Facilities, processing Facilities, Nuclear Material Control Systems ( aterial Control Systems for Fuel Fabrication Facilities (A ng Licenses (2/73) Nuclear Fuel Reprocessing Facilities,

ling Airborne Radioactive Materials in Nuclear Facilities,

operators for Nuclear Power Generating Stations, Trial Use Metric Practic

Cooling and Containment Heat Removal System Pumps (Safety Category 1 Concrete Structures (Revision 1, 1/2/73 Safety ment Lines Penetrating Primary Reactor Containment (Safety ry Containment Liner Welds (Revision 1, 8/11/72, of Safety Thermal Shock to Reactor Pressure Vessels (Safety

c Testing of Protection System Actuation Functions (Safety Onsite Meteorological Programs (Safety water Reactor Radioactive Gas Storage Tank Failure (Safety acility for Boiling and Pressurized Water Reactors (Safet nce Program Requirements (Design and Construction) (Safety Testing of Instrumentation and Electric Equipment (Safety quality Assurance Program Requirements (Operation) (Safet eam Line Break Accident for Boiling Water Reactors (Safety wer Sources and Between Their Distribution Systems (Safety t Accident (Safety Guide 7, 3/10/71) Supplement to (Safety n Containment Following a Loss of Coolant Accident (Safety Generator Set Capacity for Standby Power Supplies (Safet 969) ASTM E290-1968 \$1.75

$0.1971 \$ 1.75$ Methods for SemiMethod for

components at Elevated Temperature (9-74) Supersedes F9/ Cobalt- $\epsilon 0$ and Cesium- 137 Tele therapy Equipment

ograms (1974) ANS $10.3 \$ 8.50$

ntamination (1965)

nd Materials) (1955-1975) $\$ 1.00 \mathrm{ea}$

Fire Protection Specification for Aluminum-Alloy Die and

Aluminum-Alloy Die and Std. Specifications for

aluating the Potential Radiological Consequences of a Fuel

Design Objectives for Highly Radioactive Solid Materia gical Consequences of a Fuel Handling Accident in the Fuel ources Intended for Use in the Production, Processing, and construction/ Packaging, Shipping, Receiving, Storage and uirements for Packaging, Shipping, Receiving, Storage, and

tion Practice for (1975) $\$ 2.50$

(1967) $\$ 4.00$

$\$ 4.00$

(5-72)

$-73)$

$4 \$ 1.75$

Supersedes M8-1T, (2-73) orging Stock for High Tempe ing Stock for High Temperat/ $k$ for High Temperature Serv/ $\mathrm{k}$ for High Temperature Service (ASTM a 637/ Precipitation hape/ Specification for Hot Rolled and Cold Finished Agesme SA-564 with Additional Requirements)/ materials Methods of Test for (1974) \$1.75 ween Brinell Hardness, Vickers Hardness, Rockwe/ Standard for $(1968) \$ 1.75$

C748-73 \$1.75

ters (1974) ASTM EIIO 197/

Scratch

Allo 197 Method of Test for Indentation

E92-1972 \$1.75

74) $\$ 1.75$

Rockwell Hardness and Rockwell Superficial for Indentation Hardness of Metallic Materials by Portable Recommended Practice for Scleroscope ockwell Hardness, Rockwell Superficial Hardness, and Knoop Vickers Hardness, Rockwell Hardness, Rockwell Superficia for Metals (Relationship Between Brinell Hardness, Vickers nship Between Brinell Hardness, Vickers Hardness, Rockwell conversion Tables for Metals (Relationship Between Brinell (1955-1975) $\$ 1.00 \mathrm{ea}$ Zinc Coating (Hot-Dip) on Iron and Stee Hygienic Guides (For Instrument Purging for Reduction of Electrical Instruments in ty of Nuclear Power Plant Control Room During a Postulated
Guide for (1975) ANS-8.7\$12.00

Guide for ( I 975$) \$ 5.00$

Guide For, (1976) IEEE 334-1971 \$4.40

Guide lssued for Use and Comment)

Guide to Calibrating (1975) $\$ 5.75$

Guide to Design and Use of (1975) $\$ 5.00$

Guide to Practice (1971) $\$ 4.50$

Guide to Practice) (1974) \$3.00

Guide to Practice) (1975) $\$ 3.00$

Guide to Principle Design Criteria for (1973) $\$ 5.00$

Guide to the Contents of Applications for Uranium Mill

Guide to (1969) ISO $2889 \$ 7.00$

Guide (Issued for Trial Use and Comment) (IEEE 379

Guide (Issued for Trial Use and Comment) (1974) IEEE 38 Seismic Qualification of IEEE

Guide (1976) ASTM E380-1976 \$1.75

Guide $1,11 / 2 / 70$ )

Guide 10)

Guide $11,3 / 10 / 71$

Guide 19)

Guide 2, 11/2/70)

Tve Suction Head for Emergency Core NRC

IAl (Cadweld) Splices in Reinforcing Bars of NRC

Guide 22, 2/17/72

Guide $23,2 / 17 / 72$ )

Guide $24,3 / 23 / 72$ )

Guide $25,3 / 23 / 72$

Guide $28,6 / 7 / 72$ )

Guide $30,8 / 11 / 72$ )

Guide $33,11 / 3 / 72$

Guide 5, 3/10/71)

Guide $6,3 / 10 / 71$ )

Nondestructive Examination of Prima

/Cal Consequences of a Pressurized NRC

in the Fuel Handling and Storage F NRC

/Irements for the Installation, and NRC

Tween Redundant Standby (Onsite) Po NRC

Guide 7, Backfitting Considerations, 10/27/71

Guide 7,3/10/71)

Guide $9,3 / 10 / 71$ )

(Safety Guide

Guided Bend Test for Ductility of Metallic Materials (1

Guided Bend Test for Ductility of Welds (1973) ASTM E

Guidelines and Procedures for Design of Nuclear System

Guidelines for Maintaining (1974) $\$ 3.50$

Guidelines for Nuclear Power Plants $(6 / 76)$

Guidelines for the Documentation of Digital Computer $\mathrm{Pr}$

Guides for Environmental $\mathrm{Sr}-89, \mathrm{Sr}-90$, and Cs-137 Co

Guides (For Hazard Evaluation of Industrial Chemicals a

Habitability of Nuclear Power Plant Control Room During

Halogen Leak Detectors (Alkali-lon Diode) (1971) $\$ 1.75$

Hand Forgings (1974) ASTM B247-1973 \$1.75

Hand Forgings, Specification for (1974) $\$ 1.75$

Hand Operated Chain Hoists (1974) $\$ 0.50$

Handling Accident in the Fuel Handling and Storage Fac

Handling and Storage Facilities in a Reprocessing Plant

Handling and Storage Facility for Boiling and Pressuriz

Handling of Food (1975) \$6.75/Diation and Ra

Handling of ltems for Water Cooled Nuclear Power Plants

Handling of Radioactive Materials (1964) \$2.00

Handling Radioactive Materials, Recommended Fire Protec

Handling Systems for Nuclear Power Plants (2/76)

Hangers and Supports-Material, Design and Manufacture

Hangers and Supports-Selection and Application (1966)

Hangers, Supports and Snubbers for Liquid Metal Service

Hard Surface for Core Components (5-73) Amendment 1 (9

Hardenability of Steel, Method of (1974) ASTM A255-197

Hardenable Nickel-Chromium-Iron Alloy Springs (5-75)

Hardened Washers, Specification for (1974) \$1.75

Hardening Cobalt Containing Alloy Bars, Forgings, and F

Hardening Iron Base Superalloy Bars, Forgings, and Forg

Hardening Nickel Alloy Bars, Forgings, and Forging Stoc

Hardening Nickel Alloy Bars, Forgings, and Forging Stoc

Hardening Stainless and Heat Resisting Steel Bars and S

Hardening Stainless Steel Bars, Shapes, and Forgings ( $\mathbf{A}$

Hardness and Rockwell Superficial Hardness of Metallic

Hardness Conversion Tables for Metals (Relationship Bet

Hardness of Coarse Aggregate Particles, Method of Test

Hardness of Fine Grained Graphite Materials (1974) ASTM

Hardness of Metallic Materials by Portable Hardness Tes

Hardness of Metallic Materials, Method of Test for ASTM

Hardness of Metallic Materials, Methods of Test for (19

Hardness Testers (1974) ASTM E110 1972 \$1.75

Hardness Testing of Metallic Materials (1972) \$1.75

Hardness) (1973) ASTM E140-1972 \$1.75 /Rs Hardness,
Hardness, and Knoop Hardness) (1973) ASTM E140-1972 \$1

Hardness, Rockwell Hardness, Rockwell Superficial Hardn

Hardness, Rockwell Superficial Hardness, and Knoop Hard

Hardness, Vickers Hardness, Rockwell Hardness, Rockwell

Hardware, Specification for (1973) \$1.75

Hazard Evaluation of Industrial Chemicals and Materials

Hazardous Area Classification (1970) $\$ 3.00$

Hazardous Atmospheres (1960) $\$ 3.00$

Hazardous Chemical Release (6/74) S Installed in ANS Instru NRC

NRC

Periodi NRC

NRC Quality Assura NRC

NRC

7, Backff

N 16.5

344

N41.9

N41.17

N 15.20

N 14.7

N 15.4

N 15.13

N15.9

N101.3

RG 3.5

N13.1

N4l. 2

N41.6

Z210.1

RG 1.1

RG 1.10

RG 1.11

RG 1.19

RG 1.2

RG 1.22

RG 1.23

RG 1.24

RG 1.25

RG 1.28

RG 1.30

RG 1.33

RG 1.5

RG 1.6

RG 1.7

RG 1.7

RG 1.9

Z168.11

Z115.4

RDT F9-5T

N449

RG 1.120

N4 13

FRC7

A-Z

RG 1.78

E427

H 38.8

B247

200

RG 1.25

N305

RG 1.25

2 1CFR 12

N45.2.2

RG 1.38

R30

801

RG I.104

SP-58

SP-69

MSS SP-69 7-6T

$\begin{array}{ll}\text { ERDA } & \text { RDT E7-6T } \\ \text { ERDA } & \text { RDT E6-38T }\end{array}$

ANSI G58.I

ERDA RDT M8-1T

/for ASTM A 325

ANSI G81.46

ANSI G81.45

ANSI G81.44

ERDA RDT M2.18T

ASTM A56

ERDA

ASTM

ANS1

ASTM

ANS!

ANS

ANSI

ASTM

ANSI

ASTM

ANSI

ANSI

ANS

ANS

ASTM

AIHA

ISA

ISA

/Ting the Habitabili NRC

RDT M7-6T

E] 8

Z76.4

C235

K90.14

Z115.9

Z11 15.7 
Commodity List of Guidance for the Control of Radiation Safety Color Code for Marking Physical moval System Pumps (Safety Guide 1/ Net Positive Suction plug and Closure Cap for Penetrations LMFBR Reactor Vessel Std. Spec. for Carbon Steel Forgings for Seamless Drums, t. Through 1961 (1962)

nts from National Endowment for the Arts (197/

Safety and 1973) $\$ 1.75$ Chemical Analysis of Steel, Cast Iron, Open3, Amendment $2(10-73)$

des E4-6T, (1-72), Amendment 1 (1-72)

1)

Intermediate Air Cooled ss and Welded Carbon, Ferritic, and Austenitic Alloy Steel tenitic Alloy Steel Boiler, (1974B) 1.75 Superheater, and Seamless Nickel and Nickel Alloy Condenser and 2 (12-72), Amendment 3 (11-73). Amendme/ Sodium to Air Aluminum-Alloy Drawn Seamless Tubes for Condensers and elded Titanium and Titanium Alloy Tubes for Condensers and (1974A) \$1./ Welded Austenitic Steel Boiler, Superheater, tube $(6-73)$

tube $(7-71)$

Thermal Conductivity of Materials by Means of the (ASTM C312-1955) \$1.75 75 Mean Specific Mean Specific

ve Suction Head for Emergency Core Cooling and Containment elted 1750F (954.4C) Alloy Tubing, Seamless, Corrosion and $0.90 \mathrm{Ti}-0.1 \quad$ Alloy Sheet, Strip, and Plate, Corrosion and $0.90 \mathrm{Ti}-0 . /$ Alloy Sheet, Strip, and Plate, Corrosion and Spec, for Alloy Bars, Forgings, and Rings, Corrosion and duction Melted 195/ Alloy Tubing (Seamless, Corrosion and specification for (1975) \$1.75 Stainless and sheet, and Strip for Fusion-Welded Unfired Pressure Ves/ Strip, Specification for (1974) $\$ 1.75$ and Other Pressure Vess/ Specification for Stainless and

Stainless and Hot Rolled and Cold Finished Age-Hardening Stainless and Std. Spec. for Stainless and Test for Leaks in

Test for Water Vapor Transmission of Flexible Ultimate

for (1975) $\$ 1.75$ Pressure Vessel Plates, trode or Vacuum Induction Melted $1750 \mathrm{~F}$ (954.4 C) Solution trode or Vacuum Induction Melted 1750 F (954.4 C) Solution 1 Consumable Electrode or Vacuum Induction Melted Solution d High Temperature Thermal Insulation Subjected to Soaking 72) ting Procedure for Mathematical Models Selected to Predic $\begin{array}{lr}\text { Water Reactors (5-72) Supersedes E5-2T/ } & \text { Electric } \\ \text { Metal Sheathed, Mineral-Insulated Electrical Resistance }\end{array}$ Electric

) ASTM / Specification for Sheathed Electrical Resistance ification for (1971) $\$ 1.7 / \quad$ Sheathed Electrical Resistance Recommended Rules for Care and Operation of

al Grade Magnesium Oxide as Used in Sheathed Type Electric $71 \$ 1.75$

tm E186-1973 $\$ 1.75$

stm E280-1972 \$1.75

i $211.1-1974 \$ 2.75$

rings (5-75) Supersedes M 8-1T, (2-73)

nts $(2-72)$

ifications and Additional Requirements) (3-74)

-74)

Ultrasonic Examination of

Reference Radiographs for

Reference Radiographs for

Proportions for Normal and

Mass Spectrometer

High Temperature Electrical Connectors and Square and
Uranium

the Measurement of Uranium Tetrafluoride $\left(U_{4}\right)$ and Uranium Accountability of Uranium

ical, Nuclear and Radiochemical, Analysis of (19/ Uranium trochemical, Nuclear and Radiochemical Analysis of Uranium (5-76) Supersedes E6-20T, /

Austenitic Stainless Steel eratures, $\mathrm{Spec}$ Centrifugally Cast Iron-Chromium-Nickel ndment 1973 (1972) $\$ 2.00$

2.00

Sheilding for

ession Set Induced in Vulcanized Rubber During Exposure to ession Set Induced in Vulcanized Rubber During Exposure to etallic Materials, Practice for (1973) ASTM E/ etallic Materials, Rec. Practice for (1962) (/

Effects of etallic Materials, Rec. P
D1672-1966 (1971) \$1

Effects of $1970 \$ 1.75$

Exposure of Polymeric Materials to $\$ 1.75$ in Chemical Reactivity of Inorganic Material Exposed to Exposure of Polymeric Materials to rometry $(9 / 74)$
Hazardous Materials (1975) $\$ 6.80$

Hazards in Uranium Mining (1967)

Hazards (1971) $\$ 3.00$

Head for Emergency Core Cooling and Containment Heat Re Head (4-73) Amendment $1(1.74)$

Health Implications of Fallout from Nuclear Weapons Tes

Health Stds. for Federal Supply Contracts (1975) \$3.25

Health Stds. on Projects or Productions Assisted by Gra

Hearth Iron, and Wrought Iron (1975) \$1.75

Heat Exchanger and Condenser Tubes, Specification for (

Heat Exchanger for Gas Cooler (5-72) Amendment 1 (3-7

Heaî Exchanger for Liquid Metal Systems (5-74) Superse

Heat Exchanger for Nuclear Steam Supplied Systems (3-7

Heat Exchanger Tubes with Integral Fins, Specification

Heat Exchanger Tubes, Specification for
Heat Exchanger Tubes, Specification for (1974) $\$ 1.75$

Heat Exchanger (6-71), Amendment 1 (10-71), Amendment

Heat Exchangers, Specification for (1974) ASTM B234 197

Heat Exchangers, Specification for (1974) $\$ 1.75$

Heat Exchanger, and Condenser Tubes, Specification for

Heat Exchanger, Class 1, Water to Water, Straight or U

Heat Exchanger, Class 2, Water to Water, Straight or U

Heat Flow Meter, Test for (1970) \$1.75

Heat of Thermal Insulation, Practice for (1963) (R 1975)

Heat of Thermal Insulation, Test for (1961) (R1973) \$1.

Heat Removal System Pumps (Safety Guide 1, 11/2/70)

Heat Resistant Nickel Base-19Cr-3.1Mo-5.1 (Cb \& Ta)-

Heat Resistant Nickel Base-19Cr-3.1 Mo-5.1 (Cb \& Ta)

Heat Resistant Nickel Base-19Cr-3.1Mo-5.1 (Cb \& Ta)-

Heat Resistant Nickel Base-19Cr-3.1Mo-5 1 ( Cb+Ta)-0

Heat Resistant Nickel Consumable Electrode or Vacuum in

Heat Resisting Chromium Steel Plate, Sheet, and Strip,

Heat Resisting Chromium-Nickel Stainless Steel Plate,

Heat Resisting Chromium-Nickel Steel Plate, Sheet, and

Heat Resisting Steel Bars and Shapes for Use in Boilers

Heat Resisting Steel Bars and Shapes (1974) \$1.75

Heat Resisting Steel Forgings (1975) \$1.75

Heat Sealed Flexible Packages (1972) \$1.75

Heat Sealed Packages for Dry Products (1972) \$1.75

Heat Sink for Nuclear Power Plants (Revision 2, 1/76)

Heat Treated Carbon-Manganese-Silicon, Specification

Heat Treated (1973) SAE AMS 5596C-1968 \$3.00

Heat Treated (1973) SAE AMS 5662C-1972 \$3.00

Heat Treated (1975) \$3.00

$-5.1(\mathrm{Cb}+\mathrm{Ta}) 0$

Heat (1963) (R 1969) ASTM C356-1960 (1967) \$1.75

Heated Effluent Dispersion in Natural Water Bodies $(5 / 7$

Heated Steam Generator (2-74), Supersedes E4-16T, (5

Heater (3-75) Supersedes P4-3T, $(2-74)$

Heaters: Simulated LMFBR Fuel Pins (3-72)

Heaters, for Nuclear or Other Specialized Service (1973

Heaters, for Nuclear or Other Specialized Service, Spec

Heating Boilers (1977) bd $(\$ 25.00), 11(\$ 30.00)$

Heating Boilers $(1977)$ bd $(\$ 50.00)$, Il $(\$ 70.00)$

Heating Elements (1970) $\$ 1.75$

D Life Test of Electric

Heavy Steel Forgings, Practice for (1973) ASTM A 388-19

Heavy Walled ( 2 to $4-1 / 2$ in.) Steel Castings (1974) as

Heavy Walled (4-1/2 to 12 in.) Steel Castings (1973) a

Heavy Weight Concrete, Practice for Selecting (1974) Ac

Helical Age-Hardenable Nickel-Chromium-Iron Alloy Sp

Helium Leak Detection for Instruments and Small Compone

HEPA Filter Medium, Glass Fiber (MIL-F-51079 with Mod

HEPA Filters (AACC CSI with Additional Requirements) ( 8

HEPA Filters (1968) \$1.50

Hermetic Seals (3-70)

Hex Nuts (1972) $\$ 4.50$

Hexafluoride for Transport, Packaging of (1971) $\$ 6.75$

Hexafluoride $\left(U_{6}\right)$ 2/2/73)

Rd Analytical

exafluoride, Analytical Procedures for (1972) $\$ 4.50$

Hexafluoride, Chemical, Mass Spectrometric, Spectrochem

Hexafluoride, Methods for (1974) ASTM C 761-1973 \$1.75

Hexagonal Duct Tubes for Core Components and Assemblies

High Alloy Tubing for Pressure Application at High Temp

High Efficiency Gas Phase Adsorber Cells-Including Ame

High Energy Electron Accelerator Installations (1964) \$

High Energy Nuclear Radiation, Methods of Test for (197

High Energy Nuclear Radiation, Testing (1968) (R1974) \$

High Energy Radiation on the Mechanical Properties of $M$

High Energy Radiation on the Mechanical Properties of $M$

High Energy Radiation, Practice for (1968) (R 1973) ASTM

High Energy Radiation, Practice for (1973) ASTM D 1879.

High Energy Radiation, Rec. Practice for Determining (1

High Energy Radiation, Rec. Practice for (1966) (R 1971)

High Energy Radiation, Rec. Practice for (1970) \$1.75

High Enrichment Uranium Fuel Plates by Gamma-Ray Spect
DOT

EPA

ANS 1

ERDA

ANSI

EPA

DOL

ASTM

ASTM

ERDA

ERDA

ERDA

ASTM

ASTM

ASTM

RDA

ANSI

ASTM

ASTM

ERDA

ERDA

ASTM

ANSI

NRC

ANSI

ANS!

ANS!

ANSI

ASTM

ASTM

ASTM

ASTM

for ASTM

ASTM

ASTM

ASTM

NRC

ASTM

Elec ANSI

ANSI

SAE

ANSI

NRC

ERDA

ERDA

ERDA

ER DA

ANSI

ASTM

ASME

ASME

ASTM

ANS1

ANSI

ANSI

ANSI

ERDA

ERDA

ERDA

ERDA

IES

ERDA

ANSI

ANSI

NRC

ANSI

ASTM

ANSI

ERDA

ANS

IES

NCR P

ANSI

ASTM

ANSI

ASTM

ANSI

ANSI

ASTM

ASTM

ASTM

NRC

49CFR 172

FRC 8

Z53.I

RG 1.

RDT E2-4T

G55.1

FRC3

41CFR 50

29CFR 505

E30

A 179

RDT E4-20T

RDT E4-6I 
Powered Industrial Trucks Low Lift and 4 with Additional Requi/ Alloy Stccl Nuts for Bolting for ubs for Use with Lens Gaskets (1968) \$4.00

Electric-Fusion-Welded Steel Pipe for ucts, Specification for (R1973) ASTM A385-196/ Providin Thermocouples, Sheathed, Type K for Nuclear or for Othe Thermocouples, Sheathed, Type K, for Nuclear or for Othe al Service $(5-74)$ ing Suitable Nuts and Plain Hardened Washers, Specificat/ Sharp-Notch Tension Testing of

SA-453 with Additional Requirements) (8-75) Supersede/ cific/ Steel Sheet and Strip. Hot Rollcd and Cold Rolled, (1974A) \$1.75 Pressure Vesscl Plates, Alloy Steel, dditional Requirements) (8-75) Supersede/ High Strength, for $(1974) \$ 1.75$ Testing of Is $(3-70)$

cal Tape (1973) $\$ 1.75$

Seamless Austenitic Steel Pipe for

service (3-71) Amendment 1 (5-71); Su/

Std. Spec. for Nak Transmission requirements) (2-75) S/ Alloy Steel Bolting Material for requi/ Alloy Steel Nuts for Bolting for High Pressure and rdening Nickel Alloy Bars, Forgings, and Forging Stock for rdening Nickel Alloy Bars, Forgings, and Forging Stock fo iron Base Superalloy Bars, Forgings, and Forging Stock for alt Containing Alloy Bars, Forgings, and Forging Stock for 75 n-Welded Austenitic Chromium-Nickel Alloy Steel Pipe for Ferritic Alloy Steel Forged and Bored Pipe for stenitic Chromium Nickel Alloy Steel Pipe for Corrosive or $\begin{array}{ll}5 & \text { Centrifugally Cast Ferritic Alloy Steel Pipe for } \\ 5 & \text { Austenitic Steel Forged and Bored Pipe for } \\ 5 & \text { Centrifugally Cast Austenitic Stcel Pipe for }\end{array}$

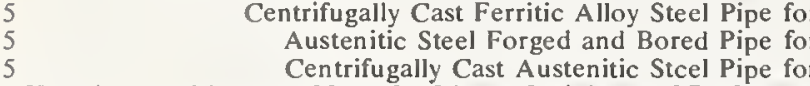

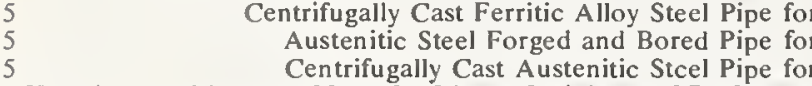
g Heat / Method of Test for Linear Shrinkage of Preformed (1963) (R 1969) ASTM C411-19/ Hot Surface Performance of Flow Properties of Lubricating Greases at mium-Nickel High Alloy Tubing for Pressure Application at ar lron, Nickel, and Cobalt-Base Alloys, Chemical Analy/ (4-73) c 612 with Additional Thermal Insulation, Flexible or Molded, 1970) $\$ 4.00$ $\$ 3.00$

of Glass Coatings on Glassed Steel Reaction Equipment by pressure Vessel Plates, Carbon Steel for Intermediate-and facilities in a Reprocessing Plant/ Design Objectives for

Equipment (8-72) Amendment 1 (10-72), Amendment 2 (7Std. Specifications for Electric Chain Std. Specifications for Hand Operated Chain Std. Specifications for Manually Lever Operated Chain Std. Specifications for Electric Wire Rope zed Bed Op/ Process $\mathrm{Q} /$ t Process /

Design Considerations for Minimizing Residual Design Considerations for Minimizing Residua Design Considerations for Minimizing Residua In Situ Assay of Plutonium Residual

In Situ Assay of Enriched Uranium Residual Determination of Fuel Pellet termination of a Figure of Merit for $\mathrm{PuO}_{2}-\mathrm{UO}_{2}$ Fuel Pellet ications (1974) ASTM A627-1968 \$1.75

ugal Pump (2-72) Amendment 1 (5-74)

ransmittance of Built-Up Sections by Means of the Guarded ure for Detecting / Safeguarding Against Embrittlement of ed, and Forged Steel Shapes, Plates, Bars and Strip, Zinc

Thermal Conductivity of Materials by Means of the Guarded

Thermal Conductivity of Materials by Means of the Guarded Std. Spec. for Copper and Copper Alloy Die Forgings Specification for 75 Specification fo nd Heat Resisting Steel Bars and Shape/

loy Bars, Rod and Wire for Nuclear Application, Specific loy Bars, Rod and Wire for Nuclear App/ Specification for lumbium and/or Vanadium, Specific/ Steel Sheet and Strip, $72 \$ 2.50$

73) ASTM A385-196/ Providing High Quality Zinc Coatings r (1974) ASTM A386-1973 \$1.75 (1973) $\$ 1.75$

for (1973) ASTM C624-1971 \$1.75

$\$ 1.75$

ower Plants (1973) $\$ 4.00$

r Plants $(3 / 16 / 73)$

cimens), Test for (1973) $\$ 1.75$

.75

ent, Specification for (1970) \$1.75 Mineral Fiber

Zinc-Coatin

Delta-In-

Delta-In-
High Lift, Safety Std. for ( 1975) $\$ 6.50$

High Pressure and High Temperature Scrvice (ASME SA-19

High Pressure Chcmical Industry Flanges and Threaded St

High Pressure Service, Specification for (1975) \$1.75

High Quality Zinc Coatings (Hot-Dip) on Assembled Prod

High Reliability Applications, Specification for (1967)

High Reliability Applications, Specification for (1973)

High Strength Alloys for Core Components for Liquid Met

High Strength Bolts for Structural Steel Joints, Includ

High Strength Sheet Materials (1973) \$1.75

High Strength, High Tempcrature Bolting Materials (ASME

High Strength, Low Alloy Columbium and/or Vanadium, Spe

High Strength, Quenched and Tempered, Specification for

High Temperature Bolting Materials (ASME SA-453 with a

High Temperature Cable for Nuclear Detectors (8-71)

High Temperature Central Station Service, Specification

High Temperature Electrical Connectors and Hermetic Sea

High Temperature Glass Cloth Pressure Sensitive Electri

High Temperature Prcssure Transmitter for Liquid Metal

High Temperature Service Specification for (1975) \$1.75

High Temperature Service (ASME SA-193 with Additional

High Temperature Service (ASME SA-194 with Additional

High Temperature Service (ASTM a 637 with Additional Re

High Temperature Service (1973) ASTM A637-1970 \$1.75

High Temperature Service (1973) ASTM A638-1970\$1.75

High Temperature Service (1973) ASTM A639-1970 \$1.75

High Temperature Service, Specification for (1974A) \$1.

High Temperature Service, Specification for (1975) \$1.7

High Temperature Service, Specification for (1975) \$1.7

High Temperature Service, Specification for (1975) \$1.7

High Temperature Service, Specification for (1975) \$1.7

High Temperature Service, Specification for (1975) $\$ 1.7$

High Temperature Service, Specification for (1975) \$1.7

High Temperature Thermal Insulation Subjected to Soakin

High Temperature Thermal Insulation, Method of Test for

High Temperatures, Measurement of (1973) $\$ 1.75$

High Temperatures, Specification for (1973) ASTM A608

High Temperature, Electrical, Magnetic, and Other Simil

High Temperature, Low Conductivity (5-72) Amendment

High Temperature, Rigid, Flexible and Loose Fill (ASTM

High Test Wrought Welding Fittings, Specification for

High Voltage ASTM C537-72 (1973) \$1.75 Jor

High Voltage Connectors for Nuclear Instruments (1971)

Higher-Temperaturc Service, Specification for (1974B)

Highly Radioactive Solid Material Handling and Storage

Highway Regulations (1975) $\$ 6.80$

Hoisting and Rigging of Critical Components and Related

Hoists (1971) $\$ 0.50$

Hoists (1974) $\$ 0.50$

Hoists (1974) $\$ 0.50$

Hoists (1974) \$3.00

Holdup of Special Nuclear Material in Drying and Fluidi

Holdup of Special Nuclear Material in Equipment for Dry

Holdup of Special Nuclear Materials in Equipment for We

Holdup (5/74)

Holdup (8/74)

Homogeneity by Alpha-Autoradiography (5-75)

Homogeneity by Use of an Electron Microprobe (9-72)

Homogeneous Tool Resisting Steel Bars for Security App

Horizontal, Electric Motor Driven, Single Stage Centrif

Hot Box, Method of Test for (1967) (R1973) ASTM C236-1

Hot Dip Galvanized Structural Steel Products and Proced

(Hot Galvanized) Coatings on Products Fabricated from Ro

Hot Plate, Method of Test for (1975) ASTM C177-1971 \$1

Hot Plate, Test for (1971) $\$ 1.75$

(Hot Pressed) (1974) \$1.75

Hot Rolled Alloy Steel Bars (1976) ASTM A322-1975 \$1.

Hot Rolled and Cold Finished Age-Hardening Stainless a

Hot Rolled and Cold Finished Zirconium and Zirconium Al

Hot Rolled and Cold Finished Zirconium and Zirconium A

Hot Rolled and Cold Rolled, High Strength, Low Alloy Co

Hot Surface Performance of High Temperature Thermal Ins

Hot Weather Concreting, Practice for (1972) ACI 305-19

(Hot-Dip) on Assembled Products, Specification for (R19

(Hot-Dip) on Assembled Steel Products, Specification Fo

(Hot-Dip) on Iron and Steel Hardware, Specification for

(DIH) Purity of Nuclear Graphite, Method of Test

Housekeeping During the Construction Phase of Nuclear P

Housekeeping Requirements for Water Cooled Nuclear Powe

Hydraulic Cement by Vicat Needle, Test for (1974) $\$ 1.75$

Hydraulic Cement Mortars (Using 2-in (50-mm) Cube Spe

Hydraulic Cement, Methods for (1970) ASTM C114-1969 \$

Hydraulic-Setting Thermal Insulating and Finishing Cem

Hydraulic-Setting Thermal Insulating and Finishing Cem

Hydrazine in Water, Test for (1972) \$1.75
ANSI

ERDA

MSS

ASTM

ANSI

ASTM

ANS1

ERDA

ASTM

ASTM

ERDA

ANSI

ASTM

ERDA

ERDA

ASTM

ERDA

ASTM

ERDA

ASTM

ERDA

ERDA

ERDA

ANSI

ANSI

ANS1

ASTM

ASTM

ASTM

ASTM

ASTM

ASTM

ASTM

ANSI

ANSI

ASTM

ANSI

ASTM

ERDA

ERDA

MSS

ANS

ANSI

ASTM

ANS1

DOT

ERDA

HMI

HMI

HMI

HMI

NRC

NRC

NRC

NRC

ERDA

ERDA

ANSI

ERDA

ANSI

A STM

ANSI

ANSI

ASTM

ASTM

ANSI

ASTM

ANSI

ASTM

ANS

ANS

ANSI

ANSI

ANSI

ASTM

ANS1

ASTM

ANS

NRC

ASTM

ASTM

ANSI

ASTM

ERDA

ASTM

B56. I

T M6-4T

P-65

G8.17

E235

N142

RDT E6-40T

A 325

E338

RDT M6-6T

G24.32

A5 17

RDT M6-6T

RDT F3.39T

A 376

RDT C17-1 T

D2754

RDT C6-1 T

A 106

RDT M6-3T

RDT M6-4T

RDT M2-18T

G81.44 
$\$ 1.75$

$72)$
1.75

evision $1,1 / 75$ )

Hydrocarbons (Askarels) by Refluxing (1972) \$1/

in Chlorinated Aromatic Dissolved and Gaseous Oxygen-
Test for emicals and Materials) (1955-1975) $\$ 1.00$ ea.

e for the (1975) $\$ 3.00$

organisms and Microscopic Matter in Water and Waste Water, Fuel Assembly Instrumentation Symbols and

llations Where Radiation Exposure May Occur (1967 pulsed Longitudinal Waves (1974/ Recommended Practice for 1972) $\$ 1.75$

Total

Shipping Containers, Incline Notched Bar Test for

Tube Method (1972) $\$ 1.75$

Health
Hese of ugh $1961(1962)$

a) $\$ 1.75$

69) (IEEE Std. 93-1968) $\$ 6.00$

Test for Consuption $\quad$ Guide for Transformer Test for Consumption of Potassium Permanganate by
) ASTM D2033-1/ Consumption of Potassium Permanganate by hod of Test for (1970) ASTM C87-1969/ Effect of Organic

orced Circulation Cold Trap Assembly for Removal of Sodium yl Nitrate Solutions for Assay, Isotopic Distribution, and Intrinsically Safe and Non Shipping Containers,

Determining
Method of Test for

974) $\$ 1.75$

hardness Testers (1974) ASTM E $110197 /$ Method of Test for ources and Between Their Distribution Systems (Safety Gu/

e Application, Siting, Design, and Plant Protection for an Significant in Specified Limiting Values, Recommended P/ for (1969) (R1973) ASTM E125-1963 \$1./ Magnetic Particle $\mathrm{t},(8-71)$

ation, Performance, Specification For/ Plugging Temperature
Direct Reading and Direct Reading and
Direct-Reading and

Specification for Nuclear Grade SilverSpecification for Nuclear Grade Silverical and Spectrochemical Analysis of Nuclear Grade SilverAssessment of the Assumption of Normality (Employing Assessment of the Assumption of Normality (Employing ) $\$ 1.75$ Test for Load Settlement Relationship for Visual Surveillance of

by the Reflection Method, Using Pulsed LongitudinaI Waves ergy Nuclear Radiation, Methods of Test / Compression Set ergy Nuclear Radiation, Testing (1968) (/ Compression Set

$5.1(\mathrm{Cb}+\mathrm{Ta})$ 0.90Ti-0.50A 1 Consumable Electrode or Vacuum ta)-0.90Ti-0.50Al-19-Fe Consumable Electrode or Vacuum 1 (Cb \& Ta)-0.90Ti-0.50A 1 Consumable Electrode or Vacuum Corrosion and Heat Resis/ Consumable Electrode or Vacuum

1 (Cb \& Ta)-0.90Ti-0.50A l Consumable Electrode or Vacuum $\mathrm{n}$ and Heat Resistant Nickel Consumable Electrode or Vacuum 64) $\$ 3.80$

tal (3-75) Supersedes C5-1T, (4-70)

Polyphase

sure Measurement System, Flush Mounted, Eddy Current Type, ea.

Hygienic Guides (For Hazard Evaluation of

ccur (1967) \$3.25 Immediate Evacuation Signal for Use in 0

Chemical Analysis of Protection of Nuclear Plants Against s-3.3) $\$ 10.00$

or $(1975) \$ 6.50$ Information for Safety Analysis Reports:

e, 13th Edition (1974) $\$ 5.00$

Requirements for Fixed Powered

) ASTM D1690/

D2334-1968 /

Gamma Radioactivity of Industrial Water and Radioactive Barium in Industrial Water and Radioactive Iodine in Industrial Water and Radioactive Barium in Industrial Water and Radioactive lodine in Industrial Water and Measurement of (1973) ASTM D1690/ Gamma Radioactivity of test for (1973) ASTM D2038-1968 \$/ Test for (1973) ASTM D2334-1968/ 1974) $\$ 1.75$

(1973) $\$ 1.75$
Radioactive Barium in Radioactive Iodine in Radioactive Barium in
Hydrocarbons (Askarels) by Refluxing (1972) \$1.75

Hydrogen in Water, Standard Method of Tests for (1974)

Hydrogen Meter Module for Service in Liquid Sodium (1 -

Hydrogen Permeability of Rubber Coated Fabrics (1973) \$ Hydrologic Engineering (1/75)

Hydrological Considerations for Nuclear Power Plants ( $R$ Hydrolyzable Chlorine Compounds in Chlorinated Aromatic Hydrostatic Testing of Steel Valves (1961) $\$ 3.00$ Hygienic Guides (For Hazard Evaluation of Industrial $\mathrm{Ch}$ Identification Markings ( $1 / 74$ )

Identification of Piping Systems by Color Coding, Schem Identification of (1974) $\$ 1.75$

Identification (1972) ANS-13.8 \$5.00

Identification (1975) $\$ 7.00$

Immediate Evacuation Signal for Use in Industrial Insta Immediate Evacuation Signal (2/16/73)

Immersed Ultrasonic Testing by Reflection Method Using Immersion Corrosion Test for Soak Tank Metal Cleaners ( Impact Test for (1973) $\$ 1.75$

Impact Testing of Metallic Materials (1972) \$1.75

Impedance and Absorption of Acoustical Materials by the

Implementing Appendix I (5/76)

Implications of Fallout from Nuclear Weapons Test. Thro

Importation of Electronic Products (1975) \$2.95

Improved Transition Properties, Specification for (1974

Impulse Tests, Appendix to C57.12.90 (Published May, 19

Impurities in Deuterium Oxide (1973) \$1.75

Impurities in Deuterium Oxide, Method of Test for $(1973$

Impurities in Fine Aggregate on Strength of Mortar, Met

Impurities in Sand for Concrete, Test for (1973) $\$ 1.75$

Impurities (1-76) Supersedes E4-5T, (12-70)

Impurity Determinations (12/74)

Incendive Electrical Instruments (1965) $\$ 5.00$

Incline Impact Test for (1973) \$1.75

Inclusion Content of Steel, Recommended Practice for (1 Indentation Hardness of Metallic Materials by Portable Independence Between Redundant Standby (Onsite) Power S Independendence of Electric Systems (Revision 1, 1/75)

Independent Spent Fuel Storage Installation (12/74)

Indicating Which Places of Figures Are to Be Considered Indication for Nuclear Power Plant Safety Systems (5/73

Indications on Ferrous Castings, Reference Photographs

Indicator Assembly for Sodium Service Supersedes E4-19

Indirect Reading Pocket Dosimeters for $X$ and Gamma Radi

Indirect-Reading Pocket Dosimeters (2/26/73)

Indium-Cadmium Alloy (1973) \$1.75

Indium-Cadmium Alloy (1974) ASTM C752-1973 \$1.75

Indium-Cadmium Alloys (1974) \$1.75

Individual Observed Values) (1974) $\$ 4.00$

Individual Observed Values) (4/74)

Individual Vertical Piles Under Static Axial Load (1974

Individuals in Material Access Areas (11/73)

Induced by Direct Contact, Practice for (1969) (R1973)

Induced in Vulcanized Rubber During Exposure to High En

Induced in Vulcanized Rubber During Exposure to High En Induction Melted Solution Heat Treated (1975) $\$ 3.00$

Induction Melted 1750 F (954.4 C) Solution Heat Treated

Induction Melted 1750 F (954.4 C) Solution Heat Treated Induction Melted 1750F (954.4C) Alloy Tubing, Seamless, Induction Melted $1950 \mathrm{~F}$ (1065.6 C) Solution Treated (19 Induction Melted 1950 F (i065.6C) Solution Treated (197 Induction Motors and Generators, Test Procedure for (19 Inductive Level Measurement Sensor for Use in Liquid Me Inductive, Absolute or Gage (10-70) Amendment 1 (10-7

Industrial Chemicals and Materials) (1955-1975) $\$ 1.00$

Industrial Controls and Systems (1970) $\$ 16.00$

Industrial Installations Where Radiation Exposure May O Industrial Laminated Thermosetting Products (1971) \$9.5 Industrial Lighting, Rec. Practice for (1973) $\$ 4.00$

Industrial Metal Cleaning Compositions (1971) \$1.75

Industrial Sabotage (Revision I, 6/73)

Industrial Security for Nuclear Power Plants (12/74)

Industrial Security for Nuclear Power Plants (1973) (An

Industrial Stairs (1968) $\$ 2.75$

Industrial Trucks Low Lift and High Lift, Safety Std. F Industrial Ventilation: a Manual of Recommended Practic Industrial Waste Water, Method for Measurement of (1973 Industrial Waste Water, Method of Test for (1973) ASTM Industrial Waste Water, Methods of Test for (1973) ASTM Industrial Waste Water, Test for (1974) \$1.75 Industrial Waste Water, Tests for (1973) \$1.75

Industrial Water and Industrial Waste Water, Method for Industrial Water and Industrial Waste Water, Method of Industrial Water and Industrial Waste Water, Methods of Industrial Water and Industrial Waste Water, Test for ( Industrial Water and Industrial Waste Water, Tests for $\begin{array}{rrr}\text { TT F } & \text { ASTM } & \text { D2441 } \\ \text { ASTM } & \text { D1588 }\end{array}$

ERDA

ASTM

NRC

NRC

ASTM

MSS

AIHA

NRC

ANSI

ASTM

ANSI

ISA

ANSI

NRC

ASTM

ASTM

ASTM

ASTM

ASTM

NRC

EPA

BRH

ASTM

ANSI

ASTM

ANSI

ANSI

ASTM

ERDA

NRC

ISA

ASTM

ASTM

ANSI

NRC

NRC

/S NRC

ASTM

NRC

ANSI

ERDA

ANSI

NRC

ASTM

ANSI

Chem ASTM

ANSI

NRC

ASTM

NRC

ANSI

ANSI

ASTM

SAE

ANSI

ANSI

ANSI

ANSI

ANSI

IEEE

ERDA

AIHA

NEMA

ANSI

NEMA

ANS1

ASTM

NRC

NRC

ANSI

ANSI

ANSI

ACGIH

ANSI

ANS1

ANS1

ASTM

ASTM

ANS

ANSI

ANSI

ASTM

ASTM

D8 15

D2441

SP-61

A-Z

RG 5.17

A 13.1

D 1128

N18.3

S 5.1

N2. 3

RG 8.5

E2 14

D 1280

D 880

E23

C384

RG 1.113

RDT E8-137

RG 1.70 .17

RG 1.70.1 
74)

askets (1968) $\$ 4.00$

Additional Information: Nearby High Pressure Chemical Protective Coatings (Paints) for the Nuclear

General

Reporting of Operating $6 / 75$

ning $(12 / 74)$

design of Mechanical and Electrical Equipment Qualificat/ $\operatorname{sign}(5 / 75)$

ineering ( $1 / 75)$

urity for Nuclear Power Plants (12/74)

rograms (5/75)

ection of ASME Code Class 2 and 3 Components (2/75)

$n$ and Controls $(2 / 75)$

erated Missiles $(6 / 75)$

tems and Components $(1 / 75)$

ials for Engineered Safety Features (2/75)

175)

r Design Procedures (12/74)

es $(5 / 75)$

lief Discharge System $(6 / 75)$

integrity $(4 / 75)$

nce During Operations Phase (12/74)

ste Management (4/75)

t Pressure Boundary Materials and Inservice Inspection (1/ als $(12 / 74)$

s (1975)

cleanup System (5/75)

ication of Instrumentation and Electrical Equipment (2/7) water System Materials (4/75)

rs $(1 / 75)$

ction with lts Antitrust Review of Operating License App/

its Antitrust Review of Construction Permit Applications/

ion Exposure as Low as Is Reasonably Achievable (Nuclear) ps for Nuclear Power Plants (12/73) ion $4,8 / 75$ )

$1 / 74)$

Power Plants (2/74)

r Nuclear Power Plants $(8 / 74)$

wer Plants (Revision 1, ]/75)

itary Facilities $(9 / 74)$

uction $(7 / 74)$

er Plants $(5 / 74)$

\section{ASTM B364-1970 \$1.75}

3) $\$ 1.75$

ASTM B350-1973 $\$ 1.75$

Supersedes M10-1T, (5-/

Zirconium and Zirconium Alloy

Columbium and Columbium Alloy

Test for Evaluating

actors $(11 / 73)$

Preoperational and

tems for Boiling Water Reactor Power / Preoperational and Information for Safety Analysis Reports:

practices for Volatile Organic Matter in Water by Aqueousn for (1973) \$1.75 Compressed Gas Cylinder Valve Outlet and fety Systems (5/73)
c. Practice for Determ/ Changes in Chemical Reactivity of ounters (12-75) Supersedes C10-3T, (3-72) Recommended Practice for Controlle Socket-Welding Reducer

$(5.75)$

nts $(2 / 75)$

(1977) bd $(\$ 60.00)$; ll ( $\$ 90.00)$

Generator Tubes (Revision 1, 7/75)

t Structures with Grouted Tendons (11/74)

d Concrete Containment Structures (Revision 2, 1/76)

is Reports: Reactor Coolant Pressure Boundary Materials and 75) $\$ 3.00$

0) $\$ 2.75$

Authorized Nuclear

70) $\$ 2.25$

Protection Against Pipe Whip

i) Type Tests of Continuous Duty Class 1 Motors Installed Qualification Tests of Electric Valve Operators Installed Qualification Tests of Continuous-Duty Motors Installed for Leaks Using the Mass Spectrometer Leak Detector in the (1974) $\$ 1.75$
Industrial, Transportation, and Military Facilities (9/) Industry Flanges and Threaded Stubs for Use with Lens G Industry (1974) $\$ 14.00$

Inert Gas Valves (5-72) Amendment 1 ( $1-74)$

Inflatable Seal Containment Vessel Airlock (6-72)

Information and Regulations (1975) $\$ 6.80$

Information for Fuel Reprocessing Plants (2/74)

Information for Safety Analysis Reports: Code Cases App Inforination for Safety Analysis Reports: Electric Power Information for Safety Analysis Reports: Emergency Plan

Information for Safety Analysis Reports: Environmental Information for Safety Analysis Reports: Fuel System De Information for Safety Analysis Reports: Hydrologic Eng Information for Safety Analysis Reports: Industrial Sec Information for Safety Analysis Reports: Initial Test P Information for Safety Analysis Reports: Inservice Insp Information for Safety Analysis Reports: Instrumentatio Information for Safety Analysis Reports: Internally Gen Information for Safety Analysis Reports: Mechanical Sys Information for Safety Analysis Reports: Metallic Mater Information for Safety Analysis Reports: Meteorology (4 Information for Safety Analysis Reports: Missile Barrie Information for Safety Analysis Reports: Plant Procedur Information for Safety Analysis Reports: Pressurizer Re Information for Safety Analysis Reports: Pump Flywheel Information for Safety Analysis Reports: Quality Assura Information for Safety Analysis Reports: Radioactive Wa Information for Safety Analysis Reports: Reactor Coolan Information for Safety Analysis Reports: Reactor Materi Information for Safety Analysis Reports: Reactor Vessel Information for Safety Analysis Reports: Reactor Water Information for Safety Analysis Reports: Seismic Qualif Information for Safety Analysis Reports: Steam and Feed Information for Safety Analysis Reports: Steam Generato Information for Safety Analysis Reports: Training (6/75 Information Needed by the AEC Regulatory Staff in Conne Information Needed by the NRC Staff in Connection with Information Relevant to Maintaining Occupational Radiat Information: Air Filtration Systems and Containment Sum Information: Appendix a Technical Specifications (Revis Information: Design of Seismic Category 1 Structures (1 Information: Fire Protection Considerations for Nuclear Information: Geography and Demography Considerations Fo Information: Hydrological Considerations for Nuclear Po Information: Nearby Industrial, Transportation, and Mil Information: Quality Assurance During Design and Constr Information: Radiation Protection (Revision 1, 11/74) Information: Water Level (Flood) Design for Nuclear Pow Information: Wind and Tornado Loadings (11/74)

lngot Form, Specification for (1972) \$1.75

Ingots and Flat Mill Products, Specification for (1973) Ingots and Flat Mill Products, Spec. for (1970) \$1.75 Ingots for Nuclear Applications, Specification for (197 Ingots for Nuclear Application, Specification for (1974 Ingots (ASTM B 350 with Additional Requirements) (1-72 lngots (1973) ASTM B391-64\$1.75

Ingots, Specification for (1964) $\$ 1.75$

Inhibitory Toxicity of Waters to Diatoms (1973) $\$ 1.75$ Initial Startup Test Programs for Water Cooled Power Re Initial Startup Testing of Feedwater and Condensate Sys Initial Test Programs (5/75)

Initiation of Protective Actions (10/73)

Injection Gas Chromatography (1974) \$1.75

Injection Molding and Extrusion Materials, Specif

Inlet Connections (1965) CGA V-1-1965\$7.00

Inoperable Status Indication for Nuclear Power Plant SA

Inorganic Material Exposed to High Energy Radiation, Re

Input Preamplifier/Discriminator for Use with Neutron C

Input Tests for Shipping Containers (1971) \$1.75

Inserts (1974) $\$ 4.00$

Inserts (3-75) Supersedes M1-21T, (4-74) Amendment Inservice Inspection of ASME Code Class 2 and 3 Compone

Inservice Inspection of Nuclear Power Plant Components Inservice Inspection of Pressurized Water Reactor Steam Inservice Inspection of Prestressed Concrete Containmen Inservice Inspection of Ungrouted Tendons in Prestresse

Inservice lnspection (1/75)

/Rmation for Safet

Inservice Inspection, Qualifications and Duties for (19

Inservice Testing of Pumps in Nuclear Power Plants (197

Inservice Testing of Valves in Nuclear Power Plants (19

Inside Containment (5/73)

Inside the Containment of Nuclear Power Generating Stat

Inside the Containment of Nuclear Power Plants (1/74)

Inside the Containment of Water Cooled Nuclear Power P

Inside-Out Testing Mode (1973) \$1.75

Insoluble Content of Copper and Iron Powders, Test for
NRC

MSS

ANSI

ERDA

ERDA

DOT

NRC

NRC

NRC

NRC

NRC

NRC

NRC

NRC

NRC

NRC

NRC

NRC

NRC

NRC

NRC

NRC

NRC

NRC

NRC

NRC

NRC
NRC

NRC

NRC

NRC

NRC

NRC

NRC

NRC

NRC

NRC

NRC

NRC

NRC

NRC

NRC

NRC

NRC

NRC

NRC

ASTM

ANSI

ASTM

ASTM

ANSI

ERDA

ANSI

ASTM

ASTM

NRC

NRC

NRC

NRC

ASTM

ASTM

ANSI

NRC

ASTM

ERDA

ASTM

MSS

ERDA

NRC

ASME

NRC

NRC

NRC

NRC

ANSI

ASME

ASME

NRC

ANSI

NRC

NRC

Tests ASTM

ASTM

RG 1.70 .8

SP-65

N512

RDT El-35T

RDT E14-5T

49CFR 171

G 3.19

RG 1.70 .13

RG 1.70 .36

RG 1.70 .14

RG 1.70 .24

RG 1.70 .34

RG 1.70 .17

RG 1.70 .15

RG 1.70 .33

RG 1.70.25

RG 1.70.22

RG 1.70.35

RG 1.70.18

RG 1.70 .26

RG 1.70.29

RG 1.70 .16

RG 1.70.31

G 1.70 .37

RG 1.70.30

RG 1.70.1]

RG 1.70 .27

RG 1.70 .20

RG 1.70 .12

RG 1.70.21

RG 1.70 .32

RG 1.70.23

RG 1.70 .28

RG 1.70 .19

RG 1.70 .38

RG 9.3

RG 9.2

RG 8.8

RG 1.70 .2 
containers (1-75)

d Bituminous Materials as Used in Construct/ uction of Nuclear Power Generating Stations, Installation, Materials and (1971) $\$ 3.00$ (1971) $\$ 2.00$ Dry Particle Magnetic Radiographic Information for Safety Analysis Reports: Inservice ification for (1973) ASTM / Longitudinal-Beam Ultrasonic

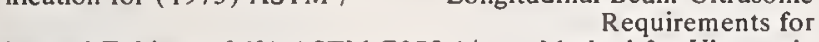
ipe and Tubing (1969) ASTM E273-1/ Method for Ultrasonic scontinuities, Method for (1974) $\$ 1.75$ $(\$ 60.00) ; 11(\$ 90.00)$

Tubes (Revision 1,7/75)

es with Grouted Tendons (11/74)

rocessing Plants $(6 / 75)$

and Inspection for (1974A)

Containment Structures (Revisitud Longit

oolant System Wear Applications (10-67)

tor Enclosure System (7.73)

(lonizing Visual in Service (s) for X-Ray Baggage Wet Magnetic Particle Reference Photographs for Liquid Penetrant Definitions of Terms Relating to Magnetic Particle Definitions of Terms Relating to Liquid Penetrant Qualifications and Duties for Authorized Nuclear $\mathrm{n}$ and Control of Steel Reference Blocks Used in Ultrasonic : Reactor Coolant Pressure Boundary Materials and Inservice tems for the Construction Phase of Nuclear/ Installation, tems (6) Quality Assurance Requirements for Installation, ctural S lementary Quality Assurance Requirements for Installation, Quality Assurance Requirements for Installation onstruction Phase of Nuclear Power Pla/ Qualifications of

1971) $\$ 1.75$

(1971) $\$ 1.75$ Qualification of Nuclear Power Plant Liquid Penetrant
Licle Authorized Nuclear Inservice Concrete rete and Structural S/ Quality Assurance Requirements for ervice (8-71) Amendment 1 (11-72), Ame/ Fabrication and and Plant Protection for an Independent Spent Fuel Storage $s(6 / 74)$ Ray Sources, Energies Up to $10-\mathrm{Mev}$, General Safety Sta/ $\$ 3.25$ Sheilding for High Energy Electron Accelerator ic Equipment (Saf/ Quality Assurance Requirements for the ing the Construction of Nuclear Power Generating Stations, ipment and Systems for the Construction Phase of Nuclear/ ipment and Systems (6/ Quality Assurance Requirements for crete A/ Supplementary Quality Assurance Requirements for
Reactors (5/73) ating Stati/ Type Tests of Continuous Duty Class 1 Motors s $(1 / 74)$

r Power P/ icenses $(3 / 76)$ Qualification Tests of Electric Valve Operators Qualification Tests of Continuous-Duty Motors Guidance to Academic ision $1,11 / 75)$

( Safety Guide 11,3/10/71 Radiation Protection in Educational sification (1970) $\$ 3.00$

Only) Amendment 1 (8-73), Amendment 2 (3-74)

ilding Practices (1/73) Amendment 1 (1/75)

Information for Safety Analysis Reports: ruction of Nuclear Power Generating Stations, Installati/ ssurance Requirements for the Installation, and Testing of tion for Safety Analysis Reports: Seismic Qualification of

) ANS $2.2 \$ 10.00$

ty in Effluents, Specification and Performance /

\section{Foil Shielded}

Earthquake On-Site

Earthquake

plants to Assess Plant Conditions During and Following A/

General

Mass Spectrometer Helium Leak Detection for Electrical Materials for $\begin{array}{ll}\text { inents, 4th Edition (1972) } \$ 12.50 & \text { Air Sampling } \\ \text { stenitic St/ } & \text { Standard Procedures for Calibrating Magnetic }\end{array}$ stenitic St/ Standard Procedures for Calibrating Magnetic
Radiological Monitoring Methods and Intrinsically Safe and Non Incendive Electrical

d. Spec. for Automatic Null Balancing Electrical Measurin
Inspection and Preventive Maintenance of Fuel Shipping

Inspection and Testing Agencies for Concrete, Steel, an

Inspection and Testing Requirements for (1972 IEEE 336-

Inspection for Reactor Vessel Closure Studs (10/73)

inspection for (1974A) $\$ 1.75$

/Dinal-Wave U

nspection Method, Quality Standard for Steel Castings

Inspection Method, Quality Standard for Steel Castings

Inspection of ASME Code Class 2 and 3 Components (2/75)

Inspection of Carbon and Low Alloy Steel Castings, Spec

Inspection of Dimensional Characteristics (8-73)

Inspection of Longitudinal and Spiral Welds of Welded P

Inspection of Metal Pipe and Tubing for Longitudinal Di

Inspection of Nuclear Power Plant Components (1977) bd

Inspection of Pressurized Water Reactor Steam Generator

Inspection of Prestressed Concrete Containment Structur

Inspection of Protective Coatings (Paints) for Fuel Rep

Inspection of Steel Plates for Pressure Vessels, Method

Inspection of Ungrouted Tendons in Prestressed Concrete Inspection Requirements for Materials Used in Reactor C

Inspection System and Associated Equipment for the Reac

Inspection Systems (1975) \$2.95

Inspection (1971) $\$ 1.75$

lnspection (1971) $\$ 1.75$

lnspection (1974) \$1.75

Inspection (1974) \$1.75

Inspection (1974) $\$ 3.50$

Inspection (1975) $\$ 1.75$

Inspection ( $1 / 75)$

nspection, and Testing of Mechanical Equipment and Sys

Inspection, and Testing of Mechanical Equipment and Sys

Inspection, and Testing of Structural Concrete and Stru

Inspection, and Testing of Structural Concrete and Stru

Inspection, Examination and Testing Personnel for the $\mathrm{C}$

Inspection, Examination, and Testing Personnel (8/73)

inspection, Method for (1969) (R1973) ASTM E109-1963 (

Inspection, Methods for (1969) (R1973) ASTM E165-1965

Inspection, Qualifications and Duties for (1975) $\$ 3.00$

Inspection, Recommended Practice for (1975) \$7.50

Installation lnspection, and Testing of Structural Conc

Installation of Overpressure Protection Devices (10/73)

Installation of Piping Subassemblies for Liquid Metal S

Installation (12/74) /Se Application, Siting, Design,

Installations Using Nonmedical Sealed Gamma-Ray Source

Installations Using Non-Medical X-Ray and Sealed Gamma

Installations Where Radiation Exposure May Occur (1967)

Installations (1964) $\$ 2.00$

Installation, and Testing of Instrumentation and Electr

Installation, Inspection and Testing Requirements for

Installation, Inspection, and Testing of Mechanical Equ

Installation, Inspection, and Testing of Mechanical Equ

Installation, Inspection, and Testing of Structural Con

Installed Biological Shielding in Research and Training

Installed Inside the Containment of Nuclear Power Gene

Installed Inside the Containment of Nuclear Power Plant

Installed Inside the Containment of Water Cooled Nuclea

Institutions Applying for Specific Byproduct Material L

Institutions (1966) $\$ 3.00$

Instruction Concerning Prenatal Radiation Exposure (Rev

Instrument $\mathrm{A}$ ir Systems (6/74)

Instrument Lines Penetrating Primary Reactor Containmen

Instrument Purging for Reduction of Hazardous Area Clas Instrument Spans and Setpoints (11/75)

Instrument Tree for Sodium Cooled Reactors (Fabrication Instrument Valves (4.72)

Instrumentation and Control Equipment Grounding and She

Instrumentation and Controls (2/75)

Instrumentation and Electric Equipment During the Const

Instrumentation and Electric Equipment (Safety Guide 30

Instrumentation and Electrical Equipment (2/75)

Instrumentation Cable (6.74)

Instrumentation Criteria for Nuclear Power Plants (1974

Instrumentation for Continuously Monitoring Radioactivi

Instrumentation for Earthquakes (Revision 1, 4/74)

Instrumentation for Fuel Reprocessing Plants (2/74)

Instrumentation for Light-Water-Cooled Nuclear Power

Instrumentation Symbols and Identification (1975) $\$ 7.00$

Instrumentation (2-72) Amendment 1 (5-73)

Instruments and Small Components (2-72)

Instruments in Hazardous Atmospheres (1960) $\$ 3.00$

Instruments in Radiation Service (1957) $\$ 5.00$

Instruments Manual for Evaluation of Atmospheric Contam

Instruments to Measure the Delta Ferritic Content of Au

Instruments (1952) $\$ 2.00$

Instruments (1965) $\$ 5.00$

lnstruments (1966) (R1972) \$4.75

Instruments (1968) (R 1973) $\$ 2.50$
ERDA

ANS1

ANS1

NRC

ASTM

MSS

MSS

NRC

ANSI

ERDA

ANSI

ASTM

ASME

NRC

NRC

ASTM

NRC

ERDA

ERDA

BRH

ASTM

ASTM

ASTM

ASTM

ANS1

ASTM

NRC

ANSI

NRC

ANSI

NRC

ANS1

NRC

ANSI

ANSI

ANSI

$\mathrm{ACI}$

NRC

NRC

ERDA

NRC

NRC

ANS

ANSI

NCRP

NRC

ANS

ANS1

NRC

ANSI

NRC

ANS1

NRC

NRC

NRC

NCRP

NRC

NRC

NRC

ISA

NRC

ERDA

ERDA

ERDA

NRC

ANSI

NRC

NRC

ERDA

ANS1

ANS

NRC

NRC

NRC

ISA

ERDA

ERDA

ISA

ISA

ACGlH

AWS

NCRP

ISA

St ANSI

ANS1

RDT E12-7T

Z267.1

45.2 .4

RG 1.65

A435

SP-53

SP-54

RG 1.70 .25

G52.7

RDT F3-15T

Z166.18

E213

SEC-XI

RG 1.83

RG 1.90

RG 3.30

A435

RG 1.35

RDT F3-7T

RDT E8-12T

21CFR 1020G

E138

E433

E269

E270 
High Voltage Connectors for Nuclear Portable $X$ or Gamma Radiation Surve (3.70), in Part Amendment 1 ; Determination of Insulation Compaction in Ceramic es P4-3T, (2-74) Metal Sheathed, Mineral Ceramic

Time Response Test for Sheathed, Mineral

p Versus Alumel, Stainless Steel Sheathed, Magnesium Oxide Chromel-P and Alumel, Solid Conductor (Bare, Fiberglas al, Iron and Constantan, Solid Conductor (Bare, Fiberglas Copper and Constantan, Solid Conductor (Bare, Fiberglass

Thermocouple Material, Iron Constantan, Mineral Oxide Thermocouple Material, Copper-Constantan, Mineral-Oxide Thermocouple Assemblies, Magnesium-Oxide Mineral Fiber Hydraulic-Setting Therma onal Requiremen/ Mineral Fiber Hydraulic-Setting Thermal 0) $\$ 1.75$ Mineral Fiber Hydraulic-Setting Thermal eel (10-72) Supersedes M1/ Test Requirements for Therma for Calibration of Standards and Equipment for Electrical
Thermal Failure Under Electric Stress of Solid Electrical 1967) $\$ 1.75$

ickness and Density of Blanket-Type or Batt-Type Thermal 8/70) Amendment $1(9 / 73)$

Determination of Nonmetallic Therma Airborne Sound

(1971) $\$ 1.75$ for Linear Shrinkage of Preformed High Temperature Thermal
Practice for Prefabricated Reflective emperatures Above temperatures Practice for Prefabricated Reflective -71) Amendment / Calcium Silicate Block and Pipe Thermal

Testing Adhesives Relative to Their Use as Electrical licone Rubber Coated Glass Fabric and Tapes for Electrical Spec. for Mineral Fiber Block and Board Thermal

ting Polymerizable Embedding Compounds Used for Electrica Sampling Preformed Thermal for Determining the Maximum Use Temperature of Preformed Std. Definitions of Terms Relating to Electric

valuating Stress Corrosion Effect of Wicking-Type Thermal ended Practice for Selection of Vapor Barriers for Thermal

(Bare, Fiberglass Insulated, and Sheathed Over Fiberglass

(Bare, Fiberglass Insulated, and Sheathed Over Fiberglass

(Bare, Fiberglass Insulated, and Sheathed Over Fiberglass onductivity (5-72) Amendment 1 (4-73)

Fill (ASTM C 612 with Additional/ Mineral Fiber Thermal 19/ Hot Surface Performance of High Temperature Thermal -1/ Compressive Strength of Preformed Block Type Thermal $-1969 \$ 1.75$

Thermal Conductivity of Pipe 5) $\$ 1.75$ Mean Specific Heat of Therma Calcium Silicate Block and Pipe Thermal Mean Specific Heat of Therma

Density of Preformed Pipe Covering Type Therma Density of Preformed Block Type Thermal lculated Flexural Strength of Preformed Block Type Thermal Fast Flux Test Facility Driver Fuel Pin Ceramic Electrical $\$ 3.50$ Administrative Guide for Liability itic, and Austenitic Alloy Steel Heat Exchanger Tubes with erapy Sources (1973) $\$ 3.50$

erapy Sources (Revision 1, 7/74)

Reactor Coolant Pump Flywheel ances and Physical Agents in the Workroom Environment with

food Additives, Subpart G. Radiation and Radiation Sources Recommended Programming Practices to Facilitate for (1975) \$1.75 Detecting Susceptibility to Bearing Alloys, Method of (/ tic Stainless Steel Components of / Detecting Susceptibility to
Detecting Susceptibility to Guidance for Avoiding 74) Supersedes E4-6T, (1-72), Amendment 1 (1-72)

1) Logarithmic Mean Square Voltage (MSV) ructural Quality, Specification for (1975) \$1.75 Low and 4A) \$1.75 Pressure Vessel Plates, Carbon Steel, Low and ation for (1974/ Pressure Vessel Plates, Carbon Steel for

Information for Safety Analysis Reports: loy Steel for Use in Fuel Reprocessing Plant Preheat and Food and Drugs: Subpart B, Statements of Policy and simeters and Companion Dosimeter Chargers (1965) (R1971)/ ents (1965) $\$ 5.00$

Perimeter m D1452-1966) $\$ 1.75$ Conduct of Nuclear Material Physical est for (1973) ASTM C624-1971 \$1.75 971) $\$ 1.75$

$(6-72)$

Gas Phase Adsorbents for Trapping R Gas Phase Adsorbents for Trapping Radioactive lodine and
Instruments (1971) $\$ 3.00$

Instruments, Specification of (1971) $\$ 4.40$

Insulated Cable Bulk Material (2-73) Supersedes C7-14

Insulated Conductors (8/70) Amendment ] (9/73)

Insulated Electrical Resistance Heater (3-75) Supersed Insulated Magnet Wire (7.70)

Insulated Thermocouple Assembly (6-72)

Insulated (2-75) Supersedes C 7-6T, (4-72), Amendmen

Insulated, and Sheathed Over Fiberglass Insulation) (1-

Insulated, and Sheathed Over Fiberglass Insulation) (4-

Insulated, and Sheathed Over Fiberglass Insulation) (4/

Insulated, Sheathed (4-70) Supersedes C7-14T, (3-70)

Insulated, Sheathed (4-70) Supersedes C7-14T, (3-70)

Insulated, Stainless Steel Sheathed (1-72)

Insulating and Finishing Cement (ASTM C 449 with Additi

nsulating and Finishing Cement, Specification for (197

Insulating Materials for Use on Austenitic Stainless St

lnsulating Materials Testing (1971) \$1.75

Insulating Materials (1973) \$1.75

Insulating Materials, Definition of Terms Relating to

Insulating Materials, Test for (1970) \$1.75

Insulation Compaction in Ceramic Insulated Conductors (

Insulation for Austenitic Stainless Steel (2/23/73)

Insulation in Buildings, Rec. Practice for Measurement

Insulation Subjected to Soaking Heat (1963) (RI969) Ast

Insulation Systems for Equipment and Pipe Operating at

Insulation Systems for Equipment and Pipe Operating at

Insulation (ASTM C 533 with Additional Requirements) (6

Insulation (1-72) Amendment 1 (10-74)

Insulation (1969) \$1.75

Insulation (1969) (R 1974) ASTM D1931-1973\$1.75

Insulation (1970) $\$ 1.75$

nsulation (1970) (ASTM D1674-1967) \$1.75

Insulation (1972) \$1.75

Insulation (1973) ASTM C447-1971 \$1.75

Insulation (1975B) \$1.75 ANSI C59.75 (1973)

Insulations on Stainless Steel (1971) \$1.75

Insulations (1973) \$1.75

Insulation) (1-73)

Insulation) (4-70)

Insulation) (4/70)

/El-P and Alumel, Solid Conductor

/N and Constantan, Solid Conductor

Insulation, Flexible or Molded, High Temperature, Low C

Insulation, High Temperature, Rigid, Flexible and Loose

Insulation, Method of Test for (1963) (R1969) ASTM C41

Insulation, Method of Test for (1963) (R1973) ASTM C165

Insulation, Method of Test for (1967) (R1969) ASTM C335

Insulation, Practice for (1963) (R1975) (ASTM C312-195

Insulation, Specification for (1972) $\$ 1.75$

Insulation, Test for (1961) (R1973) \$1.75

Insulation, Test for (1972) $\$ 1.75$

Insulation, Test for (1972) $\$ 1.75$

Insulation, Test for (1972) $\$ 1.75$

Insulator Pellet (6-71)

Insulators (8-74) Supersedes C18-1T, (7-70)

Insurance Aspects of Shipping Nuclear Materials (1973)

Integral Fins, Specification for (1973) \$1.75

Integrity and Test Specifications for Selected Brachyth

Integrity and Test Specifications for Selected Brachyth

Integrity (Revision 1, 8/75)

Integrity (4/75)

Intended Changes (1975) \$.75

Interchange of Digital Computer Processing, and Han

Intergranular Attack in Stainless Steels, Rec. Practice

Intergranular Attack in Wrought Nickel-Rich, Chromium

Intergranular Corrosion and Stress Corrosion in Austeni

Intermediate Heat Exchanger for Liquid Metal Systems ( 5

Intermediate Range Neutron Flux Monitoring System (7-7

Intermediate Tensile Strength Carbon Steel Plates of St

Intermediate-Tensile Strength, Specification for (197

Intermediate-and Higher-Temperature Service, Specific

Internal Emitters (1961) Free

Internal Transfers of Special Nuclear Material (3/75)

Internally Generated Missiles (6/75)

Interpass Temperature Control for the Welding of Low Al

Interpretation (1975) $\$ 2.95$

Interrelationship of Quartz-Fiber Electrometer Type Do

Intrinsically Safe and Non Incendive Electrical Instrum

Intrusion Alarm Systems (1/75)

Inventories of Nuclear Materials (1972) $\$ 3.25$

Inventories $(11 / 73)$

Investigation and Sampling by Auger Borings (1972) (Ast

In-Hours (DIH) Purity of Nuclear Graphite, Method of T

In-Hours (D1HI) Purity of Nuclear Graphite, Test for (1

Iodine and Iodine Compounds (10-73) Supersedes M16-1T

lodine Compounds (10-73) Supersedes M16-1T, (6-72)
ANSI

ANSI

N42.4

ARDA

ERDA

ERDA

ERDA

ERDA

ERDA

ERDA

ERDA

ERDA

ERDA

ERDA

ERDA

ERDA

ERDA

Test for ASTM

ASTM

th ASTM

ERDA

NRC

ASTM

ANSI

ANSI

ASTM

ERDA

ERDA

ASTM

Si ANSI

ASTM

ANSI

ASTM

ANSI

ASTM

ASTM

ERDA

ERDA

ERDA

ERDA

ANSI

ANS

ANSI

ASTM

ASTM

ASTM

ASTM

ASTM

ERDA

ERDA

ANSI

IN, Ferr ASTM

ANSI

NRC

NRC

NRC

ACGIH

FDA

ANS

ASTM

ANSI

NRC

ERDA

ERDA

ATTM

ASTM

ASTM

NRC

NRC

NRC

ANSI

ISA

NRC

ANS

NRC

ANS1

ANSI

ASTM

ERDA

ERDA

N1 3.4

DT C 17-5T

RDT C2-1T

DT P4-3T

RDT M7-13T

RDT C2-3T

RDT C7-6T

RDT C 7.5T

RDT C7-1T

RDT C7-3T

DT C7-2T

RDT C7-4T

RDT C7-16T

RDT M12-3T

RDT M12-1T 
methods of Test for (1973) ASTM D2334-1968/ Radioactive Recommendations for Waste Disposal of Phosphorus-32 and Test for Strontium esting for Leaks Using the Halogen Leak Detectors (AlkaliMethods of Sampling of Particulate f Test for Physical and Chemical Properties of Particulate Tests for Physical and Chemical Properties of Particulate

Sulfate

Nitrate

Fluoride

Water and Waste Water, Tests for Chloride Continuous Determination of Sodium in Water b ion) (7-71) Amendment 1 (8.73, Amend/ Gamma Compensated Systems (1975) \$2.95

Gas Discharge Tubes (1975) \$2.95

ray Systems and Their Major Components/

equipment (1975) $\$ 2.95$

Radio Frequency Emitting Products (19/

equipment (1975) $\$ 2.95$

ceivers (1975) $\$ 2.95$

Inspection Systems (1975) \$2.95

Performance Sid. Performance Std Performance Std. Performance Std. Performance Std Performance Std. Performance Std Performance Std

(utions Section 57 Exposure to Radioactive Substances and $53-1971)(1973) \$ 1.7$

Polymeric Materials for Service in .75 Polymeric Materials for Service in dditional Requirements) (1-75) Supers/

1973) ASTM BI68-1970 \$1.75

Nickel-ChromiumS 7-4T.

Nickel-Chromium

Nickel-Chromium-

Specification for Nickel-ChromiumNickel-Molybdenum-Chromium-

Helical Age-Hardenable NickeI-Chromium-

hemical Analysis of Nickel-Chromium and Nickel-Chromium insulated, and Sheathed Over Fibe/ Thermocouple Material,

for High Temperat/

Zinc Coating (Hot-Dip) on Std. Spec. for Precipitation Hardening 70) Supersedes C7.14T, $(3.70)$,

Thermocouple Material, for (1974) $\$ 1.75$ Cast

0) $\$ 3.00$

Fast Neutron Flux by Radioactivation of Acid Insoluble Content of Copper and $\$ 3.00$ Cast

hods for Measuring Fast Neutron Flux by Radioactivation of alysis of Steel, Cast Iron, Open-Hearth Iron, and Wrough 409 with Additional Requirements) (9.75) Supers/ Nickel. tion for (1974) ASTM B409-1973 $\$ 1.75$

itional Requirements) (9-75) Supersedes M7-10T

Nickel-

$3 \$ 1.75$ Specification for Nickel407 with Additional Requirements) (7-75) Super/ Nickel1.75

e (1974) $\$ 1.75$

pplication at High Temperatures, Spec/ $\begin{array}{r}\text { Specification for Nickel } \\ \text { Centrifugally Cast }\end{array}$ $.1969 \$ 1.75$

Chemical Analysis of Steel, Cast Iron, Open-Hearth High Temperature, Electrical, Magnetic, and Other Similar Chemical Analysis of Steel, Cast Spectrophotometric Determination of Fission Zirconium in tm C625-1972\$1.75

rting (1972) $\$ 1.75$

on in Truck Transport (2-75)

on $1,6 / 76$ )

resources (Revision 1, 6/76)

er Reactor Nuclear Power Plants (Re/ Design of Main Steam

2-70) Amendment $1(5-74)$

Carbon Steel Valve,

7-1970\$1.75 Uranium and Plutonium Concentrations and ds for the Analysis of Uranyl Nitrate Solutions for Assay, Selection of Material Balance Areas and

ce Sampling Procedures for Exempted and Generally Licensed Packaging, Shipping, Receiving, Storage and Handling of $\$ 2.00$

r Packaging, Shipping, Receiving, Storage, and Handling of

Cast Bronze Solder

Silver Brazing Joints for Cast and Wrought Solder

) $\$ 3.00$

1976) $\$ 1.50$

ers, Specificat/ Alloy Steel Bolts for Structural Stee Carbon Steel Sheet, Cold Rolled, Drawing Quality, Special ess, Rockwell Hardness, Rockwell Superficial Hardness, and significance, and Control Technology (1975) $\$ 4.00$ lodine in Industrial Water and Industrial Waste Water, odine in Industrial Water and Industrial Waste Water, lodine-131 for Medical Use (1951) $\$ 2.00$

Ion Brackish Water, Sea Water, and Brines (1974) $\$ 1.75$ Ion Diode) (1971) $\$ 1.75$ Recommended Practice oxchange Materials (1973) ASTM D2687 on Exchange Resins (1973) \$1.75 Ion Exchange Resins (1974) $\$ 1.75$
lon Exchanger, Non Regenerative Type (5-72) Ion in Water and Waste Water, Tests for (1974) \$1.75 Ion in Water, Standard Method of Test for (1971) $\$ 1.75$ on in Water, Standard Method of Tests for (1972) \$1.75 Ion in (1974) \$1.75

Ion Selective Electrode (1973) \$1.75

Ionization Chamber Assembly (Fixed Electrical Compensat (lonizing Radiation Emitting Products) for Cabinet X-Ray (lonizing Radiation Emitting Products) for Cold-Cathode (lonizing Radiation Emitting Products) for Diagnostic X(Ionizing Radiation Emitting Products) for Fluoroscopic (lonizing Radiation Emitting Products) for Microwave and (lonizing Radiation Emitting Products) for Radiographic (lonizing Radiation Emitting Products) for Television Re (lonizing Radiation Emitting Products) for X-Ray Baggage lonizing Radiations (1971) \$6.85 Child Lab lonizing Radiation, Classification System for (ASTM D
lonizing Radiation, Classification System for (1971) \$1 Iron Alloy Plate, Sheet, and Strip (ASME SB-168 with a ron Alloy Plate, Sheet, and Strip, Specification for Iron Alloy Rod and Bar (ASME SB-166 with Additional Re lron Alloy Seamless Pipe and Tube (1973) ASTM B 167-197 Iron Alloy Sheet and Plate, Specification for (1973) as Iron Alloy Springs (5-75) Supersedes M8-1T, (2-73) Iron Alloys (1973) $\$ 1.75$

ron and Constantan, Solid Conductor (Bare, Fiberglass Iron and Steel Gas Welding Rods (1969) \$2.50 lron and Steel Hardware, Specification for (1973) $\$ 1.75$ Iron Base Superalloy Bars, Forgings, and Forging Stock Iron Constantan, Mineral Oxide Insulated, Sheathed (4Iron Gate Valves, Flanged and Threaded Ends (1970) \$4.0 Iron in Water and Waste Water, Standard Method of Tests Iron Measuring (1970) \$1.75

Iron Powders, Test for (1974) $\$ 1.75$

Iron Swing Check Valves, Flanged and Threaded Ends (197 Iron Threaded Pipe Unions 150, 250, and $300 \mathrm{lbs}$. (1970) Iron (1973) ASTM E263-1970\$1.75

Iron (1975) $\$ 1.7 \$$

Iron-Chromium Alloy Plate, Sheet, and Strip (ASME SB

lron-Chromium Alloy Plate, Sheet, and Strip, Specifica Iron-Chromium Alloy Rod and Bar (ASME SB-408 with Add Iron-Chromium Alloy Rod and Bar, (1974) ASTM B408-197 Iron-Chromium Alloy Seamless Pipe and Tubing (ASME SBIron-Chromium Alloy (UNS N08800) Rod and Bar, (1974) Iron-Chromium Alloy (UNS N08800) Seamless Pipe and Tub Iron-Chromium-Nickel High Alloy Tubing for Pressure a Iron-59 in Water, Method of Test for (1973) ASTM D246I Iron-59 in Water, Test for (1969) (R1975) \$1.75

Iron, and Wrought lron (1975) $\$ 1.75$

Iron, Nickel, and Cobalt-Base Alloys, Chemical Analysi Iron, Open-Hearth Iron, and Wrought Iron (1975) $\$ 1.75$ Irradiated Nuclear Fuels (1973T) \$1.75/Hod of Test Fo lrradiation Results on Graphite, Practice for (1973) as Irradiation Results on Graphite, Rec. Practice for Repo Irradiations Experiment Resistance to Shock and Vibrati lrretrievable Commitments of Material Resources (Revisi Irreversible and Irretrievable Commitments of Material lsolation Valve Leakage Control Systems for Boiling Wat 1solation Valves (4-73) Amendment 1 (5-74)

Isolation, Butterfly Type (8.72)supersedes E1-13T, (1 1sotopic Abundances, Method of Test for (1970) $\$ 1.75$ lsotopic Abundances, Method of Test for (1973) ASTM E26 Isotopic Distribution, and Impurity Determinations (12/ ltem Control Areas (Revision 1, 4/75)

ltems Containing Byproduct Material (6/74)

Items for Nuclear Power Plants (During the Construction

Items for Water Cooled Nuclear Power Plants (3/16/73)

Joint Between Tapping Sleeves and Tapping Valves (1969)

Joint Containment Vessel Airlock (3-72) Amendment 1 ( 8

Joint Fittings for Sovent Drainage Systems (1973) $\$ 3.50$

Joint Fittings (1970) $\$ 3.00$

Joints for Cast and Wrought Solder Joint Fittings (1970

Joints Using ASTM A325 or A490 Bolts (Approved February

Joints, Including Suitable Nuts and Plain Hardened Wash

Joints, Specification for (1975) \$1.75

Killed, Specification for (1975) $\$ 1.75$

Knoop Hardness) (1973) ASTM E140-1972 \$1.75 /Rs Hardn

Krypton-85 in the Atmosphere Accumulation, Biological
ANSl

ASTM

NCRP

ASTM

ANS1

ANS]

ASTM

ERDA

ASTM

ASTM

ASTM

ASTM

ASTM

ERDA

BRH

BRH

BRH

BRH

BRH

BRH

ANSI

ASTM

ERDA

ANSl

ERDA

ANSI

ANSI

ERDA

ERDA

AWS

ASTM

ANSI

ERDA

MSS

ASTM

ASTM

ASTM

MSS

MSS

ANSI

ASTM

ERDA

ANSI

ERDA

ANSI

ERDA

ASTM

ASTM

ANS

ANSI

ASTM

ASTM

ASTM

ASTM

ASTM

ANS

ASTM

ERDA

NRC

NRC

ERDA

ERDA

ASTM

ANSI

NRC

NRC

ANS

NRC

MSS

ERDA

ANS

MSS

MSS

AISC

ASTM

U ASTM ASTM ANS1 NCRP

N159

D2334

R9

D 3352

E427

Z111.12

Z111.1

D21 87

RDT E11-1T

D5 16

D992

D 1179

D5 12

D2791

DT C15-7T

$21 \mathrm{CFR} 1020 \mathrm{~F}$ 
bstances and lonizing Radiations (1971) \$6.85

Child (7-7) Qualification and Control of Analytical Chemistry Qualification and Control of Analytical Chemistry Control and Removal of Radioactive Contamination in onic Elastic Constants of Rock (1972) (ASTM D2845-1969)/ pore Diameter and Permeability of Rigid Porous Filters for Making and Curing Concrete Test Specimens in the Safety Requirements for Portable Metal Safety Requirements for Portable Wood

Fixed

0

Steel Sheet, Corrosion Resistant, Industrial

ion, and Use of Radioisotopic Power Generators for Certain ts) (4-75) Super/ Austenitic Stainless Steel Welded Pipe nickel Alloy Steel Pipe for Corrosive or High Tem/ Welded

torage Batterie/ Maintenance, Testing, and Replacement of Recommended Rules for Design and Construction of

69) (R/975) $\$ 1.75$

astm C558-1969 \$1.75

Nomenclature for Rubbers and Rubber

cement of Large

Measurement of 72) .75 Mass Spectrometer Helium Testing for Leaks Using the Mass Spectromete
Tests for Leaks Using the Mass Spectromete obe Mode (/ Testing for Leaks Using the Mass Spectrometer Electrical Continuity Type Liquid Metal commended Practice for Testing for Leaks Using the Halogen $71 \$ 1.75$

n $1,7 / 74$ )

3.50

.75

Rec. Guide for Preparation of Terms Relating to

ar Power Plants ( $\mathrm{Re} / \quad$ Design of Main Steam Isolation Valve Reactor Coolant Pressure Boundary
aterials (Issued for Trial Use and Commen/ Draft Std. for aterials $(6 / 75)$

lear Reactors (1971) ANS-7.60 \$7.50

de) (1971) $\$ 1.75$ Recommended Practice for Testing for inside-Out Testing Mode (1973) \$1.75

detector Probe Mode (1973) $\$ 1.75$

dual Gas Analyzer in the Tracer Probe Mode (/ Testing for Chemical Industry Flanges and Threaded Stubs for Use with Recommended Practice for Measurement of Low

73) Amendment 1 (12-74) ervice (Fabrication Only) (7.72) Amendment 1 (7.73/ Low ) Supersedes C5-1T, (4-70)

Amendment 1 (10-71)

Inductive

Resistive

Additional Information: Water Std. Specifications for Manually

Is (1973) $\$ 3.50$

ntrol and Accounting Section of a Special Nuclear Material staff in Connection with lts Antitrust Review of Operating fabrication Plants $(1 / 76) \quad$ Standard Format and Content of eactor Fuel and Associate/ Standard Format and Content of on for an Independent Spent Fuel Storage/ Guidance on the

in Certain Devices to Be Distributed for Use Under General

Acceptance Sampling Procedures for Exempted and Generally Termination of Operating

e Preparation of Applications for Special Nuclear Material Guide for the Prepations for Uranium Milling Guide to the Contents of Applications for Uranium Milling
emic Institutions Applying for Specific Byproduct Material
thed Type Electric Heating Elements (1) Accelerated n Sheathed Type Electric Heating Elements (1/ Accelerated trial Trucks Low Lift and High $6 \$ 2.00 \quad$ Radioactive Self-Luminous 2) $\$ 3.00 \quad$ Protective Coatings (Paints) for $\$ 4.50$ here Cleanup System Air Filtration and Adsorption Units of Industrial

cation for (1970) ASTM C330-1969\$1.75 $69 \$ 2.75 \quad$ Selecting Proportions for Structural $\$ 1.75$ for Corrosive or High Tem/ Welded Large Outside Diameter Cost-Benefit Analysis for Radwaste Systems for nt Conditions During and Following A/ instrumentation for radioactive Materials in Liquid and Gaseous Effluents from Serial Numbering of Fuel Assemblies for radioactive Materials in Gaseous and Liquid Effluents from d Dispersion of Gaseous Effluents in Routine Releases from n Nuclear Materials Control (1974) $\$ 3.00$
Labor Regulations Section 57 Exposure to Radioactive Su Laboratories for Control Rod Absorber Material Analysis Laboratories for Mixed Oxide Fuel Analysis (7-73) Laboratories (1951) $\$ 2.00$

Laboratory Determination of Pulse Velocities and Ultras Laboratory Use, Test for (1969) \$1.75

Laboratory, Method of (1973) ASTM C 192-1969 \$1.75

Ladders (1972) $\$ 4.25$

Ladders (1975) $\$ 5.00$

Ladders, Safety Requirements for (1974) $\$ 5.50$

Laminar-Flow Clean Air Devices (1968) $\$ 1.50$

Laminated Surface Bonded (1973) SAE AMS5500A-1969\$3.0

Laminated Thermosetting Products (1971) $\$ 9.50$

Land and Sea Applications (3/74)

Design, Cons

Large Outside Diameter Light-Wall Austenitic Chromium

Large Shipping Cases and Crates, Testing (1973) \$1.75

Large Stationary Type Power Plant and Substation Lead S

Large, Welded, Low Pressure Storage Tanks (1973) \$4.00

Latices, Practice for (1972B) \$1.75

Lattice Spacing of Nuclear Graphite, Measurement of (19

Lattice Spacing of Nuclear Graphite, Method for (1973)

Lead Storage Batteries, Rec. Practice for (1972) $\$ 5.40$

Leak Detection for Instruments and Small Components (2.

Leak Detector in the Detector Probe Mode (1973) \$1.75

Leak Detector in the Inside-Out Testing Mode (1973) \$

Leak Detector or Residual Gas Analyzer in the Tracer $\mathrm{Pr}$

Leak Detector (10-72) Amendment 1 (6-73)

Leak Detectors (Alkali-Ion Diode) (1971) \$1.75

Leak Testing Method, Guide for the (1973) ASTM E432-19

Leak Testing Radioactive Brachytherapy Sources (Revisio

Leak Testing Radioactive Brachytherapy Sources (1973) \$

Leak Testing Specification (1973) \$1.75

Leak Testing, Definitions of (1973) ASTM E425-1971 \$1

Leakage Control Systems for Boiling Water Reactor Nucle

Leakage Detection Systems (5/73)

Leakage Tests on Packages for Shipment of Radioactive M Leakage Tests on Packages for Shipment of Radioactive M Leakage-Rate Testing of Containment Structures for Nuc

Leaks in Heat Sealed Flexible Packages (1972) \$1.75

Leaks Using Bubble Emission Techniques (1974) $\$ 1.75$

Leaks Using the Halogen Leak Detectors (Alkali-Ion Dio

Leaks Using the Mass Spectrometer Leak Detector in the

Leaks Using the Mass Spectrometer Leak Detector in the

Leaks Using the Mass Spectrometer Leak Detector or Resi

Lens Gaskets (1968) $\$ 4.00$

Level Activity in Water (1972T \$1.75

High Pressure

Level Control Monitor, Port Plug (Fabrication Only) ( 10

Level Flux Monitor Mechanical System for Liquid Metal S

Level Measurement Sensor for Use in Liquid Metal (3-75

Level Measurement Sensor for Use in Liquid Metal (4-70

Level (Flood) Design for Nuclear Power Plants (5/74)

Levels of Nuclear Power Plants (Revision 1, 12/73)

Lever Operated Chain Hoists (1974) \$0.50

Liability Insurance Aspects of Shipping Nuclear Materia

License Application (Including That for a Uranium Enric

License Applications for Nuclear Power Plants (10/74)

License Applications for Plutonium Processing and Fuel

License Applications for Storage Only of Unirradiated R

License Application, Siting, Design, and Plant Protecti

License (Revision I, 5/75) /Oactive Sources Contained

Licensed Items Containing Byproduct Material (6/74)

Licenses for Nuclear Reactors (6/74)

Licenses of Less Than Critical Mass Quantities (7/76)

Licenses to Process Source Material (7/76)

Licenses $(2 / 73)$

Licenses $(3 / 76)$

Life Test of Electrical Grade Magnesium Oxide as Used I
Lift and High Lift, Safety Std. for (1975) $\$ 6.50$

Lift. Safety Std. for (1975) \$6.50

Light Sources, Classification of (1975) NBS Handbook 11

Light Water Nuclear Reactor Containment Facilities (197

Light-Water Cooled Nuclear Power Plants (Revision 1,

Lighting, Practice for (1956) (R1970) (IES RP 10-1956

Lighting, Rec. Practice for (1973) $\$ 4.00$

Lightweight Aggregates for Structural Concrete, Specifi

Lightweight Concrete, Practice for (1971) ACl 211.2-19

Lightweight Pieces in Aggregate (1970) ASTM C123-1969

Light-Wall Austenitic Chromium Nickel Alloy Steel Pipe

Light-Water-Cooled Nuclear Power Reactors (3/76)

Light-Water-Cooled Nuclear Power Plants to Assess Pla

Light-Water-Cooled Nuclear Power Plants (Revision 1,

Light-Water-Cooled Nuclear Power Reactors (12/20/72)

Light-Water-Cooled Power Reactors (4/76)

Light-Water-Cooled Reactors (3/76)

Limit of Error Concepts and Principles of Calculation

DOL

ERDA

ERDA

NCRP

ANS1

ASTM

ANSI

ANSI

ANS

IES

ANSI

NEMA

NRC

ERDA

ASTM

ASTM

IEEE

API

ASTM

ASTM

ANSI

IEEE

ERDA

ASTM

ASTM

ASTM

ERDA

Re ASTM

ANSl

NRC

ANS1

ASTM

ANSI

NRC

NRC

ANSI

NRC

ANSI

ASTM

ASTM

ASTM

ASTM

ASTM

ASTM

MSS

ASTM

ERDA

ERDA

ERDA

ERDA

NRC

NRC

HMI

NRC

NRC

NRC

NRC

NRC

NRC

NRC

NRC

NRC

NRC
ASTM

ANS

ANS1

ANSI

ANSI

NRC

ANSI

ANSI

ANSI

ANSI

ANSI

ASTM

NRC

NRC

NRC

NRC

29CFR 70

RDT F2-8T

RDT F2-6T R8

A 37.176

128

A 37.81

A 14.2

A14.

A 14.3

CS-2T

G87.1

LI-1

RG 6.3

RDT M3-7T

A 409

D 1083

450

STD. 620

D1418

C558

K90.I

RDT F3-11T

E499

E493

498

RDT C $8-4 T$

E427 
n Nuclear Materials Control (1.74)

$\mathrm{s}$ in the Workroom Environment with Intended $\mathrm{Ch} /$ Threshold n Plutonium/ Welder Qualification for Welding in Areas of Welder Qualification for Areas o s of Figures Are to Be Considered Significant in Specified or Containment System Components (6/73)

Preferred fluid System Components (5/73)

Design luating the Potential Radiological Consequences of a Steam insulation Subjected to Soaking Heat / Method of Test for cal and Airflow Performance, Testing (1973) \$1.75 Duct (5/75)

Nondestructive Examination of Primary Containment uide $11,3 / 10 / 71$ Nondestructive Examination of Welds in the $y$ in Solid Wastes and Releases of Radioactive Materials in lation of Releases of Radioactive Materials in Gaseous and ly) (10-73) Amendment 1 (12-74) (11-7I)

(1 I-71) Amendment । (12-73), / Temperature and Control Rod Absorber Pin for Control Rod Assembly for Electrical Continuity Type Mixing Component for 3), Amendment 2 (6-74) (8-71) Permanent Magnet Flowmeter for , Eddy Current Type, Inductive, Absolute or Gage (10-70) dment $1(12.74)$ hanical System for nak Transmission High Temperature Pressure Transmitter for ment 2 (1-74), Amendment 3 (5-/ Electromagnetic Pump for Fabrication of Core Component Pot for in Core Permanent Magnet Flow Through Type Flowmeter for Pipe Hangers, Supports and Snubbers for ston Rings of High Strength Alloys for Core Components for ) Class I Valves for Eddy Current Probe Type Flow Sensor for
Class 2 Valves for Fabrication and Installation of Piping Subassemblies for ment 2 (5-74) Thermowell Systems for Amendment 1 (3-72), Amendment 2 (11-72), Amendm/ Tank , Amendment 1 (1-72) Intermediate Heat Exchanger for Inductive Level Measurement Sensor for Use in Resistive Level Measurement Sensor for Use in Reference Photographs for ASTM E165-1965 (1971) $\$ 1.75$ Definitions of Terms Relating to

ce Transducer, Proximity Measurement System (1-76)

Electrochemical Oxygen Meter for Service in Diffusion Carbon Meter for Service in Oxygen-Hydrogen Meter Module for Service in Carbon Meter Equilibration Module for Service in (Or Multipurpose Sampler) for the Analysis of Nonmetals in Venturi Flow Tube for m Processing and Fuel Fabrication Plants (6/73)

5

Penetration of

or Other Dangerous Articles or Substances and Combustible or Other Dangerous Articles or Substances and Combustible Design Considerations: Systems for Measuring the Mass of 1.75 Commodity Austenitic Stainless SteeI Tubing for Electric Heaters: Simulated Shield Plug and Closure Cap for Penetrations Floor Valve, Reactor Refueling and Maintenance for rmal Insulation, Test for (1972) \$1.7/ Breaking

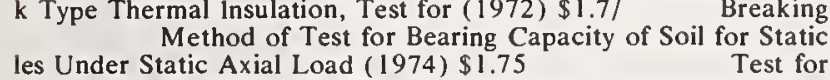
ationship for Individual Vertical Piles Under Static Axial

Automatic Spring eth/ Strength Properties of Adhesives in Shear by Tension ent System Components (6/73) m Components $(5 / 73)$

Design Limits and Design Limits and st for Fatigue Properties of Adhesives in Shear by Tension Additional Information: Wind and Tornado I Strength of Concrete (Using Simple Beam with Third Point pecial Nuclear Materials (11/73) General Use of

ring System (7-71)

e Neutron Flux Monitoring System (7-71)

(1973) IEEE 91-1973\$6.00

Protection System

d Practice for Standard Calibration and Format for Nuclear (1969) ASTM E273-1/ Method for Ultrasonic Inspection of Ultrasonic Inspection of Metal Pipe and Tubing for Ultrasonic Testing by the Reflection Method, Using Pulsed ersed Ultrasonic Testing by Reflection Method Using Pulsed low Alloy Steel Castings, Specification for (1973) ASTM / $\mathrm{s}$ for Pressure Vessels, Method and Inspection for (1974A)
Limit of Error Concepts and Principles of Calculation I Limit Values for Chemical Substances and Physical Agent Limited Accessibility in Fuel Reprocessing Plants and I Limited Accessibility (12/73)

Limiting Values, Recommended Practice for (1973) $\$ 1.75$ Limits and Fits for Cylindrical Parts (1967) (R1974) \$4

Limits and Loading Combinations for Metal Primary React Limits and Loading Combinations for Seismic Category 1 Line Break Accident for Boiling Water Reactors (Safety Linear Shrinkage of Preformed High Temperature Thermal Liner Materials and Prefabricated Silencers for Acousti Liner Welds (Revision 1, 8/11/72, of Safety Guide 19) Liners of Concrete Barriers in Fuel Reprocessing Plants Lines Penetrating Primary Reactor Containment (Safety G Liquid and Gaseous Effluents from Light-Water-Cooled Liquid Effluents from Light-Water-Cooled Power Reacto Liquid Level Control Monitor, Port Plug (Fabrication on Liquid Metal Fast Reactors (5-73) Supersedes E6-25T, Liquid Metal Fast Reactors (5-73) Supersedes E6-33T, Liquid Metal Leak Detector (10-72) Amendment 1 (6-73) Liquid Metal Piping Systems (11-71) Amendment 1 (12-7 Liquid Metal Piping Systems (4-74) Supersedes C4-5T, Liquid Metal Pressure Measurement System, Flush Mounted Liquid Metal Service (Fabrication Only) (7-72) Amendme Liquid Metal Service (12-73) Supersedes (10-72), Amen Liquid Metal Service (3-71) Amendment 1 (5-71); Super Liquid Metal Service (3-71) Amendment 1 (9-71), Amend Liquid Metal Service (3-72) Amendment 1 (3-74)

Liquid Metal Service (4-73)

Liquid Metal Service (5-72)

Liquid Metal Service (5-74)

Liquid Metal Service (5-75) Supersedes E 1-18T, (2-71

Liquid Metal Service (6-73)

Liquid Metal Service (6-74) Supersedes E1-19T, (9/70)

Liquid Metal Service (8-71) Amendment 1 (11-72), Amen

Liquid Metal Service (8-72) Amendment 1 (8-73), Amend

Liquid Metal Service (9-71) Supersedes E 10-3T, (9-70

Liquid Metal Systems (5-74) Supersedes E4-6T, (1-72)

Liquid Metal (3-75) Supersedes C5-1T, (4-70)

Liquid Metal (4-70) Amendment 1 (10-71)

Liquid Penetrant Inspection (1971) \$1.75

Liquid Penetrant Inspection (1974) $\$ 1.75$

Liquid Penetrant Inspection, Methods for ( 1969) (R 1973)

Liquid Phase Evaluation of Activated Carbon (1970) \$1.7

Liquid Sodium Bearing Film Thickness, Variable Reluctan

Liquid Sodium (1-72)

Liquid Sodium (1-72)

Liquid Sodium (1-72)

Liquid Sodium (1-72)

Liquid Sodium (1-72) Amendment I (6-73)

Liquid Sodium (8-74) Supersedes C4-4T, (1-71)

Liquid Waste Treatment System Design Guide for Pluton

Liquids into Submerged Containers, Test for (1973) $\$ 1.7$

Liquids on Board Vessels (1975) $\$ 7.50$

Liquids on Board Vessels (1975) $\$ 7.50$

Liquids (2/75)

List of Hazardous Materials (1975) $\$ 6.80$

Lithium Metal in Ingot Form, Specification for (1972) \$

LMFBR Core Components (5-72)

LMFBR Fuel Pins (3-72)

LMFBR Reactor Vessel Head (4-73) Amendment 1 (1-74

LMFBR(6-72) Amendment 1 (9-73), Amendment 2 (6-74)

Load and Calculated Flexural Strength of Preformed Bloc

Load on Spread Footings (1972) (ASTM D1194-1972) \$1.75

Load Settlement Relationship for Individual Vertical Pi

Load (1974) \$1.75

Test for Load Settlement Rel

Loaded Safety Valves (3-72) Amendment 1 (1-73)

Loading at Elevated Temperatures (Metal-to-Metal), M

Loading Combinations for Metal Primary Reactor Containm

Loading Combinations for Seismic Category I Fluid Syste

Loading (1973) $\$ 1.75$

Loadings $(11 / 74)$

Loading), Method of Test for (1966) (R1973) ASTM C78-

Locking Devices (3-69) Amendment 1 (10-71)

Locks in the Protection and Control of Facilities and $S$

Logarithmic Count Rate Source Range Neutron Flux Monito

Logarithmic Mean Square Voltage (MSV) Intermediate Rang

Logic Diagrams (Two State Devices), Graphic Symbols for

Logic (4-72) Amendment 1 (6-73)

Logs (1974) $\$ 1.00$

Recommende

Longitudinal and Spiral Welds of Welded Pipe and Tubing

Longitudinal Discontinuities, Method for (1974) \$1.75

Longitudinal Waves Induced by Direct Contact, Practice

Longitudinal Waves (1974) \$1.75 /Nded Practice for Imm

Longitudinal-Beam Ultrasonic Inspection of Carbon and

Longitudinal-Wave Ultrasonic Inspection of Steel Plate
NRC

ACGIH

NRC

NRC

ASTM

ANS

NRC

NRC

NRC

ANSI

ASTM

NRC

NRC

NRC

NRC

NRC

ERDA

ERDA

ERDA

ERDA

ERDA

ERDA

ERDA

ERDA

ERDA

ERDA

Pi ERDA

ERDA

ERDA

ERDA

ERDA

ERDA

ERDA

ERDA

ERDA

ERDA

ASTM

ASTM

ANS1

ASTM

ERDA

ERDA

ERDA

ERDA

ERDA

ERDA

NRC

DOT

USCG

NRC

DOT

ERDA

ERDA

ERDA

ERDA

ASTM

ANSI

ASTM

ASTM

ERDA

ANSI

NRC

NRC

Te ASTM

NRC

ANSI

ERDA

NRC

ERDA

ERDA

ANSI

ERDA

ANSI

ASTM

ASTM

ANSI

ASTM

RG 5.18

RG 3.28 RG 1.71 E29

B4.

RG 1.57

RG 1.48

RG 1.5

Z98.19

E477

RG 1.19

RG 3.27

RG 1.11

RG 1.21

RG 1.112

RDT E6-10T

RDT E6-25T

RDT E6-33T

RDT C8-4T

RDT E7-4T

RDT C4-5T

RDT C6-3T 
l (5-72), Amendment $2(1-74)$

FFTF Closed e to Abrasion of Small Size Coarse Aggregate by Use of the or Evaluating the Potential Radiological Consequences of A or Evaluating the Potential Radiological Consequences of $\mathrm{A}$ Combustible Gas Concentrations in Containment Following A choice of Sample Size to Estimate the Average Quality of A heet and Strip, Hot Rolled and Cold Rolled, High Strength,

Longitudinal-Beam Ultrasonic lnspection of Carbon and Control of Stainless Steel Weld Cladding of cation for (1973) AWS A5.5-1969 $\$ 3.50$

cation for (1974)

5 with Additional Requirements) (3-75) Supersedes M 1-/

eheat and Interpass Temperature Control for the Welding of requirements) (4-76) Supersedes $\mathrm{M} 2-2 \mathrm{~T}$, (/

quirements) (5-75) Supersedes M5-5T, (7-71)

ditional Requirements) (12-74) Supersedes M5-3T, (5-7/

al Requirements) (5-75) Supersedes M 3-11T,/

Carbon and Control of Preheat Temperature for Welding of piping Components/ Specification for Forgings, Carbon and es of Structural Quality, Specification for (1975) \$1.75 for (1974A) \$1.75 Pressure Vessel Plates, Carbon Steel, relevant to Maintaining Occupational Radiation Exposure as losophy for Maintaining Occupational Radiation Exposure as ecification for (1973) $\$ 1.75$

Seamless Cold Drawn Sodium Carbonate,

Thermal Insulation, Flexible or Molded, High Temperature, mendment 1 (9.73)

Recommended Practice for Measurement of -72) Amendment 1 (7.73)

mended Rules for Design and Construction of Large, Welded, equirements) (2-75) Su/ Alloy Steel Bolting Material for Specification for Seamless and Welded Steel Pipe for iping Fittings of Wrought Carbon Steel and Alloy Steel for Seamless and Welded Carbon and Alloy Steel Tubes for Protection Against

7) Pressure Vessel Plates, Carbon Steel for Moderate and or Electric-Fusion-Welded Steel Pipe for Atmospheric and f ( 1973$) \$ 1.75$ Measurement of Extreme Pressure Properties of d1367-1964 (R1973) \$1.75

ndbook $116 \$ 2.00$

st for (1973) ASTM C142-1971 \$1.75 Flow Properties of Method of Test for Radioactive SelfClay

$n$ of Small Size Coarse Aggregate by Use of the Los Angeles

gs, Spec. for (1973) $\$ 1.75$

Specification for (1973) (ASTM B366-1972) \$1./ Factory-

Factory-

ng Elements (1) Accelerated Life Test of Electrical Grade embly, Chromel-P Versus Alumel, Stainless Steel Sheathed, 72) vice (4-73)

) Supersedes C4-5T, (8-71)

Thermocouple Assemblies, in Core Permanent

castings (1971) $\$ 3.00$

ent of Austenitic St/ Ceramic-Insulated

for (1974) $\$ 1.75$

rence Photographs for (1969) (R1973) ASTM E125-1963 \$1./ Wet ASTM E109-1963 (1971) \$1.75 Dry Powder bols, Conventions, and References Relating to ( $1 /$ Nuclear $1 \$ 1$ Eddy-Current Testing of Steel Tubular Products with Recommended Practice for Measuring Coating Thickness by ase Alloys, Chemical Analy/ High Temperature, Electrical, als (1975)

boiling Water Reactor Nuclear Power Plants ( $\mathrm{Re} /$ Design of s Reasonably A chievable (Revisi/ Operating Philosophy for s Reasonably Achievable (Nuclear/ Information Relevant to -60 and Cesium-137 Teletherapy Equipment, Guidelines for filtration and Adsorption Units of / Design, Testing, and ment 2 (6-74) Floor Valve, Reactor Refueling and Operation and Inspection and Preventive $\begin{array}{rr}\text { cords (Revision 1, 12/75) } & \text { Collection, Storage, and } \\ \text { wer Plants (19/ Requirements for Collection, Storage, and }\end{array}$ 6/73)

ry Type Power Plant and Substation Lead Storage Batterie/ Emitting Products) for Diagnostic X-Ray Systems and Their ength Test Specimens in the Field, Method of (1970) AST.M/ tory, Method of (1973) ASTM C192-1969 \$1.75

Radiological Factors Affecting Decision

Preparation of an Environmental Report to Support a Rule
Loop in Reactor Assembly Fabrication (12-71) Amendment Los Angeles Machine, Method of Test for (1970) ASTM C13 Loss of Coolant Accident for Boiling Water Reactors ( $R e$ Loss of Coolant Accident for Pressurized Water Reactors Loss of Coolant Accident (Safety Guide 7, 3/10/71) Supp Lot or Process, Practice for (1972) \$1.75

Low Alloy Columbium and/or Vanadium, Specification for Low Alloy Steel Castings, Specification for (1973) ASTM Low Alloy Steel Components (5/73)

Low Alloy Steel Covered Arc Welding Electrodes, Specifi Low Alloy Steel Covered Arc Welding Electrodes, Specifi Low Alloy Steel Covered Welding Electrodes (ASME SFA-5 Low Alloy Steel for Use in Fuel Reprocessing Plants and Low Alloy Steel Forgings (ASME SA-182 with Additional Low Alloy Steel Plates (ASME SA-387 with Additional Re Low Alloy Steel Plates (ASME SA-533 with Additional Ad Low Alloy Steel Welded Pipe (ASME SA-155 with Addition Low Alloy Steel (5/73)

Low Alloy Steel, Requiring Notch Toughness Testing for Low and Intermediate Tensile Strength Carbon Steel Plat Low and Intermediate-Tensile Strength, Specification Low as Is Reasonably Achievable (Nuclear Power Reactors Low as Is Reasonably Achievable (Revision 1, 9/75)

Low Carbon Steel Heat Exchanger and Condenser Tubes, $\mathrm{Sp}$ Low Chloride Fire Extinguishing Agent (12-73)

Low Conductivity (5-72) Amendment 1 (4-73)

Low Friction Hard Surface for Core Components (5-73) a

Low Level Activity in Water (1972T \$1.75

Low Level Flux Monitor Mechanical System for Liquid Met

Low Lift and High Lift, Safety Std. for (1975) \$6.50

Low Pressure Storage Tanks (1973) \$4.00

Low Temperature Service (ASME SA-320 with Additional R

Low Temperature Service (1975) \$1.75

Low Temperature Service (1975) \$1.75

Low Temperature Service, Specification

Lower Temperature Service, Specification for (1974A) \$

Lower Temperatures (1974) ASTM A671-1972 \$1.75

Lubricating Grease (Four Ball Method) (1974) $\$ 1.75$

Lubricating Greases at High Temperatures, Measurement $O$

Lubricating Qualities of Graphites (1964) (R1974) ASTM

Luminous Light Sources, Classification of (1975) NBS Ha

Lumps and Friable Particles in Aggregates, Method of Te

Lungs (1975) $\$ 3.00$

Machine, Method of Test for (1970) ASTM C131-1969\$1. Macroetching Metals and Alloys (1974) \$1.75

Made Wrought Aluminum and Aluminum Alloy Welding Fittin Made Wrought Nickel and Nickel-Alloy Welding Fittings,

Made Wrought Steel Butt Welding Fittings (1971) $\$ 4.00$

Magnesium Oxide as Used in Sheathed Type Electric Heati

Magnesium Oxide Insulated (2-75) Supersedes C 7-6T, (

Magnesium Sulfate, Method of Test for (1973) \$1.75

Magnesium-Oxide Insulated, Stainless Steel Sheathed (1

Magnet Flow Through Type Flowmeter for Liquid Metal Ser

Magnet Flowmeter for Liquid Metal Piping Systems (4-74

Magnet Wire (7-70)

Magnetic Inspection Method, Quality Standard for Steel

Magnetic Instruments to Measure the Delta Ferritic Cont

Magnetic Particle Examination of Steel Forgings, Method

Magnetic Particle Indications on Ferrous Castings, Refe

Magnetic Particle Inspection (1971) \$1.75

Magnetic Particle Inspection (1974) \$1.75

Magnetic Particle Inspection, Method for (1969) (R1973)

Magnetic Resonance (NMR) Spectroscopy, Definitions, Sym

Magnetic Saturation, Practice for (1973) ASTM E309-197

Magnetic-Field or Eddy-Current (Electromagnetic) Test

Magnetic, and Other Similar Iron, Nickel, and Cobalt-B

Magnetized Materials (1975) $\$ 5.00$

Mailable Matter Under Special Rules, Radioactive Materi

Main Steam Isolation Valve Leakage Control Systems for

Maintaining Occupational Radiation Exposure as Low as I

Maintaining Occupational Radiation Exposure as Low as

Maintaining (1974) $\$ 3.50$

Maintenance Criteria for Atmosphere Cleanup System Air

Maintenance for LMFBR(6-72) Amendment 1 (9-73), Amend

Maintenance Manuals (10-71)

Maintenance of Fuel Shipping Containers (1-75)

Maintenance of Nuclear Power Plant Quality Assurance Re

Maintenance of Quality Assurance Records for Nuclear Po

Maintenance of Water Purity in Boiling Water Reactors (

Maintenance, Testing, and Replacement of Large Stationa

Major Components (1975) \$2.95 /Td. (Ionizing Radiation

Making and Curing Concrete Compressive and Flexural Str

Making and Curing Concrete Test Specimens in the Labora

Making in a Nuclear Attack (1974) $\$ 4.00$

Making Petition Seeking an Exemption for a Radionuclide
ERDA

ANSI

NRC

NRC

NRC

ASTM

ANSI

NRC

ANSI

ASME

ERDA

NRC

ERDA

ERDA

ERDA

NRC

ASTM

ASTM

ASTM

NRC

/Hi NRC

ASTM

ERDA

ERDA

ERDA

ASTM

ERDA

ANSI

API

ERDA

ASTM

ASTM

ASTM

NRC

ASTM

Ion F ANSI

ASTM

ASTM

ANS1

ANSI

ANSI

NCRP

ANSI

ASTM

ASTM

ANSI

ANS1

ASTM

ERDA

ASTM

ERDA

ERDA

ERDA

ERDA

MSS

AWS

ASTM

ANS1

ASTM

ASTM

ANSI

ASTM

ANS1

ASTM

ASTM

DOT

USPS

NRC

NRC

NRC

Cobalt ANS1

NRC

ERDA

ERDA

ERDA

NRC

ANSI

NRC

IEEE
BRH

ANS

ANS1

NCRP

NRC

RDT E8-11T

A37.7

RG 1.3

RG 1.4

RG 1.7

E122

G24.32

G52.7

RG 1.43

W3. 5

SFA-5.5

RDT M 1-4T

RG 3.29

RDT M2-2T

RDT M5-5T

RDT M5-3T

RDT M3-11T

RG 1.50

A

RG 8.8

RG 8.10

A 179

RDT M17-1T

RDT M 12-5T

RDT E6-38T

D3085

RDT E6-36T 
bs. $(1970) \$ 3.00$

purpose of Evaluating Com/ Calculation of Annual Doses to ounts of Radionuclides (1970) $\$ 4.00$ statistical Terminology and Notation for Nuclear Materials information for Safety Analysis Reports: Radioactive Waste inistrative Practices in Radiation Monitoring ( A Guide for $9-1971 \$ 1.75$ Radioactive
Radioactive

Specification For/ ressure Vessel Plates, Alloy Steel, Quenched and Tempered,

oy Steel, Quenched and Tempered, Manganese-Molybdenum and sure Vessel Plates, Alloy Steel, Manganese-Molybdenum and Pressure Vessel Plates, Carbon Steel, Pressure Vessel Plates, Heat Treated CarbonStainless Steel Globe and Angle Valves, Stainless Steel Gate Valves,

edition (1972) $\$ 12.50$

Air Sampling Instruments

1 and Biological Applications (1961) $\$ 3.00$

$$
00
$$

Industrial Ventilation: A

Std. Specifications for Operating

Operation and Maintenance Pipe Hangers and Supports-Material, Design and rature, Method of Test for (19/ easurements, Method of Test for (1973)/ Electrical Resistivity of Standard Definitions and Terms Relating to ection Contingency Measures for Uranium and Plutonium Fuel $3 \mathrm{~T},(11.74)$

supersedes F7-2T, (2-69) Amend/ Packaging, Packing, and

(1964) $\$ 4.00$ Safety Color Code for Standard

s Containers to Identify the Material Contained, Method of Truck Identification with Additional Requirements) (4-75) Supersedes M7-1T/ a-182 with Additional Requirements) (3-75) Supersedes / Nuclear Material ControI, Design Considerations: Systems for Measuring the or Special Nuclear Material Licenses of Less Than Critical and Small Components (2-72)

ode (1973) $\$ 1.75$

ing Mode (1973) $\$ 1.75$ $r$ in the Tracer Probe Mode (/ Testing for Leaks Using the st for Atom Percent Fission in Uranium and Plutonium Fuel stm / Atom Percent Fission in Uranium and Plutonium Fuel uranium Dioxide Powders and Pellets, Methods for Chemical, utonium Dioxide Powders and Pellets, Methods for Chemical, lear Grade Uranium Dioxid/ Standard Methods for Chemical, lear Grade Plutonium Diox/ Standard Methods for Chemical,

ear Grade Mixed Oxides ( (U,Pu)O( 2$)$ ), Methods for Chemical,

clear Grade Uranium Dioxide Powders and Pellets, Chemical,

ear Grade Plutonium Dioxide Powders and Pellets, Chemical, 74) \$/ Nuclear Grade Mixed Oxides ((U,Pu)O( 2$)$ ), Chemical, 75) $\$ 1.75$

Berylium Bride Powders, Chemical, d Physical Tests on (/ Beryllium Oxide Powders, Chemical, emical Analysis of Nuclear Grade Plutonium Nit/ Chemical, hemical Analysis of Nuclear Grade Plutonium Me/ Chemical, hemical Analysis of Uranium Hexafluoride, Meth/ Chemical, hemical Analysi/ Nuclear Grade Plutonium Metal, Chemical,
hemical, Analysis of (19/ Uranium Hexafluoride, Chemical, lutions and Plutonium Metal Standard Methods for Chemical, onium Nitrate Solutions, Methods for (1974) As/ Chemical, Visual Surveillance of Individuals in

I of Personnel Access to Protected Areas, Vital Areas, and analytical Chemistry Laboratories for Control Rod Absorber lumel, Stainless SteeI Sheathed, Magnesium / Thermocouple $1,4 / 75$ )

Selection of

Nondestructive Assay for Plutonium in Scrap Nondestructive Assay of Special Nuclear a C4 / Portable Compressed Gas Containers to ldentify the clea/ Standard Format and Content for the Special Nuclear de to Practice (1971) $\$ 4.50$

Nuclear

Nuclear s (A Guide to
sion $1,6 / 75$ )

Nuclear

3.00

$\$ 5.50$

e for Determ/

(1960)

1961)

h Additional Requirements) (2-75) S/

Additional Requirements) (2-75) $\mathrm{Su}$ /

Nuclear Power Reactors, Nuclear

Fuel Reprocessing Facilities, Nuclear

Nuclear

Special Nuclear
Changes in Chemical Reactivity of Inorganic

Background

Background

Alloy Steel Bolting

Alloy Steel Bolting
Malleable Iron Threaded Pipe Unions 150, 250, and $300 \mathrm{~L}$

Man from Routine Releases of Reactor Effluents for the

Management of Patients Who Have Received Therapeutic Am

Management (1972) $\$ 3.00$

Management (4/75)

Management) (1969) $\$ 4.25$

Manganese in Water, Method of Test for (1973) ASTM D203

Manganese in Water, Test for (1974) \$1.75

Manganese-Molybdenum and Manganese-Molybdenum-Nickel

Manganese-Molybdenum and Manganese-Molybdenum-Nickel

Manganese-Molybdenum-Nickel Alloy, (1974) \$1.75

Manganese-Molybdenum-Nickel, Specification for (1974a

Manganese-Silicon, Specification for (1974A) \$1.75

Manganese-Silicon, Specification for (1975) \$1.75

Manual and Power Operated (3-72)

Manual and Power Operated (3-72) Amendment 1 (5-74)

Manual for Evaluation of Atmospheric Contaminents, 4 th

Manual Initiation of Protective Actions (10/73)

Manual of Radioactivity Procedures (A) Stds. (B) Medica

Manual of Recommended Practice, 13 th Edition (1974) \$5

Manual of Steel Construction (1973) $\$ 20.00$

Manually Lever Operated Chain Hoists (1974) $\$ 0.50$

Manuals for Fuel Shopping Containers (1-75)

Manuals (10-71)

Manufacture (1967) \$4.00

Manufactured Carbon and Graphite Articles at Room Tempe

Manufactured Carbon and Graphite Articles by Physical M

Manufactured Carbon and Graphite (1975) \$1.75

Manufacturing Plants (6/74)

Marking of Components and Parts (6-75) (Supersedes F7

Marking of Components for Shipment and Storage (9-75)

Marking Physical Hazards (1971) $\$ 3.00$

Marking System for Valves, Fittings, Flanges and Unions

Marking (1954) (R1971) CGA C4 \$2.00 /Ble Compressed Ga

Markings (1/74)

Martensitic Stainless Steel (Type 403) Bars (ASTM a 276

Martensitic Stainless Steel (Type 403) Forgings (ASME S

Mass Calibration Techniques for (1975) $\$ 5.50$

Mass of Liquids (2/75)

Mass Quantities (7/76)

/ Preparation of Applications F

Mass Spectrometer Helium Leak Detection for Instruments

ass Spectrometer Leak Detector in the Detector Probe M

Mass Spectrometer Leak Detector in the Inside-Out Test

Mass Spectrometer Leak Detector or Residual Gas Analyze

(Mass Spectrometric Method) (1974) \$1.75

(Mass Spectrometric Method), Method of Test for (1973) a

Mass Spectrometric, and Spectrochemical Analysis of Nuc

Mass Spectrometric, and Spectrochemical Analysis of Nuc

Mass Spectrometric, and Spectrochemical Analysis of Nuc

Mass Spectrometric, and Spectrochemical Analysis of Nuc

Mass Spectrometric, and Spectrochemical Analysis of (19

Mass Spectrometric, and Spectrochemical Analysis of (19

Mass Spectrometric, and Spectrochemical Analysis of ( 19

Mass Spectrometric, and Spectrochemical Analysis of (19

Mass Spectrometric, and Spectrochemical Analysis of (19

Mass Spectrometric, and Spectrochemical Analysis Of, an

Mass Spectrometric, and Spectrochemical Analysis Of, an

Mass Spectrometric, Spectrochemical Nuclear and Radioch

Mass Spectrometric, Spectrochemical, Nuclear and Radioc

Mass Spectrometric, Spectrochemical, Nuclear and Radioc

Mass Spectrometric, Spectrochemical, Nuclear and Radioc

Mass Spectrometric, Spectrochemical, Nuclear and Radioc

Mass Spectromętric, Spectrochemical, Nuclear and Radioc

Mass Spectrometric, Spectrochemical, Nuclear Grade Plut

Material Access Areas (11/73)

Material Access Areas (6/73)

Material Analysis (7.73)

Contro
/Alification and Control of

Material and Thermocouple Assembly, Chromel-P Versus a

Material Balance Areas and Item Control Areas (Revision

Material by Spontaneous Fission Detection (6/74)

Material Contained in Scrap and Waste (10/73)

Material Contained, Method of Marking (1954) (R1971) Cg

Material Control and Accounting Section of a Special Nu

Material Control Systems for Conversion Facilities, Gui

Material Control Systems for Fuel Fabrication Facilitie

Material Control Systems for Nuclear Power Plants (Revi

Material Control Systems for (1974) $\$ 3.50$

Material Control Systems (A Guide to Practice) (1974) \$

Material Control, Mass Calibration Techniques for ( 1975

Material Doorway Monitors (6/74)

Material Exposed to High Energy Radiation, Rec. Practic

Material for Development of Radiation Protection Stds.

Material for Development of Radiation Protection Std. (

Material for High Temperature Service (ASME SA.193 Wit

Material for Low Temperature Service (ASME SA-320 with

Material for Nuclear and Other Special Applications Ast
MSS

NRC

NCRP

ANSI

NRC

ANSI

ANSI

ASTM

ASTM

ASTM

/All ASTM

ASTM

ASTM

ASTM

ERDA

ACGlH

NRC

NCRP

ACGIH

AISC

HMI

ERDA

ERDA

ANSI

ANSI

ASTM

NRC

ERDA

ERDA

ANSI

MSS

ANS

NRC

ERDA

ERDA

NRC

NRC

ERDA

ASTM

ASTM

Te ASTM

ANSI

ANSI

NRC

NRC

ANSI

ASTM

ASTM

ASTM

ASTM

ANS1

ASTM

ASTM

ANSI

ANSI

ASTM

ASTM

NRC

ANSI

NRC

NRC

ERDA
ERDA

NRC

NRC

NRC

ANS1

NRC

ANSI

ANSI

NRC

ANS1

ANS1

ANSI

NRC

ASTM

EPA

EPA

ERDA

ERDA

ANSI

SP-76

RG 1.109

R37

N15.5

RG 1.70.27

N13.2

N156

D2039

A 302

A 533

A5 33

A 302

A299

A 537

DT E'1-21T 
ecification for Special Requirements for (1973)/ ditional Requirements) (2-75) Super/

Alloy Steel Bolting Background ing Plant/Design Objectives for Highly Radioactive Solid erations for Minimizing Residual Holdup of Special Nuclea erations for Minimizing Residual Holdup of Special Nuclear terial Control and Accounting Section of a Special Nuclea de for the Preparation of Applications for Special Nuclear e to Academic Institutions Applying for Specific Byproduct Conduct of Nuclear

ion Sy/ Specifications of Ge(Li) Spectroscopy Systems for Irreversible and Irretrievable Commitments of

Exemptions from Certain NRC Requirements Over Radioactive eaf $(\$ 55.00)$

Power Boilers

Statistical Evaluation of

icle and Armed Guards for Road Shipment of Special Nuclear

ly of Unirradiated Reactor Fuel and Associated Radioactive aschig Rings as a Neutron Absorber in Solutions of Fissile aschig Rings as a Neutron Absorber in Solutions of Fissile ty Seals for the Protection and Control of Special Nuclear mendment 1/ Metal Sheathed, Mineral Insulated Cable Bulk Control and Accountability of Plutonium in Waste Internal Transfers of Special Nuclea dures for Picking Up and Receiving Packages of Radioactive istrative Guide for Packaging and Transporting Radioactive Use of Process Data for the Protection of Special Nuclear exempted and Generally Licensed Items Containing Byproduct

Analytical Chemistry Methods for Boron Carbide Absorbe preparation of Applications for Licenses to Process Source ts (1968) (R197/ Calculation of Neutron Dose to Polymeric

Safety Analysis Reports: Reactor Coolant Pressure Boundary ds $(10 / 73)$

d Airflow Performance, Testing (1973) $\$ 1.75$

Duct Liner

$\mathrm{n}$ and Testing Agencies for Concrete, Steel, and Bituminous test for (1975) ASTM C177-1971/ Thermal Conductivity of 1971) $\$ 1.75$

70) $\$ 1.75$ 1971

Thermal Conductivity of Thermal Conductivity of

of Test for Indentation Hardness of Metallic sticity and Fundamental Frequencies of Carbon and Graphite Test for lmpedance and Absorption of Acoustical Statistical Terminology and Notation for Special Nuclea Records and Reporting Units for Nuclear of Error Concepts and Principles of Calculation in Nuclear

of Error Concepts and Principles of Calculation in Nuclea tric Assay of Plutonium-Bearing Solids Applied to Nuclear $s$ by Washing, Method of Test for (1970) ASTM C117-1969) ystem for (1975) $\$ 1.75$

(R1975) ASTM C171-1969 (1975) \$1.75

Elastomeric

Information for Safety Analysis Reports: Metallic

5.00

tion System for (ASTM D2953-1971) (1973) \$1.7/ Polymeric tion System for (1971) \$1.75

1970) $\$ 1.75$

Alloy Steel Bolting

) Supersedes M1/ Operating Performance of Anion Exchange erations for Minimizing Residual Holdup of Special Nuclea ater-Cooled Powe/ Calculation of Releases of Radioactive Radioactivity in Solid Wastes and Releases of Radioactive $89 \$ 7.00$ Sampling Airborne Radioactive

Test for Sound Absorption of Acoustical

Statistical Terminology and Notation for Nuclea

Nuclear Criticality Safety in Operations with Fissionable

Nuclear Criticality Safety in Operations with Fissionable nd Plutonium Fuel Manufacturing Plants (6/74)

partment of Transportation Special Permits for Radioactive

Auditing Nuclear

ation of Standards and Equipment for Electrical lnsulating (R 1973) ASTM D1672-1966 (1971) \$/ Exposure of Polymeric 1966) (R1971) \$1.75

ons (10-67)

Exposure of Polymeric

for Leakage Tests on Packages for Shipment of Radioactive

Code Case Acceptability: ASME Section Ii

e Protection and Control of Facilities and Special Nuclear Information for Safety Analysis Reports: Reacto Safe Handling of Radioactive

thods for Semi-Guided Bend Test for Ductility of Metallic

Test for Airflow Resistance of Acoustical

Tension Testing of Metallic

ice for Constant Amplitude Axial Fatigue Tests of Metallic on of Constant Amplitude Fatigue Test Results for Metallic

Notched Bar Impact Testing of Metallic

nded Practice for Scleroscope Hardness Testing of Metallic Physical Inventories of Nuclear
Material for Nuclear and Other Special Applications, Sp Material for Special Applications (ASME SA-540 with Ad Material for the Development of Radiation (1964)

Material Handling and Storage Facilities in a Reprocess Material in Drying and Fluidized Bed Operations (Revisi Material in Equipment for Dry Process Operations ( $1 / 75$ ) Material License Application (Including That for a Uran Material Licenses of Less Than Critical Mass Quantities Material Licenses (3/76)

Material Physical Inventories (11/73)

Material Protection Measurements, Part I: Data Acquisit

Material Resources (Revision 1, 6/76)

Material Shipments (6/75)

Material Specifications ( 1977 )

Material Symbol (1971) $\$ 2.75$

Material Unaccounted for $(6 / 74)$

Material (Revision 1, 4/75)

Material (10/73)

Material (1971) ANS-8.3\$7.50

Material (1/73)

Material ( $1 / 74)$

Material (2-73)
Material $(2 / 75)$

Material $(3 / 75)$

Material (5/75)

Material (6/74)

Material $(6 / 74)$

Material $(6 / 74)$

Material (7.73)

Material (7/76)

Materials and Appli

Appection (1/75)

Materials and Prefabricated Silencers for Acoustical an

Materials as Used in Construction (1973) ASTM E329-197

Materials by Means of the Guarded Hot Plate, Method of

Materials by Means of the Guarded Hot Plate, Test for (

Materials by Means of the Heat Flow Meter, Test for (19

Materials by Portable Hardness Testers (1974) ASTM E 110

Materials by Sonic Resonance (1974) $\$ 1.75$

Materials by the Tube Method (1972) $\$ 1.75$

Materials Control Accountability (2/2/73)

Materials Control (1971) $\$ 3.25$

Materials Control (1974) $\$ 3.00$

Materials Control (1975) $\$ 5.50$

Materials Control (1.74)

Materials Control, Calibration Techniques for the (1975

Materials Finer Than No. 200 Sieve in Mineral Aggregate

Materials for Automotive Applications, Classification S

Materials for Curing Concrete, Specifications for (1970

Materials for Engineered Safety Features (2/75)

Materials for Instruments in Radiation Service (1957) \$

Materials for Service in Ionizing Radiation, Classifica

Materials for Service in lonizing Radiation, Classifica

Materials for Special Applications, Specification for (

Materials for Strong Acid Removal (1972) \$1.75

Materials for Use on Austenitic Stainless Steel (10-72

Materials in Equipment for Wet Process Operations (6/74

Materials in Gaseous and Liquid Effluents from Light-W

Materials in Liquid and Gaseous Effluents from Light-W

Materials in Nuclear Facilities, Guide to (1969) ISO 28

Materials in Reverberation Rooms (1972) \$1.75

Materials Management (1972) $\$ 3.00$

Materials Outside Reactors (1975) ANS-8.1 \$10.00

Materials Outside Reactors (1/73)

Materials Protection Contingency Measures for Uranium a

Materials Shipments, Administrative Guide for (1973) \$3

Materials Statements (1973) $\$ 3.50$

Materials Testing (1971) \$1.75

Ed Practice for Calibr

Materials to High Energy Radiation, Practice for (1968)

Materials to High Energy Radiation, Rec. Practice for (

Materials Used in Reactor Coolant System Wear Applicati

Materials (ASME SA-453 with Additional Requirements)

Materials (Issued for Trial Use and Comment) (1973) \$4.

Materials (Revision L, 5/76)

Materials (11/73)

Materials (12/74)

Materials (1964) $\$ 2.00$

Materials ( 1969) ASTM E290-1968 \$1.75

Materials (1969) $\$ 1.75$

Materials (1969) $\$ 1.75$

Materials (1972T) $\$ 1.75$

Materials (1972T) $\$ 1.75$

Materials (1972) $\$ 1.75$

Materials (1972) $\$ 1.75$

Materials (1972) $\$ 3.25$
ASTM

ERDA

EPA

ANSI

NRC

NRC

NRC

NRC

NRC

NRC

NRC

NRC

NRC

ANSI

NRC

NRC

ANSI

Securi NRC

ERDA

NRC

NRC

Proce NRC

Admin NRC

nalysis and NRC

NRC

ERDA

NRC

ASTM

NRC

NRC

ASTM

ANS1

ANS1

ASTM

ASTM

ANS1

Duli of Ela ASTM

ASTM

NRC

ANS1

Limit ANS1

ANS1

Limit NRC

ANS1

ANS1

ASTM

ANSl

NRC

ISA

ANS1

ASTM

ASTM

ASTM

ERDA

NRC

NRC

NRC

ANS1

ASTM

ANSI

ANSI

NRC

NRC

ANSl

ANS1

ASTM

ANSI

ASTM

ERDA

ERDA

ANSI

NRC

General Use of Locks in th NRC

NRC

NCRP

Me ANSI

ASTM

ASTM

Recommended Pract ASTM

/Ended Practice for Presentati

ASTM

ASTM

Recomme ASTM

ANSI

A614

RDT M6-5T

FRC5

N305

RG 5.8

RG 5.42

RG 5.45

RG 10.3

RG 10.2

RG 5.13

RG 5.9

RG 4.10

RG 7.5

SEC-I

NI2.I

RG 5.33

RG 5.31

RG 3.15

NG 3.4

RDT C17-57

RG 5.47

RG 5.49 
Methods of Sampling of Particulate Ion Exchange Sharp-Notch Tension Testing of High Strength Sheet Recommended Practice for Ultrasonic Velocity in ilure Under Electric Stress of Solid Electrical Insulatin relating to Acoustical Tests of Building Constructions and nd Transportation of Radioactively Contaminated Biologica Guide for Liability Insurance Aspects of Shipping Nuclea Administrative Guide for Transporting Radioactive hod of Test for Rockwell Hardness of Fine Grained Graphite nded Practice for Determination of Corrosivity of Adhesive ing Pressure Sealing Properties of Rubber and Rubber-Like Definitions of Terms Relating to Rubber and Rubber Like Nonmailable Matter, Radioactive Mailable Matter Under Special Rules, Radioactive e with Packaging Requirements for Shipments of Radioactive Transportation of Dangerous Articles and Magnetized Commodity List of Hazardous Part A: Ferrous Part B: Nonferrous on for Safety Analysis Reports: Steam and Feedwater System nd Transportation of Radioactively Contaminated Biologica $r$-Receiver Differences in the Transfer of Special Nuclea Leakage Tests on Packages for Shipment of Radioactive Seals on Containers for Onsite Storage of Special Nuclear 1 Elements on Predicted Radiation Damage to Reactor Vesse

Guides (For Hazard Evaluation of Industrial Chemicals and

$r$-Receiver Differences in the Transfer of Special Nuclea Thermal Insulating Neutron Activation Detecto Selection of Neutron Activation Detecto Nuclear Criticality Safety in the Storage of Fissile Shipping Packages for Type a Quantities of Radioactive Vickers Hardness of Metallic

Test for Plane-Strain Fracture Toughness of Metallic ell Hardness and Rockwell Superficial Hardness of Metallic Tension Testing of Carbon Graphite Mechanical Std. Grade (8-72) Amendm/ Thermocouple Elevated Temperature Tension Tests of Metallic Energy Radiation on the Mechanical Properties of Metallic 75) $\$ 2.50$ Facilities Handling Radioactive Energy Radiation on the Mechanical Properties of Metallic Nylon Injection Molding and Extrusion Polyethylene Plastics Molding and Extrusion Density of Blanket-Type or Batt-Type Thermal Insulating Fiberglass Insulated, and Sheathed Over Fi/ Fiberglass Insulated, and Sheathed Over Fi/
Sheathed (4-70) Supersedes C7-14T, (3-7/ Thermocouple Thermocoupl Pipe Hangers and Supportsiberglass Insulated, and Sheathed Over Fibe/ Thermocouple athed (4-70) Supersedes C7-14T, (3-70),

Thermocouple Dispersion in Natural Water Bod/ Reporting Procedure for eposit) (1969) $\$ 1.75$

4) $\$ 1.75$ y (1974) $\$ 1.7$ Test for Particulate I Rules ( 1975)

Types of Microorganisms and Microscopic Recommended Practices for Volatile Organic Particulate and Dissolved

Mailable Radioactive Std. Method for Sampling Stacks for Particulate Nonmailable Matter: Written, Printed and Graphic Regulatory Staff Position Statement on Antitrust Nonmailabl Nonmailable

e Concentrations of Radionuclides in Air and in Water Fo/ air and in Water Fo/ Maximum Permissible Body Burdens and filters for Laboratory Use, Test for (1969) $\$ 1.75$

astm C447-1971 \$1.75 Method of Test for Determining the (1963) (R1975) (ASTM C312-1955) \$1.75

1) $(\mathrm{R} 1973) \$ 1.75$

ux Monitoring System (7-71)

Logarithmic

mal Conductance and Transmittance of Built-Up Sections by 5) ASTM C177-1971/ Thermal Conductivity of Materials by Thermal Conductivity of Materials by Thermal Conductivity of Materials by

tandard Procedures for Calibrating Magnetic Instruments to of Neutrons and Gamma Rays (1961) \$2.00 ng Grease (Four Ball Method) (1974) \$1.75 5 hod for (1973) ASTM C558-1969 \$1.75

Test for d Biological Applications (1960) $\$ 2.00$

Recommended Practice for d Biological Application
hexafluoride $\left(\mathrm{UF}_{6}\right) 2 /$

Standard Analytical Methods for the Lattice Spacing of Nuclear Graphite

in Nuclear Reactor Coolant Water During Reactor Operation, of Industrial Water and Industrial Waste Water, Method for Alpha Particle Radioactivity of Water, Method of
Materials (1973) ASTM D2687-1972 \$1.75 Materials (1973) $\$ 1.75$

Materials (1973) $\$ 1.75$

Materials (1973) $\$ 1.75$

Materials (1973) $\$ 1.75$

Materials (1973) $\$ 3.50$

Materials (1973) $\$ 3.50$

Materials (1973) $\$ 4.50$

Materials (1974) ASTM C748-73 \$1.75

Materials (1974) $\$ 1.75$

Materials (1974) $\$ 1.75$

Materials (1975A) $\$ 1.75$

Materials (1975)

Materials (1975)

Materials (1975) $\$ 4.50$

Materials (1975) $\$ 5.00$

Materials (1975) $\$ 6.80$

Materials (1977) bd (\$90.00), $11(\$ 125.00)$

Materials (1977) bd $(\$ 90.00), 11(\$ 125.00)$

Materials (4/75)

Materials $(6 / 74)$

Materials $(6 / 74)$

Mator:- (v/ 15 )

Materials $(7 / 73)$

Materials (7/75)

Materials) (1955-1975) $\$ 1.00$ ea.

Materials

Materials, Guide for Selection of (1973) \$1.75

Materials, Guide for (1974) ASTM E419-1973\$1.75

Materials, Guide for (1975) ANS-8.7 \$12.00

Materials, Guide to Design and Use of (1975) $\$ 5.00$

Materials, Method of Test for ASTM E92-1972 \$1.75

Materials, Method of (1974) \$1.75

Materials, Methods of Test for (1974) $\$ 1.75$

Materials, Methods of (1973) ASTM C565-1971 \$1.75

Materials, Platinum and Platinum 10 Percent Rhodium Wi

Materials, Practice for (1970) $\$ 1.75$

Materials, Practice for (1973) ASTM E184-1962 \$1.75

Materials, Recommended Fire Protection Practice for ( 19

Materials, Rec. Practice for (1962) (R1968) \$1.75

Materials, Specification for (1973) $\$ 1.75$

Materials, Specification for (1974) $\$ 1.75$

Materials, Test for (1970) $\$ 1.75$

Material, Chromel-P and Alumel, Solid Conductor (Bare,

Material, Copper ano Constantan, Solid Conductor (Bare,

Material, Copper-Constantan, Mineral-Oxide Insulated,

Material, Design and Manufacture (1967) $\$ 4.00$

Material, Iron and Constantan, Solid Conductor (Bare, F

Material, lron Constantan, Mineral Oxide Insulated, She

Mathematical Models Selected to Predict Heated Effluent

Matter in the Atmosphere (Optical Density of Filtered D

Matter in Water and Waste Water, Identification of (197

Matter in Water by Aqueous-Injection Gas Chromatograph

Matter in Water, Tests for (1974) $\$ 1.75$

Matter Nonmailable Articles and Substances Under Specia

Matter Under Special Rules, Radioactive Materials (1975

Matter (1971) Free

Matter (1973) ASTM D2928-1971 \$1.75

Matter (1975)

Matters (12/73)

Matter: Written, Printed and Graphic Matter (1975)

Matter, Radioactive Materials (1975)

Maximum Permissible Body Burdens and Maximum Permissib

Maximum Permissible Concentrations of Radionuclides in

Maximum Pore Diameter and Permeability of Rigid Porous

Maximum Use Temperature of Preformed Insulation (1973)

Mean Specific Heat of Thermal Insulation, Practice for

Mean Specific Heat of Thermal Insulation, Test for (196

Mean Square Voltage (MSV) Intermediate Range Neutron F

Means of the Guarded Hot Box, Method of Test for (1967)

Means of the Guarded Hot Plate, Method of Test for (197

Means of the Guarded Hot Plate, Test for (1971) \$1.75

Means of the Heat Flow Meter, Test for (1970) $\$ 1.75$

Measure the Delta Ferritic Content of Austenitic Stain

Measurement of Absorbed Dose of Neutrons, and Mixtures

Measurement of Extreme Pressure Properties of Lubricati

Measurement of Gamma Radioactivity of Water (1973) $\$ 1.7$

Measurement of Lattice Spacing of Nuclear Graphite, Met

Measurement of Low Level Activity in Water (1972T \$1.75

Measurement of Neutron Flux and Spectra for Physical an

Measurement of Uranium Tetrafluoride $\left(U F_{4}\right)$ and Uranium

Measurement of (1969) (R1975) $\$ 1.75$

Measurement of (1970) \$1.75

/Mitting Fission Products

Measurement of (1973) ASTM D1690-1961 (1969) \$1.75

Measurement of (1973) ASTM D1943-1966\$1.75
ANSI

ASTM

ASTM

ASTM

ASTM

ANS1

ANS1

Met ANSI

ASTM

ASTM

ASTM

USPS

USPS

ANS1

DOT

ASME

ASME

formati NRC

NRC

NRC

NRC

NRC

NRC

ANSI

ASTM

ASTM

ANSI

ANSI

ANSI

NSI

ASTM

ASTM

ANSI

ERDA

ASTM

ANS1

NFPA

lgh ASTM

ASTM

ASTM

ASTM

ERDA

ERDA

ERDA

MSS

RDA

ERDA

NRC

ASTM

A STM

ASTM

ATM

USPS

ISPS

USPS

ANSI

USPS

NRC

USPS

USPS

NCRP

NCRP

ASTM

ANS1

ANS1

ASTM

ERDA

ANSI

ANSI

ASTM

ASTM

AWS

ASTM

ASTM

ANSI

NCRP

NRC

ASTM

ASTM

ANS

ANSI

Z111.12

E338

E494

D3151

C634

N14 GUIDE

N14.10.1

K90.14

D3310

D 1081

D 1566

POSTL 123.2

POSTL 124.2

N14.10.3

14CFR 103

49CFR 172

SEC-IIA

SEC-11B

RG 1.70 .28

RG 7.2

RG 5.28

RG 7.4 
reactor Coolant Water During Reactor Operation, Method for ow Properties of Lubricating Greases at High Temperatures, rsedes C5-1T, (4-70)

dment $1(10-71)$

nductive Level nductive, Absolute or Gage (10-70/ $\quad$ Liquid Metal Pressure Temperature

Airborne Sound Insulation in Buildings, Rec. Practice for Definitions of Terms Relating to Temperature Fast Neutron Flux Fast Neutron Flux ) ASTM E418-1973\$1.75 Conducting Subcritical Neutron Multiplication is of I-131 in Milk (9/73)

ing and Analysis of Plutonium in Soil (5/74)

tium-89 and Strontium-90 Analyses (5/74)

Thyroid Radioiodine Uptake

to Polymeric Materials and Application of Threshold-Foil gth of Undrained Rock Core Specimens Without Pore Pressure

$r$ of Manufactured Carbon and Graphite Articles by Physical ons of Ge(Li) Spectroscopy Systems for Material Protection lants $(6 / 74)$

Materials Protection Contingency Current (Electromagnetic) Test/ Recommended Practice for num (1973) ASTM E266-1970\$1.75 Method for (1973) ASTM E263-1970 \$1.75 1 ( 1973) ASTM E264-1970 \$1.75 (1973) ASTM E265-1970 \$1.75 Methods for Method for Method for Method for es (1973) ASTM E262-70 \$1.75 uranium-288 Fission (1974) ASTM E393-1973 \$/ Method for stometer (1973) $\$ 1.75$

the Earth, Guide for (1962) $\$ 3.60$

Std. Spec. for Automatic Null Balancing Electrical 973) ASTM E261-1970 \$1.75 balt and Silver (1973T)

Design Considerations: Systems for Thermal Neutron Flux by Radioactivation Techniques, Fast Neutron Flux by Radioactivation of Iron Fast Neutron Flux by Radioactivation of Nickel,

Fast Neutron Flux by Radioactivation of Aluminum, analysis of Barium-140 Produced by Uranium-238 Fission, olid Wastes and Releases of Radioactive Materials in Liq/ Practice for (1973) ACl 304-1973 \$2.75

ation for Safety Analysis Reports: Environmental Design of hase of Nuclear/ Installation, Inspection, and Testing of Requirements for Installation, Inspection, and Testing of

$\$ 1.75$

$d$ for (1972) $\$ 4.00$

or (1973) ASTM E/ Effects of High Energy Radiation on the ice for (1962) (/ Effects of High Energy Radiation on the

$f$ Fuel Element Cladding lncluding the Determination of the

Fuel Element Cladding lncluding the Determination of the Only) (7-72) Amendment I (7-73/ Low Level Flux Monitor Information for Safety Analysis Reports: Methods and Definitions for Standard Methods for Seamless Stainless Steel

egory 1 Concrete Structures (Revision 1, 1/2/73 Safety G/ (10-72) Amendment I (3-74) Core Restraint

2), Amen/ Collapsible Rotor, Roller Nut Control Rod Drive

a Manual of Radioactivity Procedures (A) Stds. (B)

$s$ for Waste Disposal of Phosphorus-32 and Iodine-131 for to $10 \mathrm{Mev}$ : Equipment Design and Use (1968) $\$ 3.00$

to $10 \mathrm{MeV}$ Structural Sheilding Design and Evaluation (19/ to $10-\mathrm{Mev}$, General Safety Sta/ Installations Using NonRadiation in Veterinary
Seamless 2-73)

ification for (1973) $\$ 1.75$

nd Additional Requirements) (3-74)

Seamless

i-0.50Al-19-Fe Consumable Electrode or Vacuum Induction

-0.90Ti-0.50A 1 Consumable Electrode or Vacuum Induction and Heat Resis/ Consumable Electrode or Vacuum Induction

-0.90Ti-0.50A 1 Consumable Electrode or Vacuum Induction

Resistant Nickel Consumable Electrode or Vacuum Induction Safety Considerations for Nuclear Power Plants on Method of Test for Total

n Electron Microprobe (9-7/ rements) (4-75) Supersede/ $1969 \$ 2.50$ Test for Buffering Action of Test for Rinsing Properties of

Chemical Analysis of Industrial s ANSI C37.20A-1970, C/
Measurement of (1973) ASTM

Measurement of (1973) \$1.75

Measurement Sensor for Use in Liquid Metal (3-75) Supe

Measurement Sensor for Use in Liquid Metal (4-70) Amen

Measurement System (1-76)

Measurement System, Flush Mounted, Eddy Current Type, 1

Measurement Thermocouples (1964) (R1969) \$6.00

Measurement (1971) $\$ 1.75$

Measurement (1974) \$1.75

Measurements by Track-Etch Technique (1973) $\$ 1.75$

Measurements by Track-Etch Technique, Method for (1974

Measurements in Situ, Safety in (1975) ANS-8.6 \$6.50

Measurements of Radionuclides in the Environment-Analy

Measurements of Radionuclides in the Environment: Sampl

Measurements of Radionuclides in the Environment: Stron

Measurements Using a Neck Phantom (1973) $\$ 3.00$

Measurements (1968) (R1973) \$1.75 /Ion of Neutron Dose

Measurements (1974) \$1.75

( Triaxial Compressive Stren

Measurements, Method of Test for (1973) ASTM C559-1969

Measurements, Part I: Data Acquisition Systems (Revisio

Measures for Uranium and Plutonium Fuel Manufacturing $P$

Measuring Coating Thickness by Magnetic-Field or Eddy-

Measuring Fast Neutron Flux by Radioactivation of Alumi

Measuring Fast Neutron Flux by Radioactivation of Iron

Measuring Fast Neutron Flux by Radioactivation of Nicke

Measuring Fast Neutron Flux by Radioactivation of Sulfu

Measuring Fast Neutron Flux by Radioactivation Techniqu

Measuring Fast Neutron Flux for Barium 140 Produced by

Measuring Flow Rates of Thermoplastics by Extrusion Pla

Measuring Ground Resistance and Potential Gradients in

Measuring Instruments (1966) (R 1972) \$4.75

Measuring Neutron Flux by Radioactivation Techniques (1

Measuring Neutron Flux Density by Radioactivation of Co

Measuring the Mass of Liquids (2/75)

Measuring (1970) $\$ 1.75$

Measuring (1970) $\$ 1.75$

Measuring (1970) $\$ 1.75$

Measuring (1970) $\$ 1.75$

Measuring (1973) $\$ 1.75$

Measuring, Evaluating, and Reporting Radioactivity in S

Measuring, Mixing, Transporting and Placing of Concrete

Mechanical and Electrical Equipment Qualification Tests

Mechanical Equipment and Systems for the Construction P

Mechanical Equipment and Systems (6/76)

/lty Assurance

Mechanical Locking Devices (3-69) Amendment 1 (10-71)

Mechanical Materials, Methods of (1973) ASTM C565-1971

Mechanical Power Transmission Apparatus, Safety Standar

Mechanical Properties of Metallic Materials, Practice F

Mechanical Properties of Metallic Materials, Rec. Pract

Mechanical Properties (1973) ASTM E453- $1972 \$ 1.75$

Mechanical Properties, Rec. Practice for Examination of

Mechanical System for Liquid Metal Service (Fabrication

Mechanical Systems and Components (1/75)

Mechanical Testing of Steel Products (1975A) $\$ 1.75$

Mechanical Testing of Welds (1974) $\$ 5.00$

Mechanical Tubing, Specification for (1974) \$1.75

Mechanical (Cadweld) Splices in Reinforcing Bars of Cat

Mechanism for Sodium Cooled Reactors (Fabrication Only)

Mechanism for Sodium Service (3-71) Amendment 1 (12-7

Medical and Biological Applications (1961) $\$ 3.00$

Medical Use (1951) $\$ 2.00$

Recommendation

Medical X-Ray and Gamma Ray Protection for Energies Up

Medical X-Ray and Gamma Ray Protection for Energies Up

Medical X-Ray and Sealed Gamma Ray Sources, Energies Up

Medicine (1970) $\$ 4.00$

Medium Carbon Steel Boiler and Superheater Tubes (ASME

Medium Voltage Switchgear (10-75) Supersedes P2-5T, (

Medium-Carbon Steel Boiler and Superheater Tubes, Spec

Medium, Glass Fiber (MIL-F-51079 with Modifications a

Melted Solution Heat Treated (1975) \$3.00

1-5.1 (Cb\&

Melted $1750 \mathrm{~F}$ (954.4 C) Solution Heat Treated (1973) SA

Melted $1750 \mathrm{~F}$ (954.4 C) Solution Heat Treated (1973) SA

Melted 1750F (954.4C) Alloy Tubing, Seamless, Corrosion

Melted 1950 F (1065.6 C) Solution Treated (1973) SAE Am

Melted 1950 F (1065.6C) Solution Treated (1973) SAE AMS

Merchant Ships (1965) $\$ 7.50$

Mercury in Water (1973) $\$ 1.75$

Merit for $\mathrm{PuO}_{2}-\mathrm{UO}_{2}$ Fuel Pellet Homogeneity by Use of a

Metal Arc Welding (ASME SFA-5.18 with Additional Requi

Metal Arc Welding, Specification for (1973) AWS A5.18-

Metal Arc Welding, Specification for (1974)

Metal Cleaners (1971) \$1.75

Metal Cleaners (1972) \$1.75

Metal Cleaners (1972) $\$ 1.75$

Metal Cleaning Compositions (1971) $\$ 1.75$

Metal Enclosed Bus (1974) Consolidated Edition (Include
ANSI

] ASTM

ERDA

ERDA

ERDA

ERDA

ANSI

ASTM

ASTM

A STM

ANSI

NS1

NRC

NRC

NRC

ANSI

STM

STM

NS1

NRC

STM

ANSI

ANS1

ANS1

ANS1

ANS1

ASTM

EEE

ANS1

ANSI

ASTM

NRC

ASTM

ASTM

ASTM

ASTM

ASTM

NRC

ANSI

NRC

ANSI

NRC

ERDA

ANSI

ANSI

ANSI

ASTM

IO ANSI

ASTM

ERDA

NRC

ASTM

AWS

ASTM

NRC

ERDA

ERDA

NCRP

NCRP

NCRP

NCRP

ANSI

NCRP

ERDA

ERDA

ASTM

ERDA

ANSI

ANSI

ANS

ANSI

SNAM

ASTM

ERDA

ERDA

ANSI

ASME

ASTM

ASTM

ASTM

ASTM

ANSI

N 163

D3232

RDT C5-1T

RDT C5-2T

RDT C8-2T

RDT C6-3T

C96. 1

E336

E418

N639

N16.3

RG 4.3

RG 4.5

RG 4.6

N44.3

D2365

D2664

K90.2

RG 5.9 
) Control Rod Absorber Pin for Liquid ) Amendment 1 (12-73), / Control Rod Assembly for Liquid (ASTM B349-) Zirconium Sponge and Other Forms of Virgin Zirconium Sponge and Other Forms of Virgin Remelted Lithium Safety Requirements for Portable Electrical Continuity Type Liquid Ultrasonic Inspection of

Method for (1974) $\$ 1.75$ ndment 2 (6-74) Mixing Component for Liquid Permanent Magnet Flowmeter for Liquid current Type, Inductive, Absolute or Gage (10-70/ Liquid 73) Design Limits and Loading Combinations for -73/ Low Level Flux Monitor Mechanical System for Liquid (12-74) Reactor Vessel for Liquid nsmission High Temperature Pressure Transmitter for Liquid (1-74), Amendment 3 (5-/ Electromagnetic Pump for Liquid Fabrication of Core Component Pot for Liquid re Permanent Magnet Flow Through Type Flowmeter for Liquid Pipe Hangers, Supports and Snubbers for Liquid ngs of High Strength Alloys for Core Components for Liquid Class 1 Valves for Liquid Eddy Current Probe Type Flow Sensor for Liquid Class 2 Valves for Liquid cation and Installation of Piping Subassemblies for Liquid (5-74) Thermowell Systems for Liquid ment 1 (3-72), Amendment 2 (11-72), Amendm/ Tank Liquid 2-73) Supersedes C7-14T, (3-70), in Part Amendment 1/ e Heater (3-75) Supersedes P4-3T, (2-74)

Spectr/ Grade Plutonium Nitrate Solutions and Plutonium $1973 \$ 1.75$

ment $1(1-72)$

stm E452-1972 \$1.7/

Practice for Intermediate Heat Exchanger for Liquid $72 \$ 1.7 / \quad$ Method for Calibration of Refractory 75) Supersedes M $1-9 \mathrm{~T},(7-71)$ Brazing Filler

Delta Ferritic Content of Austenitic Stainless Steel Weld Inductive Level Measurement Sensor for Use in Liquid Resistive Level Measurement Sensor for Use in Liquid Analytical Chemistry Methods for

astm E110 197/ Method of Test for Indentation Hardness of ) Information for Safety Analysis Reports: Methods for Semi-Guided Bend Test for Ductility of Tension Testing of

ded Practice for Constant Amplitude Axial Fatigue Tests of resentation of Constant Amplitude Fatigue Test Results for Notched Bar Impact Testing of Recommended Practice for Scleroscope Hardness Testing of
Vickers Hardness of 1.75

Test for Plane-Strain Fracture Toughness of Rockwell Hardness and Rockwell Superficial Hardness of Elevated Temperature Tension Tests of $s$ of High Energy Radiation on the Mechanical Properties of $s$ of High Energy Radiation on the Mechanical Properties of Preparation of preparation of Micrographs of Metals and Alloys (Including tion (1972) \$1.75 Sampling Wrought Nonferrous or Photography as Applied to Preparation of Macroetching ectrophotometry (1970) $\$ 1.75$

hardness, Rockwe/ Standard Hardness Conversion Tables for Part C-Welding Rods, Electrodes and Filler Estimating the Average Grain Size of Photometric Methods for Chemical Analysis of ives in Shear by Tension Loading at Elevated Temperatures uclear and Radiochemical Analysi/ Nuclear Grade Plutonium

lear and Radiochemical Analysis of Nuclear Grade Plutonium Primary Columbium Nuclear Grade Plutonium Brazing Filler Brazing Filler

Nuclear Grade Plutonium Onsite

$(1-72)$

Information for Safety Analysis Reports:

Electrochemical Oxygen Diffusion Carbon Oxygen-Hydrogen hermal Conductivity of Materials by Means of the Heat Flow

nded Practice for Photography as Applied to Preparation of e Water, Identification of (1974) \$1.75

or $\mathrm{PuO}_{2}-\mathrm{UO}_{2}$ Fuel Pellet Homogeneity by Use of an Electron $t$ for $(1975) \$ 1.75$

tion of (1974) $\$ 1.75$

Types of Microorganisms and $\mathrm{n}$ for (1973) AWS A5.1-1969\$3.50

$\mathrm{n}$ for $(1974)$
Metal Fast Reactors (5-73) Supersedes E6-25T, (1 1-71 Metal Fast Reactors (5-73) Supersedes E6-33T, (11-71 Metal for Nuclear Application, Specification for (1973) Metal for Nuclear Application, Spec. for (1973) \$1.75 Metal in lngot Form, Specification for (1972) \$1.75 Metal Ladders (1972) $\$ 4.25$

Metal Leak Detector (10-72) Amendment 1 (6-73)

Metal Pipe and Tubing for Longitudinal Discontinuities,

Metal Piping Systems (11-71) Amendment 1 (12-73), Ame

Metal Piping Systems (4-74) Supersedes C4-5T, (8-71)

Metal Pressure Measurement System, Flush Mounted, Eddy

Metal Primary Reactor Containment System Components (6/

Metal Service (Fabrication OnIy) (7-72) Amendment 1 (7

Metal Service (12-73) Supersedes (10-72), Amendment 1

Metal Service (3-71) Amendment 1 (5-71); Superseded B

Metal Service (3-71) Amendment 1 (9-71), Amendment 2

Metal Service (3-72) Amendment 1 (3.74)

Metal Service (4-73)

Metal Service (5-72)

Metal Service (5-74)

Metal Service (5-75) Supersedes E1-18T, (2-71)

Metal Service (6-73)

Metal Service (6-74) Supersedes E1-19T, (9/70)

Metal Service (8-71) Amendment 1 (11-72), Amendment 2

Metal Service (8-72) Amendment 1 (8-73), Amendment 2

MetaI Service (9-71) Supersedes E10-3T, (9-70) Amend

Metal Sheathed, Mineral Insulated Cable Bulk Material

Metal Sheathed, Mineral-Insulated Electrical Resistanc

Metal Standard Methods for Chemical, Mass Spectrometric

Metal Surfaces for Adhesive Bonding (1973) ASTM D2651-

Metal Systems (5-74) Supersedes E4-6T, (1-72), Amend

Metal Thermocouples Using an Optical Pyrometer (1973) a

Metal), Method of Test for (1973) ASTM D2295-1972 (Re

Metal (ASME SFA-5.8 with Additional Requirements) (7-

Metal (1974) \$3.00 /Agnetic Instruments to Measure the

Metal (3-75) Supersedes C5-1T, (4-70)

MetaI (4-70) Amendment 1 (10-71)

Metallic Core Components (9-75)

Metallic Materials by Portable Hardness Testers (1974)

Metallic Materials for Engineered Safety Features (2/75

Metallic Materials (1969) ASTM E290-1968 \$1.75

Metallic Materials (1969) $\$ 1.75$

Metallic Materials (1972T) $\$ 1.75$

Metallic Materials (1972T) \$1.75

Metallic Materials (1972) $\$ 1.75$

Metallic Materials (1972) $\$ 1.75$

Metallic Materials, Method of Test for ASTM E92-1972 \$

Metallic Materials, Method of (1974) \$1.75

Metallic Materials, Methods of Test for (1974) \$1.75

Metallic Materials, Practice for (1970) \$1.75

Metallic Materials, Practice for (1973) ASTM E 184-1962

Metallic Materials, Rec. Practice for (1962) (R1968) \$1

Metallographic Specimens (1974) \$1.75

Metallography) (1974) \$1.75

/Hotography as Applied to

Metals and Alloys for Determination of Chemical Composi

Metals and Alloys (Including Metallography) (1974) \$1.7

Metals and Alloys (1974) $\$ 1.75$

Metals in Water and Waste Water by Atomic Absorption Sp

Metals (Relationship Between Brinell Hardness, Vickers

Metals (1977) bd $(\$ 30.00)$, II $(\$ 40.00)$

Metals, Methods for (1974) \$1.75

Metals, Recommended Practice for (1974) $\$ 1.75$

Metal-to-Metal), Method of Test for (1973) ASTM D229

Metal, Chemical, Mass Spectrometric, Spectrochemical, N

Metal, Methods for (1974) ASTM C758-1973 \$1.75

Metal, Specification for (1973) ASTM B383-1964 \$1.75

Metal, Specification for (1973) ASTM C701-1972 \$1.75

Metal, Specification for (1973) AWS A5.8-1969 \$2.50

Metal, Specification for (1974)

Metal, Spec. for (1972) \$1.75

Meteorological Programs (Safety Guide 23, 2/17/72)

Meteorology (4/75)

Meter Equilibration Module for Service in Liquid Sodium

Meter for Service in Liquid Sodium (1-72)

Meter for Service in Liquid Sodium (1-72)

Meter Module for Service in Liquid Sodium (1-72)

Meter, Test for (1970) $\$ 1.75$

Metric Practice Guide (1976) ASTM E380-1976 \$1.75

Micrographs of Metals and Alloys (Including Metallograp

Microorganisms and Microscopic Matter in Water and Wast

Microprobe (9-72) /Termination of a Figure of

Microquanties of Un wan in Water by Fuorometry, Tes

Microwave and Radio Frequency Emitting Products (1975)

Mild Steel Covered Arc Welding Electrodes, Specificatio

Mild Steel Covered Arc Welding Electrodes, Specificatio
ERDA

ERDA

ANSI

ASTM

ASTM

ANSI

ERDA

ASTM

ERDA

ERDA

ERDA

NRC

ERDA

ERDA

ERDA

ERDA

ERDA

in Co ERDA

ERDA

Piston Ri ERDA

ERDA

ERDA

ERDA

ERDA

ERDA

ERDA

ERDA

ERDA

NRC

ANSI

ERDA

ANSI

ANSI

ERDA

AWS

ERDA

ERDA

ERDA

ANSI

NRC

ANSI

ASTM

ASTM

ASTM

ASTM

ASTM

ANSI

ASTM

ASTM

ASTM

ANSI

ASTM

ASTM

ASTM

ASTM

ASTM

ASTM

ANSI

ASME

ASTM

ASTM

ANSI

ASTM

Nuc ANSI

ANSI

ANSI

ANSI

ASME

ASTM

NRC

NRC

ERDA

ERDA

ERDA

ERDA

ASTM

ANSI

ASTM

ASTM

ERDA

ASTM

ASTM

BRH

ANSI

ASME

E6-25T RDT E6-33T N121 B349

B357

A 14.2

RDT C8-4T

E213

DT E7-4T

RDT C4-5T

RDT C6.3T

RG 1.57

RDT E6-36T

RDT E2-3T

RDT C6-1T

RDT E3-9T

RDT E6-34T

RDT C4-6T

RDT E7-6T

RDT E6-40T

RDT E1-18T

RDT C4-7T

RDT E1-19T

RDT F6-11T

RDT C7-18T

RDT E 10-3T

RDT C17-5T

RDT P4-3T 
th Additional Requirements) (3.75) Supersedes MI-3T, (/ ing, Specification for (1973) AWS A5.17-1969 $\$ 2.50$

ing, Specification for (1974)

ing (ASME SFA-5.17 with Additional Requirements) (3-75/

SFA -5.20 with Additional Requirements) (7.75) Supers/ ification for (1973) AWS A5.20-1969\$2.50

ification for (1974)

fa-5. I 8 with Additional Requirements) (4-75) Supersedc/ ication for (1973) AWS A5.18-1969\$2.50

ication for (1974)

tional Information: Nearby Industrial, Transportation, and of Radionuclides in the Environment-Analysis of I-131 in

$\$ 1.75$

Tantalum Ingots and Fla Guide to the Contents of Applications for Uranium Stabilization of Uranium-Thorium

$\$ 1.50$ Uranium-Thorium

Preparation of Environmental Reports for Uranium sign Stability of Embankment Retention Systems for Uranium ASTM C117-1969/ Materials Finer Than No. 200 Sieve in $\$ 1.75$

Finishing Cement, Specification for (1970) $\$ 1.75$

Finishing Cement (ASTM C 449 with Additional Requiremen/ id, Flexible and Loose Fill (ASTM C 612 with Additional s C7-14T, (3-70), in Part Amendment $1 /$ Metal Sheathed Time Response Test for Sheathed, 14T, $(3-70), /$ Thermocouple Material Iron Constantan, Supersedes P4-3T, (2-74) Metal Sheathed, 7-14T, (3-7) Thermocouple Material, Copper-Constantan, and N7.1A-1973 $\$ 5.00 \quad$ Radiation Protection in Uranium in Equipment for Dry Process O/ Design Considerations for in Drying and Fluidized Bed Op/ Design Considerations for in Equipment for Wet Process / Design Considerations for Guidance for the Control of Radiation Hazards in Uranium Information for Safety Analysis Reports:

Protection Against Low Trajectory Turbine ormation for Safety Analysis Reports: Internally Generated

00 or $(1975) \$ 1.75$

for (1975) $\$ 1.75$

ation and Control of Analytical Che Fast Flux Test Facility Driver Fuel Pin Ceramographic Preparation C

Analytical Chemistry Methods for

de Plutonium Dioxide Powders and Pellets and Nuclear Grade and Spectrochemical Analysis of (1974) \$/ Nuclear Grade pectrometric, and Spectrochemical Analysis/ Nuclear Grade

uble Chlorides Present as Admixes in Graded Aggregate Road Amendment 1 (12-73), Amendment 2 (6-74)

for (1973) ACl 304-1973 $\$ 2.75$ Measurement of Absorbed Dose of Neutrons, and nse Analysis (Revision 1, 2/76) mass Spectrometer Leak Detector in the Inside-Out Testing leak Detector or Residual Gas Analyzer in the Tracer Probe n Natural Water Bod/ Reporting Procedure for Mathematical am (9/73) or $(1974 \mathrm{~A}) \$ 1.7$ ! Acceptable Concepts

ted Systems, Structures and Equipment for Water Cooled and HEPA Filter Medium, Glass Fiber (M1L-F-51079 with Oxygen-Hydrogen Meter Carbon Meter Equilibration

bon and Graphite Materials by Sonic Resonance (1974) \$1./ 1972) $\$ 1.75$

n of Cylindrical Concrete Specimens, Meth/

Test for Elastic Test for Shear Strength and Shear Nuclear Methods (Shallow Depth) (197/ Method of Test for

Nuclear Methods (Shallow Depths), Test for (1972) $\$ 1.75$ g) Rammer and $18(457 \mathrm{~mm}) \mathrm{I} / \quad$ Standard Methods of Test for

$62-1969 \$ 1.75$

5-kg) Rammer and 12-in. (304.8-mm) Drop, Tests for (/ ined Soils (1972) (ASTM D1558-1971)/ Method of Test for dment $1(4-73)$

4) $\$ 1.75$

3) $\$ 1.75$

5) Amendment 1 (1/

c Welding (9-75)

onal Requirements

h Additional Requ/

with Additional /

Thermal Insulation, Flexible or

Polyethylene Plastics

Nylon lnjection

2-1/4-Percent-Chromium, 1-Percent-

2-1/4-Percent-Chromium, 1-Percent-

2-1/4-Percent-Chromium, 1-Percent-

2-1/4-Percent-Chromium, 1-Percent-

2-1/4-Percent-Chromium, 1-Percent-

sel Plates, Alloy Steel, Quenched and Tempered, Manganesetion For/ Pressure Vessel Plates, Alloy Steel, Manganeseodes (7-75) Supersedes M1-15T, (1-72) Amendme/ ditional Requirements) (10-75) Supersedes M4-5/ additional Requirements) (7-75) Supersedes M2-/

Nickel-

Nickel-
Mild Steel Covered Weiding Electrodes (ASME SFA-5.1 Wi Mild Steel Electrodes and Fluxes for Submerged Arc Weld Mild Steel Electrodes and Fluxes for Submerged Arc Weld Mild Steel Electrodes and Fluxes for Submerged Arc Weld Mild Steel Electrodes for Flux-Cored Arc Welding (ASME Mild Steel Electrodes for Flux-Cored Arc Welding, Spec Mild Steel Electrodes for Flux-Cored Arc Welding, Spec Mild Steel Electrodes for Gas Metal Arc Welding (ASME S Mild Steel Electrodes for Gas Metal Arc Welding, Specif Mild Steel Electrodes for Gas Metal Arc Welding, Specif

Military Facilities $(9 / 74)$

Milk (9/73)

Mill Products, Specification for (1973) ASTM B364-1970

Mill Products, Spec. for (1970) \$I.75

Milling Licenses (2/73)

Milling Waste Retention Systems (11/74)

Milling Waste Retention Systems, Stablilzation of (1974

Mills $(4 / 73)$

Mills (6/73)

Mineral Aggregates by Washing, Method of Test for (1970

Mineral Fiber Block and Board Thermal Insulation (1970)

Mineral Fiber Hydraulic-Setting Thermal Insulating and

Mineral Fiber Hydraulic-Setting Thermal Insulating and

Mineral Fiber Thermal Insulation, High Temperature, Rig

Mineral Insulated Cable Bulk Material (2-73) Supersede

Mineral Insulated Thermocouple Assembly (6-72)

Mineral Oxide Insulated, Sheathed (4-70) Supersedes C7

Mineral-Insulated Electrical Resistance Heater (3-75)

Mineral-Oxide Insulated, Sheathed (4-70) Supersedes C

Mines Operation (1973), Partial Revision of N7.1-1960

Minimizing Residual Holdup of Special Nuclear Material

Minimizing Residual Holdup of Special Nuclear Material

Minimizing Residual Holdup of Special Nuclear Materials

Mining (1967)

Missile Barrier Design Procedures (12/74)

Missiles (3/76)

Missiles (6/75)

Missiles-Issued for Trial Use and Comment ANS 58.1 \$12

Mixed Concrete by the Pressure Method, Method of Test $\mathrm{F}$

Mixed Concrete by the Volumetric Method, Method of Test

Mixed Oxide Fuel Analysis (7-73)

Mixed Oxide Fuel Pellet (6-71) Amendment 1 (12-74)

Mixed Oxide Fuel Pellets (1-73)

Mixed Oxide Fuel (7-73) Amendment 1 (12-74)

Mixed Oxides ((U, Pu $\left.) \mathrm{O}_{2}\right)(5 / 73)$

Nalysis of Nuclear Gra

Mixed Oxides ( (U,Pu)O( $\left.\left.{ }_{2}\right)\right)$, Chemical, Mass Spectrometric

Mixed Oxides ( (U,Pu) $\left({ }_{2}\right)$ ), Methods for Chemical, Mass S

Mixes, Method of Test for (1975) $\$ 1.75$

Mixing Component for Liquid Metal Piping Systems (11-7

Mixing, Transporting and Placing of Concrete, Practice

Mixtures of Neutrons and Gamma Rays (1961) $\$ 2.00$

Modal Responses and Spatial Components in Seismic Respo

Mode (1973) $\$ 1.75$

Mode (1973) $\$ 1.75$

Mode (1973) $\$ 1.75$

Testing for Leaks Using

to Predict Heated Effluent Dispersion I

odels, Equations, and Assumptions for a Bioassay Progr

Moderate and Lower Temperature Service, Specification F

Moderated Nuclear Power Generating Plants, Fire Protect

Modifications and Additional Requirements) (3-74)

Module for Service in Liquid Sodium (1.72)

Module for Service in Liquid Sodium (1-72)

Moduli of Elasticity and Fundamental Frequencies of Car

Moduli of Rock Core Specimens in Uniaxial Compression

Modulus of Elasticity and Poisson's Ratio in Compressio

Modulus of Structural Adhesives (1970) \$1.75

Moisture Content of Soil and Soil Aggregate in Place by

Moisture Content of Soil and Soil Aggregate in Place by

Moisture Density Relations of Soils Using $10 \mathrm{lb}$. (4.5 M

Moisture in Activated Carbon, Test for (1970) \$1.75

Moisture in Graphite, Method of Test for (1973) ASTM C5

Moisture-Density Relations of Soils, Using 5.5-lb. ( 2

Moisture-Penetration Resistance Relations of Fine-Gra

Molded, High Temperature, Low Conductivity (5-72) Amen

Molding and Extrusion Materials, Specification for (197

Molding and Extrusion Materials, Specification for (197

Molybdenum Alloy Bare Welding Rods and Electrodes (9-7

Molybdenum Alloy Electrodes and Fluxes for Submerged Ar

Molybdenum Alloy Steel Plates (ASME SA-387 with Additi

Molybdenum Alloy Steel Seamless Tubes (ASME SA-213 Wit

Molybdenum Alloy Steel Tubesheet Forgings (ASME SA-336

Molybdenum and Manganese-Molybdenum-Nickel Alloy, (19

Molybdenum and Manganese-Molybdenum-Nickel, Specifica

Molybdenum-Chromium Alloy Bare Welding Rods and Electr

Molybdenum-Chromium Alloy Castings (ASTM a 494 with Ad

Molybdenum-Chromium Alloy Forgings (ASME SA-182 with
ERDA

ANS1

A SME

ERDA

ERDA

ANSI

ASME

ERDA

ANSI

ASME

Addi NRC

NRC

ANSI

ASTM

NRC

NRC

ANSI

NRC

De NRC

ANS1

ASTM

ASTM

ERDA

ERDA

ERDA

ERDA

ERDA

ERDA

RDA

ANSI

NRC

NRC

EPA

NRC

NRC

$\operatorname{lnf}$ NRC

ANSI

ASTM

RDA

ERDA

RRA

ASTM

ANS1

ASTM

ERDA

ANS1

NCRP

NRC

ASTM

ASTM

ASTM

NRC

RC

ASTM

ANSI

ERDA

ERDA

ERDA

ASTM

ASTM

ANS

ASTM

ANSI

ASTM

ASTM

ATM

ANSI

ASTM

ANS1

ERDA

ASTM

A STM

ERDA

ERDA

ERDA

ERDA

ERDA

ASTM

ASTM

ERDA

ERDA

ERDA

DT MI-3T

W3.17

FA-5.17

RDT M l-17T

DT M1-20T

W3.20

SFA-5.20

RDT M1-6T

W3.18 
th Additional Requirements) (9-75) Supersedes M/ e SB-167 with Additional Requirements) (7-75) / 3 with Additional Requirements) (4-76) Supersed/ 34 with Additional Requirements) (1/-75) Supers/ th Additional Requirements) (7-75) Supersedes M fication for (1973) ASTM B434-1971 \$1.75 lates, Alloy Steel, Quenched and Temp s 5596 with Additional Requirements) (/ 7 with Additional Requirements) (8-75/ ecification for (1973) (ASTM B443-197/

th Additional Requirements) (7.75) Su/

th Additional Requirements) (8-75) Su/

(6-75) Supersedes M 1-19T, (3-75) Plates, Aloy Sted, Manganese-Molybdenum and ManganesePlates, Alloy Steel, Manganese-Molybdenum and ManganeseMethod of Test for Fast Neutron Flux by Analysis of
for (1972) $\$ 1.75$
Fast Neutron Flux by Analysis of

ecification for (1974A) $\$ 1.75$

el Plates, Alloy Steel, Five Percent Chromium, 0.5 Percent Pressure Vessel Plates, Alloy Steel, Chromium essel Plates, Alloy Steel, Ouenched and Tempered Chromiumrication Only) (7-72) Amendment 1 (7-73/ Low Level Flux Wide Range ( 10 Decade) Neutron Flux Radiological

Processing and Fuel Fabrication Plants (3/73) d Performance / On-Site Instrumentation for Continuously er Plants (Revision 1, 2/75) Programs fo Logarithmic Count Rate Source Range Neutron Flux Direct Current Power Range Neutron Flux Mean Square Voltage (MSV) Intermediate Range Neutron Flux Administrative Practices in Radiation Guide for Administration Practices in Radiation Special Nuclear Material Doorway

t $1(12-74)$

(1973) $\$ 1.75$

Temperature and Liquid Level Control Compressive Strength of Hydraulic Cement ntial Alkali Reactivity of Cement-Aggregate Combinations ect of Organic Impurities in Fine Aggregate on Strength of dment $1(5-74)$

ndment $1(5-74)$

ersedes E3-3T, (10-70), Amendm/ Vertical, Canned or Wet Horizontal, Electric Thermal Overload Protection for Electric Motors on

r Generating Stati/ Nuclear Power P/

(10-70/

(7-71) Type Tests of Continuous Duty Class Thermal Overload Protection for Electric

e Std. $301-1970 \$ 3.00$ Logarithmic Mean Square Voltage Standard Test Procedure for Geigerneutron Counters (12-75) Supersedes C10-3T, (3-72)

ns-8.6 $\$ 6.50$

Scintillation Count/

liquid Sodium (1-72)/

Conducting Subcritical Neutron Standard Test Procedures for PhotoSpecimen Equilibration Device (Or Shared Emergency and Shutdown Electric Systems fo for Liquid Metal Service (3-71) Amendment 1 (5-71); Su/ ) $\$ 5.00$ h Stds. on Projects or Productions Assisted by Grants from

1973) ASTM/ Specification for Fly Ash and Raw or Calcined I Models Selected to Predict Heated Effluent Dispersion in of Explosions Postulated to Occur on Transportation Routes ies (9/74) Additional Information: Thyroid Radioiodine Uptake Measurements Using A Time of Setting of Hydraulic Cement by Vica 4) $\$ / \quad$ Atom Percent Fission in Uranium and Plutonium Fue st for A tom Percent Fission in Uranium and Plutonium Fuel d Containment Heat Removal System Pumps (Safety Guide 1, ) ANS-8.3/Use of Borosilicate Glass Raschig Rings as A Use of Borosilicate-Glass Raschig Rings as A stimating the (1971) $\$ 1.75$ Thermal ethods for (1973) ASTM C626-1971/ Estimating the Thermal d of Test for (1974) ASTM/ Oxygen Content Using a 14-Mev d of Test for (1973) \$1.7/ Oxygen Content Using a 14-Mev ion of (1973) $\$ 1.75$

ASTM E419-1973\$1.75 Multiple Input Preamplifier/Discriminator for Use with

$-72$

threshold-Foil Measurements (1968) (R197) (1976) $\$ 3.50$

olant Water During Reactor Operation, Method For/ plications (1960) $\$ 2.00$ nium-238 Fission, Measuring (1973) $\$ 1.75$
Molybdenum-Chromium Alloy Rod and Bar (ASME SB-336 Wi Molybdenum-Chromium Alloy Seamless Pipe and Tubes (Asm Molybdenum-Chromium Alloy Seamless Tubes (ASME SB - 16 Molybdenum-Chromium Alloy Sheet and Plate (ASME SB -4 Molybdenum-Chromium Alloy Welded Pipe (ASME SA-358 Wi Molybdenum-Chromium-Iron Alloy Sheet and Plate, Speci Molybdenum-Chromium, Specification for (1973) ASTM A60 Molybdenum-Columbium Alloy Plate, Sheet, and Strip (Am Molybdenum-Columbium Alloy Plate, Sheet, and Strip 559 Molybdenum-Columbium Alloy Plate, Sheet, and Strip, Sp Molybdenum-Columbium Alloy Seamless Tubes (AMS 5589 Wi Molybdenum-Columbium Alloy Seamless Tubes (AMS 5590 Wi Molybdenum-Columbium Bare Welding Rods and Electrodes Molybdenum-Nickel Alloy, (1974) \$1.75/Alloy Steel, Quen Molybdenum-Nickel, Specification for (1974A) \$1.75 Molybdenum-99 Activity from Uranium-238 Fission (1974 Molybdenum-99 Activity from Uranium-238 Fission, Test Molybdenum, Alloy Steel Plates for Pressure Vessels, $\mathrm{Sp}$ Molybdenum, Specification for (1972A) ASTM A357-1972 \$ Molybdenum, Specification for (1974A) $\$ 1.75$

Molybdenum, Specification for (1974) \$1.75

Monitor Mechanical System for Liquid Metal Service (Fab Monitoring Channel (2-71)

Monitoring Methods and Instruments (1952) $\$ 2.00$

Monitoring of Combustible Gases and Vapors in Plutonium

Monitoring Radioactivity in Effluents, Specification an

Monitoring Radioactivity in the Environs of Nuclear Pow

Monitoring System (7-71)

Monitoring System (7-71)

Monitoring System (7-71)

Monitoring (A Guide for Management) (1969) $\$ 4.25$

Monitoring $(2 / 2 / 73)$

Monitors (6/74)

Monitor, Port Plug (Fabrication Only) (10-73) Amendmen

Mortars (Using 2 -in ( $50-\mathrm{mm}$ ) Cube Specimens), Test for

Mortar-Bar Method), Test for (1971) \$1.75

Mortar, Method of Test for (1970) ASTM C87-1969 \$1.75

Motor Driven Single Stage Centrifugal Pump (6-72) Amen

Motor Driven, Single Stage Centrifugal Pump (2-72) Ame

Motor Driven, Single Stage Centrifugal Pump (7-72) Sup

Motor Operated Valves (11/75)

Motors and Generators (1972) $\$ 22.50$

Motors and Generators, Test Procedure for (1964) $\$ 3.80$

Motors Installed Inside the Containment of Nuclear Powe

Motors Installed Inside the Containment of Water Cooled

Motors on Motor Operated Valves (11/75)

Mounted, Eddy Current Type, Inductive, Absolute or Gage

(MSV) Intermediate Range Neutron Flux Monitoring System

Muller Counters ( $5 / 73$ )

Muller Counters, Test Procedures for (1969) (R 1974) Iee

Multiple Input Preamplifier/Discriminator for Use with

Multiplication Measurements in Situ, Safety in (1975)

Multipliers for Scintillation Counting and Glossary for

Multipurpose Sampler) for the Analysis of Nonmetals in

Multi-Unit Nuclear Power Plants (Revision 1, 1/75)

Nak Transmission High Temperature Pressure Transnitter

National Electrical Code (1975) $\$ 5.50$

National Endowment for the Arts (1975) $\$ 6.85$

Natural Background Radiation in the United States ( 197

Natural Pozzolans for Use in Portland Cement Concrete

Natural Water Bodies (5/74) /Procedure for Mathematica

Near Nuclear Power Plant Sites (1/75)

Nearby Industrial, Transportation, and Military Facilit

Neck Phantom (1973) \$3.00

Needle, Test for (1974) $\$ 1.75$

(Neodymium 148 Method), Standard Method of Test for (197

Neodymium-148 Method) (1973) ASTM E321-1969) \$1.75

Net Positive Suction Head for Emergency Core Cooling an

Neutron Absorber in Solutions of Fissile Material (1971

Neutron Absorber in Solutions of Fissile Material (1/73

Neutron Absorption Cross Section of Nuclear Graphite, E

Neutron Absorption Cross Section of Nuclear Graphite, M

Neutron Activation and Direct Counting Technique, Metho

Neutron Activation and Direct Counting Technique, Metho

Neutron Activation Detector Materials, Guide for Select

Neutron Activation Detector Materials, Guide for (1974)

Neutron Counters (12-75) Supersedes C10-3T, (3-72)

Neutron Detector Assembly (12-71) Amendment 1 (10-73)

Neutron Detector Tubes (12-75) Supersedes C15-11T, (

Neutron Dose to Polymeric Materials and Application of

Neutron Dosimeters (Neutron Energies) Less Than $20 \mathrm{MeV}$

Neutron Dosimeters $(6 / 76)$

Neutron Emitting Fission Products in Nuclear Reactor Co

(Neutron Energies) Less Than $20 \mathrm{MeV}$ (1976) \$3.50

Neutron Flux and Spectra for Physical and Biological Ap

Neutron Flux by Analysis of Barium-140 Produced by Ura
ERDA

ERDA

ERDA

ERDA

ERDA

ANSI

ANSI

ERDA

ERDA

ANSI

ERDA

ERDA

ASTM

ASTM

ASTM

ANSI

ASTM

ATM

ERDA

ERDA

NCRP

ANS1

NRC

ERDA

ERDA

ANSI

NRC

NRC

ERDA

ASTM

Pote ASTM

ANSl

ERDA

ERDA

ERDA

NRC

NEM A

IEEE

ANS

NRC

NRC

ERDA

ERDA

NRC

ANSI

ERDA

ANSI

ERDA

NRC

ERDA

NFPA

DOL

NCRP

ANS

NRC

NRC

NRC

ANSI

ASTM

ASTM

ANS

NRC

ANSI

ASTM

ANSI

ANSI

ASTM

ASTM

ANSI

ERDA

ERDA

ERDA

ASTM

ANSI

NRC

ANSI

ANSI

NCRP

ASTM

RDT M7-1 1T RDT M3-10T

RDT M3-18T

RDT M5-8T

RDT M3-17T

H34.44

G35.26

RDT M5-21T

RDT M5-20T

H34.19

RDT M3-29T

RDT M3-30T

RDT M1-19T

A 533

A 302

N636

E343

A 204 
m Uranium-238 Fission (1974) As/

Method of Test for Fast m Uranium-238 F

(1970) $\$ 1.75$

) $\$ 1.75$

$3.1970 \$ 1.75$

264-1970 $\$ 1.75$

970) $\$ 1.75$

265-1970\$1.75

e $261-1970 \$ 1.75$

e $262-70 \$ 1.75$

1970) $\$ 1.75$

$\$ 1.75$ Fast

Method for Measuring Fast

Fast

Fast

Methods for Measuring Fast

Fast

Method for Measuring Fast

Fast

Method for Measuring Fast

Method of Measuring

Method for Measuring Fasi

Thermal

Neutron Generators by Radioactivatio/ ilver (1973T)
ssion (1974) ASTM E393-1973\$/ Method for Measuring Fast

Method of Test for 3) $\$ 1.75$

hod for (1974) ASTM E418-1973\$1.75

Fast

Wide Range ( 10 Decade)

Logarithmic Count Rate Source Range

Logarithmic Mean Square Voltage (MSV) Intermediate Range Direct Current Power Range

or Neutron Flux Density and Average Energy from $3 \mathrm{H}(\mathrm{D}, \mathrm{N}) 4 \mathrm{He}$ utron-Flux Density and Average Energy from ${ }^{3} \mathrm{H}(\mathrm{d}, \mathrm{n})^{4} \mathrm{He}$ (1975) ANS-8.6 \$6.50 Conducting Subcritical uclear Reactors, Determination of (1975) ANS $19.3 \$ 7.50$ Protection Against

Measurement of Absorbed Dose of Neutrons, and Mixtures of $\$ 2.00$ Measurement of Absorbed Dose of oolant Water During Reactor Operation, Measureme/ Delayed (4)he Neutron Generators by Radioactivation Techniques, /

Temperature Serv/ Std. Spec. for Precipitation Hardening Temperature Service (ASTM a 637/ Precipitation Hardening ication for (1974) $\$ 1.75 \quad$ Seamless Nickel and with Additional Requirements) (3-75) Supers/ Nickel and ification for (1975A) \$1.75 Copperion for (1971) ASTM B509-1 Supplementary Requirements for supplementary Requirements for (1970) $\$ 1.75$

for Supplementary Requirements for (1970) $\$ 1.75$

tions, Specification for / Supplementary Requirements for

tions, Spec. for Supplementary Requirements for (1970) \$/ al Requirements) (7-75) Supersedes M3-4T, (1-74)

ded Large Outside Diameter Light-Wall Austenitic Chromium pecificati/

Electric-Fusion-Welded Austenitic Chromiumtempered Manganese-Molybdenum anMMghdenambes, Specification for (1974) $\$ 1.75$ Seamless es, Specification for (1973) AWS A5.14-1969 \$2.50

es, Specification for (1974)

es (ASME SFA-5.14 with Additional Requirements) (3-75) ecification for (1973) AWS A5.11-1969\$2.50

ecification for (1974)

$\mathrm{n}$ for (1973) (ASTM B366-1972) \$1./ Factory-Made Wrought cation for (1974A) $\$ 1.75$

4.4C) Alloy Tubing, Seamless, Corrosion and Heat Resistant lloy Sheet, Strip, and Plate, Corrosion and Heat Resistant lloy Sheet, Strip, and Plate, Corrosion and Heat Resistant oy Bars, Forgings, and Rings, Corrosion and Heat Resistant 195/Alloy Tubing (Seamless, Corrosion and Heat Resistant

gh Temperatures, Spec/ Centrifugally Cast Iron-Chromium-
Radioactive 1.75

$\$ 1.75$

Test for 75. on-Welded Unfired Pressure Ves: Specification for Seamless Copper$n$ for $(1974 \mathrm{~A}) \$ 1.75$

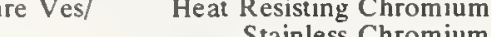
for (1973) A/ Corrosion-Resisting Chromium and Chromiumfor (1974) Corrosion-Resisting Chromium and ChromiumFlux Core Corrosion-Resisting Chromium and Chromium(1974) $\$ 1.75$ ation for ( $1 /$ ation for (1/ Stainless and Heat Resisting Chromium Corrosion-Resisting Chromium and ChromiumCorrosion-Resisting Chromium and Chromium-

Fast Neutron Flux by Radioactivation of thod for Measuring Fast Neutron Flux by Radioactivation of alloy Steel, Quenched and Tempered, Eight and Nine Percent Chemical Analysis of -5.14 with Additional Requirements) (3.75)/ Nickel and cation for (1973) AWS A5.14-1969 \$2.50 Nickel and cation for (1974)

for (1973) AWS A5.11-1969 \$2.50

for $(1974)$
Neutron Flux by Analysis of Molybdenum-99 Activity Fro Neutron Flux by Analysis of Molybdenum-99 Activity Fro

Neutron Flux by Radioactivation of Aluminum, Measuring Neutron Flux by Radioactivation of Iron Measuring (1970 Neutron Flux by Radioactivation of lron (1973) ASTM E26 Neutron Flux by Radioactivation of Nickel (1970) $\$ 1.75$ Neutron Flux by Radioactivation of Nickel (1973) ASTM E Neutron Flux by Radioactivation of Nickel, Measuring (I Neutron Flux by Radioactivation of Sulfur (1973) ASTM E Neutron Flux by Radioactivation Techniques (1973) ASTM Neutron Flux by Radioactivation Techniques (1973) ASTM Neutron Flux by Radioactivation Techniques, Measuring ( Neutron Flux by Radioactivation (1970) \$1.75

Neutron Flux Density and Average Energy from $3 \mathrm{H}(\mathrm{D}, \mathrm{N}) 4 \mathrm{He}$ Neutron Flux Density by Radioactivation of Cobalt and $\mathbf{S}$ Neutron Flux for Barium 140 Produced by Uranium-288 Fi Neutron Flux Measurements by Track-Etch Technique (197 Neutron Flux Measurements by Track-Etch Technique, Met Neutron Flux Monitoring Channel (2.71)

Neutron Flux Monitoring System (7-71)

Neutron Flux Monitoring Sysiem (7-71)

Neutron Flux Monitoring System (7-71)

Neutron Generators by Radioactivation Techniques (1974)

Neutron Generators by Radioactivation Techniques, Test

Neutron Multiplication Measurements in Situ, Safety in

Neutron Radiation (1971) $\$ 5.00$

Neutron Reaction Rate Distributions and Reactivity of $\mathrm{N}$

Neutrons and Gamma Rays (1961) $\$ 2.00$

Neutrons, and Mixtures of Neutrons and Gamma Rays (1961

Neutron-Emitting Fission Products in Nuclear Reactor C

Neutron-Flux Density and Average Energy from (3)h(D, N)

Nickel Alloy Bars, Forgings, and Forging Stock for High

Nickel Alloy Bars, Forgings, and Forging Stock for High

Nickel Alloy Condenser and Heat Exchanger Tubes, Specif

Nickel Alloy Covered Welding Electrodes (ASME SFA-5.11

Nickel Alloy Plate and Sheet for Pressure Vessels, Spec

Nickel Alloy Plate for Nuclear Applications, Specificat

Nickel Alloy Plate for Nuclear Applications, Spec. for

Nickel Alloy Rod and Bar for Nuclear Applications, Spec

Nickel Alloy Seamless Pipe and Tube for Nuclear Applica

Nickel Alloy Seamless Pipe and Tube for Nuclear Applica

Nickel Alloy Seamless Tubes (ASME SB-163 with Addition

Nickel Alloy Steel Pipe for Corrosive or High Temperatu

Nickel Alloy Steel Pipe for High Temperature Service, S

Nickel Alloy, (1974) \$1.75 /Alloy Steel, Quenched and

Nickel and Nickel Alloy Condenser and Heat Exchanger Tu

Nickel and Nickel Alloy Covered Welding Electrodes (Asm

Nickel and Nickel-Alloy Bare Welding Rods and Electrod

Nickel and Nickel-Alloy Bare Welding Rods and Electrod

Nickel and Nickel-Alloy Bare Welding Rods and Electrod

Nickel and Nickel-Alloy Covered Welding Electrodes, Sp

Nickel and Nickel-Alloy Covered Welding Electrodes, Sp

Nickel and Nickel-Alloy Welding Fittings, Specificatio

Nickel and Nickel-Base Alloy Clad Steel Plate, Specifi

Nickel Base-19Cr-3.1 Mo-5.1 (Cb \& Ta)-0.90Ti-0.50A l

Nickel Base-19Cr-3.1 Mo-5.1 (Cb \& Ta)-0.90Ti-0.50A 1

Nickel Base-19Cr-3.1Mo-5.1 (Cb \& Ta)-0.90Ti-0.50A

Nickel Base-19Cr-3.1 Mo-5.1 (Cb+Ta)-0.90Ti-0.50Al-

Nickel Consumable Electrode or Vacuum Induction Melted

Nickel High Alloy Tubing for Pressure Application at $\mathrm{Hi}$

Nickel in Water (1974T) $\$ 1.75$

Nickel in Water, Standard Methods of Tests for (1971)

Nickel on Steel by Photometric Analysis (1972) \$1.75

Nickel Pipe and Tube (1975) \$1.75

Nickel Plate, Sheet, and Strip, Specification for (1974

Nickel Seamless Pipe and Tube (1971) ASTM B167-1970 \$1

Nickel Stainless Steel Plate, Sheet, and Strip for Fusi

Nickel Steel Clad Plate, Sheet, and Strip, Specificatio

Nickel Steel Covered Welding Electrodes, Specification

Nickel Steel Covered Welding Electrodes, Specification

Nickel Steel Electrodes (1974) $\$ 3.50$

Nickel Steel Plate, Sheet, and Strip, Specification for

Nickel Steel Welding Rods and Bare Electrodes, Specific

Nickel Steel Welding Rods and Bare Electrodes, Specific

Nickel Wire (3-70)

Nickel (1970) $\$ 1.75$

Nickel (1973) ASTM E264-1970 \$1.75

/Pec. for Pressure Vessel Plates,

Nickel (1975) \$1.75

Nickel-Alloy Bare Welding Rods and Electrodes (ASME Sf

Nickel-Alloy Bare Welding Rods and Electrodes, Specifi

Nickel-Alloy Bare Welding Rods and Electrodes, Specifi

Nickel-Alloy Covered Welding Electrodes, Specification

Nickel-Alloy Covered Welding Electrodes, Specification

Nickel-Alloy Welding Fittings, Specification for ( 1973
ANSI

ASTM

ANSl

ASTM

ASTM

ANSI

ASTM

ANSI

ASTM

ANS1

ANS1

ANS1

ASTM

ASTM

ANSI

ASTM

ANSI

ASTM

ANSI

ERDA

ERDA

ERDA

ERDA

ANSI

ASTM

ANSI

NCRP

ANSI

NCRP

NCRP

ASTM

ASTM

ANS1

ERDA

ASTM

ERDA

ASTM

ANS1

ASTM

ASTM

ANS1

ASTM

ERDA

ASTM

ASTM

ASTM

ASTM

ERDA

ANSI

A SME

ERDA

ANSI

ASME

ANSI

ASTM

ANSI

ANSI

ANSI

ANSI

ANSI

ANSI

ASTM

ASTM

ASTM

ASTM

ASTM

ANSI

ASTM

A STM

ANSI

ASME

AWS

ASTM

ANSI

ASME

ERDA

ASTM

Me ANSI

ASTM

ASTM

ERDA

ANSI

ASME

ANSI

ASME

ANSI

N636

E343

N1 14

E266

E263

E265

N11 12

E264

N1 13

109

N110

262

E261
N580

E481

N638 
(1974A) $\$ 1.75$ (ASME SA 637 with Additional Requirements) (4-76) Sup/ 3) $\$ 1.75$ ecification with Addior (1973) ASTM B168-1970 \$1.75

73) ASTM B 167-1970 \$1.75

M8-1T, (2-73)

Helical Age-Hardenable Chemical Analysis of Nickel-Chromium and eet, and Strip, Specification for (1973) (ASTM B443-197/ eet, and Strip 5597 with Additional Requirements) (8-75 eet, and Strip (AMS 5596 with Additional Requirements) ( tubes (AMS 5589 with Additional Requirements) (7-75) Su/ tubes (AMS 5590 with Additional Requirements) (8-75) Su/ ds and Electrodes (6-75) Supersedes M1-19T, (3-75)

ressure Vessel Plates, Alloy Steel, Quenched and Tempered, p, Specification for (1974) $\$ 1.75$

e (1971) \$1.75 (9-75) Supers/

with Additional Requirements) (9-75) Supersedes M7-10T $73 \$ 1.75 \quad$ Specification for asme SB-407 with Additional Requirements) (7-75) Super/

(1974) $\$ 1.75$

and Tube (1974) $\$ 1.75$

Specification for

d Electrodes (7-75) Supersedes M1-15T, (1-72) Amendme/ with Additional Requirements) (10-75) Supersedes M4-5/ 82 with Additional Requirements) (7-75) Supersedes M2-/ -336 with Additional Requirements) (9-75) Supersedes M/ bes (ASME SB-167 with Additional Requirements) (7-75) SB - 163 with Additional Requirements) (4-76) Supersed/ e SB -434 with Additional Requirements) (1/-75) Supers/ .358 with Additional Requirements) (7-75) Supersedes M fication for (1973) ASTM B434-1971 \$1.75 etecting Susceptibility to Intergranular Attack in Wrought
snsumable Electrode or Vacuum/ Bars, Forgings, and Rings, temperature, Electrical, Magnetic, and Other Similar Iron, Fast Neutron Flux by Radioactivation of oy Steel, Manganese-Molybdenum and Manganese-Molybdenum(1970) ASTM / Conducting Drop-Weight Test to Determine $\$ 1.75$ sel Plates, Alloy Steel, Quenched and Tempered, Eight and

Fast Flux Test Facility Uranyl Fast Flux Facility Plutonium or Chemical, Mass Spectrometric, Spectr/ Grade Plutonium Impurity Det/ General Methods for the Analysis of Uranyl lear and Radiochemical Analysis of Nuclear Grade Plutonium Methods for the Accountability of Plutonium

ss Spectrometric, Spectrochemical, Nuclear Grade Plutonium f (1975) $\$ 1.75$ Nuclear Grade Uranyl Plutonium Ammonia nd References Relating to (1/ Nuclear Magnetic Resonance Electrical Transduce

or $(1972 B) \$ 1.75$

Aggregates for Radiation-Sheilding Concrete, Descriptive Aggregates for Radiation-Shielding Concrete, Descriptive Intrinsically Safe and Ion Exchanger,

Spontaneous Fission Detection (6/74)

ates by Gamma-Ray Spectrometry (9/74)

ned in Scrap and Waste $(10 / 73)$

5) $\$ 5.75$

Welds (Revision 1, 8/11/72, of Safety Guide 19)

in Fuel Reprocessing Plants and in Plutonium Processing /

ncrete Barriers in Fuel Reprocessing Plants (5/75)

nd Pressure Vessel Code, Section V) (10-75) Supersedes /

00)

ification, Recommended Practice for $\$ 10.50$

Standard Welding and

ray Spectrometry $(4 / 74)$

cal Composition (1972) $\$ 1.75$

Part B:

materials, Platinum and Platinum 10 Percent Rhodium Wires, (1975)

(1975)

\section{(1971) $\$ 1.75$}

General Safety Standard for Installations Using

Steel $(2 / 23 / 73)$

ation Device (Or Multipurpose Sampler) for the Analysis of es Up to 10-Mev, General Safety Sta/

g (1974) ACI $211.1-1974 \$ 2.75$

$\$ 4.00$

nstallations Using

Proportions for
Nickel-Base Alloy Clad Steel Plate, Specification for Nickel-Chromium Alloy Bars, Forgings, and Forging Stoc Nickel-Chromium and Nickel-Chromium-Iron Alloys (197 Nickel-Chromium-Iron Alloy Plate, Sheet, and Strip (A Nickel-Chromium-lron Alloy Plate, Sheet, and Strip, S Nickel-Chromium-Iron Alloy Rod and Bar (ASME SB-166 Nickel-Chromium-Iron Alloy Seamless Pipe and Tube (19 Nickel-Chromium-Iron Alloy Springs (5-75) Supersedes Nickel-Chromium-lron Alloys (1973) \$1.75

Nickel-Chromium-Molybdenum-Columbium Alloy Plate, Sh Nickel-Chromium-Molybdenum-Columbium Alloy Plate, Sh Nickel-Chromium-Molybdenum-Columbium Alloy Plate, Sh Nickel-Chromium-Molybdenum-Columbium Alloy Seamless Nickel-Chromium-Molybdenum-Columbium Alloy Seamless Nickel-Chromium-Molybdenum-Columbium Bare Welding Ro Nickel-Cobalt-Molybdenum-Chromium, Specification for Nickel-Copper Alloy (UNS N04400) Plate, Sheet and Stri Nickel-Copper Alloy (UNS N04400) Seamless Pipe and Tub Nickel-Iron-Chromium Alloy Plate, Sheet, and Strip (A Nickel-lron-Chromium Alloy Plate, Sheet, and Strip, S Nickel-lron-Chromium Alloy Rod and Bar (ASME SB-408 Nickel-1ron-Chromium Alloy Rod and Bar, (1974) ASTM B Nickel-lron-Chromium Alloy Seamless Pipe and Tubing ( Nickel-1ron-Chromium Alloy (UNS N08800) Rod and Bar, Nickel-1ron-Chromium Alloy (UNS N08800) Seamless Pipe Nickel-Molybdenum-Chromium Alloy Bare Welding Rods an Nickel-Molybdenum-Chromium Alloy Castings (ASTM a 494 Nickel-Molybdenum-Chromium Alloy Forgings (ASME SA-1 Nickel-Molybdenum-Chromium Alloy Rod and Bar (ASME SB Nickel-Molybdenum-Chromium Alloy Seamless Pipe and Tu Nickel-Molybdenum-Chromium Alloy Seamless Tubes (ASME Nickel-Molybdenum-Chromium Alloy Sheet and Plate (Asm Nickel-Molybdenum-Chromium Alloy Welded Pipe (ASME SA Nickel-Molybdenum-Chromium-Iron Alloy Sheet and Plat Nickel-Rich, Chromium-Bearing Alloys, Method of (1973 Nickel-19Cr-19Fe-3.1Mo-5.1 (Cb+Ta) 0.90Ti-0.50A l C Nickel, and Cobalt-Base Alloys, Chemical Analysis of ( Nickel, Measuring (1970) \$1.75

Nickel, Specification for (1974A) $\$ 1.75$

Nil-Ductility Transition Temperature of Ferritic Steel Nine Percent Nickel (1974) \$1.75 /Pec. for Nitrate lon in Water, Standard Method of Test for (1971

Nitrate Solution (6-71)

Nitrate Solution (6-71)

Nitrate Solutions and Plutonium Metal Standard Methods

Nitrate Solutions ASTM C710-72 (1973) \$1.75

Nitrate Solutions for Assay, lsotopic Distribution, and

Nitrate Solutions (1973) \$1.75

/C, Spectrochemical Nuc

Nitrate Solutions (1/74)

Nitrate Solutions, Methods for (1974) ASTM C759-1973

Nitrate Solutions, Nuclear and Radiochemical Analysis 0

Nitrate Solutions, Specification for (1973) $\$ 1.75$

Nitrogen in Water, Tests for (1974) $\$ 1.75$

NMR) Spectroscopy, Definitions, Symbols, Conventions, a

Nomenclature and Terminology (1975) $\$ 5.00$

Nomenclature for Rubbers and Rubber Latices, Practice

Nomenclature of $(18$

Non Incendive Electrical Instruments (1965) \$5.00

Non Regenerative Type (5-72)

Nondestructive Assay for Plutonium in Scrap Material by

Nondestructive Assay of High Enrichment Uranium Fuel P

Nondestructive Assay of Special Nuclear Material Contai

Nondestructive Assay Systems, Guide to Calibrating (197

Noridestructive Examination of Primary Containment Liner

Nondestructive Examination of Tubular Products for Use

Nondestructive Examination of Tubular Products (10/73)

Nondestructive Examination of Welds in the Liners of Co

Nondestructive Examination (Supplement to ASME Boiler

Nondestructive Examination (1977) bd $(\$ 50.00), 11(\$ 70$

Nondestructive Symbols Testing (1976) $\$ 5.00$

Nondestructive Testing Personnel Qualification and Cert

Nondestructive Uranium-235 Enrichment Assay by Gamma-

Nonferrous Materials (1977) bd (\$90.00), 11 (\$125.00)

Nonferrous Metals and Alloys for Determination of Chemi

Noninsulated, Std. Grade (8-72) Amendment 1 (11-74)

Nonmailable Articles and Substances Under Special Rules

Nonmailable Matter: Written, Printed and Graphic Matte

Nonmailable Matter, Radioactive Materials (1975)

Nonmedical Sealed Gamma-Ray Sources (6/74)

Nonmetallic Gaskets for Corrosive Service, Practice for

Nonmetallic Thermal Insulation for Austenitic Stainless

Nonmetals in Liquid Sodium (1-72) Amendment 1 (6-73)

Non-Medical X-Ray and Sealed Gamma Ray Sources, Energi

Normal and Heavy Weight Concrete, Practice for Selectin

Normality (Employing Individual Observed Values) (1974) ASTM

ASTM

ERDA

ASTM

ERDA

ANS1

ERDA

ERDA

ASTM

ANSI

ERDA

ERDA

ERDA

ERDA

ERDA

ANSI

ASTM

ASTM

ERDA

ANSI

ERDA

ANSI

ERDA

ASTM

ASTM

ERDA

ERDA

ERDA

ERDA

ERDA

ERDA

ERDA

ERDA

ANS

ANSI

SAE

ANSI

ASTM

ASTM

ERDA

ERDA

NRC

ANS

NRC

ASTM

NRC

ANSI

ASTM

ASTM

ASTM

ASTM

ASTM

ASTM

ANSI

ISA

ERDA

NRC

NRC

ANS

NRC

NRC

NRC

NRC

ERDA

ASME

AWS

ASN

NRC

ASME

ASTM

ERDA

USPS

USPS

NRC

ASTM

NRC

ERDA

ANSI

ANSI

ANSI

A265

RDT M2-15T

E38

RDT M5-4T

H34.10

RDT M7-4T

H34.3

RDT M8-1T

E38

H34.19

RDT M5-20T

RDT M5-21T

RDT M3-29T

RDT M3-30T

RDT M1-19T

G35.26

B127

B 165

RDT M5-7T

H34.40

RDT M7-10T

H34.39

RDT M3-9T

B408

B407

RDT M1-15T 
Assessment of the Assumption of Statistical Terminology and Statistical Terminology and

bility $(2 / 2 / 73)$ Sharp-

(1973) $\$ 1.7 \$$ $\$ 1.75$

cation for Forgings, Carbon and Low Alloy Steel, Requiring

95

50

Food and Drugs:
Selecting Proportions for

fication for Special Requirements for Bolting Material for ification for Special Requirements for Pipe and Tubing for cification for Special Requirements for Steel Castings for -19/ Spec. for Special Requirements for Steel Plates fo -1/ Specification for Wrought Steel Welding Fittings for Spec. for Special Requirements for Forgings and Bars for or (1974) A/ Special Requirements for Pipe and Tubing fo or Special Requirements for (1973/ Steel Castings for the or Special Requirements for (1973)/ Bolting Material for or Special Requirements for (1973) \$1.7/ Steel Plates for or Special Requiremen/ Wrought Steel Welding Fittings for or Special Requirements for (1973)/ Forgings and Bars for tonium Me/ Chemical, Mass Spectrometric, Spectrochemical tonium Nit/ Chemical, Mass Spectrometric, Spectrochemical methods for Chemical, Mass Spectrometric, Spectrochemical ide, Meth/ Chemical, Mass Spectrometric, Spectrochemical, nium Metal, Chemical, Mass Spectrometric, Spectrochemical, Nuclear Grade Uranyl Nitrate Solutions, xafluoride, Chemical, Mass Spectrometric, Spectrochemical ished Zirconium and Zirconium Alloy Bars, Rod and Wire for 9-/ Supplementary Requirements for Nickel Alloy Plate for y Requirements for Nickel Alloy Seamless Pipe and Tube for nts for $(1970) \$ 1.75$ $n t$ for $(1970) \$ 1.75$ nts for $(1970) \$$ Zirconium and Zirconium-Alloy lngots fo Nickel Alloy Plate for Nickel Alloy Rod and Bar for Nickel Alloy Seamless Pipe and Tube for Zirconium and Zirconium Alloy Sheet, Strip, and Plate for ished Zirconium and Zirconium Alloy Bars, Rod and Wire for

Zirconium and Zirconium Alloy Sheet, Strip, and Plate for 9-1 Zirconium Sponge and Other Forms of Virgin Metal for $-1973 \$ 1.75 \quad$ Zirconium and Zirconium Alloy Ingots for Zirconium Sponge and Other Forms of Virgin Metal for Radiological Factors Affecting Decision Making in A pecial Construction, Arrangement, and Other Provisions fo ure Vessel Code, Section lii, Subsection/ ure Vessel Code, Section lii, Subsection/ ure Vessel Code, Section lii, Subsection/ ure Vessel Code, Section lii, Subsectio/ mendment 1 (4-/ Cleaning and Cleanliness Requirements for Shielding Protects Personnel (1975) ANS 8./ le Materials Outside Reactors (1975) ANS-8.1 \$10.00 le Materials Outside Reactors (1/73)

terials, Guide for (1975) ANS-8.7\$12.00

Validation of Calculational Methods fo Validation of Calculational Methods for

) ANS-19.1\$12.50

Testing of High Temperature Cable for Quality Assurance for Protective Coatings Applied to Sampling Airborne Radioactive Materials in e Design Criteria for (1973) $\$ 5.00$

Methods for Radiochemical Determination of Cesium-137 in Radiochemical Determination of Cesium-137 in rical Penetration Assemblies in Containment Structures for 73) $\$ 1.75$

otometric Determination of Fission Zirconium in lrradiated Specification for Specification for

ic, and Spectrochemical A nalysis of (1975) \$1.75 Pecification for

of Nuclear Grade Plutonium Dioxide Powders and Pellets and

Spectrometric, and Spectrochemical Analysis of (1974) \$ emical, Mass Spectrometric, and Spectrochemical Analysis/ mical, Mass Spectrometric, and Spectrochemical Analysis of emical, Mass Spectrometric, and Spectrochemical Analysis/ tric, Spectrochemical, Nuclear and Radiochemical A nalysi/

ic, Spectrochemical, Nuclear and Radiochemical Analysis of ASTM C701-1972 \$1.75

ric, Spectrochemical Nuclear and Radiochemical Analysis of (1974) As/ Chemical, Mass Spectrometric, Spectrochemical, 4) ASTM C760-1/ Chemical and Spectrochemical Analysis of

C752-1973\$1.75 75 a) $\$ 1.75$ $\$ 1.75$ Specification for
Chemical and Spectrochemical Analysis of Specification for Specification for
Normality (Employing lndividual Observed Values) (4/74) Notation for Nuclear Materials Management (1972) $\$ 3.00$ Notation for Special Nuciear Materials Control Accounta Notch Tension Testing of High Strength Sheet Materials Notch Toughness Testing for Piping Components (1974) \$1 Notched Bar Impact Testing of Metallic Materials (1972) Notification of Defects or Failure to Comply (1975) \$2.

No-Slump Concrete, Recommended Practice for (1975) $\$ 9$. Nuclear Air Cleaning Systems, Testing of (1975) $\$ 5.00$ Nuclear and Other Special Applications ASTM A614-73 ( Nuclear and Other Special Applications (1973) \$1.75

Nuclear and Other Special Applications (1974) ASTM A613

Nuclear and Other Special Applications (1974) ASTM A647

Nuclear and Other Special Applications (1974) ASTM A652 Nuclear and Other Special Applications (1974) ASTM A654 Nuclear and Other Special Applications, Specification F Nuclear and Other Special Applications, Specification F Nuclear and Other Special Applications, Specification F Nuclear and Other Special Applications, Specification F Nuclear and Other Special Applications, Specification F Nuclear and Other Special Applications, Specification F Nuclear and Radiochemical Analysis of Nuclear Grade Plu Nuclear and Radiochemical Analysis of Nuclear Grade Plu Nuclear and Radiochemical Analysis of Nuclear (Revision Nuclear and Radiochemical Analysis of Uranium Hexafluor Nuclear and Radiochemical Analysis of (1973) \$1.75 Nuclear and Radiochemical Analysis of (1975) \$1.75 Nuclear and Radiochemical, Analysis of (1975) \$1.75 Nuclear Application (1973) \$1.75 / Rolled and Col Nuclear Applications, Specification for (1971) ASTM B50 Nuclear Applications, Specification for (1971) $\$ 1.75$ as Nuclear Applications, Specification for (1973) $\$ 1.75$ Nuclear Applications, Spec. for Supplementary Requireme Nuclear Applications, Spec. for Supplementary Requireme Nuclear Applications, Spec. for Supplementary Requireme Nuclear Application, Specification for (1967) \$1.75 Nuclear Application, Specification for (1973) ASTM B351 Nuclear Application, Specification for (1973) ASTM B352 Nuclear Application, Specification for (1973) (ASTM B34 Nuclear Application, Specification for (1974) ASTM B350 Nuclear Application, Spec. for (1973) $\$ 1.75$

Nuclear Attack (1974) $\$ 4.00$

Nuclear Cargo Vessels (Ships and Barges) (1975) \$1.95

Nuclear Components (Supplement to ASME Boiler and Press Nuclear Components (Supplement to ASME Boiler and Press Nuclear Components (Supplement to ASME Boiler and Press Nuclear Components (Supplement to ASME Boiler and Press Nuclear Components (2-72) Supersedes F5-1 T, (3-69) a Nuclear Components (2-75) Supersedes E8-18T, (10-71) Nuclear Criticality Safety Controls in Operations Where Nuclear Criticality Safety in Operations with Fissionab Nuclear Criticality Safety in Operations with Fissionab Nuclear Criticality Safety in the Storage of Fissile Ma Nuclear Criticality Safety (1975) ANS-8.11

Nuclear Criticality Safety (6/76)

Nuclear Data Sets for Reactor Design Calculations ( 1975

Nuclear Detectors (8-71)

Nuclear Facilities (1972) $\$ 3.00$

Nuclear Facilities, Guide to (1969) ISO $2889 \$ 7.00$

Nuclear Fuel Reprocessing Facilities, Guide to Principl

Nuclear Fuel Solutions (1973) ASTM E320-1970 \$1.75

Nuclear Fuel Solutions, Standard Method for (1970) \$1.7 Nuclear Fueled Power Generating Stations (1973) 1EEE 31 Nuclear Fuels (1973T) \$1.75 /Hod of Test for Spectroph Nuclear Grade Beryllium Oxide Powder ASTM C708-72a ( 19

Nuclear Grade Beryllium Oxide Powder (1972A) \$1.75

Nuclear Grade Boron Carbide Powder (1974) \$1.75

Nuclear Grade Boron Carbide, Chemical, Mass Spectrometr

Nuclear Grade Mixed Oxides ((U,Pu)O $\left.)_{2}\right)(5 / 73)$

Nuclear Grade Mixed Oxides ((U,Pu)O(2)), Chemical, Mass

Nuclear Grade Mixed Oxides ((U,Pu)O(2)), Methods for $\mathrm{Ch}$ Nuclear Grade Plutonium Dioxide Powders and Pellets and Nuclear Grade Plutonium Dioxide Powders and Pellets, $\mathrm{Ch}$ Nuclear Grade Plutonium Metal, Chemical, Mass Spectrome Nuclear Grade Plutonium Metal, Methods for (1974) ASTM Nuclear Grade Plutonium Metal, Specification for (1973) Nuclear Grade Plutonium Metal, Spec. for (1972) $\$ 1.75$

Nuclear Grade Plutonium Nitrate Solutions (1973) \$1.75 Nuclear Grade Plutonium Nitrate Solutions, Methods for Nuclear Grade Silver-Cadmium Alloys, Methods for (197 Nuclear Grade Silver-Indium-Cadmium Alloy (1973) \$1.7 Nuclear Grade Silver-1ndium-Cadmium Alloy (1974) ASTM Nuclear Grade Silver-Indium-Cadmium Alloys (1974) \$1. Nuclear Grade Sinterable Plutonium Dioxide Powder (1974 Nuclear Grade Sinterable Uranium Dioxide Powder (1973) Nuclear Grade Uranium Dioxide Powders and Pellets (2/9/
NRC

ANS1

NRC

ASTM

ASTM

ASTM

BRH

$\mathrm{ACl}$

ANSI

ANS1

C ASTM

ANSI

ANS

ANS

ANS

ANS1

ASTM

ASTM

ASTM

ASTM

ANSI

ASTM

NRC

to ASTM

ASTM

/E ASTM

ASTM

ANS1

ANSI

ASTM

ASTM

ASTM

ASTM

ASTM

ANS1

ANS1

ANS1

ANSI

ASTM

NCRP

USCG

ERDA

ERDA

ERDA

ERDA

ERDA

ERDA

ANSI

ANSI

NRC

ANSI

ANSI

NRC

ANS1

ERDA

ANSI

ANSI

ANSI

ASTM

ANSI

ASTM

ANSI

ASTM

ASTM

NRC

ASTM

ANS1

NRC

ASTM

ASTM

ANS

ANSI

ASTM

ANSI

ANSI

ASTM

ASTM

ASTM

ASTM

RG 5.22

N15.5

G 5.3

E338

A 350

E23

2 ICFR 1003

211.3

N510

N265

A 655

N558

N559

N560

N56I

N564

A6 13

A614

A 647 .

A 652

A 654

N572

C75

RG 5.16 
ical, Mass Spectrometric, and Spectrochemical Analysis O/ iochemical Analysis of (1975) \$1.75

mical, Mass Spectrometric, and Spectrochemical Analysis of mical, Mass Spectrometric, and Spectrochemical Analysis of ASTM C753-1973 \$1.75

ASTM C757-1974a $\$ 1.75$

Specification for

Thermal Neutron Absorption Cross Section of Lattice Spacing of

75

$1971 \$ 1.75$ estimating the Thermal Neutron Absorption Cross Section .75

osimetry Results on Delta-In-Hours (DIH) Purity of

for $(1975) \$ 3.00$ Protective Coatings (Paints) for the Authorized

Qualifications and Duties for Authorized Signal Connectors for High Voltage Connectors for commended Practice for Standard Calibration and Format for ons, Symbols, Conventions, and References Relating to ( 1 /

Nondestructive Assay of Special ecial Nuclea/ Standard Format and Content for the Special ies, Guide to Practice (1971) $\$ 4.50$ acilities (A Guide to Practice) (1975) $\$ 3.00$

ts (Revision $1,6 / 75$ )

(1974) $\$ 3.00$

or $(1975) \$ 5.50$

Nuclear Power Reactors, Fuel Reprocessing Facilities,

n Considerations for Minimizing Residual Holdup of Special n Considerations for Minimizing Residual Holdup of Special $n$ Considerations for Minimizing Residual Holdup of Special
clear Material Control and Accounting Section of a Special an/ Guide for the Preparation of Applications for Special Conduct of gned Vehicle and Armed Guards for Road Shipment of Special Security Seals for the Protection and Control of Special Internal Transfers of Special

ysis and Use of Process Data for the Protection of Special Statistical Terminology and Notation for Special Records and Reporting Units for Limit of Error Concepts and Principles of Calculation in Volume Calibration Techniques for

Limit of Error Concepts and Principles of Calculation in calorimetric Assay of Plutonium-Bearing Solids Applied to n Considerations for Minimizing Residual Holdup of Special Statistical Terminology and Notation for

Auditing

ks in the Protection and Control of Facilities and Special Physical Inventories of strative Guide for Liability Insurance Aspects of Shipping f Shipper-Receiver Differences in the Transfer of Special ensitive Seals on Containers for Onsite Storage of Special

f Shipper-Receiver Differences in the Transfer of Special

Moisture Content of Soil and Soil Aggregate in Place by or Moisture Content of Soil and Soil Aggregate in Place by Density of Soil and Soil-Aggregate in Place by

cification for (197/ Thermocouples, Sheathed, Type K, for cification for (1967/ Thermocouples, Sheathed, Type K for cification for Sheathed Electrical Resistance Heaters, for (1971) \$1.7/ Sheathed Electrical Resistance Heaters, for 6/73)

pecial Construction, Arrangenent, and Other Provisions for s, Structures and Equipment for Water Cooled and Moderated iteria for the (1975) $\$ 5.00$ Periodic Testing of

ft Standard Application of the Single Failure Criterion to Definitions of Terms Used in IEEE Standards on ass IE Electric Cables, Field Splices, and Connections for ieee Std. $279-1971 \$ 4.00$ ieee Std. 308-1974 $\$ 4.00$ Protection Systems for ign Bases for Systems That Performs $1 \mathrm{E}$ Power Systems for 00 Seismic Qualification of Electric Equipment for us Duty Class I Motors Installed Inside the Containment of entation and Electric Equipment During the Construction of esel Generator Units Applied as Standby Power Supplies for andard Type Test of Class 1 Electrical Valve Operators for for Usel Draft Std. for Class $1 \mathrm{E}$ Control Switchboards for

bd $(\$ 40.00)$, Il $(\$ 65.00)$ $00)$, Il $(\$ 40.00)$

$\$ 90.00$ )

90.00)

zardous C/ cardental $\mathrm{Ch}$
General Requirements for

Rules for Inservice Inspection of Appendices to Sec. 11I Div. 1,
Nuclear Grade Uranium Dioxide Powders and Pellets, Chem Nuclear Grade Uranyl Nitrate Solutions, Nuclear and Rad

Nuclear Grade (1973) ASTM C696-1972 \$2.00

Nuclear Grade (1973) ASTM C697-1972 \$2.00

Nuclear /Ds for Che

Nuclear Grade, Sinterable Uranium Dioxide Powder (1974)

Nuclear Graphite, Estimating the (1971) \$1.75

Nuclear Graphite, Measurement of (1969) (R1975) \$1.75

Nuclear Graphite, Method for (1973) ASTM C558-1969\$1.

Nuclear Graphite, Method of Test for (1973) ASTM C624.

Nuclear Graphite, Methods for (1973) ASTM C626-1971 \$1

Nuclear Graphite, Rec. Practice for Reporting (1974) \$ I

Nuclear Graphite, Test for (1971) \$1.75

Nuclear Industry (1974) \$14.00

Nuclear Inservice Inspection, Qualifications and Duties

Nuclear Inspection (1974) $\$ 3.50$

Nuclear Instruments (1968) (R1973) \$2.50

Nuclear Instruments (1971) $\$ 3.00$

Nuclear Logs (1974) $\$ 1.00$

Nuclear Magnetic Resonance (NMR) Spectroscopy, Definiti

Nuclear Material Contained in Scrap and Waste (10/73)

Nuclear Material Control and Accounting Section of a Sp

Nuclear Material Control Systems for Conversion Facilit

Nuclear Material Control Systems for Fuel Fabrication F

Nuclear Material Control Systems for Nuclear Power Plan

Nuclear Material Control Systems for (1974) $\$ 3.50$

Nuclear Material Control Systems (A Guide to Practice)

Nuclear Material Control, Mass Calibration Techniques F

Nuclear Material Doorway Monitors (6/74)

Nuclear Material in Drying and Fluidized Bed Operations

Nuclear Material in Equipment for Dry Process Operation

Nuclear Material License Application (Including That Fo

Nuclear Material Licenses of Less Than Critical Mass Qu

Nuclear Material Physical Inventories (11/73)

Nuclear Material (Revision 1,4/75)

Nuclear Material (1/74)

Nuclear Material (3/75)

Nuclear Material (6/74)

Nuclear Materials Control Accountability (2/2/73)

Nuclear Materials Control (1971) $\$ 3.25$

Nuclear Materials Control (1974) $\$ 3.00$

Nuclear Materials Control (1975) $\$ 5.50$

Nuclear Materials Control (1.74)

Nuclear Materials Control, Calibration Techniques for T

Nuclear Materials in Equipment for Wet Process Operatio

Nuclear Materials Management (1972) $\$ 3.00$

Nuclear Materials Statements (1973) \$3.50

Nuclear Materials (11/73)

Nuclear Materials (1972) $\$ 3.25$

Nuclear Materials (1973) $\$ 3.50$

Nuclear Materials (6/74)

Nuclear Materials ( $7 / 73)$ Ction and Use of
Nuclear Materials, Concepts and Principles for the (197

Nuclear Methods (Shallow Depths), Test for (1972) \$1.75

Nuclear Methods (Shallow Depth) (1972) \$1.75 (ASTM D30

Nuclear Methods (Shallow Depth), Tests for (1971) $\$ 1.75$

Nuclear or for Other High Reliability Applications, Spe

Nuclear or for Other High Reliability Applications, Spe

Nuclear or Other Specialized Service (1973) ASTM E420-

Nuclear or Other Specialized Service, Specification for

Nuclear Passenger Vessels (Ships and Barges) (1975) \$2.

Nuclear Plants Against Industrial Sabotage (Revision 1,

Nuclear Power Generating Plants, Fire Protection Criter

Nuclear Power Generating Station Protection Systems, C

Nuclear Power Generating Station Protection Systems, Tr

Nuclear Power Generating Stations (1972) $\$ 4.00$

Nuclear Power Generating Stations (1975) lEEE Std. 383-

Nuclear Power Generating Stations, Criteria for (1972)

Nuclear Power Generating Stations, Criteria for (1975)

Nuclear Power Generating Stations, Criteria (Issued for

Nuclear Power Generating Stations, Guide for (1975) \$5.

Nuclear Power Generating Stations, Guide For, (1976) Ie

Nuclear Power Generating Stations, Installation, Inspec

Nuclear Power Generating Stations, Trial Use Criteria

Nuclear Power Generating Stations, Trial Use Guide (Is

Nuclear Power Generating Stations, (Trial Guide Issued

Nuclear Power Piping Sold Separately (1971) $\$ 4.25$

Nuclear Power Piping with Addenda (1969) $\$ 19.00$

Nuclear Power Piping, Sold Separately (1971) \$4.25

Nuclear Power Piping, Sold Separately (1972) \$1.25

Nuclear Power Plant Components Div. I and Div. 2 (1977)

Nuclear Power Plant Components Supports (1977) bd $(\$ 30$.

Nuclear Power Plant Components (1977) bd (\$60.00); II (

Nuclear Power Plant Components (1977) bd $(\$ 70.00)$ II $(\$$

Nuclear Power Plant Control Room During a Postulated $\mathrm{Ha}$

Nuclear Power Plant Control Room Operators Against an a
ASTM

ASTM

ANSI

ANSI

ANSI

ANSI

ASTM

ANS1

ANSl

ANSl

ASTM

ASTM

ANSI

ANSI

ANSI

ANSI

ANSI

Re APl

ASTM

NRC

NRC

ANSl

ANS1

ANSI

ANSI

ANS

NRC

NRC

NRC

NRC

NRC

NRC

NRC

NRC
NRC

Anal NRC

NRC

ANS!

ANS

ANSI

NRC

ANSI

NRC

ANSI

ANSI

NRC

ANSI

Admini ANSI

NRC

ANSI

ASTM

ANSI

ASTM

ANSI

ASTM

ANSI

ASTM

USCG

NRC

ANS

IEEE

ANSI

IEEE

ANSI

ANSI

ANSI

ANS

1EEE

ANSI

ANSI

ANSI

ANS

ANSI

ANSI

ANSI

ANS

ANSI

ASME

ASME

ASME

ASME

NRC

NRC

C696 C799

N104

N567

N568

C626

C558

K90.

K90.8

K90.10

N5 12

N626.1

N626

N544

N42.4

RP 33

E386

RG 5.11

RG 5.45

N 15.4

N15.9

RG 5.29 
g Personnel (8/73)

$1,12 / 75)$ plosions Postulated to Occur on Transportation Routes Near Class 1 Components for Class 3 Components for

Class MC Components for Class 2 Components for Guidance on Being Operator at the Controls of A Draft Standard for Design Basis for Protection of Seismic Requirements for Design of Safety Considerations for and Following A/ Instrumentation for Light-Water-Cooled ng, Shipping, Receiving, Storage and Handling of ltems for on Valve Leakage Control Systems for Boiling Water Reactor Power Levels of

Design Response Spectra for Seismic Design of Additional Information: Hydrological Considerations for ed Emergency and Shutdown Electric Systems for Multi-Unit

Programs for Monitoring Radioactivity in the Environs of Design Basis Floods for rete and Structural Steel During the Construction Phase of Criteria for Safety-Related Electric Power Systems for in Liquid and Gaseous Effluents from Light-Water-Cooled Nuclear Material Control Systems for s Antitrust Review of Construction Permit Applications for ir Filtration and Adsorption Units of Light-Water Cooled Quality Assurance Program Requirements for the Design of standard Format and Content of Safety Analysis Reports for Ultimate Heat Sink for Steam-, and Radioactive-Waste-Containing Components of Damping Values for Seismic Design of tion Assemblies in Containment Structures for Water Cooled its Antitrust Review of Operating License Applications for Flood Protection for Qualification of Class 1E Equipment for Emergency Planning for Concrete Radiation Shields for ormation: Air Filtration Systems and Containment Sumps for ation for Safety Analysis Reports: Industrial Security for Environmental Technical Specifications for Inservice Testing of Valves in Inservice Testing of Pumps in Selection and Training of Personnel for Quality Assurance Program Requirements for Administrative Controls for

Housekeeping During the Construction Phase of nation and Testing Personnel for the Construction Phase of and Associated Components During the Construction Phase of Industrial Security for

Earthquake Instrumentation Criteria for Siorage, and Maintenance of Quality Assurance Records for rete and Structural Steel During the Construction Phase of Quality Assurance Requirements for the Design of ectric Valve Operators Installed Inside the Containment of additional Information: Fire Protection Considerations for Overhead Crane Handling Systems for Housekeeping Requirements for Water Cooled receiving, Storage, and Handling of Items for Water Cooled ty Motors Installed Inside the Containment of Water Cooled g Fluid Systems and Associated Components of Water-Cooled Seismic Qualification of Electric Equipment for Design Basis Tornado for

Additional Information: Water Level (Flood) Design for quirements for Protective Coatings Applied to Water Cooled Fire Protection Guidelines for

I Information: Geography and Demography Considerations for Testing Biological Sheilding in anical Equipment and Systems for the Construction Phase of rial Numbering of Fuel Assemblies for Light-Water-Cooled

it Analysis for Radwaste Systems for Light-Water-Cooled

nal Radiation Exposure as Low as Is Reasonably Achievable $s$ for (1974) $\$ 3.50$

General Site Suitability Criteria for Preparation of Environmental Reports for Terrestrial Environmental Studies for pecial Construction, Arrangement, and Other Provisions for nduced in Vulcanized Rubber During Exposure to High Energy nduced in Vulcanized Rubber During Exposure to High Energy Protective Coatings (Paints) for Light W ater 72) Amendment 2 (/ Electrical Penetration Assemblies for Method For/ Delayed Neutron Emitting Fission Products in Measureme/ Delayed Neutron-Emitting Fission Products in Radiation Protection in Practice for Surveillance Tests for
Nuclear Power Plant Inspection, Examination, and Testin Nuclear Power Plant Protection Systems (6/73)

Nuclear Power Plant Quality Assurance Records (Revision

Nuclear Power Plant Safety Systems (5/73)

Nuclear Power Plant Sites (1/75)

Nuclear Power Plant (1977) bd (\$S:

NRC

Nuclear Power Plant (1977) bd (\$55.00), II (\$85.00)

Nuclear Power Plant (1977) bd (\$55.00), Il (\$85.00)

Nuclear Power Plant $(1977)$ bd $(\$ 55.00),(\$ 85.00)$

Nuclear Power Plant (2/76)

Nuclear Power Plants Against Effects of Postulated Pipe

Nuclear Power Plants and Test Facilities (1-74)

Nuclear Power Plants on Merchant Ships (1965) $\$ 7.50$

Nuclear Power Plants to Assess Plant Conditions During

Nuclear Power Plants (During the Construction Phase) ( 1

Nuclear Power Plants (Revision 1, (6/76)

Nuclear Power Plants (Revision 1, 12/73)

Nuclear Power Plants (Revision 1, 12/73)

Nuclear Power Plants (Revision 1, 1/75)

Nuclear Power Plants (Revision 1, 1/75)

Nuclear Power Plants (Revision 1, 2/75)

Nuclear Power Plants (Revision 1, 4/76)

Nuclear Power Plants (Revision 1, 4/76)

Nuclear Power Plants (Revision 1, 6/73)

Nuclear Power Plants (Revision 1, 6/74)

Nuclear Power Plants (Revision 1, 6/75)

Nuclear Power Plants (Revision 1, 6/76)

Nuclear Power Plants (Revision 1, 7/76)

Nuclear Power Plants (Revision 2, (6/76)

Nuclear Power Plants (Revision 2, (9/75)

Nuclear Power Plants (Revision 2, 1/76)

Nuclear Power Plants (Revision 3, 2/76)

Nuclear Power Plants (10/73)

Nuclear Power Plants (10/73)

Nuclear Power Plants (10/74)

Nuclear Power Plants (10/75

Nuclear Power Plants (11/74)

Nuclear Power Plants $(11 / 75)$

Nuclear Power Plants $(12 / 73)$

Nuclear Power Plants (12/73)

Nuclear Power Plants $(12 / 74)$

Nuclear Power Plants (12/75)

Nuclear Power Plants (1970) $\$ 2.25$

Nuclear Power Plants (1970) $\$ 2.75$

Nuclear Power Plants (1971) ANS-3.1 $\$ 10.00$

Nuclear Power Plants (1971) $\$ 4.00$

Nuclear Power Plants (1972) ANS-3.2 \$10.00

Nuclear Power Plants (1973) $\$ 4.00$

Nuclear Power Plants (1973) $\$ 4.00$

Nuclear Power Plants (1973) $\$ 4.00$

Nuclear Power Plants (1973) (ANS-3.3) \$10.00

TTeam Isolati

ASME

Nuclear Power Plants (1974) ANS 2.2\$10.00

Nuclear Power Plants (1974) $\$ 4.00$

Nuclear Power Plants (1974) $\$ 4.50$

Nuclear Power Plants (1974) $\$ 5.50$

Nuclear Power Plants $(1 / 74)$

Nuclear Power Plants (2/74)

Nuclear Power Plants (2/76)

Nuclear Power Plants $(3 / 16 / 73)$

Nuclear Power Plants (3/16/73)

Nuclear Power Plants (3/16/73)

Nuclear Power Plants $(3 / 16 / 73)$

Nuclear Power Plants (3/76)

Nuclear Power Plants $(4 / 74)$

Nuclear Power Plants (5/74)

Nuclear Power Plants $(6 / 73)$

Nuclear Power Plants $(6 / 76)$

Nuclear Power Plants $(8 / 74)$

Nuclear Power Plants, Program for (1972) ANS-6.3 \$5.0

Nuclear Power Plants, Supplementary Quality Assurance R

Nuclear Power Reactors (12/20/72)

Nuclear Power Reactors (3/76)

Nuclear Power Reactors) (Revision 1, 9/75)

Nuclear Power Reactors, Nuclear Material Control System

Nuclear Power Stations (Revision 1, 11/75)

Nuclear Power Stations (Revision 1, 1/75)

Nuclear Power Stations ( $7 / 76$ )

Nuclear Powerplant Components (1975) $\$ 4.40$

Nuclear Radiation, Methods of Test for (1971) ASTM D230

Nuclear Radiation, Testing (1968) (R1974) \$1.75

Nuclear Reactor Containment Facilities (1972) \$3.00

Nuclear Reactor Containment Structures Amendment 1 (4-

Nuclear Reactor Coolant Water During Reactor Operation,

Nuclear Reactor Coolant Water During Reactor Operation,

Nuclear Reactor Fuel Fabrication Plants (1963) $\$ 5.50$

Nuclear Reactor Vessels (1973) ASTM E185-1970 \$1.75
ASME

ASME

ASME

NRC

ANS1

ERDA

SNAME

NRC

ANS

RG 1.58

RG 1.53

RG 1.88

RG 1.47

RG 1.91

SEC-IIINB

SEC-IIIND

SEC-IIINE

SEC-IIINC

RG .1.114

N176

RG 1.97

N45.2.2

RG 1.96

RG 1.49

RG 1.60

RG 1.70.1

RG 1.81

RG 4.1

RG 1.59

RG 1.94

RG 1.32

RG 1.21

RG 5.29

RG 9.2

RG 1.52

RG 1.64

RG 1.70

RG 1.27

RG 1.26

RG 1.61

RG 1.63

RG 9.3

RG 1.102

RG 1.89

RG 1.101

RG 1.69

RG 1.70.2

RG 1.70 .15

RG 4.8

PTC 34

PTC 35

N18.1

N45.2

N18.7

N45.2.3

N45.2.6

N45.2.1

N18.17

N18.5

N45.2.9

N45.2.5

N45.2.11

RG 1.73

RG 1.70.4

RG 1.104

RG 1.39

RG 1.38

RG 1.40

RG 1.37

RG 1.100

RG 1.76

RG 1.70.5

RG 1.54

RG 1.120

RG 1.70 .7

N18.9

N452.8

RG 5.1

RG 1.110

RG 8.8

N1 5.8

RG 4.7

RG 4.2

RG 4.11

46CFR55

J2.33

D2309

N101.2

RDT P3-IT

$\begin{array}{ll}\text { ANSI } & \text { N163 } \\ \text { ASTM } & \text { D2470 }\end{array}$

$\begin{array}{ll}\text { ASTM } & \text { D247 } \\ \text { ANSI } & \text { N7.2 }\end{array}$

ANSI 
Guide for in Service Annealing of Water Cooled recommended Guide for in Service Annealing of Water Cooled Surveillance Tests for Leakage-Rate Testing of Containment Structures for Simulated Core Assemblies for Termination of Operating Licenses for 0 Neutron Reaction Rate Distributions and Reactivity of for $(1974) \$ 3.50$

iling Water Reactor Plants: Issued Fo/ Draft Standard for essurized Water Reactor Plants (1973) ANS-51.1 $\$ 30.50$ essurized Water Reactor Plants (1975) \$5.50

Standard Glossary of Terms in irconium and Zirconium Alloy Seamless and Welded Tubes for irconium and Zirconium Alloy Seamless and Welded Tubes for Classification of Air Cooled Heat Exchanger for

4) Supersedes F9/ Guidelines and Procedures for Design of plement to ASME Code Ca/ Requirements for Construction of Orifice Assemblies for ecial Consideration, Arrangement, and Other Provisions for Health Implications of Fallout from ic, Spectrochemical, Nuclear and Radiochemical Analysis of (R1972) $\$ 4.75$

uclear Power Reactors (12/20/72)

Std. Spec. for Automatic

71) Amendment I (12-72), Amen/ Collapsible Rotor, Roller ngth Bolts for Structural Steel Joints, Including Suitable Service (ASME SA-194 with Additional Requi/ Alloy Steel

ication for (1973) $\$ 1.75$

$\mathrm{ng}$ and Storage Facilities in a Reprocessing Plant/ Recommended Practice for Dealing with Outlying

sment of the Assumption of Normality (Employing Individual

sment of the Assumption of Normality (Employing Individual concrete, Method of (1969) ASTM C42-1968 \$1.75

for Radioactive Materials Shipments, Administrative Guid/ Radioactive Material Shipments/ Administrative Guide for

le Concentrations of Radionuclides in Air and in Water for Achievable (Nuclear/ Information Relevant to Maintaining nt $2(11-75)$

ce for (Reaffirmation and Redesignation of N2.2-1966) (/ Preparation of Unusual g the Potential Radiological Consequences of a Radioactive Process

X-Ray Protection in Dental Welded Steel Tanks for nter Tubes (1965) (R1971) 3.00 and N42.6 Are Contained in ) (ASTM D2435-1970) \$1.75 Method of Test for 2)

ion and Use of Pressure-Sensitive Seals on Containers for stems (Safety Gu/. Independence Between Redundant Standby dioactivity in Effluents, Specification and Performance/

or (1973) $\$ 3.00$

Floor and Wall Chemical Analysis of Steel, Cast lron,
ional Specification Standard (1975) $\$ 3.00$ Std. Specifications for $\mathrm{Hand}$ Std. Specifications for Manually Lever Standard ( 1975 ) $\$ 3.00$
Thermal Overload Protection for Electric Motors on Moto Thermal Overload Protection for Electric Motors on Motor
Stainless Steel Globe and Angle Valves, Manual and Power Stainless Steel Gate Valves, Manual and Powe cated Reflective Insulation Systems for Equipment and Pipe cated Reflective Insulation Systems for Equipment and Pipe

4)

ons (Revision $4,8 / 75$ ) egulatory Staff in Connection with Its Antitrust Review of Termination of

trong Acid Removal (1972) $\$ 1.75$

5T, 5.73

tion Exposure as Low as Is Reasonably Achievable (Revisi/

$0.00)$

$107 \$ 3.00$

1A-1973 $\$ 5.00$ s 8.1 tion for Safety Analysis Reports: Quality Assurance During Criteria for Nuclear Criticality Safety Controls in
Crity (1975) ANS-8.1 \$10.00

(1/73) Nuclear Criticality Safety in Nuclear Criticality Safety in up of Special Nuclear Material in Drying and Fluidized Bed $p$ of Special Nuclear Material in Equipment for Dry Process of Special Nuclear Materials in Equipment for Wet Process
Nuclear Reactor Vessels (1974) ASTM E509-74 \$1.75 Nuclear Reactor Vessels (1974) $\$ 1.75$

Nuclear Reactor Vessels, Rec. Practice for (1973) \$1.75

Nuclear Reactors (197I) ANS-7.60 \$7.50

Nuclear Reactors (3-73) Amendment 1 (12-74)

Nuclear Reactors (6/74)

Nuclear Reactors, Determination of (1975) ANS $19.3 \$ 7.5$

Nuclear Reactors, Recommended Fire Protection Practice

Nuclear Safety Criteria for the Design of Stationary Bo

Nuclear Safety Criteria for the Design of Stationary Pr

Nuclear Safety Criteria for the Design of Stationary Pr

Nuclear Science and Technology (1967) \$7.95

Nuclear Service, Specification for (1973) ASTM B353-19

Nuclear Service, Spec. for (1971) $\$ 1.75$

Nuclear Ships, Guide for the (1962) $\$ 1.00$

Nuclear Steam Supplied Systems (3-71)

Nuclear Steam Supply Systems (1974) $\$ 5.50$

Nuclear System Components at Elevated Temperature (9-7

Nuclear System Components at Elevated Temperatures (Sup

Nuclear Systems (8-73)

Nuclear Tank Vessels (Ships and Barges) (1975) \$2.15

Nuclear Weapons Test. Through 1961 (1962)

Nuclear (Revision 1, 5/75)

/Chemical, Mass Spectrometr

(1966)

Numbering of Fuel Assemblies for Light-Water-Cooled N

Nut Control Rod Drive Mechanism for Sodium Service (3

Nuts and Plain Hardened Washers, Specification for (197

Nuts for Bolting for High Pressure and High Temperature

Nuts (1972) $\$ 4.50$

Nylon Injection Molding and Extrusion Materials, Specif

Objectives for Highly Radioactive Solid Material Handli

Observations $(6 / 74)$

Observed Values) (1974) $\$ 4.00$

Observed Values) (4/74)

Obtaining and Testing Drilled Cores and Sawed Beams of

Obtaining Department of Transportation Special Permits

Obtaining Exemptions from Certain NRC Requirements Ove

Occupational Exposure (1959) $\$ 2.00$ / Maximum Permissib

Occupational Radiation Exposure as Low as Is Reasonably

Occupational Radiation Exposure as Low as Is Reasonably

Occupational Radiation Exposure Records Systems (5/73)

Occupational Radiation Exposure Records Systems, Practi

Occurrence Reports (2-74) Amendment 1 (1-75), Amendme

Ocean (1954) \$2.00

Offgas System Failure in a Boiling Water Reactor $(3 / 76)$

Offgas Systems for Fuel Reprocessing Plants (2/74)

Offices (1970) $\$ 4.00$

Oil Storage (1973) $\$ 4.00$

One Booklet Priced at $\$ 3.00$

One Dimensional Consolidation

Onsite Meteorological Programs (Safety Guide 23 2/17/7

Onsite Storage of Special Nuclear Materials (7/73)

(Onsite) Power Sources and Between Their Distribution Sy

On-Site Instrumentation for Continuously Monitoring $\mathrm{Ra}$

Open Test Assembly Fabrication (10-73)

Openings, Railings and Toeboards, Safety Requirements F

Open-Hearth Iron, and Wrought lron (1975) \$1.75

Operated and Power Operated Safety Related Valves Funct

Operated Chain Hoists (1974) \$0.50

Operated Chain Hoists (1974) $\$ 0.50$

Operated Safety Related Valves Functional Specification

Operated Valves (11/75)

Operated (3-72)

Operated (3-72) Amendment 1 (5-74)

Operating at Temperatures Above Ambient Air (1972) $\$ 1.7$

Operating at Temperatures Above Ambient Air (1974) ASTM

Operating Information for Fuel Reprocessing Plants $(2 / 7$

Operating Information: Appendix a Technical Specificati

Operating License Applications for Nuclear Power Plants

Operating Licenses for Nuclear Reactors (6/74)

Operating Manuals for Fuel Shopping Containers (1-75)

Operating Performance of Anion Exchange Materials for $S$

Operating Philosophy for Maintaining Occupational Radia

Operating Sodium Reactor Systems (3/76) Supersedes A1-

Operation and Maintenance Manuals (10-71)

Operation of Fast Pulse Reactors (1975) ANS 14.1 $\$ 7.50$

Operation of Heating Boilers (1977) bd $(\$ 25.00), 11$ ( $\$ 3$

Operation of Particle Accelerators (1969) NBS Handbook

Operation (1973), Partial Revision of N7.1-1960 and N7

Operations Phase (12/74)

Operations Where Shielding Protects Personnel (1975) an

Operations with Fissionable Materials Outside Reactors

Operations with Fissionable Materials Outside Reactors

/Inimizing Residual Hol

Operations (Revision 1, 5/74)

Operations (1/75)

/Tions for Minimizing Residual Holdu NRC
/lons for Minimizing Residual Holdup NRC

ANSI

ASTM

ANS1

ERDA

NRC

ANSI

NFPA

ANSI

ANS1

ANS1

ANSI

ASTM

ABS

ERDA

ERDA

ERDA

EPA

NRC
ANSI

ERDA

ASTM

ERDA

ANS1

ANS1

NRC

Asses ANSI

NRC

ANSI

ANSI

NRC

NCRP

NRC

NRC

NRC

ANSI

NCRP

NRC

NRC

NCRP

API

ANSI

ANSI

NRC

Ct NRC

NRC

ANSI

ERDA

ASTM

ANSI

HM

HMI

ANSI

NRC

ERDA

ERDA

ANSI

NRC
NRC
NRC

ERDA

ASTM

NRC

ERDA

ERDA

ANSI

ASME

ANSI

ANSI

NRC

ANSI

NSI

Operations (6/74)

N577

E509

E185

N45. 4

DT E6-11T

RG 1.86

N412

N212

N18.2

N18.2A

N1.1

N124

B353

$* 1$

RDT E4-18T

PTC 32.1

RDT F9-5T

RDT F9-4T

RDT C4-8T

46CFR 37

FRC 3

RG 5.16

C39.4

RG 5.1

RDT E6-5T

A 325

RDT M6-4T

B 1 8.2.2

D789 
Quality Assurance Program Requirements $\mathrm{n}$ Products in Nuclear Reactor Coolant Water During Reactor $\mathrm{n}$ Products in Nuclear Reactor Coolant Water During Reactor Guidance on Being Protection of Nuclear Power Plant Control Room use/ Draft Standard Type Test of Class I Electrical Valve ower Plants (1/74) Qualification Tests of Electric Valve Test for Particulate Matter in the Atmosphere for Calibration of Refractory Metal Thermocouples Using an tar, Method of Test for (1970) ASTM C87-1969/ Effect of ) $\$ 1.75$

atography (1974) \$1.7/ Recommended Practices for Volatile

s Using the Mass Spectrometer Leak Detector in the Insidefor (1964) (R1970) IEEE 21-1964 \$4.00

$0 \quad$ Compressed Gas Cylinder Valve Recommended Practice for Dealing with Differential Pressure Transmitter, Pneumatic or Electric Alloy Steel Pipe for Corrosive or High Tem/ Welded Large riticality Safety in Operations with Fissionable Materials riticality Safety in Operations with Fissionable Materials

Solid Conductor (Bare, Fiberglass Insulated, and Sheathed

Solid Conductor (Bare, Fiberglass Insulated, and Sheathed

Solid Conductor (Bare, Fiberglass Insulated, and Sheathed s $(2 / 76)$

de for Obtaining Exemptions from Certain NRC Requirements

Specifications for Electric
for Top Running and Under Running Single Girder Electric ed Valves $(11 / 75)$

Thermal

Installation of

c-Fusion (Arc)-Welded Steel Plate Pipe (Sizes 16 in. and Test for

s (1/ Accelerated Life Test of Electrical Grade Magnesium for Spectrochemical Analysis of (1972) ASTM E40/ Uranium od for Spectrochemical A nalysis of (1970) \$1.75 Uranium cal Analysis of (1972) ASTM E40/ Uranium Oxide by Gallium mical Analysis of (1970) $\$ 1.75$ Uranium Oxide by Gallium

and Control of Analytical Chemistry Laboratories for Mixed Fast Flux Test Facility Driver Fuel Pin Mixed Ceramographic Preparation Cf Mixed Analytical Chemistry Methods for Mixed 3-70) omel-P Versus Alumel, Stainless Steel Sheathed, Magnesium 3-7) Thermocouple Material, Copper-Constantan, MineralThermocouple Assemblies, MagnesiumSpecification for Nuclear Grade Beryllium Specification for Nuclear Grade Beryllium ochemical Analysis Of, and Physical Tests on (/ Beryllium ochemical Analysis Of, and Physical Tests on (/ Beryllium ption of Potassium Permanganate by Impurities in Deuterium tonium Dioxide Powders and Pellets and Nuclear Grade Mixed spectrochemical Analysis of (1974) \$/ Nuclear Grade Mixed metric, and Spectrochemical Analysis/ Nuclear Grade Mixed ption of Potassium Permanganate by Impurities in Deuterium Deuterium Deuterium Deuterium

Testing Deuterium Test for Content of irect Counting Technique, Method of Test for (1974) ASTM/ irect Counting Technique, Method of Test for (1973) \$1.7/ Tcsts for Dissolved Dissolved

Electrochemica

ium $(1-72)$

$1970 \$ 1.75 \quad$ Method of Test for Accelerated Test for Water Vapor Transmission of Flexible Heat Sealed for Trial Use and Commen/ Draft Std. for Leakage Tests on Guide to Design and Use of (1975) $\$ 5.00 \quad$ Leakage Tests on Procedures for Picking Up and Receiving Test for Leaks in Heat Sealed Flexible ted Biologica! Materials (1973) $\$ 3.50$ ted Biological Materials (6/74)

Administrative Guide for Uranium Hexafluoride for Transport, erial/Administrative Guide for Verifying Compliance with Container

ent and Storage (9-75) Supersedes F7-2T, (2-69) Amend/ Items for Nuclear Power Plants (During the Construction/ f ltems for Water Coo/ Quality Assurance Requirements for rage (9-75) Supersedes F7-2T, (2-69) Amend/

Packaging,

ction, Application, and Inspection of Protective Coatings ilities (1972) $\$ 3.00$
Operation) (Safety Guide 33, 11/3/72

Operation, Measurement of (1970) $\$ 1.75$

Operation, Method for Measurement of (1973) ASTM D2470-

Operator at the Controls of a Nuclear Power Plant (2/76

Operators Against an Accidental Chlorine Release (2/75)

Operators for Nuclear Power Generating Stations, Trial

Operators Installed Inside the Containment of Nuclear P

(Optical Density of Filtered Deposit) (1969) $\$ 1.75$

Optical Pyrometer (1973) ASTM E452-1972 \$1.75

Organic Impurities in Fine Aggregate on Strcngth of Mor

Organic Impurities in Sand for Concrete, Test for (1973

Organic Matter in Water by Aqueous-Injection Gas Chrom

Orifice Assemblies for Nuclear Systems (8-73)

Out Testing Mode (1973) \$1.75

Outdoor Apparatus Bushings, Requirements and Test Code

Outlet and lnlet Connections (1965) CGA V-1-1965 \$7.0

Outlying Observations $(6 / 74)$

Output Signal (4-74)

Outside Diameter Light-Wall Austenitic Chromium Nicke!

Outside Reactors (1975)

Over Fiberglass Insulation) (1-73)

Over Fiberglass Insulation) (4-70)

Over Fiberglass Insulation) (4/70)

Overhead Crane Handling Systems for Nuclear

Overhead Traveling Crane (1971) $\$ 3.00$

Overhead Traveling Cranes (1974) $\$ 3.00$

Overload Protection for Electric Motors on

Over), Specification for (1974) $\$ 1.75$

Oxidation-Reduction Potential of Water (1970) $\$ 1.75$

Oxide as Used in Sheathed Type Electric Heating Element

Oxide by Gallium Oxide Carrier DC Arc Technique, Method

Oxide by Gallium Oxide Carrier D-C Arc Technique, Meth

Oxide Carrier DC Arc Technique, Method for Spectrochemi

Oxide Carrier D-C Arc Technique, Method for Spectroche

Oxide Fuel Analysis (7-73)

Oxide Fuel Pellet (6-71) Amendment 1 (12-74)

Qualification

Oxide Fuel Pellets ( $1-73)$

Oxide Fuel (7-73) Amendment 1 (12-74)

Oxide Insulated (2-75) Supersedes C 7-6T, (4-72), Am

Oxide Insulated, Sheathed (4-70) Supersedes C7-14T,

Oxide Insulated, Sheathed (4-70) Supersedes C7-14T,

Oxide Insulated, Stainless Steel Sheathed (1-72)

Oxide Powder ASTM C708-72a (1973) \$1.75

Oxide Powder (1972A) \$1.75

Oxide Powders, Chemical, Mass Spectrometric, and Spectr

Oxide Powders, Chemical, Mass Spectrometric, and Spectr

Oxide (1973) $\$ 1.75$

Test for Consum

Oxides ((U,Pu) $\left.\mathrm{O}_{2}\right)(5 / 73)$

Nalysis of Nuclear Grade Plu

Oxides ((U,Pu)O( $)$ ), Chemical, Mass Spectrometric, and

Oxides ( (U,Pu)O( $\left.{ }_{2}\right)$ ), Methods for Chemical, Mass Spectro

Oxide, Method of Test for (1973) ASTM D2033-1968 \$1.75

Oxide, Method of Testing (1973) ASTM D2184-1968 \$1.75

Oxide, Specification for (1973) ASTM D2032-1968 \$1.75

Oxide, Spec. for (1968) (R1975) \$1.75

Oxide, Standard Method of (1972) $\$ 1.75$

Oxidizing Substances in the Atmosphere (1970) $\$ 1.75$

Oxygen Content Using a 14-MeV Neutron Activation and D

Oxygen Content Using a 14-MeV Neutron Activation and D

Oxygen in Waste Water (1974) $\$ 1.75$

Oxygen in Water, Tests for (1971) $\$ 1.75$

Oxygen Meter for Service in Liquid Sodium (1-72)

Oxygen-Hydrogen Meter Module for Service in Liquid Sod

Ozone Cracking of Vulcanized Rubber (1971) ASTM D1149.

Packages for Dry Products (1972) $\$ 1.75$

Packages for Shipment of Radioactive Materials (1ssued

Packages for Shipment of Radioactive Materials (6/75)

Packages for Type a Quantities of Radioactive Materials

Packages of Radioactive Material (5/75)

Packages (1972) \$1.75

Packaging and Transportation of Radioactively Contamina

Packaging and Transportation of Radioactively Contamina

Packaging and Transporting Radioactive Material (6/74)

Packaging of (1971) \$6.75

Packaging Requirements for Shipments of Radioactive Mat Packaging Spec. (1975) \$6.80

Packaging, Packing, and Marking of Components for Shipm Packaging, Shipping, Receiving, Storage and Handling of Packaging, Shipping, Receiving, Storage, and Handling $\mathrm{O}$

Packing, and Marking of Components for Shipment and Sto

(Paints) for Fuel Reprocessing Plants (6/75)

(Paints) for Light Water Nuclear Reactor Containment Fac

(Paints) for the Nuclear Industry (1974) \$14.00

Pallets, Standard Methods of Testing (1973) \$1.75
ERDA

NRC

ASTM

ANS!

NRC

ANS!

NRC

ASTM

ANSI

ASTM

ASTM

ASTM

ANSI

ANS!

NRC

ERDA

ASTM

ANS!

NRC

lumel, ERDA

ERDA

ERDA

NRC

Spec CMAA

NR.C

NRC

ASTM

ASTM

ASTM

ANSI

ASTM

ANS1

ASTM

ERDA

EKDA

ERDA

ERDA

ERDA

ERDA

ERDA

ERDA

ANSI

ASTM

ANSI

ASTM

ASTM

NRC

ASTM

ANSI

ANSI

ANSI

ANSI

ASTM

ASTM

ASTM

ANSI

ASTM

ASTM

ASTM

ERDA

ERDA

ANSI

ASTM

ANSI

NRC

ANSI

NRC

ASTM

ANSI

NRC

NRC

ANSI

ANSI

DOT

ERDA

ANS1

NRC

ERDA

Sele NRC

ANS1

ANS1

ASTM

RG 1.33

D2470

N163

1.114

R 1.95

N41.6

RG 1.73

D1704

N144

A37.129

C40

D2908

RDT C4-8T

E493

76.1

B57.1

G 5.36

RDT C6-2T

A 409

NI 6.1

RG 3.4

RDT C $7-5 T$

RDT C7-1T

RDT C7-3T

RG 7.5

1.104

70

RG 1.106

RG 1.67

A 134

D 1498

D2900

2128.27

E402

Z128.27

$\mathrm{E} 402$

RDT F2-6T 
Thermocouple Connectors and Thermocouple Connector Radiological Safety in the Design and Operation of 4) $\$ 1.75$ Magnetic tographs for (1969) (R1973) ASTM E125-1963 \$1./ Magnetic Definitions of Terms Relating to Magnetic $9-1963$ (1971) $\$ 1.75$

or Steel Castings (1971) $\$ 3.00$

of (1973) ASTM D1943-1966\$1.75

73) ASTM D1890-1966 (1971) \$1.75

) $\$ 1.75$

) $\$ 1.75$

Test for (1970) $\$ 1.75$

(1972) $\$ 1.75$

C142-1971 \$1.75 Dry Powder Magnetic

Dry
Alpha

Alpha

Beta

Alpha

Devices for Removal of

of Air Cleaning Systems Containing Devices for Removal of 974) $\$ 1.75$ Scratch Hardness of Coarse Aggregate

$972 \$ 1.75$

Testing and Certification of Methods of Sampling of Methods of Test for Physical and Chemical Properties of Tests for Physical and Chemical Properties of f Filtered Deposit) (1969) $\$ 1.75$ Test for ieee $200 \$ 6.00$ Std. Method for Sampling Stacks for Electrical and Electronics Forged or Rolled Steel Pipe FIanges, and Valves and Preferred Limits and Fits for Cylindrica

Marking of Components and onstruction, Arrangenent, and Other Provisions for Nuclear nuclides (1970) $\$ 4.00$ method of Test for (1972) $\$ 1.75$

Precautions in the Management of

Determination of Fue Determination of a Figure of Merit for $\mathrm{PuO}_{2}-\mathrm{UO}$ Fuel Absorber Pin Boron Carbide Fast Flux Test Facility Driver Fuel Pin Insulator Fast Flux Test Facility Driver Fuel Pin Mixed Oxide Fue al Analysis of Nuclear Grade Plutonium Dioxide Powders and Ceramographic Preparation Cf Mixed Oxide Fuel

ical Analysis of Nuclear Grade Uranium Dioxide powders and cal Analysis O/ Nuclear Grade Uranium Dioxide Powders nd cal Analysis/ Nuclear Grade Plutonium Dioxide Powders and spectrochemical Analysis of / Uranium Dioxide Powders and spectrochemical Analysis O/ Plutonium Dioxide Powders and Reference Photographs for Liquid $165.1965(1971) \$ 1.75$ Definitions of Terms Relating to Liquid

$1,3 / 10 / 7$ Liquid structures Amendment 1 (4-72), Amendment 2 (/ Instrument Lines clear Fueled Power Generating Stations (1973)/ ter Cooled Nuclear Power Plants (10/73)

f Test for (1964) (R1969) ASTM C360-1963\$1.75 Electrical Electric for (1973) $\$ 1.75$

(1972) (ASTM D1558-1971)/ Method of Test for Moisturet $1(1-74)$

hield Plug and Closure Cap for ations for (1973) ASTM E323-1970 \$1.75

Standard for Preparation of Design Bases for Systems That sting Systems (1969) ASTM E317-/ Practice for Evaluating

Removal (1972) \$1.75

Film Badge

hod of Test for (1963) (R1969) ASTM C411-19/ Hot Surface y Monitoring Radioactivity in Effluents, Specification and

5) $\$ 2.95$ Critical Experiments, Safety Guide for the

for Television Receivers (1975) $\$ 2.95$

for Cold-Cathode Gas Discharge Tubes ( 1975) \$2.95

for Diagnostic X-Ray Systems and Their Major Components/ for Radiographic Equipment (1975) \$2.95

for Fluoroscopic Equipment (1975) \$2.95

for Cabinet X-Ray Systems (1975) \$2.95

for X-Ray Baggage Inspection Systems (1975) $\$ 2.95$

for Microwave and Radio Frequency Emitting Products (19/

0

Film Badge

irect Reading Pocket Dosimeters for X and Gamma Radiation, als and Prefabricated Silencers for Acoustical and Airflow

Thermoluminescence Dosimetry-Environmental Application/

tems $(6 / 76)$

system Actuation Functions (6/74)

otection Systems, Criteria for the (1975) $\$ 5.00$

ns (Safety Guide 22, 2/17/72)

Metal Service (4-73)

ems (4-74) Supersedes C4-5T, (8-71)

in Core
Panels (1-72) Amendment 1 (1-73)

Particle Accelerators (1969) NBS Handbook $107 \$ 3.00$

Particle Examination of Steel Forgings, Method for (197

Particle Indications on Ferrous Castings, Reference Pho

Particle Inspection (1971) \$1.75

Particle Inspection (1974) \$1.75

Particle Inspection, Method for (1969) (R 1973) ASTM E10

Particle Magnetic Inspection Method, Quality Standard F

Particle Radioactivity of Water, Method of Measurement

Particle Radioactivity of Water, Method of Test for (19

Particle Radioactivity of Water, Test for (1966) (R197

Particle Radioactivity of Water, Test for (1966) (R1971

Particle Size Distribution of Granular Activated Carbon

Particle Size of Alumina and Silica by Air Permeability

Particles in Aggregates, Method of Test for (1973) ASTM

Particles in Lungs (1975) $\$ 3.00$

Particles (1972) $\$ 2.50$

Particles (1/73)

Particles, Method of Test for (1968) $\$ 1.75$

Particulate and Dissolved Matter in Water, Tests for ( 1

Particulate Clean Rooms (1970) \$5.00

Particulate Ion Exchange Materials (1973) ASTM D2687-1

Particulate Ion Exchange Resins (1973) \$1.75 ASTM D2187

Particulate Ion Exchange Resins (1974) $\$ 1.75$

Particulate Matter in the Atmosphere (Optical Density O

Particulate Matter (1973) ASTM D2928-1971 \$1.75

Parts and Equipment, Reference Designations for (1975)

Parts for General Service, Spec. for (1976) $\$ 1.75$

Parts (1967) (R1974) \$4.00

Parts (6-75) (Supersedes F7-3T, (11-74)

Passenger Vessels (Ships and Barges) (1975) $\$ 2.05$

Patients Who Have Received Therapeutic Amounts of Radio

Peel or Stripping Strength of Adhesive Bonds, Standard

Pellet Homogeneity by Alpha-Autoradiography (5-75)

Pellet Homogeneity by Use of an Electron Microprobe (9-

Pellet (5-73) Supersedes E6-30T, (8-71)

Pellet $(6-71)$

Pellet (6-71) Amendment 1 (12-74)

Pellets and Nuclear Grade Mixed Oxides ((U,Pu)O $\left.)_{2}\right)(5 / 73$

Pellets $(1.73)$

Pellets $(2 / 9 / 73)$

Pellets, Chemical, Mass Spectrometric, and Spectrochemi

Pellets, Methods for Chemical, Mass Spectrometric, and

Pellets, Methods for Chemical, Mass Spectrometric, and

Penetrant Inspection (1971) \$1.75

Penetrant Inspection (1974) $\$ 1.75$

Penetrant Inspection, Methods for (1969) (R 1973) ASTM E

Penetrating Primary Reactor Containment (Safety Guide 1

Penetration Assemblies for Nuclear Reactor Containment

Penetration Assemblies in Containment Structures for $\mathrm{Nu}$

Penetration Assemblies in Containment Structures for W a

Penetration in Fresh Portland Cement Conicrete, Method O

Penetration of Liquids into Submerged Containers, Test

Penetration Resistance Relations of Fine-Grained Soils

Penetrations LMFBR Reactor Vessel Head (4-73) Amendmen

Perforated-Plate Sieves for Testing Purposes, Specific

Perform Protective Functions in Nuclear Power Generatin

Performance Characteristics of Pulse-Echo Ultrasonic Te

Performance Criteria (2/2/73)

Performance of Anion Exchange Materials for Strong Acid

Performance of High Temperature Thermal Insulation, Met

Performance of (1974) $\$ 5.00 \quad$ /Mentation for Continuous
Performance of (1975) ANS-1 $\$ 8.00$

Performance Stds. for Electronic Products: General ( 197

Performance Std. (Ionizing Radiation Emitting Products)

Performance Std. (Ionizing Radiation Emitting Products)

Performance Std. (Ionizing Radiation Emitting Products)

Performance Std. (Ionizing Radiation Emitting Products)

Performance Std. (lonizing Radiation Emitting Products)

Performance Std. (lonizing Radiation Emitting Products)

Performance Std. (Ionizing Radiation Emitting Products)

Performance Std. (Ionizing Radiation Emitting Products)

Performance Test Code for Centrifugal Pumps (1965) $\$ 5.0$

Performance Test Code for Displacement Pumps (1962) $\$ 4$

Performance, Criteria for (1972) $\$ 4.25$

Performance, Specification for (1972) $\$ 3.00$

Performance, Testing (1973) $\$ 1.75$

Performance, Testing, and Procedural Specif

Perimeter Intrusion Alarm Systems (1/75)

Periodic Testing of Ele

Peric Testing of Fuel Reprocessing Plant Protection

Periodic Testing of Nuclear Power Generating Station Pr

Periodic Testing of Protection System Actuation Functio

ERDA

ANSI

ASTM

ANSI

ASTM

ASTM

ANSI

MSS

ANSI

ANSI

ASTM

ASTM

ASTM

ASTM

ANSI

NCRP

ANS

NRC

ASTM

ANS

ANSI.

ASTM

ASTM

ANSI

ANSI

ASTM

ANSI

ERDA

L C USCG

NCRP

ASTM

ERDA

ERDA

ERDA

ERDA

ERDA

NRC

ERDA

NRC

ASTM

ANSI

ANSI

ASTM

ASTM

ANS

NRC

ERDA

ANSI

ANSI

ASTM

ANSI

ERDA

ANSI

ANSI

ANSI

NRC

ASTM

ANSI

ANSI

ANSI

BRH

BRH

BRH

BRH

BRH

BRH

BRH

BRH

ASME

ASME

ANSI

$\mathrm{G}$ and Ind ANSI

ASTM

ANSI

NRC

NRC

NRC

IEEE

NRC

Permanent Magnet Flowmeter for Liquid Metal Piping Syst

RDT $7-15$

N43. 1

A275

Z166.4

E 138

E269

SP-53

N 152

N 151

D 1890

D 1943

D2862

A 37.28

R46

N 101.1

RG 3.2

C235

D 1888

CS-6T

Z111.12

Z111.1

D2 187

D 1704

Z257.3 
.75 Test for (1973) ASTM D2033-1/

Test for Consumption of Potassium Test for (1969) $\$ 1.75$

Consumption of Potassium

Maximum Pore Diameter and Test for Hydrogen est for Average Particle Size of Alumina and Silica by Air trations of Radionuclides in Air and in Water Fo/ Maximum in Water Fo/ Maximum Permissible Body Burdens and Maximum ff in Connection with Its Antitrust Review of Construction tive Guid/ Obtaining Department of Transportation Special aterial Access Areas $(6 / 73)$

Std. Rel

00 la/ Qualifications of Inspection, Examination and Testing an $20 \mathrm{MeV}(1976) \$ 3.50$

practice for $\$ 10.50$

Nondestructive Testing

ity Safety Controls in Operations Where Shielding Protects

f Nuclear Power Plant Inspection, Examination, and Testing Complication of Reporting Requirements for

ration of an Environmental Report to Support a Rule Making c. Practice for (1973) $\$ 1.75$

Thyroid Radioiodine Uptake Measurements Using a Neck dine Compounds (10-73) Supersedes M16-1T, (6-72) Gas 2.00 High Efficiency Gas
Practice for Liquid Recommended Practice for Liquid

ural Concrete and Structural Steel During the Construction Housekeeping During the Construction

on, Examination and Testing Personnel for the Construction
Systems and Associated Components During the Construction

Systems and Associated Components During the Construction
ural Concrete and Structural Steel During the Construction

of Mechanical Equipment and Systems for the Construction

fety Analysis Reports: Quality Assurance During Operations

of ltems for Nuclear Power Plants (During the Construction ure as Low as Is Reasonably Achievable (Revisi/ Operating Review of the Current State of Radiation Protection $2-1962$ (1968) $\$ 1.75$ Recommendations for Waste Disposal of

Analysis of Reference gnetic Particle Indications on Ferrous Castings, Reference Metals and Alloys (Including M/ Recommended Practice for Copper Base Alloys (1975) \$1.75 commended Practice for (1974) $\$ 1.75$

and Potassium in Water and Water Formed Deposits by Flame ary for Scintillation Count/ Standard Test Procedures for ed $\mathrm{Ch}$ / Threshold Limit Values for Chemical Substances and Measurement of Neutron Flux and Spectra for hange Resins (1973) \$1.75 ASTM D2187/ Methods of Test for hange Resins (1974) \$1.75 Tests for $1,1 / 75)$

Safety Color Code for Marking

Conduct of Nuclear Material ity in Air of Manufactured Carbon and Graphite Articles by Mass Spectrometric, and Spectrochemical Analysis Of, and , Mass Spectrometric, and Spectrochemical Analysis Of, and al $(5 / 75)$ Procedures for Method of Test for Lightweight t for Load Settlement Relationship for Individual Vertical
-71$.
$6-25 \mathrm{~T},(11-71)$

Fast Flux Facility Driver Fuel Control Rod Absorber Fast Flux Test Facility Driver Fuel Fast Flux Test Facility Driver Fuel Fast Flux Test Facility Driver Fuel Fast Flux Test Facility Driver Fuel Fast Flux Test Facility Driver Fuel Fast Flux Test Facility Driver Fuel

Fast Flux Test Facility Driver Fuel Fast Flux Facility Driver Fuel Electric Heaters: Simulated LMFBR Fuel 1.75 Specification for Aluminum-Alloy Seamless or / Supplementary Requirements for Nickel Alloy Seamless ementary Requirements for (1970) \$/ Nickel Alloy Seamless Specification for Nickel Seamless ecification for Nickel-Copper Alloy (UNS N04400) Seamless Specification for Nickel-Chromium-Iron Alloy Seamless ion for Nickel-Iron-Chromium Alloy (UNS N08800) Seamless Specification for Seamless Copper-Nickel ts) (7-75) / Nickel-Molybdenum-Chromium Alloy Seamless d for (1974) $\$ 1.75 \quad$ Ultrasonic Inspection of Metal ons, Specification for (1974) A/ Special Requirements for ons / Standard Specification for Special Requirements for nts) (7-75) Super/ Nickel-Iron-Chromium Alloy Seamless
Permanganate by Impurities in Deuterium Oxide (1973) \$1 Permanganate by Impurities in Deuterium Oxide, Method 0 Permeability of Rigid Porous Filters for Laboratory Use Permeability of Rubber Coated Fabrics (1973) $\$ 1.75$ Permeability (1972) \$1.75

Permissible Body Burdens and Maximum Permissible Concen Permissible Concentrations of Radionuclides in Air and Permit Applications for Nuclear Power Plants (Revision Permits for Radioactive Materials Shipments, Administra Personnel Access to Protected Areas, Vital Areas, and M Personnel Dosimeter Service (1971) \$0.50

Personnel for Nuclear Power Plants (1971) ANS-3.1 \$10. Personnel for the Construction Phase of Nuclear Power $\mathbf{P}$ Personnel Neutron Dosimeters (Neutron Energies) Less th Personnel Neutron Dosimeters (6/76)

Personnel Qualification and Certification, Recommended Personnel Selection and Training (Revision 1, 1/9/75) Personnel (1975) ANS $8.10 \$ 8.00$ Personnel (8/73)

Persons Subject to NRC Regulations (Revision 2, 8/75) Petition Seeking an Exemption for a Radionuclide-Conta
Petrographic Examimation of Aggregates for Concrete, Re Phantom (1973) $\$ 3.00$

Phase Adsorbents for Trapping Radioactive Iodine and Io Phase Adsorber Cells-Including Amendment 1973 (1972) \$ Phase Evaluation of Activated Carbon (1970) $\$ 1.75$ Phase of Nuclear Power Plants (Revision 1, 4/76)

Phase of Nuclear Power Plants (1973) $\$ 4.00$

Phase of Nuclear Power Plants (1973) $\$ 4.00$

Phase of Nuclear Power Plants (1973) $\$ 4.00$ Phase of Nuclear Power Plants (1974) $\$ 4.50$ Phase of Nucle

Phase $(12 / 74)$

Phase) (1972) $\$ 4.50$

Philosophy for Maintainin

Philosophy (1975) $\$ 3.00$

Phosphorus-32 and lodine-131 for Medical Use (1951) \$

Phosphorus-32, Methods for Analysis of (1973) ASTM E18

Phosphorus-32, Methods for (1974) \$1.75

Photographs for Liquid Penetrant Inspection (1971) $\$ 1.7$

Photographs for (1969) (R1973) ASTM E125-1963 \$1.75

Photography as Applied to Preparation of Micrographs of

Photometric Analysis (1972) $\$ 1.75$

Photometric Methods for Chemical Analysis of Copper and

Photometric Methods for Chemical Analysis of Metals, Re

Photometry, Tests for (1971) \$1.75

Photo-Multipliers for Scintillation Counting and Gloss

Physical Agents in the Workroom Environment with Intend

Physical and Biological Applications (1960) $\$ 2.00$

Physical and Chemical Properties of Particulate Ion Exc

Physical and Chemical Properties of Particulate Ion Exc

Physical Hazards (1971) $\$ 3.00$

Physical Independendence of Electric Systems (Revision

Physical Inventories of Nuclear Materials (1972) $\$ 3.25$

Physical Inventories (11/73)

Physicai Measurements, Method of Test for (1973) ASTM C

Physical Tests on (1972) $\$ 1.75$

Physical Tests on (1973) ASTM C699-1972 \$1.75

Picking Up and Receiving Packages of Radioactive Mater

Pieces in Aggregate (1970) ASTM C123-1969 \$1.75

Piles Under Static Axial Load (1974) \$1.75

Pin Boron Carbide Pellet (5-73) Supersedes E6-30T, (8

Pin End Caps (6-71)

Pin for Liquid Metal Fast Reactors (5-73) Supersedes E

Pin Insulator Pellet (6-71)

Pin Mixed Oxide Fuel Pellet (6-71) Amendment 1 (12-74

Pin Plenum Spacer (6-71)

Pin Plenum Spring (6-71)

Pin Reflectors (6-71)

Pin Seamless Cladding Tube (6-71)

Pin Wrap Wire (6-71)

Pin (6-71)

Pins (3-72)

Pipe and Seamless Extruded Tube (1974) ASTM B241 1973 \$

Pipe and Tube for Nuclear Applications, Specification $F$

Pipe and Tube for Nuclear Applications, Spec. for Suppl

Pipe and Tube (1971) ASTM B 167-1970 \$1.75

Pipe and Tube (1971) $\$ 1.75$

Pipe and Tube (1973) ASTM B 167-1970 \$1.75

Pipe and Tube (1974) $\$ 1.75$

Pipe and Tube (1975) \$1.75

Pipe and Tubes (ASME SB-167 with Additional Requiremen

Pipe and Tubing for Longitudinal Discontinuities, Metho

Pipe and Tubing for Nuclear and Other Special Applicati

Pipe and Tubing for Nuclear and Other Special Applicati

Pipe and Tubing (ASME SB-407 with Additional Requireme
ASTM

ANSI

ASTM

ASTM

ASTM

NCRP

NCRP

NRC

ANSI

NRC

NSF

ANSI

ANSI

ANSI

NRC

ASNT

NRC

ANSI

NRC

NRC

NRC

ASTM

ANS1

ERDA

IES

ASTM

/Ruct NRC

ANSI

Inspecti ANSI

of Fluid ANS

of Struct ANSI

ANSI

NRC

ANSI

ANS

NCRP

NCRP

ANSI

ASTM

ASTM

ANSI

ASTM

ASTM

ASTM

odium ASTM

ANSI

ACGIH

NCRP

ANSI

ASTM

ANSI

NRC

ANS

NRC

ANSI

ASTM

ANSI

NRC

ANSI

Tes ASTM

ERDA

ERDA

ERDA

ERDA

ERDA

ERDA

ERDA

ERDA

ERDA

ERDA

ERDA

ERDA

ANSI

ANSI

ASTM

ANSI

Sp ASTM

ANSI

ASTM

ASTM

ERDA

ASTM

ANSI

ASTM

ERDA

D2033

N 154

E128

D815

C721

RG 9.2

N 14.10 .2

RG 5.7

N18.1

N45.2.6

N319

RG 8.14

SNT-TC-1A

RG 1.8

N16.8

RG 1.58

RG 10.1

RG 6.7

C295

N44.3

RDT M 16-1T

CS-8T

D2355

RG 1.94 
$\$ 1.75$

onic Inspection of Longitudinal and Spiral Welds of Welded

es and Fittings (1974) $\$ 2 . /$

Spec. for (1976) $\$ 1.75$

671-/ iameter Light-Wall Austenitic Chromium Nickel Alloy Stee ) $\$ 1.75$

ification for (1974) $\$ 1.75$

974A) $\$ 1.75$

ic-Fusion-Welded Auster

975) $\$ 1.75$

975) $\$ 1.75$

975) $\$ 1.75$

975) $\$ 1.75$

ture (1967) $\$ 4.00$

966) $\$ 4.00$

rvice $(5-72)$

C335-1969\$1.75

rements) (4-75) Super/ fabricated Reflective Insulation Systems for Equipment and fabricated Reflective Insulation Systems for Equipment and tion of Nuclear Power Plants Against Effects of Postulated uirements) (6-71) Amendment / Calcium Silicate Block and Calcium Silicate Block and

Malleable Iron Threaded Protection Against ) Supersedes M3.1T, (5.73) ) Supersedes M 3-11T, Carbon Steel Seamles Supersedes M3-6T, (11-73) Supersedes M3-16T, (8-75) ) Supersedes M3-12T, (12-1 Carbon and Low Alloy Steel Welded

Austenitic Stainless Steel Carbon and Alloy Stee ) Supersedes M/ Nickel-Molybdenum-Chromium Alloy Welded 4) Supersedes M3-3T/

Supersedes M3-31T, $\$ 1.75$

ustenitic Stainless Steel Seamles Stainless Steel Centrifugally Cas Electric-Fusion (Arc)-Welded Steel Plate Specification for Electric-Resistance-Welded Steel Specification for Welded and Seamless Stee Specification for Specialized Carbon and Alloy Stee Specification for Standard Sizes of Seamless Copper Seamless and Welded Austenitic Stainless Steel Qualification of Welding Procedures and Welders fo ments) (7-75) Supersedes M2-/ Carbon Steel Forgings for
and Low Alloy Steel, Requiring Notch Toughness Testing for

Carbon Steel Forgings for or Low Temperature Service (1975) \$1.75 Std. Spec. for mendment 1 (11-72), Ame/ Std. Spec. for 3.00 $2(6-74)$

Fabrication and Installation of Identification of Permanent Magnet Flowmeter for Liquid Metal Nuclear Powe

Spray Pond Plastic Power

Nuclear Power Nuclear Power

s for Liquid Metal Service (5-74) 72) $\$ 1.75 \quad$ Test for Average Velocity in a Duct 71) $\$ 1.75$ of Test for Moisture Content of Soil and Soil Aggregate in 1971) $\$ 1.75$ or Soil and Soil-Aggregate in pecified Limiting Values, Recommended P/ Indicating Which $\$ 2.75$ pecification $\mathrm{Fo} /$

75) $\$ 1.75$ Measuring, Mixing, Transporting and $s$ for Structural Steel Joints, Including Suitable Nuts and Method of (1974) $\$ 1.75$ Test for

Information for Safety Analysis Reports: Emergency Acceptance Sampling

e, Testing, and Replacement of Large Stationary Type Powe $11(\$ 65.00)$

General Requirements for Nuclear Power Nuclear Power

Rules for Inservice Inspection of Nuclear Power Appendices to Sec. 111 Div. 1, Nuclear Powe

on for Light-Water-Cooled Nuclear Power Plants to Asses sumptions for Evaluating the Habitability of Nuclear Powe rine Release (2/75) Comment ANS 58.1\$12.00 (73) Protection of Nuclear Power Draft Standard fo Qualification of Nuclear Powe Information for Safety Analysis Reports:
Pipe and Tubing (1969) ASTM E273-1968 \$1.75 /R Ultras ANSI Pipe Covering Type Thermal Insulation, Test for (1972)

Pipe Fittings, Symbols for (1968) (R1973) \$1.75 Pipe Flanges and Connecting End Flanges of Ferrous Valv Pipe Flanges, and Valves and Parts for General Service, Pipe Flanges, Flanged Valves and Fittings (1973) \$12.00 Pipe for Atmospheric and Lower Temperatures (1974) ASTM Pipe for Corrosive or High Temperature Service, Specifi Pipe for High Pressure Service, Specification for (1975 Pipe for High Temperature Central Station Service, Spec Pipe for High Temperature Service, Specification for (1 Pipe for High Temperature Service, Specification for (1 Pipe for High Temperature Service, Specification for ( Pipe for High Temperature Service, Specification for ( Pipe for High Temperature Service, Specification for ( Pipe for High Temperature Service, Specification for (1 Pipe for Low Temperature Service (1975) \$1.75 Pipe Hangers and Supports-Material, Design and Manufac Pipe Hangers and Supports-Selection and Application (1 Pipe Hangers, Supports and Snubbers for Liquid Metal Se Pipe Insulation, Method of Test for (1967) (R 1969) ASTM Pipe Large Diameter (ASME SA-358 with Additional Requi Pipe Operating at Temperatures Above Ambient Air (1972) Pipe Operating at Temperatures Above Ambient Air (1974) Pipe Rupture (Issued for Trial Use and Comment) ANS 55. Pipe Thermal Insulation (ASTM C 533 with Additional Req Pipe Thermal Insulation, Specification for (1972) \$1.75 Pipe Threads (Except Dryseal) (1968) \$4.75

Pipe Unions 150,250 , and $300 \mathrm{lbs}$. (1970) $\$ 3.00$

Pipe Whip Inside Containment (5/73)

Pipe (ASME SA-106 with Additional Requirements) (7-75 Pipe (ASME SA-155 with Additional Requirements) (5.75 Pipe (ASME SA-312 with Additional Requirements) (3-75 Pipe (ASME SA.333 with Additional Requirements) (4-76 Pipe (ASME SA-335 with Additional Requirements) (4-76 Pipe (ASME SA-358 with Additional Requirements) (7-75 Pipe (ASME SA-376 with Additional Requirements) (11-7 Pipe (ASME SA-45I with Additional Requirements) (4.76 Pipe (Sizes 16 in. and Over), Specification for (1974) Pipe (1973A) $\$ 1.75$

Pipe (1973) \$1.75

Pipe (1975) \$1.75

Pipe (1975) $\$ 1.75$

Pipe, Specification for (1974) $\$ 1.75$

Piping and Tubing, Standard for (1969) $\$ 6.00$

Piping Components (ASME SA-105 with Additional Require

Piping Components (1974) \$1.75 / for Forgings, Carbon Piping Fittings of Wrought Carbon Steel and Alloy Steel Piping Sold Separately (1971) \$4.25

Piping Subassemblies for Liquid Metal Service (8-71) a Piping Systems by Color Coding, Scheme for the (1975) \$

Piping Systems (11-71) Amendment 1 (12-73), Amendment Piping Systems (4-74) Supersedes C4-5T, (8-71)

Piping with Addenda (1969) \$19.00

Piping (12/73)

Piping (1973) $\$ 40.00$

Piping, Sold Separately (1971) $\$ 4.25$

Piping, Sold Separately (1972) \$1.25

Piston Rings of High Strength Alloys for Core Component

(Pitot Tube Method) (1972) \$1.75

Place by Nuclear Methods (Shallow Depths), Test for (19 Place by Nuclear Methods (Shallow Depth) (1972) \$1.75 ( Place by Nuclear Methods (Shallow Depth), Tests for (19 Place by the Drive Cylinder Method (1972) (ASTM D2937. Placement in Category 1 Structures (6/73)

Places of Figures Are to Be Considered Significant in S Placing of Concrete, Practice for (1973) ACl 304-1973 Plain and Clad Steel Plates for Special Applications, S Plain Billet-Steel Bars for Concrete Reinforcement (19 Plain Hardened Washers, Specification for (1974) \$1.75 Plane-Strain Fracture Toughness of Metallic Materials, Planning for Nuclear Power Plants (11/75)

Planning the Sampling of the Atmosphere (1973) ASTM D13

Planning (12/74)

Plans $(11.73)$

Plant and Substation Lead Storage Batteries, Rec. Pract

Plant Components Div. I and Div. 2 (1977) bd (\$40.00)

Plant Components Supports (1977) bd $(\$ 30.00), 11(\$ 40.0$

Plant Components (1977) bd $(\$ 60.00) ; 11(\$ 90.00)$

Plant Components (1977) bd (\$70.00) 11 (\$90.00)

Plant Conditions During and Following an Accident (12/7

Plant Control Room During a Postulated Hazardous Chemic

Plant Control Room Operators Against an Accidental Chlo

Plant Design Against Missiles-Issued for Trial Use and

Plant Inspection, Examination, and Testing Personnel ( 8

Plant Procedures (5/75)

\section{ASTM}

MSS

ASTM

ANSI

ANS1

ASTM

ASTM

ASTM

ASTM

ASTM

ASTM

ASTM

ASTM

ASTM

ASTM

MSS

MSS

ERDA

ANSI

ERDA

ASTM

ANSI

ANSI

ERDA

ASTM

ANS

MSS

NRC

ERDA

ERDA

ERDA

ERDA

ERDA

ERDA

ERDA

ASTM

ASTM

ASTM

ASTM

ASTM

ASTM

AWS

ERDA

ASTM

ASTM

ANSI

ERDA

ANSI

ERDA

ERDA

ANSI

ANSI

ANSI

ANSI

ERDA

ASTM

ASTM

ANSI

A STM

ANSI

NRC

ASTM

A NSI

ANSI

ASTM

ASTM

ASTM

NRC

ANSI

NRC

ERDA

IEEE

ASME

ASME

ASME

ASME

NRC

NRC

NRC

ANSI

NRC

NRC

Z166.18

C302

D2749

SP-6

A 181

B 16.5

B 125.53

A409

A 155

A 376

A335

A 358

A 369

A426

A430 
Guidance on the License Application, Siting, Design, and Periodic Testing of Fuel Reprocessing Supplementary Criteria and Requirements for RDT Reactor lication of the Single-Failure Criterion to Nuclear Power Collection, Storage, and Maintenance of Nuclear Power ypassed and Inoperable Status Indication for Nuclear Power

lated to Occur on Transportation Routes Near Nuclear Power material Handling and Storage Facilities in a Reprocessing Class 1 Components for Nuclear Power Class 3 Components for Nuclear Power Class MC Components for Nuclear Power Class 2 Components for Nuclear Power dance on Being Operator at the Controls of a Nuclear Power Standard for Design Basis for Protection of Nuclear Power Protection of Nuclear ality Assurance Program Requirements for Fuel Reprocessing ing in Areas of Limited Accessibility in Fuel Reprocessing he Welding of Low Alloy Steel for Use in Fuel Reprocessing amination of Tubular Products for Use in Fuel Reprocessing Seismic Requirements for Design of Nuclear Power ments for Protective Coatings Applied to Fuel Reprocessing Safety Considerations for Nuclear Power

Instrumentation for Light-Water-Cooled Nuclear Power receiving, Storage and Handling of Items for Nuclear Power pated Transients Without Trip on Pressurized Water Reactor ge Control Systems for Boiling Water Reactor Nuclear Power Power Levels of Nuclear Power esign Response Spectra for Seismic Design of Nuclear Power information: Hydrological Considerations for Nuclear Power nd Shutdown Electric Systems for Multi-Unit Nuclear Power Monitoring Radioactivity in the Environs of Nuclear Power g Plants and for Plutonium Processing and Fuel Fabrication Design Basis Floods for Nuclear Power tural Steel During the Construction Phase of Nuclear Power r Safety-Related Electric Power Systems for Nuclear Power Gaseous Effluents from Light-Water-Cooled Nuclear Power Nuclear Material Control Systems for Nuclear Power view of Construction Permit Applications for Nuclear Power and Adsorption Units of Light-Water Cooled Nuclear Power rance Program Requirements for the Design of Nuclear Power $t$ and Content of Safety Analysis Reports for Nuclear Power Ultimate Heat Sink for Nuclear Power radioactive-Waste-Containing Components of Nuclear Power

Damping Values for Seismic Design of Nuclear Power ide for Acceptable Waste Storage Methods at UF ${ }_{6}$ Production assification for Plutonium Processing and Fuel Fabrication $s$ in Containment Structures for Water Cooled Nuclear Power review of Operating License Applications for Nuclear Power Flood Protection for Nuclear Power

Qualification of Class IE Equipment for Nuclear Power Emergency Planning for Nuclear Dower

Concrete Radiation Shields for Nuclear Power filtration Systems and Containment Sumps for Nuclear Power

ty Analysis Reports: 1ndustrial Security for Nuclear Power Environmental Technical Specifications for Nuclear Power ter and Condensate Systems for Boiling Water Reactor Power

Radiation Protection in Nuclear Reactor Fuel Fabrication Inservice Testing of Valves in Nuclear Power Inservice Testing of Pumps in Nuclear Power

Selection and Training of Personnel for Nuclear Power

Quality Assurance Program Requirements for Nuclear Power Administrative Controls for Nuclear Power

ria for the Design of Stationary Pressurized Water Reactor ousekeeping During the Construction Phase of Nuclear Power

ting Personnel for the Construction Phase of Nuclear Power Components During the Construction Phase of Nuclear Power industrial Security for Nuclear Power Earthquake Instrumentation Criteria for Nuclear Power maintenance of Quality Assurance Records for Nuclear Power tural Steel During the Construction Phase of Nuclear Power ity Assurance Requirements for the Design of Nuclear Power ria for the Design of Stationary Pressurized Water Reacfor ection Guide for Plutonium Processing and Fuel Fabrication perators Installed Inside the Containment of Nuclear Power applications for Plutonium Processing and Fuel Fabrication Earthquake Instrumentation for Fuel Reprocessing Confinement Barriers and Systems for Fuel Reprocessing

Reporting of Operating Information for Fuel Reprocessing Process Offgas Systems for Fuel Reprocessing ormation: Fire Protection Considerations for Nuclear Power d Content of Safety Analysis Reports for Fuel Reprocessing

Overhead Crane Handling Systems for Nuclear Power Housekeeping Requirements for Water Cooled Nuclear Power rage, and Handling of Items for Water Cooled Nuclear Power alled Inside the Containment of Water Cooled Nuclear Power
Plant Protection for an Independent Spent Fuel Storage Protection System Actuation Functions (6/74)

Plant Protection Systems (12-69)

Plant Protection Systems (6/73)

Plant Quality Assurance Records (Revision 1, 12/75)

Plant Safety Systems (5/73)

Plant Security Duties (1/75)

Plant Sites ( $1 / 75)$

Plant (1975) $\$ 7.50$

Plant $(1977)$ bd $(\$ 55.00)$, ll $(\$ 85.00)$

Plant (1977) bd $(\$ 55.00)$, ll $(\$ 85.00)$

Plant (1977) bd $(\$ 55.00)$, $(\$ 85.00)$

Plant $(2 / 76)$

Plants Against Effects of Postulated Pipe Rupture (Issu

Plants Against Industrial Sabotage (Revision I, 6/73)

Plants and for Plutonium Processing and Fuel Fabricatio

Plants and in Plutonium Processing and Fuel Fabrication

Plants and in Plutonium Processing and Fuel Fabrication

Plants and in Plutonium Processing and Fuel Fabrication

Plants and Test Facilities (1-74)

Plants and to Plutonium Processing and Fuel Fabrication

Plants on Merchant Ships (1965) \$7.50

Plants to Assess Plant Conditions During and Following

Plants (During the Construction Phase) (1972) $\$ 4.50$

Plants (1ssued for Trial Use and Comment) $\$ 10.00$

(Revision 1, (6/76)

Plants (Revision 1, 12/73)

Plants (Revision 1, 12/73)

Plants (Revision 1, 1/75)

Plants (Revision $1,1 / 75$ )

Plants (Revision 1, 2/75)

Plants (Revision 1, 3/74)

Plants (Revision 1, 4/76)

Plants (Revision 1, 4/76)

Plants (Revision 1, 6/73)

Plants (Revision I, 6/74)

Plants (Revision 1, 6/75)

Plants (Revision 1, 6/76)

Plants (Revision 1, 7/76)

Plants (Revision 2, (6/76)

Plants (Revision 2, (9/75)

Plants (Revision 2, 1/76)

Plants (Revision 3, 2/76)

Plants $(10 / 73)$

Plants $(10 / 73)$

Plants $(10 / 73)$

Plants $(10 / 73)$

Plants $(10 / 74)$

Plants $(10 / 75$

Plants $(11 / 74)$

Plants $(11 / 75)$

Plants $(12 / 73)$

Plants $(12 / 73)$

Plants $(12 / 74)$

Plants $(12 / 75)$

Plants (12/75)

Plants (1963) $\$ 5.50$

Plants (1970) $\$ 2.25$

Plants (1970) $\$ 2.75$

Plants (1971) ANS-3.1 \$10.00

Plants (1971) $\$ 4.00$

Plants (1972) ANS-3.2 \$10.00

Plants (1973) ANS-51.1 \$30.50

Plants (1973) $\$ 4.00$

Plants (1973) $\$ 4.00$

Plants (1 973) $\$ 4.00$

Plants (1973) (ANS-3.3) \$10.0

Plants (1974) ANS 2.2 $\$ 10.00$

Plants (1974) $\$ 4.00$

Plants (1974) $\$ 4.50$

Plants (1974) \$5.50

Plants (1975) $\$ 5.50$

Plants $(1 / 74)$

Plants $(1 / 74)$

Plants $(1 / 76)$

Plants $(2 / 74)$

Plants $(2 / 74)$

Plants $(2 / 74)$

Plants $(2 / 74)$

Plants $(2 / 74)$

Plants $(2 / 75)$

Plants $(2 / 76)$

Plants $(3 / 16 / 73)$

Plants $(3 / 16 / 73)$

Plants $(3 / 16 / 73)$
fTeam Isolation Valve Leaka

NRC

NRC

ERDA RDT Cl6-1T

App NRC

$\begin{array}{lll}\text { NRC RG } 1.88 & \end{array}$

NRC RG 1.47

NRC RG 5.43

RG 1.91

N305

SEC-IIINB

SEC-IIIND

SEC-IIINE

SEC-IIINC

RG 1.114

N 176

NRC RG 1.17

NRC RG 3.3

NRC $\quad$ RG 3.28

NRC RG 3.36

ERDA RDT F9-2T

NRC RG 3.21

SNAME $3-18$

NRC RG 1.97

ANSI

TTici ANSI

RG 1.97

N661

RG 1.96

RG 1.49

RG 1.60

RG 1.70.1

RG 1.81

RG 4.1

RG 3.3

RG 1.59

RG 1.94

RG 1.32

RG 1.21

RG 5.29

RG 9.2

RG 1.52

RG 1.64

RG 1.70

RG 1.27

RG 1.26

RG 1.61

RG 3.13

RG 3.14

Seismic Design Cl NRC

Electric Penetration Assemblie NRC

RG 1.63

RG 9.3

RG 1.102

RG 1.89

RG 1.101

RG 1.69

RS 1.70 .2

RG 1.70 .15

RG 4.8

RG 1.68.1

N7. 2

PTC34

PTC 35

N18.1

N45.2

N18.7

N18.2

N45.2.3

N45.2.6

N45.2.1

N18.17

N18.5

N45.2.9

N45.2.5

N45.2.11

N18.2A

RG 3.16

RG 1.73

RG 3.39

RG 3.17

RG 3.18

RG 3.19

RG 3.20

RG 1.70 .4

RG 3.26

RG 1.104

RG 1.39

RG 1.38

RG 1.40 
$s$ and Associated Components of Water-Cooled Nuclear Power es and Vapors in Plutonium Processing and Fuel Fabrication ng Plants and to Plutonium Processing and Fuel Fabrication smic Qualification of Electric Equipment for Nuclear Power Content of Technical Specifications for Fuel Reprocessing Design Basis Tornado for Nuclear Power Information: Water Level (Flood) Design for Nuclear Power ds in the Liners of Concrete Barriers in Fuel Reprocessing ng Plants and in Plutonium Processing and Fuel Fabrication ng Plants and in Plutonium Processing and Fuel Fabrication design Guide for Plutonium Processing and Fuel Fabrication Protective Coatings Applied to Water Cooled Nuclear Power ency Measures for Uranium and Plutonium Fuel Manufacturing tion of Protective Coatings (Paints) for Fuel Reprocessing

Fire Protection Guidelines for Nuclear Power General Fire Protection Guide for Fuel Reprocessing ation Systems of Plutonium Processing and Fuel Fabrication Geography and Demography Considerations for Nuclear Power ng Plants and in Plutonium Processing and Fuel Fabrication

Emergency Water Supply Systems for Fuel Reprocessing austenitic Stainless Steel Components of Fuel Reprocessing riteria for the Design of Stationary Boiling Water Reactor nt for Water Cooled and Moderated Nuclear Power Generating Testing Biological Sheilding in Nuclear Power nt and Systems for the Construction Phase of Nuclear Power Dimensions of )

for $(1974) \$ 1.75$

.75

.75

Fiberglass-Reinforced Polyethylene Carbon Black in Ethylene Environmental Stress-Cracking of Ethylene Flammability of Self-Supporting Measuring Flow Rates of Thermoplastics by Extrusion (1975A) $\$ 1.75$ ASTM B509Copper-Nickel Alloy Requirements for (1970) \$1.75

$\$ 1.75$ Nickel Alloy ASTM B3/ Zirconium and Zirconium Alloy Sheet, Strip, and 1974) $\$ 1.75$ 1973) ASTM E323-1970 \$1.75 Electric-Fusion (Arc)-Welded Steel 75) Supers/ Nickel-Molybdenum-Chromium Alloy PerforatedNondestructive Assay of High Enrichment Uranium Fuel ) ASTM A647-19/ Spec. for Special Requirements for Steel ification for Special Requirements for (1973) \$1.7/ Steel (1974A/ Longitudinal-Wave Ultrasonic Inspection of Steel requirements for (1975) $\$ 1.75$

Molybdenum, Alloy Steel aight-Beam Ultrasonic Examination of Plain and Clad Steel Low and Intermediate Tensile Strength Carbon Steel 1/4-Percent-Chromium, 1-Percent-Molybdenum Alloy Steel
75) Supersedes M5-5T, (7-71) 5) Supersedes M5-5T, $(7-71)$

75) Supersedes M5-2T, (5-73)

ments) (12-74) Supersedes M5-3T, (5-7)

$\mathrm{n}$ for $(1974 \mathrm{~A}) \$ 1.75$

Molybdenum, Specification for (1972A) A/

ed, Specification for (1974A) \$1.75

e-Molybdenum-Nickel, Specification For/

lybdenum, Specification for (1974) \$1.75

ine Percent Nickel (1974)/

molybdenum and Mangane/

alt-Molybdenum-Chromiu or Pressure Vessel Specification for Pressure Vessel Pressed, and Forged Steel Shapes, erature Service, Specification for (1974/)

Service, Specification for (1974A) \$1.7/ pecification for $(1974 \mathrm{~A}) \$ 1.75$

rength, Specification for (1974A) $\$ 1.75$ for $(1974 \mathrm{~A}) \$ 1.75$

ication for (1975) \$1.75

Pressure Vessel research Reactors (Revision 1, / $15.2 \$ 8.50$

3.1Mo-5.1 (Cb \& Ta)-0.90Ti-0./

3.1 Mo-5.1 (Cb \& Ta)-0.90Ti-0./ rmal Conductivity of Materials by Means of the Guarded Hot Corrosion-Resisting Chromium Steel Clad Nickel-Copper Alloy (UNS N04400) A ustenitic Stainless Stee sure Ves/ Heat Resisting Chromium-Nickel Stainless Steel Nickel-Chromium-Molybdenum-Columbium Alloy
equirements) (11-74) Supersedes M5-1T,/ Stainless Stee equirements) (1-75) Supers/ equirements) (9-75) Supers/ uirements) (1-72) Superse/ Nickel-Chromium-Iron Alloy Nickel-lron-Chromium Alloy ts) $(8-75 \%$ Nickel-Chromium-Molybdenum-Columbium Alloy b168-1970 $\$ 1.75$
Plants $(3 / 16 / 73)$

Plants $(3 / 73)$

Plants $(3 / 74)$

Plants $(3 / 76)$

Plants $(4 / 73)$

Plants $(4 / 74)$

Plants $(5 / 74)$

Plants $(5 / 75)$

Plants $(5 / 75)$

Plants $(5 / 75)$

Plants $(6 / 73)$

Plants $(6 / 73)$

Plants $(6 / 74)$

Plants $(6 / 75)$

Plants $(6 / 76)$

Plants $(6 / 76)$

Plants $(8 / 73)$

Plants $(8 / 74)$

Plants $(8 / 75)$

Plants $(9 / 75)$

Plants $(9 / 75)$

Plants: Issued for Trial Use and Corrosion and Stress Corrosion in

Plants, Fire Protection Criteria For, Issued for Trial

Plants, Program for (1972) ANS-6.3 $\$ 5.00$

Plants, Supplementary Quality Assurance Requirements Fo

Plastic Pipe Fittings, Symbols for (1968) (R 1973) \$1.75

Plastic Piping (12/73)

Plastic Pressure Vessels $(1977)$ bd $(\$ 40.00)$, Il $(\$ 60.00$

Plastics Molding and Extrusion Materials, Specification

Plastics, Method of Test for (1971) ASTM D1603-1968 \$1

Plastics, Method of Test for (1971) ASTM D 1693-1970 \$1

Plastics, Test for (1974) \$1.75

Plastometer (1973) \$1.75

Plate and Sheet for Pressure Vessels, Specification for Plate for Nuclear Applications, Specification for (1971 Plate for Nuclear Applications, Spec. for Supplementary Plate for Nuclear Application, Specification for (1967) Plate for Nuclear Application, Specification for (1973) Plate Pipe (Sizes 16 in. and Over), Specification for Plate Sieves for Testing Purposes, Specifications for Plate (ASME SB -434 with Additional Requirements) (1/Plates by Gamma-Ray Spectrometry $(9 / 74)$

Plates for Nuclear and Other Special Applications (1974 Plates for Nuclear and Other Special Applications, Spec Plates for Pressure Vessels, Method and Inspection for Plates for Pressure Vessels, Specification for General Plates for Pressure Vessels, Specification for (1974A) Plates for Special Applications, Specification for (197 Plates of Structural Quality, Specification for (1975)

Plates (ASME SA-387 with Additional Requirements) (2 Plates (ASME SA-387 with Additional Requirements) (5 Plates (ASME SA-516 with Additional Requirements) (8Plates (ASME SA-533 with Additional Additional Require Plates, Alloy Steel, Chromium-Molybdenum, Specificatio Plates, Alloy Steel, Five Percent Chromium, 0.5 Percent Plates, Alloy Steel, High Strength, Ouenched and Temper Plates, Alloy Steel, Manganese-Molybdenum and Manganes Plates, Alloy Steel, Quenched and Tempered Chromium-Mo Plates, Alloy Steel, Quenched and Tempered, Eight and N Plates, Alloy Steel, Quenched and Tempered, Manganese. Plates, Alloy Steel, Quenched and Tempered, Nickel-Cob Plates, Bars and Strip, Zinc (Hot Galvanized) Coatings Plates, Carbon Steel for Intermediate-and Higher-Temp Plates, Carbon Steel for Moderate and Lower Temperature Plates, Carbon Steel, Improved Transition Properties, S Plates, Carbon Steel, Low and Intermediate-Tensile S Plates, Carbon Steel, Manganese-Silicon, Specification Plates, Heat Treated Carbon-Manganese-Silicon, Specif Plates, Specification for (1973) \$1.75

Plate-Type Uranium-Aluminum Fuel Elements for Use in Plate-Type Uraniurn-Aluminum Fuel Elements (1974) ANS Plate, and Rolled Bar, Specification for (1974A) $\$ 1.75$ Plate, Corrosion and Heat Resistant Nickel Base-19CrPlate, Corrosion and Heat Resistant Nickel Base-19Cr Plate, Method of Test for (1975) ASTM C177-1971 \$1.75 Plate, Sheet and Strip, Specification for (1974A) \$1.75 Plate, Sheet and Strip, Specification for (1974) \$1.75 Plate, Sheet, and Strip for Core Components (3-73) Plate, Sheet, and Strip for Fusion-Welded Unfired Pres Plate, Sheet, and Strip (AMS 5596 with Additional Requ Plate, Sheet, and Strip (ASME SA-240 with Additional R Plate, Sheet, and Strip (ASME SB-168 with Additional R Plate, Sheet, and Strip (ASME SB-409 with Additional R Plate, Sheet, and Strip (ASTM B 352 with Additional Req Plate, Sheet, and Strip 5597 with Additional Requiremen Plate, Sheet, and Strip, Specification for (1973) ASTM
RG 1.37

RG 3.7

RG 3.21

RG 1.100

RG 3.6

RG 1.76

RG 1.70 .5

RG 3.27

RG 3.29

RG 3.28

RG 3.10

RG 1.54

RG 5.30

RG 1.120

RG 3.38

RG 3.12

RG 1.70 .7

RG 3.36

RG 3.31

RG 3.37

N 212

N 18.10

N 18.9

N45.2.8

D2749

RG 1.72

SEC-X

D1 248

K 65.89

K65.226

D635

D1238

B402

H34.33

B509

B352

N123

A134

Z168.12

RDT M5-8T

RG 5.38

N559

A647

A435

A20

A204

G35.25

A283

RDT M5-22T

RDT M5-5T

RDT M5-2T

RDT M5-3T

A387

G35.16

A5 17

A 302

A542

A553

A533

G35.26

G8.1

A5 15

A516

A442

A285

A299

A537

A577

RG 2.3

N393

B152

G87.84

G87.85

Z98.

A263

B 127

RDT M5-19T

A240

RDT M5-21T

RDT M5-1T

RDT M5-4T

RDT M5-7T

RDT M5-6T

RDT M5-20T

H34.10 
KWIC Index of U.S. Nuclear Standards

B443-197/ Nickel-Chromium-Molybdenum-Columbium Alloy 5
b409-1973 $\$ 1.75 \quad$ Stainless Chromium-Nickel Steel Clad
Nickel-Iron-Chromium Alloy Stainless and Heat Resisting Chromium-Nickel Stee Nickel

Stainless and Heat Resisting Chromium Steel Titanium and Titanium Alloy Strip, Sheet, and Columbium and Columbium Alloy Strip, Sheet, Foil, and Nickel-Molybdenum-Chromium-Iron Alloy Sheet and

Nickel and Nickel-Base Alloy Clad Stee Aluminum-Alloy Sheet and

Titanium and Titanium Alloy Strip, Sheet, and

rmal Conductivity of Materials by Means of the Guarded Hot lated, Std. Grade (8-72) Amendm/

17T, (3-73)

rade (8-72) Amendm/ Thermocouple Materials, Platinum and Fast Flux Test Facility Driver Fuel Pin Fast Flux Test Facility Driver Fuel Pin sel Head (4-73) Amendment I (1-74) Shield Temperature and Liquid Level Control Monitor, Por ice Supersedes E4-19T, (8-71)

Classification of Unirradiated d of Test for (1973) ASTM E267-1970 \$1.75 Uranium and d of Test for $(1970) \$ 1.75$

Uranium an Methods for the Accountability of Specification for Nuclear Grade Sinterable ectrometric, and Spectrochemical A nalysis of Nuclear Grade pectrometric, and Spectrochemical Analysis/ Nuclear Grade ical, Mass Spectrometric, and Spectrochemical Analysis $\mathrm{O}$ Fast Flux Test Facility Ceramic Grade

Materials Protection Contingency Measures for Uranium and Test for Atom Percent Fission in Uranium and est for (1973) ASTM / Atom Percent Fission in Uranium and of Test for (1974) \$/ Atom Percent Fission in Uranium and ction (6/74)

Method of Test for Atom Percent Fission in Uranium and

radionuclides in the Environment: Sampling and Analysis of Control and Accountability of ctrometric, Spectr/ Grade Plutonium Nitrate Solutions and hemical, Nuclear and Radiochemical A nalysi/ Nuclear Grade mical, Nuclear and Radiochemical Analysis of Nuclear Grade $72 \$ 1.75$ Nuclear Grade Nuclear Grade Fast Flux Facility d Methods for Chemical, Mass Spectrometric, Spectr/ Grade Specification for emical Nuclear and Radiochemical Analysis of Nuclear Grade Methods for the Accountability of emical, Mass Spectrometric, Spectrochemical, Nuclear Grade 1.75

Program Requirements for Fuel Reprocessing Plants and for Seismic Design Classification fo General Fire Protection Guide for Standard Format and Content of License Applications for Monitoring of Combustible Gases and Vapors in ective Coatings A pplied to Fuel Reprocessing Plants and to $f$ Limited Accessibility in Fuel Reprocessing Plants and in low Alloy Steel for Use in Fuel Reprocessing Plants and in Liquid Waste Treatment System Design Guide for General Design Guide for Ventilation Systems of ubular Products for Use in Fuel Reprocessing Plants and in

In Situ Assay of Unirradiated Calorimetric Assay of
Calorimetric Assay of

control, Calibration Techniques Fo/ Differential Pressure Transmitter

e, Specification For/

Direct Reading and Indirect Reading Direct-Reading and Indirect-Reading lexural Strength of Concrete (Using Simple Beam with Third specimens, Meth/ Static Young's Modulus of Elasticity and Food and Drugs: Subpart B, Statements of specification for (1974) $\$ 1.7 \$$

measurements (1968) (R197/ Calculation of Neutron Dose to classification System for (ASTM D2953-1971) (1973) \$1.7) classification System for (1971) $\$ 1.75$

for (1968) (R1973) ASTM D1672-1966 (1971) \$/ Exposure of tice for (1966) (R1971) \$1.75

nsulation (1970) (ASTM D1674-1967) \$/ Methods of Testing re for (1964) $\$ 3.80$

for Laboratory Use, Test for (1969) \$1.75

Spray 5 pressive Strength of Undrained Rock Core Specimens Withou 74) Maximum Pore Diameter and Permeability of Rigid Temperature and Liquid Level Control Monitor, of Test for Indentation Hardness of Metallic Materials by
Plate, Sheet, and Strip, Specification for (1973) (ASTM Plate, Sheet, and Strip, Specification for (1974A) \$1.7 Plate, Sheet, and Strip, Specification for (1974) ASTM Plate, Sheet, and Strip, Specification for (1974) \$1.75 Plate, Sheet, and Strip, Specification for (1974) \$1.75 Plate, Sheet, and Strip, Specification for (1975) \$1.75 Plate, Specification for (1973) ASTM B265-1972 \$1.75 Plate, Specification for (1973) ASTM B393-1964 \$1.75 Plate, Specification for (1973) ASTM B434-1971 \$1.75 Plate, Specification for (1974A) \$1.75

Plate, Specification for (1974) ASTM B209-1973 \$1.75 Plate, Spec. for (1974) $\$ 1.75$

Plate, Test for (1971) $\$ 1.75$

Platinum and Platinum 10 Percent Rhodium Wires, Noninsu

Platinum Resistance Thermometer (4-75) Supersedes C7

Platinum 10 Percent Rhodium Wires, Noninsulated, Std. G Plenum Spacer (6-71)

Plenum Spring (6-71)

Plug and Closure Cap for Penetrations LMFBR Reactor Ves Plug (Fabrication Only) (10-73) Amendment 1 (12-74) Plugging Temperature Indicator Assembly for Sodium Serv Plutonium and Uranium Scrap (12/20/72)

Plutonium Concentrations and Isotopic Abundances, Metho Plutonium Concentrations and Isotopic Abundances, Metho Plutonium Dioxide Powder (12/74)

Plutonium Dioxide Powder (1974A) \$1.75

Plutonium Dioxide Powders and Pellets and Nuclear Grade Plutonium Dioxide Powders and Pellets, Chemical, Mass S Plutonium Dioxide Powders and Pellets, Methods for Chem Plutonium Dioxide (6-71)

Plutonium Fuel Manufacturing Plants (6/74)

Plutonium Fuel (Mass Spectrometric Method) (1974) $\$ 1.75$

Plutonium Fuel (Mass Spectrometric Method), Method of T

Plutonium Fuel (Neodymium 148 Method), Standard Method

Plutonium Fuel (Neodymium-148 Method) (1973) ASTM E321

Plutonium in Scrap Material by Spontaneous Fission Dete

Plutonium in Soil (5/74)

Measurements of

Plutonium in Waste Material (2/75)

Plutonium Metal Standard Methods for Chemical, Mass Spe

Plutonium Metal, Chemical, Mass Spectrometric, Spectroc

Plutonium Metal, Methods for (1974) ASTM C758-1973 \$1.

Plutonium Metal, Specification for (1973) ASTM C701-19

Plutonium Metal, Spec. for (1972) $\$ 1.75$

Plutonium Nitrate Solution (6-71)

Plutonium Nitrate Solutions and Plutonium Metal Standar

Plutonium Nitrate Solutions ASTM C710-72 (1973) $\$ 1.75$

Plutonium Nitrate Solutions (1973) \$1.75

Plutonium Nitrate Solutions (1/74)

/C, Spectroch

Plutonium Nitrate Solutions, Methods for (1974) ASTM C7

Plutonium Nitrate Solutions, Specification for (1973) \$

Plutonium Processing and Fuel Fabrication Plants (Revis

Plutonium Processing and Fuel Fabrication Plants (10/73

Plutonium Processing and Fuel Fabrication Plants (1/74)

Plutonium Processing and Fuel Fabrication Plants (1/76)

Plutonium Processing and Fuel Fabrication Plants (3/73)

Plutonium Processing and Fuel Fabrication Plants (3/74)

Plutonium Processing and Fuel Fabrication Plants (5/75)

Plutonium Processing and Fuel Fabrication Plants $(5 / 75)$

Plutonium Processing and Fuel Fabrication Plants (6/73)

Plutonium Processing and Fuel Fabrication Plants (8/73)

Plutonium Processing and Fuel Fabrication Plants $(8 / 75)$

Plutonium Residual Holdup (5/74)

Plutonium Scrap, Classification of (1972) $\$ 4.25$

Plutonium (6/74)

Plutonium-Bearing Solids Applied to Nuclear Materials

Pneumatic or Electric Output Signal (4-74)

Pocket Dosimeters for X and Gamma Radiation, Performanc

Pocket Dosimeters (2/26/73)

Point Loading), Method of Test for (1966) (R 1973) ASTM

Poisson's Ratio in Compression of Cylindrical Concrete

Policy and Interpretation (1975) \$2.95

Polyethylene Plastics Molding and Extrusion Materials,

Polymeric Materials and Application of Threshold-Foil

Polymeric Materials for Service in Ionizing Radiation,

Polymeric Materials for Service in Ionizing Radiation,

Polymeric Materials to High Energy Radiation, Practice

Polymeric Materials to High Energy Radiation, Rec. Prac

Polymerizable Embedding Compounds Used for Electrical

Polyphase Induction Motors and Generators, Test Procedu

Pond Plastic Piping (12/73)

Pore Diameter and Permeability of Rigid Porous Filters

Pore Pressure Measurements (1974) $\$ 1.75$ / Triaxia

Porous Filters for Laboratory Use, Test for (1969) $\$ 1.7$

Portable Compressed Gas Containers to Identify the Mate

Portable Hardness Testers (1974) ASTM E110 $1972 \$ 1.75$
NRC

ASTM

ANSI

ERDA

NRC

ASTM

ANSI

ASTM

ANSI

NRC

NRC

NRC
NRC

ASTM

ANSI

ANSI

ANSI

ERDA

NRC

ANSI

ASTM

NRC

ANSI

ASTM

NRC

NRC

NRC

NRC

NRC

NRC

NRC

NRC

NRC

NRC

NRC

NRC

ANSI

NRC

ANSI

ERDA

ANSI

NRC

ANSI

ANSI

BRH

ASTM

ASTM

ANSI

ASTM

ANSI

ASTM

ANSI

IEEE

NRC

ASTM

ASTM

ASTM

ERDA

ANSI

ANSI

H34.19

A264

H34.40

A 167

B 162

A 176

2179.1

Z1 79.20

H34.44

A 265

H38.2

B265

C 177

RDT C7-7T

RDT C7-17T

RDT C7-7T

RDT E13-11

RDT E13-12

RDT E2-4T

RDT E6-10T

RDT E4-19T

RG 5.2

N1 15

E267

RG 5.40

C757

RG 5.6

C697 


\section{fication of (1971) $\$ 4.40$}

.75

r Fly Ash and Raw or Calcined Natural Pozzolanis 969) Sampling and Testing Fly Ash for Use as an Admixture in 75 Ball Penetration in Fresh

Regulatory Staff Reciprocating ntainment Heat Removal System Pumps (Safety Guide 1,/ Net Habitability of Nuclear Power Plant Control Room During A for Protection of Nuclear Power Plants Against Effects of ar Power Plant Sites (1/75) or Vessels and Containments (11/75) ) Fabrication of Core Component hotometry, Tests for (1971) $\$ 1.75$
Method of Test for (1973) ASTM D2033-1/ Codium and (1973) \$1.75 Test for Consumption of ations (Mortar-Bar Method), Test for (1971) $\$ 1.75$

17.1970\$1.75 0

accident in the Fuel/ t Accident for Boili/ t Accident for Press/ ter Reactor Radioact/ fgas System Failure / ak Accident for Boil/ Uranium by Controlled Uranium by Controlled Measuring Ground Resistance and Test for Oxidation-Reduction Assumptions Used for Evaluating the Assumptions Used for Evaluating the Assumptions Used for Evaluating the Assumptions Used for Evaluating the Assumptions Used for Evaluating the Assumptions Used for Evaluating the ethod of Test for (1973) ASTM C289-1971 \$1.75

Specification for Nuclear Grade Beryllium Oxide (R1973) ASTM E109-1963 (1971) \$1.75

Methods for the Accountability of Plutonium Dioxid Specification for Nuclear Grade Beryllium Oxide specification for Nuclear Grade Sinterable Uranium Dioxide ecification for Nuclear Grade Sinterable Plutonium Dioxide pecification for Nuclear Grade, Sinterable Uranium Dioxide Specification for Nuclear Grade Boron Carbide

pecification for Nuclear Grade, Sinterable Uranium Dioxide pectrochemical Analysis of Nuclear Grade Plutonium Dioxide
Spectrochemical Analysis of Nuclear Grade Uranium Dioxide spectrochemical Analysis O/ Nuclear Grade Uranium Dioxide spectrochemical Analysis/ metric, and Spectrochemical Analysis of / metric, and Spectrochemical Analysis O/ cal Analysis Of, and Physical Tests on ( cal Analysis Of, and Physical Tests on (/

Uranium Dioxice

Plutonium Dioxide Beryllium Oxide Beryllium Oxide Acid Insoluble Content of Copper and Iron Periodic Testing of Electrical (IEEE Std 262-1973), Including Draft Sup/ $.00)$, Loose-Leaf ( $\$ 55.00)$

$4 \$ 5.00$

Recommended Rules for Care of tures and Equipment for Water Cooled and Moderated Nuclea or the (1975) $\$ 5.00 \quad$ Periodic Testing of Nuclea ard Application of the Single Failure Criterion to Nuclear Definitions of Terms Used in IEEE Standards on Nuclea on Assemblies in Containment Structures for Nuclear Fueled lectric Cables, Field Splices, and Connections for Nuclear $279-1971 \$ 4.00$ $308-1974 \$ 4.00$ Protection Systems for Nuclear Seismic Qualification of Electric Equipment for Nuclea class 1 Motors Installed Inside the Containment of Nuclear and Electric Equipment During the Construction of Nuclea erator Units Applied as Standby Power Supplies for Nuclea

ype Test of Class I Electrical Valve Operators for Nuclea

Draft Std. for Class $1 \mathrm{E}$ Control Switchboards for Nuclear $(3 / 74)$ Design, Construction, and Use of Radioisotopic

cation Standard (1975) $\$ 3.00$ Stainless Steel Globe and Angle Valves, Manual and Stainless Steel Gate Valves, Manual and Nuclear

Nuclear

Nuclear
Nuclear

tenance, Testing, and Replacement of Large Stationary Type $.00), \mathrm{ll}(\$ 65.00)$ $(\$ 40.00)$ General Requirements for Nuclear

Nuclear

Rules for Inservice Inspection of Nuclear Appendices to Sec. 111 Div. 1, Nuclea c/ Assumptions for Evaluating the Habitability of Nuclea I Chlorine Release (2/75)
Portable Metal Ladders (1972) $\$ 4.25$

Portable Wood Ladders (1975) $\$ 5.00$

Portable X or Gamma Radiation Survey Instruments, Speci

Portland Cement by the Turbidimeter, Test for (1974) \$1

Portland Cement Concrete (1973) ASTM C618-1972 \$1.75

Portland Cement Concrete (1974) $\$ 1.75$

Portland Cement Concrete, Method of Test for (1964) (RI

Portland Cement Concrete, Method of Test for (1974) \$1.

Position Statement on Antitrust Matters (12/73)

Positive Displacement Pump (3-72) Amendment 1 (5-74)

Positive Suction Head for Emergency Core Cooling and $\mathrm{Co}$

Postulated Hazardous Chemical Release (6/74)

Postulated Pipe Rupture (Issued for Trial Use and Comme

Postulated to Occur on Transportation Routes Near Nucle

Post-Tensioned Prestressing Systems for Concrete React

Pot for Liquid Metal Service (3-72) Amendment 1 (3-74

Potassium in Water and Water Formed Deposits by Flame P

Potassium Permanganate by Impurities in Deuterium Oxide

Potassium Permanganate by Impurities in Deuterium Oxide

Potential Alkali Reactivity of Cement-Aggregate Combin

Potential Coulometry, Method of Test for (1970) $\$ 1.75$

Potential Coulometry, Method of Test for (1973) ASTM E2

Potentiai Gradients in the Earth, Guide for (1962) $\$ 3.6$

Potential of Water (1970) $\$ 1.75$

Potential Radiological Consequences of a Fuel Handling

Potential Radiological Consequences of a Loss of Coolan

Potential Radiological Consequences of a Loss of Coolan

Potential Radiological Consequences of a Pressurized Wa

Potential Radiological Consequences of a Radioactive of

Potential Radiological Consequences of a Steam Line Bre

Potential Reactivity of Aggregates (Chemical Method), M

Powder ASTM C708-72a (1973) \$1.75

Powder Magnetic Particle Inspection, Method for (1969)

Powder (12/74)

Powder (1972A) \$1.75

Powder (1973) \$1.75

Powder (1974A) \$1.75

Powder (1974) ASTM C753-1973 \$1.75

Powder (1974) $\$ 1.75$

Powder (1975) ASTM C757-1974a \$1.75

Powders and Pellets and Nuclear Grade Mixed Oxides ( $(U$,

Powders and Pellets $(2 / 9 / 73)$ / Mass Spectrometric, Mass Spectrometric, and
Powders and Pellets, Chemical,

Powders and Pellets, Chemical, Mass Spectrometric, and

Powders and Pellets, Methods for Chemical, Mass Spectro

Powders and Pellets, Methods for Chemical, Mass Spectro

Powders, Chemical, Mass Spectrometric, and Spectrochem

Powders, Chemical, Mass Spectrometric, and Spectrochemi

Powders, Test for (1974) $\$ 1.75$

Power and Protection Systems (6/76)

Power and Regulating Transformers, Test Code for (1973)

Power Boilers Material Specifications (1977) Bound ( $\$ 40$

Power Boilers (1977) bd $(\$ 25.00), 1](\$ 30.00)$

Power Circuits, Surge Arresters for (1975) IEEE 28-197

Power Generating Plants, Fire Protection Criteria For,

Power Generating Station Protection Systems, Criteria F

Power Generating Station Protection Systems, Trial Use

Power Generating Stations (1972) $\$ 4.00$

Power Generating Stations (1973) IEEE 317-1972 \$3.00

Power Generating Stations (1975) IEEE Std. 383-1974 \$4

Power Generating Stations, Criteria for (1972) IEEE Std

Power Generating Stations, Criteria for (1975) IEEE Std

Power Generating Stations, Criteria (Issued for Trial U

Power Generating Stations, Guide for (1975) $\$ 5.00$

Power Generating Stations, Guide For, (1976) IEEE 334

Power Generating Stations, Installation, Inspection and

Power Generating Stations, Trial Use Criteria (Issued F

Power Generating Stations, Trial Use Guide (Issued for

Power Generating Stations, (Trial Guide Issued for Use

Power Generators for Certain Land and Sea Applications

Power Levels of Nuclear Power Plants (Revision 1, 12/73

Power Operated Safety Related Valyes Functional Specif

Power Operated (3-72)

Power Operated (3-72) Amendment 1 (5-74)

Power Piping Sold Separately (1971) $\$ 4.25$

Power Piping with Addenda (1969) \$19.00

Power Piping (1973) $\$ 40.00$

Power Piping, Sold Separately (1971) $\$ 4.25$

Power Piping, Sold Separately (1972) $\$ 1.25$

Power Plant and Substation Lead Storage Batteries, Rec.

Power Plant Components Div. 1 and Div. 2 ( 1977$)$ bd $(\$ 40$

Power Plant Components Supports (1977) bd $(\$ 30.00)$, II

Power Plant Components (1977) bd (\$60.00); ll (\$90.00)

Power Plant Components (1977) bd $(\$ 70.00)$ Il ( $\$ 90.00)$

Power Plant Control Room During a Postulated Hazardous

Power Plant Control Room Operators Against an Accidenta
ANS1

ANSI

ANSI

ASTM

ANSI

ASTM

ANS]

ASTM

NRC

ERDA

NRC

NRC

ANSI

NRC

NRC

ERDA

ASTM

ANSI

ASTM

ASTM

ASTM

ANSI

IEEE

ASTM

NRC

NRC

NRC

NRC

NRC

NRC

ANSI

ANSI

ANS1

NRC

ASTM

ASTM

Sp ASTM

ANSI

ASTM

ANSI

NRC

NRC

ASTM

ASTM

ANSI

ANSI

ANS!

ASTM

ASTM

NRC

ANSI

ASME

ASME

ANSI

ANSI

IEEE

ANSI

IEEE

ANSI

ANS!

ANSI

ANSI

ANSI

IEEE

ANS!

ANS1

ANSl

ANS1

ANS1

NRC

NRC

ANS1

ERDA

ERDA

ANSI

ANSI

ANSI

ANSI

ANSl

IEEE

ASME

ASME

ASME

ASME

NRC

NRC

Al4. 2

A 14.

N 13.4

Cl15

A 37.122

C 311

A 37.92

Cl 43

RG 91

RDT E3-7T

RG 1.1

RG 1.78

N 176

RG 1.91

RG 1.103

RDT E6-34T

D 1428 
ncl $(8 / 73)$

Application of the Single-Failure Criterion to Nuclea Collection, Storage, and Maintenance of Nuclear Bypassed and Inoperable Status Indication for Nuclear Postulated to Occur on Transportation Routes Near Nuclear Class 1 Components for Nuclea Class 3 Components for Nuclea

Class MC Components for Nuclear Class 2 Components for Nuclear Guidance on Being Operator at the Controls of a Nuclear Draft Standard for Design Basis for Protection of Nuclear Seismic Requirements for Design of Nuclear Safety Considerations for Nuclear

owing A/ Instrumentation for Light-Water-Cooled Nuclear ping, Receiving, Storage and Handling of Items for Nuclea Leakage Control Systems for Boiling Water Reactor Nuclear Power Levels of Nuclea

Design Response Spectra for Seismic Design of Nuclear ional Information: Hydrological Considerations for Nuclear ency and Shutdown Electric Systems for Multi-Unit Nuclea $\mathrm{ms}$ for Monitoring Radioactivity in the Environs of Nuclear Design Basis Floods for Nuclear Structural Steel During the Construction Phase of Nuclear ria for Safety-Related Electric Power Systems for Nuclea id and Gaseous Effluents from Light-Water-Cooled Nuclear Nuclear Material Control Systems for Nuclear ust Review of Construction Permit Applications for Nuclear ation and Adsorption Units of Light-Water Cooled Nuclear

y Assurance Program Requirements for the Design of Nuclear

Format and Content of Safety Analysis Reports for Nuclear Ultimate Heat Sink for Nuclear and Radioactive-Waste-Containing Components of Nuclear Damping Values for Seismic Design of Nuclea emblies in Containment Structures for Water Cooled Nuclear trust Review of Operating License Applications for Nuclear Flood Protection for Nuclea

Qualification of Class IE Equipment for Nuclea Emergency Planning for Nuclear

Concrete Radiation Shields for Nuclear

Air Filtration Systems and Containment Sumps for Nuclear

Safety Analysis Reports: Industrial Security for Nuclear Environmental Technical Specifications for Nuclear feedwater and Condensate Systems for Boiling Water Reactor Inservice Testing of Valves in Nuclear Inservice Testing of Pumps in Nuclear

Selection and Training of Personnel for Nuclear Quality Assurance Program Requirements for Nuclear Administrative Controls for Nuclear

Housekeeping During the Construction Phase of Nuclear nd Testing Personnel for the Construction Phase of Nuclear ciated Components During the Construction Phase of Nuclear Industrial Security for Nuclear Earthquake 1nstrumentation Criteria for Nuclear and Maintenance of Quality Assurance Records for Nuclear Structural Steel During the Construction Phase of Nuclea Quality Assurajce Requirements for the Design of Nuclear alve Operators Installed Inside the Containment of Nuclear al Information: Fire Protection Considerations for Nuclear Overhead Crane Handling Systems for Nuclear

Housekeeping Requirements for Water Cooled Nuclea g, Storage, and Handling of ltems for Water Cooled Nuclear $s$ Installed Inside the Containment of Water Cooled Nuclear systems and Associated Components of Water-Cooled Nuclear

Seismic Qualification of Electric Equipment for Nuclear Design Basis Tornado for Nuclear tional Information: Water Level (Flood) Design for Nuclear ts for Protective Coatings Applied to Water Cooled Nuclear Fire Protection Guidelines for Nuclear ation: Geography and Demography Considerations for Nuclear Testing Biological Sheilding in Nuclear quipment and Systems for the Construction Phase of Nuclear Direct Curren

ational and Initial Startup Test Programs for Water Cooled bering of Fuel Assemblies for Light-Water-Cooled Nuclear sis for Radwaste Systems for Light-Water-Cooled Nuclear

in Gaseous and Liquid Effluents from Light-Water-Cooled ation Exposure as Low as Is Reasonably Achievable (Nuclear 974) $\$ 3.50$ afety $\mathrm{Gu} /$

Nuclear Independence Between Redundant Standby (Onsite) Availability of Electric General Site Suitability Criteria for Nuclear Preparation of Environmental Reports for Nuclear Terrestrial Environmental Studies for Nuclear

Draft Standard Diesel Generator Units Applied as Standby Selection of Diesel Generator Set Capacity for Standby Eddy Current Flowmeter
Power Plant Inspection, Examination, and Testing Person Power Plant Protection Systems (6/73)

Power Plant Quality Assurance Records (Revision 1, 12/7

Power Plant Safety Systems (5/73)

Power Plant Sites (1/75)

Power Plant (1977) bd (\$55.00), Il (\$85.00)

Power Plant $(1977)$ bd $(\$ 55.00)$, ll $(\$ 85.00)$

Power Plant (1977) bd $(\$ 55.00)$, Il $(\$ 85.00)$

Power Plant (1977) bd (\$55.00), (\$85.00)

Power Plant (2/76)

Power Plants Against Effects of Postulated Pipe Rupture

Power Plants and Test Facilities (1-74)

Power Plants on Merchant Ships (1965) $\$ 7.50$

Power Plants to Assess Plant Conditions During and Foll

Power Plants (During the Construction Phase) (1972) \$4.

Power Plants (Revision 1, (6/76)

Power Plants (Revision 1, 12/73)

Power Plants (Revision 1, 12/73)

Power Plants (Revision 1, 1/75)

Power Plants (Revision 1, 1/75)

Power Plants (Revision 1, 2/75)

Power Plants (Revision 1, 4/76)

Power Plants (Revision 1, 4/76)

Power Plants (Revision 1, 6/73

Power Plants (Revision 1, 6/74)

Power Plants (Revision 1, 6/75)

Power Plants (Revision 1, 6/76)

Power Plants (Revision 1, 7/76)

Power Plants (Revision 2, (6/76)

Power Plants (Revision 2, (9/75)

Power Plants (Revision 2, $1 / 76$ )

Power Plants (Revision 3, 2/76)

Power Plants (10/73)

Power Plants $(10 / 73)$

Power Plants (10/74)

Power Plants (10/75

Power Plants (11/74)

Power Plants (11/75)

Power Plants (12/73)

Power Plants (12/73)

Power Plants $(12 / 74)$

Power Plants $(1.2 / 75)$

Power Plants (12/75)

Power Plants (1970) $\$ 2.25$

Power Plants (1970) $\$ 2.75$

Power Plants (1971) ANS-3.1 \$10.00

Power Plants (1971) $\$ 4.00$

Power Plants (1972) ANS-3.2 \$10.00

Power Plants (1973) $\$ 4.00$

Power Plants (1973) $\$ 4.00$

Power Plants (1973) \$4.00

Power Plants (1973) (ANS-3.3) $\$ 10.0$

Power Plants (1974) ANS 2.2 \$10.00

Team Isolation Valve

$\begin{aligned} & \text { NRC } \\ & \text { NRC } \\ \text { Addit } & \text { NRC } \\ \text { Shared Emerg } & \text { NRC }\end{aligned}$

Progra NRC

NRC

/Ructural Concrete and NRC

Crite NRC

/lve Materials in Liqu NRC

NRC

/Ction with lts Antitr NRC

/Anup System Air Filtr NRC

Qualit NRC

Standard NRC

NRC

/ for Water-, Steam- NRC

NRC

Electric Penetration Ass NRC

Taff in Connection with Its Anti NRC

NRC

NRC

NRC

NRC Additional Information NRC
Information Fo NRC

NRC

/ and Initial Startup Testing of NRC

ASME

ASME

ANSI

ANS1

ANS1

ANSI

F Inspection, Examination a ANSI $G$ of Fluid Systems and Asso ANSI

ANSI

ANSI

Power Plants (1974) \$4.00

Power Plants (1974) $\$ 4.50$

Power Plants (1974) $\$ 5.50$

Power Plants (1/74)

Power Plants (2/74)

Power Plants $(2 / 76)$

Power Plants $(3 / 16 / 73)$

Power Plants $(3 / 16 / 73)$

Power Plants $(3 / 16 / 73)$

Power Plants $(3 / 16 / 73)$

Power Plants $(3 / 76)$

Power Plants (4/74)

Power Plants (5/74)

Power Plants (6/73)

Power Plants $(6 / 76)$

Power Plants $(8 / 74)$

Power Plants, Program for (1972) ANS-6.3 $\$ 5.00$

/Nts for Collection, Storage

ANSI

/ of Structural Concrete and ANS1

ANS1

Qualification Tests of Electric V NRC

Addition

NRC

NRC

NRC

/ Packaging, Shipping, Receivin NRC

/Ests of Continuous-Duty Motor NRC

/Quirements for Cleaning Fluid

NRC

NRC

Addi NRC

Quality Assurance Requiremen

NRC

Additional Inform

Power Plants, Supplementary Quality Assurance Requireme

Power Range Neutron Flux Monitoring System (7-71)

Power Reactors (1 1/73)

Power Reactors (12/20/72)

Power Reactors $(3 / 76)$

Power Reactors (4/76)

Power Reactors) (Revision 1, 9/75)

Power Reactors, Nuclear Material Control Systems for (1

Power Sources and Between Their Distribution Systems (S

Power Sources (12/74)

Power Stations (Revision 1, 11/75)

Power Stations (Revision 1, 1/75)

Power Stations (7/76)

Power Supplies for Nuclear Power Generating Stations, T

erial Num

Power Supplies (Safety Guide 9, 3/10/71)

Power Supply and Signal Conditioning Electronics (2-73
ANSI

ERDA

NRC

NRC

NRC

NRC

NRC

ANS

NRC

NRC

NRC

NRC

NRC

ANSI

NRC

ERDA

RG 1.58

RG 1.53

RG 1.88

RG 1.47

RG 1.9 I

SEC-IIINB

SEC-1IIND

SEC-IIINE

SEC-IIINC

RG 1.114

N 176

RDT F9.2T

3-18

RG 1.97

N45.2.2

RG 1.96

RG 1.49

RG 1.60

RG 1.70.1

RG 1.81

RG 4. I

RG 1.59

RG 1.94

RG 1.32

RG 1.21

RG 5.29

RG 9.2

RG 1.52

RG 1.64

RG 1.70

RG 1.27

RG 1.26

RG 1.61

RG 1.63

RG 9.3

RG 1.102

RG 1.89

RG 1.101

RG 1.69

RG 1.70 .2

RG 1.70 .15

RG 4.8 

iteria for (1975) IEEE Std. 308-1974 $\$ 4.00 \quad$ Class 1E
3) Criteria for Safety-Related Electric y Std. for (1975) $\$ 6.50$ Information for Safety Analysis Reports: Electric onstruction, Arrangement, and Other Provisions for Nuclear Stopping $\mathrm{tm} / \quad$ Specification for Fly Ash and Raw or Calcined Natural

us-Injection Gas Chromatography (1974) \$1.7/ Recommended tibility to Intergranular Attack in Stainless Steels, Rec. nt) (1969) $\$ 4.25$

Programs (1971) $\$ 7.50$ Administrative Recommended Programming trumentation and Control Equipment Grounding and Sheilding st Procedures for (1969) IEEE Std. 301-1/ ndment 1 (6-73), Amendment 2 (10-74) $s(12-75)$ Supersedes C10-3T, (3-72) (1970) $\$ 4.00$ orgings, and Forging Stock for High Tempe/ ings, and Forging Stock for High Temperat/ d Forging Stock for High Temperature Serv/ Std. Spec. for Std. Spec. for Std. Spec. for d Forging Stock for High Temperature Service (ASTM a 637) and Forgings (ASME SA-564 with Additional Requirements)/

$\$ 1.75$

Std. Spec. for
Recommended Practice for Determination of Reporting Procedure for Mathematical Models Selected to Effects of Residual Elements on Fallout Estimates for 1964-1965 and Verification of 1963 nt and Pipe Operating at Temperatures Above/ Practice for nt and Pipe Operating at Temperatures / Rec. Practice for ormance, Testing (1973) \$1.75 Duct Liner Materials and (R1974) $\$ 4.00$

for (1963) (R1973) ASTM C 165-1/ Compressive Strength of ) $\$ 1.7 / \quad$ Breaking Load and Calculated Flexural Strength of ) $\$ 1.75$ Density of

Soaking Heat / Method of Test for Linear Shrinkage of

hod of Test for Determining the Maximum Use Temperature of or (1972) $\$ 1.75$ Density of Sampling 3) ng of Low Alloy Steel for Use in Fuel Reprocessing Plant/ dment $1(10-71)$

Control of

ter Cooled Power Reactors (11/73)

Instruction Concerning

and Condensate Systems for Boiling Water Reactor Power s for Pressurized Water Reactors (Revision 1, 1/75)

sedes F1-1, (7-72) Amendment 1 (11-74)

Ceramographic

e Making Petition Seeking an Exemption for a Radionuclid/ rce Material (7/76)

1 Licenses of Less Than Critical Mass Quan/

otective Functions in Nuclear Power G/

nium Enrichment Facilities (Revision 1, 10/75)

stations (Revision 1, 1/75)

(4/73)

\section{3) ASTM D2651-1973\$1.75}

Guide for the

Guide for the Draft Standard fo

ing M/ Recommended Practice for Photography as Applied to rsedes $(3-72)$

ment 1 (1-75), Amendment 2 (11-75)

od of Test for (1975) \$1.75

for Metallic Materials (1972T)/

Water Soluble Chloride Std. Spec. for Copper and Copper Alloy Die Forgings (Ho $\mathrm{p}$, Zinc (Hot Galvanized) Coatings on Products Fabricated Tungsten Forgings

h Additional Requi/ Alloy Steel Nuts for Bolting for High ifugally Cast Iron-Chromium-Nickel High Alloy Tubing for analysis Reports: Code Cases Applicable to Reactor Coolant Reactor Coolan

Information for Safety Analysis Reports: Reactor Coolan or Use with Lens Gaskets (1968) $\$ 4.00$

t Type, Inductive, Absolute or Gage (10-70/ Liquid Metal ive Strength of Undrained Rock Core Specimens Without Pore Air Content of Freshly Mixed Concrete by the thod) (1974) $\$ 1.75$ Measurement of Extreme Test for Evaluating Std. Spec. for High Temperature Glass Cloth Electric-Fusion-Welded Steel Pipe for High ed Rules for Design and Construction of Large, Welded, Low mendment 1 (5-7i); Su/ Nak Transmission High Temperature al (4-74) Differentia all Sections: Bound Edition \$1200.00: Lo/ ASME Boiler and

Class 1 Nuclear Components (Supplement to ASME Boiler and
Power Systems for Nuclear Power Generating Stations, $\mathrm{Cr}$ Power Systems for Nuclear Power Plants (Revision 1, 6/7 Power Transmission Apparatus, Safety Standard for (1972 Power (6/75)

Powered Industrial Trucks Low Lift and High Lift, Safet Powerplant Components (1975) $\$ 4.40$

$\$ 2.00$

Pozzolans for Use in Portland Cement Concrete (1973) as PPS Buffers (10-71) Amendment 1 (12-71)

Practices for Volatile Organic Matter in Water by Aqueo Practices for (1975) \$1.75

Practices in Radiation Monitoring (A Guide for Manageme

Practices in Radiation Monitoring (2/2/73)

Practices to Facilitate Interchange of Digital Computer

Practices (1/73) Amendment 1 (1/75)

Preamplifiers for Semiconductor Radiation Detectors, Te

Preamplifiers for Use with Fission Counters (8-71) Ame

Preamplifier/Discriminator for Use with Neutron Counter

Precautions in the Management of Patients Who Have Rece

Precipitation Hardening Cobalt Containing Alloy Bars, F

Precipitation Hardening Iron Base Superalloy Bars, Forg

Precipitation Hardening Nickel Alloy Bars, Forgings, an

Precipitation Hardening Nickel Alloy Bars, Forgings, an

Precipitation-Hardening Stainless Steel Bars, Shapes,

Precision Electroformcd Sieves (1973) ASTM E161-1970

Precision of Methods of Committee D-19 on Water (1972)

Predict Heated Effluent Dispersion in Natural Water Bod

Predicted Radiation Damage to Reactor Vessel Materials

Predictions (1964)

Prefabricated Reflective Insulation Systems for Equipme

Prefabricated Reflective Insulation Systems for Equipme

Prefabricated Silencers for Acoustical and Airflow Perf

Preferred Limits and Fits for Cylindrical Parts (1967)

Preformed Block Type Thermal Insulation, Method of Test

Preformed Block Type Thermal Insulation, Test for (1972

Preformed Block Type Thermal Insulation, Test for (1972

Preformed High Temperature Thermal Insulation Subjected Preformed Insulation (1973) ASTM C447-1971 \$1.75

Preformed Pipe Covering Type Thermal Insulation, Test F

Preformed Thermal Insulation (1972) $\$ 1.75$

Preheat and Interpass Temperature Control for the Weldi

Preheat Temperature for Welding of Low Alloy Steel (5/7

Preloading Threaded Fasteners and Closures (2-69) Amen

Prenatal Radiation Exposure (Revision 1, 11/75)

Preoperational and Initial Startup Test Programs for Wa

Preoperational and Initial Startup Testing of Feedwater

Preoperational Testing of Emergency Core Cooling System

Preoperational Testing of Instrument Air Systems (6/74)

Preparation and Application of RDT Stds. (12-73) Super

Preparation Cf Mixed Oxide Fuel Pellets (1-73)

Preparation of an Environmental Report to Support a Ru

Preparation of Applications for Licenses to Process Sou

Preparation of Applications for Special Nuclear Materia

Preparation of Design Bases for Systems That Perform Pr

Preparation of Environmental Reports for Commercial Ura

Preparation of Environmental Reports for Nuclear Power

Preparation of Environmental Reports for Uranium Mills

Preparation of Leak Testing Specification (1973) $\$ 1.75$

Preparation of Metal Surfaces for Adhesive Bonding (197

Preparation of Metallographic Specimens (1974) $\$ 1.75$

Preparation of Micrographs of Metals and Alloys (Includ

Preparation of System Design Descriptions (12-75) Supe

Preparation of Unusual Occurrence Reports (2-74) Amend

Present as Admixes in Graded Aggregate Road Mixes, Meth

Presentation of Constant Amplitude Fatigue Test Results

Pressed) (1974) $\$ 1.75$

Pressed, and Forged Steel Shapes, Plates, Bars and Stri

Pressed, Sintered, and Forged (1966) $\$ 3.00$

Pressure and High Temperature Service (ASME SA-194 Wit

Pressure Application at High Temperatures, Specificatio

Pressure Boundary Components (12/74) /Tion for Safety

Pressure Boundary Leakage Detection Systems ( $5 / 73$ )

Pressure Boundary Materials and Inservice Inspection (1/

Pressure Chemical Industry Flanges and Threaded Stubs F

Pressure Measurement System, Flush Mounted, Eddy Curren

Pressure Measurements (1974) \$1.75

i Triaxial Compress

Pressure Properties of Lubricating Grease (Four Ball Me

Pressure Sealing Properties of Rubber and Rubber-Like

Pressure Sensitive Electrical Tape (1973) \$1.75

Pressure Service, Specification for (1975) $\$ 1.75$

Pressure Storage Tanks (1973) $\$ 4.00$

Pressure Transmitter for Liquid Metal Service (3-71)

Pressure Transmitter, Pneumatic or Electric Output Sign

Pressure Vessel Code-1977 Edition; Special Price for

Pressure Vessel Code, Section Iii, Subsection NA and NB
ANS1

NRC

ANS1

ANS

USCG

ANSI

ERDA

ASTM

ANSI

NRC

ANS

Ins ERDA

ANSI

ERDA

ERDA

NCRP

ANSI

ANS

ANS

ERDA

ERDA

ANS

ASTM

NRC

NRC

Revised EPA

ANS1

ASTM

ASTM

ANSI

ANS1

ASTM

ASTM

ANS!

Met ANSI

ASTM

ASTM

NRC

NRC

ERDA

NRC

NRC

NRC

NRC

NRC

ERDA

ERDA

NRC

NRC

NRC

ANSI

NRC

NRC

NRC

ASTM

ANSI

ASTM

ASTM

ERDA

ERDA

ASTM

ASTM

ASTM

ANSI

SAE

ERDA

ANSI

NRC

NRC

MSS

ERDA

ASTM

ASTM

ASTM

ASTM

ASTM

ASTM

API

ERDA

ERDA

ASME

ERDA

N41.12

RG 1.32

B 15.1

RG 1.70.36

B56. 1

46CFRSS

R27

A 37.122

RDT C 16-3T

D2908

A262

N 13.2

RG 8.2

STD.

RDT CI-IT

N42.2

RDT C15-3T

RDT CI0-3T

R37

G81.46

G81.45 
Class 2 Nuclear Components (Supplement to ASME Boiler and Class 3 Nuclear Components (Supplement to ASME Boiler and class MC Nuclear Components (Supplement to ASME Boiler and and Brazing Qualifications (Supplement to ASME Boiler and

Nondestructive Examination (Supplement to ASME Boiler and carbon Steel Forgings for Seamless Drums, Heads, and Other el Forgings, Carbon and Alloy, Quenched and Tempered, for

Unfired

um, Specification for (1974A) $\$ 1.75$

ium, 0.5 Percent Molybdenum, Specification for (1972A) A/ nched and Tempered, Specification for (1974A) $\$ 1.75$

num and Manganese-Molybdenum-Nickel, Specification For red, Nickel-Cobalt-Molybdenum-Chromium, Specification/ red, Manganese-Molybdenum and Mangane/ Specification for red Chromium-Molybdenum, Specification for (1974) \$1.75 red, Eight and Nine Percent Nickel (1974)/ Std. Spec. for and Higher-Temperature Service, Specification for (1974/ ower Temperature Service, Specification for (1974A) \$1.7/ on Properties, Specification for (1974A) \$1.75

ate-Tensile Strength, Specification for (1974A) $\$ 1.75$

$\mathrm{n}$, Specification for (1974A) \$1.75

Silicon, Specification for (1975) $\$ 1.75$

$.00)$

Accumulators, Class 2

d $(\$ 65.00), 11(\$ 95.00)$

Thermal Shock to Reactor Std. Spec. for Carbon Steel Sheets for empered Vacuum Treated Carbon and Alloy Steel Forgings for sisting Steel Bars and Shapes for Use in Boilers and Othe Fiberglass-Reinforced Plastic ngitudinal-Wave Ultrasonic Inspection of Steel Plates for s for $(1975) \$ 1.75$ Steel Plates for Molybdenum, Alloy Steel Plates for Copper-Nickel Alloy Plate and Sheet for Steel Plate, Sheet, and Strip for Fusion-Welded Unfired age of Special Nuclear Materials ( $7 / \quad$ Selection and Use of ndard Evaluation of Anticipated Transients Without Trip on Nuclear Safety Criteria for the Design of Stationary ndard Nuclear Safety Criteria for the Design of Stationary or Evaluating the Potential Radiological Consequences of $\mathbf{A}$ on $1,7 / 75$ ) Inservice lnspection of eoperational Testing of Emergency Core Cooling Systems for adiological Consequences of a Loss of Coolant Accident for in the Fuel Handling and Storage Facility for Boiling and

(10-69) Coolant Composition in Steam Generator for

electric Heater and Connector Assembly for Pressurizer for 12-70) ns Used for Evaluating a Control Rod Ejection Accident for Fuel Assemblies for rsedes E5-2T/ Electric Heater and Connector Assembly for rsedes E5-1T, (12-70)

d Tendons (11/74)

1/76) ontainments (11/75)

Information for Safety Analysis Reports: Inservice Inspection of 75) b383-1964\$1.75

f Safety Guide 19) Qualifications for Cement Grouting for
Inspection and Inspection and Design Limits and Loading Combinations for Meta Instrument Lines Penetrating Structural Acceptance Test for Concrete $1(7.70)$ Guard Vessel for

Nuclear Fuel Reprocessing Facilities, Guide to in the Transfer of Special Nuclear Materials, Concepts and (1974) $\$ 3.00$ Limit of Error Concepts and (1.74)

Limit of Error Concepts and Nonmailable Matter: Written, Using the Mass Spectrometer Leak Detector in the Detecto meter Leak Detector or Residual Gas A nalyzer in the Tracer Eddy Current

try-Environmental Application/ Performance, Testing, and lement of Hot Dip Galvanized Structural Steel Products and Standard Test eated Effluent Dispersion in Natural Water Bod/r Reporting
Polyphase Induction Motors and Generators, Test for (1969) $\$ 6.00$

Polyphase lnduction Motors and Generat Welding ure the Delta Ferritic Content of Austenitic St/ Standard levated Temperature (9-74) Supersedes F9/ Guidelines and ntaining Byproduct Material (6/74)

nting and Glossary for Scintillation Count/ Acceptance Sampling ioactive Material (5/75)

es with IEC 333)/ Semiconductor Radiation Detectors, Test Preamplifiers for Semiconductor Radiation Detectors, Tes
Pressure Vessel Code, Section lii, Subsection NA and NC Pressure Vessel Code, Section Iii, Subsections NA and N Pressure Vessel Code, Section Iii, Subsections NA Ne) ( Pressure Vessel Code, Section IX) (8-74) Supersedes F6 Pressure Vessel Code, Section V) (10-75) Supersedes F3 Pressure Vessel Components (1970) ASTM A266-1969\$1.7 Pressure Vessel Components (1973) \$1.75

Pressure Vessel Flange Dimensions (1969) $\$ 4.00$ /Ation for Ste

Pressure Vessel Plates, Alloy Steel, Chromium-Molybden

Pressure Vessel Plates, Alloy Steel, Five Percent Chrom Pressure Vessel Plates, Alloy Steel, High Strength, Que Pressure Vessel Plates, Alloy Steel, Manganese-Molybde Pressure Vessel Plates, Alloy Steel, Quenched and Tempe Pressure Vessel Plates, Alloy Steel, Quenched and Tempe Pressure Vessel Plates, Alloy Steel, Quenched and Tempe Pressure Vessel Plates, Alloy Steel, Quenched and Tempe Pressure Vessel Plates, Carbon Steel for Intermediate-

Pressure Vessel Plates, Carbon Steel for Moderate and L Pressure Vessel Plates, Carbon Steel, Improved Transiti Pressure Vessel Plates, Carbon Steel, Low and Intermedi Pressure Vessel Plates, Carbon Steel, Manganese-Silico

Pressure Vessel Plates, Heat Treated Carbon-Manganese-

Pressure Vessel (3-73)

Pressure Vessels Division 1 (1977) bd (\$65.00), 11 ( $\$ 95$

Pressure Vessels Division 2: Alternative Rules (1977) B

Pressure Vessels (Safety Guide 2, 11/2/70)

Pressure Vessels (1972) ASTM A414-1971 \$1.75

Pressure Vessels (1974A) \$1.75

Pressure Vessels (1975) $\$ 1.75$

Pressure Vessels $(1977)$ bd $(\$ 40.00), 11(\$ 60.00)$

/Ec. for Quenched and $T$

Pressure Vessels, Method and Inspection for (1974A) \$1

Pressure Vessels, Specification for General Requirement

Pressure Vessels, Specification for (1974A) \$1.75

Pressure Vessels, Specification for (1975A) \$1.75

Pressure Vessels, Specification for (1975) $\$ 1.75$

Pressure-Sensitive Seals on Containers for Onsite Stor

Pressurized Water Reactor Plants (lssued for Trial Use

Pressurized Water Reactor Plants (1973) ANS-51.1 \$30.5

Pressurized Water Reactor Plants (1975) $\$ 5.50$

Pressurized Water Reactor Radioactive Gas Storage Tank

Pressurized Water Reactor Steam Generator Tubes (Revisi

Pressurized Water Reactors (Revision 1, 1/75)

Pressurized Water Reactors (Revision 2, 6/74)

Pressurized Water Reactors (Safety Guide 25, 3/23/72)

Pressurized Water Reactors (10/71)

Pressurized Water Reactors (12-71) Supersedes E4-1 T

Pressurized Water Reactors (5-72) Supersedes E5-2T,

Pressurized Water Reactors (5/74)

Pressurized Water Reactors (6-72) Supersedes E5-1T, (

Pressurized Water Reactors (7-71) Amendment 1 (5-72)

Pressurizer for Pressurized Water Reactors (5-72) Supe

Pressurizer for Pressurized Water Reactors (6-72) Supe

Pressurizer Relief Discharge System (6/75)

Prestressed Concrete Containment Structures with Groute Prestressed Concrete Containment Structures (Revision 2

Prestressing Systems for Concrete Reactor Vessels and C

Prestressing Tendons in Containment Structures (11/75)

Preventive Maintenance of Fuel Shipping Containers (1.

Primary Columbium Metal, Specification for (1973) ASTM

Primary Containment Liner Welds (Revision 1, 8/11/72, O

Primary Reactor Containment System Components (6/73)

Primary Reactor Containment (Safety Guide 11,3/10/71

Primary Reactor Containments (Revision 1, 12/28/72)

Primary Sodium Containing Components (11-70) Amendment

Principle Design Criteria for (1973) $\$ 5.00$

Principles for the (1975) $\$ 2.75$

Principles of Calculation in Nuclear Materials Control
Principles of Calculation in Nuclear Materials Control

Printed and Graphic Matter (1975)

Probe Mode (1973) \$1.75

Probe Mode (1973) $\$ 1.75$

Testing for Leaks

Probe Type Flow Sensor for Liquid Metal Service (6-73)

Procedural Specifications for Thermoluminescence Dosime

Procedure for Detecting Embrittlement, Rec. Practice Fo

Procedure for Geiger-Muller Counters (5/73)

Procedure for Mathematical Models Selected to Predict H Procedure for (1964) $\$ 3.80$

Procedures and Welders for Piping and Tubing, Standard

Procedures for Calibrating Magnetic Instruments to Meas

Procedures for Design of Nuclear System Components at E

Procedures for Exempted and Generally Licensed ltems Co

Procedures for Photo-Multipliers for Scintillation Cou

Procedures for Picking Up and Receiving Packages of Rad

Procedures for (1968) (R1974) IEEE Std. 300-1969 (Agre

Procedures for (1969) IEEE Std. 301-1969 (Agrees with
ERDA

ERDA

ERDA

ERDA

ANSI

ASTM

ANSI

ASTM

ANSI

ASTM

ASTM

ANSI

ASTM

ASTM

ASTM

ASTM

ASTM

ASTM

ASTM

ASTM

ASTM

ERDA

ASME

ASME

NRC

ANSI

ASTM

ASTM

ASME

ASTM

A STM

ASTM

ASTM

Nles ASTM

NRC

ANSI

ANS

Sta ANSI

NRC

NRC

Pr NRC

Ntial R NRC

NRC

ERDA

ERDA

ERDA

NRC

ERDA

ERDA

ERDA

ERDA

NRC

NRC

NRC

NRC

NRC

ERDA

ANSI

NRC

NRC

NRC

NRC

ERDA

ANSI

ANSI

ANSI

NRC

USPS

ASTM

ASTM

ERDA

ANS1

NRC

NRC

IEE

AWS

AWS

ERDA

NRC

ANSl

NRC

ANSI

ANSI

ANSI

RDT E15-2C

RDT E15-2D

RDT E15-2E

RDT F6-5T

F3-6

G55.1

A54

B 6.30

A387

G35.16

A5 17

A 302

A 542

A553

A515

A5 16

A442

A 285

A 299

A 537 
Geranium Gamma-Ray Detectors, Test Accountability of Uranium Hexafluoride, Analytical Accountability of Uranium Tetrafluoride, Analytical tions (1961) $\$ 3.00$ a Manual of Radioactivity

mation for Safety Analysis Reports: Missile Barrier Design Recommended Practice for General Ambient Air Analyzer Information for Safety Analysis Reports: Plant General Gas Chromatography
Analysis and Use of rial $(6 / 74)$

74)

al Holdup of Special Nuclear Material in Equipment for Dry Holdup of Special Nuclear Materials in Equipment for Wet Guide for the Preparation of Applications for Licenses to equirements for Fuel Reprocessing Plants and for Plutonium Seismic Design Classification for Plutonium General Fire Protection Guide for Plutonium

d Format and Content of License Applications for Plutonium Monitoring of Combustible Gases and Vapors in Plutonium tings Applied to Fuel Reprocessing Plants and to Plutonium steel for Use in Fuel Reprocessing Plants and in Plutonium accessibility in Fuel Reprocessing Plants and in Plutonium Liquid Waste Treatment System Design Guide for Plutonium General Design Guide for Ventilation Systems of Plutonium ducts for Usc in Fuel Reprocessing Plants and in Plutonium and Radiation Sources Intended for Use in the Production, of Sample Size to Estimate the Average Quality of a Lot or Electronic

tition Seeking an Exemption for a Radionuclide-Containing Guide for Acceptable Waste Storage Methods at Uf6 for the Arts (197/ Safety and Health Stds. on Projects or g. Radiation and Radiation Sources Intended for Use in the ainst Embrittlement of Hot Dip Galvanized Structural Steel

Plates, Bars and Strip, Zinc (Hot Galvanized) Coatings on tonium Processing / Nondestructive Examination of Tubular r Operation, Method For/Delayed Neutron Emitting Fission r Operation, Measureme/ Delayed Neutron-Emitting Fission astm E309-1971 \$/ Eddy-Current Testing of Steel Tubular Nondestructive Examination of Tubular Industrial Laminated Thermosetting apor Transmission of Flexible Heat Sealed Packages for Dry Methods and Definitions for Mechanical Testing of Steel Repurchase, Repairs, or Replacement of Electronic Importation of Electronic

tting Products) for Microwave and Radio Frequency Emitting $\$ 2.95 \quad$ Performance Std. (lonizing Radiation Emitting components/ Performance Std. (lonizing Radiation Emitting oducts (19/ $\quad$ Performance Std. (Ionizing Radiation Emitting Performance Std. (lonizing Radiation Emitting Performance Std. (Ionizing Radiation Emitting Performance Std. (Ionizing Radiation Emitting Performance Stds. for Electronic oviding High Quality Zinc Coatings (Hot-Dip) on Assembled 5 Sponge and Expanded Cellular Rubber Zinc-Coating (Hot-Dip) on Assembled Steel Tantalum Ingots and Flat Mill $\mathrm{g}$ in Research and Training Reactors (5/73) Shield Test Testing Biological Sheilding in Nuclear Power Plants, or Plutonium Processing and Fuel Fabri/ .00 ants (Revision 2, (6/76) guide $28,6 / 7 / 72$ )

172) Quality Assurance Quality Assurance Quality Assurance Quality Assurance Quality Assurance Quality Verification Calibration

dment 2 (3-74), Amendment 3 (7-75), / Quality Assurance oncepts, Models, Equations, and Assumptions for a Bioassay tal Computer Programs (1971) $\$ 7.50$

f Nuclear Power Plants (Revision 1, 2/75)

Preoperational and Initial Startup Test Onsite Meteorological

ng Practices to Facilitate Interchange of Digital Computer Guidelines for the Documentation of Digital Computer Information for Safety Analysis Reports: Initial Test 1 Endowment for the Arts (197/ Safety and Health Stds. on elevated Temperatures (Metal-to-Metal), Meth/ Strength 73) $\$ 1.75$

74) $\$ 1.75$ Test for Fatigue Measurement of (1973) $\$ 1.75$ Measurement of Extreme Pressure Test for Rinsing stm E/ Effects of High Energy Radiation on the Mechanical 62) (/ Effects of High Energy Radiation on the Mechanical .75 ASTM D2187/ Methods of Test for Physical and Chemical
Procedures for (1972) IEEE Std. 325-1971 \$4.00

Procedures for (1972) $\$ 4.50$

Procedures for (1972) $\$ 6.00$

Procedures (A) Stds. (B) Medical and Biological Applica

Procedures (12/74)

Procedures (1973T) $\$ 1.75$

Procedures $(5 / 75)$

Procedures, Recommended Practice for (1973) $\$ 1.75$

Process Data for the Protection of Special Nuclear Mate

Process Offgas Systems for Fuel Reprocessing Plants (2)

Process Operations (1/75)

Process Operations (6/74)

Process Source Material (7/76)

Processing and Fuel Fabrication Plants (Revision 1, 3/7

Processing and Fuel Fabrication Plants (10/73)

Processing and Fuel Fabrication Plants (1/74)

Processing and Fuel Fabrication Plants (1/76)

Processing and Fuel Fabrication Plants (3/73)

Processing and FueI Fabrication Plants (3/74)

Processing and Fuel Fabrication Plants (5/75)

Processing and Fuel Fabrication Plants $(5 / 75)$

Processing and Fuel Fabrication Plants $(6 / 73)$

Processing and Fuel Fabrication Plants $(8 / 73)$

Processing and Fuel Fabrication Plants (8/75)

Processing, and Handling of Food (1975) \$6.75

Process, Practice for (1972) $\$ 1.75$

Product Radiation Control (1968) $\$ 5.15$

/O Support a Rule Making Pe

Product (Revision 1, 6/76)

Production Plants (10/73)

Productions Assisted by Grants from National Endowment

Production, Processing, and Handling of Food (1975) $\$ 6$

Products and Procedure for Detecting Embrittlement, Rec

Products Fabricated from Rolled, Specification for (197

Products for Use in Fuel Reprocessing Plants and in Plu

Products in Nuclear Reactor Coolant Water During Reacto

Products in Nuclear Reactor Coolant Water During Reacto

Products with Magnetic Saturation, Practice for (1973)

Products (10/73)

Products (1971) $\$ 9.50$

Products (1972) $\$ 1.75$

Products (1975A) $\$ 1.75$

Products (1975) $\$ 2.95$

Products (1975) $\$ 2.95$

Products (1975) $\$ 2.95$

Products) for Cabinet X-Ray Systems (1975) $\$ 2.95$

Products) for Cold-Cathode Gas Discharge Tubes (1975)

Products) for Diagnostic X-Ray Systems and Their Major

Products) for Fluoroscopic Equipment (1975) \$2.95

Products) for Microwave and Radio Frequency Emitting Pr

Products) for Radiographic Equipment (1975) \$2.95

Products) for Television Receivers (1975) \$2.95

Products) for X-Ray Baggage Inspection Systems (1975) \$

Products: General (1975) \$2.95

Products, Specification for (R 1973) ASTM A385-1962 \$1.

Products, Specification for (1973) ASTM B364-1970 \$17

Products, Specification for (1973) $\$ 1.75$

Products, Specification for (1974) ASTM A386-1973\$1.7

Products, Spec. for (1970) \$1.75

Program for Evaluation of Installed Biological Shieldin

Program for New Fuel Assembly Designs (6/76)

Program for (1972) ANS-6.3 $\$ 5.00$

Program Requirements for Fuel Reprocessing Plants and F Program Requirements for Nuclear Power Plants (1971) \$4 Program Requirements for the Design of Nuclear Power PI Program Requirements (Design and Construction) (Safety Program Requirements (Operation) (Safety Guide 33, 11/3 Program Requirements (12-74) Supersedes F2-4T, (10-6 Program Requirements (2-73) Supersedes F3-2T, (2-69) Program Requirements (8-73) Amendment 1 (12-73), Amen Program (9/73) Acceptable Programming Practices to Facilitate Interchange of Digi Programs for Monitoring Radioactivity in the Environs Programs for Water Cooled Power Reactors (11/73) Programs (Safety Guide 23, 2/17/72)

Programs (1971) $\$ 7.50$

Programs (1974) ANS $10.3 \$ 8.50$

Recommended Programm

Programs (5/75)

Projects or Productions Assisted by Grants from Nationa Properties of Adhesives in Shear by Tension Loading at Properties of Adhesives in Shear by Tension Loading ( 19 Properties of Lubricating Grease (Four Ball Method) (19 Properties of Lubricating Greases at High Temperatures, Properties of Metal Cleaners (1972) $\$ 1.75$

Properties of Metallic Materials, Practice for (1973) a

Properties of Metallic Materials, Rec. Practice for (19

Properties of Particulate Ion Exchange Resins (1973) \$1

\section{ANSI \\ ANS1 \\ ANS1 N15.6 \\ NRC \\ ASTM \\ NRC \\ N42.8 \\ N15.6 \\ RG 1.70 .16 \\ D 3249 \\ RG 1.70 .31}

ASTM

NRC

NRC

NRC

NRC

NRC

NRC

NRC

NRC

Standar NRC

NRC

Alloy NRC

Imited NRC

NRC

NRC

Lar Pro NRC

Diation FDA

Choice ASTM

USCG

NRC

NRC

FDA

ASTM

ANSI

NRC

ANS

ASTM

NRC

NEMA

ASTM

BRH

BRH
BRH

BRH

BRH

BRH

BRH

BRH

BRH

BRH

BRH

ANS

ANSI

ASTM

ANSI

ASTM

NRC

NRC

ANSI

NRC

ANSI

NRC

NRC

NRC

ERDA

ERDA

ERDA

NRC

ANS

NRC

NRC

NRC
ANS

ANS

NRC

DOL

ANS1

ASTM

ASTM

ASTM

ASTM

ANSI

ASTM

ANSI

E260

RG 5.24

RG 3.20

RG 5.42

RG 5.25

RG 10.4

RG 3.3

RG 3.14

RG 3.16

RG 3.39

RG 3.7

RG 3.21

RG 3.29

RG 3.28

RG 3.10

RG 3.12

RG 3.36 
.75

$\$ 1.75$

ertain Devices to Be Distr/

Tests for Physical and Chemical Test for Evaluating Pressure Sealing Classification of Containment Method of Test for One Dimensional Consolidation Control of Electroslag Weld ent Cladding Including the Determination of the Mechanica ent Cladding Including the Determination of the Mechanical Pressure Vessel Plates, Carbon Steel, Improved Transition ice for Selecting (1974) ACl 211.1-1974 \$2.75 e for (1975) $\$ 9.50$

ce for (1971) ACl $211.2-1969 \$ 2.75$

Selecting (6/73) $0100 \mathrm{MeV}$ (1954) $\$ 2.00$

6)

(1972) $\$ 4.00$

r Materials (11/73)

4)

um Fuel Manufacturing Plants (6/74)

General Use of Locks in the Security Seals for the Additional Information: Fire cooled and Moderated Nuclear Power Generating Plants Fire Basic Radiation Installation of Overpressure (11/75) ance on the License Application, Siting, Design, and Plant nesign and Evaluation (19/ Medical X-Ray and Gamma Ray and Use (1968) $\$ 3.00$ Medical X-Ray and Gamma Ray Flood

ication Plants $(1 / 74)$

General Fire

General Fire

Fire

X-Ray

Radiation

Radiation

Radiation

(1960 and N7.1A-1973\$5.00

specifications of $\mathrm{Ge}$ ( $\mathrm{Li}$ ) Spectroscopy Systems for Material e (Revision 1, 6/73)

s Against an Accidental Chlorine Release (2/75)

ostulated Pipe Ruptu/

Draft Standard for Design Basis for Analysis and Use of Process Data for the Review of the Current State of Radiation

Nuclear Reactors, Recommended Fire

acilities Handling Radioactive Materials, Recommended Fire Background Material for Development of Radiation Background Material for Development of Radiation

Periodic Testing of Fuel Reprocessing Plant

s, Criteria for (1972) IEEE Std. 279-1971 \$4.00

plementary Criteria and Requirements for RDT Reactor Plan on of the Single-Failure Criterion to Nuclear Power Plant Periodic Testing of Electrical Power and Periodic Testing of Nuclear Power Generating Station

ngle Failure Criterion to Nuclear Power Generating Station Additional Information: Radiation 90, and Cs-137 Contamination (1965)

Manual Initiation of
) $\$ 3.00$

er Plants $(6 / 73)$

ts $(6 / 75)$

actor Containm

1974) $\$ 14.00$ p $10-1956) \$ 4.50$

Criticality Safety Controls in Operations Where Shielding

mbled Products, Specification for (R1973) AS'TM A 385-196/ (1975) $\$ 1$. ges) $(1975) /$ 40 Special Construction, Arrangement, and Other Special Construction, Arrangenent, and Other Special Construction, Arrangement, and Other Special Consideration, Arrangement, and Othe Special Construction, Arrangement, and Other

1975) $\$ 2.40$

or Other Da/

es and Supp/ and to Plutonium Pro/

d for Preparation of Design Bases for Systems That Perform Food and Drugs: Subpart A, General

um Bearing Film Thickness, Variable Reluctance Transducer, Practice for Evaluating Performance Characteristics of

Thermal Diffusivity of Carbon and Graphite by a Thermal

Thermal Diffusivity of Carbon and Graphite by a Thermal 1) Amendment I (6-73), Amendment 2 (10-74)

Current

Operation of Fas ck (1972) (ASTM D2845-1969)/ Laboratory Determination of actic/ Ultrasonic Testing by the Reflection Method, Using for Immersed Ultrasonic Testing by Reflection Method Using
Properties of Particulate Ion Exchange Resins (1974) \$1 Properties of Rubber and Rubber-Like Materials (1974) Properties of Sealed Radioactive Sources Contained in C Properties of Soils (1972) (ASTM D2435-1970) \$1.75 Properties (12/28/72)

Properties (1973) ASTM E453-1972 \$1.75 Properties, Rec. Practice for Examination of
Properties, Specification for (1974A) \$1.75

Propcrtions for Normal and Heavy Weight Concrete, Pract Proportions for No-Slump Concrete, Recommended Practic Proportions for Structural Lightweight Concrete, Practi Protected Areas, Vital Areas, and Material Access Areas Protection Against Betatron-Synchrotron Radiation Up T Protection Against Low Trajectory Turbine Missiles (3/7 Protection Against Neutron Radiation (1971) $\$ 5.00$ Protection Against Pipe Whip Inside Containment (5/73) Protection Against Radiation from Brachythreapy Sources Protection and Control of Facilities and Special Nuclea Protection and Control of Special Nuclear Material (1/7 Protection Considerations for Nuclear Power Plants (2/7 Protection Contingency Measures for Uranium and Pluton Protection Criteria For, lssued for Trial Use and Comme Protection Criteria (1971) $\$ 4.00$

Protection Devices (10/73)

Protection for an Independent Spent Fuel Storage Insta Protection for Electric Motors on Motor Operated Valves Protection for Energies Up to $10 \mathrm{MeV}$ Structural Sheildi Protection for Energies Up to $10 \mathrm{Mev}$ : Equipment Design Protection for Nuclear Power Plants (10/75

Protection Guide for Fuel Reprocessing Plants (6/76) Protection Guide for Plutonium Processing and Fuel Fabr Protection Guidelines for Nuclear Power Plants (6/76) Protection in Dental Offices (1970) $\$ 4.00$

Protection in Educational Institutions (1966) \$3.00

Protection in Nuclear Reactor Fuel Fabrication Plants ( Protection in Uranium Mines Operation (1973), Partial R Protection Measurements, Part I: Data Acquisition Syste Protection of Nuclear Plants Against Industrial Sabotag Protection of Nuclear Power Plant Control Room Operator Protection of Nuclear Power Plants Against Effects of P Protection of Special Nuclear Material (6/74)

Protection Philosophy (1975) $\$ 3.00$

Protection Practice for (1974) \$3.50

Protection Practice for (1975) \$2.50

Protection Stds. (1960)

Protection Std. (1961)

Protection System Actuation Functions (Safety Guide 22

Protection System Actuation Functions (6/74)

Protection System Comparator (4-72) Amendment 1 (6-73

Protection System Logic (4-72) Amendment I (6-73)

Protection Systems for Nuclear Power Generating Station

Protection Systems (12-69)

Protection Systems (6/73)

Protection Systems (6/76)

Protection Systems, Criteria for the (1975) $\$ 5.00$

Protection Systems, Trial Use

Protection (Revision 1, 11/74)

Protective Action Guides for Environmental Sr-89, Sr

Protective Actions (10/73)

Protective Coatings Applied to Fuel Reprocessing Plants

Protective Coatings Applied to Nuclear Facilities (1972

Protective Coatings Applied to Water Cooled Nuclear Pow

Protective Coatings (Paints) for Fuel Reprocessing Plan

Protective Coatings (Paints) for Light Water Nuclear Re

Protective Coatings (Paints) for the Nuclear Industry (

Protective Functions in Nuclear Power Generating Statio

Protective Lighting, Practice for (1956) (R1970) (IES R

Protects Personnel (1975) ANS 8.10\$8.00

Providing High Quality Zinc Coatings (Hot-Dip) on Asse

Provisions for Nuclear Cargo Vessels (Ships and Barges)

Provisions for Nuclear Passenger Vessels (Ships and Bar

Provisions for Nuclear Powerplant Components (1975) \$4.

Provisions for Nuclear Tank Vessels (Ships and Barges)

Provisions for Transportation or Storage of Explosives

Provisions for Use of Dangerous Articles as Ships, Stor

Provisions (Definitions) (1975) $\$ 2.95$

Proximity Measurement System (1-76)

Pulse Echo Ultrasonic Testing Systems (1969) ASTM E317

Pulse Method, Method of Test for (1973) ASTM C714-1972

Pulse Method, Test for (1972) \$1.75

Pulse Preamplifiers for Use with Fission Counters (8-7

Pulse Reactors (1975) ANS 14.1 \$7.50

Pulse Velocities and Ultrasonic Elastic Constants of Ro

Pulsed Longitudinal Waves Induced by Direct Contact, Pr

Pulsed Longitudinal Waves (1974) \$1.75

Pump Flywheel Integrity (Revision 1, 8!75) lof / for Nuclear

ASTM

ASTM

NRC

ANSI

NRC

ANS1

ASTM

ASTM

ANSI

$\mathrm{ACI}$

ANSI

NRC

NCRP

NRC

NCR P

NRC

NCRP

NRC

NRC

NRC

NRC

ANSI

NCRP

NRC

NRC

NRC

NCRP

NCRP

NRC

NRC

NRC

NRC

NCRP

NCRP

ANSI

ANSI

NRC

NRC

NRC

ANSI

NRC

NCRP

NFPA

NFPA

EPA

EPA

NRC

NRC

ERDA

ERDA

ANSl

Applicati

NRC

NRC

IEEE

NRC

EPA

NRC

NRC

ANSI

NRC

NRC

ANS1

ANS1

ANSI

ANS1

ANSI

USCG

USCG

USCG

USCG

USCG

USCG

BRH

ERDA

ANSI

ANSI

ASTM

ERDA

ANSI

ANSI

ANSI

Nded Practice ASTM

NRC

D2187

RG 6.4

A37.170

RG 1.34

N 147

E453

A442

A 167.1

211.3

A 164.

RG 5.7

R14

RG 1.115

R38 
Information for Safety Analysis Reports: 1). Amendment 2 (1-74), Amendment 3 (5-1 Electromagnetic Amendment 2 (6-74) Centrifugal Free Surface, Sodium orizontal, Electric Motor Driven, Single Stage Centrifugal Reciprocating Positive Displacemeni tical, Canned or Wet Motor Driven Single Stage Centrifuga! ical, Shaft Sealed, Motor Driven, Single Stage Centrifugal Inservice Testing of emergency Core Cooling and Containment Heat Removal System Performance Test Code for Displacement

Performance Test Code for Centrifugal

73)

(1970) $\$ 3.00$

stm C624-1971\$1.75

s (3/76) Supersedes A 1-5T, 5-73

to Man from Routine Releases of Reactor Effluents General uents from Accidental and Routine Reactor Releases for the Classification of Soils for Engineering Wire-Cloth Sieves for Testing 75 Perforated-Plate Sieves for Testing bration of Refractory Metal Thermocouples Using an Optical or $\$ 10.50$ atories for Mixed Oxide Fuel Analysis (7-73)

atories for Control Rod Absorber Material Analysis (7-7)

lity in Fuel Reprocessing Plants and in Plutonium/

Welder

lants (11/74)

enerating Stations, Guide for (1975) $\$ 5.00$

lants $(3 / 76)$

Information for Safety Analysis Reports: ation, and Testing Personnel (8/73)

ing and Tubing, Standard for (1969) $\$ 6.00$

nvironmental Design of Mechanical and Electrical Equipment

d Inside the Containment of Water Cooled Nuclear Power P/ ed Inside the Containment of Nuclear Power Plants (1/74) tion (1974) $\$ 3.50$

Authorized Nuclear Inservice Inspection, dons in Containment Structures (11/75)

ersonnel for the Construction Phase of Nuclear Power Pla/ vessel Code, Section IX) $(8-74)$ Sup/

Welding and Brazing Welding and Brazing

(R1973) $\$ 1.75$ Training, Equipping, and

Method of Test for Lubricating Additional Information: Information for Safe ty Analysis Reports: clear Facilities (1972) $\$ 3.00$

ssing Plants and for Plutonium Processing and Fuel Fabri/ r Plants (1971) $\$ 4.00$

f Nuclear Power Plants (Revision 2, (6/76)

truction) (Safety Guide 28, 6/7/72)

ety Guide $33,11 / 3 / 72$ )

t 1 (12-73), Amendment 2 (3-74), Amendment 3 (7-75), Requirements for Collection, Storage, and Maintenance of ollection, Storage, and Maintenance of Nuclear Power Plant $\mathrm{ms}$ and Associated Components of Water-Cooled Nuclear Po/ ion, and Testing of Structural Concrete and Structural S/ tion, and Testing of Structural Concrete A/ Supplementary tion, and Testing of Mechanical Equipment and Systems (6) Receiving, Storage, and Handling of Items for Water Coo/ applied to Water Cooled Nuclear Power Plants (6/73)

applied to Fuel Reprocessing Plants and to Plutonium Pro/ r Power Plants (1974) \$5.50

d Testing of Instrumentation and Electric Equipment (Saf) Construction Phase of Nuclear Power Plants, Supplementary

elements (1974) ANS $15.2 \$ 8.50$

, Steam-, and Radioactive-Waste-Containing Components/

E142-1972 \$1.75 Choice of Sample Size to Estimate the Average Controlling Radiographic Inspection Method, Dry Particle Magnetic Inspection Method,
Visual Method,

fuel Elements for Use in Research Reactors (Revision 1, rsedes F2-4T, (10-69)

Specification for (R1973) ASTM A385-196/ Providing High Std. Spec. for Steel, Carbon, Cold Rolled, Commercia Carbon Steel Sheet, Cold Rolled, Drawing Cold Rolled Carbon Steel Sheets, Commercia mediate Tensile Strength Carbon Steel Plates of Structural d Use of (1975) $\$ 5.00$ Shipping Packages for Type A ecial Nuclear Material Licenses of Less Than Critical Mass
Pump Flywheel Integrity (4/75)

Pump for Liquid Metal Service (3-71) Amendment 1 (9-7

Pump with Electrical Drive (5-71) Amendment 1 (2-72)

Pump (2-72) Amendment 1 (5-74)

Pump (3-72) Amendment 1 (5-74

Pump (6-72) Amendment I (5-74)

Pump (7-72) Supersedes E3-3T, (10-70), Amendment I (

Pumps in Nuclear Power Plants (1970) $\$ 2.75$

Pumps (Safety Guide 1, 11/2/70)

Pumps (1962) $\$ 4.00$

Pumps (1965) $\$ 5.00$

Purchase Specifications (7-72) Amendment 1 (1-75)

Purchase Specifications (9-73) Supersedes M13-1T, (4

Purging for Reduction of Hazardous Area Classification

Purity in Boiling Water Reactors (6/73)

Purity of Nuclear Graphite, Method of Test for (1973) a

Purity of Nuclear Graphite, Test for (1971) \$1.75

Purity Requirements for Operating Sodium Reactor System

Purpose Ball Valves (1970) $\$ 4.00$

Purpose of Evaluating Compliance with 10 CFR Part 50, a

Purpose of Implementing Appendix I (5/76)

Purposes (1972) (ASTM D2487-1969) \$1.75

Purposes, Specification for (1973) ASTM E11-1970 \$1.75

Purposes, Specifications for (1973) ASTM E323-1970\$1.

Pyrometer (1973) ASTM E452-1972 \$1.75 /Ethod for Cali

Qualification and Certification, Recommended Practice

Qualification and Control of Analytical Chemistry Labor

Qualification and Control of Analytical Chemistry Labor

Qualification for Areas of Limited Accessibility (12/73

Qualification for Welding in Areas of Limited Accessibi

Qualification of Class 1E Equipment for Nuclear Power P

Qualification of Electric Equipment for Nuclear Power G

Qualification of Electric Equipment for Nuclear Power P

Qualification of Instrumentation and Electrical Equipme

Qualification of Nuclear Power Plant Inspection, Examin

Qualification of Welding Procedures and Welders for Pip

Qualification Tests and A nalyses (2/75)

Qualification Tests of Continuous-Duty Motors Installe

Qualification Tests of Electric Valve Operators Instal!

Qualifications and Duties for Authorized Nuclear Inspec

Qualifications and Duties for (1975) \$3.00

Qualifications for Cement Grouting for Prestressing Ten

Qualifications of Inspection, Examination and Testing $P$

Qualifications (Supplement to ASME Boiler and Pressure

Qualifications (1977) bd ( $\$ 40.00)$, Il $(\$ 55.00)$

Qualifying of Guards and Watchmen (1/74)

Qualities of Graphites (1964) (R1974) ASTM D1367-1964

Quality Assurance During Design and Construction (7/74)

Quality Assurance During Operations Phase (12/74)

Quality Assurance for Protective Coatings Applied to $\mathrm{Nu}$

Quality Assurance Program Requirements for Fuel Reproce

Quality Assurance Program Requirements for Nuclear Powe

Quality Assurance Program Requirements for the Design O

Quality Assurance Program Requirements (Design and Cons

Quality Assurance Program Requirements (Operation) (Saf

Quality Assurance Program Requirements (8-73) Amendmen

Quality Assurance Records for Nuclear Power Plants ( 197

Quality Assurance Records (Revision 1, 12/75)

Quality Assurance Requirements for Cleaning Fluid Syste

Quality Assurance Requirements for Installation Inspect

Quality Assurance Requirements for Installation, Inspec

Quality Assurance Requirements for Installation, Inspec

Quality Assurance Requirements for Packaging, Shipping

Quality Assurance Requirements for Protective Coatings

Quality Assurance Requirements for Protective Coatings

Quality Assurance Requirements for the Design of Nuclea

Quality Assurance Requirements for the Installation, an

Quality Assurance Requirements for (1975) $\$ 4.00$

Quality Assurance Terms and Definitions (1973) $\$ 3.00$

Quality Assurance Terms and Definitions (2/74)

Quality Control for Plate-Type Uranium-Aluminum Fuel

Quality Group Classifications and Standards for Water-

Quality of a Lot or Process, Practice for (1972) \$1.75

Quality of Radiographic Testing, Method for (1973) ASTM

Quality Standard for Steel Castings (1971) $\$ 2.00$

Quality Standard for Steel Castings (1971) $\$ 3.00$

Quality Standard for Steel Castings (1971) $\$ 8.00$

Quality Verification for Plate-Type Uranium-Aluminum

Quality Verification Program Requirements (12-74) Supe

Quality Zinc Coatings (Hot-Dip) on Assembled Products,

Quality (1974) ASTM A366-1972 \$1.75

Quality, Special Killed, Specification for (1975) $\$ 1.75$

Quality, Specification for (1972) $\$ 1.75$

Quality, Specification for (1975) $\$ 1.75$ Low

Quantities (7/76)
ASTM

NRC

ERDA

ERDA

ERDA

ERDA

Ver ERDA

ERDA

ASME

NRC

ASME

ERDA

ERDA

ISA

NRC

ANS1

ASTM

ERDA

MSS

NRC

ANS

ANSI

ANSI

ASNT

ERDA

ERDA

NRC

NRC

EEE

NRC

NRC

NRC

AWS

NRC

NRC

NRC

ANSI

ANS1

NRC

ERDA

ASME

NRC

ANS

NRC

NRC

ANSI

NRC

ANSI

NRC

NRC

NRC

ERDA

ANS1

NRC

NRC

NRC

ANSI

NRC

NRC

NRC

ANSI

NRC

/R the ANSI

ANSI

NRC

ANSI

NRC

ASTM

ANS

MSS

MSS

MSS

ERDA

ANS

ANS

ASTM

NRC

RG 1.70 .30

RDT E3-9T

RDT E3-2T

RDT E3-6T

RDT E3-7T

RDT E3-1T

RDT E3-3T

PTC35

RG 1 .

PTC7.1

PTC8 2

RDT M 14-1T

RDT M13-1T

S1 2.4

RG 1.56

K90.8

RDT A 1-5T

SP-72

RG 1.109

RG 1.113

A 37.173

Z23.

Z168.12

N144

SNT-TC-1A

RDT F2-6T

RDT F2-8T

RG 1.71

RG 3.28

RG 1.89 
n Dosimeter Chargers (1965) (R 1971)/ ASTM A255-1974\$1.75

steel Joints, Specification for (1975) $\$ 1.75$

Interrelationship of

Endon for (1974) $\$ 1.75$

Pressure Vessel Plates, Alloy Steel, teel Forgings for Pressure Vessels ( 1974A/

Std. Spec. for

974)/ Std. Spec. for Pressure Vessel Plates, Alloy Steel,

1971 Specification for Steel Forgings, Carbon and Alloy,

e/ Specification for Pressure Vessel Plates, Alloy Steel, mium, Specification/ Pressure Vessel Plates, Alloy Steel,

Pressure Vessel Plates, Alloy Steel, High Strength, n Only) (8.72) Amendment 1 (4-73)

ment 1 (4-72), Amendment 2 (7-73), Amendment 3 (3/ Core Production, Processing, and / Food Additives, Subpart G. Electronic Product Effects of Residual Elements on Predicted IEEE Std. 300-1969 (Agrees with IEC 333)/ Semiconductor d. 301-1/ Amplifiers and Preamplifiers for Semiconductor Std. Method of Test for Absorbed Gamma of Test for (1973) (ASTM D3/ Absorbed Gamma and Electron Dosimeter, Method of Test F/ Absorbed Gamma and Electron Dosimeter, Test for (1971) Absorbed Gamma and Electron (1975) $\$ 2.95$

harge Tubes (1975) \$2.95

ma and Their Major Components

(1975) $\$ 2.95$

equency Emitting Products (19/

(1975) $\$ 2.95$

1975) $\$ 2.95$

on Systems (1975) $\$ 2.95$

for Maintaining Occupational

Information Relevant to Maintaining Occupational vacuation Signal for Use in Industrial Installations Where Occupational irmation and Redesignation of N2.2-1966) (/ Occupational Instruction Concerning Prenatal Protection Against Guidance for the Control of Natural Background

Administrative Practices in Guide for Administration Practices in rials, Practice for (1973) ASTM E/ Effects of High Energy rials, Rec. Practice for (1962) (/ Effects of High Energy

$\$ 3.00$

n Plants (1963) $\$ 5.50$

Partial Revision of N7.1-1960 and N7.IA-1973\$5.00

Review of the Current State of

Background Material for Development of Background Material for Development of Additional Information: Analysis Equipment (1971) NBS Handbook $111 \$ 3.00$

Materials for Instruments in

Concrete

Concrete

Concrete

rocessing, and / Food Additives, Subpart G. Radiation and

4.40

Portable $X$ or Gamma

Protection Against Betatron-Synchrotron

Background Material for the Development of

Rec. Practice for Calculation of Absorbed Dose from Gamma Protection Against Neutron section 57 Exposure to Radioactive Substances and lonizing of (1973) Constituents of Aggregates for Aggregates for

of (1975) ASTM C638.197/ ASTM C637-1973\$1.75 Constituents of Aggregates for Aggregates for (1973) $\$ 1.71$

Polymeric Materials for Service in lonizing n Vulcanized Rubber During Exposure to High Energy Nuclear ing and Indirect Reading Pocket Dosimeters for X and Gamma (1971) \$1 Exposure of Polymeric Materials to High Energy Exposure of Adhesive Specimens to High Energy

al Reactivity of Inorganic Material Exposed to High Energy Exposure of Polymeric Materials to High Energy Exposure of Adhesive Specimens to High Energy n Vulcanized Rubber During Exposure to High Energy Nuclear (Ionizing Radiation Emitting Products) for Microwave and Method for Measuring Fast Neutron Flux by Fast Neutron Flux by Measuring Neutron Flux Density by Fast Neutron Flux by Methods for Measuring Fast Neutron Flux by Fast Neutron Flux by
Quartz-Fiber Electrometer Type Dosimeters and Companio Quench Test for Hardenability of Steel, Method of (1974 Quenched and Tempered Alloy Steel Bolts for Structura! Quenched and Tempered Chromium-Molybdenum, Specificati Quenched and Tempered Vacuum Treated Carbon and Alloy S Quenched and Tempered, Eight and Nine Percent Nickel ( 1 Quenched and Tempered, for Pressure Vessel Components ( Quenched and Tempered, Manganese-Molybdenum and Mangan Quenched and Tempered, Nickel-Cobalt-Molybdenum-Chro Quenched and Tempered, Specification for (1974A) \$1.75 Radial Reflector for Sodium Cooled Reactors (Fabricatio Radial Shield for Sodium Cooled Reactors (12.71) Amend Radiation and Radiation Sources Intended for Use in the Radiation Control (1968) \$5.15

Radiation Damage to Reactor Vessel Materials (7/75)

Radiation Detectors, Test Procedures for (1968) (R1974)

Radiation Detectors, Test Procedures for (1969) IEEE St Radiation Dose in the Fricke Dosimeter (1972) $\$ 1.75$ Radiation Dose with the Ceric Sulfate Dosimeter, Method Radiation Dose with the Ferrous Sulfate-Cupric Sulfate Radiation Dose with the Ferrous Sulfate-Cupric Sulfate Radiation Emitting Products) for Cabinet X-Ray Systems Radiation Emitting Products) for Cold-Cathode Gas Disc Radiation Emitting Products) for Diagnostic X-Ray Syste Radiation Emitting Products) for Fluoroscopic Equipment Radiation Emitting Products) for Microwave and Radio Fr Radiation Emitting Products) for Radiographic Equipment Radiation Emitting Products) for Television Receivers ( Radiation Emitting Products) for X-Ray Baggage Inspecti Radiation Exposure as Low as Is Reasonably Achievable ( Radiation Exposure as Low as Is Reasonably Achievable ( Radiation Exposure May Occur (1967) \$3.25 Immediate E Radiation Exposure Records Systems (5/73)

Radiation Exposure Records Systems, Practice for (Reaff Radiation Exposure (Revision 1, 11/75)

Radiation from Brachythreapy Sources (1972) $\$ 4.00$

Radiation Hazards in Uranium Mining (1967)

Radiation in the United States (1975) $\$ 5.00$

Radiation in Veterinary Medicine (1970) $\$ 4.00$

Radiation Monitoring (A Guide for Management) ( 1969) \$4

Radiation Monitoring (2/2/73)

Radiation on the Mechanical Properties of Metallic Mate

Radiation on the Mechanical Properties of Metallic Mate Radiation Protection Criteria (1971) \$4.00

Radiation Protection in Educational Institutions (1966)

Radiation Protection in Nuclear Reactor Fuel Fabricatio

Radiation Protection in Uranium Mines Operation (1973),

Radiation Protection Philosophy (1975) $\$ 3.00$

Radiation Protection Stds. (1960)

Radiation Protection Std. (1961)

Radiation Protection (Revision 1, 11/74)

Radiation Safety for X-Ray Diffraction and Fluorescence Radiation Service (1957) \$5.00

Radiation Shields for Nuclear Power Plants (12/73)

Radiation Shields (1972) ANS-1 1.13\$10.00

Radiation Shields (6/73)

Radiation Sources Intended for Use in the Production, P

Radiation Survey Instruments, Specification of (1971)

Radiation Symbol (1969) \$2.75

Radiation Symbol (2/2/73)

Radiation Up to $100 \mathrm{MeV}$ ( 1954) $\$ 2.00$

Radiation (1964)

Radiation (1971) ASTM D2568-1970\$1.75

Radiation (1971) $\$ 5.00$

Radiations (1971) $\$ 6.85$

Radiation-Sheilding Concrete, Descriptive Nomenclature
Radiation-Sheilding Concrete, Spec. for (1973) \$1.75

Radiation-Shielding Concrete, Descriptive Nomenclature

Radiation-Shielding Concrete, Specification for (1975)

Radiation, Classification System for (ASTM D2953-1971)

Radiation, Classification System for (1971) \$1.75

Radiation, Methods of Test for (1971) ASTM D2309.1968

Radiation, Performance, Specification for (1972) $\$ 3.00$

Radiation, Practice for (1968) (R1973) ASTM D1672-1966

Radiation, Practice for (1973) ASTM D1879-1970 \$1.75

Radiation, Rec. Practice for Determining (1962) (R1968)

Radiation, Rec. Practice for (1966) (R1971) \$1.75

Radiation, Rec. Practice for (1970) $\$ 1.75$

Radiation, Testing (1968) (R1974) \$1.75

Radioactivation of Aluminum, Measuring (1970) \$1.75

Radioactivation of Cobalt and Silver (1973T)

Radioactivation of Iron Measuring (1970) \$1.75

Radioactivation of Iron (1973) ASTM E263-1970 \$1.75

Radioactivation of Nickel (1970) $\$ 1.75$
ANSI

ANSI

ASTM

ASTM

ASTM

ASTM

ASTM

ASTM

ANSI

ASTM

ERDA

ERDA

FDA

USCG

ANS

ANS

ASTM

ANS

ANSI

ASTM

BRH

BRH

BRH

BRH

BRH

BRH

BRH

BRH

NRC

NRC

ANSI

NRC

ANS

NRC

NCRP

EPA

NCRP

NCRP

ANS1

NRC

ANSI

ASTM

NCRP

NCRP

ANS1

ANS

NCRP

EPA

EPA

NRC

ANS

ISA

NRC

ANS

NRC

FDA

ANS

ANS

NRC

NCRP

EPA

ANSI

NCRP

DOL

ASTM

ASTM

ANSI

ANSI

ANS

ANSI

ANSI

ASTM

ASTM

ASTM

Set Induced I ASTM Ce Std BRH

BRH
ANS1

ASTM

ASTM

ASTM

ANS1

ASTM

N42.6

490

A542

A508

A553

A541

A533

G35.26

A517

RDT E6-19T

RDT E6-23T

21CFR 121

42CFR 78

RG 1.99

N42.1

N42.2

D1671

K 65.230

K65.229

D2954

2 I CFR 1020F

2 ICFR 1020B

2 ICFR 1020C 
Method for Measuring Fast Neutron Flux by Fast Neutron Flux by Method for Measuring Fast Neutron Flux by Method of Measuring Neutron Flux by Method for Measuring Fast Neutron Flux by $\mathrm{y}$ and Average Energy from $3 \mathrm{H}(\mathrm{D}, \mathrm{N}) 4 \mathrm{He}$ Neutron Generators by d Average Energy from ${ }^{3} \mathrm{H}(d, n)^{4} \mathrm{He}$ Neutron Generators by Neutron Flux by aste Water, Method of Test for (1973) ASTM D2038-1968 \$/ aste Water, Test for (1974) $\$ 1.75$

astm D2577-1969 \$1.75

Leak Testing

Leak Testing

Control and Removal of

I Radiological Consequences of a Pressurized Water Reactor edes M16-1T, (6-72)

Gas Phase Adsorbents for Trapping

aste Water, Methods of Test for (1973) ASTM D2334-1968 / aste Water, Tests for (1973) $\$ 1.75$

3) ASTM D2039-1971 \$1.75

or Obtaining Exemptions from Certain NRC Requirements Over

r Storage Only of Unirradiated Reactor Fuel and Associated Procedures for Picking Up and Receiving Packages of Administrative Guide for Packaging and Transporting rom Light-Water-Cooled Powe/ Calculation of Releases of nd Reporting Radioactivity in Solid Wastes and Releases of 1969) ISO $2889 \$ 7.00$ Sampling Airborne obtaining Department of Transportation Special Permits for Draft Std. for Leakage Tests on Packages for Shipment of Safe Handling of Administrative Guide for Transporting Nonmailable Matter, Mailable Matter Under Special Rules, ng Compliance with Packaging Requirements for Shipments of ) $\$ 5.00$ tice for $(1975) \$ 2.50$ Leakage Tests on Packages for Shipment of Shipping Packages for Type a Quantities of

or Evaluating the Potential Radiological Consequences of $\mathrm{A}$ $n$ of (1975) NBS Handbook $116 \$ 2.00$

ies in a Reprocessing Plant/ Design Objectives for Highly distr/ Classification of Containment Properties of Sealed 6.85 Child Labor Regulations Section 57 Exposure to ASTM D2476-1970 \$1.75

Information for Safety Analysis Reports: $\$ 3.50$ Method of Test of Packaging and Transportation of Packaging and Transportation of up Classifications and Standards for Water-, Steam-, and ce / On-Site Instrumentation for Continuously Monitoring ve Materials in Liq/ Measuring, Evaluating, and Reporting
revision 1,2/75) Programs for Monitoring revision $1,2 / 75$ ) water, Method for Measurement of (1973) ASTM D 1690/Gamma

ASTM D1943-1966 \$1.75

d1890-1966 (1971) \$1.75

ogical Applications (1961) $\$ 3.00$ chemical, Mass Spectrometric, Spectrochemical, Nuclear and Chemical, Mass Spectrometric, Spectrochemical Nuclear and chemical, Mass Spectrometric, Spectrochemical, Nuclear and chemical, Mass Spectrometric, Spectrochemical, Nuclear and chemical, Mass Spectrometric, Spectrochemical, Nuclear and Nuclear Grade Uranyl Nitrate Solutions, Nuclear and el Solutions (1973) ASTM E320-1970 \$1.75

Methods for uel Solutions, Standard Method for (1970) $\$ 1.75$

$219.1969 \$ 1.75 \quad$ Atom Percent Fission in Uranium Fuel 4) $\$ 1.75$ Atom Percent Fission in Uranium Fuel chemical, Mass Spectrometric, Spectrochemical, Nuclear and erformance Std. (Ionizing Radiation Emitting Products) for eel Castings (1971) $\$ 2.00$

$\$ 1.75$

Controlling Quality of

stings (1974) ASTM E186-1973 \$1.75 astings (1973) ASTM E280-1972 \$1.75 $969 \$ 1.75$

973) $\$ 3.00$

Reference Reference Steel Castings Up to 2 Inches in Thickness, Reference
Radioactivation of Nickel (1973) ASTM E264-1970 \$1.75 Radioactivation of Nickel, Measuring (1970) $\$ 1.75$ Radioactivation of Sulfur (1973) ASTM E265-1970 \$1.75 Radioactivation Techniques (1973) ASTM E261-1970 \$1.75 Radioactivation Techniques (1973) ASTM E262-70 \$1.75 Radioactivation Techniques (1974) ASTM E496-1973 \$1.75 Radioactivation Techniques, Measuring (1970) $\$ 1.75$

Radioactivation Techniques, Test for (1973) $\$ 1.75$

Radioactivation (1970) \$1.75

Radioactive Barium in Industrial $W$ ater and Industrial $W$ Radioactive Barium in Industrial Water and Industrial W Radioactive Brachytherapy Sources (Revision 1, 7/74)

Radioactive Brachytherapy Sources (1973) $\$ 3.50$

Radioactive Cesium in Water, Method of Test for (1973)

Radioactive Cesium in Water, Test for (1972) \$1.75

Radioactive Contamination in Laboratories (1951) $\$ 2.00$

Radioactive Gas Compressors (8-73)

Radioactive Gas Storage Tank Failure (Safety Guide 24,

Radioactive Iodine and Iodine Compounds (10-73) Supers

Radioactive Iodine in Industrial Water and Industrial W

Radioactive Iodine in Industrial Water and Industrial W

Radioactive Manganese in Water, Method of Test for (197

Radioactive Manganese in Water, Test for (1974) \$1.75

Radioactive Material Shipments (6/75)

Radioactive Material (10/73)

Radioactive Material ( $5 / 75$ )

Radioactive Material (6/74)

Radioactive Materials in Gaseous and Liquid Effluents $F$

Radioactive Materials in Liquid and Gaseous Effluents F

Radioactive Materials in Nuclear Facilities, Guide to (

Radioactive Materials Shipments, Administrative Guide F

Radioactive Materials (Issued for Trial Use and Comment

Radioactive Materials (1964) $\$ 2.00$

Radioactive Materials (1973) $\$ 4.50$

Radioactive Materials (1975)

Radioactive Materials (1975)

Radioactive Materials (1975) $\$ 4.50$

Radioactive Materials (6/75)

Radioactive Materials, Guide to Design and Use of (1975

Radioactive Materials, Recommended Fire Protection Prac

Radioactive Matter (1971) Free

Radioactive Nickel in Water (1974T) $\$ 1.75$

Radioactive Offgas System Failure in a Boiling Water $\mathrm{Re}$

Radioactive Self-Luminous Light Sources, Classificatio

Radioactive Solid Material Handling and Storage Facilit

Radioactive Sources Contained in Certain Devices to Be

Radioactive Substances and lonizing Radiations (1971) \$

Radioactive Tritium in Water, Method of Test for (1973)

Radioactive Waste Categories, Definition of (1967) $\$ 3.0$

Radioactive Waste Disposal in the Ocean (1954) $\$ 2.00$

Radioactive Waste Management (4/75)

Radioactive Zirconium in Water (1973T) $\$ 1.75$

Radioactively Contaminated Biological Materials (1973)

Radioactively Contaminated Biological Materials (6/74)

Radioactive-Waste-Containing Components of Nuclear Po

Radioactivity in Effluents, Specification and Performan

Radioactivity in Solid Wastes and Releases of Radioacti

Radioactivity in the Environs of Nuclear Power Plants

Radioactivity of Industrial Water and Industrial Waste

Radioactivity of Water (1973) $\$ 1.75$

Radioactivity of Water, Method of Measurement of (1973)

Radioactivity of Water, Method of Test for (1973) ASTM

Radioactivity of Water, Test for (1966) (R1971) \$1.75

Radioactivity of Water, Test for (1966) (R 1971) \$1.75

Radioactivity Procedures (A) Stds. (B) Medical and Biol

Radiochemical Analysis of Nuclear Grade Plutonium Meta

Radiochemical Analysis of Nuclear Grade Plutonium Nitra

Radiochemical Analysis of Nuclear (Revision 1, 5/75)

Radiochemical Analysis of Uranium Hexafluoride, Methods

Radiochemical Analysis of (1973) $\$ 1.75$

Radiochemical Analysis of (1975) $\$ 1.75$

Radiochemical Determination of Cesium-137 in Nuclear F

Radiochemical Determination of Cesium-137 in Nuclear F

(Radiochemical Method), Method of Test for (1973) ASTM E

Radiochemical Method), Standard Method of Test for (197

Radiochemical, Analysis of (1975) $\$ 1.75$

Radiographic Equipment (1975) \$2.95

Radiographic Inspection Method, Quality Standard for St

Radiographic Testing, Method for (1973) ASTM E142-1972

Radiographic Testing, Practice for (1974) \$1.75

Radiographs for Heavy Walled ( 2 to $4-1 / 2$ in.) Steel Ca

Radiographs for Heavy Walled (4-1/2 to 12 in.) Steel C

Radiographs for Steel Fusion Welds (1973) ASTM E390-1

Radiographs for (1973) $\$ 1.75$

Radioiodine Uptake Measurements Using a Neck Phantom (1

Radioisotopes (1973) ASTM E181-1962 \$1.75
ANSI

ASTM

ANSI

ANS1

ANSI

ANSI

ASTM

I an ASTM

ASTM

ANSI

ASTM

NRC

ANSI

ANSI

ASTM

NCRP

ERDA

NRC

ERDA

ANSI

ASTM

ANSI

ASTM

NRC

NRC

NRC

NRC

NRC

NRC

ANSI

ANSI

ANSI

NCRP

ANSI

USPS

USPS

ANSI

NRC

NFPA

USPS

ASTM

NRC

ANSI

ANSI

NRC

DOI

ANSI

ANSI

NCRP

NRC

ASTM

ANSI

NRC

NRC

ANSI

NRC

ANSI

ASTM

ANS

ANS

ASTM

ASTM

NCRP

ANSI

ASTM

NRC

ANSI

ASTM

ASTM

ANSI

ASTM

ANSI

ASTM

ASTM

BRH

MSS

ANSI

ASTM

ANSI

ANSI

ANS

ASTM

ANS

ANSI

N1 12

E264

N113

N109

N110

N580

E262

N155

D2038

RG 6

D2577

R8

RDT E3-12T

RG 1.24

RDT M 16-1T

N159

D2334

N156

D2039

RG 7.5

RG 3.15

RG 7.3

RG 7.1

RG 1.112

RG 1.21

N13.1

N14.10.2

N14.5

R30

N14.10.1 
Applications (3/74)

$n$ the Fuel/

for Boili/

for Press/

$r$ Radioact/

m Failure

t for Boil/

lear Attack

$\$ 2.00$

icle Accelerators (1969) NBS Handbook $107 \$ 3.00$

ble Body Burdens and Maximum Permissible Concentrations of Milk $(9 / 73)$

of Plutonium in Soil (5/74)

ontium-90 Analyses (5/74)

973) ASTM D2460-1970 \$1.75

Measurements of Measurements of

Measurements of

ement of Patients Who Have Received Therapeutic Amounts of Support a Rule Making Petition Seeking an Exemption for A $1970 \$ 1.75$

r Reactors $(3 / 76)$

Radionuclides of

Radionuclides of

$\$ 3.00$ Cost-Benefit Analysis for

Floor and Wall Openings ture-Density Relations of Soils, Using $5.5-1 \mathrm{~b} .(2.5-\mathrm{kg}$ ) Moisture Density Relations of Soils Using $10 \mathrm{lb} .(4.5 \mathrm{mg}$ Logarithmic Count Rate Source Logarithmic Mean Square Voltage (MSV) Intermediate Direct Current Powe

1)

sile Material (1971) ANS-8.3/

sile Material (1/73)

Use of Borosilicate-Glass determination of (1975) ANS 19.3\$7.50 Neutron Reaction tors (197I) ANS-7.60\$7.50 $\$ 1.75$

Meth/

Measuring Flow $-1971 \$ 4.00$ ilding Design and Evaluation (19/ ign and Use (1968) $\$ 3.00$ Standard for Installations Using Nonmedical Sealed Gamma. Installations Using Non-Medical X-Ray and Sealed Gamma Nondestructive Uranium-235 Enrichment Assay by Gammaive Assay of High Enrichment Uranium Fuel Plates by Gammaorbed Dose of Neutrons, and Mixtures of Neutrons and Gamma of Test for Reliability of Glass Coatings on Glassed Steel eactors, Determination of (1975) ANS $19.3 \$ 7.50 \quad$ Neutron est for (1973) ASTM C289-1971 \$1.75

ar Method), Test for (1971) $\$ 1.75$

Radiation, Rec. Practice for Determ/

Potential Neutron Reaction Rate Distributions and

stm E195-1968) $\$ 1.75$

$2)$, Amendment 2 (1-74)

Chemical Analysis of

Chemical Analysis of FFTF Closed Loop in Protective Coatings (Paints) for Light Water Nuclear ndment 2 (/ Electrical Penetration Assemblies for Nuclear

Design Limits and Loading Combinations for Metal Primary instrument Lines Penetrating Primary Structural Acceptance Test for Concrete Primary tion for Safety Analysis Reports: Code Cases Applicable to tems (5/73)

e Inspection ( $1 /$

Information for Safety Analysis Reports:

me/

Inspection Requirements for Materials Used in Delayed Neutron-Emitting Fission Products in Nuclear Delayed Neutron Emitting Fission Products in Nuclear Welding of Nuclear Data Sets for alculation of Annual Doses to Man from Routine Releases of service Inspection System and Associated Equipment for the $t$ of License Applications for Storage Only of Unirradiated Shielded Shipping Cask for Spen Radiation Protection in Nuclea Information for Safety Analysis Reports: Isolation Valve Leakage Control Systems for Boiling Water g Fission Products in Nuclear Reactor Coolant Water During g Fission Products in Nuclear Reactor Coolant Water During Supplementary Criteria and Requirements for RD f Anticipated Transients Without Trip on Pressurized Water ty Criteria for the Design of Stationary Pressurized Water ty Criteria for the Design of Stationary Pressurized Water

safety Criteria for the Design of Stationary Boiling Water ting of Feedwater and Condensate Systems for Boiling Water
Radioisotopes, Analysis of (1962) (R1968) \$1.75

Radioisotopic Power Generators for Certain Land and Sea

Radiological Consequences of a Fuel Handling Accident I Radiological Consequences of a Loss of Coolant Accident Radiological Consequences of a Loss of Coolant Accident Radiological Consequences of a Pressurized Water Reacto Radiological Consequences of a Radioactive Offgas Syste Radiological Consequences of a Steam Line Break Acciden Radiological Factors Affecting Decision Making in a Nuc Radiological Monitoring Methods and Instruments (1952) Radiological Safety in the Design and Operation of Part

Radionuclides in Air and in Water for Occupational Expo Radionuclides in the Environment-Analysis of I-131 in Radionuclides in the Environment: Sampling and Analysis Radionuclides in the Environment: Strontium.89 and Str Radionuclides of Radium in Water, Method of Test for ( 1 Radionuclides of Radium in Water, Test for (1970) $\$ 1.75$ Radionuclides (1970) $\$ 4.00 \quad$ Precautions in Radium in Water, Method of Test for (1973) ASTM D2460Radium in Water, Test for (1970) \$1.75

Radwaste Systems for Light-Water-Cooled Nuclear Powe Rail Express Carriers Regulations (1975) $\$ 6.80$ Rail Freight Carriers Regulations (1975) \$6.80

Railings and Toeboards, Safety Requirements for (1973)

Rammer and 12-in. (304.8-mm) Drop, Tests for (1970) \$ Rammer and $18(457 \mathrm{~mm})$ in. Drop (1970) \$1.7

Range Neutron Flux Monitoring System (7-71)

Range Neutron Flux Monitoring System (7-71)

Range Neutron Flux Monitoring System (7-71)

Range (10 Decade) Neutron Flux Monitoring Channel (2-7

Raschig Rings as a Neutron Absorber in Solutions of Fis

Raschig Rings as a Neutron Absorber in Solutions of Fis

Rate Distributions and Reactivity of Nuclear Reactors,

Rate Source Range Neutron Flux Monitoring System (7-71

Rate Testing of Containment Structures for Nuclear Reac

Rates of Thermoplastics by Extrusion Plastometer (1973)

Ratio in Compression of Cylindrical Concrete Specimens,

Raw or Calcined Natural Pozzolans for Use in Portland C

Ray Brachytherapy Sources (1974) \$3.00

Ray Detectors, Test Procedures for (1972) IEEE Std. 325

Ray Protection for Energies Up to $10 \mathrm{MeV}$ Structural She

Ray Protection for Energies Up to $10 \mathrm{Mev}$ : Equipment Des

Ray Sources (6/74)

Ray Sources, Energies Up to 10-Mev, General Safety Sta

Ray Spectrometry $(4 / 74)$

Ray Spectrometry $(9 / 74)$

Rays (1961) $\$ 2.00$

Nondestruct

Reaction Equipment by High Voltage ASTM C537.72 (1973)

Reaction Rate Distributions and Reactivity of Nuclear R

Reactivity of Aggregates (Chemical Method), Method of T

Reactivity of Cement-Aggregate Combinations (Mortar-B

Reactivity of Inorganic Material Exposed to High Energy

Reactivity of Nuclear Reactors, Determination of (1975)

Reactor and Commercial Columbium (1974) \$1.75

Reactor and Commercial Columbium, Methods for (1973) (A

Reactor Assembly Fabrication (12-71) Amendment 1 (5-7

Reactor Containment Facilities (1972) $\$ 3.00$

Reactor Containment Structures Amendment 1 (4-72), Ame

Reactor Containment System Components (6/73)

Reactor Containment (Safety Guide 11, 3/10/71

Reactor Containments (Revision 1, 12/28/72)

Reactor Coolant Pressure Boundary Components (12/74)

Reactor Coolant Pressure Boundary Leakage Detection Sys

Reactor Coolant Pressure Boundary Materials and Inservic

Reactor Coolant Pump Flywheel Integrity (Revision 1, 8/

Reactor Coolant System Wear Applications (10-67)

Reactor Coolant Water During Reactor Operation, Measure

Reactor Coolant Water During Reactor Operation, Method

Reactor Core Components and Test Assemblies (7-73)

Reactor Design Calculations (1975) ANS-19.1\$12.50

Reactor Effluents for the Purpose of Evaluating Complia

Reactor Enclosure System (7-73)

Reactor Fuel and Associated Radioactive Material (10/73

Reactor Fuel Elements (8-73) Amendment 1 (1I-73)

Reactor Fuel Fabrication Plants (1963) $\$ 5.50$

Reactor Materials (12/74)

Reactor Nuclear Power Plants (Revision 1, (6/76)

Reactor Operation, Measurement of (1970) \$1.75

Reactor Operation, Method for Measurement of (1973) Ast

Reactor Plant Protection Systems (12-69)

Reactor Plants (Issued for Trial Use and Comment) $\$ 10.0$

Nuclear Safe

Reactor Plants (1975) \$5.50

Reactor Plants: Issued for Trial Use and Comment ANS 52

Standard Nuclear Safe
Comment ANS 52

/ and Initial Startup Tes NRC

ASTM

NRC

NRC

NRC

NRC

NRC

NRC

NRC

NCRP

NCRP

ANSI

NCRP

NRC

NRC

NRC

ANSI

ASTM

IO

NRC

ANSI

ASTM

NRC

DOT

ANSI

ASTM

ASTM

ERDA

ERDA

ERDA

ERDA

ANS

NRC

ANSI

ERDA

ANSI

ASTM

ANS1

ANSI

NCRP

ANSI

NCRP

NCRP

NRC

ANSI

NRC

NRC
NCRP

ANSI

ANSI

ANSI

ASTM

ASTM

ANSI

ASTM

ANSI

ERDA

ANSI

ERDA

NRC

NRC

NRC

NRC

NRC

NRC

NRC

ERDA

ASTM

ANSI

ERDA

ANSI

NRC

Reactor Power Plants (12/75)

E181

RG 6.3

RG 1.25

RG 1.3

RG 1.4

RG 1.24

RG 1.98

RG 1.5

R42

R 10

N43.1

R22

RG 4.3

RG 4.5

RG 4.6

Ni61

D2460

R37

RG 6.7

N1 61

D2460

RG 1.110

49CFR 175

49CFR 174

A 12 . 1

D698

D 1557

RDT C 15.10

RDT C15.6T

RDT C15-8T

RDT C15-2T

N16.4

RG 3 .

N412

RDT C $15-10$ 
Thermal Shock to potential Radiological Consequences of a Pressurized Wate dment 1 (9-73), Amendment 2 (6-74) Floor Valve, quatic Dispersion of Effluents from Accidental and Routine Inservice Inspection of Pressurized Water Purity Requirements for Operating Sodium dium (8-74) Test Vehicles for Transient

edes (10-72), Amendment 1 (12-74) Materials and Inspection for

Shield Plug and Closure Cap for Penetrations LMFBR ects of Residual Elements on Predicted Radiation Damage to $(\$ 100.00)$ Code for Concrete Practice for Surveillance Tests for Nuclear Guide for in Service Annealing of Water Cooled Nuclea ded Guide for in Service Annealing of Water Cooled Nuclea Information for Safety Analysis Reports: Surveillance Tests for Nuclear Information for Safety Analysis Reports: of a Radioactive Offgas System Failure in a Boiling Wate ent 2 (3-74) Instrument Tree for Sodium Cooled

), Amendment 2 / Core Support Structure for Sodium Cooled

) Core Restraint Mechanism for Sodium Cooled Core Radial Reflector for Sodium Cooled ng of Emergency Core Cooling Systems for Pressurized Wate -Type Uranium-Aluminum Fuel Elements for Use in Research uences of a Loss of Coolant Accident for Pressurized Wate nsequences of a Loss of Coolant Accident for Boiling Wate

ing and Storage Facility for Boiling and Pressurized Water sequences of a Steam Line Break Accident for Boiling Wate onstruction of Class 1 Components in Elevated-Temperature Coolant Composition in Pressurized Water nt of Technical Specifications for Experiments in Research I and Initial Startup Test Programs for Water Cooled Powe 73), Amendment 3 (3/ Core Radial Shield for Sodium Cooled Steam Generator for Pressurized Water of Fuel Assemblies for Light-Water-Cooled Nuclear Powe eakage-Rate Testing of Containment Structures for Nuclea Records and Reports for Research Operation of Fast Pulse

ty Safety in Operations with Fissionable Materials Outside ty Safety in Operations with Fissionable Materials Outside Simulated Core Assemblies for Nuclea

r Radwaste Systems for Light-Water-Cooled Nuclear Power us Effluents in Routine Releases from Light-Water-Cooled

Fabrication of Control Rod Driveline for Sodium Cooled seous and Liquid Effluents from Light-Water-Cooled Powe d Connector Assembly for Pressurizer for Pressurized Wate Control Rod Absorber Pin for Liquid Metal Fast 1 (12-73), / Control Rod Assembly for Liquid Metal Fas of Installed Biological Shielding in Research and Training ting a Control Rod Ejection Accident for Pressurized Wate Pressurizer for Pressurized Water Maintenance of Water Purity in Boiling Water Termination of Operating Licenses for Nuclea Fuel Assemblies for Pressurized Water Review of Experiments for Research

exposure as Low as is Reasonably Achievable (Nuclear Powe tron Reaction Rate Distributions and Reactivity of Nuclear 1974) ANS-15.1 \$12.00

3.50

4) $\$ 3.50$

Research

50

d Gamma Radiation, Perfor 3)

rformance, Specification For/

Direct

Direct-

Materials, Concepts /

Direct Reading and Indirect

Direct-Reading and Indirect-

Materials $(6 / 74)$ Statistical Evaluation of ShipperEvaluation of Shipperstd. (Ionizing Radiation Emitting Products) for Television

Procedures for Picking Up and

wer Plants (During the Construction/ Packaging, Shipping, Quality Assurance Requirements for Packaging, Shipping, ent $1(5-74)$

) $\$ 2.00$

d lodine-131 for Medical Use (1951) $\$ 2.00$

ol (1971) $\$ 3.25$

$.3 \$ 8.50$

Food and Drugs:

Collection, Storage, and Maintenance of Ouality Assurance Occupational Radiation Exposure Occupational Radiation Exposure gnation of N2.2-1966) (/ and Maintenance of Nuclear Power Plant Quality Assurance Socket-Welding Instrument Purging for Test for Oxidation-
Reactor Pressure Vessels (Safety Guide 2, 11/2/70)

Reactor Radioactive Gas Storage Tank Failure (Safety Gu Reactor Refueling and Maintenance for LMFBR(6-72) Amen

Reactor Releases for the Purpose of Implementing Append

Reactor Steam Generator Tubes (Revision 1, 7/75)

Reactor Systems (3/76) Supersedes A l-5 T, 5-73

Reactor Test Facility (Treat) Experiments Containing So

Reactor Vessel Closure Studs (10/73)

Reactor Vessel for Liquid Metal Service (12-73) Supers

Reactor Vessel Head (4-73) Amendment 1 (1-74)

Reactor Vessel Materials (7/75)

Reactor Vessels and Containments (11/75)

Reactor Vessels and Containments (1977) bd (\$75.00), Il

Reactor Vessels (1973) ASTM E185-1970 \$1.75

Reactor Vessels (1974) ASTM E509-74 \$1.75

Reactor Vessels (1974) $\$ 1.75$

Reactor Vessels (1975)

Reactor Vessels, Rec. Practice for (1973) \$1.75

Reactor Water Cleanup System (5/75)

Reactor (3/76) /He Potential Radiological Consequences Reactors (Fabrication Only) Amendment 1 (8-73), Amendm

Reactors (Fabrication Only) (1-72) Amendment 1 (12-72

Reactors (Fabrication Only) (10-72) Amendment 1 (3-74

Reactors (Fabrication Only) (8-72) Amendment 1 (4-73)

Reactors (Revision 1, 1/75)

Reactors (Revision 1, 7/76)

Preoperational Testi

Reactors (Revision 2,6/74)

Ty Verification for Plate

Reactors (Revision 2, 6/74)

Reactors (Safety Guide 25, 3/23/72)

Reactors (Safety Guide 5, 3/10/71)

Nial Radiological Conseq NRC

Potential Radiological Co NRC

/in the Fuel Handl NRC

L Radiological Con NRC

Reactors (Supplement to ASME Section IIl Code Cases 159

Reactors (10/71)

Reactors (11/73)

Reactors (11/73)

Developme

Reactors (12-71) Amendment 1 (4-72), Amendment 2 (7-

Reactors (12-71) Supersedes E4-1T, (10-69)

Reactors (12/20/72)

Reactors (197I) ANS-7.60\$7.50

Reactors (1974) ANS 15.3\$8.50

Reactors (1975) ANS 14.1 \$7.50

Reactors (1975) ANS-8.1 $\$ 10.00$

Reactors (1/73)

Reactors (3-73) Amendment 1 (12-74)

Reactors (3/76)

Reactors (3/76) /Ric Transp
Reactors (4-73) Amendment 1 (3-74

Cost-Benefit Analysis Fo

Serial Numbering

Reactors (4/76)

Reactors (5-72) Supersedes E5-2T (12-70)

Reactors (5-73) Supersedes E6-25T, (11-71

Reactors (5-73) Supersedes E6-33T, (11-71) Amendmen

Reactors $(5 / 73)$

Reactors (5/74)

Reactors (6-72) Shield Test Program for Evaluation
Assumptions Used for Evalua

Reactors $(6 / 73)$

Reactors (6/74)

Reactors (7-71) Amendment 1 (5-72)

Reactors (7/76)

Reactors) (Revision 1, 9/75)

/ Occupational Radiation

(1975) ANS $19.3 \$ 7.50$

Reactors, Nuclear Material Control Syecifications for (

Reactors, Recommended Fire Protection Practice for (197

Reactors, Review of Experiments for (1974) ANS 15.6 \$8.

Reading and Indirect Reading Pocket Dosimeters for $\mathrm{X}$ an

Reading and Indirect-Reading Pocket Dosimeters (2/26/7

Reading Pocket Dosimeters for $\mathrm{X}$ and Gamma Radiation, $\mathrm{Pe}$

Reading Pocket Dosimeters (2/26/73)

Receiver Differences in the Transfer of Special Nuclear

Receiver Differences in the Transfer of Special Nuclear

Receivers (1975) $\$ 2.95$

Receiving Packages of Radioactive Material (5/75)

Performance

Receiving Storage and Handling of Items for Nuclear Po

Receiving, Storage, and Handling of Items for Water Coo

Reciprocating Positive Displacement Pump (3-72) Amendm

Recommendations for Disposal of Carbon-14 Wastes (1953

Recommendations for Waste Disposal of Phosphorus-32 an

Records and Reporting Units for Nuclear Materials Cont

Records and Reports for Research Reactors (1974) ANS 15

Records and Reports (1975) $\$ 2.95$

Records for Nuclear Power Plants (1974) $\$ 4.00$

Records Systems (5/73)

Records Systems, Practice for (Reaffirmation and Redesi

Records (Revision 1, 12/75)

Reducer Inserts (1974) \$4.00

Reduction of Hazardous Area Classification (1970) \$3.00

Reduction Potential of Water (1970) $\$ 1.75$
NRC

ERDA

NRC

ERDA

ERDA

NRC

ERDA

NRC

ASME

ANSI

ANSI

ASTM

ASTM

NRC

NRC

ERDA

ERDA

ERDA

NRC

NRC

ERDA

NRC

NRC

ERDA

NRC

ANSI

ANSI

ANSI

ANS

NRC
ERDA

NRC

NRC

ERDA

NRC

ERDA

ERDA

ERDA

NRC

ERDA

NRC

NRC

ERDA

NRC

NRC

ANSI

ANSI

NFPA

ANSI

ANS

NRC

ANSI

ANS

NRC

BRH

NRC

ANS

NRC

ERDA

NCR P

NCRP

ANSI

ANSI

BRH

NRC

ANSI

NRC

MSS

ISA

ASTM

RG 1.2

RG 1.24

RDT E1-36T

RG 1.113

RG 1.83

RDT A I-5T

RDT E16-1T

RG 1.65

RDT E2-3T

RDT E2-4T

RG 1.99

RG 1.103

SEC-III/2

N 146

N577

E509

RG 1.70.21

E185

RG 1.70 .32

RG 1.98

RDT E6-18T

RDT E6-13T

RDT E6-17T 
eir Distribution Systems (Safety Gu/

Independence Between

Recommended Practice for Fabrication and Control of Steel Electrical and Electronics Parts and Equipment,

1971) $\$ 1.75$

$3 \$ 1.1$

Magnetic Particle Indications on Ferrous Castings,

Steel Castings (1974) ASTM E186-1973 \$1.75

.) Steel Castings (1973) ASTM E280-1972\$1.75

m E390-1969 \$1.75

Steel Castings Up to 2 Inches in Thickness,

NMR) Spectroscopy, Definitions, Symbols, Conventions, and Recommended Practice for Immersed Ultrasonic Testing by ced by Direct Contact, Practic/ erating at Temperatures Above/ erating at Temperatures /

Ultrasonic Testing by the Practice for Prefabricated (8-72) Amendment 1 (4-73)

Core Radial Fast Flux Test Facility Driver Fuel Pin mpounds in Chlorinated Aromatic Hydrocarbons (Askarels) by er (1973) ASTM E452-1972 \$1.7/ Method for Calibration of (9-73), Amendment 2 (6-74)

262-1973), Including Draft Sup es and lonizing Radiations (1971) \$6.85

ation of Reporting Requirements for Persons Subject Labor General Information and Shippers

Rail Freight Carriers Rail Express Carriers Highway w of Operating License App/ Information Needed by the Aec s $(12 / 73)$

72) $\mathrm{ACl} 318 \cdot 1971$, lncluding Supp. A89.1A-1975 $\$ 13.50$

$11(\$ 60.00) \quad$ Fiberglassion for Deformed and Plain Billet-Steel Bars for Concrete vision $1,12 / 28 / 72$ )

ision $1,1 / 2 / 73$ Safety $G$ / Testing of

(Revision 1, 6/73)

Mechanical (Cadweld) Splices in Criteria for Safetynt 2 (7-) Hoisting and Rigging of Critical Components and led and Moderated Nuclear Power Ge/ Draft Standard Safety $\$ 3.00 \quad$ Self Operated and Power Operated Safety 71) Method of Test for Moisture-Penetration Resistance (457 mm) I/ Standard Methods of Test for Moisture Density 12-in. (304.8-mm) Drop, Tests for (/

Rockwe/ Standard Hardness Conversion Tables for Metals Axial Load (1974) $\$ 1.75$

49-1969) $\$ 1.75$

1.75

Test for Load Settlement Test for

stm D $13901968 \$ 1.75$

Testing Adhesive

Plant Control Room During a Postulated Hazardous Chemical ispersion of Effluents from Accidental and Routine Reactor c Transport and Dispersion of Gaseous Effluents in Routine

Effluents from Light-Water-Cooled Powe/ Calculation of valuating and Reporting Radioactivity in Solid Wastes and ting Com/ Calculation of Annual Doses to Man from Routine as Low as Is Reasonably Achievable (Nuclear/ Information rmocouples, Sheathed, Type K for Nuclear or for Other High mocouples, Sheathed, Type K, for Nuclear or for Other High

Equipment by High Voltage ASTM C537-/. Method of Test for Information for Safety Analysis Reports: Pressurize 76) Liquid Sodium Bearing Film Thickness, Variable (1972) $\$ 1.75$

ncy Testing of Air Cleaning Systems Containing Devices for 951) $\$ 2.00$ ncy Testing of Air Cleaning Systems Containing Devices for $(12-70)$

Forced Circulation Cold Trap Assembly for Analysis of Solvent Systems Used for ction Head for Emergency Core Cooling and Containment Heat 2.95

ng Performance of Anion Exchange Materials for Strong Acid Repurchase, Repairs,

bstation Lead Storage Batterie/ mption for a Radionuclid

Maintenance, Testing, and

(1973) ASTM C625-1972 \$1.75

g Plants (2/74)

I Specifications (Revision 4,8/75)

Predict Heated Effluent Dispersion in Natural Water Bod/

Radioactive Materials in Liq/

ations (Revision 2, 8/75)

method for (1974) $\$ 1.75$

25

Measuring, Evaluating, and Complication of

Irradiation Results on Graphite, Rec. Practice for Dosimetry Results on Nuclear Graphite, Rec. Practice fo evision $1,10 / 75$ ) Preparation of Environmental Standard Format and Content of Safety Analysis
Redundant Standby (Onsite) Power Sources and Between th Reference Blocks Used in Ultrasonic Inspection (1975) \$ Reference Designations for (1975) IEEE $200 \$ 6.00$ Reference Photographs for Liquid Penetrant Inspection Reference Photographs for (1969) (R1973) ASTM E125-196 Reference Radiographs for Heavy Walled ( 2 to $4-1 / 2$ in. Reference Radiographs for Heavy Walled (4-1/2 to 12 in Reference Radiographs for Steel Fusion Welds (1973) Ast Reference Radiographs for (1973) \$1.75

References Relating to (1974) \$1.75

Gnetic Reso

Reflection Method Using Pulsed Longitudinal Waves (1974

Reflection Method, Using Pulsed Longitudinal Waves Indu Reflective Insulation Systems for Equipment and Pipe Op Reflective Insulation Systems for Equipment and Pipe Op Reflective Insulation (1-72) Amendment 1 (10-74)

Reflector for Sodium Cooled Reactors (Fabrication Only) Reflectors (6-71)

Refluxing (1972) $\$ 1.75 \quad$ T for Hydrolyzable Chlorine Co Refractory Metal Thermocouples Using an Optical Pyromet Refueling and Maintenance for LMFBR(6-72) Amendment I Regenerative Type (5-72)

Regulating Transformers, Test Code for (1973) (IEEE Std Regulations Section 57 Exposure to Radioactive Substanc Regulations (Revision 2, 8/75)

Regulations (1975) $\$ 6.80$

Regulations (1975) \$6.80

Regulations (1975) $\$ 6.80$

Regulations (1975) \$6.80

Regulations (1975) $\$ 6.80$

Regulatory Staff in Connection with lts Antitrust Revie

Regulatory Staff Position Statement on Antitrust Matter

Reinforced Concrete, Building Code Requirements for ( 19

Reinforced Plastic Pressure Vessels (1977) bd (\$40.00),

Reinforcement (1975) \$1.75

Reinforcing Bars for Category 1 Concrete Structures ( $R e$

Reinforcing Bars of Category 1 Concrete Structures (Rev

Related Electric Power Systems for Nuclear Power Plants

Related Equipment (8-72) Amendment 1 (10-72), Amendme

Related Systems, Structures and Equipment for Water Coo

Related Valves Functional Specification Standard (1975)

Relations of Fine-Grained Soils (1972) (ASTM D 1558-19

Relations of Soils Using $10 \mathrm{lb}$. (4.5 mg) Rammer and 18

Relations of Soils, Using 5.5-lb. (2.5-kg) Rammer and

Relationship Between Brinell Hardness, Vickers Hardness

Relationship for Individual Vertical Piles Under Static

Relative Density of Cohesionless Soils (1972) (ASTM D20

Relative to Their Use as Electrical Insulation (1969) \$

Relaxation of Vulcanized Rubber in Compression (1971) a

Release (2/75)

Protection of Nuclear Powe

Release (6/74)

Ting the Habite

Releases for the Purpose of Implementing Appendix 1 (5)

Releases from Light-Water-Cooled Reactors (3/76)

Releases of Radioactive Materials in Gaseous and Liquid

Releases of Radioactive Materials in Liquid and Gaseous

Releases of Reactor Effluents for the Purpose of Evalua

Relevant to Maintaining Occupational Radiation Exposure

Reliability Applications, Specification for (1967) \$1.7

Reliability Applications, Specification for (1973) ASTM

Reliability Assurance (6-74)

Reliability of Glass Coatings on Glassed Steel Reaction

Relief Discharge System (6/75)

Reluctance Transducer, Proximity Measurement System (1-

Remelted Lithium Metal in Ingot Form, Specification for

Removal of Particles (1972) $\$ 2.50$

Removal of Particles (1/73)

Removal of Radioactive Contamination in Laboratories (1

Removal of Sodium Impurities $(1-76)$ Supersedes E4-5T

Removal of Water Formed (1973) $\$ 1.75$

Removal System Pumps (Safety Guide 1, 11/2/70)

Removal (1972) $\$ 1.75$

Repairs, or Replacement of Electronic Products (1975) \$

Replacement of Electronic Products (1975) $\$ 2.95$

Replacement of Large Stationary Type Power Plant and Su Report to Support a Rule Making Petition Seeking an Exe Reporting Irradiation Results on Graphite, Practice for Reporting of Operating Information for Fuel Reprocessin Reporting of Operating Information: Appendix a Technica Reporting Procedure for Mathematical Models Selected to Reporting Radioactivity in Solid Wastes and Releases of Reporting Requirements for Persons Subject to NRC Regul Reporting Results of Analysis of Waste Water, Standard Reporting Units for Nuclear Materials Control (1971) \$3 Reporting (1972) $\$ 1.75$

Reporting ( 1974) \$1.75

Reports for Commercial Uranium Enrichment Facilities ( $R$ Reports for Fuel Reprocessing Plants (2/75)
NRC

ASTM

ANSI

ASTM

ANSI

ANSI

ANSI

ANSI

ASTM

ASTM

ASTM

ANSI

ANS1

ASTM

ERDA

ERDA

ERDA

ASTM

ANSI

ERDA

ERDA

ANSI

DOL

Complic

DOT

DOT

DOT

NRC

NRC

ANSI

ASME

ASTM

NRC

NRC

NRC

ERDA

ANSI

ANS1

ANS1

ASTM

ASTM

ANS1

ASTM

ANSI

ASTM

ANSI

NRC

NRC

NRC

Ri NRC

NRC

NRC

NRC

NRC

ASTM

ANSI

ERDA

ANSI

NRC

ERDA

ASTM

Efficie ANSI Efficie

NRC
NCRP

ERD

ASTM

ASTM

llve Su NRC

ASTM

BRH

BRH

IEEE

NRC

ANSI

NRC

NRC

NRC

NRC

NRC

ASTM

ANSI

ASTM

ASTM

NRC

NRC

RG 1.6

428

Y 32.16

E433

66.4

166.10

166.19

Z166.24

E446

386

214

Z166.3

Z98.48 
Standard Format and Content of Safety Analysis Preparation of Environmental

Standard Format and Content of Safety Analysis Preparation of Environmental Food and Drugs: Records and

5) ure Boundary Components

cal Equipment Qualificat/

12/74)

3 Components (2/75)

res $(2 / 75)$

74)

Inservice Inspection (1/

lectrical Equipment $(2 / 7$

eria for (1973) $\$ 5.00$

ms (A Guide to Practice) (1974) $\$ 3.00$

s $(6 / 74)$ active Solid Material Handling and Storage Facilities in

el Fabri/ Quality Assurance Program Requirements for Fue tion for Welding in Areas of Limited Accessibility in Fue control for the Welding of Low Alloy Steel for Use in Fue estructive Examination of Tubular Products for Use in Fuel rance Requirements for Protective Coatings Applied to Fuel Earthquake Instrumentation for Fuel Confinement Barriers and Systems for Fuel Reporting of Operating Information for Fuel Process Offgas Systems for Fuel

ard Format and Content of Safety Analysis Reports for Fuel Content of Technical Specifications for Fuel nation of Welds in the Liners of Concrete Barriers in Fuel $\mathbf{n}$, and Inspection of Protective Coatings (Paints) for Fuel General Fire Protection Guide for Fuel

Emergency Water Supply Systems for Fuel corrosion in Austenitic Stainless Steel Components of Fuel General Design Guide for Ventilation Systems for Fuel cts (1975) $\$ 2.95$

Specification for Forgings, Carbon and Low Alloy Steel, rogram for Evaluation of Installed Biological Shielding in for Plate-Type Uranium-Aluminum Fuel Elements for Use in development of Technical Specifications for Experiments in Records and Reports for ons for (1974) ANS-15.1 $\$ 12.00$ $15.6 \$ 8.50$

Review of Experiments for

tor Vessel Materials (7/75) ing for Leaks Using the Mass Spectrometer Leak Detector or nd Fluidized Bed Op/ Design Considerations for Minimizing t for Dry Process O/ nt for Wet Process

Design Considerations for Minimizing

Design Considerations for Minimizing In Situ Assay of Plutonium

In Situ Assay of Enriched Uranium

ysical and Chemical Properties of Particulate Ion Exchange

ysical and Chemical Properties of Particulate Ion Exchange for (1962) $\$ 3.60$ Measuring Ground rvice (1973) ASTM / Metal Sheathed, Mineral-Insulated Electrical Specification for Sheathed Electrica rvice, Specification for (1971) \$1.7/

Teathed Electrical

Test for Airflow m D1558-1971) / Method of Test for Moisture-Penetration 73) Platinum y Use of the Los Angeles Machine, Method of Test for (19/ tion for (1973) Design Basis for Fuel and Irradiations Experiment
Reports for Nuclear Power Plants (Revision 2, (9/75)

Reports for Nuclear Power Stations (Revision 1, 1/75)

Reports for Research Reactors (1974) ANS 15.3 $\$ 8.50$

Reports for Uranium Enrichment Facilities (12/74)

Reports for Uranium Mills (4/73)

Reports (1975) \$2.95

Reports (2-74) Amendment 1 (1-75), Amendment 2 (11-7

Reports: Code Cases Applicable to Reactor Coolant Press

Reports: Electric Power (6/75)

Reports: Emergency Planning (12/74)

Reports: Environmental Design of Mechanical and Electri

Reports: Fuel System Design (5/75)

Reports: Hydrologic Engineering (1/75)

Reports: Industrial Security for Nuclear Power Plants

Reports: Initial Test Programs (5/75)

Reports: Inservice Inspection of ASME Code Class 2 and

Reports: Instrumentation and Controls $(2 / 75)$

Reports: Internally Generated Missiles (6/75)

Reports: Mechanical Systems and Components (1/75)

Reports: Metallic Materials for Engineered Safety Featu

Reports: Meteorology (4/75)

Reports: Missile Barrier Design Procedures (12/74)

Reports: Plant Procedures (5/75)

Reports: Pressurizer Relief Discharge System (6/75)

Reports: Pump Flywheel Integrity (4/75)

Reports: Quality Assurance During Operations Phase (12/

Reports: Radioactive Waste Management (4/75)

Reports: Reactor Coolant Pressure Boundary Materials and

Reports: Reactor Materials (12/74)

Reports: Reactor Vessels (1975)

Reports: Reactor Water Cleanup System (5/75)

Reports: Seismic Qualification of Instrumentation and $E$

Reports: Steam and Feed water System Materials (4/75)

Reports: Steam Generators (1/75)

Reports: Training (6/75)

Reprocessing Facilities, Guide to Principle Design Crit

Reprocessing Facilities, Nuclear Material Control Syste

Reprocessing Plant Protection System Actuation Function

Reprocessing Plant (1975) \$7.50 /Ives for Highly

Reprocessing Plants and for Plutonium Processing and Fu

Reprocessing Plants and in Plutonium Processing and Fue

Reprocessing Plants and in Plutonium Processing and Fue

Reprocessing Plants and in Plutonium Processing and Fue

Reprocessing Plants and to Plutonium Processing and Fue

Reprocessing Plants (2/74)

Reprocessing Plants (2/74)

Reprocessing Plants (2/74)

Reprocessing Plants (2/74)

Reprocessing Plants $(2 / 75)$

Reprocessing Plants (4/73)

Reprocessing Plants (5/75)

Reprocessing Plants (6/75)

Reprocessing Plants (6/76)

Reprocessing Plants (9/75)

Reprocessing Plants (9/75)

Reprocessing Systems (9/75)

Repurchase, Repairs, or Replacement of Electronic Produ

Requiring Notch Toughness Testing for Piping Components

Research and Training Reactors (5/73)

Research Reactors (Revision 1, 7/76)

Research Reactors (11/73)

Research Reactors (1974) ANS $15.3 \$ 8.50$

Shield Test $\mathbf{P}$

Research Reactors (7/76)

Research Reactors, Development of Technical Specificati

Research Reactors, Review of Experiments for (1974) ANS

Residual Chlorine in Waste Water (1974) \$1.75

Residual Chlorine in Water (1974) $\$ 1.75$

Residual Elements on Predicted Radiation Damage to Reac

Residual Gas Analyzer in the Tracer Probe Mode (1973) \$

Residual Holdup of Special Nuclear Material in Drying a

Residual Holdup of Special Nuclear Material in Equipmen

Residual Holdup of Special Nuclear Materials in Equipme

Residual Holdup (5/74)

Residual Holdup (8/74)

Resins (1973) \$1.75 ASTM D2 187-1972\$1.75

Resins (1974) \$1.75

Resistance and Potential Gradients in the Earth, Guide

Resistance Heater (3-75) Supersedes P4-3T, (2-74)

Resistance Heaters, for Nuclear or Other Specialized Se

Resistance Heaters, for Nuclear or Other Specialized Se

Resistance of Acoustical Materials (1969) \$1.75

Resistance Relations of Fine-Grained Soils (1972) (Ast

Resistance Thermometer (4-75) Supersedes C7-17T, (3-

Resistance to Abrasion of Small Size Coarse Aggregate B

Resistance to Shock and Vibration in Truck Transport (2

Resistance-Welded Carbon Steel Boiler Tubes, Specifica
NRC

NRC

ANSI

NRC

NRC

BRH

ERDA

NRC

NRC

NRC

NRC

NRC

NRC

NRC

NRC

NRC

NRC

NRC

NRC

NRC

NRC

NRC

NRC

NRC

NRC

NRC

NRC

NRC

NRC

NRC

NRC

NRC

NRC

NRC

ANSI

ANSI

NRC

ANSI

NRC

NRC

NRC

NRC

NRC

NRC

NRC

NRC

NRC

Stand NRC

NRC

NRC

NRC

NRC

NRC

NRC

NRC

BRH

ASTM

NRC

NRC

NRC

ANSI

NRC

ANSI

ANSI

ASTM

ASTM

NRC

ASTM

NRC

NRC

NRC

NRC

NRC

/St for $\mathrm{pH}$ ANSI Tests for $\mathrm{pH}$ ASTM

IEEE

ERDA

ANSI

ASTM

ASTM

ANSI

ERDA

ANSI

ERDA

ASTM

RG 1.70

RG 4.2

N399

RG 3.25

RG 3.8

2 ICFR 1002

RDT Fl-3T

RG 1.70.13

RG 1.70.36

RG 1.70.14

RG 1.70.24

RG 1.70 .34

RG 1.70 .17

RG 1.70.15

RG 1.70.33

RG 1.70 .25

RG 1.70.22

RG 1.70.35

RG 1.70 .18

RG 1.70 .26

RG 1.70 .29

RG 1.70.16

RG 1.70 .31

RG 1.70.37

RG 1.70 .30

RG 1.70 .11

RG 1.70.27

RG 1.70 .20

RG 1.70 .12

RG 1.70.21

RG 1.70 .32

RG 1.70.23

RG 1.70 .28

RG 1.70 .19

RG 1.70.38

N101.3

N15.13

RG 3.22

N305

RG 3.3

RG 3.28

RG 3.29

RG 3.36

RG 3.21

RG 3.17

RG 3.18

RG 3.19

RG 3.20 
Specification for Electric150 lb. Corrosion $150 \mathrm{lb}$. Corrosion
$1750 \mathrm{~F}$ (954.4C) Alloy Tubing, Seamless, Corrosion and Heat ti-0./ Alloy Sheet, Strip, and Plate, Corrosion and Heat ti-0./ Alloy Sheet, Strip, and Plate, Corrosion and Heat c. for Alloy Bars, Forgings, and Rings, Corrosion and Heat on Melted 195/ Alloy Tubing (Seamless, Corrosion and Heat $-1969 \$ 3.00$

elding Electrodes, Specification for (1973) A

elding Electrodes, Specification for (1974)

s (1974) $\$ 3.50$

Steel Sheet, Corrosion

Corrosion

Corrosion ods and Bare Electrodes, Specification for (1/ Corrosionpecification for (1974A) $\$ 1.75$

fication for (1975) $\$ 1.75$ and Strip for Fusion-Welded Unfired Pressure Ves/ Heat $\mathrm{p}$, Specification for (1974) $\$ 1.75$

s (1974) ASTM A628-1973 \$1.75

other Pressure Vess/

td. Spec. for Tool stm A627-1968 \$1.75 Std. Spec. for Homogeneous Too cations (1974) ASTM A629.1971 \$1.75 Std. Spec. for Tool Std. Spec. for Stainless and Heat

tal (4-70) Amendment 1 (10-71)

$s$ at Room Temperature, Method of Test for (19/

Electrical Ultrasonic Testing by the

ventions, and References Relating to (1/ Nuclear Magnetic ntal Frequencies of Carbon and Graphite Materials by Sonic Irreversible and lrretrievable Commitments of Material ombining Modal Responses and Spatial Components in Seismic ants (Revision 1, 12/73)

ple Assembly (6-72)

alysis (Revision 1, 2/76)

tion Only) (10-72) Amendment 1 (3-74)

Time

( (1974) $\$ 1.75$

$1965 \$ 1.75$

i 214-1965) $\$ 1.75$

$2 \$ 1.75$

$\$ 1.75$

$g(1974) \$ 1.75$

Combining Moda

Reporting

Evaluation of Compression Tes

Evaluation of Compression Tes

Reporting Irradiation

Irradiation

Design Stability of Embankment

Stabilization of Uranium-Thorium Milling Waste

Uranium-Thorium Milling Waste

Test for Sound Absorption of Acoustical Materials in

$\mathrm{n}$ Needed by the NRC Staff in Connection with lts Antitrust

Research Reactors

the AEC Regulatory Staff in Connection with lts Antitrust losophy (1975) $\$ 3.00$

Thermocouple Materials, Platinum and Platinum 10 Percent

Susceptibility to Intergranular Attack in Wrought Nickel 72) Amendment 1 (10-72), Amendment 2 (7-1 Hoisting and ) $\$ 1.75$ Maximum Pore Diameter and Permeability of nal / Mineral Fiber Thermal Insulation, High Temperature erial (1971) ANS-8.3 / Use of Borosilicate Glass Raschig erial $(1 / 73)$

Use of Borosilicate-Glass Raschig

iquid Metal Service (5-74)

$3.1 \mathrm{Mo}-5.1(\mathrm{Cb}+\mathrm{Ta})-1$

Piston

$50 \mathrm{~A} 1$ Consumable Electrode or Vacuum/ Bars, Forgings, and

Test for

Soluble Chlorides Present as Admixes in Graded Aggregate $4 / 75) \quad$ Specially Designed Vehicle and Armed Guards for
5 (197/ Test for Triaxial Compressive Strength of Undrained Method of Test for Direct Tensile Strength of

Method of Test for Unconfined Compressive Strength of

on of Pulse Velocities and Ultrasonic Elastic Constants of metallic Materials, Methods of Test for (1974) \$1.75

974) ASTM C748-73 $\$ 1.75$ thods of Test for (1974) $\$ 1.75$

Method of Test for Rockwell Hardness and

een Brinell Hardness, Vickers Hardness, Rockwell Hardness,

d Control of Analytical Chemistry Laboratories for Control Supersedes E6-25T, (11-71)

entary Requirements for (1970) $\$ 1.75 \quad$ Nickel Alloy (3-75) Supersedes M7-4T,/ Nickel-Chromium-Iron Alloy (9-75) Supersedes M/ Nickel-Molybdenum-Chromium Alloy (9-75) Supersedes M7-10T/ Nickel-Iron-Chromium Alloy Specification for Nickel-Iron-Chromium Alloy

pecification for Nickel-Iron-Chromium Alloy (UNS N08800)

lled and Cold Finished Zirconium and Zirconium Alloy Bars,

lled and Cold Finished Zirconium and Zirconium Alloy Bars, (1-72) Supersedes M/ Zirconium and Zirconium Alloy Bars, Tantalum
Resistance-Welded Steel Pipe (1973A) \$1.75

ASTM

Sast Flanged Valves (1959) $\$ 3.00$

Resistant Cast Flanges and Flanged Fittings (1965) $\$ 3.0$

Resistant Nickel Base-19Cr-3.1Mo-5.1 (Cb \& Ta)-0.90

Resistant Nickel Base-19Cr-3.1 Mo-5.1 (Cb \& Ta) -0.90

Resistant Nickel Base-19Cr-3.1 Mo-5.1 (Cb \& Ta)-0.90

Resistant Nickel Base-19Cr-3.1Mo-5.1 (Cb+Ta)-0.90T

Resistant Nickel Consumable Electrode or Vacuum 1nducti

Resistant, Laminated Surface Bonded (1973) SAE AMS5500A

Resisting Chromium and Chromium-Nickel Steel Covered W

Resisting Chromium and Chromium-Nickel Steel Covered W

Resisting Chromium and Chromium-Nickel Steel Electrode

Resisting Chromium and Chromium-Nickel Steel Welding R

Resisting Chromium and Chromium-Nickel Steel Welding $\mathbf{R}$

Resisting Chromium Steel Clad Plate, Sheet and Strip, S

Resisting Chromium Steel Plate, Sheet, and Strip, Speci

Resisting Chromium-Nickel Stainless Steel Plate, Sheet

Resisting Chromium-Nickel Steel Plate, Sheet, and Stri

Resisting Composite Stee! Bars for Security Application

Resisting Steel Bars and Shapes for Use in Boilers and

Resisting Steel Bars and Shapes (1974) \$1.75

Resisting Steel Bars for Security Applications (1974) a

Resisting Steel Flat Bars and Shapes for Security Appli

Resisting Steel Forgings (1975) \$1.75

Resistive Level Measurement Sensor for Use in Liquid Me

Resistivity of Manufactured Carbon and Graphite Article

Resonance Method, Practice for (1974) \$1.75

Resonance (NMR) Spectroscopy, Definitions, Symbols, Con

Resonance (1974) \$1.75

Resources (Revision 1, 6/76)

Response Analysis (Revision 1, 2/76)

Response Spectra for Seismic Design of Nuclear Power Pl

Response Test for Sheathed, Mineral Insulated Thermocou

Responses and Spatial Components in Seismic Response an

Restraint Mechanism for Sodium Cooled Reactors (Fabrica

Results for Metallic Materials (1972T) \$1.75

Results of Field Concrete, Practice for (1968) ACI 214.

Results of Field Concrete, Rec. Practice for (1968) (Ac

Results on Graphite, Practice for (1973) ASTM C625-197

Results on Graphite, Rec. Practice for Reporting (1972)

Results on Nuclear Graphite, Rec. Practice for Reportin

Retention Systems for Uranium Mills (6/73)

Retention Systems (11/74)

Retention Systems, Stablilzation of (1974) \$1.50

Reverberation Rooms (1972) \$1.75

Review of Construction Permit Applications for Nuclear

Review of Experiments for Research Reactors (7/76)

Review of Experiments for (1974) ANS 15.6 $\$ 8.50$

Review of Operating License Applications for Nuclear Po

Review of the Current State of Radiation Protection Phi

Rhodium Wires, Noninsulated, Std. Grade (8-72) Amendme

Rich, Chromium-Bearing Allcys, Method of (1973) ASTM C

Rigging of Critical Components and Related Equipment ( 8

Rigid Porous Filters for Laboratory Use, Test for ( 1969

Rigid, Flexible and Loose Fill (ASTM C 612 with Additio

Rings as a Neutron Absorber in Solutions of Fissile Mat

Rings as a Neutron Absorber in Solutions of Fissile Mat

Rings of High Strength Alloys for Core Components for $\mathrm{L}$

Rings, Corrosion and Heat Resistant Nickel Base- $19 \mathrm{Cr}$ -

Rings, Nickel-19Cr-19Fe-3.1 Mo-5.1 (Cb+Ta) 0.90Ti-0

Rinsing Properties of Metal Cleaners (1972) \$1.75

Road Mixes, Method of Test for (1975) $\$ 1.75$

Road Shipment of Special Nuclear Material (Revision 1,

Rock Core Specimens in Uniaxial Compression (1972) $\$ 1.7$

Rock Core Specimens Without Pore Pressure Measurements

Rock Core Specimens (1972) (ASTM D2936-1971) \$1.75

Rock Core Specimens (1972) (ASTM D2938-1971A) $\$ 1.75$

Rock (1972) (ASTM D2845-1969) \$1.75

Tory Determi

Rockwell Hardness and Rockwell Superficial Hardness of

Rockwell Hardness of Fine Grained Graphite Materials (1

Rockwell Hardness, Rockwell Superficial Hardness, and K

Rockwell Superficial Hardness of Metallic Materials, Me

Rockwell Superficial Hardness, and Knoop Hardness) ( 197

Rod Absorber Material Analysis (7-73)

Alificat

Rod Absorber Pin for Liquid Metal Fast Reactors (5-73)
Rod and Bar for Nuclear Applications, Spec. for Supplem

Rod and Bar (ASME SB-166 with Additional Requirements)

Rod and Bar (ASME SB-336 with Additional Requirements)

Rod and Bar (ASME SB-408 with Additional Requirements)

Rod and Bar, (1974) ASTM B408-1973 \$1.75

Rod and Bar, (1974) \$1.75

Rod and Wire for Nuclear Application (1973) \$1.75

Rod and Wire for Nuclear Application, Specification for

Rod and Wire (ASTM B 351 with Additional Requirements)

Rod and Wire, Spec. for (1970) $\$ 1.75$
MSS

MSS

ANS

ANSI

ANS

ANS1

ANS1

ANS1

ASME

AWS

ANSI

ASME

ASTM

ASTM

ASTM

ANSI

ASTM

for Hot ASTM

ANSI

ANSI

ASTM

ERDA

ANSI

ASTM

ASTM

ASTM

NRC

NRC

ERDA

NRC

ERDA

ANS1

ANSI

ASTM

ASTM

NRC

NRC

ANSI

ASTM

NRC

NRC

ANSI

NRC

NCRP

ERDA

ANSI

ERDA

ASTM

ERDA

ANSI

ERDA

ANSI

SAE

ASTM

Wate ASTM

NRC

ASTM

ASTM

ANS1

ANS1

ASTM

ANS1

ANS1

ASTM

ANSI

ERDA

ERDA

ASTM

RDA

ERDA

ERDA

ANS1

ASTM

/ Ro ASTM

ANS1

ERDA

ASTM

A 135

-42

P-5 1

G87.77

G87.84

G87.85

87.146

G87.78

G87.1

W3.4

SFA-5.4

A5. 22

W3.9

SFA-5.9

A 176 
ersedes E6-33T, (11-71) Amendment $1(12-73), /$ Control
t I (12-72), Amen/ Collapsible Rotor, Roller Nut Control t 1 ( 12-72), Amen/ Collapsible Rotor, Roller Nut Control Assumptions Used for Evaluating a Control Requirements) (3-75) Supersede/ Stainless Steel Welding a5.10-1969 $\$ 2.50 \quad$ Aluminum and Aluminum Alloy Welding ion-Resisting Chromium and Chromium-Nickel Steel Welding Aluminum and Aluminum Alloy Welding ion-Resisting Chromium and Chromium-Nickel Steel Welding uirements) $(3-75) / \quad$ Nickel and Nickel-Alloy Bare Welding Composite Surfacing Welding

Titanium and Titanium-Alloy Bare Weldin

Nickel-Chromium-Molybdenum-Columbium Bare Welding Amendme/ Nickel-Molybdenum-Chromium Alloy Bare Welding rcent-Chromium, 1-Percent-Molybdenum Alloy Bare Welding $-1970 \$ 3.00$

$1969 \$ 2.50$ Surface Welding

Nickel and Nickel-Alloy Bare Welding Nickel and Nickel-Alloy Bare Welding al Requirements) (3-75) Supersedes M 1-5T, (7-1 Welding supersedes M1/ Zirconium and Zirconium Alloy Bare Welding Iron and Steel Gas Welding

$11(\$ 40.00) \quad$ Specification for Aluminum-Alloy Bars, Specification for Aluminum-Alloy Extruded Bars, Copper and Copper-Alloy Welding Copper and Copper-Alloy Welding Alloy Bars and

Specification for Copper-Silicon Alloy Spec. for Copper and Copper Alloy Forging Specification for Aluminum Bronze

eat Resisting Steel Bars and Shape/ Specification for Hot Specification for Hot bars, Rod and Wire for Nuclear Application, Specific/ Hot ium and/or Vanadium, Specific/ Steel Sheet and Strip, Hot Copper, Sheet, Strip, Plate, and cation for (1972) $\$ 1.75$ Copper, Sheet, Strip, Plate, and cification for Aluminum-Alloy Standard Structural Shapes, eral Service, Spec. for (1976) \$1.75

Forged or Std. Spec. for Steel, Carbon, Cold
Carbon Steel Sheet, Cold for $(1975) \$ 1.75$ ium, Specific/ Steel Sheet and Strip, Hot Rolled and Cold zinc (Hot Galvanized) Coatings on Products Fabricated from ce (3-71) Amendment 1 (12-72), Amen/ Collapsible Rotor. 2/75) evaluating the Habitability of Nuclear Power Plant Control
Protection of Nuclear Power Plant Control esistivity of Manufactured Carbon and Graphite Articles a

Testing and Certification of Particulate Clean Sound Absorption of Acoustical Materials in Reverberation Std. Specifications for Electric Wire Recommended Practice fo

m Service (3-71) Amendment 1 (12-72), Amen/ Collapsible uation of Explosions Postulated to Occur on Transportation mating Aquatic Dispersion of Effluents from Accidental and mospheric Transport and Dispersion of Gaseous Effluents in f Evaluating Com/ Calculation of Annual Doses to Man from Definitions of Terms Relating to Test for Evaluating Pressure Sealing Properties of Test for Hydrogen Permeability of Std. Spec. for Fully Cured Silicone

ulation (1969) (R197/

Methods of Test /

Testing (1968) (/

Compression Set Induced in Vulcanized Compression Set Induced in Vulcanized Method of Tests for Stress Relaxation of Vulcanized Nomenclature for Rubbers and Definitions of Terms Relating to Rubber and Sponge and Expanded Cellular ethod of Test for Accelerated Ozone Cracking of Vulcanized

$t$ for Evaluating Pressure Sealing Properties of Rubber and clid/ Preparation of an Environmental Report to Support A bd $(\$ 25.00), 11(\$ 30.00)$

$(\$ 30.00)$

Pressure Storage Tanks (1973) $\$ 4.00$

Recommended

Recommended

Recommended

Matter Nonmailable Articles and Substances Under Special Pressure Vessels Division 2: Alternative Mailable Matter Under Special Spec. for Top ad Traveling Cranes (1974) $\$ 3.00$

Spec. for Top Running and Under of Nuclear Power Plants Against Effects of Postulated Pipe Protection of Nuclear Plants Against Industrial .00 Intrinsically

175) d Structural Steel Products and Procedure for Detecting ion $2,(9 / 75)$
Rod Assembly for Liquid Metal Fast Reactors (5-73) Sup Rod Drive Mechanism for Sodium Service (3-71) Amendmen Rod Driveline for Sodium Cooled Reactors (4-73) Amendm Rod Ejection Accident for Pressurized Water Reactors $(5$ Rods and Bare Electrodes (ASME SFA-5.9 with Additiona Rods and Bare Electrodes, Specification for (1973) AWS Rods and Bare Electrodes, Specification for (1973) AWS Rods and Bare Electrodes, Specification for (1974)

Rods and Bare Electrodes, Specification for (1974)

Rods and Electrodes (ASME SFA-5.14 with Additiona: Req Rods and Electrodes (1970) $\$ 2.50$

Rods and Electrodes (1970) $\$ 3.00$

Rods and Electrodes (6-75) Supersedes M1-19T, (3-75)

Rods and Electrodes (7-75) Supersedes M1-15T, (1-72)

Rods and Electrodes (9-75) Amendment 1 (10-75)

Rods and Electrodes, Specification for (1973) AWS A5.13

Rods and Electrodes, Specification for (1973) AWS A5.14

Rods and Electrodes, Specification for (1974)

Rods and Electrodes, Surfacing (AWS A5.13 with Addition Rods (ASTM B 351 with Additional Requirements) (1-72) Rods ( 1969 ) $\$ 2.50$

Rods, and Wire (1974) ASTM B211-1973 \$1.75

Rods, Electrodes and Filler Metals (1977) bd ( $\$ 30.00)$

Rods, Shapes, and Tubes (1974) ASTM B221-73 \$1.75

Rods, Specification for (1973) AWS A5.7-1969 \$2.50

Rods, Specification for (1974)

Rods, Tantalum (90Ta-10W) (1975) $\$ 3.00$

Rod, Bar, and Shapes (1974A) \$1.75

Rod, Bar, and Shapes (1974) \$1.75

Rod, Bar, and Shapes (1974) $\$ 1.75$

Rolled Alloy Steel Bars (1976) ASTM A322-1975 \$1.75

Rolled and Cold Finished Age-Hardening Stainless and $\mathrm{H}$

Rolled and Cold Finished Zirconium and Zirconium Alloy

Rolled and Cold Finished Zirconium and Zirconium Alloy

Rolled and Cold Rolled, High Strength, Low Alloy Columb

Rolled Bar, Specification for (1974A) \$1.75

Rolled Carbon Steel Sheets, Commercial Quality, Specifi

Rolled or Extruded (1974) ASTM B308-1973 \$1.75

Rolled Steel Pipe Flanges, and Valves and Parts for Gen

Rolled, Commercial Quality (1974) ASTM A366-1972 \$1.75

Rolled, Drawing Quality, Special Killed, Specification

Rolled, High Strength, Low Alloy Columbium and/or Vanad

Rolled, Specification for (1974) ASTM A123-1973 \$1.75

Roller Nut Control Rod Drive Mechanism for Sodium Sery

Room During a Postulated Hazardous Chemical Release (6/

Room Operators Against an Accidental Chlorine Release (

Room Temperature, Method of Test for (1973) ASTM C611

Rooms (1970) $\$ 5.00$

Rooms (1972) \$1.75

Rope Hoists (1974) $\$ 3.00$

Rotameter Calibration (1973) $\$ 1.75$

Rotor, Roller Nut Control Rod Drive Mechanism for Sodiu

Routes Near Nuclear Power Plant Sites (1/75)

Routine Reactor Releases for the Purpose of Implementin

Routine Releases from Light-Water-Cooled Reactors (3/

Routine Releases of Reactor Effluents for the Purpose O

Rubber and Rubber Like Materials (1975A) \$1.75

Rubber and Rubber-Like Materials (1974) \$1.75

Rubber Coated Fabrics (1973) $\$ 1.75$

Rubber Coated Glass Fabric and Tapes for Electrical Ins

Rubber During Exposure to High Energy Nuclear Radiation

Rubber During Exposure to High Energy Nuclear Radiation

Rubber in Compression (1971) ASTM D1390 1968 \$1.75

Rubber Latices, Practice for (1972B) $\$ 1.75$

Rubber Like Materials (1975A) \$1.75

Rubber Products, Specification for (1973) $\$ 1.75$

Rubber (1971) ASTM D1 149-1970 \$1.75

Rubbers and Rubber Latices, Practice for (1972B) $\$ 1.75$

Rubber-Like Materials (1974) \$1.75

Rule Making Petition Seeking an Exemption for a Radionu

Rules for Care and Operation of Heating Boilers (1977)

Rules for Care of Power Boilers (1977) bd (\$25.00), ll

Rules for Design and Construction of Large, Welded, Low

Rules for Inservice Inspection of Nuclear Power Plant C

Rules (1975)

Rules (1977) bd (\$65.00), ll (\$95.00)

Rules, Radioactive Materials (1975)

Running and Under Running Single Girder Electric Overhe

Running Single Girder Electric Overhead Traveling Crane

Rupture (Issued for Trial Use and Comment) ANS 55.2 \$8.

Sabotage (Revision 1, 6/73)

Safe and Non Incendive Electrical Instruments (1965) \$5

Safe Handling of Radioactive Materials (1964) \$2.00

Safeguarding Against Embrittlement of Hot Dip Galvanize

Safety Analysis Reports for Fuel Reprocessing Plants (2
ERDA

ERDA

ERDA

ERDA

ANS

ANSI

ASME

Os ASME

ERDA

AWS

AWS

ERDA

ERDA

-Pe ERD

ANSI

ANSI

ASME

ERDA

ERDA

AWS

ANSI

ASME

ANS1

ANSI

ASME

SAE

ASTM

ASTM

ASTM

ANSI

ASTM

ANSI

ASTM

ANSI

ASTM

ASTM

Spe ANSI

ASTM

ANSI

ASTM

ANS

ANS1

RDA

NRC

NRC

ANS

IES

ASTM

HM1

ASTM

Eval NRC

NRC

NRC

NRC

ASTM

ASTM

ASTM

ANSI

ANSI

ASTM

ANSI

ASTM

ASTM

ANSI

ASTM

Tes ASTM

NRC

ASME

ASME

API

ASME

USPS

ASME

USPS

CMAA

DMA

ANSI

NRC

ISA

NCRP

ASTM

NRC

NRC

RDT E6-33T

RDT E6-5T

RDT E6-26T

RG 1.77

RDT M1-2T

W3.10

W3.9

SFA-5.10

SFA-5.9

RDT M1-11T

A5.21

A5.16

RDT M1-19T

RDT M1-15T

RDT M1-23T

W3.13

W3.14

SFA-5.14

RDT M 1-5T

RDT M 1-16T

A5. 2

H38.4

SEC-IIC

H38.5 
es $(12 / 74)$

Standard Format and Content of or Coolant Pressure Boundary Components /

ical and Electrical Equipment Qualificat/

\section{r Power Plants (12/74)}

ode Class 2 and 3 Components (2/75)

$2 / 75)$

(6/75)

nts (1/75)

red Safety Features (2/75)

res $(12 / 74)$

ystem $(6 / 75)$

tions Phase (12/74)

4/75)

ry Materials and Inservice Inspection (1/

\section{$5 / 75)$}

umentation and Electrical Equipment (2/7)

erials $(4 / 75)$

\section{5) $\$ 3.25$} 3.00

sted by Grants from National Endowment for the Arts (197)

\section{ant Ships (1965) $\$ 7.50$}

personnel (1975) ANS 8./

ter Reactor Plants: Issued Fo/

Criteria for Nuclear Criticality Draft Standard for Nuclear d Water Reactor Plants (1973) ANS-51.1 $\$ 30.50$ Nuclear

d Water Reactor Plants (1975) $\$ 5.50 \quad$ Standard Nuclear safety Analysis Reports: Metallic Materials for Engineered equipment (1971) NBS Handbook $111 \$ 3.00$ Radiation Critical Experiments,

cy Core Cooling and Containment Heat Removal System Pumps bars of Category 1 Concrete Structures (Revision 1, 1/2/73 Instrument Lines Penetrating Primary Reactor Containment f Primary Containment Liner Welds (Revision 1, 8/11/72, of Thermal Shock to Reactor Pressure Vessels periodic Testing of Protection System Actuation Functions Onsite Meteorological Programs urized Water Reactor Radioactive Gas Storage Tank Failure orage Facility for Boiling and Pressurized Water Reactors

Assurance Program Requirements (Design and Construction) on, and Testing of Instrumentation and Electric Equipment

Quality Assurance Program Requirements (Operation) of a Steam Line Break Accident for Boiling Water Reactors ite) Power Sources and Between Their Distribution Systems Coolant Accident (Safety Guide 7, 3/10/71) Supplement to

tions in Containment Following a Loss of Coolant Accident

Diesel Generator Set Capacity for Standby Power Supplies Reactors (1975) ANS-8.1\$10.00 Reactors (1/73) tors (1969) NBS Handbook $107 \$ 3.00$ 1975) ANS-8.7 $\$ 12.00$

Nuclear Criticality Radiological Nuclear Criticality Welding and Cutting,

Subcritical Neutron Multiplication Measurements in Situ, ter Cooled and Moderated Nuclear Power Ge/ Draft Standard (1975) $\$ 3.00$ 4.25

.00 Self Operated and Power Operated Floor and Wall Openings, Railings and Toeboards, ed Gamma-Ray Sources (6/74) Fixed Ladders, General Mechanical Power Transmission Apparatus, Sealed Gamma Ray Sources, Energies Up to 10-Mev, General Powered Industrial Trucks Low Lift and High Lift, $\mathrm{d}$ and Inoperable Status Indication for Nuclear Power Plant Automatic Spring Loaded

alidation of Calculational Methods for Nuclear Criticality alidation of Calculational Methods for Nuclear Criticality r Plants (Revision 1, 6/73)

Process, Practice for (1972) $\$ 1.75$

Criteria for Choice of (1974) $\$ 1.75 \quad$ Aqueous Corrosion Testing of lities, Guide to (1969) ISO $2889 \$ 7.00$

Measurements of Radionuclides in the Environment: Portland Cement Concrete (1974) $\$ 1.75$ 1973) $\$ 1.75$

Rec. Practice for 75 Method for Soil Investigation and
Safety Analysis Reports for Uranium Enrichment Faciliti Safety Analysis Reports: Code Cases Applicable to React Safety Analysis Reports: Electric Power (6/75)

Safety Analysis Reports: Emergency Planning (12/74)

Safety Analysis Reports: Environmental Design of Mechan Safety Analysis Reports: Fuel System Design (5/75)

Safety Analysis Reports: Hydrologic Engineering (1/75)

Safety Analysis Reports: Industrial Security for Nuclea

Safety A nalysis Reports: Initial Test Programs (5/75)

Safety Analysis Reports: Inservice Inspection of ASME C

Safety Analysis Reports: Instrumentation and Controls (

Safety Analysis Reports: Internally Generated Missiles

Safety Analysis Reports: Mechanical Systems and Compone

Safety Analysis Reports: Metallic Materials for Enginee

Safety Analysis Reports: Meteorology (4/75)

Safety Analysis Reports: Missile Barrier Design Procedu

Safety Analysis Reports: Plant Procedures (5/75)

Safety Analysis Reports: Pressurizer Relief Discharge S

Safety Analysis Reports: Pump Flywheel Integrity (4/75)

Safety Analysis Reports: Quality Assurance During Opera

Safety Analysis Reports: Radioactive Waste Management (

Safety Analysis Reports: Reactor Coolant Pressure Bounda

Safety Analysis Reports: Reactor Materials (12/74)

Safety Analysis Reports: Reactor Vessels (1975)

Safety Analysis Reports: Reactor Water Cleanup System (

Safety Analysis Reports: Seismic Qualification of Instr

Safety Analysis Reports: Steam and Feedwater System Mat

Safety Analysis Reports: Steam Generators (1/75)

Safety Analysis Reports: Training (6/75)

Safety and Health Stds. for Federal Supply Contracts ( 1

Safety and Health Stds. on Projects or Productions Assi

Safety Color Code for Marking Physical Hazards (1971) \$

Safety Considerations for Nuclear Power Plants on Merch

Safety Controls in Operations Where Shielding Protects

Safety Criteria for the Design of Stationary Boiling Wa

Safety Criteria for the Design of Stationary Pressurize

Safety Criteria for the Design of Stationary Pressurize

Safety Features (2/75)

Informa

Safety for X-Ray Diffraction and Fluorescence Analysis

Safety Guide for the Performance of (1975) ANS-1 $\$ 8.00$

Safety Guide 1,11/2/70)

Safety Guide 10)

Safety Guide 11,3/10/71

Safety Guide 19)

(Safety Guide 2, 11/2/70)

Safety Guide 22, 2/17/72)

Safety Guide 23, 2/17/72)

(Safety Guide 24, 3/23/72)

(Safety Guide 25,3/23/72)

(Safety Guide 28, 6/7/72)

Safety Guide 30,8/11/72)

(Safety Guide 33, 11/3/72)

(Safety Guide 5, 3/10/71)

(Safety Guide 7, Backfitting Considerations, 10/27/71

(Safety Guide 9,3/10/71)

/Ive Suction Head for Emergen

Al (Cadweld) Splices in Reinforcing

Nondestructive Examination $\mathrm{O}$

Safety in Operations with Fissionable Materials Outside

Safety in Operations with Fissionable Materials Outside

Safety in the Design and Operation of Particle Accelera

Safety in the Storage of Fissile Materials, Guide for (

Safety in (1973) $\$ 5.00$

Safety in (1975) ANS-8.6 $\$ 6.50$

Safety Related Systems, Structures and Equipment for W

Safety Related Valves Functional Specification Standard

Safety Requirements for Portable Metal Ladders (1972) \$

Safety Requirements for Portable Wood Ladders (1975) \$5

Safety Requirements for (1973) $\$ 3.00$

Safety Requirements for (1974) $\$ 5.50$

Safety Standard for Installations Using Nonmedical Seal

Safety Standard for (1972) $\$ 4.00$

Safety Standard for (1974) NBS Handbook $114 \$ 2.50$

Safety Std. for (1975) $\$ 6.50$

Safety Systems (5/73)

Safety Valves (3-72) Amendment 1 (1-73)

Safety (1975) ANS-8.11

Safety $(6 / 76)$

Safety-Related Electric Power Systems for Nuclear Powe

Sample Size to Estimate the Average Quality of a Lot or

Sampler) for the Analysis of Nonmetals in Liquid Sodium

Samples of Zirconium and Zirconium Alloys, Practice for

Sampling Airborne Radioactive Materials in Nuclear Faci

Sampling and Analysis of Plutonium in Soil (5/74)

Sampling and Testing Fly Ash for Use as an Admixture in

Sampling Atmospheres for Analysis of Gases and Vapors

Sampling by Auger Borings (1972) (ASTM D1452-1966) \$1.
NRC

NRC

NRC

NRC

NRC

NRC

NRC

NRC

NRC

NRC

NRC

NRC

NRC

NRC

NRC

NRC

NRC

NRC

NRC

NRC

NRC

NRC

NRC

NRC

NRC

NRC

NRC

NRC

NRC

DOL

DOL

ANS

SNAM

ANS

ANSI

ANSI

ANSI

ANSI

NRC

ANS

ANS

NRC

NRC

NRC

NRC

NRC

NRC

NRC and St NRC Quality NRC

NRC

NRC

NRC

NRC

NRC

ection of NRC

ANSI

NRC

ANSI

ANSI

ANSI

ANS

ANSI

ANS

ANS

ANS

ANSI

ANSI

NRC

ANS

land ANSI

ANSI

Bypasse NRC

ERDA

ANSI

NRC

NRC

ASTM

ERDA

ASTM

ANSI

NRC

ASTM

ASTM

ANSI

RG 3.25

RG 1.70 .13

RG 1.70 .36

RG 1.70 .14

RG 1.70.24

RG 1.70 .34

RG 1.70 .17

RG 1.70 .15

RG 1.70.33

RG 1.70.25

RG 1.70 .22

RG 1.70.35

RG 1.70 .18

RG 1.70.26

RG 1.70 .29

RG 1.70.I 6

RG 1.70.31

RG 1.70.37

RG 1.70 .30

RG 1.70.11

RG 1.70.27

RG 1.70.20

RG 1.70 .12

RG 1.70.21

RG 1.70.32 
$71 \$ 1.75$

ic Contaminents, 4th Edition (1972) $\$ 12.50$

Recommended Practice for Core Methods of

stm D2687-1972 \$1.75

5

Rec. Practice for Planning the

Acceptance

1tems Containing Byproduct Material (6/74) 8-1971 \$1.75

mination of Chemical Composition (1972) $\$ 1.75$

Acceptance

Std. Method for

Steam,

Spec. for Copper Alloy

Organic Impurities in 68 -Current Testing of Steel Tubular Products with Magnetic Identification of Piping Systems by Color Coding, Glossary of Terms in Nuclear

ount/ Standard Test Procedures for Photo-Multipliers for

2) $\$ 1.75$-Multipliers for Scintillation Counting and Glossary for destructive Assay of Special Nuclear Material Contained in

Nondestructive Assay for Plutonium in

Classification of Unirradiated Plutonium and Uranium

Unirradiated Uranium

Unirradiated Plutonium

of Test for (1968) $\$ 1.75$

f Test for (1973) ASTM C136-1971 \$1.75

Sieve or Test for Strontium Ion Brackish Water. Inflatable

Test for Leaks in Heat al Safety Sta/ Installations Using Non-Medical X-Ray and general Safety Standard for Installations Using Nonmedical Test for Water Vapor Transmission of Flexible Heat to Be Distr/ Classification of Containment Properties of 72) Supersedes E3-3T, (10-70), Amendm/ Vertical, Shaft (1974) $\$ 1.75$

Material $(1 / 74)$

ar Materials (7)

Test for Evaluating Pressure Security High Temperature Electrical Connectors and Hermetic ecification for (1974) $\$ 1.75$

or General Service, Specification for (1974) $\$ 1.75$

small-Diameter) for General Service (/

Specification for

w Temperature Service, Specification for (1974) $\$ 1.75$

loy Steel Heat Exchanger Tubes with Integral Fins, Speci/ ice (1975) $\$ 1.75$ Requirements)
Specification for or Condensers and Heat Exchangers, Specification for (19/ ation for (1973) A/ Wrought Zirconium and Zirconium Alloy r (1971) $\$ 1.75$

m B394-1970 $\$ 1.75$ Wrought Zirconium and Zirconium Alloy Columbium and Columbium Alloy tral Station Service, Specification for (1974) \$1.75

ification for (1975) $\$ 1.75$

Condenser Tubes, Specification for (1973) $\$ 1.75$

on for (1974A) $\$ 1.75$

Copper and Copper-Alloy

Specification for Standard Sizes of Specification for

ents (1970) Ast/ Std. Spec. for Carbon Steel Forgings for Specification for Aluminum-Alloy Seamless Pipe and dditional Requirements) (4-76) Supersedes M3-12T, (12-/

974B) \$1.75 Superheater, and Heat Exchanger Tubes, Speci/ astm $A 669.1972 \$ 1.75$

Specification for

es (ASME SA-210 with Additional Requirements) (7-75) S/ bes, Specification for (1973) $\$ 1.75$

hanger Tubes, Specification for (1974) $\$ 1.75$

$411973 \$ 1.75$

Specification for Aluminum-Alloy ication for / Supplementary Requirements for Nickel Alloy for Supplementary Requirements for (1970) \$/ Nickel Alloy Specification for Nicke

Specification for Nickel-Copper Alloy (UNS Non Allo pecification for NickeI-Iron-Chromium Alloy (UNS N08800) equirements) (7-75)/ Nickel-Molybdenum-Chromium Alloy requirements) (7-75) Super/

s) $(7-75)$ Supersedes M3-1T, (5-73) Nickel-Iron-Chromium Alloy s) (11-74) Supersedes M3-3T/

Carbon Steel on for (1974) $\$ 1.75$

Austenitic Stainless Stee

Specification for Welded and (7-75) Su/ Nickel-Chromium-Molybdenum-Columbium Alloy (8-75) Su/ Nickel-Chromium-Molybdenum-Columbium Alloy ts) (4-76) Supersedes M3-2T,/ Stainless and Alloy Stee 1/4-Percent-Chromium, 1-Percent-Molybdenum Alloy Stee
Sampling Fresh Concrete, Method of (1973) ASTM C172-19 Sampling Instruments Manual for Evaluation of Atmospher Sampling of Graphite Electrodes, (1974) \$1.75

Sampling of Particulate Ion Exchange Materials (1973) a Sampling of the Atmosphere (1973) ASTM D1357-1967 \$1.7 Sampling Plans (11.73)

Sampling Preformed Thermal Insulation (1972) $\$ 1.75$

Sampling Procedures for Exempted and Generally Licensed Sampling Stacks for Particulate Matter (1973) ASTM D292 Sampling Wrought Nonferrous Metals and Alloys for Deter Sampling (1975) $\$ 1.75$

Sand Castings for General Applications (1974) \$1.75

Sand for Concrete, Test for (1973) $\$ 1.75$

Saturation, Practice for (1973) ASTM E309-1971 \$1.75

Sawed Beams of Concrete, Method of (1969) ASTM C42-19

Scheme for the $(1975) \$ 3.00$

Science and Technology (1967) $\$ 7.95$

Scintillation Counting and Glossary for Scintillation C

Scintillation Counting Field (1972) IEEE Std. 398-1972

Scleroscope Hardness Testing of Metallic Materials ( 197

Scrap and Waste (10/73)

Scrap Material by Spontaneous Fission Detection (6/74) Scrap $(12 / 20 / 72)$

Scrap, Classification of (1970) $\$ 3.25$

Scrap, Classification of (1972) $\$ 4.25$

Scratch Hardness of Coarse Aggregate Particles, Method

Screen Analysis of Fine and Coarse Aggregates, Method $\mathrm{O}$

Screw Threads (UN and UNR Thread Form) (1974) $\$ 15.00$ Sea Applications (3/74)

Sea Water, and Brines (1974) $\$ 1.75$

Seal Containment Vessel Airlock (6-72)

Sealability of Enveloped Gaskets, Test for (1974) $\$ 1.75$

Sealed Flexible Packages (1972) \$1.75

Sealed Gamma Ray Sources, Energies Up to 10-Mev, Gener

Sealed Gamma-Ray Sources (6/74)

Sealed Packages for Dry Products (1972) $\$ 1.75$

Sealed Radioactive Sources Contained in Certain Devices

Sealed, Motor Driven, Single Stage Centrifugal Pump (7

Sealing Properties of Rubber and Rubber-Like Materials

Seals for the Protection and Control of Special Nuclear

Seals on Containers for Onsite Storage of Special Nucle

Seals (3-70)

Seamless and Welded Austenitic Stainless Steel Pipe, Sp

Seamless and Welded Austenitic Stainless Steel Tubing F

Seamless and Welded Austenitic Stainless Steel Tubing

Seamless and Welded Carbon and Alloy Steel Tubes for Lo

Seamless and Welded Carbon, Ferritic, and Austenitic Al

Seamless and Welded Small Diameter Austenitic Stainless

Seamless and Welded Steel Pipe for Low Temperature Serv

Seamless and Welded Titanium and Titanium Alloy Tubes F

Seamless and Welded Tubes for Nuclear Service, Specific

Seamless and WeIded Tubes for Nuclear Service, Spec. Fo

Seamless and Welded Tubes, Specification for (1973) Ast

Seamless Austenitic Steel Pipe for High Temperature Cen

Seamless Carbon Steel for High Temperature Service Spec

Seamless Cladding Tube (6-71)

Seamless Cold Drawn Low Carbon SteeI Heat Exchanger and

Seamless Condenser Tubes and Ferrule Stock, Specificati

Seamless Copper Pipe (1975) \$1.75

Seamless Copper-Nickel Pipe and Tube (1975) \$1.75

Seamless Drums, Heads, and Other Pressure Vessel Compon

Seamless Extruded Tube (1974) ASTM B241 $1973 \$ 1.75$

Seamless Ferritic Alloy Steel Pipe (ASME SA-335 with a

Seamless Ferritic and Austenitic Alloy Steel Boiler,

Seamless Ferritic-Austenitic Alloy Steel Tubes (1974)

Seamless Medium Carbon Steel Boiler and Superheater Tub

Seamless Medium-Carbon Steel Boiler and Superheater Tu

Seamless Nickel and Nickel Alloy Condenser and Heat Exc

Seamless Pipe and Seamless Extruded Tube (1974) ASTM B2

Seamless Pipe and Tube for Nuclear Applications, Specif

Seamless Pipe and Tube for Nuclear Applications, Spec.

Seamless Pipe and Tube (1971) ASTM B 167-1970 \$1.75

Seamless Pipe and Tube (1971) \$1.75

Seamless Pipe and Tube (1973) ASTM B167-1970 \$1.75

Seamless Pipe and Tube (1974) \$1.75

Seamless Pipe and Tubes (ASME SB-167 with Additional R

Seamless Pipe and Tubing (ASME SB-407 with Additional

Seamless Pipe (ASME SA-106 with Additional Requirement

Seamless Pipe (ASME SA-376 with Additional Requirement

Seamless Stainless Steel Mechanical Tubing, Specificati

Seamless Steel Pipe (1973) $\$ 1.75$

Seamless Tubes for Condensers and Heat Exchangers, Spec

Seamless Tubes (AMS 5589 with Additional Requirements)

Seamless Tubes (AMS 5590 with Additional Requirements)

Seamless Tubes (ASME SA-213 with Additional Requiremen

Seamless Tubes (ASME SA-213 with Additional Requiremen
ANSI

ACGIH

ASTM

ANS1

ANSI

ERDA

ASTM

NRC

ANSI

ASTM

ASTM

ASTM

ASTM

ANSI

ANSI

ANSI

ANSI

ANSI

ASTM

Non NRC

NRC

NRC

ANS

ANSI

ASTM

ANSI

ANSI

NRC

ASTM

ERDA

ASTM

ASTM

ANSI

NRC

ASTM

NRC

ERDA

ASTM

NRC

NRC

ERDA

ASTM

ASTM

ANS1

ASTM

ASTM

ERDA

ASTM

ASTM

ANSI

ASTM

ANSI

ASTM

ASTM

ERDA

ASTM

ASTM

ASTM

ASTM

ANSI

ANSI

ERDA

ASTM

ANSI

ERDA

ASTM

ASTM

ANSI

ANSI

ASTM

ANSI

ASTM

ANSI

ASTM

ERDA

ERDA

ERDA

ERDA

ASTM

ASTM

ANSI

ERDA

ERDA

ERDA

ERDA

A 37.30

111.12

Z257.1

DT F2-7T

C390

RG 6.6

Z257.3

E55

D1066

B584

C40

Z166.27

A 37.20

A 13.1

N1.1

N42.9

RG 5.11

RG 5.2

N15.1

N15.10

C235 
nts) (4-76) Supersed/ Nickel-Molybdenum-Chromium Alloy ts) $(7-75)$ Supersedes M3-4T, (1-74)

Nickel Alloy

e Service, Specification for (1974A) \$1.75

Aluminum-Alloy Drawn

de or Vacuum lnduction Melted $1750 \mathrm{~F}$ (954.4C) Alloy Tubing, e Electrode or Vacuum Induction Melted 195/ Alloy Tubing t For/ Thermal Conductance and Transmittance of Built-Up pressure Vessel Code-1977 Edition; Special Price for All Std. Spec. for Homogeneous Tool Resisting Steel Bars for Std. Spec. for Tool Resisting Composite Steel Bars for d. Spec. for Tool Resisting Steel Flat Bars and Shapes for

Plant

00

Information for Safety Analysis Reports: Industrial

1 Nuclear Material $(1 / 74$

bd $(\$ 70.00)$ II $(\$ 90.00)$

(o Support a Rule Making Petition Design Limits and Loading Combinations for and Fuel Fabrication Plants (10/73) Additional Information: Design of

Design Response Spectra for Damping Values for Power Generating Stations, Guide for (1975) $\$ 5.00$ Power Plants (3/76)

Equipment (2/7/ Information for Safety Analysis Reports: and Test Facilities (1-74)

Combining Modal Responses and Spatial Components in lntegrity and Test Specifications for Integrity and Test Specifications for al Water Bod/ Reporting Procedure for Mathematical Models ed Practice for (1975) \$9.50

te, Practice for (1971) ACI 211.2-1969\$2.75

ortions for Normal and Heavy Weight Concrete, Practice for

lants (1971) ANS-3.1\$10.00

Pipe Hangers and Supports-

iners for Onsite Storage of Special Nuclear Materials (7/ ASTM E432-1971 \$1.75

power Supplies (Safety Guide 9, 3/10/71)

eas (Revision 1, 4/75)

de for (1974) ASTM E419.1973 \$1.75

73) $\$ 1.75$

Recommended Practice for

Neutron Activation Detector Maierials, Guide for atings (Paints) for Fuel Reprocessing Plants (6/75)

Continuous Determination of Sodium in Water by Ion functional Specification Standard (1975) $\$ 3.00$

nbs Handbook $116 \$ 2.00$

Radioactive Flammability of

(1968) (R 1974) IEEE Std. 300-1969 (Agrees with IEC 333)/ (1969) IEEE Std. 301-1/

als (1969) ASTM E290-1968 \$1.75

Std. Spec. for High Temperature Glass Cloth Pressure cial Nuclear Materials (7) Selection and Use of PressureControl of the Use of

$t,(4-70)$

$71)$ Eddy Current Probe Type Flow Inductive Level Measurement Resistive Level Measurement td. Issued for Use and Comme/ ooled Nuclear Power Reactors (

Is (1974) ASTM E509-74 \$1.75

Is $(1974) \$ 1.75$

Draft Standard Criteria for r (1971) $\$ 1.75$

Recommended Guide for in
Polymeric Materials for Polymeric Materials for
Polymeric Materials for emical Oxygen Meter for Diffusion Carbon Meter for Diffusion Carbon Meter for
Oxygen-Hydrogen Meter Module for Carbon Meter Equilibration Module for the Reactor Enclosure System (7-73) Visual in

Seamless Carbon Steel for High Temperature Plugging Temperature Indicator Assembly for Sodium 75) S/ Alloy Steel Bolting Material for High Temperature

75) Su/ Alloy Steel Bolting Material for Low Temperature loy Bars, Forgings, and Forging Stock for High Temperature Low Level Flux Monitor Mechanical System for Liquid Metal Filter for Sodium Tank for Gas

Reactor Vessel for Liquid Metal Materials for Instruments in Radiation Std. Relating to Personnel Dosimeter loy Bars, Forgings, and Forging Stock for High Temperature loy Bars, Forgings, and Forging Stock for High Temperature loy Bars, Forgings, and Forging Stock for High Temperature rical Resistance Heaters, for Nuclear or Other Specialized nitic Stainless Steel Tubing (Small-Diameter) for General
Seamless Tubes (ASME SB - 163 with Additional Requireme Seamless Tubes (ASME SB-163 with Additional Requiremen Seamless Tubes, Specification for (1975) \$1.75

Seamless-Ferritic Alloy Steel Pipe for High Temperatur

Seamless, Corrosion and Heat Resistant Nickel Base-19C

Seamless, Corrosion and Heat Resistant Nickel Consumabl

Sections by Means of the Guarded Hot Box, Method of Tes

Sections: Bound Edition \$1200.00: Loose-Leaf Edition \$

Security Applications (1974) ASTM A627-1968 \$1.75

Security Applications (1974) ASTM A628-1973 \$1.75

Security Applications (1974) ASTM A629-1971 \$1.75

Security Duties (1/75)

Security for Nuclear Power Plants (12/74)

Security for Nuclear Power Plants (1973) (ANS-3.3) $\$ 10$

Security Seals for the Protection and Control of Specia

Sec. III Div. 1, Nuclear Power Plant Components (1977)

Seeking an Exemption for a Radionuclide-Containing Pro

Seismic Category 1 Fluid System Components (5/73)

Seismic Category 1 Structures (11/74)

Seismic Design Classification for Plutonium Processing

Seismic Design Classification (Revision 2, 2/76)

Seismic Design of Nuclear Power Plants (Revision 1, 12/

Seismic Design of Nuclear Power Plants (10/73)

Seismic Qualification of Electric Equipment for Nuclear Seismic Qualification of Electric Equipment for Nuclear

Seismic Qualification of Instrumentation and Electrical

Seismic Requirements for Design of Nuclear Power Plants

Seismic Response Analysis (Revision 1, 2/76)

Selected Brachytherapy Sources (Revision 1, 7/74)

Selected Brachytherapy Sources (1973) $\$ 3.50$

Selected to Predict Heated Effluent Dispersion in Natur

Selecting Proportions for No-Slump Concrete, Recommend Selecting Proportions for Structural Lightweight Concre

Selecting (1974) ACl 211.1-1974\$2.75

Selection and Application (1966) $\$ 4.00$

Selection and Training of Personnel for Nuclear Power $P$

Selection and Training (Revision 1, 1/9/75)

Selection and Use of Pressure-Sensitive Seals on Conta

Selection of a Leak Testing Method, Guide for the (1973

Selection of Diesel Generator Set Capacity for Standby

Selection of Material Balance Areas and Item Control Ar

Selection of Neutron Activation Detector Materials, Gui

Selection of Vapor Barriers for Thermal Insulations (19

Selection of (1973) $\$ 1.75$

Selection, Application, and Inspection of Protective Co

Selective Electrode (1973) $\$ 1.75$

Self Operated and Power Operated Safety Related Valves

Self-Luminous Light Sources, Classification of (1975)

Self-Supporting Plastics, Test for (1974) $\$ 1.75$

Semiconductor Radiation Detectors, Test Procedures for

Semiconductor Radiation Detectors, Test Procedures for

Semi-Guided Bend Test for Ductility of Metallic Materi

Sensitive Electrical Tape (1973) $\$ 1.75$

Sensitive Seals on Containers for Onsite Storage of Spe

Sensitized Stainless Steel (5/73)

Sensor for Liquid Metal Service (6-73)

Sensor for Use in Liquid Metal (3-75) Supersedes C5-1

Sensor for Use in Liquid Metal (4-70) Amendment 1 (10.

Separation of Class 1 E Equipment and Circuits, (Trial S

Serial Numbering of Fuel Assemblies for Light-Water-C

Service Annealing of Water Cooled Nuclear Reactor Vesse

Service Annealing of Water Cooled Nuclear Reactor Vesse

Service in lonizing Radiation, Classification System Fo

Service in lonizing Radiation, Classification System Fo

Service in Liquid Sodium (1-72)

Service in Liquid Sodium (1-72)

Service in Liquid Sodium (1-72)

Service in Liquid Sodium (1-72)

Service Inspection System and Associated Equipment for

Service Specification for (1975) \$1.75

Service Supersedes E4-19T, (8-71)

Service (ASME SA-193 with Additional Requirements) (2Service (ASME SA-194 with Additional Requirements) (2Service (ASME SA-320 with Additional Requirements) (2Service (ASTM a 637 with Additional Requirements) (12-

Service (Fabrication Only) (7-72) Amendment 1 (7-73)

Service $(1-73)$

Service (11-72) Amendment 1 (1-74)

Service (12-73) Supersedes (10-72), Amendment 1

Service (1957) $\$ 5.00$

Service (1971) $\$ 0.50$

Service (1973) ASTM A637-1970 \$1.75

Service (1973) ASTM A638-1970 \$1.75

Service (1973) ASTM A639-1970 \$1.75

Service (1973) ASTM E420-1971 \$1.75

Service (1974) ASTM A632-1969 \$1.75
ERDA

ERDA

ASTM

ASTM

ANSI

ANS

ANSI

ASME

ANSI

ANS1

St ANSI

NRC

NRC

ANS

NRC

ASME

NRC

NRC

NRC

NRC

NRC

NRC

NRC

IEEE

NRC

NRC

ERDA

NRC

NRC

ANSI

NRC

$\mathrm{ACI}$

ANSI

Prop ANSI

MSS

ANSI

NRC

NRC

ANSI

NRC

NRC

ANSI

ASTM

ASTM

NRC

ASTM

ANSI

ANSI

ASTM

ANS1

ANS1

ANS1

ASTM

NRC

NRC

ERDA

ERDA

ERDA

ANSI

NRC

ANS1

ASTM

ANSI

ASTM

ERDA

ERDA

ERDA

ERDA

ERDA

ASTM

ERDA

ERDA

ERDA

ERDA

ERDA

ERDA

ERDA

ERDA

ISA

NSF

[Dening Nickel Al ANS1

Ron Base Superal ANSI

/Lt Containing AI ANSI

/ Sheathed Elect ANSI

/and Welded Auste ANSI

RDT M3-18T

RDT M3-4T

B210

A335

G87.77

G87.78

Z98.2

CODE-77

G24.45

G24.46

G24.47

RG 5.43

RG 1.70.15

N18.17

RG 5.15

SEC-III-A

RG 6.7

RG 1.48

RG 1.70 .9

RG 3.14 
ion for Seamless and Welded Steel Pipe for Low Temperature f Wrought Carbon Steel and Alloy Steel for Low Temperature 1) Freeze Vent for Sodium

Rotor, Roller Nut Control Rod Drive Mechanism for Sodium ion High Temperature Pressure Transmitter for Liquid Metal ), Amendment 3 (5-) Electromagnetic Pump for Liquid Metal Fabrication of Core Component Pot for Liquid Meta Vapor Trap Assemblies for Sodium manent Magnet Flow Through Type Flowmeter for Liquid Meta Pipe Hangers, Supports and Snubbers for Liquid Metal High Strength Alloys for Core Components for Liquid Metal Class 1 Valves for Liquid Metal Eddy Current Probe Type Flow Sensor for Liquid Metal Class 2 Valves for Liquid Meta and Installation of Piping Subassemblies for Liquid Meta Thermowell Systems for Liquid Metal (3-72), Amendment 2 (11-72), Amendm/ Tank Liquid Metal sign and Construction of Nonmetallic Gaskets for Corrosive

rical Resistance Heaters, for Nuclear or Other Specialized and Zirconium Alloy Seamless and Welded Tubes for Nuclear Seamless-Ferritic Alloy Steel Pipe for High Temperature el Plates, Carbon Steel for Moderate and Lower Temperature es, Carbon Steel for Intermediate-and Higher-Temperature $s$ and Welded Austenitic Stainless Steel Tubing for Genera austenitic Steel Pipe for High Temperature Central Station nd Welded Carbon and Alloy Steel Tubes for Low Temperature Electric-Fusion-Welded Steel Pipe for High Pressure

ustenitic Steel Forged and Bored Pipe for High Temperature trifugally Cast Austenitic Steel Pipe for High Temperature tic Alloy Steel Forged and Bored Pipe for High Temperature ugally Cast Ferritic Alloy Steel Pipe for High Temperature tic Chromium-Nickel Alloy Steel Pipe for High Temperature

Nickel Alloy Steel Pipe for Corrosive or High Temperature and Zirconium Alloy Seamless and Welded Tubes for Nuclear 3/10/71) Selection of Diesel Generator
h

olled Steel Pipe Flanges, and Valves and Parts for General h Energy Nuclear Radiation, Testing (1968) (/ Compression 12.50 1974) $\$ 1.75$

449 with Additional Requiremen/ ication for (1970) $\$ 1.75$

nder Static Axial Load (1974) $\$ 1.75$

mp (7-72) Supersedes E3-3T, (10-70) nt of Soil and Soil Agregate in Place by Nuclear Methods nt of Soil and Soil Aggregate in Place by Nuclear Methods $\$ 1.75$ $y$ of Soil and Soil-Aggregate in Place by Nuclear Methods Std. Spec. for Tool Resisting Steel Flat Bars and

74) Supersedes M7-3T, (10-73/ Stainless Steel Bars and Specification for Copper-Silicon Alloy Rod, Bar, and Spec. for Copper and Copper Alloy Forging Rod, Bar, and Specification for Aluminum Bronze Rod, Bar, and age-Hardening Stainless and Heat Resisting Steel Bars and Cobalt-Chromium Alloy Bars and Prements)/ Precipitation-Hardening Stainless Steel Bars,
Specification for Aluminum-Alloy Extruded Bars, Rods, oatings on Products Fabricated/ Specification for Aluminum-Alloy Standard Structural i-Unit Nuclear Power Plants (Revision 1, 1/75) erials (1973) $\$ 1.75$ l-to-Metal), Meth/

Strength Properties of Adhesives in Test for Fatigue Properties of Adhesives in Test for Shear Strength and s (1970) $\$ 1.75$ Test for ns (1973) (ASTM D3080-1972) \$/ Method of Test for Direct other Specialized Service (1973) ASTM / Specification for other Specialized Service, Specification for (1971) \$1.7/ d Alumel, Solid Conductor (Bare, Fiberglass Insulated, and nstantan, Solid Conductor (Bare, Fiberglass Insulated, and nstantan, Solid Conductor (Bare, Fiberglass Insulated, and

d Life Test of Electrical Grade Magnesium Oxide as Used in le Assemblies, Magnesium-Oxide Insulated, Stainless Stee couple Material, Iron Constantan, Mineral Oxide Insulated, le Material, Copper-Constantan, Mineral-Oxide Insulated couple Assembly, Chromel-P Versus Alumel, Stainless Steel Supersedes C7-14T, (3-70), in Part Amendment 1 / Metal 2) er (3-75) Supersedes P4-3T, (2-74) ity Applications, Specification for (1967) Time Response Test for lity Applications, Specification for (197) ents) (1/-75) Supers/ Nickel-Molybdenum-Chromium Alloy $71 \$ 1.75$ $73 \$ 1.75$ Nickel-Molybdenum-Chromium Alloy
kel-Molybdenum-Chromium-Iron Alloy gth, Low Alloy Columbium and/or Vanadium, Specific/ Stee
Service (1975) \$1.75

Service (1975) \$1.75

Service (2-71) Amendment 1 (9-71), Amendment 2 (12-7 Service (3-71) Amendment 1 (12-72), Amendment 2 (8-7

Service (3-71) Amendment 1 (5-71); Superseded by Amen Service (3-71) Amendment 1 (9-71), Amendment 2 (1.74 Service (3-72) Amendment 1 (3-74)

Service (4-72) Amendment 1 (5-73), Amendment 2 (1-74 Service (4-73)

Service $(5-72)$

Service $(5-74)$

Service (5-75) Supersedes E1-18T, (2-71)

Service (6-73)

Service (6-74) Supersedes E1-19T, (9/70)

Service (8-71) Amendment 1 (11-72), Amendment 2 (6-7

Service (8-72) Amendment 1 (8-73), Amendment 2 (5-74

Service (9-71) Supersedes E10-3T, (9-70) Amendment 1

Service, Practice for (1971) \$1.75

Service, Specification for (1971) \$1.75

Service, Specification for (1973) ASTM B353-1971 \$1.7

Service, Specification for (1974A) $\$ 1.75$

Service, Specification for (1974A) \$1.75

Service, Specification for (1974B) $\$ 1.75$

Service, Specification for (1974) $\$ 1.75$

Service, Specification for (1974) $\$ 1.75$

Service, Specification for (1974) $\$ 1.75$

Service, Specification for (1975) $\$ 1.75$

Service, Specification for (1975) $\$ 1.75$

Service, Specification for (1975) \$1.75

Service, Specification for (1975) $\$ 1.75$

Service, Specification for (1975) $\$ 1.75$

Service, Specification for (1975) \$1.75

Service, Specification for (1975) $\$ 1.75$

Service, Spec. for (1971) \$1.75

Service, Spec. for (1976) $\$ 1.75$ For

Set Induced in Vulcanized Rubber During Exposure to Hig

Set Induced in Vulcanized Rubber During Exposure to Hig

Setpoints (11/75)

Sets for Reactor Design Calculations (1975) ANS-19.1 \$

Setting of Hydraulic Cement by Vicat Needle, Test for (

Setting Thermal Insulating and Finishing Cement (ASTM C

Setting Thermal Insulating and Finishing Cement, Speci

Settlement Relationship for Individual Vertical Piles $U$

Shaft Sealed, Motor Driven, Single Stage Centrifugal Pu

(Shallow Depths), Test for (1972) \$1.75 Moisture

(Shallow Depth) (1972) \$1.75 (ASTM

Shapes for Security Applications (1974) ASTM A629-197

Shapes for Use in Boilers and Other Pressure Vessels (1

Shapes (ASME SA-479 with Additional Requirements) (1 l-

Shapes (1974A) $\$ 1.75$

Shapes (1974) $\$ 1.75$

Shapes (1974) $\$ 1.75$

Shapes (1974) $\$ 1.75$

Shapes (4-75) Supersedes M7-7T, (7-71)

Shapes, and Forgings (ASME SA-564 with Additional Requ

Shapes, and Tubes (1974) ASTM B221-73 \$1.75

Shapes, Plates, Bars and Strip, Zinc (Hot Galvanized) C

Shapes, Rolled or Extruded (1974) ASTM B308-1973 \$1.75

Shared Emergency and Shutdown Electric Systems for Mult

Sharp-Notch Tension Testing of High Strength Sheet Mat

Shear by Tension Loading at Elevated Temperatures (Meta

Shear by Tension Loading (1973) $\$ 1.75$

Shear Modulus of Structural Adhesives (1970) $\$ 1.75$

Shear Strength and Shear Modulus of Structural Adhesive

Shear Test of Soils Under Consolidated Drained Conditio

Sheathed Electrical Resistance Heaters, for Nuclear or

Sheathed Electrical Resistance Heaters, for Nuclear or

Sheathed Over Fiberglass Insulation) (1-73)

Sheathed Over Fiberglass Insulation) (4-70)

Sheathed Over Fiberglass Insulation) $(4 / 70)$

Sheathed Type Electric Heating Elements (1970) $\$ 1.75$

Sheathed $(1-72)$

Sheathed (4-70) Supersedes C7-14T, (3-70), in Part a

Sheathed (4-70) Supersedes C7-14T, (3-70), in Part a

Sheathed, Magnesium Oxide Insulated (2-75) Supersedes

Sheathed, Mineral Insulated Cable Bulk Material (2-73)

Sheathed, Mineral Insulated Thermocouple Assembly (6-7

Sheathed, Mineral-Insulated Electrical Resistance Heat

Sheathed, Type K for Nuclear or for Other High Reliabil

Sheathed, Type K, for Nuclear or for Other High Reliabi

Sheet and Plate (ASME SB -434 with Additional Requirem

Sheet and Plate, Specification for (1973) ASTM B434-19

Sheet and Plate, Specification for (1974) ASTM B209-19

Sheet and Strip, Hot Rolled and Cold Rolled, High Stren ecificat ASTM

ASTM

ERDA

ERDA

ERDA

ERDA

ERDA

ERDA

ERDA

ERDA

ERDA
ERDA

ERDA

ERDA

ERDA

ERDA

De ASTM

ASTM

ANSI

ASTM

essel Plat ASTM

Seamles ASTM

Seamless ASTM

eamless a ASTM

ASTM

ASTM

Cen ASTM

Ferri ASTM

Centrif ASTM

ASTM

ASTM

ASTM

ASTM

ANSI

ASTM

NRC

ANSI

ASTM

ERDA

ASTM

ASTM

ERDA

ASTM

ANSI

ASTM

ASTM

ERDA

ASTM

ASTM

ASTM

ASTM

ERDA

ERDA

ANSI

ANSI

NRC

ASTM
ANSI

ASTM

ASTM

ASTM

ANSI

ANSI

ASTM

/El-P an ERDA

$\mathrm{N}$ and $\mathrm{Co}$ ERDA

Er and Co ERDA

ASTM

ERDA

ERDA

ERDA

ERDA

ERDA

ERDA

ASTM

ANSI

ERDA

ANSI

ANSI

ANSI

A 333

A420

RDT E4-13T

RDT E6-5T

RDT C6-1T

RDT E3-9T

RDT E6-34T

RDT E4-14T

RDT C4-6T

RDT E7-6T

RDT E6-40T

RDT E 1-18T

RDT C4-7T

RDT E 1-19T

RDT F6-11T

RDT C7-18T

RDT E 10-3T

F336

E420

N 124

A 335
A 516

A5 15

A269

A 376

A 334

A 155
A430

A451

A369

A426

A 358

A409

B 353
A 181

RG 1.9

$\mathrm{J} 2.33$

D2309 
Corrosion-Rcsisting Chromium Stecl Clad Platc, Nickcl-Copper Alloy (UNS N04400) Platc, 1.75 Copper-Nickel Alloy Plate and (1970) (R1975) ASTM C171-1969 (1975) \$1.75 Sharp-Notch Tension Testing of High Strength

75 $972 \$ 1.75$ Std. Spec. for Carbon Steel Cold Rolled Carbon Steel Titanium and Titanium Alloy Strip, Titanium and Titanium Alloy Strip, Austenitic Stainless Stecl Plate, s) Heat Resisting Chromium-Nickel Stainless Steel Plate, ) (/ Nickel-Chromium-Molybdenum-Columbium Alloy Plate, ents) (11-74) Supersedes M5-1T, Stainless Stecl Plate, ents) (1-75) Supers ents) (9-75) Supers Nickel-Chromium-Iron Alloy Plate, $75)$ Nickcl-Chromium-Molybdenum-Columbium Alloy Plate, $970 \$ 1.75 \quad$ Nickel-Chromium-Iron Alloy Plate, 1971 Nickel-Chromium-Molybdenum-Columbium Alloy Plate, Stainlcss Chromium-Nickel Stcel Clad Plate,
Nickel-Iron-Chromium Alloy Plate, stainless and Heat Resisting Chromium-Nickel Steel Plate,

Stainless and Heat Resisting Chro Nickel Plate, ecification for (1975) $\$ 1.75$ 973) SAE AMS5500A-1969 $\$ 3.00$ Carbon Steel 393-1964 \$1.75 Columbium and Columbium Alloy Strip. ication for (1973) ASTM B3/ Zirconium and Zirconium Alloy ication for (1967) \$1.75 Zirconium and Zirconium Alloy ickel Base-19Cr-3.1 Mo-5.1 (Cb \& Ta)-0.90Ti-0./ Alloy ickel Base-19Cr-3.1Mo-5.1 (Cb \& Ta)-0.90Ti-0./ (1974A) $\$ 1.75$

\section{Constituents of Aggregates for Radiat}

Copper Aggregates for Radiation-

Gamma Ray Protection for Energies Up to $10 \mathrm{MeV}$ Structural tions (1964) $\$ 2.00$

ns- $6.3 \$ 5.00$

Testing Biological

Instrumentation and Control Equipment Grounding and (4-72), Amendment 2 (7-73), Amendment 3 (3/ Core Radial tor Vessel Head (4-73) Amendment 1 (1-74)

cal Shielding in Research and Training Reactors (5/73)

(8-73) Amendment 1 ( 11 -73)

astm C 638-1971 Constituents of Aggregates for Radiation$1973 \$ 1.75$ A ggregates for Radiation-

shield Test Program for Evaluation of Installed Biological or Nuclear Criticality Safety Controls in Operations Where Concrete Radiation Concrete Radiation Concrete Radiation

Amend/ Packaging, Packing, and Marking of Components for and Commen/ Draft Std. for Leakage Tests on Packages for Leakage Tests on Packages for

Specially Designed Vehicle and Armed Guards for Road e for Verifying Compliance with Packaging Requirements for ns from Certain NRC Requirements Over Radioactive Material

$\mathrm{f}$ Transportation Special Permits for Radioactive Materials

Nuclear Materials, Concepts

1 Nuclear Materials $(6 / 74)$

mendment $1(11-73)$

$\$ 1.75$

Inspection and Preventive Maintenance of Fue

75

Cylindrical

Administrative Guide for Liability Insurance Aspects of materials, Guide to Design and Use of (1975) $\$ 5.00$

nuclear Power Plants (During the Construction/

Packaging, Water Coo/ Quality Assurance Requirem ents for Packaging, rangement, and Other Provisions for Nuclear Cargo Vessels enent, and Other Provisions for Nuclear Passenger Vessels rrangement, and Other Provisions for Nuclear Tank Vessel safety Considerations for Nuclear Power Plants on Merchant Classification of Nuclear ent, and Other Provisions for Use of Dangerous Articles as n Basis for Fuel and Irradiations Experiment Resistance to Recommended Practice for Controlled

170)

ion Subjected to Soaking Heat / Plants (Revision 1, 1/75)
Thermal

Operating Manuals for Fuel Method of Test for Linear Shared Emergency and
Shcct and Strip, Spccification for (1974A) \$1.75

Shect and Strip, Spccification for (1974) \$1.75

Shect for Pressurc Vesscls, Specification for (1975A) \$

Shcet Matcrials for Curing Concrcte, Specifications for

Shcct Materials (1973) \$1.75

Sheets for Pressure Vessels (1972) ASTM A414-1971\$1.7

Shcets, Commercial Quality, Specification for (1972) \$1

Sheet, and Plate, Spccification for (1973) ASTM B265-1

Shect, and Plate, Spcc. for (1974) \$1.75

Sheet, and Strip for Core Componcnts (3-73)

Sheet, and Strip for Fusion-Welded Unfired Pressure Ve

Sheet, and Strip (AMS 5596 with Additional Requircments

Sheet, and Strip (ASME SA-240 with Additional Rcquirem

Sheet, and Strip (ASME SB-168 with Additional Rcquirem

Sheet, and Strip (ASME SB-409 with Additional Rcquirem

Sheet, and Strip (ASTM B 352 with Additional Requircmen

Sheet, and Strip 5597 with Additional Requirements) (8-

Sheet, and Strip, Specification for (1973) ASTM B168-1

Sheet, and Strip, Specification for (1973) (ASTM B443-

Sheet, and Strip, Specification for (1974A) \$1.75

Sheet, and Strip, Specification for (1974) ASTM B409-1

Sheet, and Strip, Specification for (1974) \$1.75

Sheet, and Strip, Specification for (1974) \$1.75

Sheet, and Strip, Specification for (1975) \$1.75

Shect, Cold Rolled, Drawing Quality, Special Killed, Sp

Sheet, Corrosion Resistant, Laminated Surface Bonded ( 1

Sheet, Foil, and Plate, Specification for (1973) ASTM B

Sheet, Strip, and Plate for Nuclear Application, Specif

Sheet, Strip, and Plate for Nuclear Application, Specif

Sheet, Strip, and Plate, Corrosion and Heat Resistant $N$

Sheet, Strip, and Plate, Corrosion and Heat Resistant N

Sheet, Strip, Plate, and Rolled Bar, Specification for

Sheilding Concrete, Descriptive Nomenclature of (1973)

Sheilding Concrete, Spec. for (1973) \$1.75

Sheilding Design and Evaluation (1970) $\$ 4.00$

Sheilding for High Energy Electron Accelerator Installa

Sheilding in Nuclear Power Plants, Program for (1972) a

Sheilding Practices (1/73) Amendment 1 (1/75)

Shield for Sodium Cooled Reactors (12-71) Amendment 1

Shield Plug and Closure Cap for Penetrations LMFBR Reac

Shield Test Program for Evaluation of Installed Biologi

Shielded Instrumentation Cable (6-74)

Shielded Shipping Cask for Spent Reactor Fuel Elements

Shielding Concrete, Descriptive Nomenclature of (1975)

Shielding Concrete, Specification for (1975) ASTM C637-

Shielding in Research and Training Reactors (5/73)

Shielding Protects Personnel (1975) ANS 8.10 $\$ 8.00$

Shields for Nuclear Power Plants (12/73)

Shields (1972) ANS-11.13\$10.00

Shields $(6 / 73)$

Shipment and Storage (9-75) Supersedes F7-2T, (2-69)

Shipment of Radioactive Materials (Issued for Trial Use

Shipment of Radioactive Materials (6/75)

Shipment of Special Nuclear Material (Revision 1, 4/75)

Shipments of Radioactive Materials (1975) $\$ 4.50$

Shipments $(6 / 75)$

/Trative Guide for Obtai

Shipments, Administrative Guide for (1973) $\$ 3.00$

Shippers Regulations (1975) $\$ 6.80$

Shipper-Receiver Differences in the Transfer of Specia

Shipper-Receiver Differences in the Transfer of Specia

Shipping Cases and Crates, Testing (1973) \$1.75

Shipping Cask for Spent Reactor Fuel Elements (8-73) a

Shipping Container Tiedown for Truck Transport (1-75)

Shipping Containers by Cycle Method, of Test for (1973)

Shipping Containers (1-75)

Shipping Containers (1971) $\$ 1.75$

Shipping Containers, Drop Test for (1973) $\$ 1.75$

Shipping Containers, Drop Test for (1973) \$1.75

Shipping Containers, Incline Impact Test for (1973) \$1.

Shipping Containers, Vibration Test for (1975) $\$ 1.75$

Shipping Nuclear Materials (1973) $\$ 3.50$

Shipping Packages for Type a Ouantities of Radioactive

Shipping, Receiving, Storage and Handling of Items for

Shipping, Receiving, Storage, and Handling of Items for

(Ships and Barges).(1975) \$1.95

(Ships and Barges) (1975) \$2.05

(Ships and Barges) (1975) \$2.15

/Ecial Construction, Ar

/L Construction, Arrang

Ships (1965) $\$ 7.50$

Ships, Guide for the (1962) $\$ 1.00$

Ships, Stores and Supplies on Board Vessels (1975) $\$ 7.5$

Shock and Vibration in Truck Transport (2-75)

Shock Input Tests for Shipping Containers (1971) \$1.75

Shock to Reactor Pressure Vessels (Safety Guide 2, $11 / 2$

Shopping Containers (1-75)

Shrinkage of Preformed High Temperature Thermal Insulat

Shutdown Electric Systems for Multi-Unit Nuclear Power

N $\mathrm{N} O$

ANS1 A37.7

ASTM E338

G33.4

ASTM 366

ANS1 Z179.

ASTM B265

ERDA

ASTM

ERDA

ERDA

ERDA

ERDA

ERDA

ERDA

ANSI

ANSI

ASTM

ANSI

ASTM

ASTM

ASTM

ASTM

ANSI

ANSI

ANSI

ASTM

ANSI

ANSI

ASTM

ASTM

ASTM

RDT
A240

RDT M5-21T

RDT M5-1T

RDT M5-4T

RDT M5-7T

RDT M5-6T

RDT M5-20T

H34.10

H34.19

A264

H34.40

A 167

B 162

A. 76

A620

G87.1

Z179.20

N1 23

B352

G87.84

G87.85

B152

C638

C637

R34

R31

N18.9

ANSI

ERDA

RDT C 1-1T

ERDA RDT E6.23

ERDA

NRC

ERDA

ERDA

ANSI

ANSI

NRC

/ F ANSI

NRC

ANS1

NRC

ERDA

ANSI

NRC

NRC

Guid ANS1

NRC

ANS

ANSI

NRC

ASTM

ERDA

ERDA

ASTM

ERDA

ASTM

ASTM

ASTM

ASTM

ASTM

ANSI

ANSI

ANSI

NRC

RDT E2-4T 
for (1970) ASTM Cl17-1969/ Materials Finer Than No. 200 Method of Test for (1973) ASTM C136-1971 \$1.75 stm E11-1970 $\$ 1.75$ astm E323.1970 \$1.75

Wire-Cloth Perforated-Plate Std. Spec. for Precision Electroformed Eddy Current Flowmeter Power Supply and

) $\$ 2.50$

ion Exposure May Occur (1967) \$3.25 Immediate Evacuation Thermocouple Immediate Evacuation rential Pressure Transmitter, Pneumatic or Electric Output Krypton-85 in the Atmosphere Accumulation, Biological Indicating Which Places of Figures Are to Be Considered ng (1973) \$1.75

Duct Liner Materials and Prefabricated Test for Average Particle Size of Alumina and with Additional Requirements) (6-71) Amendment / Calcium on for (1972) $\$ 1.75$

Calcium

rical Insulation (1969) (R197/

Specification for CopperPressure Vessel Plates, Carbon Steel, ManganesePressure Vessel Plates, Heat Treated Carbon-ManganeseFittings (1970) $\$ 3.00$

1/ Chemical and Spectrochemical Analysis of Nuclear Grade ring Neutron Flux Density by Radioactivation of Cobalt and 75 Specification for Nuclear Grade Specification for Nuclear Grade Chemical and Spectrochemical Analysis of Nuclear Grade Analy/ High Temperature, Electrical, Magnetic, and Other or (1966) (R1973) A/ Flexural Strength of Concrete (Using amendment 1 (12-74)

Electric Heaters: ation Protection Syste/ $\$ 3.00$ 4)

4) Draft Standard Application of the Spec. for Top Running and Under Running Horizontal, Electric Motor Driven, Vertical, Canned or Wet Motor Driven Vertical, Shaft Sealed, Motor Driven,

Application of the Ultimate Heat

Specification for Nuclear Grade Specification for Nuclear Grade Specification for Nuclear Grade, Specification for Nuclear Grade,

$3 \$ 1.75$ Tungsten Forgings-Pressed,
ctivity in Effluents, Specification and Performance / On-
evision loneral evision $1,11 / 75$ )

General

to Occur on Transportation Routes Near Nuclear Power Plant
Spent Fuel Storage/ Guidance on the License Application, In

ducting Subcritical Neutron Multiplication Measurements in , Method of Test for (19/ Resistance to Abrasion of Small r (1970) $\$ 1.75$ 1.75 Particle s, Practice for (1972) $\$ 1.75$

Test for Average Particle Estimating the Average Grain Choice of Sample Specification for Standard Electric-Fusion (Arc)-Welded Steel Plate Pipe Connecting Flange Joint Between Tapping

1974) $\$ 1.75$

Selecting Proportions for No-

ass Spectrometer Helium Leak Detection for Instruments and a 632 with Additional Requirements) /

Seamless and Welded achine, Method of Test for (19/ Resistance to Abrasion of for Seamless and Welded Austenitic Stainless Steel Tubing
Pipe Hangers, Supports and Pipe Hangers, Supports and
Immersion Corrosion Test for Total Immersion Corrosion Test for

preformed High Temperature Thermal
Forged Steel Fittings,

) Amendment 1 (5-76)

Methods for the Analysis of by Flame Photometry, Tests for (1971) $\$ 1.75$

sducer, Proximity Measurement System (1-76)

(12-73)

o)

Liquid

8-73), Amendment 2 (3-74)

ment 1 (12-72), Amendment 2 /

dment $1(3-74)$

ment 1 (4-73)

endment 2 (7-73), Amendment 3 (3/

Guard Vessel for Primary Instrument Tree for Core Support Structure for

Core Restraint Mechanism for Core Radial Reflector for Fabrication of Control Rod Driveline for

ent $1(1-75)$

6T, $(5-72)$

Forced Circulation Cold Trap Assembly for Removal of

2-72), Amendment 2 (6-74) Continuous Determination of IT, $(4-73)$
Sieve in Mineral Aggregates by Washing, Method of Test Sieve or Screen Analysis of Fine and Coarse Aggregates, Sieves for Testing Purposes, Specification for (1973) a Sieves for Testing Purposes, Specifications for (1973) Sieves (1973) ASTM E161-1970

Signal Conditioning Electronics (2-73)

Signal Connectors for Nuclear Instruments (1968) (R1973 Signal for Use in Industrial Installations Where Radiat Signal Transmitter (11-71)

Signal $(2 / 16 / 73)$

Signal (4-74)

Significance, and Control Technology (1975) $\$ 4.00$ Significant in Specified Limiting Values, Recommended $\mathrm{P}$ Silencers for Acoustical and Airflow Performance, Testi Silica by Air Permeability (1972) $\$ 1.75$

Silicate Block and Pipe Thermal Insulation (ASTM C 533 Silicate Block and Pipe Thermal Insulation, Specificati Silicon Alloy Rod, Bar, and Shapes (1974A) \$1.75

Silicone Rubber Coated Glass Fabric and Tapes for Elect Silicon, Specification for (1974A) $\$ 1.75$

Silicon, Specification for (1975) $\$ 1.75$

Silver Brazing Joints for Cast and Wrought Solder Joint

Silver-Cadmium Alloys, Methods for (1974) ASTM C760-

Silver (1973T)

Silver-Indium-Cadmium Alloy (1973) \$1.75

Silver-Indium-Cadmium Alloy (1974) ASTM C752-1973 \$1

Silver-Indium-Cadmium Alloys (1974) \$1.75

Similar Iron, Nickel, and Cobalt-Base Alloys, Chemical

Simple Beam with Third Point Loading), Method of Test F

Simulated Core Assemblies for Nuclear Reactors (3-73)

Simulated LMFBR Fuel Pins (3-72)

Single Failure Criterion to Nuclear Power Generating St Single Girder Electric Overhead Traveling Cranes (1974) Single Stage Centrifugal Pump (2-72) Amendment 1 (5-7 Single Stage Centrifugal Pump (6-72) Amendment 1 (5-7 Single Stage Centrifugal Pump (7-72) Supersedes E3-3T

Single-Failure Criterion to Nuclear Power Plant Protec

Sink for Nuclear Power Plants (Revision 2, 1/76)

Sinterable Plutonium Dioxide Powder (1974A) \$1.75

Sinterable Uranium Dioxide Powder (1973) \$1.75

Sinterable Uranium Dioxide Powder (1974) ASTM C753-197

Sinterable Uranium Dioxide Powder (1975) ASTM C757-197

Sintered, and Forged (1966) $\$ 3.00$

Site Instrumentation for Continuously Monitoring Radioa

Site Suitability Criteria for Nuclear Power Stations ( $R$

Sites (1/75) Evaluation of Explosions

Siting, Design, and Plant Protection for an Independent

Situ Assay of Enriched Uranium Resiaual Holdup (8/74)

Situ Assay of Plutonium Residual Holdup (5/74)

Situ, Safety in (1975) ANS-8.6\$6.50

Size Coarse Aggregate by Use of the Los Angeles Machine

Size Distribution of Granular Activated Carbon, Test Fo

Size of Alumina and Silica by Air Permeability (1972)

Size of Metals, Methods for (1974) $\$ 1.75$

Size to Estimate the Average Quality of a Lot or Proces

Sizes of Seamless Copper Pipe (1975) $\$ 1.75$

(Sizes 16 in. and Over), Specification for (1974) $\$ 1.75$

Sleeves and Tapping Valves (1969) $\$ 2.00$

Slump Concrete, Recommended Practice for (1975) $\$ 9.50$

Slump of Portland Cement Concrete, Method of Test for (

Small Components $(2-72)$

Small Diameter Austenitic Stainless Steel Tubing (ASTM

Small Size Coarse Aggregate by Use of the Los Angeles M

Small-Diameter) for General Service (1974) ASTM A632-

Snubbers for Liquid Metal Service (5-72)

Soak Tank Metal Cleaners (1972) \$1.75

Soaking Heat (1963) (R1969) ASTM C356-1960 (1967) \$1.7

Socket-Welding and Threaded (1973) $\$ 3.00$

Socket-Welding Reducer Inserts (1974) $\$ 4.00$

Sodium and Cover Gas (1-76) Supersedes F3-40T, (1-73

Sodium and Potassium in Water and Water Formed Deposits

Sodium Bearing Film Thickness, Variable Reluctance Tran

Sodium Carbonate, Low Chloride Fire Extinguishing Agent

Sodium Containing Components (11-70) Amendment l (7-7

Sodium Cooled Reactors (Fabrication Only) Amendment 1 (

Sodium Cooled Reactors (Fabrication Only) (1-72) Amend

Sodium Cooled Reactors (Fabrication Only) (10-72) Amen

Sodium Cooled Reactors (Fabrication Only) (8-72) Amend

Sodium Cooled Reactors (12-71) Amendment 1 (4-72), Am

Sodium Cooled Reactors (4-73) Amendment 1 (3-74)

Sodium Cover Gas Purchase Specifications (7-72) Amendm

Sodium Heated Steam Generator (2-74), Supersedes E4-1

Sodium Impurities (1-76) Supersedes E4-5T, (12.70)

Sodium in Water by lon Selective Electrode (1973) $\$ 1.75$

Sodium Pump with Electrical Drive (5-71) Amendment 1

Sodium Purchase Specifications (9-73) Supersedes Ml3-
ANSI

ANSI

ANS

ANS

ANSI

ERDA

ANSI

ANSI

ERDA

NRC

Diffe ERDA

NCRP

ASTM

ASTM

ASTM

ERDA

ASTM

ASTM

ANSI

ASTM

ASTM

MSS

ANSI

ASTM

ASTM

A NSI

ASTM

STM

ANSI

ERDA

ERDA

ANSI

CMAA

ERDA

ERDA

ERDA

NRC

NRC

ASTM

ASTM

ANS

ANSI

SAE

ANS

NRC

NRC

NRC

NRC
NRC

Con ANS

ANSI

ASTM

ASTM

ASTM

ASTM

ASTM

ASTM

MSS

ASTM

ERDA

ERDA

ANSI

ANSI

ERDA

ASTM

ANSI

ANSI

MSS

ERDA

ASTM

ERDA

ERDA

ERDA

ERDA

ERDA

ERDA

ERDA

ERDA

ERDA

ERDA

ERDA

ERDA

ASTM

ERDA

ERDA

A 37.4

A 37.8

Z23.1

Z168.12

Z168.5

RDT C10-5T

N544

N2.3

RDT C10-1T

RG 8.5

RDT C6-2T

R44

E29

E477

C721 
Purity Requirements for Operating

Plugging Temperature Indicator Assembly for Filter for

(12-71) Freeze Vent for (1-74) apsible Rotor, Roller Nut Control Rod Drive Mechanism for (1973) $\$ 1.75$ Vapor Trap Assemblies for Electrochemical Oxygen Meter for Service in Liquid Diffusion Carbon Meter for Service in Liquid

Oxygen-Hydrogen Meter Module for Service in Liquid Carbon Meter Equilibration Module for Service in Liquid tipurpose Sampler) for the Analysis of Nonmetals in Liquid sient Reactor Test Facility (Treat) Experiments Containing Venturi Flow Tube for Liquid th) (197/ Method of Test for Moisture Content of Soil and ths), Test for (1972) \$1.75 Moisture Content of Soil and allow Depth) (197/ Method of Test for Moisture Content of allow Depths), Test for (1972) \$1.75 Moisture Content of hallow Depth), Tests for (1971) \$1.75 Density of 194-1972) \$1.75 Method of Test for Bearing Capacity of D2937-1971) \$1.75 Method of Test for Density of (ASTM D 1452-1966) \$1.75 Method for

Tests for Unconfined Compressive Strength of Cohesive $\$ 1.75$ in the Environment: Sampling and Analysis of Plutonium in

of Test for Unconsolidated, Undrained Strength of Cohesive m D3080-1972) \$/ Method of Test for Direct Shear Test of standard Methods of Test for Moisture Density Relations of oisture-Penetration Resistance Relations of Fine-Grained Test for Relative Density of Cohesionless

od of Test for One Dimensional Consolidation Properties of .8-mm) Drop, Tests for (/ Moisture-Density Relations of pth), Tests for (1971) $\$ 1.75$ $\$ 3.50$ Density of Soil and

Silver Brazing Joints for Cast and Wrought ed Over Fibe/ Thermocouple Material, Iron and Constantan, ed Over Fi/ Thermocouple Material, Copper and Constantan, ed Over Fi/ Thermocouple Material, Chromel-P and Alumel, Test for Thermal Failure Under Electric Stress of rocessing Plant/Design Objectives for Highly Radioactive iq/ Measuring, Evaluating, and Reporting Radioactivity in n Techniques Fo/ Calorimetric Assay of Plutonium-Bearing e Road Mixes, Method of Test for (1975) \$1.75 Water able Electrode or Vacuum Induction Melted 1750 F (954.4 C) able Electrode or Vacuum Induction Melted 1750 F (954.4 C) ti-0.50A 1 Consumable Electrode or Vacuum Induction Melted able Electrode or Vacuum Induction Melted $1950 \mathrm{~F}$ (1065.6C) ble Electrode or Vacuum Induction Melted 1950 F (1065.6 C) nt Nickel Base-19Cr-3.1Mo-5.1 (Cb \& Ta)-0.90Ti-0.50A Fast Flux Test Facility Uranyl Nitrate Fast Flux Facility Plutonium Nitrate ical, Mass Spectrometric, Spectr/ Grade Plutonium Nitrate Specification for Plutonium Nitrate y Det/ General Methods for the Analysis of Uranyl Nitrate Borosilicate Glass Raschig Rings as a Neutron Absorber in borosilicate-Glass Raschig Rings as a Neutron Absorber in Colorimetric Determination of Uranium in Aqueous ethod for Colorimetric Determination of Uranium in Aqueous radiochemical Determination of Cesium-137 in Nuclear Fuel Radiochemical Analysis of Nuclear Grade Plutonium Nitrate Methods for the Accountability of Plutonium Nitrate rometric, Spectrochemical, Nuclear Grade Plutonium Nitrate $\$ 1.75 \quad$ Nuclear Grade Uranyl Nitrate radiochemical Determination of Cesium-137 in Nuclear Fuel $\$ 1.75$ Analysis of undamental Frequencies of Carbon and Graphite Materials by on Rooms (1972) $\$ 1.75$ ement (1971) $\$ 1.75$

Test for Classification for Determination of nesium Sulfate, Method of Test for (1973) $\$ 1.75$

or the Preparation of Applications for Licenses to Process Logarithmic Count Rate

gu/ Independence Between Redundant Standby (Onsite) Power sification of Containment Properties of Sealed Radioactive and / Food Additives, Subpart G. Radiation and Radiation Leak Testing Radioactive Brachytherapy tegrity and Test Specifications for Selected Brachytherap Availability of Electric Power Protection Against Radiation from Brachythreapy Leak Testing Radioactive Brachytherapy tegrity and Test Specifications for Selected Brachytherapy Spec. of Gamma Ray Brachytherap 0 ndard for Installations Using Nonmedical Sealed Gamma-Ray
Radioactive Self-Luminous Light
Sodium Reactor Systems (3/76) Supersedes A I-5T, 5-73 Sodium Service Supersedcs E4-19T, (8-71)

Sodium Service (1-73)

Sodium Service (2-71) Amendment I (9-71), Amendment 2 Sodium Service (3-71) Amendment I (12-72), Amendment Sodium Service (4-72) Amendment I (5-73), Amcndment 2 Sodium Sulfate or Magnesium Sulfate, Method of Test for Sodium to Air Heat Exchanger (6-71), Amendment I (10Sodium $(1-72)$

Sodium (1-72)

Sodium $(1.72)$

Sodium $(1-72)$

Sodium (1-72) Amendment I (6-73)

Sodium ( 8-74)

Sodium (8-74) Supersedes C4-4T, (1-71) Soil Aggregate in Place by Nuclear Methods (Shallow Dep
Soil Aggregate in Place by Nuclear Methods (Shallow Dep Soil and Soil Aggregate in Place by Nuclear Methods (Sh Soil and Soil Aggregate in Place by Nuclear Methods (Sh Soil and Soil-Aggregate in Place by Nuclear Methods ( $S$ Soil for Static Load on Spread Footings (1972) (ASTM D 1 Soil in Place by the Drive Cylinder Method (1972) (ASTM Soil Investigation and Sampling by Auger Borings (1972) Soil (1972) (ASTM D 1266-1972) \$I.75

Soil $(5 / 74)$

Measurements of Radionuclides

Soils for Engineering Purposes (1972) (ASTM D2487-1969 Soils in Triaxial Compression (1972) (ASTM D2850-1970

Soils Under Consolidated Drained Conditions (1973) (Ast

Soils Using $10 \mathrm{lb}$. (4.5 mg) Rammer and 18 (457 mm) in.

Soils (1972) (ASTM D1558-1971) \$1.75

Soils (1972) (ASTM D2049-1969) $\$ 1.75$
Soils (1972) (ASTM D2435-1970) $\$ 1.75$

Soils, Using 5.5-lb. (2.5-kg) Rammer and 12-in. ( 304

Soil-Aggregate in Place by Nuclear Methods (Shallow De

Solder Joint Fittings for Sovent Drainage Systems (1973

Solder Joint Fittings (1970) $\$ 3.00$

Solid Conductor (Bare, Fiberglass Insulated, and Sheath

Solid Conductor (Bare, Fiberglass Insulated, and Sheath

Solid Conductor (Bare, Fiberglass Insulated, and Sheath

Solid Electrical Insulating Materials (1973) \$1.75

Solid Material Handling and Storage Facilities in a Rep

Solid Wastes and Releases of Radioactive Materials in $\mathrm{L}$

Solids Applied to Nuclear Materials Control, Calibratio

Soluble Chlorides Present as Admixes in Graded Aggregat

Solution Heat Treated (1973) SAE AMS 5596C-1968 \$3.00

Solution Heat Treated (1973) SAE AMS 5662C-1972 \$3.00

Solution Heat Treated (1975) $\$ 3.00$

$1-5.1(\mathrm{Cb}+\mathrm{Ta})$

Solution Treated (1973) SAE AMS 5590-1966 \$3.00 Base-

Solution Treated (1973) SAE AMS 5597A-1967\$3.00

Solution Treated (1973) (SAE AMS 5589-1966 \$3.00

Solution (6-71)

Solution (6-71)

Solutions and Plutonium Metal Standard Methods for Chem

Solutions ASTM C710-72 (1973) $\$ 1.75$

Solutions for Assay, Isotopic Distribution, and Impurit

Solutions of Fissile Material (1971) ANS-8.3 \$7.50

Solutions of Fissile Material (1/73)

Solutions Standard Method for (1975) \$1.75

Solutions (1973) ASTM E318-1969 \$1.75

Solutions (1973) ASTM E320-1970 \$1.75

IC, Spectrochemical Nuclear and

Solutions (1973) $\$ 1.75$

ASTM C759-1973\$1.75

Solutions, Methods for (1974) ASclear and Radiochemical Analysis of (1975)

Solutions, Specification for (1973) $\$ 1.75$

Solutions, Standard Method for (1970) $\$ 1.75$

Solvent Systems Used for Removal of Water Formed (1973)

Sonic Resonance (1974) \$1.75

Duli of Elasticity

Sound Absorption of Acoustical Materials in Reverberati

Sound Insulation in Buildings, Rec. Practice for Measur

Sound Transmission Class (1973) \$1.75

Soundness of Aggregates by Use of Sodium Sulfate or Mag

Source Material (7/76)

Source Range Neutron Flux Monitoring System (7-71)

Sources and Between Their Distribution Systems (Safety

Sources Contained in Certain Devices to Be Distributed

Sources Intended for Use in the Production, Processing,

Sources (Revision 1, 7/74)

Sources (Revision 1, 7/74)

Sources $(12 / 74)$

Sources (1972) $\$ 4.00$

Sources (1973) $\$ 3.50$

Sources (1973) $\$ 3.50$

Sources ( I 974) $\$ 3.00$

Sources $(6 / 74)$

Sources, Classification of (1975) NBS Handbook $116 \$ 2.0$
ERDA

ERDA

ERDA

ERDA

ERDA

ERDA

ASTM

ERDA

ERDA

ERDA

ERDA

ERDA

ERDA

ERDA

ANSI

ASTM

ANSI

ASTM

ASTM

ANSI

ANSI

ANS

ANSI

ANSI

ANSI

ANSI

ANSI

Meth ANSI

ASTM

ASTM

ANSI

MSS

ERDA

ERDA

ERDA

ASTM

ANSI

NRC

ANSI

ASTM

ANSI

ANSI

SAE

ANSI

/Uma ANSI

Sta ANSI

ERDA

ERDA

NRC

ANSI

NRC

IF ANSI

Use of NRC

ASTM

ANSI

ANSI

ASTM

NRC

ANSI

ASTM

ASTM

ASTM

A STM

ASTM

ASTM

ASTM

ASTM

ASTM

NRC

ERDA

NRC

NRC

FDA

NRC

i NRC

NRC

NCRP

ANSI

in ANSI

NCRP

NRC

ANSI

RDT A I-ST

RDT E4-19T

RDT E1]-2T

RDT E4-13T

RDT E6-5T

C88

RDT E4-7T

RDT C8-5T

RDT C8-7T

RDT E8-13T

RDT E8-14T

RDT C8-8T

RDT E16.1T

RDT C4-4T

A 37.184

D 3017

A 37.184

D3017

D2922

A37.158

A 37.181

A37.147

A 37.148

RG 4.5

A 37.173 
nstallations Using Non-Medical X-Ray and Sealed Gamma Ray Cast Bronze Solder Joint Fittings fo

75) $\$ 1.75$

$8-1969 \$ 1.75$ Fast Flux Test Facility Driver Fuel Pin Plenum

on $1,2 / 76$ ) Lattice Instrument

al Requirements for Bolting irements) (2-75) Super/ ial Requirements for Pipe and Tubing for Nuclear and Othe cial Requirements for Steel Castings for Nuclear and Othe pecial Requirements for Steel Plates for Nuclear and Othe

$\mathrm{n}$ for Wrought Steel Welding Fittings for Nuclear and Other

1 Requirements for Forgings and Bars for Nuclear and Other ments for (1973/ Steel Castings for the Nuclear and Othe ments for (1973) / Bolting Material for Nuclear and Othe ments for (1973) \$1.7/ Steel Plates for Nuclear and Other men/ Wrought Steel Welding Fittings for Nuclear and Other ments for (1973)/ Forgings and Bars for Nuclear and Othe Alloy Steel Bolting Materials for Ultrasonic Examination of Plain and Clad Steel Plates for

ial Requirements for Pipe and Tubing for Nuclear and Other s for Nuclear Tank Vessels (Ships and Barges) (1975) \$2./ for Transportation or Storage of Explosives or Other $\mathrm{Da}$ for Use of Dangerous Articles as Ships, Stores and Supp/ for Nuclear Powerplant Components (1975) $\$ 4.40$

for Nuclear Cargo Vessels (Ships and Barges) (1975) \$1./ for Nuclear Passenger Vessels (Ships and Barges) (1975)/ $10 / 73)$ Carbon Steel Sheet, Cold Rolled, Drawing Quality, of a Special Nuclea/ Standard Format and Content for the

Design Considerations for Minimizing Residual Holdup of Design Considerations for Minimizing Residual Holdup of ecial Nuclear Material Control and Accounting Section of A Mass Quan/ Guide for the Preparation of Applications for

lly Designed Vehicle and Armed Guards for Road Shipment of Security Seals for the Protection and Control of Internal Transfers of

Analysis and Use of Process Data for the Protection of Statistical Terminology and Notation for

Design Considerations for Minimizing Residual Holdup of e of Locks in the Protection and Control of Facilities and uation of Shipper-Receiver Differences in the Transfer of ssure-Sensitive Seals on Containers for Onsite Storage of uation of Shipper-Receiver Differences in the Transfer of ministrative Guid/ Obtaining Department of Transportation Lo/ ASME Boiler and Pressure Vessel Code-1977 Edition; nd Other Special Applications ASTM A61/ Specification for and Other Special Applications (1974) ASTM A65/ Spec. for d Other Special Applications, Specification for (1974) A d Other Special Applications /

Other Special Applications (1974) Ast/ Specification for ther Special Applications (1974) ASTM A647-19/ Spec. for

Nuclear and Other Special Applications, Specification for Nuclear and Other Special Applications, Specification for Nuclear and Other Special Applications, Specification for Nuclear and Other Special Applications, Specification for Nuclear and Other Special Applications, Specification for Matter Nonmailable Articles and Substances Under Mailable Matter Under Specification for

eathed Electrical Resistance Heaters, for Nuclear or Other eathed Electrical Resistance Heaters, for Nuclear or Other ipment of Special Nuclear Material (Revision 1, 4/75)

Guidance to Academic Institutions Applying for 74) ASTM C127-1973 $\$ 1.75$

\section{) $\$ 1.75$}

) (R1975) (ASTM C312-1955) \$1.75 Method of Test for Method of Test for Mean hich Places of Figures Are to Be Considered Significant in for the Analysis of Nonmetals in Liquid Sodium (1-72) and Curing Concrete Compressive and Flexural Strength Test $-1969 \$ 1.75$ Making and Curing Concrete Test Test for Elastic Moduli of Rock Core ASTM D1879-1970 $\$ 1.75$

1970) $\$ 1.75$ Exposure of Adhesive Exposure of Adhesive

$t$ for Triaxial Compressive Strength of Undrained Rock Core Method of Test for Direct Tensile Strength of Rock Core d of Test for Unconfined Compressive Strength of Rock Core Preparation of Metallographic gth of Hydraulic Cement Mortars (Using 2-in $(50-\mathrm{mm})$ Cube Splitting Tensile Strength of Cylindrical Concrete 75 Compressive Strength of Cylindrical Concrete $\$ 2.00$

and Poisson's Ratio in Compression of Cylindrical Concrete
Sources, Energies Up to 10-Mev, General Safety Standar Sovent Drainage Systems (1973) $\$ 3.50$

Spacer (6-71)

Spacing of Nuclear Graphite, Measurement of (1969) (R19 Spacing of Nuclear Graphite, Method for (1973) ASTM C55 Spans and Setpoints $(11 / 75)$

Spatial Components in Seismic Response Analysis (Revisi Special Applications ASTM A614-73 (1974) \$1.75

Special Applications (ASME SA-540 with Additional Requ Special Applications (1973) \$1.75 /Cification for

Special Applications (1974) ASTM A613-73 \$1.75 Special Applications (1974) ASTM A647-1973 \$1.75 Special Applications (1974) ASTM A652-1973 \$1.75 Special Applications (1974) ASTM A654-73 \$1.75 Special Applications, Specification for Special Require Special Applications, Specification for Special Require Special Applications, Specification for Special Require Special Applications, Specification for Special Require Special Applications, Specification for Special Require Special Applications, Specification for (1970) \$1.75 Special Applications, Specification for (1973) ASTM A57 Special Applications, Specification for (1974) ASTM A65 Special Consideration, Arrangement, and Other Provision Special Construction, Arrangement, and Other Provisions Special Construction, Arrangement, and Other Provisions Special Construction, Arrangement, and Other Provisions Special Construction, Arrangement, and Other Provisions Special Construction, Arrangenent, and Other Provisions Special Killed, Specification for (1975) \$1.75

Special Nuclear Material Contained in Scrap and Waste Special Nuclear Material Control and Accounting Section Special Nuclear Material Doorway Monitors (6/74)

Special Nuclear Material in Drying and Fluidized Bed Op Special Nuclear Material in Equipment for Dry Process O Special Nuclear Material License Application (Including Special Nuclear Material Licenses of Less Than Critical Special Nuclear Material (Revision 1, 4/75)

Special Nuclear Material (1/74)

Special Nuclear Material $(3 / 75)$

Special Nuclear Material $(6 / 74)$

Special Nuclear Materials Control Accountability (2/2/7

Special Nuclear Materials in Equipment for Wet Process

Special Nuclear Materials (11/73)

Special Nuclear Materials (6/74)

Special Nuclear Materials $(7 / 73)$

Special Nuclear Materials, Concepts and Principles for

Special Price for All Sections: Bound Edition $\$ 1200.00$ :

Special Requirements for Bolting Material for Nuclear Special Requirements for Forgings and Bars for Nuclear Special Requirements for Pipe and Tubing for Nuclear an Special Requirements for Pipe and Tubing for Nuclear an Special Requirements for Steel Castings for Nuclear and Special Requirements for Steel Plates for Nuclear and $O$ Special Requirements for (1973) \$1.75 Special Requirements for (1973) \$1.75 Special Requirements for (1973) \$1.75 Special Requirements for (1973) \$1.75 Special Requirements for (1973) $\$ 1.75$

Special Rules (1975)

Special Rules, Radioactive Materials (1975)

Specialized Carbon and Alloy Steel Pipe (1975) \$1.75 Specialized Service (1973) ASTM E420-1971 \$1.75 Specialized Service, Specification for (1971) \$1.75

Specially Designed Vehicle and Armed Guards for Road Sh Specific Byproduct Material Licenses (3/76)

Specific Gravity and Absorption of Coarse Aggregate (19 Specific Gravity and Absorption of Fine Aggregate (1973 Specific Heat of Thermal lnsulation, Practice for (1963 Specific Heat of Thermal Insulation, Test for (1961) (R Specified Limiting Values, Recommended Practice for (19 Specimen Equilibration Device (Or Multipurpose Sampler) Specimens in the Field, Method of (1970) ASTM C31-1969 Specimens in the Laboratory, Method of (1973) ASTM C192 Specimens in Uniaxial Compression (1972) \$1.75 Specimens to High Energy Radiation, Practice for (1973) Specimens to High Energy Radiation, Rec. Practice for ( Specimens Without Pore Pressure Measurements (1974) \$1. Specimens (1972) (ASTM D2936-1971) \$1.75 Specimens (1972) (ASTM D2938-1971A) \$1.75 Specimens (1974) \$1.75

Spect (1973) \$1.75

Specimens, Method of Test for (1974) ASTM C39-1972 \$1 Specimens, Method of Test (1967) (R1973) ASTM C469-196 Spectra for Physical and Biological Applications (1960)
ANSI

ANSI

ERDA

ASTM

ANSI

NRC

NRC

ISpeci ANSI

ERDA

ASTM

/R Spe ANSI

/R S ANSI

/Tio ANSI

/Pecia

ANSI

ASTM

ASTM

ASTM

ASTM

ASTM

ASTM

ANSI

ANSI

USCG

USCG

USCG

USCG

USCG

USCG

ASTM

NRC

NRC

NRC

NRC

NRC

NRC

Specia NRC

NRC

NRC

NRC

NRC

NRC

Eval NRC

NRC

ANSI

ASME

ANSI

ANSI

ANSI

ASTM

ANSI

ANSI

ASTM Gs and Bars for ASTM Ng Fittings for ASTM $\mathrm{Ng}$ Material for ASTM ASTM

USPS

USPS

ASTM

/ Sh ANSI

ASTM

NRC

NRC

ANSI

ASTM

ANS1

ASTM

ASTM

ERDA

ANS

ANS1

ASTM

ANS1

ASTM

ASTM

ANS1

ANS1

ASTM

ASTM

ANSI

ANS1

ANSI

NCRP

N543

B 16.32

RDT E13.11

C558

K90.1

RG 1.105

RG 1.92

N265

RDT M6-5T

A655

N558

N559

N560

N56

A613

A6 14

A647

A652

A654

A 540

G35.25

N564

46CFR 37

46CFR 146 
ision $1,12 / 73$ )

Design Response $\mathrm{x} /$ Standard Methods for Chemical, Mass Spectrometric, and ium Alloys, Methods for (1974) ASTM C760-I/ Chemical and m-Cadmium Alloys (1974) \$1.75

Chemical and

d/ Standard Methods for Chemical, Mass Spectrometric, and and Pellets, Methods for Chemical, Mass Spectrometric, and and Pellets, Methods for Chemical, Mass Spectrometric, and de by Gallium Oxide Carrier D-C Arc Technique, Method for xide by Gallium Oxide Carrier DC Arc Technique, Method for (U, Pu)o(2)), Methods for Chemical, Mass Spectrometric, and xed Oxides ( $\left.(\mathrm{U}, \mathrm{Pu}) \mathrm{O}_{2}\right)$ ), Chemical, Mass Spectrometric, and ide Powders and Pellets, Chemical, Mass Spectrometric, and ide Powders and Pellets, Chemical, Mass Spectrometric, and ear Grade Boron Carbide, Chemical, Mass Spectrometric, and beryllium Oxide Powders, Chemical, Mass Spectrometric, and beryllium Oxide Powders, Chemical, Mass Spectrometric, and 3) ASTM E158-1966 (1972) \$1.75

uclear Grade Plutonium Nit/ nuclear Grade Plutonium $\mathrm{Me} /$

Chemical, Mass Spectrometric, uranium Hexafluoride, Meth/ Chemical, Mass Spectrometric, Chemical, Mass Spectrometric, clear Grade Plutonium Metal, Chemical, Mass Spectrometric, m Metal Standard Methods for Chemical, Mass Spectrometric (19/Uranium Hexafluoride, Chemical, Mass Spectrometric, ons, Methods for (1974) As/ Chemical, Mass Spectrometric, small Components (2-72)

1973) $\$ 1.75$

ode (1973) $\$ 1.75$

the Tracer Probe Mode (/ Testing for Leaks Using the Mass

Tests for Leaks Using the Mass Testing for Leaks Using the $M$ ass Atom Percent Fission in Uranium and Plutonium Fuel (Mass Atom Percent Fission in Uranium and Plutonium Fuel (Mass um Dioxide Powders and Pellets, Methods for Chemical, Mass um Dioxide Powders and Pellets, Methods for Chemical, Mass grade Uranium Dioxid/ Standard Methods for Chemical, Mass grade Plutonium Diox/ Standard Methods for Chemical, Mass rade Mixed Oxides ( $\left.(\mathrm{U}, \mathrm{Pu}) \mathrm{O}\left({ }_{2}\right)\right)$, Methods for Chemical, $\mathrm{M}$ ass

Grade Uranium Dioxide Powders and Pellets, Chemical, Mass rade Plutonium Dioxide Powders and Pellets, Chemical, Mass Nuclear Grade Mixed Oxides ( $\left.(\mathrm{U}, \mathrm{Pu}) \mathrm{O}\left({ }_{2}\right)\right)$, Chemical, Mass 1.75 Nuclear Grade Boron Carbide, Chemical, Mass sical Tests on (/ Beryllium Oxide Powders, Chemical, Mass sical Tests on (/ Beryllium Oxide Powders, Chemical, Mass I Analysis of Nuclear Grade Plutonium Nit/ Chemical, Mass al Analysis of Nuclear Grade Plutonium Me/ Chemical, Mass al Analysis of Uranium Hexafluoride, Meth/ Chemical, Mass al Analysi/ Nuclear Grade Plutonium Metal, Chemical, Mass al, Analysis of (19/ Uranium Hexafluoride, Chemical, Mass ns and Plutonium Metal Standard Methods for Chemical, Mass Nitrate Solutions, Methods for (1974) As/ Chemical, Mass $1969 \$ 1.75 \quad$ Gamma $\$ 1.75$

Alpha Gamma

nondestructive Uranium-235 Enrichment Assay by Gamma-Ray assay of High Enrichment Uranium Fuel Plates by Gamma-Ray n lrradiated Nuclear Fuels (1973T) \$1/ S, Part I: Data Acquisition Sy/ Method of Test for ter by Atomic Absorption Specifications of $\mathrm{Ge}(\mathrm{Li})$ Terms and Symbols Relating to Emission ferences Relating to (1/ Nuclear Magnetic Resonance (NMR) $n$, Siting, Design, and Plant Protection for an Independent Shielded Shipping Cask for -1/ Method for Ultrasonic Inspection of Longitudinal and ctures (Revision I, 1/2/73 Safety G/ Mechanical (Cadweld) tations (19/ Type Test of Class 1E Electric Cables, Field imens, Method of Test for (1973) ASTM C496-1971 \$1.75 tion for (1973) $\$ 1.75$

ication, Specification for (1973) (ASTM B349-1 ication, Spec. for (1973) \$1.75

Zirconium Zirconium Titanium

Nondestructive Assay for Plutonium in Scrap Material by

Sumps for Emergency Core Cooling and Containment Test for Adhesion or Cohesive Strength of Flameod of Test for Bearing Capacity of Soil for Static Load on Automatic

Fast Flux Test Facility Driver Fuel Pin Plenum Helical Age-Hardenable Nickel-Chromium-lron Alloy nitoring System (7-71)

Logarithmic Mean Protective Action Guides for Environmental Protective Action Guides for Environmental Sr-89,

ills $(6 / 73)$ Design on Systems (11/74)

Uranium-Thorium Milling Waste Retention Systems, 1.75 Std. Method for Sampling uction Permit Applications
Spectra for Seismic Design of Nuclear Power Plants (Rev Spectrochemical Analysis of Nuclear Grade Plutonium Dio Spectrochemical Analysis of Nuclear Grade Silver-Cadm Spectrochemical Analysis of Nuclear Grade Silver-Indiu Spectrochemical Analysis of Nuclear Grade Uranium Dioxi Spectrochemical Analysis of Nuclear Grade (1973) ASTM C Spectrochemical Analysis of Nuclear Grade (1973) ASTM C Spectrochemical Analysis of (1970) $\$ 1.75$ Spectrochemical Analysis of (1972) ASTM E402-1970\$1.7 Spectrochemical Analysis of (1973) ASTM C698-1972a \$1. Spectrochemical Analysis of (1974) \$1.75 Spectrochemical Analysis of (1974) \$1.75 Spectrochemical Analysis of (1974) \$1.75 Spectrochemical Analysis of (1975) \$1.75

Spectrochemical Analysis Of, and Physical Tests on (197 Spectrochemical Analysis Of, and Physical Tests on (197 Spectrochemical Computations, Practice for (1968) (R 197 Spectrochemical Nuclear and Radiochemical Analysis of $\mathrm{N}$ Spectrochemical, Nuclear and Radiochemical Analysis of Spectrochemical, Nuclear and Radiochemical Analysis of Spectrochemical, Nuclear and Radiochemical Analysis of Spectrochemical, Nuclear and Radiochemical Analysis of Spectrochemical, Nuclear and Radiochemical, Analysis of Spectrochemical, Nuclear Grade Plutonium Nitrate Soluti Spectrometer Helium Leak Detection for Instruments and Spectrometer Leak Detector in the Detector Probe Mode ( Spectrometer Leak Detector in the Inside-Out Testing M Spectrometer Leak Detector or Residual Gas Analyzer in Spectrometric Method) (1974) $\$ 1.75$

Spectrometric Method), Method of Test for (1973) ASTM

Spectrometric, and Spectrochemical Analysis of Nuclear Spectrometric, and Spectrochemical Analysis of Nuclear Spectrometric, and Spectrochemical Analysis of Nuclear Spectrometric, and Spectrochemical Analysis of Nuclear Spectrometric, and Spectrochemical Analysis of (1973) a Spectrometric, and Spectrochemical Analysis of (1974) \$ Spectrometric, and Spectrochemical Analysis of (1974) $\$$ Spectrometric, and Spectrochemical Analysis of (1974) \$ Spectrometric, and Spectrochemical Analysis of (1975) \$ Spectrometric, and Spectrochemical Analysis Of, and Phy Spectrometric, and Spectrochemical Analysis Of, and Phy Spectrometric, Spectrochemical Nuclear and Radiochemica Spectrometric, Spectrochemical, Nuclear and Radiochemic Spectrometric, Spectrochemical, Nuclear and Radiochemic Spectrometric, Spectrochemical, Nuclear and Radiochemic Spectrometric, Spectrochemical, Nuclear and Radiochemic Spectrometric, Spectrochemical, Nuclear and Radiochemic Spectrometric, Spectrochemical, Nuclear Grade Plutonium Spectrometry of Water, Method of Test for ASTM D2459Spectrometry of Water, Recommended Practice for (1972T) Spectrometry of Water, Test for (1972) $\$ 1.75$

Spectrometry (4/74)

Spectrometry $(9 / 74)$

Spectrophotometric Determination of Fission Zirconium Spectrophotometry (1970) $\$ 1.75$

Spectroscopy Systems for Material Protection Measuremen Spectroscopy, Definition of (1975A) \$1.75

Spectroscopy, Definitions, Symbols, Conventions, and Re Spent Fuel Storage Installation (12/74) Spent Reactor Fuel Elements (8.73) Amendment 1 (II-73 Spiral Welds of Welded Pipe and Tubing (1969) ASTM E273 Splices in Reinforcing Bars of Category 1 Concrete Stru Splices, and Connections for Nuclear Power Generating S Splitting Tensile Strength of Cylindrical Concrete Spec

Sponge and Expanded Cellular Rubber Products, Specifica Sponge and Other Forms of Virgin Metal for Nuclear Appl Sponge and Other Forms of Virgin Metal for Nuclear Appl Sponge, Spec. for (1974) \$1.75

Spontaneous Fission Detection (6/74)

Spot Facing Std. (1970) \$2.00

Spray Pond Plastic Piping (12/73)

Spray Systems $(6 / 74)$

Sprayed Coatings (1974) $\$ 1.75$

Spread Footings (1972) (ASTM D1194-1972) \$1.75

Spring Loaded Safety Valves (3-72) Amendment ] (1-73) Spring (6-71)

Springs (5-75) Supersedes M8-1T, (2-73)

Square and Hex Nuts (1972) $\$ 4.50$

Square Voltage (MSV) Intermediate Range Neutron Flux Mo

Sr-89, Sr-90, and Cs- 137 Contamination (1965)

Sr-90, and Cs-137 Contamination (1965)

Stability of Embankment Retention Systems for Uranium M

Stabilization of Uranium-Thorium Milling Waste Retenti Stablilzation of (1974) \$1.50

Stacks for Particulate Matter (1973) ASTM D2928-1971 \$

Staff in Connection with Its Antitrust Review of Constr
NRC

NRC

ANS1

ASTM

NRC

ANSI

ANSI

ASTM

ANSI

ANSI

ASTM

ASTM

ASTM

Nucl ASTM

ANSI

ASTM

ANSI

ASTM

ANS1

ANS1

ASTM

NRC

ASTM

ANS1

ERDA

ASTM

ASTM

ASTM

Test Fo ASTM

ANSI

ANSI

ANSI

NRC

NRC

ANSI

ASTM

ASTM

ASTM

ASTM

ANSI

ASTM

ASTM

ANSI

ANSI

ASTM

ASTM

NRC

ANSI

ANSI

ASTM

ASTM

NRC

NRC

ASTM

ASTM

NRC

ASTM

ASTM

NRC

ERDA

ANSI

NRC

ANSI

ANSI

ASTM

ANSI

ASTM

ASTM

NRC

MSS

NRC

NRC

ASTM

ERDA

ERDA

ERDA

ANSI

ERDA

EPA

EPA

NRC

NRC

ANS

ANS

NRC

RG 1.60

RG 5.6

N574

C760

RG 5.5

N103

N 104

$\mathrm{E} 402$

Z128.27

139

C698

C696

C697

C791

N140

C699 
ing License App/ Information Needed by the AEC Regulatory Regulatory

Horizontal, Electric Motor Driven, Single Vertical, Canned or Wet Motor Driven Single 70), Amendm/ vith Additional Requirements) (4-76) Supersedes M3-2T, with Additional Requirem (1975) \$1.75

te, Sheet, and Strip, Specification for (1974) $\$ 1.75$

use in Boilers and Other Pressure Vess/ Specification for cification for Hot Rolled and Cold Finished Age-Hardening

Std. Spec. for th Additional Requirements) (4-76) Supersedes M2-2T, (/ Strip, Specification for (1974A) $\$ 1.75$ nt 1 (4-74)

Austenitic tional Requirements) (11-74) Supersedes M7-3T, (10-73/ 4 with Additional Requirements)/ Precipitation-Hardening requirements) (11-74) Supersedes M4-2T, (6-1 $\quad \begin{array}{r}\text { Wrought } \\ \text { Austenitic }\end{array}$ ith Additional Requirements) (4-76) Supersedes M3-31T, )

intergranular Corrosion and Stress Corrosion in Austenitic .4 with Additional Requirements) (3-75) Supersedes M 1(3-72) Amendment 1 (5-74)

r Operated (3-72)

s and Assemblies (5-76) Supersedes E6-20T, /

974) $\$ 1.75$

irements) (3-75) Supersedes M3-6T, (11-73)

Austenitic

Seamless

Seamless and Welded Austenitic

ents (3-73)

Austenitic

ded Unfired Pressure Ves/ Heat Resisting Chromium-Nickel ith Additional Requirements) (11-74) Supersedes M5-1T, onal Requirements) (11-74) Supersedes M3-3T/ Austenitic Thermocouple Assemblies, Magnesium-Oxide Insulated,

erial and Thermocouple Assembly, Chromel-P Versus Alumel, or (1974) \$1.75 Seamless and Welded Austenitic ) Austenitic irements) / Seamless and Welded Small Diameter Austenitic rvice (/ Specification for Seamless and Welded Austenitic ents Control of
uments to Measure the Delta Ferritic Content of Austenitic 8 with Additional Requirements) (4-75) Super/ Austenitic onal Requirements) (7-75) Supersedes M3-5T itional Requirements) (1-75) Supersedes M2-1 Austenitic Austenitic sfa-5.9 with Additional Requirements) (3-75) Supersede/ Control of Austenitic Martensitic Martensitic

onal Requirements) (4-75) Supersedes M7-1T/ additional Requirements) (3-75) Supersedes / nts for Thermal Insulating Materials for Use on Austenitic $s$ Corrosion Effect of Wicking-Type Thermal Insulations on Nonmetallic Thermal Insulation for A ustenitic Control of the Use of Sensitized Detecting Susceptibility to Intergranular Attack in Requirements for Fixed Industrial tions, / Draft Standard Diesel Generator Units Applied as Selection of Diesel Generator Set Capacity for bution Systems (Safety Gu/ Independence Between Redundan 11/73) Preoperational and Initial Boiling Water Reactor Power /

$3 \$ 6.00$ Preoperational and Initia Logic Diagrams ( Two Review of the Current Regulatory Staff Position Food and Drugs: Subpart B. Auditing Nuclear Materials

Estimates and Evaluations of Fallout in the United Natural Background Radiation in the United ettlement Relationship for Individual Vertical Piles Under ) $\$ 1.75$ Method of Test for Bearing Capacity of Soil fo 00

Periodic Testing of Nuclear Power Generating

$f$ the Single Failure Criterion to Nuclear Power Generating eamless Austenitic Steel Pipe for High Temperature Centra aft Standard for Nuclear Safety Criteria for the Design, of $51.1 \$ 30.50$ Nuclear Safety Criteria for the Design of 0

Maintenance, Testing, and Replacement of Large General Site Suitability Criteria for Nuclear Powe

Preparation of Environmental Reports for Nuclear Powe Terms Used in IEEE Standards on Nuclear Power Generating containment Structures for Nuclear Fueled Power Generating ield Splices, and Connections for Nuclear Power Generating

Terrestrial Environmental Studies for Nuclear Power Protection Systems for Nuclear Power Generating

Class 1E Power Systems for Nuclear Power Generating t Perform Protective Functions in Nuclear Power Generating ication of Electric Equipment for Nuclear Power Generating
Staff in Connection with lts Antitrust Review of Operat Staff Position Statement on Antitrust Matters (12/73)

Stage Centrifugal Pump (2-72) Amendment 1 (5-74)

Stage Centrifugal Pump (6-72) Amendment 1 (5-74)

Stage Centrifugal Pump (7-72) Supersedes E3-3T, (10Stainless and Alloy Steel Seamless Tubes (ASME SA-213 Stainless and Heat Resisting Chromium Steel Plate, Shee Stainless and Heat Resisting Chromium-Nickel Steel Pla Stainless and Heat Resisting Steel Bars and Shapes for Stainless and Heat Resisting Steel Bars and Shapes (197 Stainless and Heat Resisting Steel Forgings (1975) \$1.7 Stainless and Low Alloy Steel Forgings (ASME SA-182 Wi Stainless Chromium-Nickel Steel Clad Plate, Sheet, and Stainless Steel Bar for Core Components (3-73) Amendme Stainless Steel Bars and Shapes (ASME SA-479 with Addi Stainless Steel Bars, Shapes, and Forgings (ASME SA-56 Stainless Steel Butt Welding Fittings (1971) $\$ 4.00$ Stainless Steel Castings (ASME SA-351 with Additional Stainless Steel Centrifugally Cast Pipe (ASME SA-451 W Stainless Steel Check Valves (3-72) Amendment 1 (5-74 Stainless Steel Components of Fuel Reprocessing Plants Stainless Steel Covered Welding Electrodes (ASME SFA-5 Stainless Steel Gate Valves, Manual and Power Operated Stainless Steel Globe and Angle Valves, Manual and Powe Stainless Steel Hexagonal Duct Tubes for Core Component Stainless Steel Mechanical Tubing, Specification for (1 Stainless Steel Pipe (ASME SA-312 with Additional Requ Stainless Steel Pipe, Specification for (1974) $\$ 1.75$

Stainless Steel Plate, Sheet, and Strip for Core Compon Stainless Steel Plate, Sheet, and Strip for Fusion-Wel Stainless Steel Plate, Sheet, and Strip (ASME SA-240 W Stainless Steel Seamless Pipe (ASME SA-376 with Addit Stainless Steel Sheathed (1-72)

Stainless Steel Sheathed, Magnesium Oxide Insulated (2.

Stainless Steel Tubing for General Service, Specificati

Stainless Steel Tubing for LMFBR Core Components (5-72 Stainless Steel Tubing (ASTM a 632 with Additional Requ Stainless Steel Tubing (Small-Diameter) for General Se Stainless Steel Weld Cladding of Low Alloy Steel Compon Stainless Steel Weld Metal (1974) $\$ 3.00$ Stainless Steel Welded Pipe Large Diameter (ASME SA-35 Stainless Steel Welded Tubing (ASME SA-249 with Additi Stainless Steel Welding Fittings (ASME SA-403 with Add Stainless Steel Welding Rods and Bare Electrodes (ASME Stainless Steel Welding (Revision 1, 6/73)

Stainless Steel Wire for Core Components (3.73)

Stainless Steel (Type 403) Bars (ASTM a 276 with Addit

Stainless Steel (Type 403) Forgings (ASME SA-182 with

Stainless Steel (10-72) Supersedes M12-1T, (2-69)

Stainless Steel (1971) $\$ 1.75$

Stainless Steel $(2 / 23 / 73)$

Stainless Steel $(5 / 73)$

Stainless Steels, Rec. Practices for (1975) \$1.75

Stairs (1968) $\$ 2.75$

Standby Power Supplies for Nuclear Power Generating Sta

Standby Power Supplies (Safety Guide 9, 3/10/71)

Standby (Onsite) Power Sources and Between Their Distri

Startup Test Programs for Water Cooled Power Reactors (

Startup Testing of Feedwater and Condensate Systems for

State Devices), Graphic Symbols for (1973) IEEE 91-197

State of Radiation Protection Philosophy (1975) $\$ 3.00$

Statement on Antitrust Matters (12/73)

Statements of Policy and Interpretation (1975) $\$ 2.95$

Statements (1973) $\$ 3.50$

States from Weapons Test. Conducted Through 1962 (1963)

States (1975) $\$ 5.00$

Static Axial Load (1974) \$1.75

Lad on Spread Footings (1972) (ASTM D1 194-1972

Static Young's Modulus of Elasticity and Poisson's Rati

Station Protection Systems, Criteria for the (1975) $\$ 5$.

Station Protection Systems, Trial Use

Station Service, Specification for (1974) $\$ 1.75$

Stationary Boiling Water Reactor Plants: Issued for Tri

Stationary Pressurized Water Reactor Plants (1973) ANS

Stationary Pressurized Water Reactor Plants (1975) $\$ 5.5$

Stationary Type Power Plant and Substation Lead Storage

Stations (Revision 1, 11/75)

Stations (Revision $1,1 / 75$ )

Stations (1972) $\$ 4.00$

Stations (1973) IEEE 317-1972 \$3.00

Stations (1975) IEEE Std. 383-1974 \$4.00

Stations $(7 / 76)$

Stations, Criteria for (1972) lEEE Std. 279-1971 \$4.00

Stations, Criteria for (1975) lEEE Std. 308-1974 \$4.00

Stations, Criteria (Issued for Trial Use and Comment)

Stations, Guide for (1975) $\$ 5.00$
Assemblies in

NRC

NRC

RG 9.3

ERDA

ERDA

ERDA

STM

A STM

ASTM

ASTM

ERDA

ERDA

ERDA

ERDA

ERDA

ERDA

STM

ERDA

ASTM

STM

ERDA

ERDA

ERDA

STM

ERDA

ERDA

NRC

AWS

ERDA

ERDA

NRC

ERDA

RDA

ERDA

ASTM

ASTM

ANSI

ANSI

NRC

NRC

ANSI

NCRP

NRC

BRi

ANSI

NCRP

ASTM

ANSI

ANSI

IEEE

ANSI

ASTM

ANSI

ANSI

EEE

NRC

NRC

Definitions O IEEE

C Cables, F ANSI

NRC

ANSI

ANSI

ANSI

Seismic Qualif IEEE

A 176

A 167

A 479

A 564

A473

A264

SP-43

RG 3.37

DT E3-6T

RDT E3-1T

RDT E3-3T

RDT M3-2T

RDT M2-2T

RDT M7-23T

RDT M7.3T

RDT M7-6T

RDT M4-2T

RDT M3-31T

RDT E1-12T

RDT M1.1T

RDT El-9T

RDT E1-21T 
stalied 1nside the Containment of Nuclear Power Gencrating ipment During the Construction of Nuclear Power Generating ied as Standby Powcr Supplies for Nuclcar Power Generating

1 Electrical Valvc Operators for Nuclcar Power Generating class 1 E Control Switchboards for Nuclcar Power Generating Definitions of Terms Relating to Fatigue Testing and the

4)

in the Transfer of Special Nuclcar Materials, Concepts als Management (1972) $\$ 3.00$

r Materials Control Accountability (2/2/73)

(1973) ASTM G16-1971 \$1.75

s $(5 / 73)$

Applying Supersedes E4-1T, (10-69) Information for Safety Analysis Reports: Inservice Inspection of Pressurized Water Reacto Sodium Heated Information for Safety Analysis Reports: ng Water Reactor Nuclear Power Plants (Re/ Design of Main or Evaluating the Potential Radiological Consequences of $\mathrm{A}$ Air Cooled Heat Exchanger for Nuclear

Quality Group Classifications and Standards for Water-

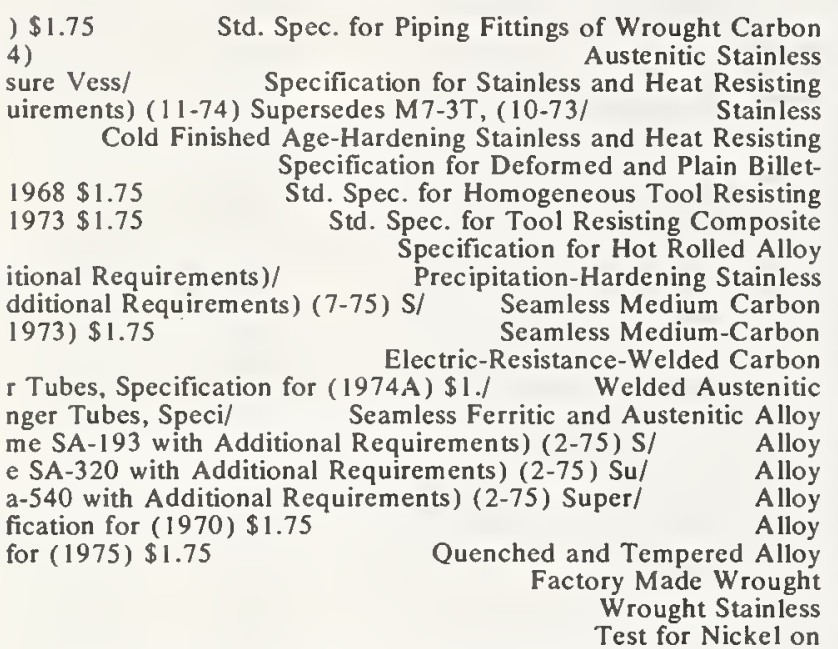
ns (1974) Ast/ Specification for Special Requirements for ations, Specification for Special Requirements for (1973/ adiographs for (1973) $\$ 1.75$

ts) (8-75) Supersedes M4-1T, (7-71)

ts) (11-74) Supersedes M4-2T, (6-)

Muthod, Quality Standard for

Visual Method, Quality Standard for
Viticle Visual Method, Quality Standard for
hs for Heavy Walled (4-1/2 to 12 in.)

Reference Radiographs for Heavy Walled (4-1/2 to 12 in.)
Reference Radiographs for Heavy Walled (2 to $4-1 / 2$ in.)

udinal-Beam Ultrasonic Inspection of Carbon and Low Alloy onal Requirements) (4-76) Supersedes M3-31T,/ Stainless
Stainless

974A) $\$ 1.75$

1974A) $\$ 1.75$

Corrosion-Resisting Chromium

Stainless Chromium-Nicke

lar Corrosion and Stress Corrosion in Austenitic Stainless
Control of Stainless Steel Weld Cladding of Low Alloy

Manual of

(1973) AWS A5.1-1969\$3.50

(1973) AWS A5.5-1969 \$3.50

(1974)

(1974)

ditional Requirements) (3-75) Supersedes M1-3T, (/

ditional Requirements) (3-75) Supersedes M1-/

ditional Requirements) (3.75) Supersedes M 1-/

Corrosion-Resisting Chromium and Chromium-Nickel

pection, and Testing of Structural Concrete and Structural

pection, and Testing of Structural Concrete and Structural

asme SFA-5.17 with Additional Requirements) (3-75/ Mild

specification for (1973) AWS A5.17-1969 \$2.50

specification for (1974)

-5.20 with Additional Requirements) (7-75) Supers/

tion for (1973) AWS A5.20-1969\$2.50

tion for (1974)

.18 with Additional Requirements) (4-75) Supersede/ on for (1973) AWS A 5.18-1969 $\$ 2.50$

on for (1974)

ux Core Corrosion-Resisting Chromium and Chromium-Nickel
Stations, Guide For, (1976) IEEE 334-1971 $\$ 4.40$ Stations, Installation, Inspection and Testing Requirem Stations, Trial Use Criteria (Issucd for Trial Use and Stations, Trial Use Guide (Issucd for Trial Use and Com Stations, (Trial Guide Issued for Use and Comment) ( 197 Statistical Analysis of Fatigue Data (1973) (ASTM E206Statistical Evaluation of Material Unaccounted for $(6 / 7$ Statistical Evaluation of Shippcr-Recciver Differences Statistical Terminology and Notation for Nuclear Materi Statistical Terminology and Notation for Special Nuclea Statistics to Analysis of Corrosion Data, Practice for Status Indication for Nuclear Power Plant Safety System Steam and Feedwater System Materials (4/75)

Steam Generator for Pressurized Water Reactors (12-71) Steam Generator Tubes (Revision 1,7/75)

Steam Generator (2-74), Superscdes E4-16T, (5-72)

Steam Generators (1/75)

Steam Isolation Valve Leakage Control Systems for Boili Steam Line Break Accident for Boiling Water Reactors (S Steam Supplied Systems (3-71)

Steam Supply Systems (1974) $\$ 5.50$

Steam-, and Radioactive-Waste-Containing Components Steam, Sampling (1975) $\$ 1.75$

Steel and Alloy Steel for Low Temperature Service (1975

Steel Bar for Core Components (3-73) Amendment ! (4-7

Steel Bars and Shapes for Use in Boilers and Other Pres

Steel Bars and Shapes (ASME SA-479 with Additional Req

Steel Bars and Shapes (1974) \$1.75/for Hot

Steel Bars for Security Applications (1974) ASTM A627-

Steel Bars for Security Applications (1974) ASTM A628

Steel Bars (1976) ASTM A322-1975 \$1.75

Steel Bars, Shapes, and Forgings (ASME SA-564 with Add

Steel Boiler and Superheater Tubes (ASME SA-2 10 with a

Steel Boiler and Superheater Tubes, Specification for (

Steel Boiler Tubes, Specification for (1973) $\$ 1.75$

Steel Boiler, Superheater, Heat Exchanger, and Condense

Steel Boiler, (1974B) \$1.75 Superheater, and Heat Excha

Steel Bolting Material for High Temperature Service (As

Steel Bolting Material for Low Temperature Service (Asm

Steel Bolting Material for Special Applications (ASME S

Steel Bolting Materials for Special Applications, Speci

Steel Bolts for Structural Steel Joints, Specification

Steel Butt Welding Fittings (1971) $\$ 4.00$

Steel Butt Welding Fittings (1971) $\$ 4.00$

Steel by Photometric Analysis (1972) $\$ 1.75$

Steel Castings for Nuclear and Other Special Applicatio

Steel Castings for the Nuclear and Other Special Applic

Steel Castings Up to 2 lnches in Thickness, Reference $R$

Steel Castings (ASME SA-216 with Additional Requiremen

Steel Castings (ASME SA-351 with Additional Requiremen

Steel Castings (1971) $\$ 2.00$

Steel Castings (1971) $\$ 3.00$

Steel Castings (1971) $\$ 8.00$

Steel Castings (1973) ASTM E280-1972 \$1.75

Steel Castings (1974) ASTM E186-1973 \$1.75

Steel Castings, Specification for (1973) ASTM A609-197

Steel Centrifugally Cast Pipe (ASME SA-45 I with Additi

Steel Check Valves (3-72) Amendment 1 (5-74)

Steel Clad Plate, Sheet and Strip, Specification for (1

Steel Clad Plate, Sheet, and Strip, Specification for

Steel Components of Fuel Reprocessing Plants (9/75)

Steel Components (5/73)

Steel Construction (1973) $\$ 20.00$

Steel Containment Vessel (12-73)

Steel Covered Arc Welding Electrodes, Specification for Steel Covered Arc Welding Electrodes, Specification for Steel Covered Arc Welding Electrodes, Specification for Steel Covered Arc Welding Electrodes, Specification for Steel Covered Welding Electrodes (ASME SFA-5.1 with Ad Steel Covered Welding Electrodes (ASME SFA-5.4 with Ad Steel Covered Welding Electrodes (ASME SFA-5.5 with Ad Steel Covered Welding Electrodes, Specification for (19 Steel Covered Welding Electrodes, Specification for (19 Steel During the Construction Phase of Nuclear Power P1 Steel During the Construction Phase of Nuclear Power P1 Steel Electrodes and Fluxes for Submerged Arc Welding ( Steel Electrodes and Fluxes for Submerged Arc Welding, Steel Electrodes and Fluxes for Submerged Arc Welding,

$M$ ild Steel Electrodes for Flux-Cored Arc Welding (ASME SFA

Mild Steel Electrodes for Flux-Cored Arc Welding, Specifica

Mild Steel Electrodes for Flux-Cored Arc Welding, Specifica

Mild Steel Electrodes for Gas Metal Arc Welding (ASME SFA-5

Mild Steel Electrodes for Gas Metal Arc Welding, Specificati Steel Electrodes for Gas Metal Arc Welding, Specificati Steel Electrodes (1974) $\$ 3.50$

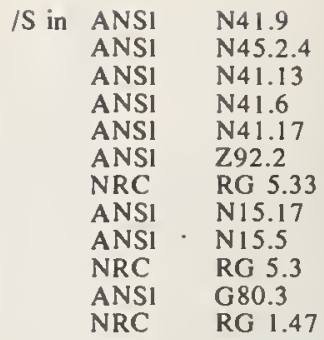

NRC RG 1.70.28

ERDA RDT E4-1T

NRC RG 1.83

ERDA RDT E4-16T

NRC $\quad$ RG 1.70 .19

NRC RG 1.96

NRC RG 1.5

ERDA RDT E4-18T

ASME

NRC

ASTM

ASTM

ERDA

ASTM

ERDA

PTC 32.1

RG 1.26

D 1066

A420

RDT M7-23T

A479

RDT M7-37

A564

A 615

ANSI G24.45

ANS1 - G24.46

ANS1 G24.11

ERDA RDT M7-6T

ERDA RDT M3-32T

ASTM A210

ASTM A 178

ASTM A249

ASTM A213

ERDA

ERDA

ERDA

ASTM

ASTM

ANSI

MSS

ASTM

ANSI

ASTM

ASTM

ERDA

ERDA

MSS

Dry MSS

MSS

ANSI

ANS

ANSI

ERDA

ERDA

ASTM

ASTM

IU NRC

NRC

AISC

ERDA

ANSI

ANS1

ASME

ASME

ERDA

ERDA

ERDA

ANS1

ASME

ANS1

NRC

ERDA

ANSI

ASME

ERDA

ANSI

ASME

ERDA

ANSI

ASME

Fl AWS
RDT M6-3T

RDT M6-1T

RDT M6-5T

A540

A490

B 16.9

SP-43

C715

N558

A613

E446

RDT M4-IT

RDT M4-2T

SP-54

SP-53

SP-55

Z166.19

Z166.10

G52.7

RDT M3-31T

RDT E1-12T

A263

A264

RG 3.37

RG 1.43

* 1

RDT E 10-8T

W3.1

W3.5

SFA-5. 1

SFA-5.5

RDT M1-3T

RDT M1-1T

RDT M1-4T

W3.4

SFA-5.4

N45.2.5

RG 1.94

RDT M 1-17T

W3.17

SFA-5.17

RDT M1-20T

W 3.20

SFA-5.20

RDT M1.6T

W3.18

SFA-5.18

A 5.22 
975) $\$ 1.75$

\section{Specification for (1974/} pec. for Piping Fittings of Wrought Carbon Steel and Alloy
Pressure Vessel Plates, Carbon

interpass Temperature Control for the Welding of Low Alloy e, Specification for (1975) $\$ 1.75$

e, Specification for (1975) $\$ 1.75$

Ferritic Alloy

Austenitic

Carbon

for Quenched and Tempered Vacuum Treated Carbon and Alloy ssure Vessel Components (1970) Ast/

ts) (4-76) Supersedes M2-2T, (/

ts) (11-74) Supersedes M2-4T, (4-72)

ts) (7-75) Supersedes M2-8T, (7-71)

Std. Spec. for Carbon

Stainless and Low Alloy
Alloy

Carbon and Alloy

Std. Spec. for Stainless and Heat Resisting d, for Pressure Vessel Components (197/ Specification for $75 \quad \begin{gathered}\text { Magnetic Particle Examination of } \\ \text { Ultrasonic Examination of Heavy }\end{gathered}$ ional Requirements) (4-76) Supersedes / Carbon and Alloy Reference Radiographs for

endment $1(5-74)$

(3-72)

for $(1973) \$ 1.75$ Carbon, Ferritic, and Austenitic Alloy mblies (5-76) Supersedes E6-20T, I

Austenitic Stainless

d Washers, Specificat/

High Strength Bolts for Structural
Tempered Alloy Steel Bolts for Structural Seamless Stainless rature Service (ASME SA-194 with Additional Requi/ Alloy rvice, Spec. for (1976) $\$ 1.75$

$\$ 12.00$

) ASTM A671-/ Specification for Electric-Fusion-Welded side Diameter Light-Wall Austenitic Chromium Nickel Alloy (1975) $\$ 1.75$

, Specification for (1974) $\$ 1.75$

for $(1974 \mathrm{~A}) \$ 1.75$

Electric-Fusion-Welded Seamless Austenitic

Seamless-Ferritic Alloy electric-Fusion-Welded Austenitic Chromium-Nickel Alloy for $(1975) \$ 1.75$ for (1975) $\$ 1.75$ Centrifugally Cast Ferritic Alloy Centrifugally Cast Austenitic Specification for Seamless and Welded (3-75) Supersedes M3-6T, (11-73) (4-76) Supersedes M3-16T, (8-75) (4-76) Supersedes M3-12T, (12-1)

Austenitic Stainless Carbon and Alloy Seamless Ferritic Alloy Specification for Electric-Resistance-Welded Specification for Welded and Seamless Specification for Specialized Carbon and Alloy for (1974) $\$ 1.75$ Seamless and Welded Austenitic Stainless Electric-Fusion (Arc)-Welded (1974) ASTM A647-19/ Spec. for Special Requirements for , Specification for Special Requirements for (1973) \$1.7/ $\mathrm{n}$ for (1974A/ Longitudinal-Wave Ultrasonic Inspection of neral Requirements for (1975) \$1.75

974A) $\$ 1.75$

Molybdenum, Alloy Straight-Beam Ultrasonic Examination of Plain and Clad 1975) \$1.75 Low and Intermediate Tensile Strength Carbon 2-1/4-Percent-Chromium, 1-Percent-Molybdenum Alloy ) (5-75) Supersedes M5-5T, (7-71)

) (8-75) Supersedes M5-2T, (5-73)

equirements) (12-74) Supersedes M5-3T, (5-7/

Low Alloy

Low Alloy

3) Ultrasonic Angle-Beam Examination of d Pressure Ves/ Heat Resisting Chromium-Nickel Stainless onal Requirements) (11-74) Supersedes M5-1T,/ Stainless $\$ 1.75$ Stainless and Heat Resisting Chromium-Nickel $\$ 1.75$ Stainless and Heat Resisting Chromium Nickel and Nickel-Base Alloy Clad ing Against Embrittlement of Hot Dip Galvanized Structural $3 \$ 1.75 \quad$ Methods and Definitions for Mechanical Testing of ethod of Test for Reliability of Glass Coatings on Glassed 975)/ Recommended Practice for Fabrication and Control of rements) (7-75) Supersedes M3-1T, (5-73)

rements) (11-74) Supersedes M3-3T/

irements) (4-76) Supersedes M3-2T, zed) Coatings on Products Fabricated Austenitic Stainles
Stainless and Alloy Stainless and Alloy
-Molybdenum Alloy mocouple Assemblies, Magnesium-Oxide Insulated Stainless thermocouple Assembly, Chromel-P Versus Alumel, Stainless

Strength, Low Alloy Columbium and/or Vanadium, Specific/ $1 \$ 1.75$
Steel Equipment by Electrical Testing (R1973) ASTM C536 Steel Fittings, Socket-Welding and Threaded (1973) \$3. Steel Flat Bars and Shapes for Security Applications (1 Steel for Buildings (Adopted February 12, 1969) $\$ 5.00$ Steel for High Temperature Service Specification for (I Steel for Intermediate-and Higher-Temperature Service Steel for Low Temperature Service (1975) \$1.75 Steel for Moderate and Lower Temperature Service, Speci Steel for Use in Fuel Reprocessing Plants and in Pluton Steel Forged and Bored Pipe for High Temperature Servic Steel Forged and Bored Pipe for High Temperature Servic Steel Forgings for Piping Components (ASME SA-105 with Steel Forgings for Pressure Vessels (1974A) $\$ 1.75$

Steel Forgings for Seamless Drums, Heads, and Other Pre Steel Forgings (ASME SA-182 with Additional Requiremen Steel Forgings (ASME SA-336 with Additional Requiremen Steel Forgings (ASME SA-541 with Additional Requiremen Steel Forgings (1975) $\$ 1.75$

Steel Forgings, Carbon and Alloy, Quenched and Tempere Steel Forgings, Method for (1974) \$1.75

Steel Forgings, Practice for (1973) ASTM A388-1971 \$1 Steel Forgings, Vacuum Treated (ASME SA-508 with Addit Steel Fusion Welds (1973) ASTM E390-1969 \$1.75

Steel Gas Welding Rods (1969) $\$ 2.50$

Steel Gate Valves, Manual and Power Operated (3-72) Am Steel Globe and Angle Valves, Manual and Power Operated Steel Hardware, Specification for (1973) $\$ 1.75$

Steel Heat Exchanger and Condenser Tubes, Specification

Steel Heat Exchanger Tubes with Integral Fins, Specific

Steel Hexagonal Duct Tubes for Core Components and Asse Steel Isolation Valves (4-73) Amendment 1 (5-74)

Steel Joints, 1ncluding Suitable Nuts and Plain Hardene Steel Joints, Specification for (1975) $\$ 1.75$

Steel Mechanical Tubing, Specification for (1974) $\$ 1.75$ Steel Nuts for Bolting for High Pressure and High Tempe Steel Pipe Flanges, and Valves and Parts for General Se Steel Pipe Flanges, Flanged Valves and Fittings (1973) Steel Pipe for Atmosphcric and Lower Temperatures (1974 Steel Pipe for Corrosive or High Temperature Service, $\mathbf{S}$ Steel Pipe for High Pressure Service, Specification for Steel Pipe for High Temperature Central Station Service Steel Pipe for High Temperature Service, Specification Steel Pipe for High Temperature Service, Specification Steel Pipe for High Temperature Service, Specification Steel Pipe for High Temperature Service, Specification Steel Pipe for Low Temperature Service (1975) \$1.75 Steel Pipe (ASME SA-312 with Additional Requirements) Steel Pipe (ASME SA-333 with Additional Requirements) Steel Pipe (ASME SA-335 with Additional Requirements) Steel Pipe (1973A) $\$ 1.75$

Steel Pipe (1973) $\$ 1.75$

Steel Pipe (1975) $\$ 1.75$

Steel Pipe, Specification for (1974) $\$ 1.75$

Steel Plate Pipe (Sizes 16 in. and Over), Specification

Steel Plates for Nuclear and Other Special Applications Steel Plates for Nuclear and Other Special Applications Steel Plates for Pressure Vessels, Method and Inspectio Steel Plates for Pressure Vessels, Specification for Ge Steel Plates for Pressure Vessels, Specification for (1 Steel Plates for Special Applications, Specification Fo Steel Plates of Structural Quality, Specification for

Steel Plates (ASME SA-387 with Additional Requirements Steel Plates (ASME SA-387 with Additional Requirements Steel Plates (ASME SA-516 with Additional Requirements Steel Plates (ASME SA-533 with Additional Additional R Steel Plates, Specification for (1973) \$1.75

Steel Plate, Sheet, and Strip for Core Components (3-7 Steel Plate, Sheet, and Strip for Fusion-Welded Unfire Steel Plate, Sheet, and Strip (ASME SA-240 with Additi Steel Plate, Sheet, and Strip, Specification for (1974)

Steel Plate, Sheet, and Strip, Specification for (1975)

Steel Plate, Specification for (1974A) $\$ 1.75$

Steel Products and Procedure for Detecting Embrittlemen Steel Products (1975A) \$1.75

Steel Products, Specification for (1974) ASTM A386-197

Steel Reaction Equipment by High Voltage ASTM C 537-72 Steel Reference Blocks Used in Ultrasonic Inspection (1 Steel Seamless Pipe (ASME SA-106 with Additional Requi Steel Seamless Pipe (ASME SA-376 with Additional Requi Steel Seamless Tubes (ASME SA-213 with Additional Requ Steel Seamless Tubes (ASME SA-213 with Additional Requ Steel Shapes, Plates, Bars and Strip, Zinc (Hot Galvani Steel Sheathed (1-72)

Steel Sheathed, Magnesium Oxide Insulated (2-75) Super Steel Sheet and Strip, Hot Rolled and Cold Rolled, High Steel Sheets for Pressure Vessels (1972) ASTM A4 14-197
ANS1

ANS1

ANS1

AISC

ASTM

ASTM

Std. S ASTM ASTM

NRC

ASTM

ASTM

ERDA

/Ec. ASTM

ANS1

ERDA

ERDA

ERDA

ASTM

ASTM

ASTM

ANS1

ERDA

ANS1

AWS

ERDA

ERDA

ASTM

ERDA

ERDA

ASTM

ASTM

ASTM

ERDA

ASTM

ANS1

ANSI

ASTM

ASTM

ASTM

ASTM

ASTM

ASTM

ASTM

ASTM

ERDA

ERDA

ERDA

ASTM

ASTM

ASTM

ASTM

ASTM

ANS1

ASTM

ASTM

ASTM

ASTM

ANS1

ASTM

ERDA

ERDA

ERDA

ASTM

ERDA

ASTM

ERDA

ASTM

ASTM

ASTM

ASTM

ASTM

ANSI

ANSI

ASTM

ERDA

ERDA

ERDA

ANSI

Ther ERDA

ERDA

ANSI

ANS1

Z167.8

B 16.1

G24.47

S310

A106

A5 15

A420

A5 16

A369

A430

RDT M2-1T

A508

G55.1

RDT M2-2T 
72) $\$ 1.75$

ed, Specification for (1975) \$1.75

Cold Rolled Carbon Carbon

Welded

for (1974) \$1.75 Seamless and Welded Carbon and Alloy Specification for Seamless Ferritic-Austenitic Alloy

2-1/4-Percent-Chromium, 1-Percent-Molybdenum Alloy

(1974A) \$1./ Carbon, Ferritic Alloy and Austenitic Alloy

74) $\$ 1.75 \quad$ Seamless and Welded Austenitic Stainless Austenitic Stainless

Seamless and Welded Small Diameter Austenitic Stainless specification for Seamless and Welded Austenitic Stainless ce for (1973) ASTM E309-1971 \$/ Eddy-Current Testing of Hydrostatic Testing of

measure the Delta Ferritic Content of Austenitic Stainless itional Requirements) (4-75) Super/ ments) (5-75) Supersedes M 3-11T,/ rements) (7-75) Supersedes M3-5T, plications (1974) ASTM A652-1/ Specification for Wrought Special Requiremen/ Wrought quirements) (5-75) Supersedes M2-3T, / Carbon and Alloy quirements) (1-75) Supersedes M2-/ Austenitic Stainless ith Additional Requirements) (3-75) Supersede/ Stainless or ( I/ Corrosion-Resisting Chromium and Chromium-Nickel or (1) Corrosion-Resisting Chromium and Chromium-Nickel Control of Stainless Austenitic Stainless Martensitic Stainless Martensitic Stainless

rements) (4-75) Supersedes M7-1T/

Requirements) (3-75) Supersedes ( ermal Insulating Materials for Use on Austenitic Stainless n Effect of Wicking-Type Thermal Insulations on Stainless

Nonmetallic Thermal Insulation for Austenitic Stainless Control of the Use of Sensitized Stainless Control of Preheat Temperature for Welding of Low Alloy etermine Nil-Ductility Transition Temperature of Ferritic Drop-Weight Tear Tests of Ferritic

ecting Susceptibility to Intergranular Attack in Stainless practice for lnspection and Testing Agencies for Concrete, stm A 366-1972\$1.75 $1975) \$ 1.75$

$\$ 1.75$

pecification for (1972A) A/

ion for (1974A) $\$ 1.75$

r (1974A) $\$ 1.75$

cation for (1974A) $\$ 1.75$

Nickel, Specification For/ 75

Std. Spec. for Chemical Analysis of Pressure Vessel Plates, Alloy Pressure Vessel Plates, Alloy Pressure Vessel Plates, Alloy Pressure Vessel Plates, Carbon

Pressure Vessel Plates, Carbon Pressure Vessel Plates, Alloy Pressure Vessel Plates, Carbon End-Quench Test for Hardenability of Pressure Vessel Plates, Alloy

ification for (1974) \$1.75 ckel (1974)/ Std. Spec. for Pressure Vessel Plates, Alloy Mangane/ Specification for Pressure Vessel Plates, Alloy m-Chromium, Specification/ Pressure Vessel Plates, Alloy ponents/ Specification for Forgings, Carbon and Low Alloy Electrodeposited Coatings of Zinc on Structural itation Hardening Nickel Alloy Bars, Forgings, and Forging itation Hardening Nickel Alloy Bars, Forgings, and Forging hardening Iron Base Superalloy Bars, Forgings, and Forging dening Cobalt Containing Alloy Bars, Forgings, and Forging ) Sup/ Nickel-Chromium Alloy Bars, Forgings, and Forging 00

per and Copper-Alloy Seamless Condenser Tubes and Ferrule

(During the Construction/

Packaging, Shipping, Receiving,

$t$ of Large Stationary Type Power Plant and Substation Lead ectives for Highly Radioactive Solid Material Handling and Fuel

ences of a Fuel Handling Accident in the Fuel Handling and design, and Plant Protection for an Independent Spent Fuel Guide for Acceptable W aste bstances and Combustible Liquids on Bo/ Transportation or n, Arrangement, and Other Provisions for Transportation or
$\$ 12.00$ Use of Pressure-Sensitive Seals on Containers for Onsite Standard Format and Content of License Applications for onsequences of a Pressurized Water Reactor Radioactive Gas for Design and Construction of Large, Welded, Low Pressure Welded Steel Tanks for Oil

aging, Packing, and Marking of Components for Shipment and

assurance Requirements for Packaging, Shipping, Receiving, Assurance Records (Revision 1, 12/75)

Collection, or Nuclear Power Plants (19/ Requirements for Collection, d Other Provisions for Use of Dangerous Articles as Ships, Heat Exchanger, Class I, Water to Water, Heat Exchanger, Class 2, Water to Water,
Steel Sheets, Commercial Quality, Specification for ( 19 Steel Sheet, Cold Rolled, Drawing Quality, Special Kill Steel Sheet, Corrosion Resistant, Laminated Surface Bon Steel Tanks for Oil Storage (1973) $\$ 4.00$

Steel Tubes for Low Temperature Service, Specification Steel Tubes (1974) ASTM A669-1972 \$1.75

Steel Tubesheet Forgings (ASME SA-336 with Additional Steel Tubes, Specification for General Requirements for Steel Tubing for General Service, Specification for (19 Steel Tubing for LMFBR Core Components (5-72) Steel Tubing (ASTM a 632 with Additional Requirements) Steel Tubing (Small-Diameter) for General Service (197

Steel Tubular Products with Magnetic Saturation, Practi Steel Valves (1961) $\$ 3.00$

Steel Weld Cladding of Low Alloy Steel Components (5/73

Agnetic Instrument

Steel Welded Pipe Large Diameter (ASME SA-358 with Add

Steel Welded Pipe (ASME SA-155 with Additional Require

Steel Welded Tubing (ASME SA-249 with Additional Requi

Steel Welding Fittings for Nuclear and Other Special Ap

Steel Welding Fittings for Nuclear and Other Special Ap

Steel Welding Fittings (ASME SA-234 with Additional Re

Steel Welding Fittings (ASME SA-403 with Additional Re

Steel Welding Rods and Bare Electrodes (ASME SFA-5.9 W

Steel Welding Rods and Bare Electrodes, Specification F

Steel Welding Rods and Bare Electrodes, Specification F

Steel Welding (Revision 1, 6/73)

Steel Wire for Core Components (3-73)

Steel (Type 403) Bars (ASTM a 276 with Additional Requi

Steel (Type 403) Forgings (ASME SA-182 with Additional

Steel (10-72) Supersedes M12-1T, (2-69)

Steel (1971) \$1.75

Steel $(2 / 23 / 73)$

Steel $(5 / 73)$

Steel $(5 / 73)$

Steels (1970) ASTM E208-1969 \$1.75

Steels, Method for (1974) \$1.75 /Nts for th
Evaluating Stress Corrosio

Steels, Rec Practices for (1975) \$1.75

Steel, and Bituminous Materials as Used in Construction

Steel, Carbon, Cold Rolled, Commercial Quality (1974) a

Steel, Cast Iron, Open-Hearth Iron, and Wrought Iron (

Steel, Chromium-Molybdenum, Specification for (1974A)

Steel, Five Percent Chromium, 0.5 Percent Molybdenum, S

Steel, High Strength, Quenched and Tempered, Specificat

Steel, Improved Transition Properties, Specification Fo

Steel, Low and Intermediate-Tensile Strength, Specifi

Steel, Manganese-Molybdenum and Manganese-Molybdenum-

Steel, Manganese-Silicon, Specification for (1974A) \$1

Steel, Method of (1974) ASTM A255-1974 \$1.75

Steel, Quenched and Tempered Chromium-Molybdenum, Spec

Steel, Quenched and Tempered, Eight and Nine Percent Ni

Steel, Quenched and Tempered, Manganese-Molybdenum and

Steel, Quenched and Tempered, Nickel-Cobalt-Molybdenu

Steel, Recommended Practice for (1974) \$1.75

Steel, Requiring Notch Toughness Testing for Piping Com

Steel, Specification for ASTM A I 64-1971 \$1.75

Steel, Specification for (1975) \$1.75

Stock for High Temperature Service (ASTM a 637 with Add

Stock for High Temperature Service (1973) ASTM A637-19

Stock for High Temperature Service (1973) ASTM A638-19

Stock for High Temperature Service (1973) ASTM A639-19

Stock (ASME SA 637 with Additional Requirements) (4-76

Stock, Specification for (1974A) $\$ 1.75$

Stopping Powers for Use with Cavity Chambers (1961) \$2.

Storage and Handling of Items for Nuclear Power Plants

Storage Batteries, Rec. Practice for (1972) $\$ 5.40$

Storage Facilities in a Reprocessing Plant (1975) $\$ 7.50$

Storage Facility Design Basis (Revision 1, 12/75)

Storage Facility for Boiling and Pressurized Water Reac

Storage Installation $(12 / 74) \quad$ Se App
Storage Methods at UF 6 Production Plants (10/73)

Se Application, Siting,

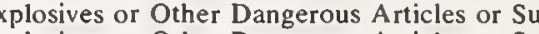

Storage of Explosives or Other Dangerous Articles or Su

Storage of Fissile Materials, Guide for (1975) ANS-8.7

Storage of Special Nuclear Materials (7/73)

Storage Only of Unirradiated Reactor Fuel and Associate

Storage Tank Failure (Safety Guide 24, 3/23/72)

Storage Tanks (1973) $\$ 4.00$

Storage (1973) $\$ 4.00$

Storage (9-75) Supersedes F7-2T, (2-69) Amendment 1

Storage, and Handling of Items for Water Cooled Nuclear

Storage, and Maintenance of Nuclear Power Plant Ouality

Storage, and Maintenance of Quality Assurance Records F

Stores and Supplies on Board Vessels (1975) $\$ 7.50$

Straight or U Tube (6-73)

Straight or U Tube (7-71)
ASTM

ASTM

ANSI

API

ASTM

ANSI

ERDA

ASTM

ASTM

ERDA

ERDA

ANS

ANSI

MSS

NRC

AWS

ERDA

ERDA

ER DA

ASTM

ERDA

ERDA

ERDA

ANSI

ASME

NRC

ERDA

ERDA

ERDA

ERDA

ASTM

NRC

NRC

ARC

ASTM

Det ASTM

ANSI

ANS1

ASTM

A STM

ANSI

ASTM

ASTM

ASTM

ASTM

ASTM

ANSI

ASTM

ASTM

ASTM

ANSI

ASTM

ASTM

ANSI

ASTM

ERDA

ANSl

ANSI

ANSI

ERDA

Cop ASTM

NCRP

/Men AEEE

ANSI

NRC

NRC

NRC

NRC

USCG

ANSI

NRC

NRC

NRC

API

API

ERDA

NRC

NRC

ANSI

I an USCG

ERDA

ERDA

A 366

A 620

G87.1

STD.

A334

B 125.52

RDT M2-19T

450

A269

RDT M3-28T

RDT M3-27T

B125.49

166.27

SP-61

RG 1.43

A 4.2 
Steel Plates for Special Applications, Specification Fo/ of (1974) $\$ 1.75$ Test for Planervice (5-74)

Method of Test for Tensile StressPiston Rings of High Test for Shea

0) $\$ 1.75$

uitable Nuts and Plain Hardened Washers, Specificat/High cification for (1975) \$1.75 Low and Intermediate Tensile (1972) $\$ 1.75$

Peel or Stripping Tests for Unconfined Compressive 2) (ASTM D2/ Method of Test for Unconsolidated, Undrained t Loading), Method of Test for (1966) (R1973) A/ Flexural est for (1973) ASTM C496-1971 \$1.75 Splitting Tensile est for (1974) ASTM C39-1972 \$1.75 Compressive $95-1971 \mathrm{~T} \$ 1.75$ Test for Adhesion or Cohesive Compressive (Crushing) Compressive (Crushing) mm) Cube Specimens), Test for (1973) $\$ 1.75$ Compressive 1969 / Effect of Organic Impurities in Fine Aggregate on thod of Test for (1963) (R1973) ASTM C165-1/ Compressive st for (1972) $\$ 1.7 / \quad$ Breaking Load and Calculated Flexural 1) $\$ 1.75$

1 A) $\$ 1.75$ Method of Test for Direct Tensile ading at Elevated Temperatures (Metal-to-Metal), Meth Sharp-Notch Tension Testing of High

astm/ Making and Curing Concrete Compressive and Flexura 453 with Additional Requirements) (8-75) Supersede/ High Steel Sheet and Strip, Hot Rolled and Cold Rolled, High 4A) $\$ 1.75$ Pressure Vessel Plates, Alloy Steel, High essel Plates, Carbon Steel, Low and Intermediate-Tensile tions on Stainless Steel (1971) \$1.75

Evaluating

ts of / Guidance for Avoiding Intergranular Corrosion and $\$ 1.75$ Test for Thermal Failure Under Electric 1971) ASTM D1390 $1968 \$ 1.75$ or (1971) ASTM Dl693-1970\$1.75 $-75 \$ 1.75$ Method of Test for Tensile Austenitic Stainless Steel Plate, Sheet, and sisting Chromium-Nickel Stainless Steel Plate, Sheet, and -Chromium-Molybdenum-Columbium Alloy Plate, Sheet, and 74) Supersedes M5-1T, Stainless Steel Plate, Sheet, and 5) Supers/ Nickel-Chromium-Iron Alloy Plate, Sheet, and 5) Supers/ Nickel-Iron-Chromium Alloy Plate, Sheet, and Superse/ Zirconium and Zirconium Alloy Plate, Sheet, and l-Chromium-Molybdenum-Columbium Alloy Plate, Sheet, and f Test for (1972) $\$ 1.75$ for (1973) ASTM B3 for $(1967) \$ 1.75$

Zirconium and Zirconium Alloy Sheet Zirconium and Zirconium Alloy Sheet, ase-19Cr-3.1 Mo-5.1 (Cb \& Ta)-0.90Ti-0./ ase-19Cr-3.1 Mo-5.1 (Cb \& Ta)-0.90Ti-0./

lloy Columbium and/or Vanadium, Specific/ $\$ 1.75$

b265-1972 \$1.75

Alloy Sheet, Alloy Sheet, Steel Sheet and Copper, Sheet, Nickel-Chromium-Iron Alloy Plate, Sheet, and

1-Chromium-Molybdenum-Columbium Alloy Plate, Sheet, and Corrosion-Resisting Chromium Steel Clad Plate, Sheet and Stainless Chromium-Nickel Steel Clad Plate, Sheet, and Nickel-Iron-Chromium Alloy Plate, Sheet, and Nickel-Copper Alloy (UNS N04400) Plate, Sheet and Nickel Plate, Sheet, and nd Heat Resisting Chromium-Nickel Steel Plate, Sheet, and inless and Heat Resisting Chromium Steel Plate, Sheet, and cated/Pressed, and Forged Steel Shapes, Plates, Bars and 74) $\$ 1.75$ Operating Performance of Anion Exchange Materials for

Measurements of Radionuclides in the Environment: nts of Radionuclides in the Environment: Strontium- 89 and Containments (Revision 1, 12/28/72)

ments) (6-73)

Test for Shear Strength and Shear Modulus of

Requirements for Installation, Inspection, and Testing of e Requirements for Installation Inspection, and Testing of ncluding Addenda A 138.1A-1974 (ACl 301-1972) $\$ 3.50$

$-1969 \$ 1.75$

ed February 1976) $\$ 1.50$

i $211.2-1969 \$ 2.75$

Lightweight Aggregates for Specification for w and Intermediate Tensile Strength Carbon Steel Plates of $1973 \$ 1.75$

IX-Ray and Gamma Ray Protec lation, Inspection, and Testing of Structural Concrete and llation Inspection, and Testing of Structural Concrete and Specification for the Design, Fabrication and Erection of ain Hardened Washers, Specificat/

High Strength Bolts for Quenched and Tempered Alloy Steel Bolts for

Safeguarding Against Embrittlement of Hot Dip Galvanized
Straight-Beam Ultrasonic Examination of Plain and Clad Strain Fracture Toughness of Metallic Materials, Method Strain of Carbons and Graphite (1974) ASTM C749-75 \$1 Strength Alloys for Core Components for Liquid Metal Se Strength and Shear Modulus of Structural Adhesives (197 Strength Bolts for Structural Steel Joints, Including S Strength Carbon Steel Plates of Structural Quality, Spe Strength of Adhesive Bonds, Standard Method of Test for Strength of Cohesive Soil (1972) (ASTM D 266-1972) \$1 Strength of Cohesive Soils in Triaxial Compression (197 Strength of Concrete (Using Simple Beam with Third Poin Strength of Cylindrical Concrete Specimens, Method of T Strength of Cylindrical Concrete Specimens, Method of T Strength of Flame-Sprayed Coatings (1974) $\$ 1.75$ Strength of Graphite, Method of Test for (1973) ASTM C6 Strength of Graphite, Test for (1975) \$1.75

Strength of Hydraulic Cement Mortars (Using 2-in (50 Strength of Mortar, Method of Test for (1970) ASTM C87 Strength of Preformed Block Type Thermal Insulation, Me Strength of Preformed Block Type Thermal Insulation, Te Strength of Rock Core Specimens (1972) (ASTM D2936-197 Strength of Rock Core Specimens (1972) (ASTM D2938-197 Strength of Undrained Rock Core Specimens Without Pore Strength Properties of Adhesives in Shear by Tension Lo Strength Sheet Materials (1973) \$1.75

Strength Test Specimens in the Field, Method of (1970) Strength, High Temperature Bolting Materials (ASME SA Strength, Low Alloy Columbium and/or Vanadium, Specific Strength, Quenched and Tempered, Specification for (197 Strength, Specification for (1974A) \$1.75 Pre Stress Corrosion Effect of Wicking-Type Thermal Insula
Stress Corrosion in Austenitic Stainless Steel Componen Stress of Solid Electrical Insulating Materials (1973) Stress Relaxation of Vulcanized Rubber in Compression Stress-Cracking of Ethylene Plastics, Method of Test F Stress-Strain of Carbons and Graphite (1974) ASTM C749 Strip for Core Components (3-73)

Strip for Fusion-Welded Unfred Pressure Vessels, Spec Strip (AMS 5596 with Additional Requirements) (4-75) S Strip (ASME SA-240 with Additional Requirements) (11 Strip (ASME SB-168 with Additional Requirements) (1-7 Strip (ASME SB-409 with Additional Requirements) (9-7 Strip (ASTM B 352 with Additional Requirements) (1-72) Strip 5597 with Additional Requirements) (8-75) Supers Stripping Strength of Adhesive Bonds, Standard Method O Strip, and Plate for Nuclear Application, Specification Strip, and Plate for Nuclear Application, Specification Strip, and Plate, Corrosion and Heat Resistant Nickel B Strip, and Plate, Corrosion and Heat Resistant Nickel B Strip, Hot Rolled and Cold Rolled, High Strength, Low a Strip, Plate, and Rolled Bar, Specification for (1974A) Strip, Sheet, and Plate, Specification for (1973) ASTM Strip, Sheet, and Plate, Spec. for (1974) $\$ 1.75$

Strip, Sheet, Foil, and Plate, Specification for (1973) Strip, Specification for (1973) ASTM B I 68-1970 \$1.75 Strip, Specification for (1973) (ASTM B443-1972) $\$ 1.75$

Strip, Specification for (1974A) $\$ 1.75$

Strip, Specification for (1974A) \$1.75

Strip, Specification for (1974) ASTM B409-1973 \$1.75 Strip, Specification for (1974) $\$ 1.75$

Strip, Specification for (1974) $\$ 1.75$

Strip, Specification for (1974) \$1.75

Strip, Specification for (1975) \$1.75

Strip, Zinc (Hot Galvanized) Coatings

Strontium Ion Brackish Water, Sea Water, and Brines (19

Strontium-89 and Strontium-90 Analyses (5/74)

Strontium-90 Analyses (5/74)

Structural Acceptance Test for C

Structural Components (AWS D1.1 with Additional Require

Structural Concrete and Structural Steel During the Con Structural Concrete and Structural Steel During the Con Structural Concrete for Buildings, Specification For, 1

Structural Concrete, Specification for (1970) ASTM C330

Structural Joints Using ASTM A325 or A490 Bolts (Approv

Structural Lightweight Concrete, Practice for (1971) Ac

Structural Quality, Specification for (1975) $\$ 1.75$

Structural Shapes, Rolled or Extruded (1974) ASTM B308

Structural Sheilding Design and Evaluation (1970) $\$ 4.00$

Structural Steel During the Construction Phase of Nucle Structural Steel During the Construction Phase of Nucle Structural Steel for Buildings (Adopted February 12,19 Structural Steel Joints, Including Suitable Nuts and P Structural Steel Joints, Specification for (1975) \$1.75 Structural Steel Products and Procedure for Detecting E
ANSI

ASTM

ANSI

ERDA

ASTM

ASTM

ASTM

ASTM

ANSI

ANS1

ANSI

ANSI

ANS!

ASTM

ASTM

ANSI

ANSI

ASTM

ANS

ANSI

ASTM

ANSI

ASTM

ANSI

ERDA

ANSI

ASTM

ASTM

NRC

ASTM

ANS

ANS

ERDA

ASTM

ERDA

ERDA

ERDA

ERDA

ERDA

ERDA

ASTM

ANSI

ASTM

ANS

ANS

ANSI

ASTM

ANSI

ASTM

ANS

ANSI

STM

ASTM

ANSI

ASTM

ASTM

Stainless a ASTM

Sta ASTM

ANSI

ASTM

NRC

NRC

NRC

ASTM

ERDA

ANS

NRC

ANSI

ANS

AISC

ANSI

Lo ASTM

ANSI

NCRP

ANSI

NRC

AISC

ASTM

ASTM

ASTM

G35.25

E399

K90.15

RDT E6-40T

E229

A 325

D903

A37. 148

A 37.177

A 37.22

A 37.121

A 37.18

C633

K90.11

C695 
(1-72) Amendment 1 (12-72), Amendment 2/ Core Support

cal Penetration Assemblies for Nuclear Reactor Containment Nuclear Power Ge/ Draft Standard Safety Related Systems, (1973)/ Electrical Penetration Assemblies in Containment Leakage-Rate Testing of Containment Electric Penetration Assemblies in Containment Inservice Inspection of Prestressed Concrete Containment Testing of Reinforcing Bars for Category 1 Concrete adweld) Splices in Reinforcing Bars of Category 1 Concrete $n$ of Ungrouted Tendons in Prestressed Concrete Containmen Additional Information: Design of Seismic Category 1 or Cement Grouting for Prestressing Tendons in Containmen Core Suppor Concrete Placement in Category High Pressure Chemical Industry Flanges and Threaded Terrestrial Environmenta Materials and Inspection for Reactor Vessel Closure 1 (11-72), Ame/ Fabrication and Installation of Piping Safety in (1975) ANS-8.6\$6.50 Conducting Complication of Reporting Requirements for Persons shrinkage of Preformed High Temperature Thermal Insulation equirements) (3-75/ Mild Steel Electrodes and Fluxes for

um, 1-Percent-Molybdenum Alloy Electrodes and Fluxes for 17-1969\$2.50 Bare Mild Steel Electrodes and Fluxes for Mild Steel Electrodes and Fluxes for Penetration of Liquids into

on or Storage of Explosives or Other Dangerous Articles or

on or Storage of Explosives or Other Dangerous Articles or

child Labor Regulations Section 57 Exposure to Radioactive ent with Intended $\mathrm{Ch} /$ Threshold Limit Values for Chemical Test for Content of Oxidizin Matter Nonmailable Articles and

and Replacement of Large Stationary Type Power Plant and Heat Removal System Pumps (Safety Guide 1,/ Net Positive on $1,11 / 75$ )

General Site

high Strength Bolts for Structural Steel Joints, Including d Electron Radiation Dose with the Ferrous Sulfate-Cupric Absorbed Gamma and Electron Radiation Dose with the Ceric $\$ 1.75$

d Electron Radiation Dose with the Ferrous Sulfate-Cupric

$\$ 1.75$

Soundness of Aggregates by Use of Sodium

bsorbed Gamma and Electron Radiation Dose with the Ferrous

bsorbed Gamma and Electron Radiation Dose with the Ferrous

ndness of Aggregates by Use of Sodium Sulfate or Magnesium

thod for Measuring Fast Neutron Flux by Radioactivation of systems $(6 / 74)$

tional Information: Air Filtration Systems and Containmen emperat/ Std. Spec. for Precipitation Hardening Iron Base test for (1974) $\$ 1.75 \quad$ Rockwel! Hardness and Rockwell

Il Hardness, Vickers Hardness, Rockwell Hardness, Rockwell ments) (7-75) S/ Seamless Medium Carbon Steel Boiler and Seamless Medium-Carbon Steel Boiler and Ferritic and Austenitic Alloy Steel Boiler, (1974B) 1.75 fication for (1974A) \$1./ Welded Austenitic Steel Boiler, Electrical and Electronics Diagrams (1966) Includes Air Cooled Heat Exchanger for Nuclear Steam t Standard Diesel Generator Units Applied as Standby Power visions for Use of Dangerous Articles as Ships, Stores and lection of Diesel Generator Set Capacity for Standby Power Eddy Current Flowmeter Powe Safety and Health Stds. for Federal Emergency Wate Nuclear Steam a Radionuclid/ Preparation of an Environmental Report to on Only) (1-72) Amendment 1 (12-72), Amendment 2/ Core

Flammability of SelfPipe Hangers,

Nuclear Power Plant Components Pipe Hangers and Pipe Hangers and Blowdown

Steel Sheet, Corrosion Resistant, Laminated Method of Test for the Cleanability of Low Friction Hard ion, Method of Test for (1963) (R1969) ASTM C411-19/ Hot (1973) AWS A5.13-1970 \$3.00

1.75 Practice for Preparation of Metal Descaling and Cleaning Titanium and Titanium Alloy dment 1 (2-72), Amendment 2 (6-74) Centrifugal Free 75) Supersedes M1-5T, (7-/ Welding Rods and Electrodes, Alternating Current Power Circuits,
Structural Steel, Specification for (1975) $\$ 1.75$ Structural Welding Code (1975) $\$ 24.00$

Structure for Sodium Cooled Reactors (Fabrication Only)

Structures Amendment 1 (4-72), Amendment 2 (3-73), Am

Structures and Equipment for Water Cooled and Moderated

Structures for Nuclear Fueled Power Generating Stations

Structures for Nuclear Reactors (1971) ANS-7.60\$7.50

Structures for Water Cooled Nuclear Power Plants (10/73

Structures with Grouted Tendons (11/74)

Structures (Revision 1, 12/28/72)

Structures (Revision 1, 1/2/73 Safety Guide 10)

Structures (Revision 2, 1/76)

Structures (11/74)

Structures (11/75)

Structures (1977) bd (\$40.00), Il (\$70.00)

Structures $(6 / 73)$

Stubs for Use with Lens Gaskets (1968) $\$ 4.00$

Studies for Nuclear Power Stations (7/76)

Studs (10/73)

Subassemblies for Liquid Metal Service (8-71) Amendmen

Subcritical Neutron Multiplication Measurements in Situ

Subject to NRC Regulations (Revision 2, 8/75)

Subjected to Soaking Heat (1963) (R1969) ASTM C356-196

Submerged Arc Weldiug (ASME SFA-5.17 with Additional R

$\begin{array}{ll}\text { Submerged Arc Welding (9-75) } & \text { 2-1/4-Percent-C } \\ \text { Submerged Arc Welding, Specification for (1973) AWS A5. }\end{array}$

Submerged Arc Welding, Specification for (1974)

Submerged Containers, Test for (1973) $\$ 1.75$

Substances and Combustible Liquids on Board Vessels (19

Substances and Combustible Liquids on Board Vessels (19

Substances and lonizing Radiations (1971) \$6.85

Substances and Physical Agents in the Workroom Environm

Substances in the Atmosphere (1970) \$1.75

Substances Under Special Rules (1975)

Substation Lead Storage Batteries, Rec. Practice for ( 1

Suction Head for Emergency Core Cooling and Containment

Suitability Criteria for Nuclear Power Stations (Revisi

Suitable Nuts and Plain Hardened Washers, Specification

Sulfate Dosimeter, Method of Test for (1973) (ASTM D295

Sulfate Dosimeter, Method of Test for (1973) (ASTM D300

Sulfate Dosimeter, Test for (1971)

Sulfate lon in Water and Waste Water, Tests for (1974)

Sulfate or Magnesium Sulfate, Method of Test for (1973)

Sulfate-Cupric Sulfate Dosimeter, Method of Test for (

Sulfate-Cupric Sulfate Dosimeter, Test for (1971)

Sulfate, Method of Test for (1973) $\$ 1.75$

Sulfur (1973) ASTM E265-1970 \$1.75

Sumps for Emergency Core Cooling and Containment Spray

Sumps for Nuclear Power Plants (12/73)

Superalloy Bars, Forgings, and Forging Stock for High T

Superficial Hardness of Metallic Materials, Methods of

Superficial Hardness, and Knoop Hardness) (1973) ASTM E

Superheater Tubes (ASME SA-210 with Additional Require

Superheater Tubes, Specification for (1973) $\$ 1.75$

Superheater, and Heat Exchanger Tubes, Specification Fo

Superheater, Heat Exchanger, and Condenser Tubes, Speci

Supplements Y 14.15a and Y 14.15B \$8.00

Supplied Systems (3-71)

Supplies for Nuclear Power Generating Stations, Trial U

Supplies on Board Vessels (1975) \$7.5

Supplies (Safety Guide 9, 3/10/71)

Supply and Signal Conditioning Electronics (2-73)

Supply Contracts (1975) $\$ 3.25$

Supply Systems for Fuel Reprocessing Plants (9/75)

Supply Systems (1974) $\$ 5.50$

Support a Rule Making Petition Seeking an Exemption for

Support Structure for Sodium Cooled Reactors (Fabricati

Support Structures (1977) bd (\$40.00), 11 (\$70.00)

Supporting Plastics, Test for (1974) $\$ 1.75$

Supports and Snubbers for Liquid Metal Service (5-72)

Supports (1977) bd $(\$ 30.00)$, ll $(\$ 40.00)$

Supports-Material, Design and Manufacture (1967) $\$ 4.00$

Supports-Selection and Application (1966) $\$ 4.00$

Suppression Tank (5-72)

Surface Bonded (1973) SAE AMS5500A-1969 \$3.00

Surface Finishes (1973) \$1.75

Surface for Core Components (5-73) Amendment 1 (9-73)

Surface Performance of High Temperature Thermal Insulat

Surface Texture (1962) (R 1971) $\$ 4.50$

Surface Welding Rods and Electrodes, Specification for

Surfaces for Adhesive Bonding (1973) ASTM D2651-1973 \$

Surfaces, Rec. Practice for (1974) $\$ 1.75$

Surface, Sodium Pump with Electrical Drive (5-71) Amen

Surfacing Welding Rods and Electrodes (1970) $\$ 2.50$

Surfacing (AWS A5.13 with Additional Requirements) (3-

Surge Arresters for (1975) IEEE 28-1974 \$5.00
ASTM

AWS

ERDA

ERDA

ANS1

ANSI

ANSI

NRC

NRC

NRC

IAl (C NRC

NRC

NRC

NRC

ASME

NRC

MSS

NRC

NRC

ERDA

ANSI

NRC

ANSI

ERDA

ERDA

ANSI

ASME

ASTM

DT

USCG

DOL

ACGIH

ASTM

USPS

IEEE

NRC

NRC

ASTM

ANSI

ANSI

ASTM

ASTM

ASTM

ANSI

ASTM

Sou ASTM

Me ANSI

NRC

Addi NRC

ANSI

ASTM

ANSI

ERDA

ASTM

ASTM

ASTM

ANSI

ERDA

ANSI

USCG

Se NRC

ERDA

DOL

NRC

ASME

NRC

ERDA

ASME

ASTM

ERDA

ASME

MSS

MSS

ERDA

ANSI

ASTM

ERDA

ANS1

ANS1

ANS1

ANSI

ASTM

ERDA

AWS

ERDA

ANSI

A 36

D1.1

DT E6-13T

RDT P3-1T

N 18.10

N45.3

N45.4

RG 1.63

RG 1.90

RG 1.15

RG 1.10

RG 1.35

RG 1.70 .9

RG 1.107

SEC-IIING

RG 1.55

SP-65

RG 4.11

RG 1.65

RDT F6-11T

N 16.3

RG 10.1

Z98.19

RDT M1-17T

RDT M1-22T

W3. 17

SFA-5.17

D998

46CFR 146

46CFR 146

29CFR 70

*1

D2912 
1/73)

6)

stm E185-1970 \$1.75

actice for (1973) $\$ 1.75$

els, Rec. Practices for (1975) \$1.7

-Rich Chromium-Bearing Alloys, Detecting

$\begin{array}{ll}\text { l-Rich, Chromium-Bearing Alloys, Method of (/ Detecting } \\ .00 & \text { Cast Iron }\end{array}$

Guide Issued for Use/

Draft Std. for Class $1 \mathrm{E}$ Control

74) Consolidated Edition (Includes ANSI C37.20A-1970, C/

Medium Voltage Radiation

Fissile Material Radiation

Dimensions of Logic Diagrams (Two State Devices), Graphic

f (1975A) $\$ 1.75$ Electrical and Electronics Diagrams, Graphic Terms and

Standard Welding and Nondestructive Standard Welding and Nondestructive Protection Against BetatronPeriodic Testing of Protection Periodic Testing of Fuel Reprocessing Plant Protection

Testing, and Maintenance Criteria for Atmosphere Cleanup re System (7-73)

Visual in Service Inspection

Guidelines and Procedures for Design of Nuclear sedes F9/ Guidelines and Procedures for Design of Nuclear
to ASME Code Ca/ Requirements for Construction of Nuclear to ASME Code Ca/ Requirements for Coismic Category I Fluid

loading Combinations for Metal Primary Reactor Containment abrication Plants (6/73)

Preparation of Liquid Waste Treatment otential Radiological Consequences of a Radioactive Offgas 72) Amendment I (7-73) Low Level Flux Monitor Mechanical $\$ 4.00$

Standard Marking

aterials for Service in Ionizing Radiation, Classification aterials for Service in Ionizing Radiation, Classification eric Materials for Automotive Applications, Classification Protection

formation for Safety Analysis Reports: Steam and Feedwater ad for Emergency Core Cooling and Containment Heat Removal pection Requirements for Materials Used in Reactor Coolant ess, Variable Reluctance Transducer, Proximity Measurement Criticality Accident Alarm

rmation for Safety Analysis Reports: Reactor Water Cleanup for Safety Analysis Reports: Pressurizer Relief Discharge ogarithmic Count Rate Source Range Neutron Flux Monitoring Direct Current Power Range Neutron Flux Monitoring

e Voltage (MSV) Intermediate Range Neutron Flux Monitoring

System and Associated Equipment for the Reactor Enclosure on Phase of Nuclear Power Plants (1973/ Cleaning of Fluid ear Po/ Quality Assurance Requirements for Cleaning Fluid
Information for Safety Analysis Reports: Mechanical $(12 / 73)$ Additional Information: Air Filtration ionizing Radiation Emitting Products) for Diagnostic X-Ray 72) $\$ 2.50$ Identification of Piping 73) Efficiency Testing of Air Cleaning Efficiency Testing of Air Cleaning (Re/ Design of Main Steam Isolation Valve Leakage Control $11 / 75)$ 971) $\$ 4.50$ s Abovel $\begin{array}{ll}\text { s Above/ } & \text { Practice for Prefabricated Reflective Insulation } \\ \text { s / } & \text { Rec. Practice for Prefabricated Reflective Insulation }\end{array}$ Post-Tensioned Prestressing Nuclear Material Control ctice) (1975) $\$ 3.00 \quad$ Nuclear Material Control Confinement Barriers and Process Offgas Emergency Water Supply

s $(3 / 76)$

-73), Amendment 2 (5-74) ata Acquisition Sy/ 1, $1 / 75)$
for (1975) IEEE Std. $308-1974 \$ 4.00$ for (1972) IEEE Std. 279-1971 \$4.00 Preoperational Overhead Crane Handling Nuclear Material Contro
Overhead Crane Handling ation, Inspection, and Testing of Mechanical Equipment and Design Stability of Embankment Retention Nuclear Power Reactors, Nuclear Material Control ants $(8 / 73)$
General Design Guide for Ventilation Cost-Benefit Analysis for Radwaste of Ge(Li) Spectroscopy Design Considerations: Cldown Electric IE Power
Protection n

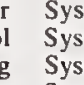

Systems for Nuclear Power Plants (2/76) Systems for the Construction Phase of Nuclear Power Pla
Systorized $1,1 / 7$ Systems for Uranium Mills (6/73)

Systems for (1974) $\$ 3.50$

Systems of Plutonium Processing and Fuel Fabrication PI
Surveillance of Individuals in Material Access Areas ( 1 Surveillance Program for New Fuel Assembly Designs (6/7 Surveillance Tests for Nuclear Reactor Vessels, Rec. Pr Survey Instruments, Specification of (1971) $\$ 4.40$

Susceptibility to Intergranular Attack in Stainless Ste Susceptibility to Intergranular Attack in Wrought Nicke Swing Check Valves, Flanged and Threaded Ends (1970) \$3 Switchboards for Nuclear Power Generating Stations, (Tr Switchgear (10-75) Supersedes P2-5T, (2-73)

Symbol (1969) \$2.75

Symbol (1971) $\$ 2.75$

Symbol $(2 / 2 / 73)$

Symbols and Identification (1975) $\$ 7.00$

Symbols for (1968) (R1973) \$1.75

Symbols for (1973) IEEE 91-1973 $\$ 6.00$

Symbols for (1975) IEEE 315-1975 \$8.00

Symbols Testing (1976) $\$ 5.00$

Symbols, Conventions, and References Relating to (1974)

Synchrotron Radiation Up to $100 \mathrm{MeV}$ (1954) \$2.00

System Actuation Functions (Safety Guide 22, 2/17/72)

System Actuation Functions (6/74)

System Air Filtration and Adsorption Units of Light-W

System and Associated Equipment for the Reactor Enclosu

System Components at Elevated Temperature (9-74) Super

System Components at Elevat

System Components $(6 / 73)$

System Design Descriptions (12-75) Supersedes (3-72)

System Design Guide

System Failure in a Boiling Water Reactor (3/76)

System for Liquid Metal Service (Fabrication Only) (7-

System for Valves, Fittings, Flanges and Unions (1964)

System for (ASTM D2953-

System for (1975) $\$ 1.75$

System Logic (4-72) Amendment 1 (6-73)

System Materials (4/75)

System Pumps (Safety Guide 1, 11/2/70)

System Wear Applications (10-67)

(1-76)

System $(5 / 75)$

System $(6 / 75)$

System (7-71)

System $(7-71)$

System $(7-71)$

System

Systems and Associated Components of Water-Cooled Nucl Systems and Components (1/75)

Systems and Containment Sumps for Nuclear Power Plants Systems and Their Major Components (1975) $\$ 2.95$

Systems by Color Coding, Scheme for the (1975) $\$ 3.00$ Systems Containing Devices for Removal of Particles (1) Systems for Boiling Water Reactor Nuclear Power Plants Systems for Boiling Water Reactor Power Plants (12/75)

Systems for Concrete Reactor Vessels and Containments ( Systems for Conversion Facilities, Guide to Practice (1 Systems for Equipment and Pipe Operating at Temperature Systems for Equipment and Pipe Operating at Temperature Systems for Fuel Fabrication Facilities (A Guide to Pra Systems for Fuel Reprocessing Plants (2/74) Systems for Fuel Reprocessing Plants $(2 / 74)$

Systems for Fuel Reprocessing Systems (9/75)

Systems for Light-Water-Cooled Nuclear Power Reactor Systems for Liquid Metal Service (8-72) Amendment 1 ( 8 Systems for Material Protection Measurements, Part

Systems for Multi-Unit Nuclear Power Plants (Revision

yystems for Nuclear Power Generating Stations, Criteria ystems for Nuclear Power Generating Stations, Criteria ystems for Nuclear Power Plants (Revision 1, 6/73)

esign Li NRC

NRC

NRC

NRC

/He P NRC

ERDA

MSS

Olymeric M ANS

ASTM

ERDA

in NRC

Ins ERDA

ERDA

ANSI

nfo NRC

formation NRC

ERDA

ERDA

ERDA

ANS1

NRC

NRC

NRC

Td ( BRH

ANSI

ANSI

NRC

NRC

NRC

NRC

ANSI

ANS1

ASTM

ANS

NRC

NRC

NRC

NRC

NRC

ERDA

NRC

NRC

NRC

ANSI

NRC

NRC

NRC

NRC

ANSI

NRC

ANSI

NRC

RG 5.14

RG 1.119

N146

E185

N13.4

A 262

G80.4

SP-71

N41.17

C 37.20

RDT P2-5T

N2.I

N12.1

RG 8 .

S 5.1

D2749

Y 32.14

Y 32.2

E] 35

A2.4

E386

R 14

RG 1.22

RG 1.52

RDT E8-12T

RDT C 16-4T

RDT F9-5T

RDT F9-4T

RG 1.48

RG 1.57

RDT F1-2T

RG 3.10

RG 1.70 .34

RG 1.98

RDT E6-36T

SP-25

N4. 1

D2953

D2000

RDT Cl6-2T

RG 1.70.28

RG 1.1

RDT F3-7T

RDT C8-2T

N16.2

RG 1.70 .32

RG 1.70 .37

RDT C $15-10$

RDT C15-8T

RDT C15-6T

RDT E8-12T

N45.2.1

RG 1.37

RG 1.70 .18

RG 1.70 .2 
Fuel Reprocessing Facilities, Nuclear Material Control Physical Independendence of Electric material Protection Measurements, Part I: Data Acquisition ndby (Onsite) Power Sources and Between Their Distribution

74) Mixing Component for Liquid Metal Piping Stabilization of Uranium-Thorium Milling Waste Retention criteria and Requirements for RDT Reactor Plant Protection Criticality Accident Alarm rformance Characteristics of Pulse Echo Ultrasonic Testing Industrial Controls and

Cast Bronze Solder Joint Fittings for Sovent Drainage Nuclear Steam Supply

(Ionizing Radiation Emitting Products) for Cabinet X-Ray Radiation Emitting Products) for X-Ray Baggage Inspection Perimeter Intrusion Alarm

A ir Cooled Heat Exchanger for Nuclear Steam Supplied Purity Requirements for Operating Sodium Reactor Permanent Magnet Flowmeter for Liquid Metal Piping (1-72) Intermediate Heat Exchanger for Liquid Metal Reactor Coolant Pressure Boundary Leakage Detection Occupational Radiation Exposure Records noperable Status Indication for Nuclear Power Plant Safety ingle-Failure Criterion to Nuclear Power Plant Protection Preoperational Testing of Instrument Air Sumps for Emergency Core Cooling and Containment Spray Periodic Testing of Electrical Power and Protection ation, Inspection, and Testing of Mechanical Equipment and Orifice Assemblies for Nuclear design Guide for Ventilation Systems for Fuel Reprocessing dic Testing of Nuclear Power Generating Station Protection Nondestructive Assay of N2.2-1966) (/ Occupational Radiation Exposure Records Uranium-Thorium Milling Waste Retention moderated Nuclear Power Ge/ Draft Standard Safety Related Nuclear Air Cleaning

e Criterion to Nuclear Power Generating Station Protection solute or Gage (10-70/ Liquid Metal Pressure Measurement s, Vickers Hardness, Rockwe/ Standard Hardness Conversion
Temperatures: Electromotive Force (EMF) Temperatures: Electromotive Force (EMF)
Fuel and Control Assem bly

ces of a Pressurized Water Reactor Radioactive Gas Storage

9-70) Amendment 1 (3-72), Amendment 2 (11-72), Amendm/ Total Immersion Corrosion Test for Soak

nsideration, Arrangement, and Other Provisions for Nuclear Blowdown Suppression Welded Steel

gn and Construction of Large, Welded, Low Pressure Storage 1974) $\$ 1.75$ or (1973) ASTM B364-1970 \$1.75 ) $\$ 1.75$

Alloy Bars and Rods, high Temperature Glass Cloth Pressure Sensitive Electrica c. for Fully Cured Silicone Rubber Coated Glass Fabric and Connecting Flange Joint Between Connecting Flange Joint Between Tapping Sleeves and actors $(11 / 73)$ $4 / 73$ ) Drop-Weight 5)

Development of Content of Environmental Research Reactors, Development of Reporting of Operating Information: Appendix A Fast Neutron Flux Measurements by Track-Etch Volume Calibration g Solids Applied to Nuclear Materials Control, Calibration Dielectric Tests, Nuclear Material Control Mass Calibration Calibration of Thermocouples by Comparison Method of Measuring Neutron Flux by Radioactivation Method for Measuring Fast Neutron Flux by Radioactivation rgy from $3 \mathrm{H}(\mathrm{D}, \mathrm{N}) 4 \mathrm{He}$ Neutron Generators by Radioactivation Testing for Leaks Using Bubble Emission Thermal Neutron Flux by Radioactivation from ${ }^{3} \mathrm{H}(\mathrm{d}, \mathrm{n})^{4} \mathrm{He}$ Neutron Generators by Radioactivation ) $\$ 1.75 \quad$ Uranium Oxide by Gallium Oxide Carrier D-C Arc ASTM E40/ Uranium Oxide by Gallium Oxide Carrier DC Arc Fast Neutron Flux Measurements by Track-Etch ent Using a 14-MeV Neutron Activation and Direct Counting ent Using a 14-MeV Neutron Activation and Direct Counting Glossary of Terms in Nuclear Science and osphere Accumulation, Biological Significance, and Control
Systems That Perform Protective Functions in Nuclear Po Systems Used for Removal of Water Formed (1973) \$1.75 ANS Systems (A Guide to Practice) (1974) \$3.00

Systems (Revision 1, I/75)

Systems (Revision 1, 5/74)

Systems (Safety Guide 6,3/10/71)

Systems (10-72) Amendment 1 (8-73)

Systems (11-71) Amendment 1 (12-73), Amendment 2 (6-

Systems (11/74)

Systems (12-69)

Systems $(12 / 74)$

Systems (1969) ASTM E317-1968\$1.75

Systems (1970) $\$ 16.00$

Systems (1973) $\$ 3.50$

Systems (1974) $\$ 5.50$

Systems (1975) \$2.95

Systems (1975) \$2.95

Systems $(1 / 75)$

Systems (3-71)

Systems (3/76) Supersedes A 1-5T, 5-73

Systems (4-74) Supersedes C4-5T, (8-71)

Systems (5-74) Supersedes E4-6T, (1-72), Amendment 1

Systems $(5 / 73)$

Systems $(5 / 73)$

Systems $(5 / 73)$

Systems $(6 / 73)$

Systems $(6 / 74)$

Systems $(6 / 74)$

Systems $(6 / 76)$

Systems $(6 / 76)$

Systems (8-73)

Systems $(9 / 75)$

Systems, Criteria for the (1975) $\$ 5.00$

Systems, Guide to Calibrating (1975) $\$ 5.75$

Systems, Practice for (Reaffirmation and Redesignation Application of the $\mathrm{S}$

NRC

pectroscopy Systems for NRC
/Tween Redundant Sta NRC

ERDA

ERDA

NRC

Supplementary ERDA

NRC

lor Evaluating $\mathrm{Pe}$ ANSI

NEMA

ANSI

ASME

Performance Std BRH

Performance Std. (Ionizing

BRH

NRC

ERDA

ERDA

ERDA

ERDA

NRC

NRC

Systems, Stablilzation of (1974) $\$ 1.50$

Systems, Structures and Equipment for Water Cooled and

Systems, Testing of (1975) $\$ 5.00$

Systems, Trial Use

ID Application of the Single Failur

System, Flush Mounted, Eddy Current Type, Inductive, Ab

Tables for Metals (Relationship Between Brinell Hardnes

Tables for Thermocouples (1973) ASTM E230-1972\$3.00

Tag Gas (10-72)

Tank Failure (Safety Guide 24, 3/23/72)

Tank for Gas Service (11.72) Amendment 1 (1.74)

/Cal Consequen

Tank Liquid Metal Service (9-71) Supersedes E10-3T,

Tank Metal Cleaners (1972) $\$ 1.75$

Tank Vessels (Ships and Barges) (1975) \$2.15

Tank (5-72)

Tanks for Oil Storage (1973) $\$ 4.00$

Tanks (1973) \$4.00

Tanks (1973) $\$ 4.00 \quad$ Recommended Ru

antalum and Tantalum Alloy Tubing, Specification for

Tantalum Ingots and Flat Mill Products, Specification F

Tantalum Ingots and Flat Mill Products, Spec. for ( 1970

Tantalum Rod and Wire, Spec. for (1970) \$1.75

Tantalum (90Ta-10W) (1975) $\$ 3.00$

Tape (1973) $\$ 1.75$

Tapes for Electrical Insulation (1969) (R1974) ASTM. S

Tapping Sleeves and Tapping Valves (1969) $\$ 2.00$

Tapping Valves (1969) $\$ 2.00$

Tear Tests of Ferritic Steels, Method for (1974) $\$ 1.75$

Technical Specifications for Experiments in Research $\operatorname{Re}$

Technical Specifications for Fuel Reprocessing Plants (

Technical Specifications for Nuclear Power Plants (12/7

Technical Specifications for (1974) ANS-15.1 \$12.00

Technical Specifications (Revision 4, 8/75)

Technique (1973) $\$ 1.75$

Techniques for Nuclear Materials Control (1975) $\$ 5.50$

Techniques for the (1975) $\$ 5.75$

Techniques for (1968) (R 1973) IEEE 4-1969 55.00

Techniques for $(1975) \$ 5.50$

Techniques (1972) $\$ 1.75$

Techniques (1973) ASTM E261-1970 \$1.75

Techniques (1973) ASTM E262-70 \$1.75

Techniques (1974) ASTM E496-1973\$1.75

Techniques (1974) $\$ 1.75$

Techniques, Measuring (1970) \$1.75

Techniques, Test for (1973) \$1.75

Technique, Method for Spectrochemical Analysis of (1970

Technique, Method for Spectrochemical Analysis of (1972
Technique, Method for (1974) ASTM E418-1973 \$1.75

/Ecial Co

NRC

NRC

NRC

NRC

NRC

NRC

General NRC

Perio IEEE

ANSI

ANSI

ANSI

ANSI

ANSI

ANSI

ANSI

ANSI

ERDA
NRC

ERDA

ERDA

ASTM

USCG

ERDA

API

API

ASTM

ASTM

ANSI

ASTM

ASTM

SAE

ASTM

ANSI

MSS

MSS

ASTM

NRC

NRC

NRC

ANSI

NRC

ASTM

ANSI

Technique, Method of Test for (1973) \$1.75

$-1973$

Technology (1967) \$7.95

Technology (1975) $\$ 4.00$

Krypton-85 in the Atm NCRP

N 18.8

D2790

15.13

RG 1.75

RG 5.9

RG 1.6

RDT C 17-8T

RDT E7-4T

RG 3.23

RDT C16-1T

RG 8.12

166.21

CS

B 16.32

PTC 32.1

21 CFR 1020F

ICFR 1020C

RG 5.44

RDT E4-18T

RDT A 1-5T

RDT C4-5T

RDT E4-6T

RG 1.45

RG 8.7

RG 1.47

RG 1.53

RG 1.80

RG 1.82

RG 1.118

RG 1.116

RDT C4-8T

RG 3.32

338

N15.20

N13.6

N313

N 18.10

N510

N41.2

RDT C6-3T

Z76.4

C96.2

RDT M14-2T

RG 1.24

RDT E10-6T 
) $\$ 3.50$ Cobalt-60 and Cesium-137 onal Requirements) (8-75) Supersede/ High Strength, High (1974) $\$ 1.75 \quad$ Seamless Austenitic Steel Pipe for High for Use in Fuel Reprocessing Plant/ Preheat and Interpass -70)

Control of Preheat

ape (1973) $\$ 1.75$

sedes E4-19T, (8-71)

Plugging

.00

Definitions of Terms Relating to g Drop-Weight Test to Determine Nil-Ductility Transitio 971 \$1.75 Method of Test for Determining the Maximum Use ce (3-7l) Amendment l (5-7l); Su/ Nak Transmission High idance for Construction of Class 1 Components in Elevated Seamless Carbon Steel for High rements) (2-75) S/ Alloy Steel Bolting Material for High Alloy Steel Nuts for Bolting for High Pressure and High rements) (2-75) Su/ Alloy Steel Bolting Material for Low ng Nickel Alloy Bars, Forgings, and Forging Stock for High ng Nickel Alloy Bars, Forgings, and Forging Stock for High base Superalloy Bars, Forgings, and Forging Stock for High ontaining Alloy Bars, Forgings, and Forging Stock for High ontaining Ation for Seamless and Welded Steel Pipe for Low $g$ Fittings of Wrought Carbon Steel and Alloy Steel for Low Seamless-Ferritic Alloy Steel Pipe for High ressure Vessel Plates, Carbon Steel for Moderate and Lowe Vessel Plates, Carbon Steel for Intermediate-and HigherSeamless and Welded Carbon and Alloy Steel Tubes for Low Ferritic Alloy Steel Forged and Bored Pipe for High Centrifugally Cast Ferritic Alloy Steel Pipe for High Austenitic Steel Forged and Bored Pipe for High Centrifugally Cast Austenitic Steel Pipe for High Ided Austenitic Chromium-Nickel Alloy Steel Pipe for High tic Chromium Nickel Alloy Steel Pipe for Corrosive or High ce for $(1970) \$ 1.75$

Elevated

t/ Method of Test for Linear Shrinkage of Preformed High 3) (R1969) ASTM C411-19/ Hot Surface Performance of High edures for Design of Nuclear System Components at Elevated

ive Insulation Systems for Equipment and Pipe Operating at ive Insulation Systems for Equipment and Pipe Operating at rties of Adhesives in Shear by Tension Loading at Elevated

for Construction of Nuclear System Components at Elevated

ctric-Fusion-Welded Steel Pipe for Atmospheric and Lower mocouples (1973) ASTM E230-1972 $\$ 3.00$

Flow Properties of Lubricating Greases at High

Nickel High Alloy Tubing for Pressure Application at High on, Nickel, and Cobalt-Base Alloys, Chemical Analy/ High

3) Thermal Insulation, Flexible or Molded, High ivity of Manufactured Carbon and Graphite Articles at Room with Additional / Mineral Fiber Thermal Insulation, High Specification for (1975) $\$ 1.75$

$\$ 1.75$ Pressure Vessel Plates, Alloy Steel, Quenched and for Pressure Vessels (1974A/ Std. Spec. for Quenched and pec. for Pressure Vessel Plates, Alloy Steel, Quenched and cation for Steel Forgings, Carbon and Alloy, Quenched and tion for Pressure Vessel Plates, Alloy Steel, Quenched and cation/ Pressure Vessel Plates, Alloy Steel, Quenched and Qualifications for Cement Grouting for Prestressing (Revision 2, 1/76) Inservice Inspection of Ungrouted

Prestressed Concrete Containment Structures with Grouted ity, Specification for (1975) $\$ 1.75$ Low and Intermediate hod of Test for (1973) ASTM C496-1971 \$1.75 Splitting 936-1971) $\$ 1.75$ Method of Test for Direct essure Vessel Plates, Carbon Steel, Low and Intermediate stm C749-75 \$1.75 Method of Test fo tal), Meth/ Strength Properties of Adhesives in Shear by Test for Fatigue Properties of Adhesives in Shear by Methods of (1973) ASTM C565-1971 \$1.75

$\$ 1.75$

Sharp-Notch

) $\$ 1.75$

sels and Containments (11/75)

Elevated Temperature

$(6 / 74)$

control Accountability (2/2/73) Electrical Transducer Nomenclature and Quality Assurance Quality Assurance

Glossary of Definition of Definitions of

tions and Materials (1973) $\$ 1.75$ (Fabrication Only) (10-73) Amendment 1 (12-74) Testing of High re Vessel Plates, Alloy Steel, High Strength, Quenched and

nt (1972) $\$ 3.00$

finition of (1975A) $\$ 1.75$

Teletherapy Equipment, Guidelines for Maintaining (1974 Television Receivers (1975) \$2.95

Temperature and Liquid Level Control Monitor, Port Plug Temperature Bolting Materials (ASME SA-453 with Addit Temperature Cable for Nuclear Detectors (8-71)

Temperature Central Station Service, Specification for Temperature Control for the Welding of Low Alloy Steel Temperature Electrical Connectors and Hermetic Seals ( 3 Temperature for Welding of Low Alloy Steel $(5 / 73)$

Temperature Glass Cloth Pressure Sensitive Electrical T

Temperature Indicator Assembly for Sodium Service Super Temperature Measurement Thermocouples (1964) (R1969) \$6 Temperature Measurement (1974) \$1.75

Temperature of Ferritic Steels (1970) ASTM E208-1969 \$ Temperature of Preformed Insulation (1973) ASTM C447-1 Temperature Pressure Transmitter for Liquid Metal Servi

Temperature Reactors (Supplement to ASME Section IIl Co Temperature Service Specification for (1975) \$1.75

Temperature Service (ASME SA-193 with Additional Requi Temperature Service (ASME SA-194 with Additional Requi Temperature Service (ASME SA-320 with Additional Requi Temperature Service (ASTM a 637 with Additional Require Temperature Service (1973) ASTM A637-1970 \$1.75

Temperature Service (1973) ASTM A638-1970 \$1.75

Temperature Service (1973) ASTM A639-1970 \$1.75

Temperature Service (1975) \$1.75

Temperature Service (1975) \$1.75

Temperature Service, Specification for (1974A) \$1.75

Temperature Service, Specification for (1974A) \$1.75

Temperature Service, Specification for (1974B) \$1.75

Temperature Service, Specification for (1974) \$1.75

Temperature Service, Specification for (1975) $\$ 1.75$

Temperature Service, Specification for (1975) \$1.75

Temperature Service, Specification for (1975) \$1.75

Temperature Service, Specification for (1975) \$1.75

Temperature Service, Specification for (1975) $\$ 1.75$

Temperature Service, Specification for (1975) \$1.75

Temperature Tension Tests of Metallic Materials, Practi

Temperature Thermal Insulation Subjected to Soaking Hea

Temperature Thermal Insulation, Method of Test for (196

Temperature (9-74) Supersedes F9-5T, (3-74)

Temperatures Above Ambient Air (1972) \$1.75

Temperatures Above Ambient Air (1974) ASTM C667-1972 \$

Temperatures (Metal-to-Metal), Method of Test for (I

Temperatures (Supplement to ASME Code Cases 1592, 1593,

Temperatures (1974) ASTM A671-1972 \$1.75 /lon for

Temperatures: Electromotive Force (EMF) Tab

Temperatures, Specification for (1973) ASTM A608-1970

Temperature, Electrical, Magnetic, and Other Similar Ir

Temperature, Low Conductivity (5-72) Amendment 1 (4-7

Temperature, Method of Test for (1973) ASTM C611-1969

Temperature, Rigid, Flexible and Loose Fill (ASTM C 612

Tempered Alloy Steel Bolts for Structural Steel Joints,

Tempered Chromium-Molybdenum, Specification for (1974)

Tempered Vacuum Treated Carbon and Alloy Steel Forging

Tempered, Eight and Nine Percent Nickel (1974) $\$ 1.75$

Tempered, for Pressure Vessel Components (1973) \$1.75

Tempered, Manganese-Molybdenum and Manganese-Molybden

Tempered, Nickel-Cobalt-Molybdenum-Chromium, Specifi

Tempered, Specification for (1974A) $\$ 1.75$

Tendons in Containment Structures (11/75)

Tendons in Prestressed Concrete Containment Structures

Tendons $(11 / 74)$

Inservice Insp

Tensile Strength Carbon Steel Plates of Structural Qual

Tensile Strength of Cylindrical Concrete Specimens, Met

Tensile Strength of Rock Core Specimens (1972) (ASTM D2

Tensile Strength, Specification for (1974A) $\$ 1.75$

Tensile Stress-Strain of Carbons and Graphite (1974) a

Tension Loading at Elevated Temperatures (Metal-to-Me

Tension Loading (1973) $\$ 1.75$

Tension Testing of Carbon Graphite Mechanical Materials

Tension Testing of High Strength Sheet Materials (1973)

Tension Testing of Metallic Materials (1969) \$1.75

Tension Tests of Metallic Materials, Practice for ( 1970

Tensioned Prestressing Systems for Concrete Reactor Ves

Termination of Operating Licenses for Nuclear Reactors

Terminology and Notation for Nuclear Materials Manageme

Terminology and Notation for Special Nuclear Materials

Terminology (1975) $\$ 5.00$

Terms and Definitions (1973) $\$ 3.00$

Terms and Definitions (2/74)

Terms and Symbols Relating to Emission Spectroscopy, De

8) $\$ 1.75$
Terms in Nuclear Science and Technology (1967) \$7.95

Terms Relating to Dosimetry (1973) ASTM E170-1963 (196
ANSI

BRH

ERDA

ERDA

ERDA

ASTM

NRC

ERDA

NRC

ASTM

ERDA

ANSI

ASTM

ANSI

ANSI

ERDA

NRC

ASTM

ERDA

ERDA

ERDA

Deni ANSI

Ron ANSI

ANSI

ASTM

ASTM

ASTM

ASTM

ASTM

ASTM

ASTM

ASTM

ASTM

ASTM

/E ASTM

/I ASTM

ASTM

ANSI

ANSI

ERDA

ASTM

ANSI

ANSI

ERDA

ANSI

ANSI

ASTM

ANSI

ASTM

ANSI

ERDA

ASTM

ASTM

ASTM

ASTM

ASTM

ASTM

ANSI

Pressu ASTM

NRC

NRC

NRC

ASTM

ANSI

ANSI

Pr ASTM

ANSI

ANSI

ASTM

ANSI

ASTM

ASTM

ASTM

NRC

ANSI

NRC

ISA

ANSI

NRC

ASTM

ANSI

ASTM

ANSI

N449

2ICFR 1020A

RDT E6-10T

RDT M6-6T

RDT F3-39T

A376

RG 329

RDT C17-1T

RG 1.50

D 2754

RDT E4-19T

C96.1

Z] 78.5

Z98.28

RDT C6-1T

RG 1.87

A 106 
$2681968 \$ 1.75$

nalysis of Fatigue Data (1973) (ASTM E206)

stm E425-197!\$1.75

.75

1.75

5) $\$ 1.75$

5A) $\$ 1.75$ i C59.75 (1973)

Std. Definitions of Definitions of Definitions of

Definitions of Definitions of

Standard Definitions and Definitions of Definitions of Definitions of Definition of

Dosimetry, Definition of Thermal Insulating Materials, Definition of Activated Carbon, Definition of Definitions of g Stations (1972) $\$ 4.00$ tions $(7 / 76)$

tation Hardness of Metallic Materials by Portable Hardness standard Analytical Methods for the Measurement of Uranium Accountability of Uranium Abbreviations for Use in Drawings and in Surface

recautions in the Management of Patients Who Have Received ions by Means of the Guarded Hot Box, Method of Test For/ ed Hot Plate, Method of Test for (1975) ASTM C177-1971/ ed Hot Plate, Test for (1971) \$1.75

flow Meter, Test for (1970) $\$ 1.75$

for (1967) (R1969) ASTM C335-1969\$1.75

Pulse Method, Method of Test for (1973) ASTM C714-1972/ Pulse Method, Test for (1972) $\$ 1.75$

al lnsulating Materials (1973) \$1.75

Mineral Fiber Hydraul for (1970) $\$ 1.75$ Mineral Fiber Hydraulic-Setting nless Steel (10-72) Supersedes MI/ ing to (1967) $\$ 1.75$

173)

Thickness and Density of Blanket-Type or Batt-Type Nonmetallic

of Test for Linear Shrinkage of Preformed High Temperature ents) (6-71) Amendment / Calcium Silicate Block and Pipe Spec. for Mineral Fiber Block and Board Sampling Preformed

Evaluating Stress Corrosion Effect of Wicking-Type

Recommended Practice for Selection of Vapor Barriers for e, Low Conductivity (5-72) Amendment I (4-73)

nd Loose Fill (ASTM C 612 with Additional/ Mineral Fiber stm C411-19/ Hot Surface Performance of High Temperature stm Cl65-1/ Compressive Strength of Preformed Block Type $312.1955) \$ 1.75$ Mean Specific Heat of Calcium Silicate Block and Pipe Mean Specific Heat of

Density of Preformed Pipe Covering Type Density of Preformed Block Type

d and Calculated Flexural Strength of Preformed Block Type phite, Methods for (1973) ASTM C626-1971/ Estimating the phite, Estimating the (1971) \$1.75

suring (1970) \$1.75

r Operated Valves $(11 / 75)$

14-1972/ Thermal Diffusivity of Carbon and Graphite by A $2,11 / 2 / 70)$

ainless Steel Sheathed (1-72)

Time Response Test for Sheathed, Mineral Insulated ess Steel Sheathed, Magnesium / 3) Thermocouple Material and

Is (1-72) Amendment 1 (1-73)

1-P Versus Alumel, Stainless Steel Sheathed, Magnesium /

t Rhodium Wires, Noninsulated, Std. Grade (8-72) Amendm/ ductor (Bare, Fiberglass Insulated, and Sheathed Over Fi/ ductor (Bare, Fiberglass Insulated, and Sheathed Over Fi/ de Insulated, Sheathed (4-70) Supersedes C7-14T, (3-7) ctor (Bare, Fiberglass Insulated, and Sheathed Over Fibe/ nsulated, Sheathed (4-70) Supersedes C7-14T, (3-70),

Calibration of 52-1972\$1.7/ Method for Calibration of Refractory Metal Temperature Measurement

Temperatures: Electromotive Force (EMF) Tables for High Reliability Applications, Specification for (1967) er High Reliability Applications, Specification for (197/ Performance, Testing, and Procedural Specifications for Platinum Resistance Measuring Flow Rates of

ndment 1 (8-73), Amendment 2 (5-74) Industrial Laminated ermal Insulating Materials, Test for (1970) \$1.75

agnetic) Test/ Recommended Practice for Measuring Coating Steel Castings Up to 2 lnches in
Terms Relating to Electric Insulation (1975B) \$1.75 ANS

Terms Relating to Electromagnetic Testing (1974) ASTM E

Terms Relating to Fatigue Testing and the Statistical a

Terms Relating to Leak Testing, Definitions of (1973) a

Terms Relating to Liquid Penetrant Inspection (1974) \$1

Terms Relating to Magnetic Particle Inspection (1974) \$

Terms Relating to Manufactured Carbon and Graphite (197

Terms Relating to Rubber and Rubber Like Materials (197

Terms Relating to Temperature Measurement (1974) \$1.75

Terms Relating to Ultrasonic Testing (1974) \$1.75

Terms Relating to Water (1974) $\$ 1.75$

Terms Relating to (1963) (R 1968) \$1.75

Terms Relating to (1967) $\$ 1.75$

Terms Relating to (1974) \$1.75

Terms Used in IEEE Standards on Nuclear Power Generatin

Terrestrial Environmental Studies for Nuclear Power Sta

Testers (1974) ASTM EII0 1972 \$1.75

lof Test for

Tetrafluoride $\left(\mathrm{UF}_{4}\right)$ and Uranium Hexafluoride $\left(\mathrm{UF}_{6}\right) 2 / 2$

Tetrafluoride, Analytical Procedures for (1972) $\$ 6.00$

Text (1972) \$12.00

Texture (1962) (R1971) \$4.50

Therapeutic Amounts of Radionuclides (1970) $\$ 4.00$

Thermal Conductance and Transmittance of Built-Up Sect

Thermal Conductivity of Materials by Means of the Guard

Thermal Conductivity of Materials by Means of the Guard

Thermal Conductivity of Materials by Means of the Heat

Thermal Conductivity of Pipe Insulation, Method of Test

Thermal Diffusivity of Carbon and Graphite by a Thermal

Thermal Diffusivity of Carbon and Graphite by a Therma

Thermal Failure Under Electric Stress of Solid Electric

Thermal Insulating and Finishing Cement (ASTM C 449 Wit

Thermal Insulating and Finishing Cement, Specification

Thermal Insulating Materials for Use on Austenitic Stai

Thermal Insulating Materials, Definition of Terms Relat

Thermal Insulating Materials, Test for (1970) $\$ 1.75$

Thermal Insulation for Austenitic Stainless Steel (2/23

Thermal Insulation Subjectcd to Soaking Heat (1963) (R I

Thermal Insulation (ASTM C 533 with Additional Requirem

Thermal Insulation (1970) $\$ 1.75$

Thermal Insulation (1972) $\$ 1.75$

Thermal Insulations on Stainless Steel (1971) $\$ 1.75$

Thermal Insulations (1973) $\$ 1.75$

Thermal Insulation, Flexible or Molded, High Temperatur

Thermal Insulation, High Temperature, Rigid, Flexible a

Thermal Insulation, Method of Test for (1963) (R 1969) a

Thermal Insulation, Method of Test for (1963) (R 1973) a

Thermal Insulation, Practice for (1963) (R1975) (ASTM C

Thermal Insulation, Specification for (1972) $\$ 1.75$

Thermal Insulation, Test for (1961) (R1973) \$1.75

Thermal Insulation, Test for (1972) $\$ 1.75$

Thermal Insulation, Test for (1972) \$1.75

Thermal Insulation, Test for (1972) $\$ 1.75$

Thermal Neutron Absorption Cross Section of Nuclear Gra

Thermal Neutron Flux by Radioactivation Techniques, Mea

Thermal Overload Protection for Electric Motors on Moto

Thermal Pulse Method, Method of Test for (1973) ASTM C7

Thermal Pulse Method, Test for (1972) \$1.75

Thermal Shock to Reactor Pressure Vessels (Safety Guide

Thermocouple Assemblies, Magnesium-Oxide Insulated, St

Thermocouple Assembly (6-72)

Thermocouple Assembly, Chromel-P Versus Alumel, Stainl

Thermocouple Connector Panels (1-72) Amendment 1 (1-7

Thermocouple Connectors and Thermocouple Connector Pane

Thermocouple Material and Thermocouple Assembly, Chrome

Thermocouple Materials, Platinum and Platinum 10 Percen

Thermocouple Material, Chromel-P and Alumel, Solid Con

Thermocouple Material, Copper and Constantan, Solid Con

Thermocouple Material, Copper-Constantan, Mineral-Oxi

Thermocouple Material, Iron and Constantan, Solid Condu

Thermocouple Material, Iron Constantan, Mineral Oxide

Thermocouple Signal Transmitter (11-71)

Thermocouples by Comparison Techniques (1972) $\$ 1.75$

Thermocouples Using an Optical Pyrometer (1973) ASTM E4

Thermocouples (1964) (R1969) $\$ 6.00$

Thermocouples (1973) ASTM E230-1972 $\$ 3.00$

Thermocouples, Sheathed, Type K for Nuclear or for Othe

Thermocouples, Sheathed, Type K, for Nuclear or for Oth

Thermoluminescence Dosimetry-Environmental Application

Thermometer (4-75) Supersedes C7-17T, (3-73)

Thermoplastics by Extrusion Plastometer (1973) $\$ 1.75$

Thermosetting Products (1971) $\$ 9.50$

Thermowell Systems for Liquid Metal Service (8-72) Ame

Thickness and Density of Blanket-Type or Batt-Type th

Thickness by Magnetic-Field or Eddy-Current (Electrom

Thickness, Reference Radiographs for (1973) \$1.75
ASTM

ANS1

ANS

ANS1

ASTM

ASTM

ASTM

ASTM

ASTM

ASTM

ASTM

ASTM

ASTM

ASTM

IEEE

NRC

ANSI

ANSI

ANSI

ANSI

ANSI

NCRP

ANSI

ANSI

ASTM

ASTM

ANSI

ANSI

ASTM

ASTM

ERDA

ASTM

ERDA

ASTM

ASTM

NRC

ANS1

ERDA

ASTM

ASTM

ASTM

ASTM

ERDA

ERDA

ANS

ANSI

ANSI

ASTM

ASTM

ASTM

ASTM

ASTM

ANS1

ASTM

ASTM

NRC

ANSI

ASTM

NRC

ERDA

ERDA

ERDA

ERDA

ERDA

ERDA

ERDA

ERDA

ERDA

ERDA

ERDA

ERDA

ERDA

ASTM

ANSI

ANSI

ANSI

ASTM

ANSI

ANS1

ERDA

ASTM

NEMA

ERDA

A STM

ASTM

ASTM

D1711 Z166.31

792.2

Z166.25

E270

C709

D1566

E344

E500

DI 129

El 70

C168
D2652

380

RG 4.11

ZI 15.9

RG 5.4

N15.6

Y 1.1

B46.

R37 
asurement System (1-76)

A Flexural Strength of Concrete (Using Sium Bearing Film 973) ASTM D2333.1968 \$1.75

of (1974) \$1.50

Stabilization of UraniumUraniumUnified Screw Threads (UN and Unr Cast Iron Swing Check Valves, Flanged and Cast Iron Gate Valves, Flanged and

-71)

sedes E8-18T, (10-71)

Preloading

0

High Pressure Chemical Industry Flanges and Forged Steel Fittings, Socket-Welding and

ical Agents in the Workroom Environment with Intended Ch/ of Neutron Dose to Polymeric Materials and Application of antom (1973) $\$ 3.00$

st for (1974) $\$ 1.75$

mocouple Assembly (6-72)

Fuel Shipping Container

Titanium and

Specification for Titanium and

Spec. for Titanium and

Titanium and

or $\$ 1.75$

Specification for (19/

$\$ 1.75$

$1969 \$ 1.75$

Descaling and Cleaning Titanium and
Seamless and Welded Titanium and

ecification for (1973) ASTM B265-1972 \$1.75

ec. for (1974) $\$ 1.75$

(1974) $\$ 1.75$

at Exchangers, Specification for (19/

trodes (1970) $\$ 3.00$

f (1971) $\$ 1.75$

Specification for Spec. for

$\$ 3.00$ 5

Titanium and Titanium and Floor and Wall Openings, Railings and Dimensioning and BF3 Gamma Std. Spec. for

$-11 \mathrm{~T},(8-72)$

ations (1974) ASTM A628-1973 \$1.75 74) ASTM A627-1968 \$1.75 Std. Spec. for Homogeneous applications (1974) ASTM A629-197I \$1.75 Std. Spec. for erhead Traveling Cranes (1974) $\$ 3.00$

Spec. for

Design Basis

$\$ 1.75$

Additional Information: Wind and

ners (1972) $\$ 1.75$

Method of Test for Test for Plane-Strain Fracture for Forgings, Carbon and Low Alloy Steel, Requiring Notch Test for Evaluating Acute Test for Evaluating Inhibitory Shear by Tension Loading at Elevated Temperatures (Metalspectrometer Leak Detector or Residual Gas Analyzer in the Fast Neutron Flux Measurements by Fast Neutron Flux Measurements by

$3 \$ 1.75$ Selection and aluation of Installed Biological Shielding in Research and Personnel Selection and men $(1 / 74)$ Information for Safety Analysis Reports:

Protection Against Low Electrical

Liquid Sodium Bearing Film Thickness, Variable Reluctance Evaluation of Shipper-Receiver Differences in the istical Evaluation of Shipper-Receiver Differences in the

Internal shed May, 1969) (IEEE Std. 93-1968) \$6.00 Guide for Including Draft Sup taining Sodium $(8.74)$ ants (Issued $\mathrm{Fo} /$

Distribution, Power and Regulating Test Vehicles fo 0 Conducting Drop-Weight Test to Determine Nil-Ductility Mechanical Powe Classification for Determination of Sound liquid Metal Service $(3-71)$ Amendment 1 (5-71); Su/ $\quad$ Nak
roducts (1972) $\$ 1.75$ roducts $(1972) \$ 1.75$ Test for (1973) \$1.75 Water Vapor rded Hot Box, Method of Test For/ Thermal Conductance and l (5-71); Su/ Nak Transmission High Temperature Pressure
Thickness, Variable Reluctance Transducer, Proximity Me Third Point Loading), Method of Test for (1966) (R 1973) Thorium in Water and Waste Water, Method of Test for (1 Thorium in Water and Waste Water, Test for (1974) \$1.75 Thorium Milling Waste Retention Systems (11/74)

Thorium Milling Waste Retention Systems, Stablilzation

Thread Form) (1974) \$15.00

Threaded Ends (1970) \$3.00

Threaded Ends (1970) $\$ 4.00$

Threaded Fasteners and Closures (2-69) Amendment 1 ( 10

Threaded Fasteners for Nuclear Components (2-75) Super

Threaded Pipe Unions 150, 250; and 300 lbs. (1970) $\$ 3.0$

Threaded Stubs for Use with Lens Gaskets (1968) $\$ 4.00$

Threaded (1973) $\$ 3.00$

Threads (Except Dryseal) (1968) $\$ 4.75$

Threads (UN and UNR Thread Form) (1974) $\$ 15.00$

Threshold Limit Values for Chemical Substances and Phys

Threshold-Foil Measurements (1968) (R1973) \$1.75

Thyroid Radioiodine Uptake Measurements Using a Neck pH

Tiedown for Truck Transport (1-75)

Time of Setting of Hydraulic Cement by Vicat Needle, Te

Time Response Test for Sheathed, Mineral Insulated Ther

Titanium Alloy Castings, Spec. for (1969) $\$ 1.75$

Titanium Alloy Forgings (1970) ASTM B381-1969 \$1.75

Titanium Alloy Forgings (1975) \$1.75

Titanium Alloy Strip, Sheet, and Plate, Specification F

Titanium Alloy Strip, Sheet, and Plate, Spec. for ( 1974

Titanium Alloy Surfaces, Rec. Practice for (1974) \$1.75

Titanium Alloy Tubes for Condensers and Heat Exchangers

Titanium and Titanium Alloy Castings, Spec. for (1969)

Titanium and Titanium Alloy Forgings (1970) ASTM B381-

Titanium and Titanium Alloy Forgings (1975) \$1.75

Titanium and Titanium Alloy Strip, Sheet, and Plate, Sp

Titanium and Titanium Alloy Strip, Sheet, and Plate, Sp

Titanium and Titanium Alloy Surfaces, Rec. Practice for

Titanium and Titanium Alloy Tubes for Condensers and He

Titanium and Titanium-Alloy Bare Welding Rods and Elec

Titanium and Titanium-Base Alloys, Chemical Analysis O

Titanium Sponge, Spec. for (1974) \$1.75

Titanium-Alloy Bare Welding Rods and Electrodes (1970)

Titanium-Base Alloys, Chemical Analysis of (1971) \$1.7

Toeboards, Safety Requirements for (1973) $\$ 3.00$

Tolerancing for Engineering Drawings (1973) $\$ 10.00$

Tolerant Neutron Detector Tubes (12-75) Supersedes C15

Tool Resisting Composite Steel Bars for Security Applic

Tool Resisting Steel Bars for Security Applications (19

Tool Resisting Steel Flat Bars and Shapes for Security

Top Running and Under Running Single Girder Electric Oy

Tornado Design Classification (6/76)

Tornado for Nuclear Power Plants (4/74)

Tornado Loadings (1 1/74)

Total Ash Content of Activated Carbon, Test for (1970)

Total Immersion Corrosion Test for Soak Tank Metal Clea

Total Mercury in Water (1973) \$1.75

Toughness of Metallic Materials, Method of (1974) \$1.75

Toughness Testing for Piping Components (1974) \$1.75

Toxicity of Water to Fresh Water Fishes (1970) $\$ 1.75$

Toxicity of Waters to Diatoms (1973) \$1.75

to-Metal), Method of Test for (1973) ASTM D2295-1972

Tracer Probe Mode (1973) \$1.75/Leaks Using the Mass

Track-Etch Technique (1973) \$1.75

Track-Etch Technique, Method for (1974) ASTM E418-197

Training of Personnel for Nuclear Power Plants (1971) a

Training Reactors (5/73) Shield Test Program for Ev

Training (Revision 1, 1/9/75).

Training (6/75)

Training, Equipping, and Qualifying of Guards and Watch

Trajectory Turbine Missiles (3/76)

Transducer Nomenclature and Terminology (1975) $\$ 5.00$

Transducer, Proximity Measurement System (1-76)

Transfer of Special Nuclear Materials (6/74)

Transfer of Special Nuclear Materials, Concepts and Pri

Transfers of Special Nuclear Material (3/75)

Transformer Impulse Tests, Appendix to C57.12.90 (Publi

Transformers, Test Code for (1973) (IEEE Std 262-1973)

Transient Reactor Test Facility (Treat) Experiments Con

Transients Without Trip on Pressurized Water Reactor Pl

Transition Properties, Specification for (1974A) \$1.75

Transition Temperature of Ferritic Steels (1970) ASTM E

Transmission Apparatus, Safety Standard for (1972) $\$ 4.0$

Transmission Class (1973) \$1.75

Transmission High Temperature Pressure Transmitter for Transmission of Flexible Heat Sealed Packages for Dry P

Transmission of Shipping Containers by Cycle Method, of

Transmittance of Built-Up Sections by Means of the Gua

Transmitter for Liquid Metal Service (3-71) Amendment
ERDA

ANS1

ANSI

ASTM

NRC

ANSI

ANS

MSS

MSS

ERDA

ERDA

MSS

ANSI

ANSI

ACGIH

Ion ASTM

ANSI

ERDA

ERDA

ASTM

ANSI

ASTM

ANSI

ASTM

ASTM

ASTM

ASTM

ANSI

ASTM

ANSI

ASTM

ASTM

ASTM

AWS

ASTM

ASTM

AWS

ASTM

ANS

ANSI

ERDA

ANSI

ANSI

ANS

CMAA

NRC

NRC

NRC

ASTM

ASTM

ASTM

ASTM

ASTM

ASTM

ASTM

ANSI

ASTM

ASTM

ANS

ANSI

NRC

NRC

NRC

NRC

NRC

ISA

ERDA

NRC

ANSI

NRC

ANSI

ANS!

ERDA

ANSI

ASTM

ANS!

ANS

ASTM

ERDA

ASTM

ASTM

ANSI

ERDA

RDT C8-2T

A 37.22

N158

2333

RG 3.23

N313

BI. I

SP 71

SP-7.0

RDT F8-1T

RDT E8-18T

SP-76

SP-65

B 16.11

B2.1

B 1.1 
Thermocouple Signal Differential Pressure e Releases from Light/_ Methods for Estimating Atmospheric Communication with Fuel Shipping Container Tiedown for Truck 6) ions Experiment Resistance to Shock and Vibration in Truck erials $(1975) \$ 5.00$

Materials (1973) $\$ 3.50$

Materials $(6 / 74)$

Packaging and ous Articles or Substances and Combustible Liquids on $\mathrm{Bo}$ pecial Construction, Arrangement, and Other Provisions for 175) Shipments, Administrative Guid/ 3) $\mathrm{ACl} 304-1973 \$ 2.75$ dditional Information: Nearby Industrial, Measuring, Mixing, Administrative Guide for Packaging and Administrative Guide for Uranium Hexafluoride for Vapor

(5-73), Amendment $2(1-74)$ supersedes E4-5T, (12-70)

3) Supersedes M16-1T, (6-72)

Forced Circulation Cold Gas Phase Adsorbents for Specifications for Electric Overhead

Running and Under Running Single Girder Electric Overhead ssels (1974A/ Std. Spec. for Quenched and Tempered Vacuum 1975) \$1.75 Pressure Vessel Plates, Heat 76) Supersedes / Carbon and Alloy Steel Forgings, Vacuum trode or Vacuum Induction Melted 1950 F (1065.6C) Solution or Vacuum Induction Melted $1750 \mathrm{~F}(954.4 \mathrm{C}$ ) Solution Heat rode or Vacuum Induction Melted $1950 \mathrm{~F}(1065.6 \mathrm{C})$ Solution or Vacuum Induction Melted $1750 \mathrm{~F}$ ( $954.4 \mathrm{C}$ ) Solution Heat Base-1 9Cr-3.1 Mo-5.1 (Cb \& Ta)-0.90Ti-0.50A I Solution sumable Electrode or Vacuum Induction Melted Solution Heat and Fuel Fabrication Plants (6/73) Test Vehicles for Transient Reactor Test Facility dment 1 (8-73), Amendment 2 (3-74) Instrument or Unconsolidated, Undrained Strength of Cohesive Soils in ecimens Without Pore Pressure Measurements (197/ Test for raft Standard Evaluation of Anticipated Transients Without $1970 \$ 1.75$ Radioactive

Fuel Shipping Container Tiedown for 6.50

radiations Experiment Resistance to Shock and Vibration in 1) Powered Industrial Venturi Flow

plementary Requirements for Nickel Alloy Seamless Pipe an requirements for $(1970) \$ /$ Nickel Alloy Seamless Pipe and Test for Average Velocity in a Duct (Pito Specification for Nickel Seamless Pipe and

on for Nickel-Copper Alloy (UNS N04400) Seamless Pipe and ication for Nickel-Chromium-Iron Alloy Seamless Pipe and on for Aluminum-Alloy Seamless Pipe and Seamless Extruded ickel-Iron-Chromium Alloy (UNS N08800) Seamless Pipe and Specification for Seamless Copper-Nickel Pipe and

Fast Flux Test Facility Driver Fuel Pin Seamless Cladding Heat Exchanger, Class 1, Water to Water, Straight or U Heat Exchanger, Class 2, Water to Water, Straight or U 5 Copper and Copper-Alloy Seamless Condense for (19) Seamless and WeIded Titanium and Titanium Alloy edes E6-20T, / Austenitic Stainless Steel Hexagonal Duct $974) \$ 1.75$ Seamless and Welded Carbon and Alloy Steel

Wrought Zirconium and Zirconium Alloy Seamless and Welded

Wrought Zirconium and Zirconium Alloy Seamless and Welded arbon, Ferritic, and Austenitic Alloy Steel Heat Exchanger u/ Nickel-Chromium-Molybdenum-Columbium Alloy Seamless u/ Nickel-Chromium-Molybdenum-Columbium Alloy Seamless

5) S/ Seamless Medium Carbon Steel Boiler and Superheate ent-Chromium, 1-Percent-Molybdenum Alloy Steel Seamless 6) Supersedes M3-2T,/ Stainless and Alloy Steel Seamless 76) Supersed/ Nickel-Molybdenum-Chromium Alloy Seamless 5) Supersedes M 3-4T, (1-74) Nickel Alloy Seamless 5) Nickel-Molybdenum-Chromium Alloy Seamless Pipe and Supersedes M3.8T, (5-70/ Zirconium and Zirconium Alloy ce Inspection of Pressurized Water Reactor Steam Generato BF3 Gamma Tolerant Neutron Detecto

ne Booklet Priced at $\$ 3.00$ Bases for GM Counter pecification for Seamless Ferritic-A ustenitic Alloy Steel ation for Aluminum-Alloy Extruded Bars, Rods, Shapes, and diation Emitting Products) for Cold-Cathode Gas Discharge 1/4-Percent-Chromium, 1-Percent-Molybdenum Alloy Stee teel Boiler, (1974B) 1.75 Superheater, and Heat Exchanger a) $\$ 1 . /$ Carbon, Ferritic Alloy and Austenitic Alloy Stee Columbium and Columbium Alloy Seamless and Welded Electric-Resistance-Welded Carbon Steel Boiler
Transmitter (11-71)

Transmitter, Pneumatic or Electric Output Signal (4-74 Transport and Dispersion of Gaseous Effluents in Routin Transport Vehicles (Revision 1, 5/75)

Transport (1-75)

Transport (2-75)

Design Basis for Fuel and Irradiat

Transportation of Critical Components and Equipment (1-

Transportation of Dangerous Articles and Magnetized Mat

Transportation of Radioactively Contaminated Biologica

Transportation of Radioactively Contaminated Biological

Transportation or Storage of Explosives or Other Danger

Transportation or Storage of Explosives or Other Danger

Transportation Routes Near Nuclear Power Plant Sites (1

Transportation Special Permits for Radioactive Material

Transportation, and Military Facilities (9/74)

Transporting and Placing of Concrete, Practice for (197

Transporting Radioactive Material (6/74)

Transporting Radioactive Materials (1973) $\$ 4.50$

Transport, Packaging of (1971) $\$ 6.75$

Trap Assemblies for Sodium Service (4-72) Amendment 1

Trap Assembly for Removal of Sodium Impurities (1-76)

Trapping Radioactive Iodine and Iodine Compounds (10-7

Traveling Crane (1971) $\$ 3.00$

Traveling Cranes (1974) $\$ 3.00$

Treated Carbon and Alloy Steel Forgings for Pressure Ve

Treated Carbon-Manganese-Silicon, Specification for (

Treated (ASME SA-508 with Additional Requirements) (4-

Treated (1973) SAE AMS 5590-1966 $\$ 3.00$ Base-19Cr-3.1

Treated (1973) SAE AMS 5596C-1968 $\$ 3.00$

Treated (1973) SAE AMS 5597A-1967 \$3.00

Treated (1973) SAE AMS 5662C-1972 $\$ 3.00$

Treated (1973) (SAE AMS 5589-1966 \$3.00

Umable Elect

/Le Electrode ANSI

Treated (1975) \$3.00 /.5.1 (Cb+Ta) 0.90Ti-0.50A Con

Treatment System Design Guide for Plutonium Processing

(Treat) Experiments Containing Sodium (8-74)

Tree for Sodium Cooled Reactors (Fabrication Only) Amen

Triaxial Compression (1972) (ASTM D2850-1970) \$1.75

Triaxial Compressive Strength of Undrained Rock Core Sp

Trip on Pressurized Water Reactor Plants (Issued for Tr

Tritium in Water, Method of Test for (1973) ASTM D2476.

Truck Identification Markings (1/74)

Truck Transport (1-75)

Trucks Low Lift and High Lift, Safoty Design Basis for F

Tube for Liquid Sodium (8-74) Supersedes C4-4T, (1-7

Tube for Nuclear Applications, Specification for (1971)

Tube for Nuclear Applications, Spec. for Supplementary

Tube Method (1972) $\$ 1.75$

Tube Method) (1972) \$1.75

Tube (1971) ASTM B167-1970 \$1.75

Tube (1971) \$1.75

Tube (1973) ASTM B167-1970\$1.75

Tube (1974) ASTM B241 $1973 \$ 1.75$

Tube (1974) $\$ 1.75$

Tube (1975) $\$ 1.75$

Tube $(6-71)$

Tube (6-73)

Tube $(7.71)$

Tubes and Ferrule Stock, Specification for (1974A) $\$ 1.7$

Tubes for Condensers and Heat Exchangers, Specification

Tubes for Condensers and Heat Exchangers, Specification

Tubes for Core Components and Assemblies (5-76) Supers

Tubes for Low Temperature Service, Specification for (1

Tubes for Nuclear Service, Specification for (1973) Ast

Tubes for Nuclear Service, Spec. for (1971) \$1.75

Tubes with Integral Fins, Specification for (1973) \$1.7

Tubes (AMS 5589 with Additional Requirements) (7-75) S

Tubes (AMS 5590 with Additional Requirements) (8-75) S

Tubes (ASME SA-210 with Additional Requirements) (7-7

Tubes (ASME SA-213 with Additional Requirements) (2-7

Tubes (ASME SA-213 with Additional Requirements) (4-7

Tubes (ASME SB -163 with Additional Requirements) (4-

Tubes (ASME SB-163 with Additional Requirements) (7-7

Tubes (ASME SB-167 with Additional Requirements) (7-7

Tubes (ASTM B 353 with Additional Requirements) (1-72)

Tubes (Revision 1, 7/75)

Tubes (12-75) Supersedes C15-11T, (8-72)

Tubes (1965) (R1971) $\$ 3.00$ and N42.6 Are Contained in $O$

Tubes (1974) ASTM A 669-1972 \$1.75

Tubes (1974) ASTM B221.73 \$1.75

Tubes (1975) $\$ 2.95$

Specific A

Tubesheet Forgings (ASME SA-336 with Additional Requir

Tubes, Specification for

/Ritic and Austenitic Al

Tubes, Specification for General Requirements for (1974

Tubes, Specification for (1973) ASTM B394-1970 \$1.75

Tubes, Specification for (1973) \$1.75
ERDA

ERDA

NRC

NRC

ERDA

ERDA

ANSI

NRC

DOT

USCG

NRC

ANSI

NRC

NRC

ANSI

ERDA

ERDA

ERDA

CMAA

CMAA

ASTM

ASTM

ERDA

ANSI

ANSI

SAE

ERDA

ERDA

ANSI

ASTM

ANSI

ANSI

NRC

ERDA

ERDA

ANSI

ERDA

ANSI

ASTM

Test F ASTM

ASTM

ANSI

ficati ASTM

Specif ANSI

pecifficati ANSI

ASTM

ASTM

ERDA

ERDA

ERDA

ASTM

ANSI

ASTM

ERDA

ASTM

ANSI

ASTM

ASTM

ERDA

ERDA

ERDA

ERDA

ERDA

ERDA

ERDA

ERDA

ERDA

NRC

ERDA

ANSI

ANSI

ANSI

ERDA

ASTM

ASTM

ANSI

ASTM

RDT C10-1T

RDT C6-2T

RG 1.111

RG 5.32

RDT F8-1IT

RDT F8-9T

DT F8-7T

CFR 103

N14.3

RG 7.2

46CFR 146

CFR146

RG 191

N14.10.2

RG 1.70 .8

A 186.1

RG 7.1 
Seamless Medium-Carbon Steel Boiler and Superheater s Cold Drawn Low Carbon Steel Heat Exchanger and Condense c Steel Boiler, Superheater, Heat Exchanger, and Condense mless Nickel and Nickel Alloy Condenser and Heat Exchanger Aluminum-AIloy Drawn Seamles

.75 Seamless and Welded Austenitic Stainless Stee andard Specification for Special Requirements for Pipe and ification for (1974) A/ Special Requirements for Pipe and pec/ Centrifugally Cast lron-Chromium-Nickel High Alloy $75)$ Supersedes M3-5T, Austenitic Stainless Steel Welded 75 ) Super/ Nickel-Iron-Chromium Alloy Seamless Pipe and mless and Welded Small Diameter Austenitic Stainless Stee onsumable Electrode or Vacuum Induction Melted 195/ Alloy ication for Seamless and Welded Austenitic Stainless Stee ection of Longitudinal and Spiral Welds of Welded Pipe and

Electrode or Vacuum Induction Melted 1750F (954.4C) Alloy Seamless Stainless Steel Mechanica Tantalum and Tantalum Alloy ification of Welding Procedures and Welders for Piping and d in Plutonium Processing / (1973) ASTM E309-1971 \$/ Nondestructive Examination of Eddy-Current Testing of Stee Nondestructive Examination of

$\$ 3.00$

$\$ 1.75$

Fineness of Portland Cement by the

$1973 \$ 6.00$

sign and Use of (1975) $\$ 5.00$

Protection Against Low Trajectory Logic Diagram (R1971)/ Interrelationship of Quartz-Fiber Electromete st of Electrical Grade Magnesium Oxide as Used in Sheathed Eddy Current Probe in Core Permanent Magnet Flow Through ations, Specification for (1967) cations, Specification for (197/

-73 )

$-73)$

or (1970) $\$ 1.75$

Thermocouples, Sheathed, Thermocouples, Sheathed, Electrical Continuity Fission Pesting, and Replacement of Large Stationary ower Generating Stations, Trial Use/ Draft Standard

nd Connections for Nuclear Power Generating Stations (19/ inside the Containment of Nuclear Power Generating Stati/ Thickness and Density of Blanket-Type or BattEvaluating Stress Corrosion Effect of Wicking

73) ASTM C165-1/ Compressive Strength of Preformed Block Density of Preformed Pipe Covering Density of Preformed Block

g Load and Calculated Flexural Strength of Preformed Block h Reactors (Revision 1, / .50 Quality Verification for PlateQuality Control for Plate-

Ion Exchanger, Non Regenerative Valve, Isolation, Butterfly Martensitic Stainless Steel Martensitic Stainless Steel 74) ) (4-75) Supersedes M7-1T/ ements) (3-75) Supersedes and Waste Water, Identification of (1974) \$1.75

1 Pressure Measurement System, Flush Mounted, Eddy Current 1/76)

cification for (1973) $\$ 1.75$

(1974) $\$ 1.75$

$-1969) /$

Laboratory Determination of Pulse Velocities and e for (1973) ASTM A388-1971 \$1.75

or Special Applications, Specification Fo/

tings, Specification for (1973) ASTM itudinal Discontinuities, Method for (1974) $\$ 1.75$

els, Method and Inspection for (1974A/ Longitudinal-Wave Fabrication and Control of Steel Reference Blocks Used in ngitudinal Waves (1974/ Recommended Practice for Immersed ed Longitudinal Waves Induced by Direct Contact, Practic/ r (1974) $\$ 1.75$

e for Evaluating Performance Characteristics of Pulse Echo Definitions of Terms Relating to Recommended Practice for Statistical Evaluation of Materia

(ASTM D 1266-1972) $\$ 1.75$ (1972) (ASTM D2938-1971A) \$1.75 Tests for surements (197/ Test for Triaxial Compressive Strength of ssion (1972) (ASTM D2/ Method of Test for Unconsolidated,

stainless SteeI Plate, Sheet, and Strip for Fusion-Welded tructures (Revision 2, 1/76) Inservice Inspection of 15.00
Tubes, Specification for (1973) $\$ 1.75$

Tubes, Specification for (1973) \$1.75

Tubes, Specification for (1974A) \$1.75

Tubes, Specification for (1974) \$1.75

Tubes, Specification for (1975) \$1.75

Tubing for General Service, Specification for (1974) \$1

Tubing for LMFBR Core Components (5-72)

Tubing for Longitudinal Discontinuities, Method for ( 19

Tubing for Nuclear and Other Special Applications (1973

Tubing for Nuclear and Other Special Applications, Spec

Tubing for Pressure Application at High Temperatures, S

Tubing (ASME SA-249 with Additional Requirements) (7-

Tubing (ASME SB-407 with Additional Requirements) (7-

Tubing (ASTM a 632 with Additional Requirements) (4-76

Tubing (Seamless, Corrosion and Heat Resistant Nickel C

Tubing (Small-Diameter) for General Service (1974) Ast

Tubing (1969) ASTM E273-1968 \$1.75/R Ultrasonic Insp

Tubing, Seamless, Corrosion and Heat Resistant Nickel B

Tubing, Specification for (1974) $\$ 1.75$

Tubing, Specification for (1974) \$1.75

Tubing, Standard for (1969) $\$ 6.00$

Tubular Products for Use in Fuel Reprocessing Plants an

Tubular Products with Magnetic Saturation, Practice for

Tubular Products (10/73)

Tungsten Arc Welding Electrodes (1969) \$2.00

Tungsten Forgings-Pressed, Sintered, and Forged (1966)

Turbidimeter, Test for (1974) $\$ 1.75$

Turbidity of Water, Standard Method of Tests for (1971)

Turbine Missiles (3/76)

Two State Devices), Graphic Symbols for (1973) IEEE 9

Type a Quantities of Radioactive Materials, Guide to De

Type Dosimeters and Companion Dosimeter Chargers (1965)

Type Electric Heating Elements (1970) $\$ 1.75$

Type Flow Sensor for Liquid Metal Service (6-73)

Type Flowmeter for Liquid Metal Service (4-73)

Type $\mathrm{K}$ for Nuclear or for Other High Reliability Applic

Type K, for Nuclear or for Other High Reliability Appli

Type Liquid Metal Leak Detector (10-72) Amendment 1 (6

Type Neutron Detector Assembly (12-71) Amendment 1 (10

Type or Batt-Type Thermal Insulating Materials, Test F

Type Power Plant and Substation Lead Storage Batteries,

Type Test of Class 1 Electrical Valve Operators for Nuc

Type Test of Class $1 \mathrm{E}$ Electric Cables, Field Splices, a

Type Tests of Continuous Duty Class 1 Motors Installed

Type Thermal Insulating Materials, Test for (1970) \$1.7

Type Thermal Insulations on Stainless Steel (1971) \$1.7

Type Thermal Insulation, Method of Test for (1963) (RI9

Type Thermal Insulation, Test for (1972) \$1.75

Type Thermal Insulation, Test for (1972) \$1.75

Type Thermal Insulation, Test for (1972) $\$ 1.75$

Type Uranium-Aluminum Fuel Elements for Use in Researc

Type Uranium-Aluminum Fuel Elements (1974) ANS $15.2 \$ 8$

Type $(5-72)$

Type (8-72)supersedes E1-13T, (12-70) Amendment 1 (5

(Type 403) Bars (ASTM a 276 with Additional Requirements

(Type 403) Forgings (ASME SA-182 with Additional Requir

Types of Microorganisms and Microscopic Matter in Water

Type, Inductive, Absolute or Gage (10-70) Amendment 1

Ultimate Heat Sink for Nuclear Power Plants (Revision 2

Ultrasonic Angle-Beam Examination of Steel Plates, Spe

Ultrasonic Contact Examination of Weldments, Method for

Ultrasonic Elastic Constants of Rock (1972) (ASTM D2845

Ultrasonic Examination of Heavy Steel Forgings, Practic

Ultrasonic Examination of Plain and Clad Steel Plates F

UItrasonic Inspection of Carbon and Low Alloy Steel Cas

Ultrasonic Inspection of Longitudinal and Spiral Welds

Ultrasonic Inspection of Metal Pipe and Tubing for Long

Ultrasonic Inspection of Steel Plates for Pressure Vess

Ultrasonic Inspection (1975) \$1.75/Ended Pra

Ultrasonic Testing by the Reflection Method Using

Ultrasonic Testing by the Resonance Method, Practice Fo

Ultrasonic Testing Systems (1969) ASTM E317-1968 \$1.75

Ultrasonic Testing (1974) \$1.75

Ultrasonic Velocity in Materials (1973) \$1.75

Unaccounted for $(6 / 74)$

Unconfined Compressive Strength of Cohesive Soil (1972)

Unconfined Compressive Strength of Rock Core Specimen

Unconsolidated, Undrained Strength of Cohesive Soils in

Undrained Rock Core Specimens Without Pore Pressure Mea

Undrained Strength of Cohesive Soils in Triaxial Compre

Unfired Pressure Vessel Flange Dimensions (1969) $\$ 4.00$

Unfired Pressure Vessels, Specification for (1975) \$1.7

Ungrouted Tendons in Prestressed Concrete Containment S

Uniaxial Compression (1972) \$1.75

Unified Screw Threads (UN and UNR Thread Form) (1974) \$
ASTM

eamles ASTM

ASTM

ASTM

ASTM

ASTM

ERDA

ASTM

ASTM

ANSI

ANSI

ERDA

ERDA

ANSI

ANSl

ANSI

ANSI

ASTM

ASTM

AWS

NRC

ANSI

NRC

AWS

SAE

ASTM

ASTM

NRC

ANSI

ANSI

ANSI

ASTM

ERDA

ERDA

ASTM

ANSI

ERDA

ERDA

ASTM

IEEE

ANSI

ANSI

ANSI

ASTM

ASTM

ANSI

ASTM

ASTM

ASTM

NRC

ANSI

ERDA

ERDA

ERDA

ERDA

ERDA

NRC

ASTM

ASTM

ANSI

ANS

ANSI

ANS

ANSI

ASTM

ASTM

ASTM

ASTM

ANSI

ASTM

ANSI

ASTM

ASTM

NRC

ANS!

ANS

ANSI

ASTM

ANSI

ANS

ASTM

NRC

ASTM

ANSI

A 210

A 179

A 249

B163

B210

RDT M3-28T

E213

A65

N56

G82.

RDT M3-5T

RDT M3-9T

RDT M3-27T

G87.78

B125.49

Z166.18 
Standard Marking System for Valves, Fittings, Flanges and Malleable Iron Threaded Pipe Classification of $\$ 4.25$

at and Content of License Applications for Storage Only of

Shared Emergency and Shutdown Electric Systems for Multincrete (1975) \$1.75 (1963)

Test for Estimates and Evaluations of Fallout in the Natural Background Radiation in the $\begin{array}{rr}\text { er Generating Stations, / Draft Standard Diesel Generator } & \text { Records and Reporting } \\ \text { or Atmosphere Cleanup System Air Filtration and Adsorption }\end{array}$ $\begin{array}{rr}\text { er Generating Stations, / Draft Standard Diesel Generator } & \text { Records and Reporting } \\ \text { or Atmosphere Cleanup System Air Filtration and Adsorption }\end{array}$ Unified Screw Threads (UN and

1974) $\$ 1.75$ Nickel-Copper Alloy Specification for Nickel-Copper Alloy Specification for Nickel-1ron-Chromium Alloy Specification for Nickel-lron-Chromium Alloy Amendment 2 (11-75) Preparation of Thyroid Radioiodine ances, Method of Test for (1973) ASTM E267-1970 \$1.75 ances, Method of Test for (1970) $\$ 1.75$

Materials Protection Contingency Measures for (1974) $\$ 1.75$ Test for Atom Percent Fission in Method of Test for (1973) ASTM / Atom Percent Fission in dard Method of Test for (1974) \$/ Atom Percent Fission in 3) ASTM E321/ Method of Test for Atom Percent Fission in est for $(1970) \$ 1.75$

test for (1973) ASTM E217-1970 \$1.75

Depleted

Specification for Nuclear Grade Sinterable Specification for Nuclear Grade, Sinterable Specification for Nuclear Grade, Sinterable

ectrometric, and Spectrochemical Analysis of Nuclear Grade ctrometric, and Spectrochemical Analysis o/ Nuclear Grade al, Mass Spectrometric, and Spectrochemical Analysis of / Ceramic Grade

Preparation of Environmental Reports for Commercial standard Format and Content of Safety Analysis Reports for nuclear Material License Application (lncluding That for A Nondestructive Assay of High Enrichment (1973) ASTM E219-1969\$1.75 Atom Percent Fission in Test for (1974) $\$ 1.75$
$\$ 6.75$ Atom Percent Fission in

ods for the Measurement of Uranium Tetrafluoride (UF $)_{4}$ and $\$ 4.50$ Accountability of ctrochemical, Nuclear and Radiochemical, Analysis of (19/ $\$ 1.75$

c, Spectrochemical, Nuclear and Radiochemical Analysis of Method for Colorimetric Determination of Microquantities of
Guide to the Contents of Applications for Preparation of Environmental Reports for Design Stability of Embankment Retention Systems for -1960 and N7.1 A-1973\$5.00 Radiation Protection in Guidance for the Control of Radiation Hazards in

Method for Spectrochemical Analysis of (1972) ASTM E40/ ue, Method for Spectrochemical Analysis of (1970) \$1.75

In Situ Assay of Enriched Classification of Unirradiated Plutonium and Unirradiated

f6) $2 /$ Standard Analytical Methods for the Measurement of $\$ 6.00$ Accountability of Fast Neutron Flux by Analysis of Barium-140 Produced by ctors (Revision $1, /$ Applications of Bioassay for Quality Control for Plate-Type ilzation of (1974) $\$ 1.50$ y $(4 / 74)$ Stabilization of

Neutron Flux by Analysis of Molybdenum-9

t Neutron Flux by Analysis of Molybdenum-99 Activity from for Measuring Fast Neutron Flux for Barium 140 Produced by Fast Flux Test Facility on, and Impurity Det/ General Methods for the Analysis of lysis of (1975) $\$ 1.75$

Nuclear Grade

3.1 Mo-5.1 ( Cb+Ta) 0.90Ti-0.50 Al Consumable Electrode or .1 (Cb+Ta)-0.90Ti-0.50Al-19-Fe Consumable Electrode or

IMo-5.I ( $\mathrm{Cb} \& \mathrm{Ta}$ )-0.90Ti-0.50Al Consumable Electrode or amless, Corrosion and Heat Resis/ Consumable Electrode or IMo-5.I (Cb \& Ta)-0.90Ti-0.50A I Consumable Electrode or orrosion and Heat Resistant Nickel Consumable Electrode or sure Vessels (1974A/ Std. Spec: for Quenched and Tempered ts) (4-76) Supersedes / lity Safety (1975) ANS-8.11 lity Safety (6/76) Carbon and Alloy Steel Forgings,
Unions (1964) $\$ 4.00$

Unions 150, 250, and 300 lbs. (1970) $\$ 3.00$

Unirradiated Plutonium and Uranium Scrap (12/20/72)

Unirradiated Plutonium Scrap, Classification of (1972)

Unirradiated Reactor Fuel and Associated Radioactive $\mathrm{Ma}$

Unirradiated Uranium Scrap, Classification of (1970) \$3

Unit Nuclear Power Plants (Revision 1, 1/75)

Unit Weight, Yield, and Air Content (Gravimetric) of Co

United States from Weapons Test. Conducted Through 1962

United States (1975) $\$ 5.00$

Units Applied as Standby Power Supplies for Nuclear Pow

Units for Nuclear Materials Control (1971) $\$ 3.25$

Units of Light-Water Cooled Nuclear Power Plants (Rev

UNR Thread Form) (1974) $\$ 15.00$

(UNS N04400) Plate, Sheet and Strip, Specification for (

(UNS N04400) Seamless Pipe and Tube (1971) $\$ 1.75$

(UNS N08800) Rod and Bar, (1974) $\$ 1.75$

(UNS N08800) Seamless Pipe and Tube (1974) $\$ 1.75$

Unusual Occurrence Reports (2-74) Amendment I (1-75),

Uptake Measurements Using a Neck Phantom (1973) $\$ 3.00$

Uranium and Plutonium Concentrations and 1sotopic Abund

Uranium and Plutonium Concentrations and Isotopic Abund

Uranium and Plutonium Fuel Manufacturing Plants (6/74)

Uranium and Plutonium Fuel (Mass Spectrometric Method)

Uranium and Plutonium Fuel (Mass Spectrometric Method),

Uranium and Plutonium Fuel (Neodymium 148 Method), Stan

Uranium and Plutonium Fuel (Neodymium-148 Method) (197

Uranium by Controlled Potential Coulometry, Method of T

Uranium by Controlled-Potential Coulometry, Method of

Uranium Castings (1975) $\$ 3.00$

Uranium Dioxide Powder (1973) $\$ 1.75$

Uranium Dioxide Powder (1974) ASTM C753.1973 \$1.75

Uranium Dioxide Powder (1975) ASTM C757-1974a \$1.75

Uranium Dioxide Powders and Pellets (2/9/73) / Mass

Uranium Dioxide Powders and Pellets, Methods for Chemic

Uranium Dioxide (6-71) Amendment 1 (12-74)

Uranium Enrichment Facilities (Revision 1, 10/75)

Uranium Enrichment Facilities-(12/74)

Uranium Enrichment Facility) (12/74)

Ion of a Specia

(

Uranium Fuel (Radiochemical Method), Method of Test for

Uranium Fuel (Radiochemical Method), Standard Method of

Uranium Hexafluoride $\left(\mathrm{UF}_{6}\right)$ 2/2/73) /Rd Analytical Meth

Uranium Hexafluoride, Analytical Procedures for (1972)

Uranium Hexafluoride, Chemical, Mass Spectrometric, Spe

Uranium Hexafluoride, Methods for (1974) ASTM C761-197

Uranium in Aqueous Solutions Standard Method for (1975)

Uranium in Aqueous Solutions (1973) ASTM E318-1969 \$1.

Uranium in Water by Fluorometry, Test for (1975) $\$ 1.75$

Uranium Milling Licenses (2/73)

Uranium Mills (4/73)

Uranium Mills (6/73)

Uranium Mines Operation (1973), Partial Revision of N7

Uranium Mining (1967)

Uranium Oxide by Gallium Oxide Carrier DC Arc Technique

Uranium Oxide by Gallium Oxide Carrier D-C Arc Techniq

Uranium Residual Holdup (8/74)

Uranium Scrap (12/20/72)

Uranium Scrap, Classification of (1970) $\$ 3.25$

Uranium Tetrafluoride $\left(\mathrm{UF}_{4}\right)$ and Uranium Hexafluoride (U

Uranium Tetrafluoride, Analytical Procedures for (1972)

Uranium-238 Fission, Measuring (1973) \$1.75

Uránium (6/74)

Uranium-Aluminum Fuel Elements for Use in Research Rea Uranium-Aluminum Fuel Elements (1974) ANS 15.2 \$8.50

Uranium-Thorium Milling Waste Retention Systems ( I 1/74

Uranium-Thorium Milling Waste Retention Systems, Stabl

Uranium-235 Enrichment Assay by Gamma-Ray Spectrometr

Uranium-238 Fission (1974) ASTM E343-1972 \$1.75

Uranium-238 Fission, Test for (1972) $\$ 1.75$

Uranium-288 Fission (1974) ASTM E393-1973 \$1.75

Uranyl Nitrate Solution (6-7I)

Uranyl Nitrate Solutions for Assay, Isotopic Distributi

Uranyl Nitrate Solutions, Nuclear and Radiochemical Ana

Vacuum Induction Melted $1750 \mathrm{~F}$ (954.4 C) Solution Heat

Vacuum Induction Melted $1750 \mathrm{~F}$ (954.4 C) Solution Heat

Vacuum Induction Melted 1750F (954.4C) Alloy Tubing, Se

Vacuum Induction Melted 1950 F (1065.6 C) Solution Trea

Vacuum Induction Melted $1950 \mathrm{~F}$ (1065.6C) Solution Treat

Vacuum Treated Carbon and Alloy Steel Forgings for Pres

Vacuum Treated (ASME SA-508 with Additional Requiremen

Validation of Calculational Methods for Nuclear Critica

Validation of Calculational Methods for Nuclear Critica
MSS

MSS

NRC

ANS1

NRC

ANS1

NRC

ASTM

EPA

NCRP

ANSI

ANS1

NRC

ANS1

ASTM

ASTM

ASTM

ASTM

ERDA

ANSI

ANS1

ASTM

NRC

A STM

ANSl

ASTM

ANSI

ASTM

ANS1

SAE

ASTM

ANS1

ANSI

NRC

ASTM

ANSI

ERDA

NRC

NRC

NRC

NRC

ANSI

ASTM

ANS

NRC

ANS1

ASTM

ANS1

ASTM

ANS

ASTM

NRC

NRC

NRC

ANS1

EPA

ANSI

ASTM

NRC

NRC

ANSI

NRC

ANSI

ASTM

NRC

NRC

ANSI

NRC

ANSI

NRC

/Fas ANSI

Fas ASTM

/Od ANSI

ERDA

NRC

ASTM

SAE

ANS1

ANSI

ANSI

ANSI

ANS1

ASTM

ERDA

ANSI

NRC

SP-25

P-76

RG 5.2

N15.10

RG 3.15

N15.I

RG 1.81

C 138

FRC4

R45

N41.13

N15.2

RG 1.52

B 1.1

B 127

B 165

B408

B407

RDT F1-3T

N44.3

N1 15 
he Workroom Environment with Intended $\mathrm{Ch} /$ Threshold Limit 3) Damping

Assumption of Normality (Employing Individual Observed the Assumption of Normality (Employing Individual Observed res Are to Be Considered Significant in Specified Limiting Nuclear Power Plants ( $\mathrm{Re} /$ Design of Main Steam lsolation trial Use/ Draft Standard Type Test of Class 1 Electrical lear Power Plants (1/74) Qualification Tests of Electric $5 \$ 7.00 \quad$ Compressed Gas Cylinder Steel Pipe Flanges, Flanged aces of Pipe Flanges and Connecting End Flanges of Ferrous
Forged or Rolled Steel Pipe Flanges, and

$18 \mathrm{~T},(2-71)$ Class 1 Self Operated and Power Operated Safety Related Inservice Testing of Overload Protection for Electric Motors on Motor Operated i $50 \mathrm{lb}$. Corrosion Resistant Cast Flanged Hydrostatic Testing of Steel onnecting Flange Joint Between Tapping Sleeves and Tapping Butterfly General Purpose Ball Face-to-Face and End-to-End Dimensions of Ferrous Automatic Spring Loaded Safety Stainless Steel Check Instrument Carbon Steel Isolation Inert Gas Standard Marking System for Cast Iron Swing Check Cast lron Gate

5.74)

Stainless Steel Globe and Angle

13T, (12.70) Amendment 1 (5.74)

Stainless Steel Gate

2) Amendment 1 (9.73), Amendment 2 (6-74)

and Cold Rolled, High Strength, Low Alloy Columbium Dry Products (1972) $\$ 1.75$ od, of Test for (1973) $\$ 1.75$

ent 1 (5-73). Amendment 2 ( $1-74)$

nts (3/73) ractice for Sampling Atmospheres for Analysis of Gases and ystem $(1-76)$ Liquid Sodium Bearing Film uclear Material (Revision 1, 4/75)

periments Containing Sodium (8-74

Specially Designed

Communication with Transport

72) (ASTM D2845-1969)/ Laboratory Determination of Pulse

Test for Average Recommended Practice for Ultrasonic Freeze

endment 2 (12-71)

brication Plants $(8 / 73)$

tion (1974) $\$ 5.00$

c4-4T, (1-71)

ments for Use in Research Reactors (Revision 1, /

Revised Fallout Estimates for 1964-1965 and

$2.4 \mathrm{~T},(10-69)$

ipments of Radioactive Material/

Administrative

hermocouple Material and Thermocouple Assembly, Chromel-P Test for Load Settlement Relationship for Individua

ifugal Pump (6-72) Amendment 1 (5-74)

rifugal Pump (7-72) Supersedes E3-3T, (10-70), Amendm/

Expansion Joint Containment

Inflatable Seal Containment

Gaskets Containment

Materials and Inspection for Reactor ons: Bound Edition \$1200.00: Lo/ ASME Boiler and Pressure nuclear Components (Supplement to ASME Boiler and Pressure nuclear Components (Supplement to ASME Boiler and Pressure nuclear Components (Supplement to ASME Boiler and Pressure nuclear Components (Supplement to ASME Boiler and Pressure ing Qualifications (Supplement to ASME Boiler and Pressure uctive Examination (Supplement to ASME Boiler and Pressure eel Forgings for Seamless Drums, Heads, and Other Pressure gs, Carbon and Alloy, Quenched and Tempered, for Pressure

2), Amendment 1 (12-74) Unfired Pressure Reactor Guard

) Amendment 1 (7-70)

shield Plug and Closure Cap for Penetrations LMFBR Reactor residual Elements on Predicted Radiation Damage to Reactor fication for (1974A) $\$ 1.75$

percent Molybdenuin, Specification for (1972A) A/

Tempered, Specification for (1974A) \$1.75

anganese-Molybdenum-Nickel, Specification For/

ium-Molybdenum, Specification for (1974) $\$ 1.75$

Pressure

Pressure

Pressure

Pressure

Pressure
Values for Chemical Substances and Physical Agents in T Values for Seismic Design of Nuclear Power Plants (10/7

Values) (1974) $\$ 4.00$

Values) $(4 / 74)$

Values, Recommended Practice for (1973) $\$ 1.75$

alues, Recommended Practice for (1973) $\$ 1.75$

Valve Leakage Control Systems for Boiling Water Reacto

Valve Operators for Nuclear Power Generating Stations,

Valve Operators Installed Inside the Containment of Nuc

Valve Outlet and Inlet Connections (1965) CGA V-1-196

Valves and Fittings (1973) $\$ 12.00$

Valves and Fittings (1974) $\$ 2.00$

Valves and Parts for General Service, Spec. for (1976)

Valves for Liquid Metal Service (5-75) Supersedes EI

Valves for Liquid Metal Service (6-74) Supersedes E1-

Valves Functional Specification Standard (1975) $\$ 3.00$

Valves in Nuclear Power Plants (1970) $\$ 2.25$

Valves $(11 / 75)$

Valves (1959) $\$ 3.00$

Valves (1961) $\$ 3.00$

Valves (1969) $\$ 2.00$

Valves (1970) $\$ 3.00$

Valves (1970) $\$ 4.00$

Valves (1973) $\$ 4.00$

Valves (3-72) Amendment 1 (1-73)

Valves (3-72) Amendment 1 (5-74)

Valves (4-72)

Valves (4-73) Amendment 1 (5-74)

Valves (5-72) Amendment 1 (1-74)

Valves, Fittings, Flanges and Unions (1964) $\$ 4.00$

Valves, Flanged and Threaded Ends (1970) $\$ 3.00$

Valves, Flanged and Threaded Ends (1970) $\$ 4.00$

Valves, Manual and Power Operated (3-72)

Valves, Manual and Power Operated (3-72) Amendment 1

Valve, Isolation, Butterfly Type (8-72)supersedes E1 -

Valve, Reactor Refueling and Maintenance for LMFBR(6-7

Vanadium, Specification for (1973) ASTM A607-1970 \$1.7

Vapor Barriers for Thermal Insulations (1973) $\$ 1.75$

Vapor Transmission of Flexible Heat Sealed Packages for

Vapor Transmission of Shipping Containers by Cycle Meth

Vapor Trap Assemblies for Sodium Service (4-72) Amendm

Vapors in Plutonium Processing and Fuel Fabrication Pla Vapors (1973) $\$ 1.75$

Variable Reluctance Transducer, Proximity Measurement

Vehicle and Armed Guards for Road Shipment of Special N

Vehicles for Transient Reactor Test Facility (Treat) Ex

Vehicles (Revision 1, 5/75)

Velocities and Ultrasonic Elastic Constants of Rock (19

Velocity in a Duct (Pitot Tube Method) (1972) $\$ 1.75$

Velocity in Materials (1973) \$1.75

Vent for Sodium Service (2-71) Amendment 1 (9-71), Am

Ventilation Systems for Fuel Reprocessing Systems ( $9 / 75$

Ventilation Systems of Plutonium Processing and Fuel Fa

Ventilation: a Manual of Recommended Practice, 13th Edi

Venturi Flow Tube for Liquid Sodium (8-74) Supersedes

Verification for Plate-Type Uranium-Aluminum Fuel Ele

Verification of 1963 Predictions (1964)

Verification Program Requirements (12-74) Supersedes F

Verifying Compliance with Packaging Requirements for Sh

Versus Alumel, Stainless Steel Sheathed, Magnesium Oxid

Vertical Piles Under Static Axial Load (1974) \$1.75

Vertical, Canned or Wet Motor Driven Single Stage Centr

Vertical, Shaft Sealed, Motor Driven, Single Stage Cent

Vessel Airlock (3-72) Amendment 1 (8-73)

Vessel Airlock (6-72)

Vessel Airlock (6-72)

Vessel Closure Studs (10/73)

Vessel Code-1977 Edition; Special Price for All Secti

Vessel Code, Section lii, Subsection NA and Nb) Superse

Vessel Code, Section Iii, Subsection NA and Nc) Superse

Vessel Code, Section Iii, Subsections NA and Nd) (3-75

Vessel Code, Section Iii, Subsections NA Ne) (8.75) Su

Vessel Code, Section IX) (8-74) Supersedes F6-5T, (7-

Vessel Code, Section V) (10-75) Supersedes F3-6T, (12

Vessel Components (1970) ASTM A266-1969\$1.75

Vessel Components (1973) \$1.75

Vessel Flange Dimensions (1969) $\$ 4.00$

Vessel for Liquid Metal Service (12.73) Supersedes (10

Vessel for Primary Sodium Containing Components (1 1-70

Vessel Head (4-73) Amendment 1 (1-74)

Vessel Materials (7/75)

Vessel Plates, Alloy Steel, Chromium-Molybdenum, Speci

Vessel Plates, Alloy Steel, Five Percent Chromium, 0.5

Vessel Plates, Alloy Steel, High Strength, Quenched and

Vessel Plates, Alloy Steel, Manganese-Molybdenum and $M$

Vessel Plates, Alloy Steel, Quenched and Tempered Chrom

Vessel Plates, Alloy Steel, Quenched and Tempered, Eigh

$\mathrm{ACGlH} *$

NRC RG 1.6

N15.15

RG 5.22

E29

RG 1.96

N41.6

RG 1.73

B57.1

B 16.5

SP-6

A 181

RDT E1-18T

RDT EI-I TT

N278.

PTC 34

RG 1.106

SP-42

SP.6I

SP-60

SP-67

SP-72

B16.10

RDT E1-6T

RDT E1-12T

RDT E1-25T

RDT E1-31T

RDT E1-35T

SP-25

SP-71

SP 70

RDT El-21T

RDT E1-9T

RDT El-13T

RDT E1-36T

G24.32

C755

D3079

D1276

RDT E4-14T

RG 3.7

D 1605

RDT C8-2T

RG 5.31

RDT EI6-1T

RG 5.32

A 37.176

D3154

RDT E4-13T

RG 3.32

RG 3.12

ACGIH

ERD

NRC

EPA

ERDA

ANSI

ERDA

ASTM

ERDA

ERDA

ERDA

ERDA

ERDA

NRC

ASME

ERDA

ERDA

ERDA

ERDA

ERDA

ERDA

lon St ANSI

RDT C4-4T

RG 2.3

FRC6

RDT F2-4T

NI 4.10 .3

RDT C $7-6 \mathrm{~T}$

D 1143

RDT E3-1T

RDT E3-3T

RDT E 10-5T

RDT E14-5T

RDT E14-6T

RG 1.65

CODE-77

RDT E15-2B

RDT E15-2C

RDT E15.2D

RDT E15-2E

RDT F6-5T

RDT F3-6T

G55.1

A541

B 16.30

RDT E2-3T

RDT E10-2T

RDT E2-4T

RG 1.99

A 387

G35.16 
anese-Molybdenum and Mangane/

Specification for Pressure el-Cobalt-Molybdenum-Chromium, Specification/ r-Temperature Service, Specification for (1974/ erature Service, Specification for (1974A) \$1.7/ ties, Specification for ( 1974 A) $\$ 1.75$ sile Strength, Specification for (1974A) \$1.75 ication for (1974A) $\$ 1.75$

Specification for $(1975) \$ 1.75$

Steel Containment Accumulators, Class 2 Pressure Post-Tensioned Prestressing Systems for Concrete Reactor 0) Code for Concrete Reactor Pressure ) ll $(\$ 95.00)$ Pressure

Thermal Shock to Reactor Pressure ction, Arrangement, and Other Provisions for Nuclear Cargo n, Arrangenent, and Other Provisions for Nuclear Passenger ration, Arrangement, and Other Provisions for Nuclear Tank Std. Spec. for Carbon Steel Sheets for Pressure Practice for Surveillance Tests for Nuclear Reacto acuum Treated Carbon and Alloy Steel Forgings for Pressure e for in Service Annealing of Water Cooled Nuclear Reacto e for in Service Annealing of Water Cooled Nuclear Reactor Information for Safety Analysis Reports: Reacto

teel Bars and Shapes for Use in Boilers and Other Pressure Dangerous Articles as Ships, Stores and Supplies on Board us Articles or Substances and Combustible Liquids on Board us Articles or Substances and Combustible Liquids on Board Fiberglass-Reinforced Plastic Pressure 1-Wave Ultrasonic Inspection of Steel Plates for Pressure Surveillance Tests for Nuclear Reacto Steel Plates for Pressur Molybdenum, Alloy Steel Plates for Pressure Copper-Nickel Alloy Plate and Sheet for Pressure late, Sheet, and Strip for Fusion-Welded Unfired Pressure
Radiation in

r Fuel and Irradiations Experiment Resistance to Shock and Shipping Containers, Recommended Practice for Forced for ASTM E92-1972 \$1.75 Time of Setting of Hydraulic Cement by

Tables for Metals (Relationship Between Brinell Hardness, (1973) (ASTM B349-/ Zirconium Sponge and Other Forms of $\$ 1.75$ Zirconium Sponge and Other Forms of pment for the Reactor Enclosure System (7-73)

1) $\$ 8.00$

reas $(11 / 73)$

Control of Personnel Access to Protected Areas, gas Chromatography (1974) \$1.7/ Recommended Practices for glass Coatings on Glassed Steel Reaction Equipment by High

Air Content of Freshly Mixed Concrete by the Recommended Practice for Forced Vibration Testing of r Radiation, Methods of Test / Compression Set lnduced in r Radiation, Testing (1968) (/ Compression Set lnduced in $\$ 1.75$ Method of Tests for Stress Relaxation of Method of Test for Accelerated Ozone Cracking of rrosive or High Tem/ Welded Large Outside Diameter Lightnts for (1973) $\$ 3.00$ $6-1973 \$ 1.75$

$80.1972 \$ 1.75$

Reference Radiographs for Heavy Reference Radiographs for Heavy I Steel Joints, Including Suitable Nuts and Plain Hardened aterials Finer Than No. 200 Sieve in Mineral Aggregates by Radioactive Radioactive

dical Use (1951) $\$ 2.00$ Recommendations for Information for Safety Analysis Reports: Radioactive Control and Accountability of Plutonium in Stabilization of Uranium-Thorium Milling Uranium-Thorium Millin Guide for Acceptable Liquid ssing and Fuel Fabrication Plants $(6 / 73)$ 0) $\$ 1.75$

Metals in Water and Test for Residual Chlorine in Tests for Dissolved Oxygen in ypes of Microorganisms and Microscopic Matter in Water and o/ Gamma Radioactivity of Industrial Water and lndustria \$) Radioactive Barium in Industrial Water and Industrial $\$ 1.75$ Thorium in Water and $8 /$ Radioactive lodine in Industrial Water and Industrial Reporting Results of Analysis of Iron in Water and $\mathrm{pH}$ of Water and
Vessel Plates, Alloy Steel, Quenched and Tempered, Mang Vessel Plates, Alloy Steel, Quenched and Tempered, Nick Vessel Plates, Carbon Steel for Intermediate-and Highe Vessel Plates, Carbon Steel for Moderate and Lower Temp Vessel Plates, Carbon Steel, Improved Transition Proper Vessel Plates, Carbon Steel, Low and Intermediate-Ten Vessel Plates, Carbon Steel, Manganese-Silicon, Specif Vessel Plates, Heat Treated Carbon-Manganese-Silicon, Vessel (12-73)

Vessel (3.73)

Vessels and Containments $(11 / 75)$

Vessels and Containments (1977) bd $(\$ 75.00)$, II $(\$ 100.0$

Vessels Division 1 (1977) bd (\$65.00), ll (\$95.00)

Vessels Division 2: Alternative Rules (1977) bd (\$65.00 Vessels (Safety Guide 2,11/2/70)

Vessels (Ships and Barges) (1975) \$1.95

Vessels (Ships and Barges) (1975) \$2.05

Vessels (Ships and Barges) (1975) \$2.15

Vessels (1972) ASTM A414-1971 \$1.75

Vessels (1973) ASTM E185-1970 \$1.75

/Ecial Constru USCG

/L. Constructio USCG

/Ecial Conside USCG

ANSI

ANS1

Vessels (1974A) \$1.75 (Ec for Quenched and Tempered V ASTM

Vessels (1974) \$1.75 Guid

Vessels (1975)

Recommended Guid ASTM NRC

Vessels (1975) $\$ 1.75$

Vessels (1975) $\$ 7.50$

Vessels (1975) $\$ 7.50$

Vessels (1975) $\$ 7.50$

Vessels $(1977)$ bd $(\$ 40.00)$, Il $(\$ 60.00)$

/R Stainless and Heat Resisting S ASTM

and Other Provisions for Use of USCG

E of Explosives or Other Dangero DOT

E of Explosives or Other Dangero USCG

Vessels, Rec. Practice for (1973) \$1.75

Vessels, Specification for General Requir

ASTM

Vessels, Specification for (1974A) \$1.75

Vessels, Specification for (1975A) $\$ 1.75$

Vessels, Specification for (1975) $\$ 1.75$

Veterinary Medicine (1970) $\$ 4.00$

Vibration in Truck Transport (2.75)

Vibration Test for (1975) $\$ 1.75$

Vibration Testing of Vulcanizates (1971) $\$ 1.75$

Vicat Needle, Test for (1974) $\$ 1.7 \$$

Vickers Hardness of Metallic Materials, Method of Test

Vickers Hardness, Rockwell Hardness, Rockwell Superfic

Virgin Metal for Nuclear Application, Specification for

Virgin Metal for Nuclear Application, Spec. for (1973)

Visual in Service Inspection System and Associated Equi

Visual Method, Quality Standard for Steel Castings (197

Visual Surveillance of Individuals in Material Access a

Vital Areas, and Material Access Areas (6/73)

Volatile Organic Matter in Water by Aqueous-Injection

Voltage ASTM C537.72 (1973) \$1.75 /or Reliabil

Voltage Connectors for Nuclear Instruments (1971) $\$ 3.00$

Voltage Switchgear (10-75) Supersedes P2-5T, (2-73)

Voltage (MSV) Intermediate Range Neutron Flux Monitorin

Volume Calibration Techniques for Nuclear Materials Con

Volumetric Method, Method of Test for (1975) \$1.75

Vulcanizates (1971) \$1.75

Vulcanized Rubber During Exposure to High Energy Nuclea

Vulcanized Rubber During Exposure to High Energy Nuclea

Vulcanized Rubber in Compression (197I) ASTM D1390 1968

Vulcanized Rubber (1971) ASTM D1149-1970 \$1.75

Wall Austenitic Chromium Nickel Alloy Steel Pipe for Co

Wall Openings, Railings and Toeboards, Safety Requireme

Walled (2 to 4-1/2 in.) Steel Castings (1974) ASTM E18

Walled (4-1/2 to 12 in.) Steel Castings (1973) ASTM E2

Washers, Specification for (1974) $\$ 1.75$

for Structura

Washing, Method of Test for (1970) ASTM C1 17-1969 \$1.7

Waste Categories, Definition of (1967) $\$ 3.00$

Waste Disposal in the Ocean (1954) $\$ 2.00$

Waste Disposal of Phosphorus-32 and Iodine-131 for Me

Waste Management (4/75)

Waste Material (2/75)

Waste Retention Systems (11/74)

Waste Retention Systems, Stablilzation of (1974) \$1 .50

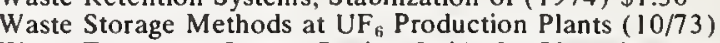

Waste Treatment System Design Guide for Plutonium Proce

Waste Water by Atomic Absorption Spectrophotometry (197

Waste Water (1974) \$1.75

Waste Water (1974) \$1.75

Waste Water, Identification of (1974) $\$ 1.75$

Waste Water, Method for Measurement of (1973) ASTM D169

Waste Water, Method of Test for (1973) ASTM D2038-1968

Waste Water, Method of Test for (1973) ASTM D2333-1968

Waste Water, Methods of Test for (1973) ASTM D2334-196

Waste Water, Standard Method for (1974) $\$ 1.75$

Waste Water, Standard Method of Tests for (1974) $\$ 1.75$

Waste Water, Test for (1970) \$1.75
A5 53

G35.26

A5 15

A516

A442

A 285

A299

A5 37

RDT E10-8T

RDT E 10.4T

RG 1.103

SEC-III/2

SEC-VIII/I

SEC.VIII/2

RG 1.2

46CFR99

46CFR 79

46CFR 37

G 33.4

N] 46

A508

N577

E509

RG 1.70.21

479

46CFR 147

46CFR 146

46CFR 146

SEC-X

A435

E 185

A 20

A204

B402

A240

R36

RDT F8-9T

D999

D2231

C19]

21 15.7

276.4

N121

B349

RDT E8-12T

SP-55

RG 5.14

RG 5.7

D2908

Z167.15

N42. 4

RDT P2-5T

RDT C15-6T

N15.19

$\mathrm{Cl} 73$

D2231

J2.33

D2309

$\mathrm{J} 2.23$

J4.5

A409

A 12.1

2166.10

2166.19

A 325

A 37.4

N5.8

R 16

R9

RG 1.70 .27

RG 5.47

RG 3.23

N3 13

RG 3.13

RG 3.10

D2576

D 1427

D 1589

D1 128

N1 50

N155

N158

N159

D596

D 1068

D 1293 
Radioactive Barium in Industrial Water and 1ndustria Thorium in Water and Water and

Radioactive Iodine in Industrial Water and Industria Sulfate Ion in Water and e Assay of Special Nuclear Material Contained in Scrap and easuring, Evaluating, and Reporting Radioactivity in Solid Recommendations for Disposal of Carbon-1

tions and Standards for Water-, Steam-, and RadioactiveTraining, Equipping, and Qualifying of Guards and $\mathrm{t}$ of (1973) ASTM D 1690/ Gamma Radioactivity of Industrial 973) ASTM D2038-1968 \$/ 1973) ASTM D2334-1968 /

Radioactive Barium in Industria Radioactive lodine in Industria Radioactive Barium in Industria Radioactive lodine in Industrial 5 metry (1970) $\$ 1.75$

Types of Microorganisms and Microscopic Matter in $2333-1968 \$ 1.75$ 74) $\$ 1.75$

horium in Iron in

$\$ 1.75$

Thorium in

sts for (1971) $\$ 1.75$

Sulfate Ion in 1.7 75 Sodium and Potassium in or Volatile Organic Matter in Metals in Water and Waste Microquantities of Uranium in Continuous Determination of Sodium in Information for Safety Analysis Reports: Reacto ndard Safety Related Systems, Structures and Equipment fo anup System Air Filtration and Adsorption Units of Light ctric Penetration Assemblies in Containment Structures for Housekeeping Requirements fo

g, Shipping, Receiving, Storage, and Handling of ltems fo ontinuous-Duty Motors Installed Inside the Containment of Assurance Requirements for Protective Coatings Applied to $74 \$ 1.75$ Guide for in Service Annealing of Recommended Guide for in Service Annealing of Preoperational and Initial Startup Test Programs fo tron-Emitting Fission Products in Nuclear Reactor Coolan

utron Emitting Fission Products in Nuclear Reactor Coolant Test for Evaluating Acute Toxicity of Water to Fresh

Permissible Concentrations of Radionuclides in Air and in 971) $\$ 1.75$ Sodium and Potassium in Water and

74) Analysis of Solvent Systems Used for Removal of Additional Information: Protective Coatings (Paints) for Ligh Maintenance of

Steam Isolation Valve Leakage Control Systems for Boiling tion of Anticipated Transients Without Trip on Pressurized r Safety Criteria for the Design of Stationary Pressurized I Safety Criteria for the Design of Stationary Pressurized clear Safety Criteria for the Design of Stationary Boiling up Testing of Feedwater and Condensate Systems for Boiling $\mathrm{g}$ the Potential Radiological Consequences of a Pressurized Inservice lnspection of Pressurized uences of a Radioactive Offgas System Failure in a Boilin Testing of Emergency Core Cooling Systems for Pressurized consequences of a Loss of Coolant Accident for Pressurized cal Consequences of a Loss of Coolant Accident for Boiling

Handling and Storage Facility for Boiling and Pressurized al Consequences of a Steam Line Break Accident for Boiling Coolant Composition in Pressurized Steam Generator for Pressurized

ter and Connector Assembly for Pressurizer for Pressurized evaluating a Control Rod Ejection Accident for Pressurized Pressurizer for Pressurized Maintenance of Water Purity in Boiling Fuel Assemblies for Pressurize gregate Road Mixes, Method of Test for (1975) \$1.75

Test for Evaluating Acute Toxicity of Heat Exchanger, Class 1 Heat Exchanger, Class 2,

es for Dry Products (1972) $\$ 1.75$

e Method, of Test for (1973) $\$ 1.75$

Test for

Cost-Benefit Analysis for Radwaste Systems for LightTest for Oxidation-Reduction Potential of ommended Practice for Measurement of Low Level Activity in etermination of Precision of Methods of Committee D-19 on Method of Test of Radioactive Zirconium in

Test for Measurement of Gamma Radioactivity of Method of Test for Total Mercury in Radioactive Nickel in Definition of Terms Relating to
Waste Water, Test for (1974) $\$ 1.75$

Waste Water, Test for (1974) \$1.75

Waste Water, Tests for Chloride lon in (1974) $\$ 1.75$

Waste Water, Tests for (1973) $\$ 1.75$

Waste Water, Tests for (1974) $\$ 1.75$

Waste $(10 / 73)$

Wastes and Releases of Radioactive Materials in Liquid

Wastes (1953) $\$ 2.00$

Waste-Containing Components of Nuclear Power Plants ( $R$

Watchmen (1/74)

Water and Industrial Waste Water, Method for Measuremen

Water and Industrial Waste Water, Method of Test for (

Water and Industrial Waste Water, Methods of Test for

Water and Industrial Waste Water, Test for (1974) \$1.75

Water and Industrial Waste Water, Tests for (1973) $\$ 1.7$

Water and Waste Water by Atomic Absorption Spectrophoto

Water and Waste Water, ldentification of (1974) $\$ 1.75$

Water and Waste Water, Method of Test for (1973) ASTM D

Water and Waste Water, Standard Method of Tests for (19

Water and Waste Water, Test for (1970) \$1.75

Water and Waste Water, Test for (1974) $\$ 1.75$

Water and Waste Water, Tests for Chloride lon in (1974)

Water and Waste Water, Tests for (1974) $\$ 1.75$

Water and Water Formed Deposits by Flame Photometry, Te

Water Bodies $(5 / 74)$

Procedure for Mathematical Model

Water by Aqueous-Injection Gas Chromatography (1974)

Water by Atomic Absorption Spectrophotometry (1970) \$1.

Water by Fluorometry, Test for (1975) $\$ 1.75$

Water by lon Selective Electrode (1973) $\$ 1.75$

Water Cleanup System (5/75)

Water Cooled and Moderated Nuclear Power Generating Pla

Water Cooled Nuclear Power Plants (Revision 1, 7/76)

Water Cooled Nuclear Power Plants (10/73)

Water Cooled Nuclear Power Plants $(3 / 16 / 73)$

Water Cooled Nuclear Power Plants $(3 / 16 / 73)$

Water Cooled Nuclear Power Plants (3/16/73)

Water Cooled Nuclear Power Plants $(6 / 73)$

Water Cooled Nuclear Reactor Vessels (1974) ASTM Quality

Water Cooled Nuclear Reactor Vessels (1974) \$1.75

Water Cooled Power Reactors (11/73)

Water During Reactor Operation, Measurement of (1970) \$

Water During Reactor Operation, Method for Measurement

Water Fishes (1970) \$1.75

Water for Occupational Exposure (1959) $\$ 2.00$

/ Maximum

Water Formed Deposits by Flame Photometry, Tests for (1

Water Formed (1973) \$1.75

Water Level (Flood) Design for Nuclear Power Plants (5

Water Nuclear Reactor Containment Facilities (1972) \$3

Water Purity in Boiling Water Reactors (6/73)

Water Reactor Nuclear Power Plants (Revision 1, (6/76)

Water Reactor Plants (Issued for Trial Use and Comment)

Water Reactor Plants (1973) ANS-51.1 \$30.50

Water Reactor Plants (1975) \$5.50

Water Reactor Plants: Issued for Trial Use and Comment

Water Reactor Power Plants (12/75)

Water Reactor Radioactive Gas Storage Tank Failure (Saf

Water Reactor Steam Generator Tubes (Revision 1, 7/75)

Water Reactor (3/76) $/ \mathrm{He}$

Water Reactors (Revision 1, 1/75)

Water Reactors (Revision 2, 6/74)

Water Reactors (Revision 2,6/74)

Water Reactors (Safety Guide 25, 3/23/72)

Water Reactors (Safety Guide 5, 3/10/71)

Water Reactors (10/71)

Water Reactors (12-71) Supersedes E4-1 T, (10-69)

Water Reactors (5-72) Supersedes E5-2T, (12-70)

Water Reactors (5/74)

Water Reactors (6-72) Supersedes E5-1T, (12-70)

Water Reactors $(6 / 73)$

Water Reactors (7-71) Amendment 1 (5-72)

Water Soluble Chlorides Present as Admixes in Graded Ag

Water Supply Systems for Fuel Reprocessing Plants (9/75

Water to Fresh Water Fishes (1970) \$1.75

Water to Water, Straight or U Tube (6-73)

Water to Water, Straight or U Tube (7-71)

Water Vapor Transmission of Flexible Heat Sealed Packag

Water Vapor Transmission of Shipping Containers by Cycl

Water-Cooled Nuclear Power Reactors (3/76)

Water (1970) $\$ 1.75$

Water (1972T \$1.75

Water (1972) $\$ 1.75$

Water (1973T) $\$ 1.75$

logical Conseq

Ntial Radiological NRC Radiologi NRC

in the Fuel NRC

L Radiologic NRC

ERDA

ERDA

Ea ERDA

NRC

ERDA

NRC

ERDA

ASTM

NRC

ASTM

ERDA

ERDA

ASTM

ASTM

NRC

ASTM

Rec ASTM

Water (1973) $\$ 1.75$

Recommended Practice for D

Water (1973) $\$ 1.75$

Water (1974T) \$1.75

Water (1974) $\$ 1.75$

D2038

D2333

D5 12

D2334

D5 16

RG 5.11

RG 1.21

R 12

RG 1.26

RG 5.20

N 150

N155

N159

D2038

D2334

D 2576

D 1128

N158

D 1068

D 1293

D2333

D5 12

D5 16

D 1428

RG 4.4

D2908

D2576

D2907

D2791

RG 1.70 .32

N18.10

RG 1.52

RG 1.63

RG 1.39

RG 1.38

RG 1.40

RG 1.54

N577

E509

RG 1.68

D2470

N 163

D 1345

R22

D 1428

D2790

RG 1.70 .5

N101.2

RG 1.56

RG 1.96

N661

N18.2

N18.2A

N2 12

RG 1.68.1

RG 1.24

RG 1.83

RG 1.98

RG 1.79

RG 1.4

RG 1.3

RG 1.25

RG 1.5

RDT A 1-1T

RDT E4-1T

RDT E5-2T

RG 1.77

RDT E5-1T

RG 1.56

RDT E13-15

D 1411

RG 3.31

D 1345

RDT E4-2T

RDT E4-17T

D3079

D 1276

RG 1.110

D 1498 
Tests for Residual Chlorine in Test for Residual Chlorine in Waste Tests for Dissolved Oxygen in Waste Test for Evaluating Inhibitory Toxicity of tions During and Following $\mathrm{A}$ Instrumentation for Lighttive Materials in Liquid and Gaseous Effluents from Lightts for Cleaning Fluid Systems and Associated Components of Serial Numbering of Fuel Assemblies for Lighttive Materials in Gaseous and Liquid Effluents from Lightrsion of Gaseous Effluents in Routine Releases from Lightmponents/ Quality Group Classifications and Standards for Test for Strontium lon Brackish Water, Sea

f Microorganisms and Microscopic Matter in Water and Waste $\$ 1.75$ mma Radioactivity of Industrial Water and Industrial Waste Gamma Spectrometry of Beta Particle Radioactivity of adioactive Barium in Industrial Water and Industrial Waste Radioactive Manganese in Thorium in Water and Waste Radionuclides of Radium in lron-59 in

Radioactive Tritium in Radioactive Cesium in adioactive lodine in Industrial $W$ ater and Industrial $W$ aste Alpha Spectrometry of Test for Strontium lon Brackish Reporting Results of Analysis of Waste

Nitrate Ion in Turbidity of Fluoride Ion in Iron in Water and Waste Dissolved and Gaseous Hydrogen in Nickel in Heat Exchanger, Class 1, Water to Heat Exchanger, Class 2, Water to Beta Particle Radioactivity of Alpha Particle Radioactivity of Iron-59 in $\mathrm{pH}$ of Water and Waste Radionuclides of Radium in Hydrazine in

Gamma Spectrometry of Radioactive Cesium in adioactive Barium in Industrial Water and Industrial Waste

Radioactive Manganese in Thorium in Water and Waste Water and Waste

Electrical Conductivity of Dissolved Oxygen in adioactive Iodine in Industrial Water and Industrial Waste Ammonia Nitrogen in Particulate and Dissolved Matter in Sulfate Ion in Water and Waste

Vessels, Method and Inspection for (1974A/

Longitudinalesting by the Reflection Method, Using Pulsed Longitudinal nic Testing by Reflection Method Using Pulsed Longitudinal mates and Evaluations of Fallout in the United States from Health Implications of Fallout from Nuclear Requirements for Materials Used in Reactor Coolant System
Cold $\$ 1.50$ 2.50 Hot

$1-1974 \$ 2.75$

$\$ 1.75$ erature of Ferritic Steels (1970) ASTM / Conducting Drope $(1975) \$ 1.75$ Test for Unit e the Delta Ferritic Content of Control of Stainless Steel Control of Electroslag Specification for Electric-FusionSeamless and High Temperature Service, Specificati/ or $(1974) \$ 1.75$ rvice, Specification for (1974) $\$ 1.75$ Seamless and er) for General Service (/ Specification for Seamless and nger, and Condenser Tubes, Specification for (1974A) \$1./ Service Specification for (1974) $\$ 1.75$ 73) $\$ 1.75$ Seamless and Electric-ResistanceSeamless and romium Nickel Alloy Steel Pipe for Corrosive or High Tem/

Ultrasonic Inspection of Longitudinal and Spiral Welds of I Requirements) (4-75) Super/ (5-75) Supersedes M 3-11T,/ Austenitic Stainless ) Sickel-Molybdenum-Chromium Alloy a 632 with Additional Requirements) / Seamless and (1974) ASTM A67!-1 Specification for Electric-Fusionion for (1975) $\$ 1.75$ Electric-Fusion-
Water (1974) $\$ 1.75$

Water (1974) $\$ 1.75$

Water (1974) $\$ 1.75$

Waters to Diatoms (1973) \$1.75

Water-Cooled Nuclear Power Plants to Assess Plant Cond

Water-Cooled Nuclear Power Plants (Revision 1, 6/74)

Water-Cooled Nuclear Power Plants (3/16/73)

Water-Cooled Nuclear Power Reactors (12/20/72)

Leases of $\mathrm{Radioac}$

Water-Cooled Power Reactors (4/76)

Water-Cooled Reactors (3/76)

/Ric Transport and Dispe

Water-, Steam-, and Radioactive-Waste-Containing Co

Water, and Brines (1974) \$1.75

Water, Identification of (1974) $\$ 1.75$

Types

Water, Method of Measurement of (1973) ASTM D1943

Water, Method of Test for (1973) ASTM D1890-1966 (1971

Water, Method of Test for (1973) ASTM D2038-1968 \$1.75

Water, Method of Test for (1973) ASTM D2039-1971 \$1.75

Water, Method of Test for (1973) ASTM D2333-1968 \$1.75

Water, Method of Test for (1973) ASTM D2460-1970 \$1.75

Water, Method of Test for (1973) ASTM D2461-1969 \$1.75

Water, Method of Test for (1973) ASTM D2476-1970 \$1.75

Water, Method of Test for (1973) ASTM D2577-1969 \$1.75

Water, Methods of Test for (1973) ASTM D2334-1968 \$1.7

Water, Recommended Practice for (1972T) $\$ 1.75$

Water, Sea Water, and Brines (1974) \$1.75

Water, Standard Method for (1974) \$1.75

Water, Standard Method of Test for (1971) $\$ 1.75$

Water, Standard Method of Tests for (1971) \$1.75

Water, Standard Method of Tests for (1972) \$1.75

Water, Standard Method of Tests for (1974) \$1.75

Water, Standard Method of Tests for (1974) $\$ 1.75$

Water, Standard Methods of Tests for (1971) $\$ 1.75$

Water, Straight or U Tube (6-73)

Water, Straight or U Tube (7-71)

Water, Test for (1966) (R1971) $\$ 1.75$

Water, Test for (1966) (R1971) $\$ 1.75$

Water, Test for (1969) (R1975) \$1.75

Water, Test for (1970) $\$ 1.75$

Water, Test for (1970) $\$ 1.75$

Water, Test for (1972) $\$ 1.75$

Water, Test for (1972) $\$ 1.75$

Water, Test for (1972) $\$ 1.75$

Water, Test for (1974) $\$ 1.75$

Water, Test for (1974) $\$ 1.75$

Water, Test for (1974) $\$ 1.75$

Water, Tests for Chloride lon in (1974) $\$ 1.75$

Water, Tests for (1971) \$1.75

Water, Tests for (1971) $\$ 1.75$

Water, Tests for (1973) \$1.75

Water, Tests for (1974) $\$ 1.75$

Water, Tests for (1974) $\$ 1.75$

Water, Tests for (1974) \$1.75

Wave Ultrasonic Inspection of Steel Plates for Pressure

Waves induced by Direct Contact, Practice for (1969) (R

Waves (1974) \$1.75 /Nded Practice for Immersed Ultraso

Weapons Test. Conducted Through 1962 (1963)

Weapons Test. Through 1961 (1962)

Wear Applications (10-67)

Weather Concreting, Practice for (1968) (ACI 306-1966)

Weather Concreting, Practice for (1972) ACl 305-1972

Weight Concrete, Practice for Selecting (1974) ACI 211.

Weight Tear Tests of Ferritic Steels, Method for (1974)

Weight Test to Determine Nil-Ductility Transition Temp

Weight, Yield, and Air Content (Gravimetric) of Concret

Weld Cladding of Low Alloy Steel Components (5/73)

Weld Metal (1974) $\$ 3.00$

Weld Properties (12/28/72)

Agnetic Instruments to Measur

Welded and Seamless Steel Pipe (1973) \$1.75

Welded Austenitic Chromium-Nickel Alloy Steel Pipe for

Welded Austenitic Stainless Steel Pipe, Specification F

Welded Austenitic Stainless Steel Tubing for General Se

Welded Austenitic Stainless Steel Tubing (Small-Diamet

Welded Austenitic Steel Boiler, Superheater, Heat Excha

Welded Carbon and Alloy Steel Tubes for Low Temperature

Welded Carbon Steel Boiler Tubes, Specification for (19

Welded Carbon, Ferritic, and Austenitic Alloy Steel Hea

Welded Large Outside Diameter Light-Wall Austenitic Ch

Welded Pipe and Tubing (1969) ASTM E273-1968 \$1.75

Welded Pipe Large Diameter (ASME SA-358 with Additiona

Welded Pipe (ASME SA-155 with Additional Requirements)

Welded Pipe (ASME SA-358 with Additional Requirements)

Welded Small Diameter Austenitic Stainless Steel Tubing

Welded Steel Pipe for Atmospheric and Lower Temperature

Welded Steel Pipe for High Pressure Service, Specificat
ASTM

ASTM

ASTM

ASTM

NRC

NRC

NRC

NRC

NRC

ASTM

ASTM

ANS1

ANSI

ANS1

ANS

ANSI

ANS

ANS

ANS

ANS

ASTM

ASTM

ASTM

ASTM

ASTM

ASTM

ASTM

ASTM

ASTM

ERDA

ERDA

ASTM

ASTM

ASTM

ASTM

ASTM

ASTM

ASTM

ASTM

ASTM

ASTM

ASTM

ASTM

ASTM

ASTM

ASTM

ASTM

ASTM

ASTM

ASTM

ANSI

ASTM

Esti EPA

ERDA

ANSI

ANS

ANSI

ASTM

ANS

ASTM

NRC

AWS

NRC

ASTM
ASTM

ASTM

ASTM

ANSI

ASTM

ASTM

ASTM

ASTM

ASTM

ANSI

ERDA

ERDA

ERDA

ERDA

ANSI

ASTM

D) 253

D1 427

1589

D2037

RG 1.97

RG 1.21

RG 1.37

RG 5.1

RG 1.112

RG 1.11

RG 1.26

3352

DI 128

N150 
and Heat Exchangers, Specification for (19/

Seamless and

73) A/ Wrought Zirconium and Zirconium Alloy Seamless and

5 Wrought Zirconium and Zirconium Alloy Seamless and $\$ 1.75$ Columbium and Columbium Alloy Seamless and s) (7-75) Supersedes M3-5T,/ Austenitic Stainless Steel (12/73)

Recommended Rules for Design

0 cessibility in Fuel Reprocessing Plants and in Plutonium/ $11(\$ 55.00)$ boiler and Pressure Vessel Code, Section 1X) (8-74) Sup/

Standard

Forged Steel Fittings, SocketStructura rements) (3-75) Supersedes M l-3T, / Mild Steel Covered
irements) (3-75) Supers/ Nickel and Nickel Alloy Covered irements) (3-75) Supers/ Nickel and Nickel Alloy Covered
rements) (3-75) Supersedes M 1-I Stainless Steel Covered rements) (3-75) Supersedes M l-1 Low Alloy Steel Covered Tungsten Arc $1969 \$ 3.50$ Mild Steel Covered Arc $1969 \$ 2.50$ Mild Steel Covered Arc
Nickel-Alloy Covered ion-Resisting Chromium and Chromium-Nickel Steel Covered $1969 \$ 3.50$ Low Alloy Steel Covered Arc Copper and Copper-Alloy Arc Mild Steel Covered Arc Nickel and Nickel-Alloy Covered Low Alloy Steel Covered Arc Copper and Copper-Alloy Arc ion-Resisting Chromium and Chromium-Nickel Steel Covered Butt ions (1974) ASTM A652-1/ Specification for Wrought Stee ions, Specification for Special Requiremen/ Wrought Stee ents) (1-75) Supersedes M2-1 Austenitic Stainless Steel Factory Made Wrought Steel Butt Wrought Stainless Steel But High Test Wrough

1972) \$1./ Factory-Made Wrought Nickel and Nickel-Alloy Factory Made Wrought Aluminum and Aluminum Alloy cessing Plants and in Plutonium/ ndment 1 (5-75)

Plant/ Preheat and Interpass Temperature Control for the

(7-73) Control of Preheat Temperature for

nal Requirements) (6-73)

tandard for (1969) $\$ 6.00$

ditional Requirements) (3-75) Supersede/

Qualification of SocketAluminum and Aluminum Alloy Corrosion-Resisting Chromium Aluminum and Aluminum Alloy Corrosion-Resisting Chromium and Chromium-Nickel Steel onal Requirements) (3-75)/ Nickel and Nickel-Alloy Bare Composite Surfacing

Titanium and Titanium-Alloy Bare (3-75) Nickel-Chromium-Molybdenum-Columbium Bare (1.72) Amendme/ Nickel-Molybdenum-Chromium Alloy Bare 1/4-Percent-Chromium, 1-Percent-Molybdenum Alloy Bare ws A5.13-1970 \$3.00 ws A5.14-1969 $\$ 2.50$

Nickel and Nickel-Alloy Bare Nickel and Nickel-Alloy Bare additional Requirements) (3-75) Supersedes M 1-5T, (7-1 (1.72) Supersedes MI/ Zirconium and Zirconium Alloy Bare $30.00)$, Il $(\$ 40.00)$ 2.50 lron and Steel Gas Copper and Copper-Alloy Copper and Copper-Alloy (7.75) Supers/ Mild Steel Electrodes for Flux-Cored Arc 3-75/ Mild Steel Electrodes and Fluxes for Submerged Arc 4-75) Supersede/ Mild Steel Electrodes for Gas Metal Arc Control of Stainless Steel

Molybdenum Alloy Electrodes and Fluxes for Submerged Arc Bare Mild Steel Electrodes and Fluxes for Submerged Arc Mild Steel Electrodes for Gas Metal Arc Mild Steel Electrodes for Flux-Cored Arc

Mild Steel Electrodes and Fluxes for Submerged Arc Mild Steel Electrodes for Gas Metal Arc Mild Steel Electrodes for Flux-Cored Arc Ultrasonic Contact Examination of
Welded Steel Pipe for Low Temperature Service (1975) \$1 Welded Steel Pipe (1973A) \$1.75

Welded Steel Plate Pipe (Sizes 16 in. and Over), Specif Welded Steel Tanks for Oil Storage (1973) $\$ 4.00$

Welded Titanium and Titanium Alloy Tubes for Condensers Welded Tubes for Nuclear Service, Specification for ( 19 Welded Tubes for Nuclear Service, Spec. for (1971) \$1.7 Welded Tubes, Specification for (1973) ASTM B394-1970 Welded Tubing (ASME SA-249 with Additional Requirement Welded Unfired Pressure Vessels, Specification for (197 Welded, Low Pressure Storage Tanks (1973) $\$ 4.00$

Welder Qualification for Areas of Limited Accessibility Welder Qualification for Welding in Areas of Limited Ac Welders for Piping and Tubing, Standard for (1969) $\$ 6.0$ Welding and Brazing Qualifications (Supplement to ASME Welding and Brazing Qualifications (1977) bd (\$40.00), Welding and Cutting, Safety in (1973) $\$ 5.00$

Welding and Nondestructive Symbols Testing (1976) $\$ 5.00$ Welding and Threaded (1973) $\$ 3.00$

Welding Code (1975) $\$ 24.00$

Welding Electrodes (ASME SFA-5.1 with Additional Requi Welding Electrodes (ASME SFA-5.11 with Additional Requ Welding Electrodes (ASME SFA-5.4 with Additional Requi Welding Electrodes (ASME SFA-5.5 with Additional Requi Welding Electrodes (1969) $\$ 2.00$

Welding Electrodes, Specification for (1973) AWS A5.1Welding Electrodes, Specification for (1973) AWS A5.11Welding Electrodes, Specification for (1973) AWS A5.4Welding Electrodes, Specification for (1973) AWS A5.5. Welding Electrodes, Specification for (1973) AWS A5.6Welding Electrodes, Specification for (1974) Welding Electrodes, Specification for (1974) Welding Electrodes, Specification for (1974) Welding Electrodes, Specification for (1974)

Welding Electrodes, Specification for (1974)

Welding Ends (1972) $\$ 4.00$

Welding Fittings for Nuclear and Other Special Applicat Welding Fittings for Nuclear and Other Special Applica Welding Fittings (ASME SA-234 with Additional Requirem Welding Fittings (ASME SA-403 with Additional Requirem Welding Fittings (1971) $\$ 4.00$

Welding Fittings (1971) $\$ 4.00$

Welding Fittings, Specification for (1970) $\$ 4.00$

Welding Fittings, Specification for (1973) (ASTM B366-

Welding Fittings, Spec. for (1973) \$1.75

Welding in Areas of Limited Accessibility in Fuel Repro

Welding Inserts (3-75) Supersedes M1-21T, (4-74) Ame

Welding of Low Alloy Steel for Use in Fuel Reprocessing

Welding of Low Alloy Steel (5/73)

Welding of Reactor Core Components and Test Assemblies Welding of Structural Components (AWS D1.l with Additio

Welding Procedures and Welders for Piping and Tubing, S

Welding Reducer Inserts (1974) $\$ 4.00$

Welding Rods and Bare Electrodes (ASME SFA-5.9 with Ad Welding Rods and Bare Electrodes, Specification for (19 Welding Rods and Bare Electrodes, Specification for (19 Welding Rods and Bare Electrodes, Specification for (19 Welding Rods and Bare Electrodes, Specification for ( 19 Welding Rods and Electrodes (ASME SFA-5.14 with Additi Welding Rods and Electrodes (1970) $\$ 2.50$

Welding Rods and Electrodes (1970) $\$ 3.00$

Welding Rods and Electrodes (6-75) Supersedes M1-19T Welding Rods and Electrodes (7-75) Supersedes M1-15T, Welding Rods and Electrodes (9-75) Amendment 1 (10-75 Welding Rods and Electrodes, Specification for (1973) a Welding Rods and Electrodes, Specification for (1973) a Welding Rods and Electrodes, Specification for (1974) Welding Rods and Electrodes, Surfacing (AWS A5.13 with Welding Rods (ASTM B 351 with Additional Requirements) Welding Rods (1969) $\$ 2.50$

Welding Rods, Electrodes and Filler Metals (1977) bd ( $\$$ Welding Rods, Specification for (1973) AWS A5.7-1969 \$ Welding Rods, Specification for (1974)

Welding (ASME SFA -5.20 with Additional Requirements) Welding (ASME SFA-5.17 with Additional Requirements) Welding (ASME SFA-5.18 with Additional Requirements) ( Welding (Revision 1, 6/73)

Welding (9-75)

2-1/4-Percent-Chromium, 1-Percent Welding, Specification for (1973) AWS A5.17-1969 \$2.50 Welding, Specification for (1973) AWS A5.18-1969 \$2.50 Welding, Specification for (1973) AWS A5.20-1969 \$2.50 Welding, Specification for (1974)

Welding, Specification for (1974)

Welding, Specification for (1974)

Weldments, Method for (1974) $\$ 1.75$

Welds in the Liners of Concrete Barriers in Fuel Reproc
ASTM

ASTM

ASTM

APl

ASTM

ANSI

ASTM

ANS1

ERDA

ASTM

AP]

NRC

NRC

AWS

ERDA

AWS

ANSI

AWS

ERDA

ERDA

ERDA

ERDA

AWS

ANS1

ANSI

ANS!

ANSI

ASME

ASME

ASME

ASME

ANSI

ANS1

ASTM

ERDA

ERDA
ANS1

MSS

MSS

ANS1

ASTM

NRC

ERDA

NRC

NRC

ERDA

AWS

MSS

ERDA

ANSI

ASME

ASME

ERDA

AWS

AWS

ERDA

ERDA

ERDA

ANS1

ASME

ERDA

AWS

ASME

ANS1

ASME

ERDA

ERDA

NRC

ANSI

ANSI

ANSI

ASME

ASME

ASME

ASTM

NRC

A 333

A 135

A 134

STD.

N 124

B353

H53.

RDT M3-5T

A240

STD. 620

RG 1.71

RG 3.28

D10.9

RDT F6-5T

SEC-IX

Z49.1

A2.4

B 16.11

Dl.]

RDT M1-3T

RDT M1-10T

RDT M1-1T

RDT M 1-4T

A5.12

W3.1

W3.1

W3.4

W3.5

W3.6

SFA-5.1 
cthod for UItrasonic Inspection of Longitudinal and Spiral Nondestructive Examination of Primary Containment Liner Method for Guided Bend Test for Ductility of Reference Radiographs for SteeI Fusion Standard Methods for Mechanical Testing of

amendment 1 (5-74)

idual Holdup of Special Nuclear Materic Evaluating Stotection Against Pipe (2-71) Aditional Thermation: Cold Finished Zirconium and Zirconium Alloy Bars, Rod and Cold Finished Zirconium and Zirconium Alloy Bars, Rod and Std. Specifications for Electric supersedes M/ Zirconium and Zirconium Alloy Bars, Rod and Specification for Aluminum-Alloy Bars, Rods, and NickeI Fast Flux Test Facility Driver Fuel Pin Wrap Ceramic-Insulated Magnet couple Materials, Platinum and Platinum 10 Percent Rhodium for (I973) ASTM EII-1970 \$1.75

Tantalum Rod and Safety Requirements for Portable Values for Chemical Substances and Physical Agents in the Concrete Form Fast Flux Test Facility Driver Fuel Pin Nonmailable Matter: Factory Made pec. for (1973) $\$ 1.75$ Service (1975) $\$ 1.75$ Std. Spec. for Piping Fittings of mical Analysis of SteeI, Cast Iron, Open-Hearth Iron, and ification for (1973) (ASTM B366-1972) \$I./ Factory-Made of (/) Detecting Susceptibility to Intergranular Attack in of Chemical Composition (1972) \$1.75 Sampling .00 Silver Brazing Joints for Cast and

ecial Applications (1974) ASTM A652-1/

Factory Made Specification for 0 ecial Applications, Specification for Special Requiremen/
High Test ed Tubes for Nuclear Service, Specification for (1973) A/ ed Tubes for Nuclear Service, Spec. for (1971) \$1.75

v: Equipment Design and Use (1968) \$3.00

v Structural Sheilding Design and Evaluation (I9/

Medical

Medical mev, GeneraI Safety Sta/ Installations Using Non-Medical erformance Std. (Ionizing Radiation Emitting Products) for 1971) NBS Handbook $111 \$ 3.00 \quad$ Radiation Safety for

std. (Ionizing Radiation Emitting Products) for Diagnostic $\$ 1.75$

ce Std. (Ionizing Radiation Emitting Products) for Cabinet cification for (1973) \$I.75

cation for (R 1973) ASTM A385-196/ Providing High Quality Electrodeposited Coatings of

Pressed, and Forged Steel Shapes, Plates, Bars and Strip, pecification for (I974) ASTM A386-1973 \$1.75

tional Requirements) ( I-72) Supersedes MI/

Zirconium and ion, Specific/ Hot Rolled and Cold Finished Zirconium and ecification for Hot Rolled and Cold Finished Zirconium and itional Requirements) (1-72) Supersedes M/ h Additional Requirements) (I-72) Superse/ cation for (1974) ASTM B350-1973 \$1.75 irements) (1-72) Supersedes M10-1T, (5-/ h Additional Requirements) (1-72) Superse/ lication, Specification for (I973) ASTM B3/ Zirconium and lication, Specification for (1967) $\$ 1.75$

rements) (1-72) Supersedes M3-8T, (5-70/

Zirconium and

Zirconium and

Aqueous Corrosion Testing of Samples of Zirconium and 351 with Additional Requirements) (1-72) Supersedes M1/ clear Application, Specific/ Hot Rolled and Cold Finished clear App/ Specification for Hot Rolled and Cold Finished b 35 I with Additional Requirements) (1-72) Supersedes M/ astm B 356 with Additional Requirements) (1-72) Superse/ ation, Specification for (1974) ASTM B350-1973 \$1.75

dditional Requirements) (1-72) Supersedes M10-1T, (5-) astm B 352 with Additional Requirements) (I-72) Superse/ for Nuclear Service, Specification for (1973) A/ Wrought for Nuclear Service, Spec. for (1971) $\$ 1.75$ Wrought or Nuclear Application, Specification for (1973) ASTM B3/ or Nuclear Application, Specification for (1967) \$1.75

ditional Requirements) (I-72) Supersedes M3-8T, (5-70/ 75 Aqueous Corrosion Testing of Samples of
Welds of Welded Pipe and Tubing (1969) ASTM E273-I968 Welds (Revision 1, 8/11/72, of Safety Guide 19)

Welds (1973) ASTM EI90-1971 \$1.75

WeIds (1973) ASTM E390-1969\$1.75

WeIds (1974) $\$ 5.00$

Wet Magnetic Particle Inspection (1971) \$1.75

Wet Motor Driven Single Stage Centrifugal Pump (6-72)

Wet Process Operations (6/74)

Whip Inside Containment (5/73)

lons for Minimizing Res

Wicking-Type Thermal Insulations on Stainless Steel (I

Wide Range ( 10 Decade) Neutron Flux Monitoring Channel

Wind and Tornado Loadings ( $I 1 / 74)$

Wire for Core Components (3-73)

Wire for Nuclear Application (1973) \$1.75

Wire for Nuclear Application, Specification for (1973)

Wire Rope Hoists (1974) \$3.00

Wire (ASTM B 351 with Additional Requirements) (1-72)

Wire (1974) ASTM B211-1973 \$1.75

Wire $(3-70)$

Wire (6-71)

Wire $(7-70)$

Wires, Noninsulated, Std. Grade (8-72) Amendment 1 (11

Wire-Cloth Sieves for Testing Purposes, Specification

Wire, Spec. for (1970) \$1.75

Wood Ladders (1975) $\$ 5.00$

Workroom Environment with Intended Changes (1975) \$.75

Work, Practice for (1968) (ACl 347-1968 \$2.50

Wrap Wire (6-71)

Written, Printed and Graphic Matter (1975)

Wrought Aluminum and Aluminum Alloy Welding Fittings, $S$

Wrought Carbon Steel and Alloy Steel for Low Temperatur

Wrought Iron (1975) \$1.75

Wrought Nickel and Nickel-Alloy Welding Fittings, Spec

Wrought Nickel-Rich, Chromium-Bearing Alloys, Method

Wrought Nonferrous Metals and Alloys for Determination

Wrought Solder Joint Fittings (I 970) $\$ 3.00$

Wrought Stainless Steel Butt Welding Fittings (1971) $\$ 4$

Wrought Steel Butt WeIding Fittings (1971) $\$ 4.00$

Wrought SteeI WeIding Fittings for Nuclear and Other Sp

Wrought Steel Welding Fittings for Nuclear and Other Sp

Wrought Welding Fittings, Specification for (1970) $\$ 4.0$

Wrought Zirconium and Zirconium Alloy Seamless and Weld

Wrought Zirconium and Zirconium Alloy Seamless and Weld

$X$-Ray and Gamma Ray Protection for Energies Up to $10 \mathrm{Me}$

$\mathrm{X}$-Ray and Gamma Ray Protection for Energies Up to $10 \mathrm{Me}$

$\mathrm{X}$-Ray and Sealed Gamma Ray Sources, Energies Up to 10-

$\mathrm{X}$-Ray Baggage Inspection Systems (1975) $\$ 2.95$

$X$-Ray Diffraction and FIuorescence Analysis Equipment

X-Ray Protection in Dental Offices (1970) $\$ 4.00$

X-Ray Systems and Their Major Components (1975) \$2.95

X-Ray Systems (1975) \$2.95

Yield, and Air Content (Gravimetric) of Concrete (1975)

Young's Modulus of Elasticity and Poisson's Ratio in Co

Zinc Coating (Hot-Dip) on Iron and Steel Hardware, Spe

Zinc Coatings (Hot-Dip) on Assembled Products, Specifi

Zinc on SteeI, Specification for ASTM A 164-197I \$I.75

Zinc (Hot Galvanized) Coatings on Products Fabricated F

Zinc-Coating (Hot-Dip) on Assembled Steel Products, S

Zirconium Alloy Bare Welding Rods (ASTM B 351 with Addi

Zirconium Alloy Bars, Rod and Wire for Nuclear Applicat

Zirconium Alloy Bars, Rod and Wire for Nuclear Applicat

Zirconium Alloy Bars, Rod and Wire (ASTM B 351 with Add

Zirconium Alloy Forgings and Extrusions (ASTM B 356 Wit

Zirconium Alloy Ingots for Nuclear Application, Specifi

Zirconium Alloy Ingots (ASTM B 350 with Additional Requ

Zirconium Alloy Plate, Sheet, and Strip (ASTM B 352 Wit

Zirconium Alloy Seamless and WeIded Tubes for Nuclear $S$

Zirconium Alloy Seamless and Welded Tubes for Nuclear S

Zirconium Alloy Sheet, Strip, and Plate for Nuclear App

Zirconium Alloy Sheet, Strip, and Plate for Nuclear App

Zirconium Alloy Tubes (ASTM B 353 with Additional Requi

Zirconium Alloys, Practice for (1974) \$I.75

Zirconium and Zirconium Alloy Bare Welding Rods (ASTM B

Zirconium and Zirconium Alloy Bars, Rod and Wire for Nu

Zirconium and Zirconium Alloy Bars, Rod and Wire for Nu

Zirconium and Zirconium Alloy Bars, Rod and Wire (ASTM

Zirconium and Zirconium Alloy Forgings and Extrusions (

Zirconium and Zirconium Alloy ingots for Nuclear Applic

Zirconium and Zirconium Alloy Ingots (ASTM B 350 with a

Zirconium and Zirconium Alloy Plate, Sheet, and Strip (

Zirconium and Zirconium Alloy Seamless and Welded Tubes

Zirconium and Zirconium Alloy Seamless and Welded Tubes

Zirconium and Zirconium Alloy Sheet, Strip, and Plate F

Zirconium and Zirconium Alloy Sheet, Strip, and Plate F

Zirconium and Zirconium Alloy Tubes (ASTM B 353 with Ad

Zirconium and Zirconium Alloys, Practice for (1974) $\$ 1$.
ANSI

NRC

ANSI

ANSI

AWS

ASTM

ERDA

NRC

NRC

ASTM

ERDA

NRC

ERDA

ASTM

ANSI

HMI

ERDA

ANSI

ERDA

ERDA

ERDA

RDA

ANSI

ASTM

ANSI

ACGIH

ANSI

ERDA

USPS

ASTM

ASTM

Che ASTM

ANSI

ANSI

ASTM

MSS

MSS

ANSI

ANSI

ASTM

MSS

ANSI

ASTM

NCRP

NCRP

ANSI

BRH

ANSI

NCRP

BRH

ASTM

ANSI

ASTM

ANSI

ANSI

ANSI

ANSI

ERDA

ANSI

ASTM

ERDA

ERDA

ANSI

ERDA

ERDA

ANSI

ASTM

ANSI

ASTM

ERDA

ASTM

ERDA

ANSI

ASTM

ERDA

ERDA

ANSI

ERDA

ERDA

ANSI

ASTM

ANSI

ASTM

ERDA

ASTM

Z166.18

RG I.19

Z115.4

ZI 66.24

B4.0

E 138

RDT E3-1 T

RG 5.25

RG 1.46

$\mathrm{C} 692$

RDT CI5-2T

RG 1.70 .10

RDT M7-24T

B35 I

N122

100

DT M7-9T

H38.4

RDT M7-12T

RDT E 13-13

RDT M7-I3T

DT C7-7T

Z23.1 
KWIC Index of U.S. Nuclear Standards

cations, Specification for (1973) $\$ 1.75$

of (1974) $\$ 1.75$

od of Test for Spectrophotometric Determination of Fission Method of Test of Radioactive clear Application, Specification for (1973) (ASTM B349-/ clear Application, Spec. for (1973) \$1.75

fication for (1973) \$1.75

75

Zirconium and Zirconium and
Zirconium and Zirconium-Alloy lngots for Nuclear Appli Zirconium and Zirconium-Base Alloys, Chemical Analysis Zirconium in Irradiated Nuclear Fuels (1973T) \$1.75

Zirconium in Water (1973T) \$1.75

Zirconium Sponge and Other Forms of Virgin Metal for $\mathrm{Nu}$ Zirconium Sponge and Other Forms of Virgin Metal for $\mathrm{Nu}$ Zirconium-Alloy Ingots for Nuclear Applications, Speci
ASTM B350

ASTM El46

/H ASTM E495

ASTM D3315

ANSI N12

ASTM B34

ASTM E146 
NBS.114A (REV. 7.73)

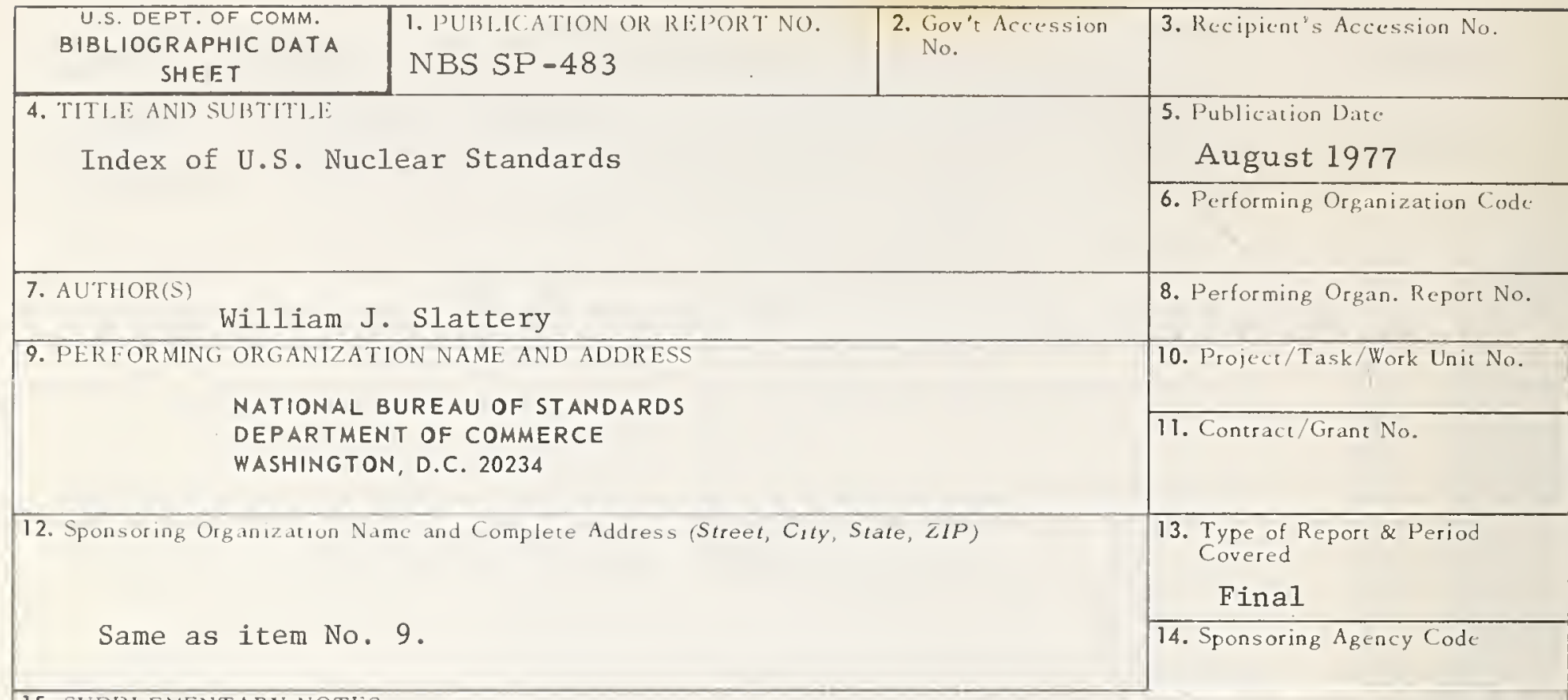

15. SUPPLEMENTARY NOTES

16. ABSTRACT (A 200-word or less factual summary of most significant information. If document includes a significant bibliography or literature survey, mention it here.)

This Index contains the permuted titles of more than 1,200 nuclear and nuclear-related standards, specifications, test methods, codes and recommended practices published by 34 U.S. Government agencies, technical societies, professional organizations, and trade associations. Each title can be found under all the significant key words which it contains. These key words are arranged alphabetically down the center of each page together with their surrounding context. Each entry includes the date of publication or last revision, the standard number, an acronym designating the standards-issuing organization, any cross reference standard number, and price.

17. KEY WORDS (six to twelve entries; alphabetical order; capitalize only the first letter of the first key word unless a proper name; separated by semicolons)

Engineering standards, index of; index of nuclear standards; nuclear standards; KWIC index of standards.

18. AVAILABILITY

$\square$ For Official Distribution. Do Not Release to NTIS

XX Order From Sup. of Doc., U.S. Government Printing Office Washington, D.C. 20402, SD Cat. No. C13, 10:483

$\square$ Order From National Technical Information Service (NTIS) Springfield, Virginia 22151

\begin{tabular}{|l|c|}
\hline $\begin{array}{l}\text { 19. SECURITY CLASS } \\
\text { (THIS REPURT) } \\
\text { UNCL ASSIFIED }\end{array}$ & 127 \\
\hline $\begin{array}{l}\text { 20. SECURITY CLASS } \\
\text { (THIS PAGE) }\end{array}$ & $\begin{array}{c}\text { 22. Price } \\
\$ 2.75\end{array}$ \\
UNCLASSIFIED & USCOMM-DC 29042.874
\end{tabular}




\section{PERIODICALS}

JOURNAL OF RESEARCH reports National Bureau of Standards research and development in physics, mathematics, and chemistry. It is published in two sections, available separately:

- Physics and Chemistry (Section A) Papers of interest primarily to scien these fields. This section covers a br cal and chemical research, witt $r$ emphasis on standards of physical neasur jull, fundamental constants, and properties of $m$. slimed six times a year. Annual subscription: D 70 . $\$ 17.00$; Foreign, $\$ 21.25$. - Mathematical Scir $\sin 8$, section B)

Studies and comr ${ }^{5} 0^{5}$. 1 s designed mainly for the mathematician and on $^{85}$ etical physicist. Topics in mathematical statis ${ }^{\circ}$ ic a $^{\text {to }}$ eory of experiment design, numerical analysir 0 retical physics and chemistry, logical design in rogramming of computers and computer sys-

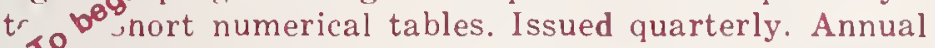
sL scription: Domestic, $\$ 9.00$; Foreign, $\$ 11.25$.

DIMENSIONS/NBS (formerly Technical News Bulletin)-This monthly magazine is published to inform scientists, engineers, businessmen, industry, teachers, students, and consumers of the latest advances in science and technology, with primary emphasis on the work at NBS. The magazine highlights and reviews such issues as energy research, fire protection, building technology, metric conversion, pollution abatement, health and safety, and consumer product performance. In addition, it reports the results of Bureau programs in measurement standards and techniques, properties of matter and materials, engineering standards and services, instrumentation, and automatic data processing.

Annual subscription: Domestic, $\$ 12.50$; Foreign, $\$ 15.65$.

\section{NONPERIODICALS}

Monographs-Major contributions to the technical literature on various subjects related to the Bureau's scientific and technical activities.

Handbooks-Recommended codes of engineering and industrial practice (including safety codes) developed in cooperation with interested industries, professional organizations, and regulatory bodies.

Special Publications-Include proceedings of conferences sponsored by NBS, NBS annual reports, and other special publications appropriate to this grouping such as wall charts, pocket cards, and bibliographies.

Applied Mathematics Series--Mathematical tables, manuals, and studies of special interest to physicists, engineers, chemists, biologists, mathematicians, computer programmers, and others engaged in scientific and technical work.

National Standard Reference Data Series-Provides quantitative data on the physical and chemical properties of materials, compiled from the world's literature and critically evaluated. Developed under a world-wide program coordinated by NBS. Program under authority of National Standard Data Act (Public Law 90-396).
NOTE: At present the principal publication outlet for these data is the Journal of Physical and Chemical Reference I) ata (JPCRD) published quarterly for NBS by the American Chemical Society (ACS) and the American Institute of Physics (AIP). Subscriptions, reprints, and supplements available from ACS, 1155 Sixteenth St. N.W., Wash. D. C. 20056.

Building Science Series-Disseminates technical information developed at the Bureau on building materials, components, systems, and whole structures. The series presents research results, test methods, and performance criteria related to the structural and environmental functions and the durability and safety characteristics of building elements and systems.

Technical Notes-Studies or reports which are complete in themselves but restrictive in their treatment of a subject. Analogous to monographs but not so comprehensive in scope or definitive in treatment of the subject area. Often serve as a vehicle for final reports of work performed at NBS under the sponsorship of other government agencies.

Voluntary Product Standards-Developed under procedures published by the Department of Commerce in Part 10, Title 15, of the Code of Federal Regulations. The purpose of the standards is to establish nationally recognized requirements for products, and to provide all concerned interests with a basis for common understanding of the characteristics of the products. NBS administers this program as a supplement to the activities of the private sector standardizing organizations.

Consumer Information Series-Practical information, based on NBS research and experience, covering areas of interest to the consumer. Easily understandable language and illustrations provide useful background knowledge for shopping in today's technological marketplace.

Order above NBS publications from: Superintendent of Documents, Government Printing Office, Washington, D.C. 201402 ,

Order following NBS publications-NBSIR's and FIPS from the National Technical Information Services, Springfield, Va. 22161.

Federal Information Processing Standards Publications (FIPS PUBS)-Publications in this series collectively constitute the Federal Information Processing Standards Register. Register serves as the official source of information in the Federal Government regarding standards issued by NBS pursuant to the Federal Property and Administrative Services Act of 1949 as amended, Public Law 89-306 (79 Stat. 1127), and as implemented by Executive Order 11717 (38 FR 12315, dated May 11, 1973) and Part 6 of Title 15 CFR (Code of Federal Regulations).

NBS Interagency Reports (NBSIR) - A special series of interim or final reports on work performed by NBS for outside sponsors (both government and non-government). In general, initial distribution is handled by the sponsor; public distribution is by the National Technical Information Services (Springfield, Va. 22161) in paper copy or microfiche form.

\section{BIBLIOGRAPHIC SUBSCRIPTION SERVICES}

The following current-awareness and literature-survey bibliographies are issued periodically by the Bureau:

Cryogenic Data Center Current Awareness Service. A literature survey issued biweekly. Annual subscription: Domestic, \$25.00 ; Foreign, \$30.00'.

Liquified Natural Gas. A literature survey issued quarterly. Annual subscription: $\$ 20.00$.
Superconducting Devices and Materials. A literature survey issued quarterly. Annual subscription: $\$ 30.00$. Send subscription orders and remittances for the preceding bibliographic services to National Bureau of Standards, Cryogenic Data Center (275.02) Boulder, Colorado 80302. 
U.5. DEPARTMENT OF COMMERCE

National Bureau of Standards

Washington, D.C. 20234

OFFICIAL BUSINESS

Penalty for Private Use. $\$ 300$
POSTAGE AND FEES PAID U.S. DEPARTMENT OF COMMERCE
COM-2 15

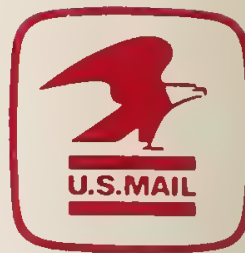

SPECIAL FOURTH-CLASS RATE BOOK 